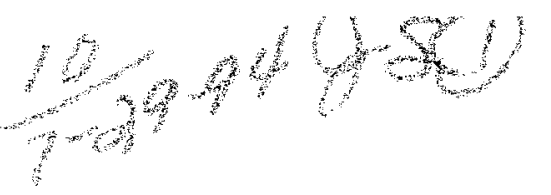

DOE-HTGR-90-389, Rev. 0 ORNL-6779
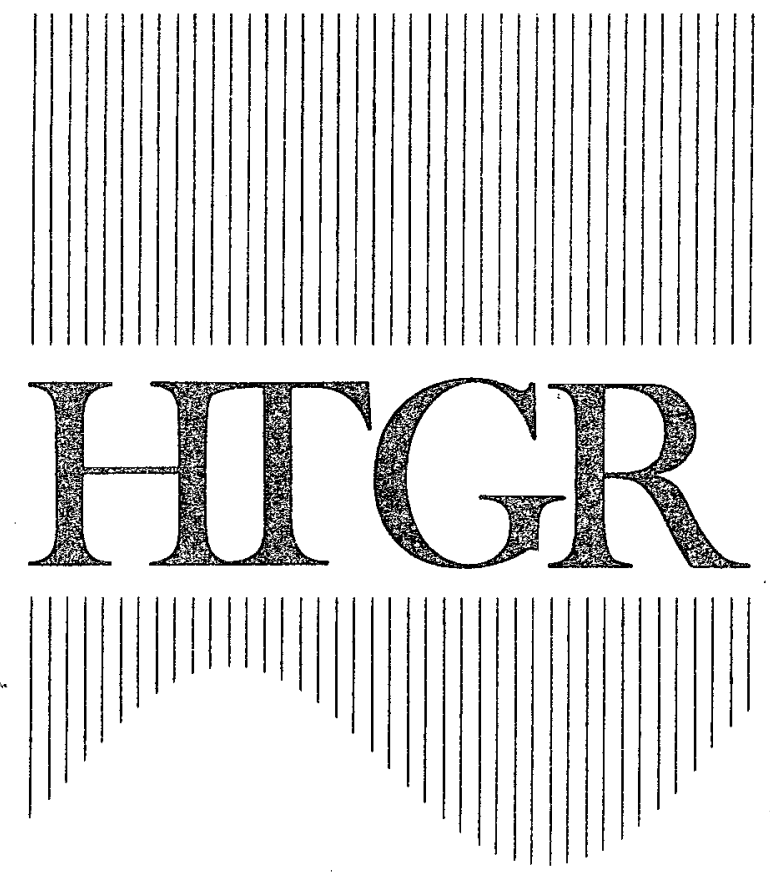

MHTGR PROGRAM ANNUAL REPORT FOR JANUARY 1, 1989, THROUGH JUNE 30, 1993

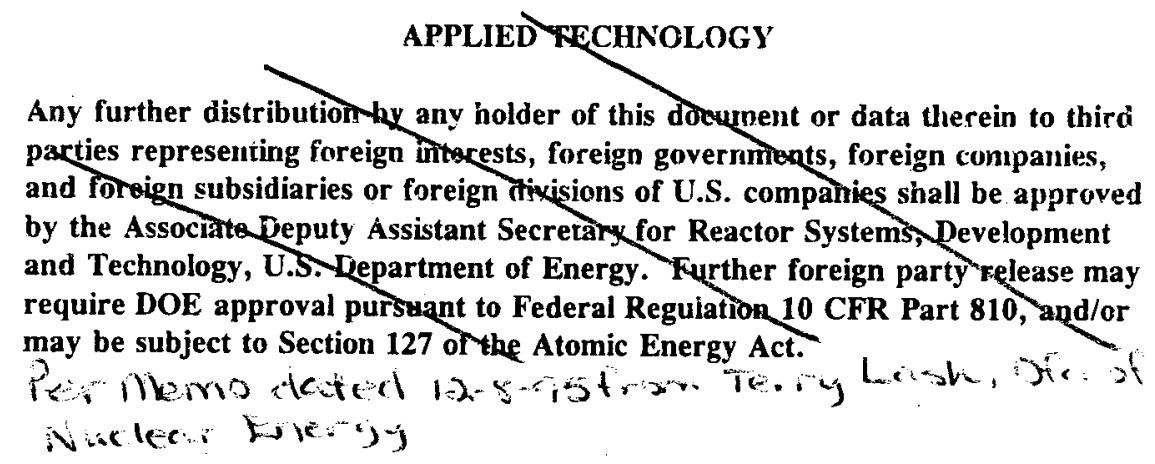

P. L. Rittenhouse, Director, Commercial MHTGR Program

D. O. Hobson, Compiler

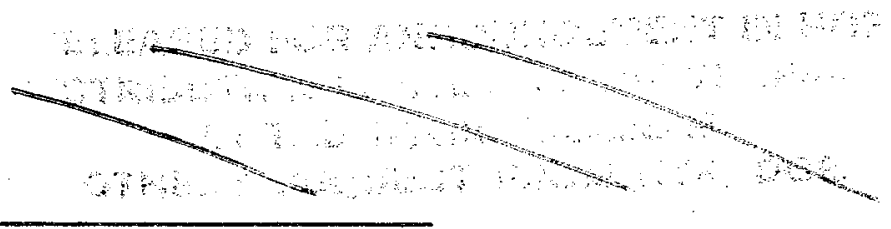

OAK RIDGE NATIONAL LABORATORY

Oak Ridge, Tennessee 37831

managed by

MARTIN MARIETTA ENERGY SYSTEMS, INC.

for the

U.S. DEPARTMENT OF ENERGY

May 1994 


\section{DISCLAIMER}

This report was prepared as an account of work sponsored by an agency of the United States Government. Neither the United States Government nor any agency Thereof, nor any of their employees, makes any warranty, express or implied, or assumes any legal liability or responsibility for the accuracy, completeness, or usefulness of any information, apparatus, product, or process disclosed, or represents that its use would not infringe privately owned rights. Reference herein to any specific commercial product, process, or service by trade name, trademark, manufacturer, or otherwise does not necessarily constitute or imply its endorsement, recommendation, or favoring by the United States Government or any agency thereof. The views and opinions of authors expressed herein do not necessarily state or reflect those of the United States Government or any agency thereof. 


\section{DISCLAIMER}

Portions of this document may be illegible in electronic image products. Images are produced from the best available original document. 
MHTGR PROGRAM ANNUAL REPORT FOR JANUARY 1, 1989, THROUGH JUNE 30, 1993

\author{
P. L. Rittenhouse, Director, Commercial MHTGR Program
}

D. O. Hobson, Compiler

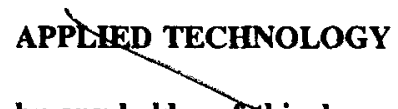

Any further distribution by any holder of this document or data therein to third parties representing foreign interests, fore ga governments, foreign companies, and foreign substdiaries or foreign divisions of U.S. companies shall beapproved by the Associate-Reputy Assistant Secretacy for Reactor Systems, Development and Technology, U.S. Department of Energy. Further foreign party release may require DOE approyal pursuant to Federat Regulation 10 CFR Paxt 810, and/or may be subfect to Section 127 of the Atomic Energy Act. Per memo dated 10-8-95 from Terry Lash, Ofr. of Nuclear Erercig Date Published - May 1994

NOTICE This document contains information of a preliminary nature. It is subject to revision or correction and therefore does not represent a final report.

Prepared for the U.S. Department of Energy

Office of Advanced Reactor Programs

AF 2050100

Prepared by the

OAK RIDGE NATIONAL LABORATORY

Oak Ridge, Tennessee 37831 managed by

MARTIN MARIETTA ENERGY SYSTEMS, INC.

for the

U.S. DEPARTMENT OF ENERGY

under contract DE-AC05-84OR21400
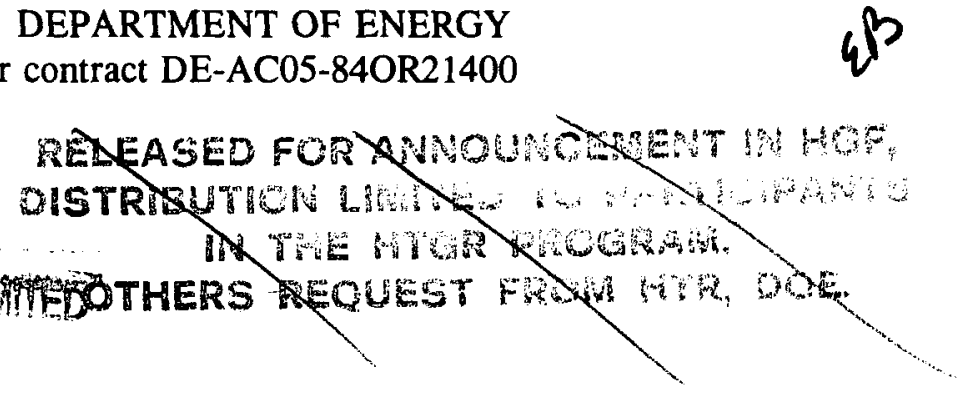
$\theta$

-

0 


\section{CONTENTS}

$\underline{\text { Page }}$

LIST OF FIGURES $\ldots \ldots \ldots \ldots \ldots \ldots \ldots \ldots \ldots \ldots \ldots \ldots \ldots$

LIST OF TABLES $\ldots \ldots \ldots \ldots \ldots \ldots \ldots \ldots \ldots \ldots \ldots \ldots \ldots \ldots \ldots \ldots$

PREFACE $\ldots \ldots \ldots \ldots \ldots \ldots \ldots \ldots \ldots \ldots \ldots \ldots \ldots \ldots \ldots \ldots$ xiii

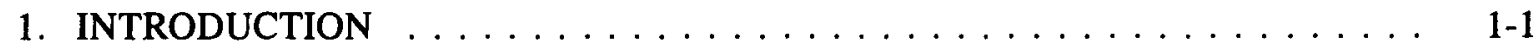

2. FUELS AND FISSION PRODUCT BEHAVIOR (WBS 1601) . . . . . . . . 2-1

2.1 FUEL MATERIALS DEVELOPMENT (1601.02) . . . . . . . . . . 2 2-1

2.1.1 Technology Planning, Assessments, and Analysis . . . . . . . . . 2-2

2.1.1.1 Fuels/Fissión Product Technology

Development Plan ................... 2-2

2.1.2 Irradiation Capsule Assembly, Operation, and PIE . . . . . . . . . 2-4

2.1.2.1 HRB-21 and HRB-22 Capsule Design . . . . . . . . . . 2-4

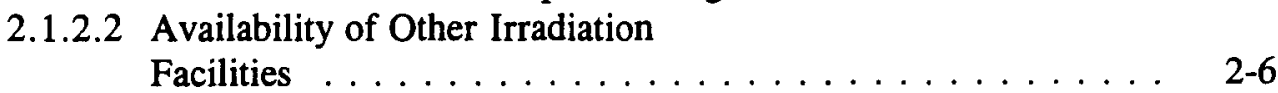

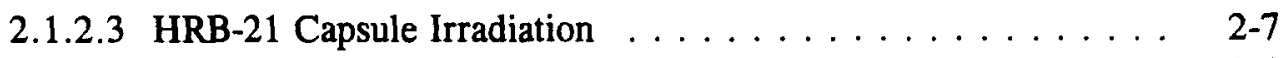

2.1.2.4 HRB-21 PIE . . . . . . . . . . . . . . . . 2-17

2.1 .3 Modeling . . . . . . . . . . . . . . . . . $2-28$

2.1.3.1 Fuel Modeling . . . . . . . . . . . . . . . . 2-28

2.1.3.2 Modeling of Fission Gas Release . . . . . . . . . . . . 2 2-30

2.1.3.3 Burnup Modeling . . . . . . . . . . . . . . . 2-32

2.1.4 Equipment Development and Maintenance ........... 2-35

2.1.4.1 Fission Gas Sampling Station . . . . . . . . . . . . 2-35

2.1.4.2 Irradiated Component Dimensional

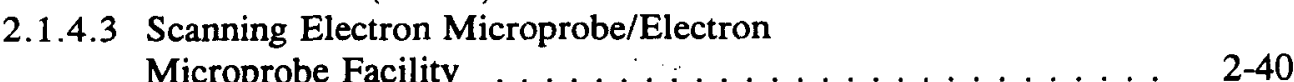

2.1.4.4 IMGA . . . . . . . . . . . . . . . . . . 2-40

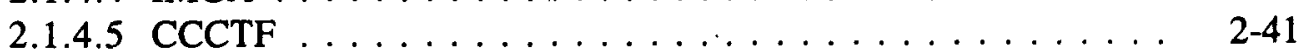

2.1.4.5.1 CCCTF Overview .............. $2-41$

2.1.4.5.2 CCCTF Characterization $\ldots \ldots \ldots \ldots \ldots \ldots . \ldots 2-52$

2.1.4.5.3 CCCTF Shakedown Run .............. . 2-58

2.1.4.6 Laser-Induced Fluorescence (LIF) . . . . . . . . . . . . . 2-67

2.1.5 International Cooperation . . . . . . . . . . . . . . . . 2-68

2.1.5.1 IMGA ............................ 2-68

2.1.5.2 U.S./FRG FFPG Subprogram Manager's Meeting . . . . . . 2-75

2.1.5.3 Proposed U.S./FRG Iodine Release Experiment . . . . . . . . . 2-76

2.1.5.4 Second Fuel Performance Experts Meeting . . . . . . . . . 2-76

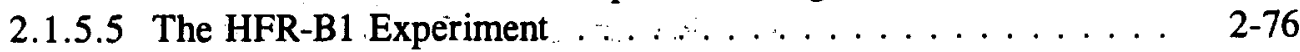

2.1.5.6 U.S./Japan Cooperation . . . . . . . . . . . . . . 2-80

2.1.5.7 IAEA Coordinated Research Program (CRP)-2 . . . . . . . . 2-80 


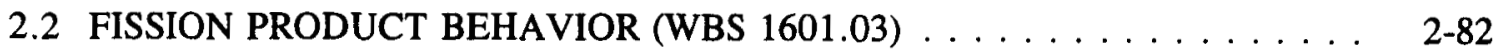

2.2.1 Fission Product Transport . . . . . . . . . . . . . . . . . 2-82

2.2.1.1 Determination of Defect or Failed Fractions . . . . . . . . 2-82

2.2.1.2 The Effect of Water Vapor on the Release of Gaseous Fission Products . . . . . . . . . . . . . 2-84

2.2.1.3 Transport of Iodine . . . . . . . . . . . . . . . . . . 2-88

2.2.1.4 Transport of Cesium . . . . . . . . . . . . . . 2-92

2.2.1.5 The Effect of Neutrons on the Uptake of Fission Product by the SiC Coating . . . . . . . . . . . . . 2-93

2.2.1.6 Washoff Studies . . . . . . . . . . . . . . . . . . . . 2 2-94

2.2.1.7 Fort St. Vrain Reactor (FSVR) Dust Characterization . . . . . 2-96

2.2.1.8 Dust Characterization Studies . . . . . . . . . . . . . . . 2-96

2.2.2 COMÉDIE Test Program . . . . . . . . . . . . . . . . . 2-97

2.2.3 MIT Subcontract (DABLE Loop) . . . . . . . . . . . . . . . . . 2-104

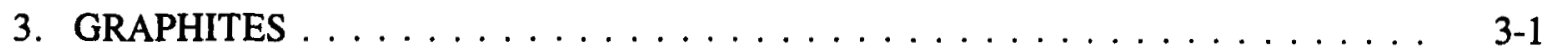

3.1 IRRADIATION BEHAVIOR $\ldots \ldots \ldots \ldots \ldots \ldots$ 3-1

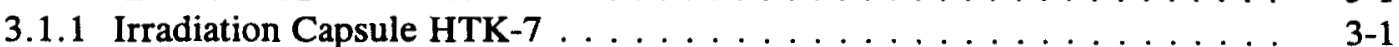

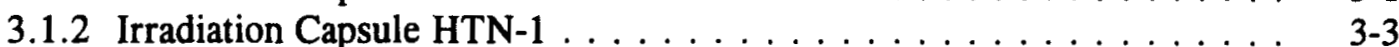

3.1 .3 Irradiation Capsule HTN-2 . . . . . . . . . . . . . . . $3-6$

3.1 .4 Capsule HTN-3 . . . . . . . . . . . . . . . . . . $3-6$

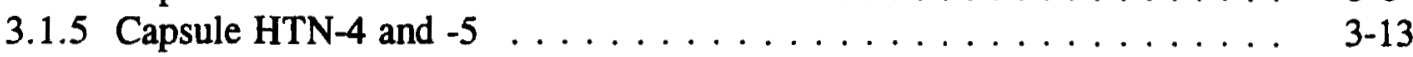

3.1.6 Fundamental Irradiation Studies . . . . . . . . . . . . . . . . . . . . 3-14

3.1.7 Irradiation Creep Studies . . . . . . . . . . . . . . . . . 3-15

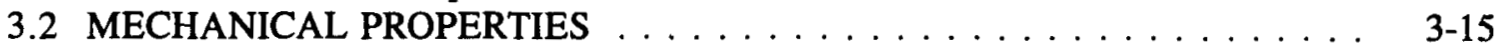

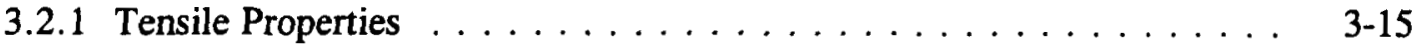

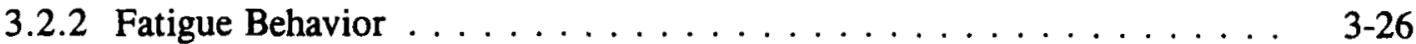

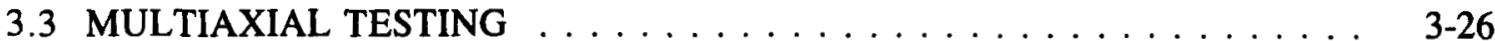

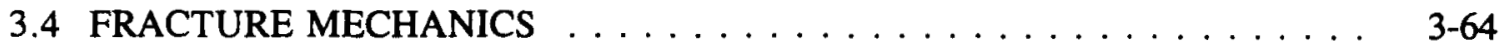

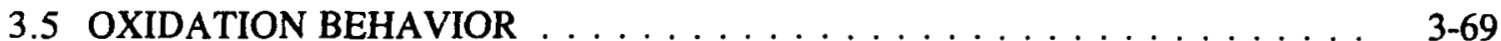

3.5.1 Air Oxidation of $\mathrm{H}-451 \ldots \ldots \ldots \ldots \ldots$ 3-69

3.5.2 Dimensional Changes Associated with Air Oxidation of $\mathbf{H}-451$ Graphite . . . . . . . . . . . . . . . . . . 3-76

3.5.3 Water Vapor Reactions . . . . . . . . . . . . . . . . . . . . . . 3-80

3.5.3.1 Spectroscopic Analyses . . . . . . . . . . . . . . . 3-82

3.5.3.2 Microscopic Analyses . . . . . . . . . . . . . . 3-82

3.5 .4 Water Vapor Reactions ... . . . . . . . . . . . . . 3-83

3.5.4.1 Temperature Effects . . . . . . . . . . . . . . 3-83

3.5.4.2 Flow-Rate Effects . . . . . . . . . . . . . . . . . 3-83

3.5.4.3 Burnoff Effects . . . . . . . . . . . . . . . 3-84

3.5.5 The Effect of Trace Elements on the Surface Oxidation of

H-451 Graphite . . . . . . . . . . . . . . . . . . . 3-85

3.5.6 Trace Inorganic Components in Nuclear Graphites . . . . . . . . . . . . 3-86

3.5.7 High-Pressure Test Loop . . . . . . . . . . . . . . . . . . . . . 3-87

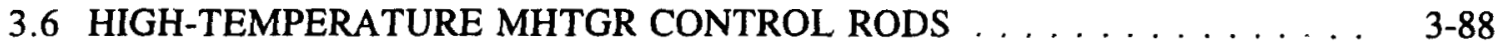

3.7 THERMAL-PHYSICAL PROPERTIES . . . . . . . . . . . . . . . . . 3-91 


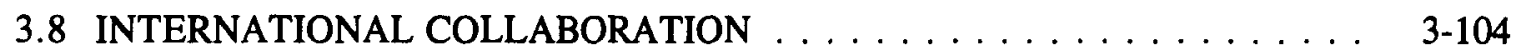

3.8.1 Collaboration with Germany . . . . . . . . . . . . . . . . . 3-104

3.8.2 Collaboration with Japan . . . . . . . . . . . . . . . . . 3-107

3.8.2.1 Fracture Mechanics Studies . . . . . . . . . . . . . 3 3-107

3.8.2.2 Graphite Fracture Modelling . . . . . . . . . . . . . . . . 3-109

3.8.2.3 Irradiation Effects . . . . . . . . . . . . . . . . 3-113

3.8.2.4 Graphite Oxidation . . . . . . . . . . . . . 3-113

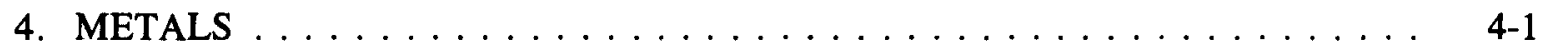

4.1 IRRADIATION TESTING OF PRESSURE-VESSEL STEELS $\ldots \ldots \ldots \ldots$ 4-1

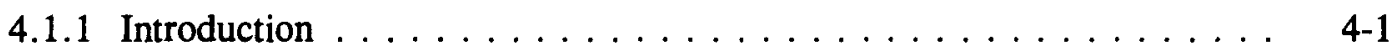

4.1.2 Irradiation Matrix and Experimental Procedure . . . . . . . . . 4-2

4.1 .3 Results and Discussion ................... 4-6

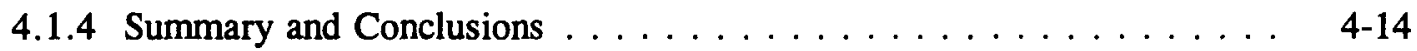

4.2 IN-REACTOR METALS $\ldots \ldots \ldots \ldots \ldots \ldots \ldots \ldots \ldots \ldots$ 4 . . . . . . . . . . . . .

4.2.1 Tensile and Creep Properties . . . . . . . . . . . . . . . 4-15

4.2.2 Fracture Mechanics Properties of Alloy $800 \mathrm{H}$ for the

NP-MHTGR Reactor . . . . . . . . . . . . . . . . . . . . 4-16

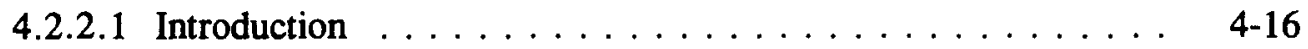

4.2.2.2 Material Preparation . . . . . . . . . . . . . . . . 4-19

4.2.2.3 Equipment and Facilities . . . . . . . . . . . . 4-19

4.2.2.4 Instrumentation and Control $\ldots \ldots \ldots \ldots$ 4-23

4.2.2.5 Current Status . . . . . . . . . . . . . . . . . . 4-23

4.3 IRRADIATION PROPERTIES OF INCOLOY $800 \mathrm{H} \ldots \ldots \ldots \ldots \ldots \ldots$. . . . . . $4-23$

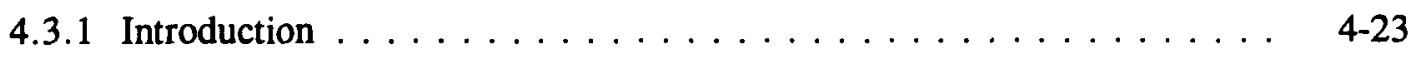

4.3 .2 Experimental Methods $\ldots \ldots \ldots \ldots \ldots \ldots \ldots$ 4 $\ldots \ldots \ldots \ldots$

4.3.3 Results and Discussion $\ldots \ldots \ldots \ldots \ldots \ldots \ldots \ldots$ 4-26

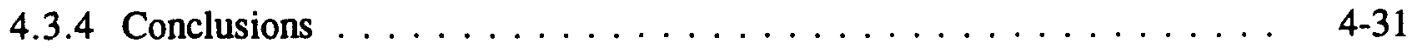

4.4 PROPERTIES OF HEAT TRANSPORT MATERIALS $\ldots \ldots \ldots \ldots \ldots \ldots$. . . 4-31

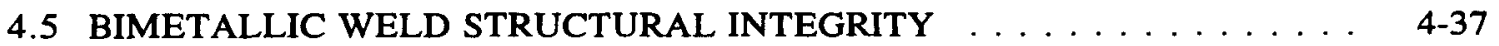

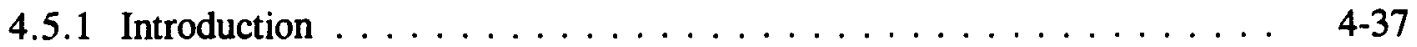

4.5 .2 Task Description . . . . . . . . . . . . . . . . . 4-38

4.5 .3 Preliminary Tests $\ldots \ldots \ldots \ldots \ldots \ldots \ldots \ldots$. . . . . . . . . . . . . .

4.5 .4 Test Results . . . . . . . . . . . . . . . . . . . . 4 4-42

4.5.5 Discussion of Results . . . . . . . . . . . . . . . . . . 4-44

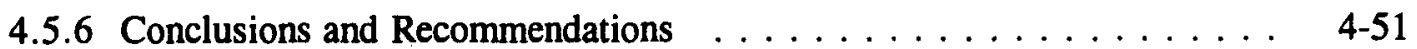

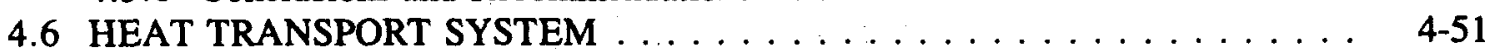

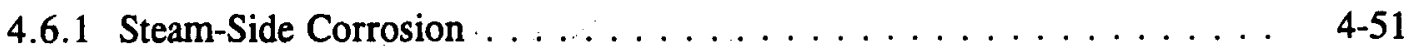

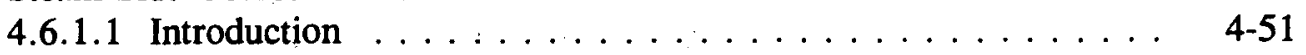

4.6.1.2 Procedures . . . . . . . . . . . . . . 4-52

4.6 .1 .3 Status . . . . . . . . . . . . . . . . . 4-54

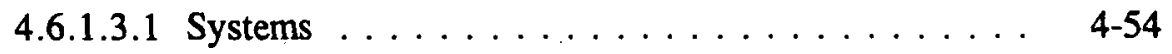

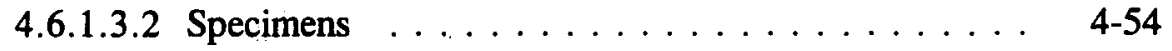

4.6.1.3.3 Test Matrix . . . . . . . . . . . . . . 4-55

4.6.2 Fort St. Vrain Ringheader Evaluation . . . . . . . . . . . . . . . . 4-61 
4.6.2.1 Introduction $\ldots \ldots \ldots \ldots \ldots \ldots \ldots \ldots \ldots$ 4 $\ldots \ldots \ldots$

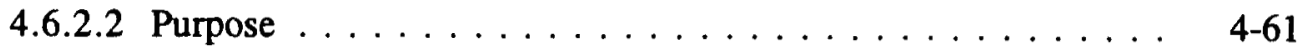

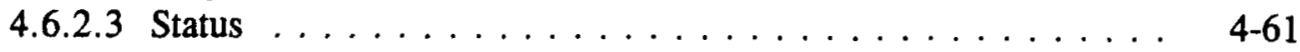

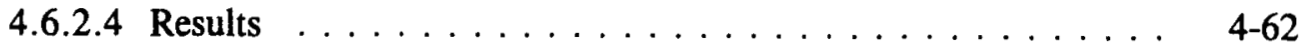

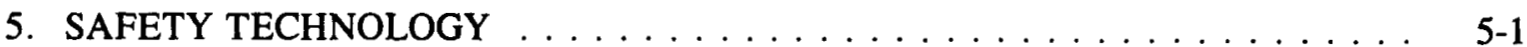

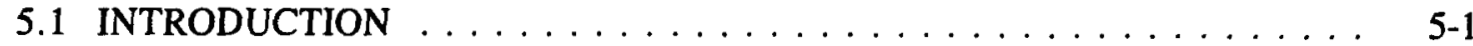

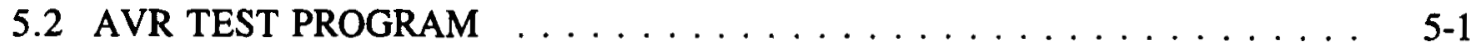

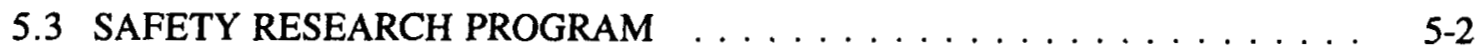

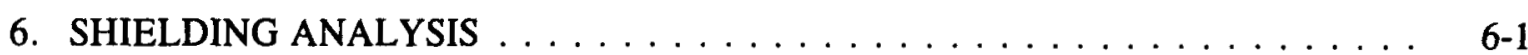

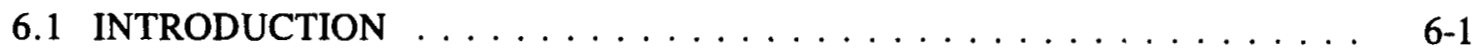

6.2 ANALYSIS OF THE BOTTOM REFLECTOR AND NEUTRON

STREAMING INTO THE HOT-GAS PLENUM . . . . . . . . . . . . . 6 6-2

6.2 .1 The Analysis and the Results . . . . . . . . . . . . . 6 6-2

6.2 .2 Initial Uncertainty Estimates . . . . . . . . . . . . . . 6-8

6.2.2.1 Review of Earlier Experiments and Analyses . . . . . . . . . 6 6-8

6.2.2.2 Statistical Uncertainty Estimates for the Fluence in the Hot-Gas Plenum of the MHTGR . . . . . . . . . . 6-10

6.2.3 Partial Validation of the Calculational Strategy and

Cross-Section Data Using One of the Earlier TSR Experiments . . . . . . 6-11

6.3 SHIELDING ANALYSIS OF THE HOLLOW CONTROL RODS AND OTHER DESIGN OPTIONS IN THE UPPER PLENUM OF THE COMMERCIAL MHTGR

6.4 ANALYSIS OF THE BORATED PIN ARRAYS IN THE PERMANENT SIDE REFLECTOR AND A PLANNED EXPERIMENTAL MOCKUP . . . . . 6-17

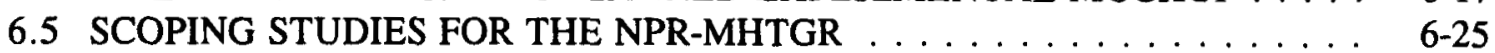

6.6 INVESTIGATION OF NEWLY PROPOSED RADIATION

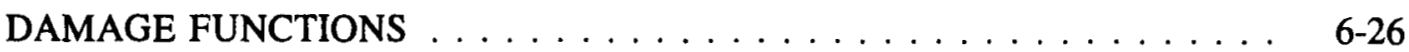

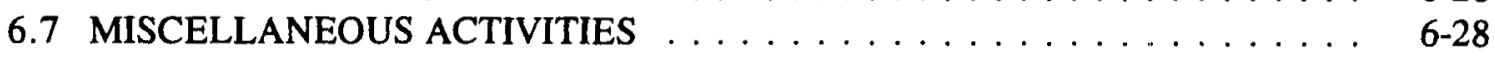

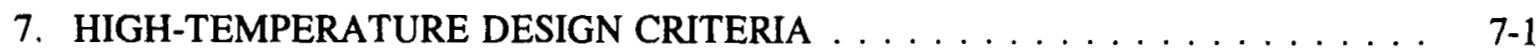

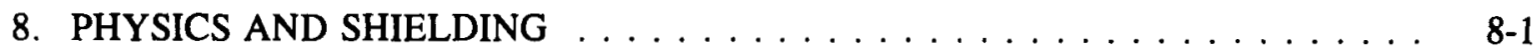

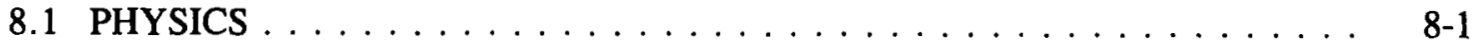

8.1 .1 Introduction . . . . . . . . . . . . . . $\ldots \ldots$ 8-1

8.1.2 Errors in ENDF/B-V Graphite Data . . . . . . . . . . . . . 8 8-1

8.1.3 Development of Graphite Cross-Section Scattering Covariances . . . . . 8 8-4

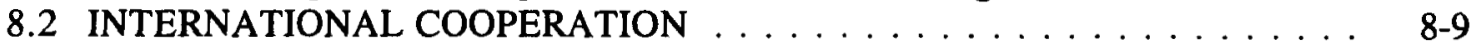

8.2.1 Introduction . . . . . . . . . . . . . . . . . . 8-9

8.2.2 CRP on the Validation of Safety-Related Physics Calculations for LEU Fueled HTGRs . . . . . . . . . . . . . . . . . . . . . . . 8-9

8.2.2.1 PROTEUS QA Program . . . . . . . . . . . . . . . 8 8-10

8.2.2.2 Assignments of ORNL Researchers to PSI . . . . . . . . . . 8-11

8.2.2.3 CRP Numerical Benchmark Program . . . . . . . . . . 8-12 
8.2.3 Cooperative Agreement with JAERI to Exchange Neutronics Information Under ANNEX-5 . . . . . . . . . . . . . . . . . 8-12

8.2.3.1 A Comparison of the VHTGR to the U.S. MHTGR Design . . . 8-14

8.2.3.2 Existing VHTGR Data of Relevance to the MHTGR

Program Needs . . . . . . . . . . . . . . . . 8-14

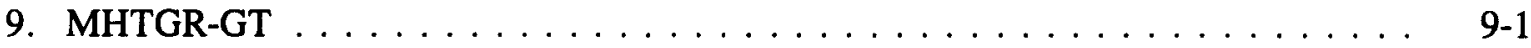

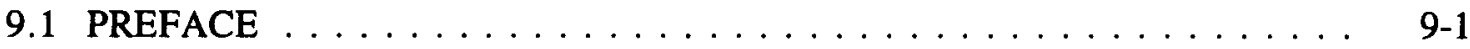

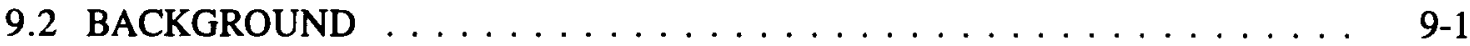

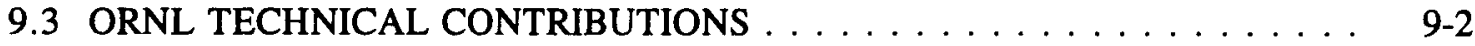

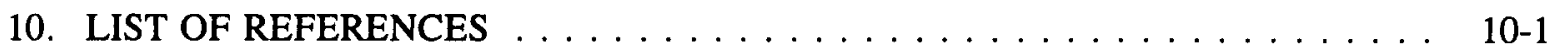


$\bullet$

$\bullet$

$\theta$ 


\section{LIST OF FIGURES}

Figure

$\underline{\text { Page }}$

2-1 Cross-section mock-up of irradation capsule HRB-21 for thermal design calculational purposes: horizontal cross section, $r-\theta$ view $\ldots \ldots \ldots \ldots \ldots$

2-2 Overview of the capsule operation showing the time evolution of the capsule average fuel temperature and the percent helium in the capsule

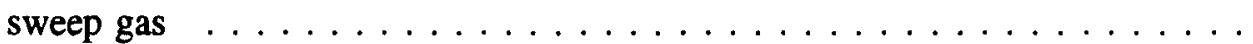

2-3 Indicated helium and neon flow rates as a function of elapsed time $\ldots \ldots \ldots$

2-4 Capsule average fuel temperature with points of interest labeled for discussion. The cycle numbers are listed just above the abscissa

2-5 Cumulative count of ionization chamber pulses (failed particles) and ${ }^{85 m} \mathrm{Kr} \mathrm{R} / \mathrm{B}$ for HRB-21 capsule $\ldots \ldots \ldots \ldots \ldots$

2-6 R/B values for $\mathrm{Xe}-133$ and $\mathrm{Xe}-138$ and the capsule average fuel temperature as a function of time from the start of the irradiation . . . . . . . . . . .

2-7 $\mathrm{R} / \mathrm{B}$ values for ${ }^{85 \mathrm{~m}} \mathrm{Kr}$ and ${ }^{88} \mathrm{Kr}$ and the capsule average fuel temperature

2-8 Comparison of the distribution sphere model calculations with measurements of $\mathrm{R} / \mathrm{B}\left({ }^{85 \mathrm{~m}} \mathrm{Kr}\right.$ and $\left.{ }^{87} \mathrm{Kr}\right)$ for an irradiated uranyl/barium stearate-graphite system

2-9 Comparison of the distribution sphere model calculations with measurements of $\mathrm{R} / \mathrm{B}\left({ }^{85 \mathrm{~m}} \mathrm{Kr}\right.$ and $\left.{ }^{87} \mathrm{Kr}\right)$ for an irradiated system of

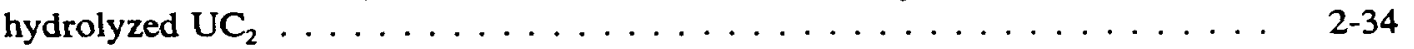

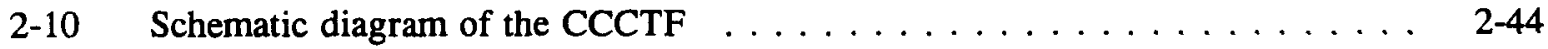

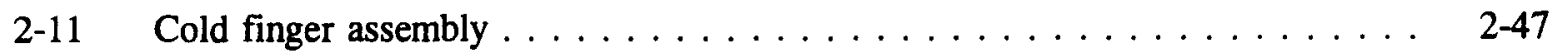

$2-12 \quad$ Cold trap cross section $\ldots \ldots \ldots \ldots \ldots \ldots \ldots \ldots \ldots \ldots \ldots \ldots$

2-13 (a)Total cesium mass balance for cesium tracer test. (b) Released

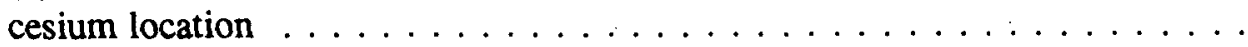

2-14 Effect of krypton migration on detected activity as a function of temperature ........................ 2-56

2-15 Furnace temperature history for the shakedown test $\ldots \ldots \ldots$ 2-62 
2-16 Integrated cesium release for the shakedown test. Corrected to

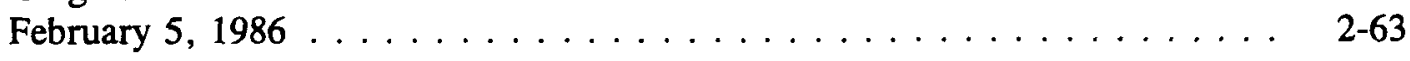

2-17 Deposition cup collection rate as a function of time for the

shakedown test. Corrected to February $5,1986 \ldots \ldots \ldots \ldots$ 2-64

2-18 Krypton collection for the shakedown test. Corrected to March 24, $1992 \ldots$ 2-65

2-19 The dependence of the cesium content of the SiC layer, normalized to the equivalent neutron damage, on the fast neutron fluence $\ldots \ldots \ldots \ldots .2-95$

3-1 Irradiation induced dimensional changes in grades $\mathrm{H}-451$ and 2020 graphics irradiated at $-600^{\circ} \mathrm{C}$ in capsule HTK-7 . . . . . . . . . 3-4

3-2 Irradiation-induced dimensional changes in grade $\mathrm{H}-451$ graphite irradiated at $\sim 600^{\circ} \mathrm{C}$ in HFIR capsule HTN $-2 \ldots \ldots \ldots$. . . . . . . .

3-3 Irradiation-induced dimensional changes in grade TS-1507 graphite irradiated at $\sim 600^{\circ} \mathrm{C}$ in HFIR capsule $\mathrm{HTN}-2 \ldots \ldots \ldots \ldots$. . . . . . .

3-4 Irradiation-induced dimensional changes in A-coke graphite irradiated at $-600^{\circ} \mathrm{C}$ in HFIR capsule HTN-2

3-5 Irradiation-induced dimensional changes in C-coke (FSV) graphite irradiated at $-600^{\circ} \mathrm{C}$ in HFIR capsule $\mathrm{HTN}-2 \ldots \ldots \ldots \ldots$

3-6 Irradiation-induced dimensional changes in D-coke graphite irradiated at $-600^{\circ} \mathrm{C}$ in HFIR capsule $\mathrm{HTN}-2 \ldots \ldots \ldots \ldots$

3-7 Irradiation-induced dimensional changes in G-coke graphite irradiated at $\sim 600^{\circ} \mathrm{C}$ in HFIR capsule HTN-2 capsule HTK-7

3-8 Irradiation-induced dimensional changes in grade $\mathrm{H}-451$ graphite irradiated at $\sim 900^{\circ} \mathrm{C}$ in HFIR capsule HTN-3 . . . . . . . . . 3-10

3-9 Irradiation-induced dimensional changes in grade TS-1507 graphite irradiated at $\sim 900^{\circ} \mathrm{C}$ in HFIR capsule HTN-3

3-10 Irradiation-induced dimensional changes in A-coke graphite irradiated at $\sim 900^{\circ} \mathrm{C}$ in $\mathrm{HFIR}$ capsule $\mathrm{HTN}-3 \ldots \ldots \ldots \ldots$

3-11 Irradiation-induced dimensional changes in C-coke graphite irradiated at $-900^{\circ} \mathrm{C}$ in HFIR capsule $\mathrm{HTN}-3 \ldots \ldots \ldots \ldots$

3-12 Irradiation-induced dimensional changes in D-coke graphite irradiated at $\sim 900^{\circ} \mathrm{C}$ in $\mathrm{HFIR}$ capsule $\mathrm{HTN}-3$ 
3-13 Irradiation-induced dimensional changes in G-coke graphite irradiated at $\sim 900^{\circ} \mathrm{C}$ in HFIR capsule $\mathrm{HTN}-3 \ldots \ldots \ldots$. . . . . . . . . . . . . .

3-14 Slabbing plan for billet 58-293 showing specimen positions $\ldots \ldots \ldots \ldots$. . . . 3-17

3-15 Radial locations for tensile specimens in billet $58-293 \ldots \ldots \ldots \ldots$. . . . . . . .

3-16 Mean tensile strength versus position along the length of billet $58-293 \ldots \ldots \ldots \ldots \ldots \ldots \ldots \ldots$ 3-20 . . . . . . . . . . . . . . . .

3-17 Mean tensile strength versus radial location through the cross-section

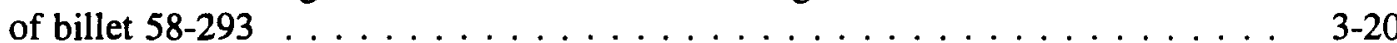

3-18 Mean tensile strengths of the four specimen sizes at radial location 6 in billet $58-293$ compared with Weibull predictions $\ldots \ldots \ldots$. . . . . . .

3-19 Mean tensile strengths of the four specimen sizes of radial location 4 in billet $58-293$ compared with Weibull predictions . . . . . . . . . . . . 3-21

3-20 Tensile data for 6.36-mm diameter specimens lying near GLCC specimens form the sample cylinder removed from billet $58-293 \ldots \ldots$. . . . . . . . . . 3-22

3-21 Tensile data for billet 58-293 compared with Burchell model predictions . . . . 3-22

3-22 H-451 graphite billet slabbing plan for determination of material variability, i.e., class-to-class, lot-to-lot, and billet-to-billet . . . . . . . . . 3-24

3-23 Comparison of radial and axial specimen orientations in billet 58-29 $\ldots \ldots$. . . 3-25

3-24 Comparison of tangential and axial specimen orientations in billet 58-29 . . . 3-25

3-25 Multiaxial graphite loading arrangement $\ldots \ldots \ldots \ldots \ldots \ldots \ldots$

3-26 Comparison of fracture data from RAXM thin-walled tubes with theories

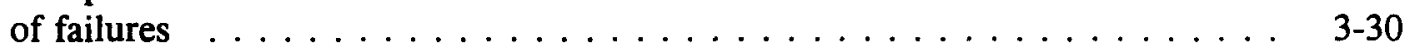

3-27 LEFM prediction of effect of wall thickness on mean strength and

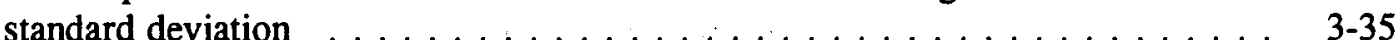

3-28 The ratio of the peak circumferential stress on the inside of pressurized cylinder to the nominal stress increases as the ratio of the inside radius to the wall thickness decreases

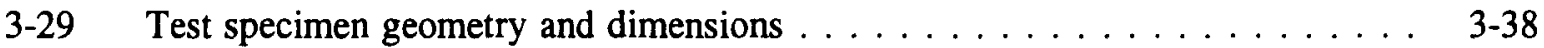

3-30 Finite element model $\ldots \ldots \ldots \ldots \ldots \ldots \ldots$ 3-40 
3-31 Stress on inside surface $0: 1$ ratio, $\mathrm{F}=4,000 \mathrm{lb} . \ldots \ldots$ 3-41

3-32 Stress on outside surface $0: 1$ ratio, $F=4,000 \mathrm{lb} \ldots \ldots \ldots . \ldots \ldots$

3-33 Stress on inside surface $1: 0$ ratio, $P=412$ PSI $\ldots \ldots \ldots$ 3-43

3-34 Stress on outside surface $1: 0$ ratio, $\mathrm{P}=412$ PSI $\ldots \ldots \ldots \ldots$ 3-44

3-35 Stress on inside surface $1: 1$ ratio, $\mathrm{P}=412 \mathrm{PSI}, \mathrm{F}=4,000 \mathrm{lb} . \ldots \ldots \ldots$

3-36 Stress on outside surface $1: 1$ ratio, $P=412$ PSI, $F=4,000 \mathrm{lb} . \ldots \ldots$ 3-47

3-37 Stress on inside surface $1: 1.3$ ratio, $P=317 \mathrm{PSI}, \mathrm{F}=4,000 \mathrm{lb} \ldots \ldots \ldots$ 3-48

3-38 Stress on outside surface $1: 1.3$ ratio, $P=317 \mathrm{PSI}, \mathrm{F}=4,000 \mathrm{lb} \ldots \ldots \ldots$

3-39 Stress on inside surface $1: 2$ ratio, $P=206 \mathrm{PSI}, \mathrm{F}=4,000 \mathrm{lb} . \ldots \ldots \ldots \ldots$

3-40 Stress on outside surface $1: 2$ ratio, $P=206 \mathrm{PSI}, \mathrm{F}=4,000 \mathrm{lb} . \ldots \ldots$

3-41 Stress on inside surface $2: 1$ ratio, $\mathrm{P}=824 \mathrm{PSI}, \mathrm{F}=4,000 \mathrm{lb} . \ldots \ldots \ldots$

3-42 Stress on outside surface $2: 1$ ratio, $P=824 \mathrm{PSI}, \mathrm{F}=4,000 \mathrm{lb} . \ldots \ldots 3-53$

3-43 Stress on inside surface $0:-1$ ratio, $F=4,000 \mathrm{lb} \ldots \ldots \ldots$ 3-55

3-44 Stress on outside surface $0:-1$ ratio, $\mathrm{F}=4,000 \mathrm{lb} . \ldots \ldots \ldots \ldots$

3-45 Strain-gaged aluminum tube verified uniformity of strain distribution predicted by elastic finite element analysis $\ldots \ldots \ldots \ldots$ 3-58

3-46 Multiaxial graphite test facility $\ldots \ldots \ldots \ldots \ldots \ldots \ldots \ldots$

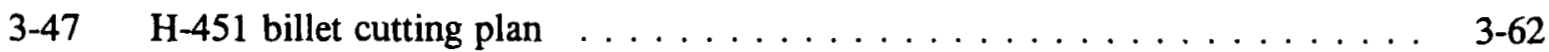

3-48 Failure data obtained in multiaxial graphite test facility $\ldots \ldots \ldots \ldots$ 3-63

3-49 The chevron-notched short-rod specimen geometry $\ldots \ldots \ldots \ldots$. . . . . . .

3-50 Chevron-notched short-rod fracture toughness versus specimen size for unirradiated H-451, stackpole 2020 and IG110 nuclear graphites under ambient conditions . . . . . . . . . . . . . . . . . . 3-66

3-51 Center slab cutting plan $\ldots \ldots \ldots \ldots \ldots \ldots \ldots \ldots$

3-52 Temperature variation of air corrosion rate with $\mathrm{H}-451$ graphite $\ldots \ldots \ldots$ 3-78 
3-53 Parameter evaluation for the reaction rate of air with $\mathrm{H}-451$ graphite (sample K018) . . . . . . . . . . . . . . . . . . . . . 3-79

3-54 Dimensional changes occurring on oxidation of graphite . . . . . . . . 3-81

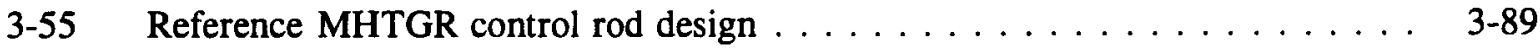

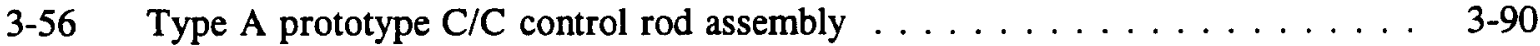

3-57 Type B prototype $\mathrm{C} / \mathrm{C}$ control rod assembly $\ldots \ldots \ldots \ldots \ldots$ 3-92

3-58 $\quad \mathrm{H}-451$ graphite billet cutting diagram $\ldots \ldots \ldots \ldots \ldots \ldots \ldots \ldots$

3-59 H-451 graphite billet center slab cutting diagram $\ldots \ldots \ldots \ldots \ldots \ldots \ldots$. . . . . . . . .

3-60 $\quad \mathrm{H}-451$ graphite thermal physical properties specimen details $\ldots \ldots \ldots$ 3-95

3-61 Room-temperature thermal conductivity data for $\mathrm{H}-451$ graphite (axial orientation) showing spatial distribution $\ldots \ldots \ldots \ldots \ldots$ 3-96 . . . . . . .

3-62 Room-temperature thermal conductivity data for $\mathrm{H}-451$ graphite (radial orientation) showing spatial distribution . . . . . . . . . . . . 3-96

3-63 Room-temperature thermal conductivity data for $\mathrm{H}-451$ graphite (tangential orientation) showing spatial distribution $\ldots \ldots \ldots \ldots$. . . . . . . . . . .

3-64 Probability plot of $\mathrm{H}-451$ graphite room-temperature thermal conductivity data (axial orientation) $\ldots \ldots \ldots \ldots \ldots \ldots$ 3-9. . . . . . . .

3-65 Probability plot of $\mathrm{H}-451$ graphite room-temperature thermal conductivity data (radial orientation) $\ldots \ldots \ldots \ldots$. . . . . . . . . . . . .

3-66 Probability plot of $\mathrm{H}-\mathbf{4 5 1}$ graphite room-temperature thermal

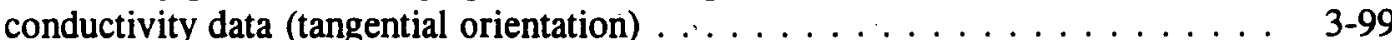

3-67 Temperature dependence of $\mathrm{H}-451$ graphite thermal conductivity

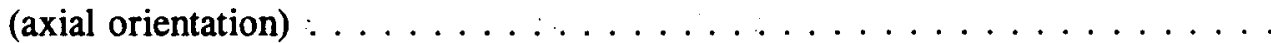

3-68 Temperature dependence of $\mathrm{H}-451$ graphite thermal conductivity

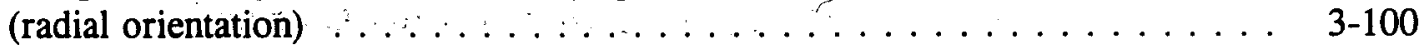

3-69 Temperature dependence of $\mathrm{H}-451$ graphite thermal conductivity (tangential orientation) . . . . . . . . . . . . . . . . . . . . 3-100

3-70 Irradiation-induced dimensional changes in ASR-1RS, ARS-2RS, and ATR-2E grade graphites irradiated at $-600^{\circ} \mathrm{C}$ in capsule HTK-7 
3-71 Failure probabilities for grade $\mathrm{H}-451$ graphite comparison of model predictions and experimental data . . . . . . . . . . . . . 3-110

3-72 Failure probabilities for grade IG-110 graphite comparison of model predictions and experimental data . . . . . . . . . . . 3-110

3-73 Failure probabilities for grade $\mathrm{H}-451$ graphite; comparison of model predictions and experimental data . . . . . . . . . . . .

3-74 Pore size distribution for $\mathrm{H}-451$ graphite (specimen 92 0751, 10 fields $@ \times 5,1673$ pores $\ldots \ldots \ldots \ldots \ldots \ldots$

3-75 Irradiation-induced dimensional changes in IG-110 and 2020 grade graphites irradiated at $\sim 600$

4-1 Effect of irradiation temperature on tensile properties of A 533 grade B class 1 plates [fluence of $0.7 \times 10^{18}$ neutrons $/ \mathrm{cm}^{2}(>1 \mathrm{MEV})$ ].

(a) plate $\mathrm{G}, 0.07 \% \mathrm{CU},(b)$ plate $\mathrm{H}, 0.14 \% \mathrm{CU} \ldots \ldots \ldots \ldots$

4-2 Effect of irradiation temperature on the charpy impact energy and the 41-J transition temperature shift $\mathrm{V}\left(\Delta \mathrm{T}_{41}\right)$ for A 533 grade B class 1 steel, plate $\mathrm{G}, 0.07 \% \mathrm{CU}$

4-3 Effect of irradiation temperature on the charpy fracture appearance and the $50 \%$ shear transition temperature shift for A 533 grade B class 1 steel, plate $\mathrm{G}, 0.07 \% \mathrm{CU} \ldots \ldots \ldots \ldots$

4-4 Effect of irradiation temperature on the charpy impact energy and the 41-J transition temperature shift $\left(\Delta \mathrm{T}^{41}\right)$ for A 533 grade B

4-5 Effect of irradiation temperature on the charpy fracture appearance and the $50 \%$ shear transition temperature shift for A 533 grade B class 1 steel, plate $\mathrm{H}, 0.14 \% \mathrm{CU}$

4-6 Charpy V-notch impact energy of A 533 grade B class 1 pressure vessel steel, plate $\mathrm{G}, 0.07 \% \mathrm{CU}$, unirradiated, and $163^{\circ} \mathrm{C}$ irradiation data . . . . .

4-7 Charpy V-notch impact energy of A 533 grade B class 1 pressure vessel steel, plate $\mathrm{H}, 0.14 \% \mathrm{CU}$, unirradiated, and $163^{\circ} \mathrm{C}$ irradiation data . . . . .

4-8 Miniature tensile specimens [24 specimens packaged equivalent to one charpy $V$-notch specimen $(1 \times 1 \times 5.5 \mathrm{~cm})] \ldots \ldots \ldots \ldots \ldots$

4-9 Comparison between regular size and miniature tensile specimens of A 533 grade B class 1 pressure vessel steel 
4-10 Correlation between transition temperature shift $\left(\Delta \mathrm{T}^{41}\right)$ and the change in yield strength due to neutron irradiation $\ldots \ldots \ldots$. . . . . . . .

4-11 Specimen geometries used in a automated ball indentation (ABI) tests $\ldots \ldots$ 4-14

4-12 Schematic of test setup for helium environment, high-temperature tests . . . . 4-20

4-13 Photo of test system equipment assembled for the current project $\ldots \ldots \ldots$. . . .

4-14 Schematic of dead-weight loading of creep crack growth specimens . . . . . . 4-22

4-15(a) Rabbit body for irradiation of four sheet tensile specimens. Four holes are provided for dosimeters and melting temperature monitors . . . . . . 4-25

4-15(b) End cap for rabbit. A single nickel wire is threaded through the holes and twisted tight to hold the end caps in place in case

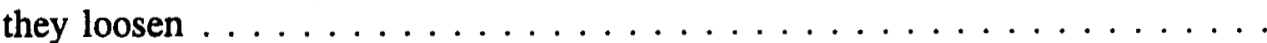

4-16 Stress vs strain for Incoloy $800 \mathrm{H}$ comparing irradiated at $400^{\circ} \mathrm{C}$ and unirradiated specimens $\mathrm{J} 29$ and $\mathrm{J} 39$, respectively $\ldots \ldots \ldots \ldots$

4-17 Stress vs strain for Incoloy $800 \mathrm{H}$ comparing irradiated at $400^{\circ} \mathrm{C}$ and unirradiated specimens $\mathrm{J} 21$ and $\mathrm{J} 33$, respectively

4-18 Stress vs strain for Incoloy $800 \mathrm{H}$ welded with Inconel 82 filler metal showing the effect of irradiation using specimens $\mathrm{J} 10$ and $\mathrm{J} 13$ containing base metal, HAZ, and fusion zone in the gage section $\ldots \ldots \ldots \ldots$

4-19 Stress vs strain for Incoloy $800 \mathrm{H}$ welded with Inconel 82 filler metal showing the effect of irradiation using specimens $\mathrm{J} 5$ and $\mathrm{J} 2$ containing base metal, HAZ, and fusion zone in the gage section $\ldots \ldots \ldots \ldots$

4-20 Stress vs strain for Incoloy $800 \mathrm{H}$ tested at $900^{\circ} \mathrm{C}$ comparing irradiated at $400^{\circ} \mathrm{C}$ and unirradiated specimens $\mathrm{J} 22$ and $\mathrm{J} 31$, respectively . . . . . . . 4-30

4-21 Fracture surface on Incoloy $800 \mathrm{H}$ specimen J29 irradiated to a thermal fluence of $3.0 \times 10^{24} \mathrm{~N} / \mathrm{M}^{2}$ and $0.014 \mathrm{DPA}$ at $400^{\circ} \mathrm{C}$ and tested at $700^{\circ} \mathrm{C} \ldots$

4-22 Fracture surface and lateral side of Incoloy $800 \mathrm{H}$ unirradiated specimen $\mathrm{J} 39$ tested at $700^{\circ} \mathrm{C}$

4-23 Fracture surface of Incoloy $800 \mathrm{H}$ unirradiated specimen $\mathrm{J} 31$ tested at $900^{\circ} \mathrm{C} \ldots \ldots \ldots \ldots \ldots \ldots \ldots \ldots \ldots$ 
4-24 Fracture surface of Incoloy $800 \mathrm{H} /$ Inconel 82 weld specimen J5 irradiated to a thermal fluence of $3.0 \times 10^{24} \mathrm{~N} / \mathrm{M}^{2}$ and $0.014 \mathrm{DPA}$ at $400^{\circ} \mathrm{C}$ and tested at $700^{\circ} \mathrm{C} \ldots \ldots \ldots \ldots$

4-25 Test specimens fabricated from prototypic steam-generator tubing . . . . . . . 4-40

4-26 Axial stress (1 KSI =6.895 MPA) vs. axial strain for austenitic-tubing specimen without weld during initial loading and next five complete stress cycles at $482^{\circ} \mathrm{C}\left(900^{\circ} \mathrm{F}\right) \ldots \ldots \ldots \ldots \ldots \ldots$

4-27 Stress amplitude ( $1 \mathrm{KSI}=6.895 \mathrm{MPA})$ vs. cycles to failure for five bimetallic-weld and two base-metal specimens (symbols) at $482^{\circ} \mathrm{C}\left(900^{\circ} \mathrm{F}\right)$. Lower solid and dashed line corresponds to BMW fatigue model and upper dashed line to fatigue model for Alloy $800 \mathrm{H} \ldots \ldots \ldots \ldots \ldots$

4-28 Average values of strain range (symbols) vs. cycles to failure for Alloy $800 \mathrm{H}$ at $482^{\circ} \mathrm{C}\left(900^{\circ} \mathrm{F}\right)$. Lines correspond to fatigue models for elastic, plastic and total strain $\ldots \ldots \ldots \ldots \ldots$

4-29 Cyclic stress amplitude (1 KSI =6.895 MPA) vs. cyclic strain amplitude corresponding to fatigue model for Alloy $800 \mathrm{H}$

4-30 Geometry of test specimens $\ldots \ldots \ldots \ldots \ldots \ldots \ldots \ldots$

6-1 Side view of the lower axial reflector, the support posts, the hot gas plenum, and the core support structure. Not drawn to scale . . . . . .

6-2 Proposed distribution of the 2160.5 -inch-diam borated graphite pins among the 1080.625 --inch-diam coolant holes in the bottom reflector block, and the right triangular wedge used to model this configuration in the 3-D morse shielding analyses

6-3(a) Detailed drawing of a typical graphite block containing the borated steel pins to be used in the experiments. Four such blocks would be required for the planned series of experiments. All dimensions are shown in inches $\ldots \ldots \ldots \ldots \ldots \ldots \ldots \ldots$

6-3(b) Top view of the four graphite pin-array blocks, arranged as shown in configuration be of Fig. 3-4

6-4 Isometric view of the planned borated pin array configurations if one were on the outside of the system looking back toward the reactor

6-5 Calculated values of the bare BF3 detector counting rates for each of the 15 originally planned configurations if the tower shielding reactor were operating at 1 kilowatt. See detailed data in Table 6-4 
6-6 Analytic sequence for calculating fluences on the upper internals and the upper head of the reactor vessel $\ldots \ldots \ldots \ldots \ldots \ldots$

6-7 Analytic sequence for calculating fluences for the lower internals and the lower head of the reactor vessel, including those in the hot gas plenum and those incident on the open end of the cross duct

8-1 Temperature coefficient of reactivity calculated with new and old scattering matrices for graphite $\ldots \ldots \ldots \ldots \ldots \ldots \ldots \ldots \ldots \ldots \ldots \ldots \ldots$

8-2 $S(\alpha, \beta)$ vs alpha for various values of beta-data from end $f / b-v$ data file $\ldots \ldots \quad 8-3$

8-3 $S(\alpha, \beta)$ vs alpha for various values of beta-data is ORNL-generated "1991 graphite scattering data"

8-4 Phonon distributions in graphite from different authors $\ldots \ldots \ldots \ldots \ldots$

8-5 The experimental results of Carvalho, graphite at $533^{\circ} \mathrm{K}, \beta=0.15$, are compared with GASKET calculations using three different spectras . . . . . . .

8-6 The experimental results of Carvalho, graphite at $533^{\circ} \mathrm{K}, \beta=0.6$, are compared with GASKET calculations using three different spectras 
$\vartheta$

0

$\theta$ 


\section{LIST OF TABLES}

$\underline{\text { Table }}$

2-1 HRB-21 irradiation dates, with time elapsed since first HFIR full-power exposure, cycle time at full power, and total time

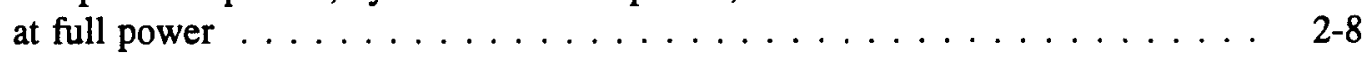

2-2 Activities in $\mathrm{MCI}$ (corrected to 5 Feb 1986) $\ldots \ldots \ldots \ldots$

2-3 Fission product activities for four particles isolated during the examination of sphere HFR/K3/1 $\ldots \ldots \ldots \ldots \ldots \ldots$ 2-69

2-4 Comparison of ORNL and FRG fission-activation product activities for HFR-K3/Sphere $3\left(1800^{\circ} \mathrm{C} \text { for } 100 \mathrm{~h}\right)^{\mathrm{a}} \ldots \ldots \ldots$. . . . . . . . .

2-5 Comparison of mean particle activities before and after heating sphere HFR-K3/3 for $100 \mathrm{~h}$ at $1800^{\circ} \mathrm{C} \ldots \ldots \ldots \ldots . \ldots \ldots . \ldots . \ldots .72$

2-6 Fraction of Cesium released to matrix graphite and condensate plates for spheres HFR-K3/1 and HFR-K3/3 . . . . . . . . . . . . 2-74

2-7 Element range of fractional retention of fission products in $\mathrm{SiC}$

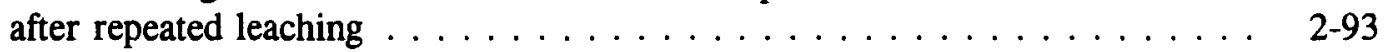

3-1 Summary of graphite irradiation experiments during period 1989 onward . . 3-2

3-2 HFIR capsules HTN-4 and -5 contents $\ldots \ldots \ldots \ldots \ldots$

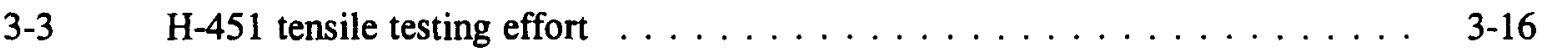

3-4 Model input parameters for grade $\mathrm{H}-451$ graphite $\ldots \ldots \ldots \ldots \ldots$ 3-23

3-5 Inventory of $\mathrm{H}-451$ graphite fatigue specimens $\ldots \ldots \ldots \ldots \ldots \ldots$

3-6 Estimated crack size distribution in large $\mathrm{H}-451$ tensile specimens $\ldots \ldots$ 3-34

3-7 $\quad \mathrm{H}-451$ graphite multiaxial test matrix $\ldots \ldots \ldots \ldots \ldots \ldots \ldots \ldots$

3-8 IG-110 graphite multiaxial test matrix $\ldots \ldots \ldots \ldots \ldots \ldots$

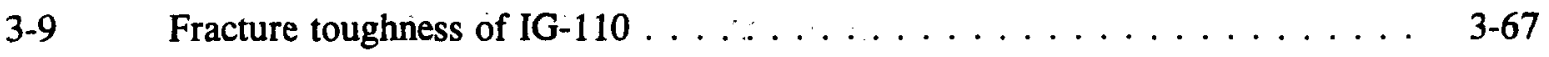

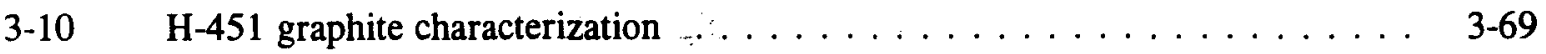

3-11 Derived values related to the rate variation with degree of consumption of $\mathrm{H}-451$ in air at $7500^{\circ} \mathrm{C} \ldots \ldots \ldots \ldots . \ldots \ldots$ 3-74 
Table

3-12 High temperature thermal conductivity of $H-451$ graphite in the axial orientation (Billet R58-357, 2-6-AIX) . . . . . . . . . . . . . . 3-101

3-13 High Temperature Thermal Conductivity of H-451 graphite in the radial orientation (Billet $\mathbf{R 5 8 - 3 5 7 , 2 - 6 - R I X ) ~ \ldots \ldots \ldots \ldots \ldots . ~ \ldots ~ . ~ . ~ . ~ . ~}$

3-14 High Temperature Thermal Conductivity of H-451 graphite in the tangential orientation (Billet R58-357, 2-6-TIX)

3-16 A comparison of $\mathrm{K}_{\mathrm{IC}}$ obtained from different test geometries of IG-110 graphite

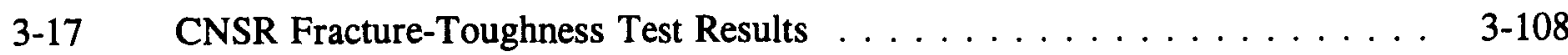

3-18 Model input parameters for grade $\mathrm{H}-451$ graphite $\ldots \ldots \ldots \ldots \ldots$ 3-111

4-1 Summary of irradiation matrix for MHTGR reactor vessel materials . . . . 4-3

4-2 MHTGR flux spectrum and weighing factors for calculating the effective fast $(>1 \mathrm{MeV})$ fluence $\ldots \ldots \ldots \ldots \ldots$

4-3 Chemical analysis of MHTGR pressure-vessel steel plates (A 533, Grade B, Class 1) . . . . . . . . . . . . .

4-4 Unirradiated properties of A 533, Grade B, Class 1 pressure-vessel steel plates

4-5 Measured and predicted transition temperature shifts from charpy impact tests on A 533, Grade B, class 1 steel after irradiation to $0.7 \times 10^{18}$ Neutrons $/ \mathrm{CM}^{2}(>1 \mathrm{Mev})$

4-6 Fracture mechanics test matrix for Alloy $800 \mathrm{H}$ reactor internals [1TC $(\mathrm{t})$ compact specimens, 0.48 in-thick with $20 \%$ side grooves;

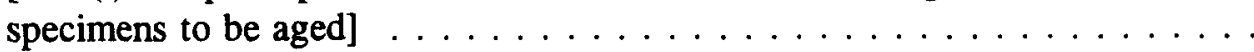

4-7 Charpy tests (all testing at room temperature unless otherwise noted) $\ldots \ldots$ 4-18

4-8 Tensile properties of Incoloy $800 \mathrm{H}$ (INCO HH 5132AG) $\ldots \ldots \ldots \ldots$. . . . 4-27

4-9 Principal results of preliminary fatigue tests $\ldots \ldots \ldots \ldots \ldots$. . . . . . . .

4-10 NP-MHTGR steam generator feedwater chemistry requirements. Maximum values $^{(2)}$ at the economizer inlet 


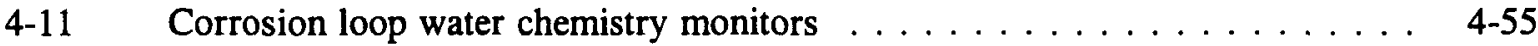

4-12 Randomized run order for the three-fractional factorial design . . . . . . . 4-60

6-1 Fluences at midplane or hot gas plenum for various cases of interest $\ldots \ldots$ 6-7

6-2 Comparisons of the measured and calculated detector count rates behind the spectral modifier (based on a 1-D XSDRNPM analysis), behind the upper pin layer and 9-inch reflector (based on a 3-D morse analysis), and at the bottom of a 7.55-inch-diam $\times 38$-inch hole through a 16-inch block of graphite, a second borated pin layer, and a 14-inch block of graphite (based on a $2-\mathrm{D}$ dot analysis) $\ldots \ldots \ldots \ldots \ldots \ldots \ldots$

6-3 Summary table showing the maximum effective fast fluence on the inner surface of the vessel near the flange and the maximum effective fast fluence on the inner surface of the upper plenum thermal shield for the eight system

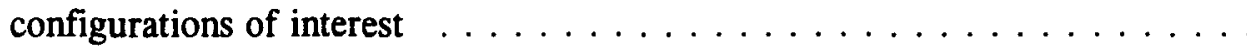

6-4 Calculated counts per minute for various detectors (with estimated fractional standard deviations) behind experimental configurations P01 through P15 with the tower shielding reactor operating at 1.0 kilowatts and a 48-inch spectral modifier between the TSR collimaator and the experimental specimens. The results here are based on the combined results obtained for the fast neutron source problem and the thermal neutron source problem. These results are therefore the best estimate of what one would actually measure in the experiment . . . . . . . . . 6-24

8-1 VHTGR core configurations and experimental items in the past and future . . 8-13

8-2 Comparison of VHTGR and MHTGR $\ldots \ldots \ldots \ldots$.15 
$\theta$

-

$\bullet$ 


\title{
MHTGR PROGRAM ANNUAL REPORT \\ FOR JANUARY 1, 1989, THROUGH JUNE 30, 1993*
}

\author{
F. J. Homan \\ Director of Reactor Programs
}

\section{PREFACE}

This report covers the four-and-a-half year period from January 1, 1989, through June 30, 1993. Oak Ridge National Laboratory (ORNL) has been involved in technology development work in support of the high-temperature gas-cooled reactor (HTGR) concept since the late 1950s. ORNL's first involvement was in testing coated particle fuels in the Oak Ridge Research Reactor. Later, the Laboratory expanded into a number of other areas, including testing and development of graphite and other structural materials, physics analyses, shielding methods development and code validation, and cost analyses, among others. Most recently, ORNL has strongly advocated the gas turbine power conversion concept as a replacement for the steam cycle.

Normally, ORNL's technical progress has been reported in a variety of publications, including monthly reports, topical reports, annual reports, and the open literature. The primary means of documenting program continuity has been through the annual reports, which have been issued on a calendar-year basis through 1988.

Beginning in late 1988 and early 1989, however, a new Department of Energy (DOE) Modular High-Temperature Gas-Cooled Reactor (MHTGR) Program was introduced in parallel with the Nuclear Energy (NE)-MHTGR (civilian reactor) Program. The New Production (NP) MHTGR Program was established during this period as a high-priority, fast-track effort to design and build a tritium production by early in the 21 st Century. The NP-MHTGR Program was funded at a much higher level than the NE-MHTGR Program. Annual budgets were in the range of $\$ 150$ million nationally, compared to less than $\$ 20$ million annually for the NE Program. The distribution of technical responsibility between these two programs was established early but remained somewhat fuzzy in implementation. The NP Program was chartered to fund NP-specific areas (such as targets and high-enriched uranium fuel development) and areas generic to both

\footnotetext{
${ }^{*}$ Research sponsored by the Office of Advanced Reactor Programs, Division of HTGRs, U.S. Department of Energy, under contract DE-AC05-84OR21400 with Martin Marietta Energy Systems, Inc.
} 
concepts (such as graphite, materials, physics, etc.). The NE Program was to fund areas unique to the commercial application, such as development of low-enriched uranium fuel. The NE Program was also to fund international cooperative work.

Because of the extreme urgency associated with the NP Program, coordination between the two programs did not keep pace with planning. Key ORNL staff supported both programs. There was uncertainty about how NP Program continuity would be documented and how the continuity documents would be coordinated with the NE Program. Several years passed without publication of an NE Program annual report. At the end of fiscal year 1992, the NP Program was canceled due to the sudden changes in the world situation caused by the collapse of the Soviet Union. The NP Program closeout period was established as October 1992 through September 1993. Once again, the responsibility for program continuity passed back to the NE Program. This report documents slightly more than four years of work on the NE Program at ORNL. It also highlights key accomplishments funded by the NP Program that are not documented elsewhere. ORNL will now return to its calendar year annual report cycle. 


\title{
SECTION 1
}

\section{INTRODUCTION}

\author{
D. O. Hobson, Compiler
}

As stated in the Preface, this report is a compilation of progress report information for Nuclear Energy-Modular High-Temperature Gas-Cooled Reactor (NE-MHTGR) [civilian reactor] activities, as well as New Production (NP)-MHTGR (new production reactor) activities that are generic to the civilian reactor program, over the time span from January 1,1989 , through June 30,1993 . Responsibility for a large amount of development work, originally slated to be performed under the NE Program, was transferred to the NP Program early in the reporting period. Since that work was directly generic to both reactor programs, it was not duplicated within both programs; rather, it was funded almost entirely by the NP Program.

This report follows a different format from previous annual reports in this series in that it concentrates on the technology and development work performed to meet design data needs (DDNs) specific to the reactor components, the fuel, and the steam generator components. It concentrates less on the management, licensing, and evaluation activities related to the national High-Temperature Gas-Cooled Reactor (HTGR) Program or with the Plant Design Control Office (PDCO). International cooperation activities, related solely to the NE part of the program, will be addressed in the individual sections of the report, as applicable.

Chapter 2, following the Chapter 1 introduction, deals with fuels and fission product activities. The fuels section addresses five major areas. The first is an assessment of the state of the technology and statements of several technical concerns related to the fuel, with possible resolutions. The second section discusses the irradiation work performed during the report period, including capsule assembly and operation, followed by the third section which addresses the postirradiation examination (PIE) and modeling of the data. The fourth section describes the various pieces of specialized equipment developed, operated, and maintained for the program, including results obtained with that equipment. The final section discusses international cooperation. The fission product section contains two parts: the first discusses fission product transport, and the second describes the Corrosion, Migration ét Distribution Irradiation Experiment (COMÉDIE) test program.

Chapter 3 contains eight sections that describe the generic technology development work performed on graphite under the NP Program. The first section describes irradiation capsules, 
their irradiation, and the subsequent PIE of the graphite specimens. The second section discusses the uniaxial mechanical properties testing, while the third and fourth describe the multiaxial testing work and the fracture mechanics studies, respectively. The fifth section contains a description of the oxidation studies, with a description of the large oxidation loop built for the program. Section six describes the fabrication of experimental carbon/carbon $(\mathrm{ClC})$ composite control rod pieces. Section seven addresses thermal physical properties evaluations, and section eight describes various aspects of international cooperation.

Chapter 4 contains descriptions of the technology development work performed on the various metallic components of the MHTGR. This, again, is work predominately funded by the NP Program but which is generic to the civilian reactor. Sections one and two pertain to the properties of SA533B pressure-vessel steels, both in the unirradiated and irradiated conditions. Section three reports mechanical properties test results for the Alloy $800 \mathrm{H}$ in-reactor structural materials, while section four describes work performed on irradiated specimens of the same alloy. Section five deals with the properties of heat-transport materials, and six addresses the strength of bimetallic welds for steam generators. Finally, section seven discusses international cooperation.

The remaining chapters of this report pertain totally to work related to the civilian reactor concept. Chapter 5 describes safety technology studies related to the Arbeitsge-meinschaft Versuchs Reaktor (AVR) and Safety Research Subprograms conducted under the U.S.-German Umbrella Agreement for Gas-Cooled Reactor (GCR) Development. Chapter 6 describes reactor physics and shielding work, and Chapter 7 covers work done for advanced system design support, including high-temperature design criteria and advanced materials. Chapter 8 reports work related to the modular gas reactor-gas turbine concept, and Chapter 9 discusses the economics of the reactor concepts. 


\section{SECTION 2}

\section{FUELS AND FISSION PRODUCT BEHAVIOR (WBS 1601)}

The MHTGR Fuel Materials Development and Fission Product Behavior Programs ORNL are part of a U.S. Department of Energy (DOE) Program sponsored with General Atomics (GA). This chapter reports the activities conducted under the Fuel Materials Development Program (Sect. 2.1) and the Fission Product Behavior Program (Sect. 2.2). The major accomplishments during this reporting period were the irradiation and PIE of capsule HRB-21, the development of the Fission Gas Monitoring Stations, and the initial operation of the Core Conduction Cooldown Test Facility (CCCTF).

\subsection{FUEL MATERIALS DEVELOPMENT (1601.02) - M. J. Kania}

The Fuel Materials Development Program is directed toward satisfying the technology development needs (TDNs) as expressed in the Modular HTGR Plant Fuel/Fission Product Technology Development Plan (F/FP TDP). ${ }^{1}$ Quantitatively, the general needs of the Fuels Program can be summarized as follows:

- Reduce the uncertainty in the fuel performance models and physical property data that are used to predict fuel behavior and fission product transport in the MHTGR core under both normal and off-normal operating conditions

- Validate fuel performance models used to predict coated particle and fuel compact integrity under both normal and off-normal operating conditions

- Demonstrate MHTGR fuel performance under both irradiation and core conduction cooldown conditions

As the lead laboratory for MHTGR technology development, ORNL is responsible for the planning, implementation, and execution of the experimental program that is necessary to meet the designer's needs. The ORNL effort is conducted in close cooperation with GA, who maintains responsibilities of interfacing with core designers, developing the fuel manufacture technology, process development; quality control; and scaleup to production capacity.

The ORNL fuels program has also conducted cooperative tasks within two international programs:

- U.S./Federal Republic of Germany (FRG) Umbrella Agreement coordinated with Forschungszentrum (KFA), Jülich, FRG (now expired) 
- U.S./Japan Atomic Energy Research Institute (JAERI) cooperative program coordinated with JAERI at the Tokai Research Establishment [currently operated as a Work for Others (WFO) Program]

Work conducted on these two international programs in the fuel materials and fission product transport areas is included in this chapter.

\subsubsection{Technology Planning, Assessments, and Analysis}

2.1.1.1 Fuels/Fission Product Technology Development Plan - M. J. Kania, J. C. Mailen, R. N. Morris, R. C. Martin, P. L. Rittenhouse, and D. L. Moses

On January 17-18, 1988, a meeting was held at GA, San Diego, California, for the purpose of reviewing the status of the planned fuels and fission products work as defined in the F/FP TDP. ${ }^{1}$ This meeting was attended by representatives from GA, Gas-Cooled Reactor Associates (GCRA), ORNL, and the PDCO. A technical review of each existing DDN in both the fission products and the fuels area was presented. A major concern for ORNL, at the time, was that the planned technology, as presented in the F/FP TDP, appeared to be insufficient to meet the broad data need requirements expressed in the DDNs. This was of particular concern for those DDNs which require validation of performance models or design methodology (computer codes). Further, explicit description of the GA proprietary correlations/models (including reference data base) and codes to be validated needed to be made publicly available to effectively plan and develop a technology program to meet requirements set forth in the DDNs. As an interim measure, it was agreed that ORNL would review each DDN in the fuels and fission product areas and provide GA with a request for specific information relative to existing data base, correlations/models, and computer codes necessary to upgrade the TDP to sufficiency. However, subsequent attempts by ORNL to anticipate information requirements and obtain them were fragmentary and out of context. This interim approach was abandoned in favor of obtaining the complete proprietary data base being validated on development of a new, nonproprietary data base.

A comprehensive review of the F/FP TDP was carried out to determine whether the existing plan (DOE-HTGR-86-027/Rev. 1) was sufficient to meet the needs expressed by the designer in the DDNs. Of particular concern was the responsiveness of the work scope outlined in Chapter 5 of the TDP to specific DDNs and the adequacy of the DDN/TDN (those which the plan is formulated on) to provide sufficient information to plan, schedule, and execute a successful TDP. 
This review, which made several recommendations for significant changes in the program, was forwarded to the DOE for further evaluation and program guidance.

Further work on this task was delayed to calendar year (CY) 1990 pending resolution of the issue of whether or not government funds can be used for the validation of proprietary codes and models. Since the majority of fuel performance and fission product transport models were proprietary at the time, a decision not to fund the validation of proprietary models would result in major program uncertainties or the duplication of previous work. This problem was finally solved when DOE, under the NE and NP Programs, arranged for the proprietary information to be made available to MHTGR Program participants. This information was later found to be unable to predict the poor performance of the HRB-21 capsule. In fact, the entire fuel specification and manufacturing process is currently under review.

In the spring of 1992, it became apparent that several design changes to the 350-MW MHTGR should be made for cost and engineering reasons. The power of the MHTGR was changed to $450 \mathrm{MW}$ for improved economics. The fertile material was changed from thorium to natural uranium so that the nuclear afterheat magnitude would be reduced. The penalty to the fuel cycle was not considered important because of the reduced emphasis on spent fuel recycling and the higher operating power level of the reactor. The important engineering changes included the consideration of filters to both the reactor vessel pressure-relief valve and the reactor building. At the present time, the addition of a filter to the reactor vessel pressure-relief valve is very likely; the building filter is still under consideration.

A new set of DDNs for the MHTGR was released in draft form in the spring of 1993. These DDNs incorporate the changes necessary for the 450-MW version of the MHTGR. The writing of a new TDP to address the new needs of the program was started in the fall of 1992 . A meeting was held at GA on April 19-20, 1993, to review the state of the DDNs and the TDP. Representatives from GA, PDCO, and ORNL were present, and numerous comments and action items were identified. Currently, the resolution of these items is still under way.

A critical program concern at present is the poor performance of the MHTGR fuel in capsule HRB-21. In addition, the NP Program had similar problems with the fuel tests in capsules NPR-1, -1A, and -2 . Both the NE and NP Programs are examining the fuel to attempt to and isolate the source of the problem. A major effort in this area is under way in the NP Program; however, this work will end with the closeout of the NP Program in fiscal year (FY) 1993. The NE Program will then have to pick up this work in FY 1994 if the program is to progress. 
Currently, the PIE has not identified the failure mechanism. In order to gain a more fundamental understanding of fuel performance, a parametric series of irradiation tests is needed. An improved specification would then be based on the more complete data set. After the specification is improved, two test capsules will be irradiated to qualify the new specifications. The successful completion of these irradiations will qualify the fuel product specifications and process for use in the production of fuel for final fuel demonstration tests.

\subsubsection{Irradiation Capsule Assembly, Operation, and PIE}

2.1.2.1 HRB-21 and HRB-22 Capsule Design - G. L. Bell, G. L. Copeland, J. T. Parks, L. C. Emerson, N. H. Packan, K. R. Thoms, M. J. Kania, and D. L. Heatherly

The HRB-21 capsule contains only U.S. MHTGR fuel, and the HRB-22 capsule contains only JAERI fuel, which is a candidate for the High-Temperature Test Reactor (HTTR) project in Japan. The HRB-22 capsule was not irradiated in this reporting period and will be modified before it is irradiated.

To design and analyze the HRB-21 capsule, a three-dimensional (3-D) numerical model (see Figure 2-1) of a $60^{\circ}$ section of the HRB-22 capsule was generated for thermal analysis by the HEATING 7.0 computer code. ${ }^{2}$ In this model, each geometric region was assigned a thermal conductivity (constant or temperature dependent); a power generation rate (power density); and specific boundary conditions (radiative emissivity, surface heat-flux, etc.) to form a mathematical model of the heat-transport problem posed by the capsule. In this model, the thermocouples (TCs) were included as regions with a nuclear heating rate determined by the average density of the TC array tube. The piggyback samples and the inlet gas passages were assumed to be filled with $\mathrm{H} 451$ graphite. The gap between the fuel and the graphite was assumed to be filled with the sweep gas. It was assumed that the fuel compact was perfectly centered in the hole and that the graphite fuel body was perfectly centered within the containment tube. Results of the HEATING 7.0 execution (nodal temperature map) were post-processed to provide:

- $\langle\mathrm{T}\rangle=$ volume-averaged fuel temperature

- $\mathrm{TC}=$ average thermocouple temperature

- Radial temperature profiles through the compact horizontal midplanes

- Axial profiles through the compacts that pass through the maximum temperature node

To facilitate day-to-day control of the fuel temperature, a program was developed to map measured TC temperatures into calculated average fuel temperatures. Due to the large amounts of time required to execute the HEATING 7.0 model of the HRB-21 capsule, a program was written 


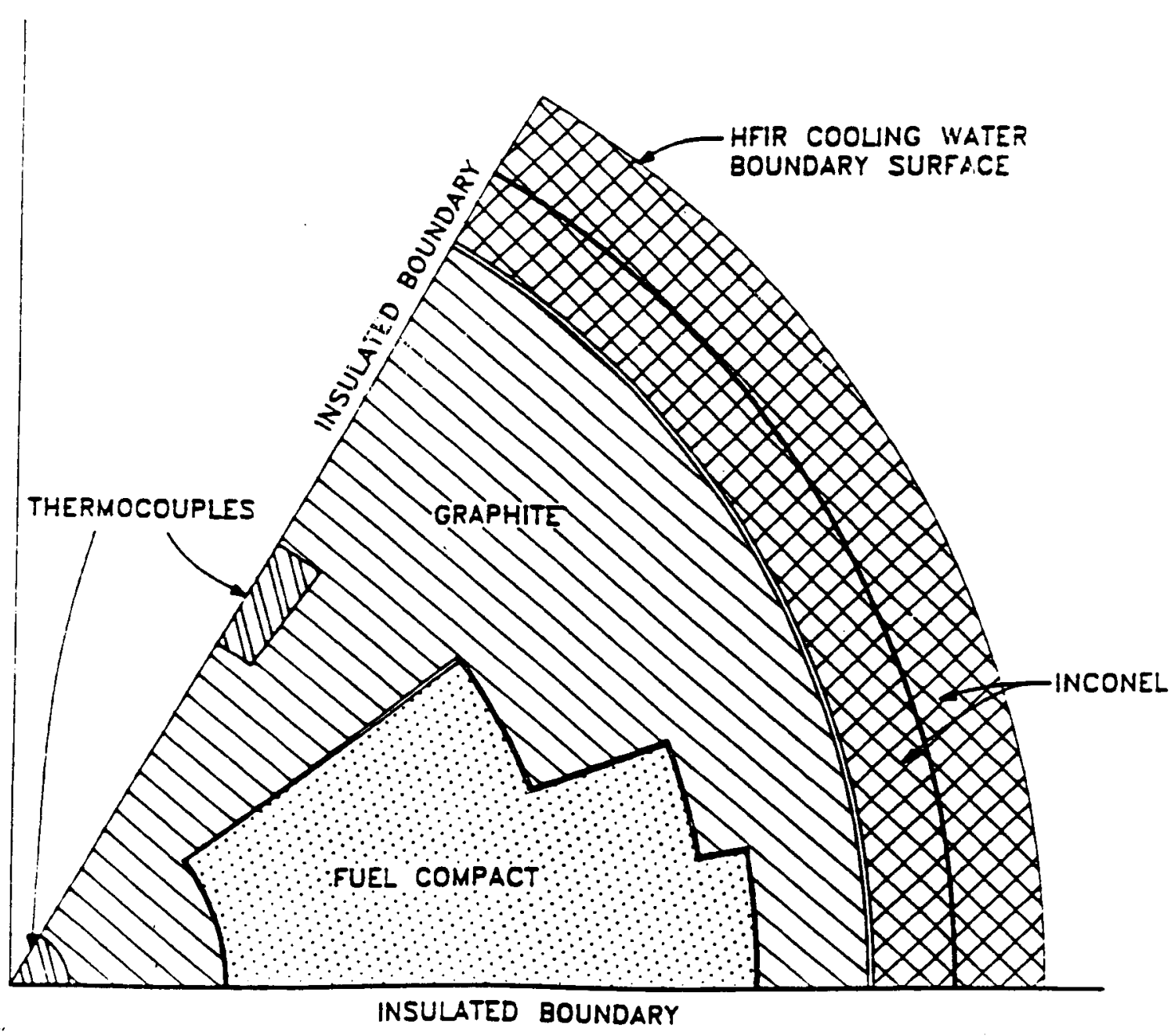

Figure 2-1.

CROSS-SECTION MOCK-UP OF IRRADIATION CAPSULE HRB-21 FOR THERMAL DESIGN CALCULATIONAL PURPOSES: HORIZONTAL CROSS SECTION, R- $\theta$ VIEW. 
to quantify the dependence of $\langle\mathrm{T}\rangle$ on the various input parameters. To develop parametric dependences, a series of HEATING 7.0 runs were executed in which the input parameters were scanned over the range of their expected values.

Final revisions were made to the HRB-21 irradiation operating plan: DOE-HTGR-88370 (ORNL/GCR-89/4), Operating Plan for Capsule HRB-21 Irradiation. Preparation continued on the HRB-21 PIE plan: Capsule HRB-21 Postirradiation Examination Plan. Both documents were issued in CY 1990.

Final editorial revisions were made to the HRB-22 experimental test plan: DOE-HTGR87090 (ORNL/TM-11346), Experimental Test Plan: USDOE/JAERI Collaborative Program for the Coated Particle Fuel Performance Test. The Operation Plan for Capsule HRB-22 Irradiation was drafted and reviewed. Both documents were issued in CY 1990.

Due to a change in plans by JAERI, capsule HRB-22 was not irradiated. An improved fuel has been developed by JAERI, and this fuel will replace the fuel in the HRB-22 capsule. Replacement fuel for the JAERI irradiation test capsule HRB-22 was shipped from Japan and received at ORNL in February 1993. A total of 20 annular fuel compacts, along with approximately $50 \mathrm{~g}$ of unbonded TRISO-coated $\mathrm{UO}_{2}$ fuel particles, were received. A JAERI representative accompanied the fuel and was available for the official receipt inspection. This fuel is an improved version of the current JAERI fuel now assembled in capsule HRB-22. Work will resume later this year to refabricate the HRB-22 capsule with the new fuel in anticipation of a four-cycle High Flux Isotope Reactor (HFIR) irradiation beginning the first half of FY 1994.

The extension of the annex to the implementing arrangement between the DOE and JAERI on Cooperation in Research and Development in the Area of High-Temperature GCR Development was endorsed by the JAERI Board of Directors. The remaining requirement to implementing the Annex 2 extension is for the DOE to fully endorse the document.

\subsubsection{Availability of Other Irradiation Facilities - M. J. Kania}

Because of the extended shutdown of the HFIR and the inability to proceed with irradiation tests of MHTGR fuel, evaluation of alternate irradiation facilities was initiated in 1989.

Discussions were held in October 1989 at ORNL with Dr. Mikael Grounes, Manager for Fuel Testing and Fuel Performance, Studsvik Nuclear, which operates the R2 research reactor at Nykoping, Sweden. The design for the current HRB series of irradiation capsules was described, together with the plans and needs of our U.S. MHTGR fuel qualification program. Dr. Grounes described the R2 reactor which is essentially the Oak Ridge Research Reactor (ORR) design 
upgraded to $50 \mathrm{MW}$. His firm is a private company, analogous to Battelle, that conducts research and provides irradiation services to both Swedish government agencies and the international nuclear community. Irradiation of both West German and U.S. HTGR fuel, including on-line fission product monitoring, has been conducted in the R2 and could be done again. Capsule construction could be done by either ORNL or Studsvik, and it may be possible to irradiate an existing HRB-series capsule with relatively minor modifications.

Because of the resumption of operations by the HFIR, this option was not pursued any further. However, it remains a future option should conditions limit the use of the HFIR.

2.1.2.3 HRB-21 Capsule Irradiation - G. L. Bell, G. L. Copeland, J. T. Parks, L. C. Emerson, and M. J. Kania

The HRB-21 capsule was installed on June 15, 1991, in the HFIR RB-3B position, during the end-of-cycle (EOC) 297 outage. The test was originally scheduled to be irradiated for six cycles, but due to loss of ability to maintain test temperatures within the allowable limit, coupled with a higher-than-expected fission gas release rate, the irradiation was terminated after the fifth cycle, cycle 302 , which ended on November 21,1991 . The total irradiation time at power was 104.7 effective full-power days (EFPDs).

The capsule was operated in the HFIR in accordance with the operating guidelines which included a staged ascent to reactor power to minimize particle failures due to rapid increases in the power generated per particle. ${ }^{3}$ Table 2-1 presents the dates bounding the HRB-21 irradiation. The startup time is taken to be the time at which the reactor reaches full-power operation [85 MW(t)]. Reactor shutdown is attained by rapidly inserting the control shims (reactor scram). The sweep gas at startup was $100 \%$ helium for all cycles. The sweep gas between cycles was $100 \%$ helium.

The HRB-21 capsule was operated to meet the goal of controlling the volume-averaged fuel temperature at $975^{\circ} \mathrm{C}$ without exceeding a local maximum fuel temperature of $1250^{\circ} \mathrm{C}$. Capsule temperatures were adjusted as required by changing the composition of the sweep gas flowing in the annular regions between the fuel compacts and the graphite fuel holders, and between the graphite fuel holders and the primary containment. Helium and neon were the sweep gases utilized to control the temperature. Greater fractions of helium, which has the higher thermal conductivity by a factor of three, decrease thermal resistance in the gap and result in lower capsule temperatures. 
Table 2-1

HRB-21 IRRADIATION DATES, WITH TIME ELAPSED SINCE FIRST HFIR FULLPOWER EXPOSURE, CYCLE TIME AT FULL POWER, AND

TOTAL TIME AT FULL POWER.

\begin{tabular}{|c|c|c|c|c|}
\hline $\begin{array}{l}\text { HFIR } \\
\text { cycle }\end{array}$ & Cycle start/end & $\begin{array}{l}\text { Cumulative } \\
\text { calendar time } \\
\text { (days) }\end{array}$ & $\begin{array}{c}\text { Cycle length } \\
\text { (days) }\end{array}$ & $\begin{array}{l}\text { Cumulative time } \\
\text { at power } \\
\text { (days) }\end{array}$ \\
\hline 298 & $\begin{array}{ll}06 / 20 / 91 & 18: 15 \\
07 / 11 / 91 & 06: 53 \\
\end{array}$ & $\begin{array}{c}0 \\
20.526 \\
\end{array}$ & 20.526 & 20.526 \\
\hline 299 & $\begin{array}{ll}07 / 25 / 91 & 22: 10 \\
08 / 15 / 91 & 08: 55\end{array}$ & $\begin{array}{l}35.163 \\
55.611\end{array}$ & 20.448 & 40.974 \\
\hline 300 & $\begin{array}{ll}08 / 28 / 91 & 11: 48 \\
09 / 17 / 91 & 17: 44\end{array}$ & $\begin{array}{l}68.731 \\
88.978\end{array}$ & 20.247 & 61.222 \\
\hline 301 & $\begin{array}{ll}09 / 27 / 91 & 21: 18 \\
10 / 19 / 91 & 17: 35\end{array}$ & $\begin{array}{r}99.127 \\
120.972\end{array}$ & 21.845 & 83.067 \\
\hline 302 & $\begin{array}{ll}10 / 30 / 91 & 12: 00 \\
11 / 21 / 91 & 02: 18\end{array}$ & $\begin{array}{l}131.781 \\
153.377\end{array}$ & 21.596 & 104.663 \\
\hline
\end{tabular}

The burnup and fluence goals for the test ${ }^{4}$ were to achieve a fast fluence ( $E \geq 29 \mathrm{fJ}$ ) of $\leq 5 \times 10^{25}$ neutrons $/ \mathrm{m}^{2}$ and a peak fissile burnup of $\leq 26 \%$ fissions per initial metal atom (FIMA). As shown in Figure 2-1, shortening the irradiation time to five cycles rather than six achieved fluence and burnup levels of 70 and $87 \%$ of the desired peaks based on the best predictions currently available. ${ }^{5,6}$ The increasing temperatures, which caused the test to be shortened, may have been partly due to larger-than-expected fissile inventory bred in fertile particles because of the much longer average time between cycles than had been anticipated during the thermal design. The higher-than-expected fissile content caused fertile power to be higher than expected. The postirradiation thermal neutron fluence and burnup analyses will provide pertinent data for these important parameters.

Figure 2-2 presents an overview of the capsule operation showing the capsule average volumetric fuel temperature and the sweep gas composition as a function of elapsed time. Figure 2-3 provides the indicated helium and neon flow rates. Figure 2-4 again illustrates the temperature chronology and is labeled to point out some events of interest. The capsule was first brought to operating temperature on June 21,1991 , by the addition of neon to the sweep gas. The sharp down spikes at points (A) in Figure 2-4 were induced by a change in the sweep gas to 
ORNL-DWG 92-16001

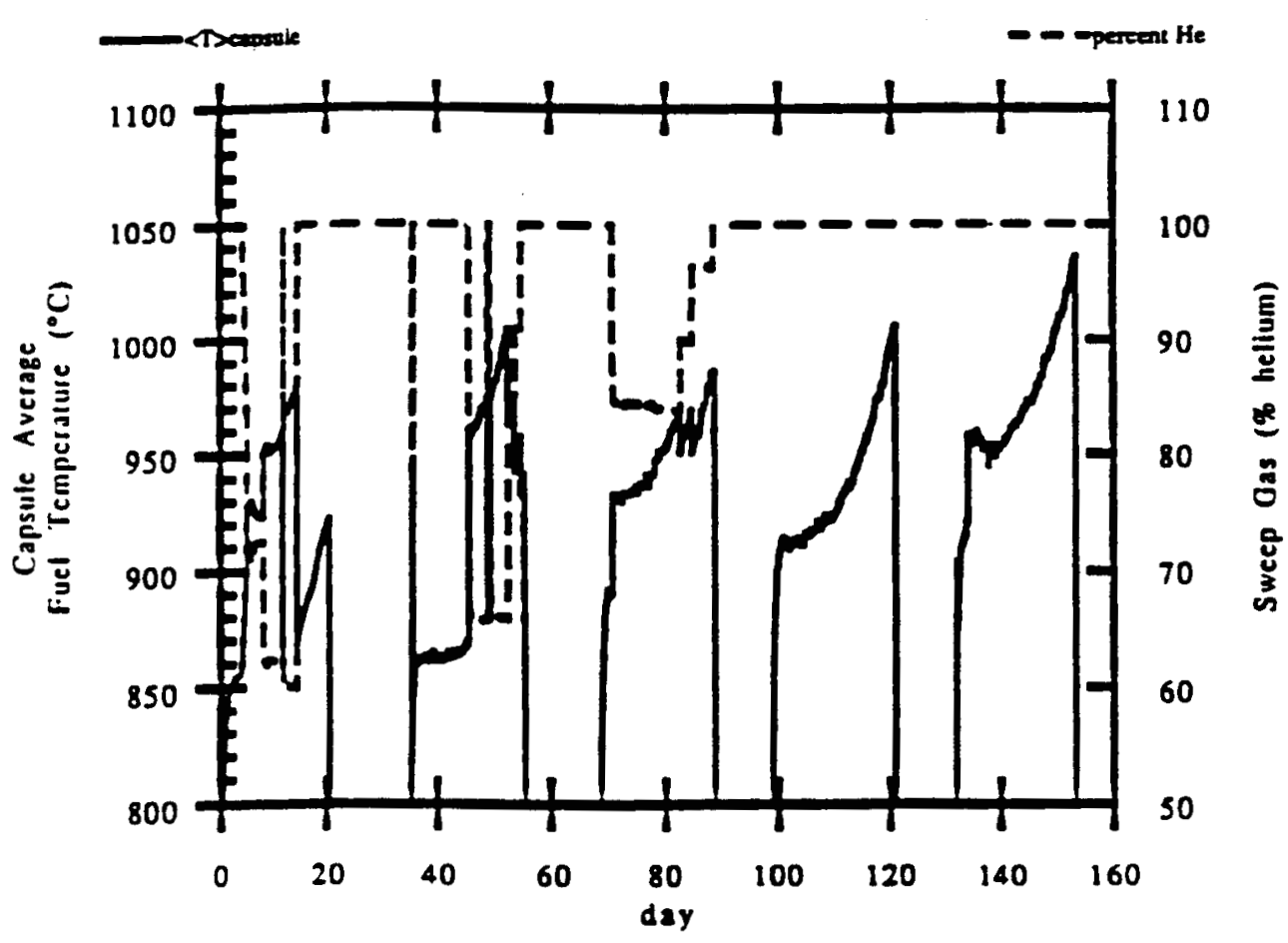

Figure 2-2.

OVERVIEW OF THE CAPSULE OPERATION SHOWING THE TIME EVOLUTION OF THE CAPSULE AVERAGE FUEL

TEMPERATURE AND THE PERCENT HELIUM

IN THE CAPSULE SWEEP GAS. 


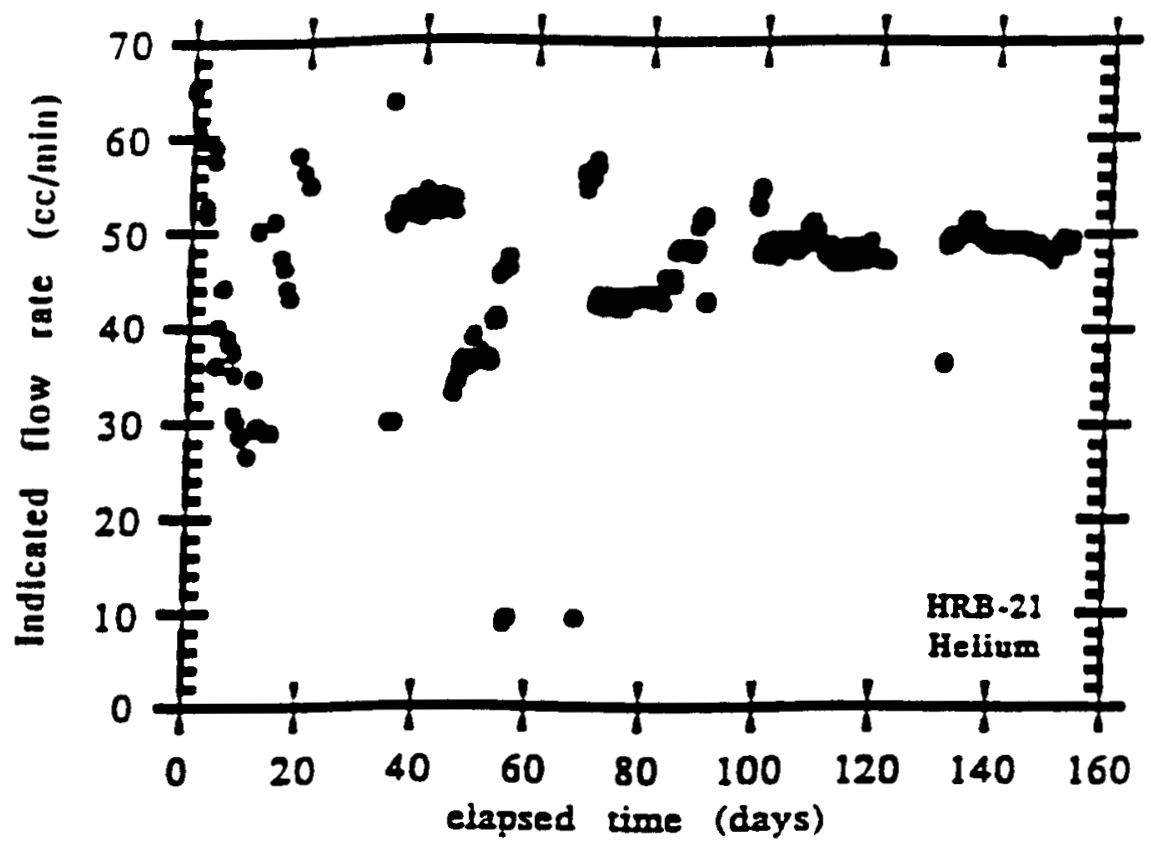

ORNL-DWG 92-16003

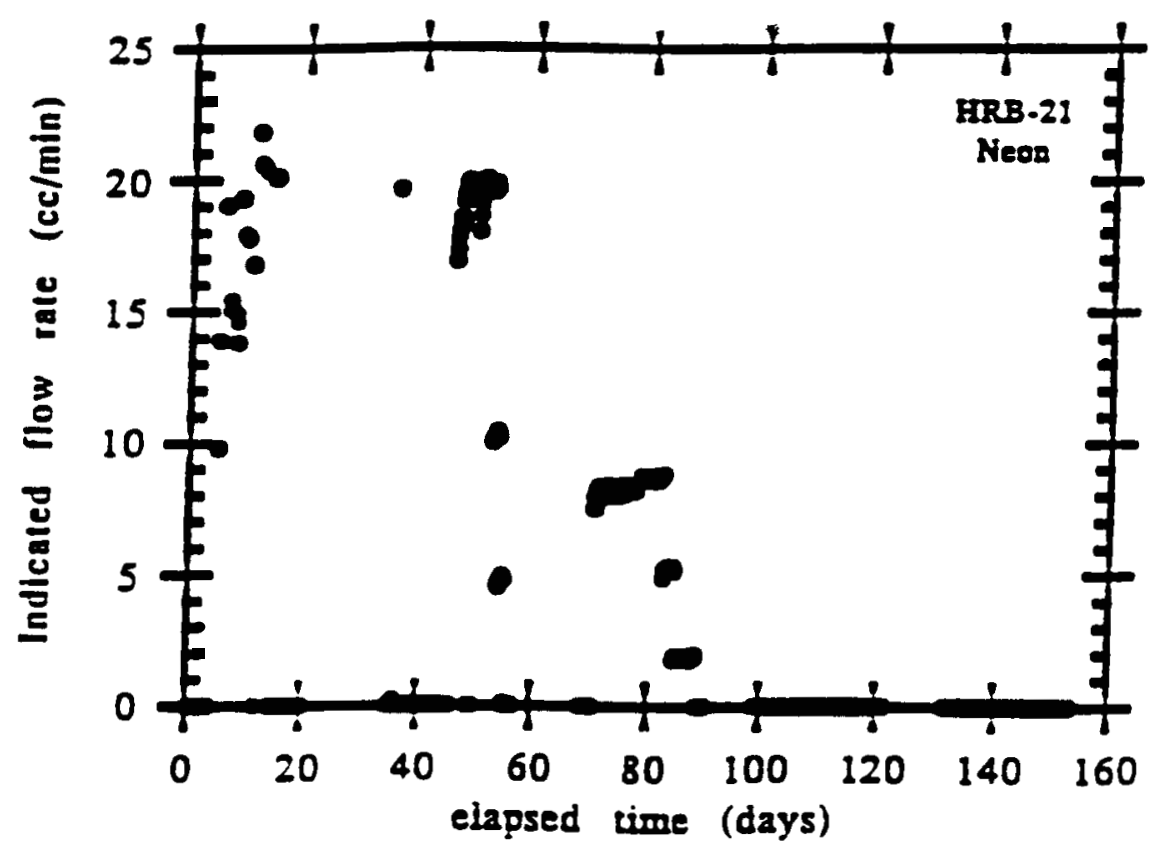

Figure 2-3.

INDICATED HELIUM AND NEON FLOW RATES AS A FUNCTION OF ELAPSED TIME. 
ORNL-DWG 92-16004

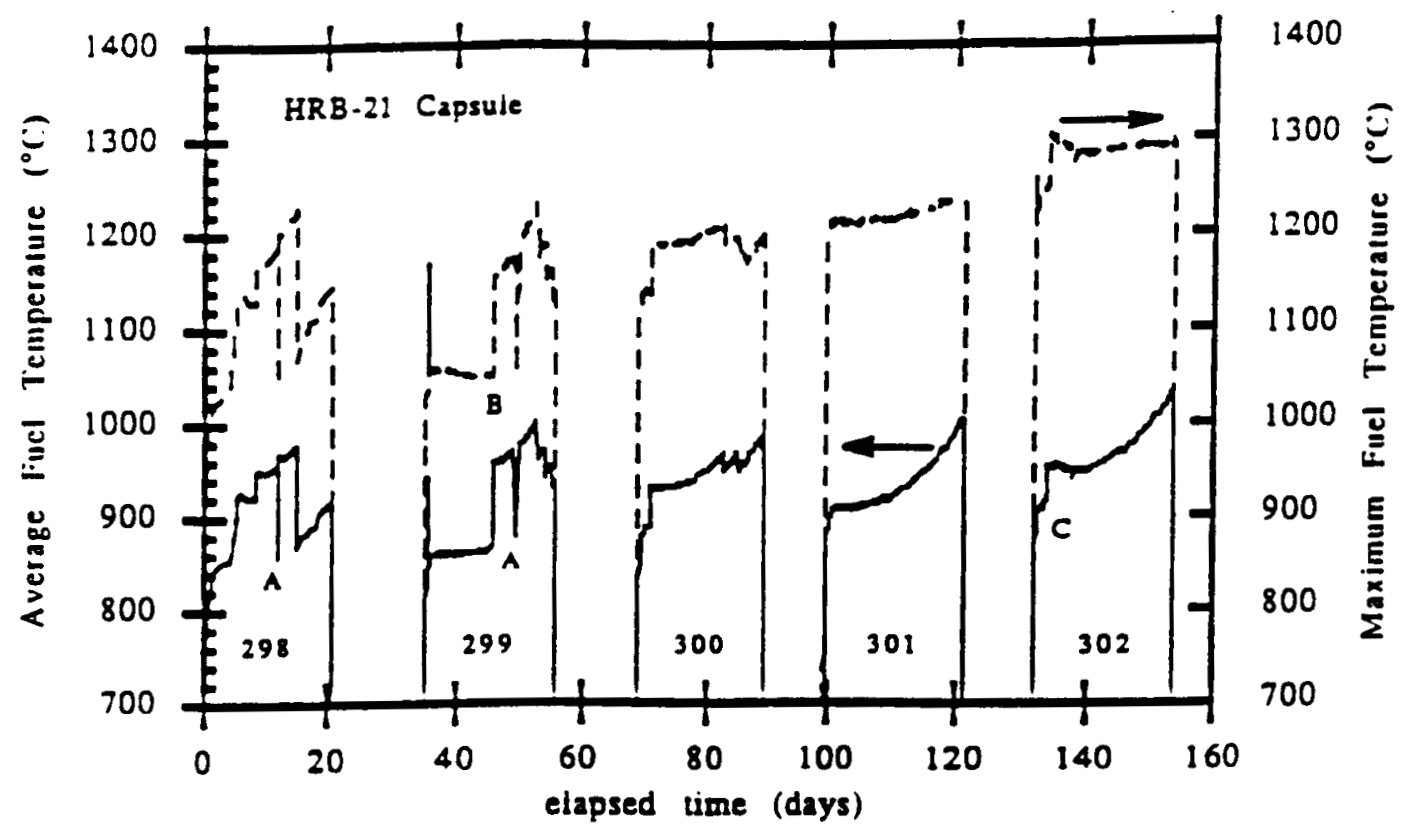

Figure 2-4.

\section{CAPSULE AVERAGE FUEL TEMPERATURE WITH POINTS OF INTEREST LABELED FOR DISCUSSION. THE CYCLE NUMBERS ARE LISTED JUST \\ ABOVE THE ABSCISSA.}

$100 \% \mathrm{He}$. The periodic operation for a short time at $100 \% \mathrm{He}$ provides valuable data under well-characterized sweep gas conditions and contributes to reducing uncertainties in the thermal analysis. Near the end of the first cycle, the sweep gas was changed to $100 \%$ helium because there was some uncertainty in the rate of the anticipated temperature increase near the ends of the capsule as the control plate withdrawal rate increases. No pulses in the activity of the sweep gas were observed during the first cycle of operation.

At the beginning of the second cycle (299), after the test was brought up to operating temperature by an increase in the neon concentration (about $12 \mathrm{~h}$ after the reactor reached full power), the ionization chamber recorded sharp pulses in sweep gas activity characteristic of particle failure (see discussion below). Since no particle failures were expected at this time in this fuel, a programmatic decision was made to lower the capsule temperature, while the experimental facility was examined to ensure that experimental anomalies were not causing the unexpected 
radioactivity pulses. The capsule temperature was reduced by changing the sweep gas back to $100 \%$ He $(14: 05 \mathrm{~h}$, July 26,1991$)$. At this point, all systems that could contribute to experimental anomalies were checked. The experimental facility was found to be functioning correctly (temperature monitoring, sweep gas integrity, $\mathrm{He}$ and $\mathrm{Ne}$ purity, etc.). With the concurrence of program management, neon was added to the sweep gas at 13:20 $\mathrm{h}$ on August 5, 1991, to raise the capsule temperature to the design operating range.

Cycle 300 progressed nominally, with the temperature of the capsule regulated as necessary to maintain the target temperature. During this cycle, it became clear that a point in time would soon be reached where the local maximum fuel temperature could exceed $1250^{\circ} \mathrm{C}$. This unexpected increase in capsule temperature may have been due to the breeding in of ${ }^{233} \mathrm{U}$ at a level greater than that anticipated due to the long shutdown periods between operation. In the thermal and neutronic analyses upon which the capsule design is based, the downtime between cycles was taken to be $1 \mathrm{~d}$ based on previous HFIR experience. The actual average downtime was about $12.2 \mathrm{~d}$, while the half life of ${ }^{233} \mathrm{~Pa}\left({ }^{233} \mathrm{U}\right.$ precursor) is $27.4 \mathrm{~d}$. Therefore, the ${ }^{233} \mathrm{U}$ concentration at the beginning of each cycle was higher than planned for.

The sweep gas was $100 \%$ He for cycles 301 and 302 . At the beginning of cycle 302 , the reactor power was lowered to $80 \mathrm{MW}(\mathrm{t}$ ) to clear a high-temperature alarm (point $\mathrm{C}$, Figure 2-4). After Reactor Experiment Review Committee (RERC) review and authorization from DOE to operate with TC temperatures up to $1100^{\circ} \mathrm{C}, 85 \mathrm{MW}(\mathrm{t})$ operation was resumed. At the end of cycle 302 , the HRB-21 capsule was removed from the reactor and placed in the experiment storage facility in the reactor pool.

There are two measures of fuel performance while the experiment is undergoing test. Both monitor the ability of the fuel to retain its gaseous fission products, and both relate to the presence of radioactive fission products in the sweep gas. The first measure is the monitoring of the radiation level of the sweep gas after it exits the capsule. The second method involves obtaining a grab sample of the sweep gas, determining its fission gas content, and computing a release-rate to birth-rate $(\mathrm{R} / \mathrm{B})$ ratio for the specific fission product isotopes in the fuel.

The radiation level of the sweep gas exiting the capsule is continuously monitored by two independent ionization chambers with chart recorders. The failure of a fuel particle in this type of fuel test has been shown to yield a sharp, distinctive pulse on the chart recordings. ${ }^{7}$ The pulse is characterized by a very rapid increase in radiation level of only 2 to $3 \mathrm{~min}$ duration at half-height, followed by a slower return to a level somewhat higher than the original. Figure 2-5 shows a plot 
ORNL-DWG 92-16006

IRB-2L R/B Values

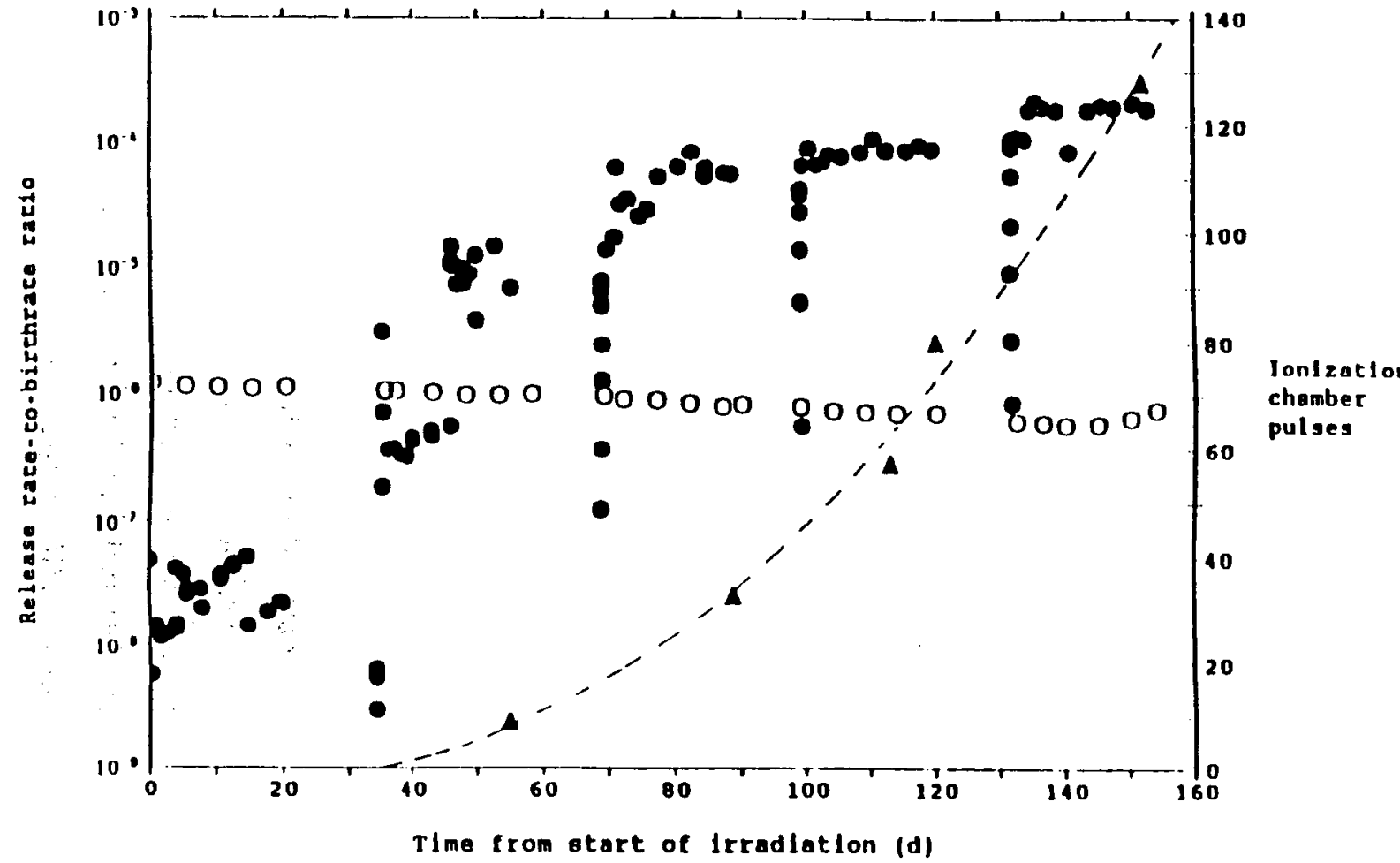

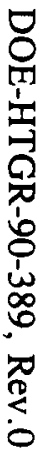

- $\mathrm{Kr}-85 \mathrm{~m}$

O Kr-B5m (predlcted)

- Number of Ionization chamber pulaes

Figure 2-5.

CUMULATIVE COUNT OF IONIZATION CHAMBER PULSES (FAILED PARTICLES) AND ${ }^{85 \mathrm{~m}} \mathrm{Kr}$ R/B FOR HRB-21 CAPSULE. 
of the cumulative number of pulses as a function of time superimposed on a plot of the R/B for ${ }^{85 \mathrm{~m}} \mathrm{Kr}$. This count is not final since some spikes are not as well defined and subject to some interpretation, as already failed particles could release a burst of gas if they should crack or otherwise change structure during irradiation. This tentative count indicates a total of about 130 particle failures.

Measurements of the fission gas release rates were carried out using the grab sample technique for sampling the sweep gas. ${ }^{8}$ The gas samples were collected in serum bottles at the HFIR. ${ }^{9}$ They were then transported to the Irradiated Fuels Examination Laboratory (IFEL) where they were analyzed for fission gas inventory using a high-efficiency germanium detector gamma spectroscopy system. ${ }^{10}$ Birth rates were calculated using the initial fuel loadings and one group of neutron flux and cross-section data as input to the CACA-2 computer program. ${ }^{6} \mathrm{R} / \mathrm{B}$ plots for $\mathrm{Xe}-133, \mathrm{Xe}-138, \mathrm{Kr}-85 \mathrm{~m}$, and $\mathrm{Kr}-88$, along with the capsule average fuel temperature, are shown in Figures 2-6 and 2-7.

The R/B ratios started out very low supporting the low heavy metal contamination reported for the fuel as well as the low measured preirradiation ${ }^{11}$ values and predictions ${ }^{12}$ for the test. For example, the $\mathrm{R} / \mathrm{B}$ for one isotope of interest, ${ }^{85 \mathrm{~m}} \mathrm{Kr}$, was:

$\begin{array}{ll}10^{-8} \text { to } 10^{-7} & \text { preirradiation } \\ 10^{-7} \text { or } 10^{-6} & \text { predicted (two models) } \\ 10^{-8} \text { increasing to } 10^{-4} & \text { during test }\end{array}$

The R/B ratios remained low during the first cycle but rose rapidly at the beginning of cycle 299 and then increased steadily during the remaining irradiation, consistent with the indications of particle failures.

Overall, the Hbb-21 experiment operated successfully in the HFIR reactor for five cycles. The mean average volumetric temperature for the fuel appears to have been very close to the desired $975^{\circ} \mathrm{C}$. At no time did the calculated maximum temperature exceed the $1250^{\circ} \mathrm{C}$ limit. Temperature control could not have been maintained within this limit for the planned sixth cycle, and the experiment was removed after the fifth cycle. Even so, fluence and burnup levels of 70 and $87 \%$ of the desired peaks were achieved. The temperature, sweep gas radiation level, and R/B sampling systems functioned properly throughout the test. 
ORNL-DWG 92-16007

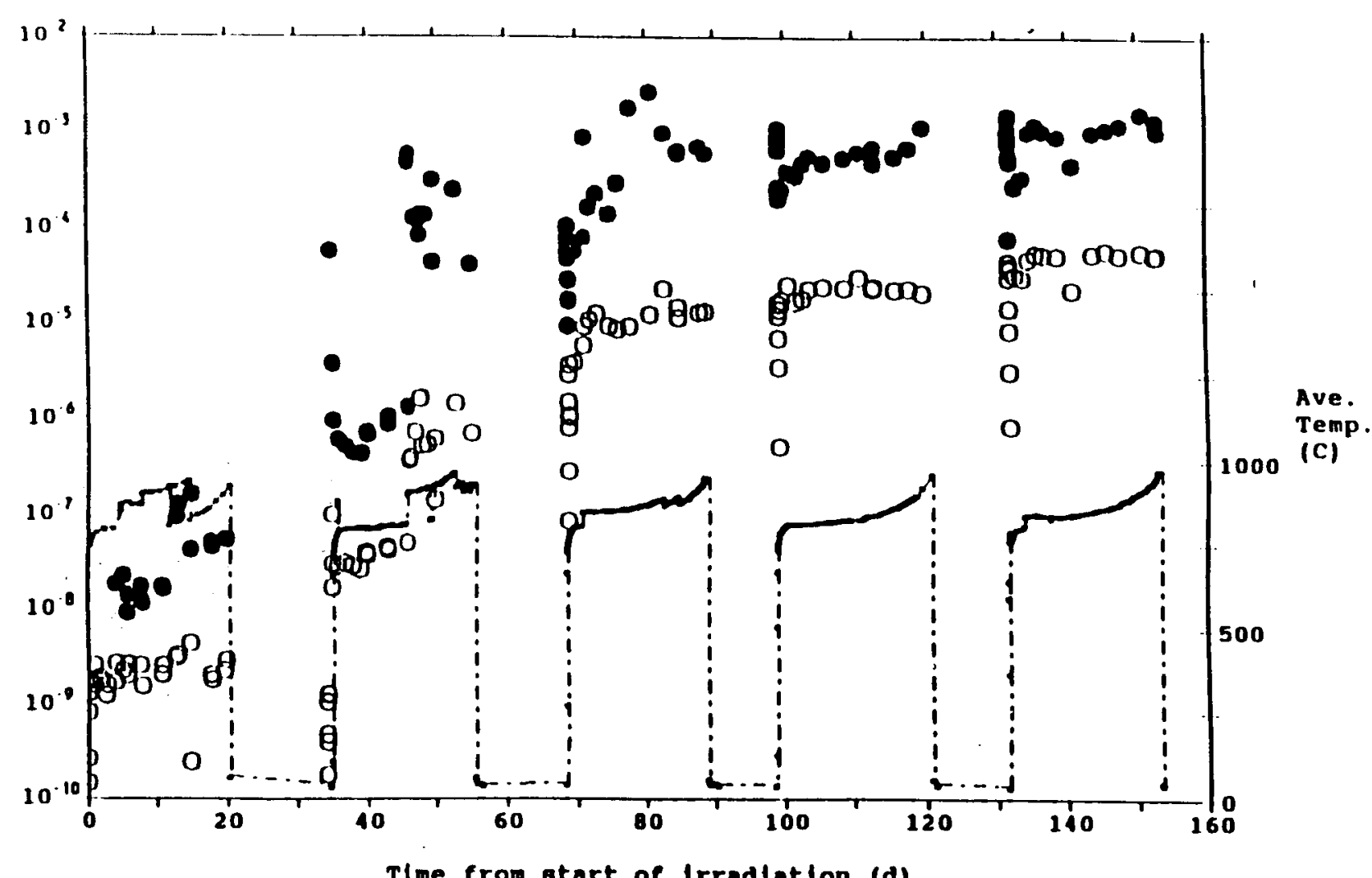

$\nabla$
0
01
1
0
0
0
0
0
$\dot{1}$
0
0
0
0
0
0

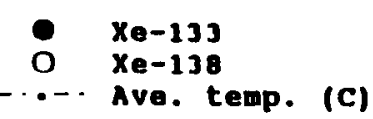

Figure 2-6.

R/B VALUES FOR Xe-133 AND Xe-138 AND THE CAPSULE AVERAGE FUEL TEMPERATURE AS A FUNCTION OF TIME FROM THE START OF THE IRRADIATION. 
ORNL-DWG 92-16008

$\stackrel{N}{a}$

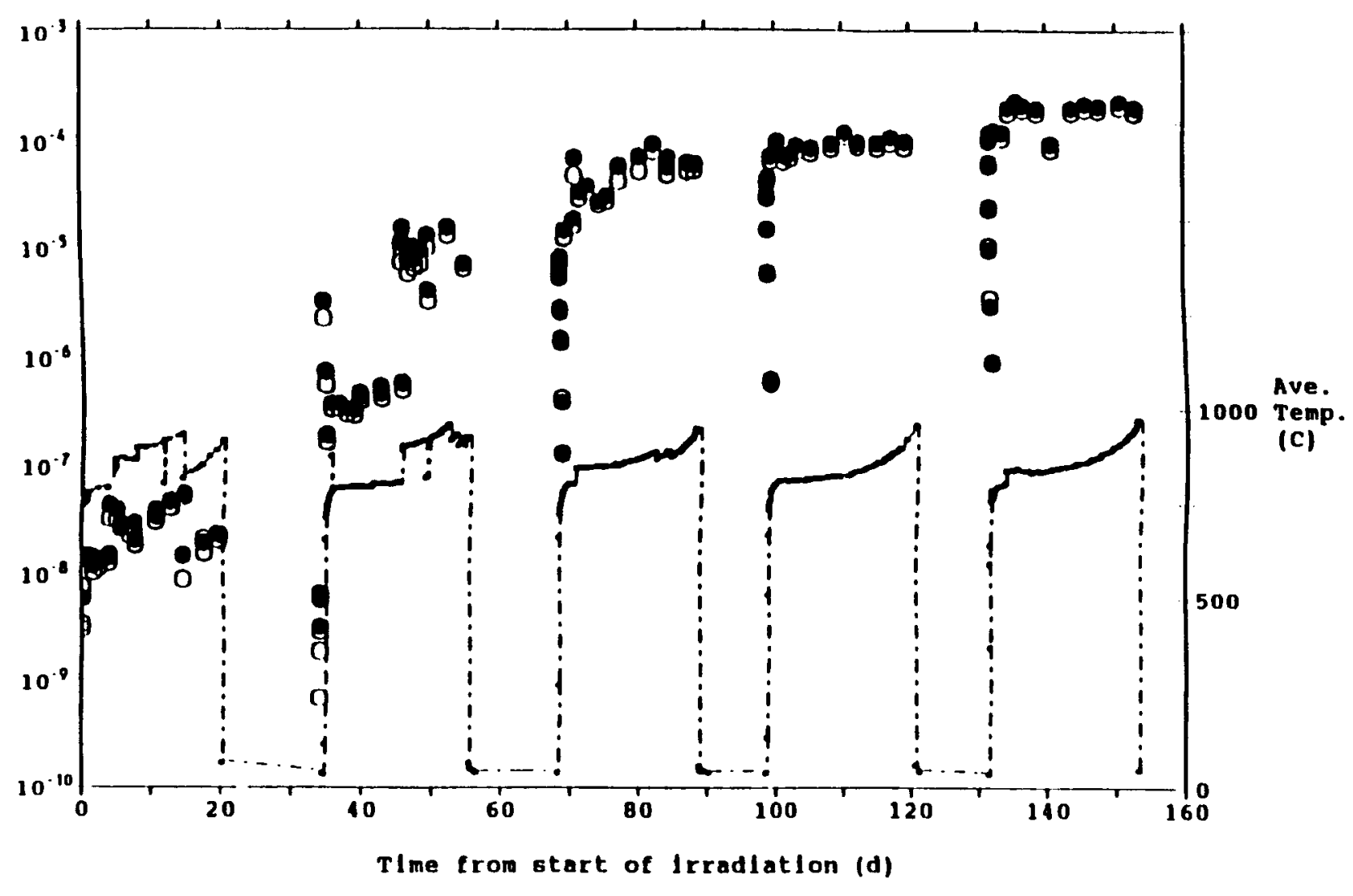

- $\quad k r-85 m$

O Kr-8B
$\ldots$ Ave. temp. (C)

Figure 2-7.

R/B VALUES FOR ${ }^{85 \mathrm{~m}} \mathrm{Kr}$ and ${ }^{88} \mathrm{Kr}$ AND THE CAPSULE AVERAGE FUEL TEMPERATURE AS A FUNCTION OF TIME FROM THE START OF THE IRRADIATION. 
2.1.2.4 HRB-21 PIE - J. T. Parks, L. C. Emerson, N. H. Packan, R. D. Taylor, M. J. Kania, R. C. Martin, C. A. Baldwin, R. N. Morris, and O. M. Stansfield

The HRB 21 capsule was the first in a planned series of capsules to demonstrate NE-MHTGR fuel [low-enriched uranium-uranium oxycarbide (LEU-UCO)/ $/ \mathrm{ThO}_{2}$ TRISO] performance under normal operating conditions. The capsule began irradiation in the HFIR at ORNL on June 21, 1991, and ended on November 21, 1991, after five HFIR cycles of irradiation. The amount of fission gas release was much greater than predicted and exceeded the NE-MHTGR design requirements during irradiation.

After irradiation was completed, the capsule was removed from the HFIR and transported to the IFEL in Building 3525 at ORNL. Disassembly of the capsule took place in the hot cell, and examination of the fuel was started in late FY 1992.

The PIE work was continued into FY 1993, and in the time period form October 1, 1992, through February 28, 1993, the following work was accomplished:

1. Selected compacts were transported to GA's TRIGA facility, and fission gas released was measured; the compacts were then returned to ORNL.

2. Scanning electron microscopy (SEM) examination of a compact fracture surface was conducted.

3. Ceramography of three compactas were carried out and the coating condition characterized.

4. Four compacts were deconsolidated, and Irradiated Microsphere Gamma Analysis (IMGA) was initiated on the debonded particles from two of the compacts.

5. Unbonded particles from the piggyback containers were subjected to IMGA, and the fraction of particles releasing fission products was estimated.

6. The schedule for PIE was updated.

7. The outline for the PIE report was issued for program comment.

After removal of the compacts, the diameter, length, and the fuel hole diameters of the graphite bodies were measured by the use of calibrated dial and bore gages. The dimensional change during irradiation was calculated based on preirradiation inspection values. The diameters and lengths decreased during irradiation by amounts varying from 0.1 to $0.3 \%$, while the fuel hole inside diameters (IDs) contracted by 0.5 to $0.9 \%$ (larger values corresponding to midcapsule locations). 
The length and diameter of the fuel compacts were measured by dial gage. The lengths were measured at three locations around the circumference and the diameter at the top, middle, and bottom of the compact. The calculated dimensional change shows an initial shrinkage in both diameter and length followed by expansion at fast neutron fluence greater than about $1.5 \mathrm{x}$ $10^{25} \mathrm{n} / \mathrm{m}^{2}$. The average diameter and length changes for the compacts ranged from $-1.5 \%$ for the low-fluence compacts to $+0.5 \%$ for the high-fluence compacts.

The expected behavior of both the graphite bodies and the fuel compacts was shrinkage relative to initial dimensions under all conditions of the irradiation test. A possible explanation for the expansion is extensive failure of the protective PyC (PPyC) and outer PyC (OPyC) coatings with consequent degrading of the mechanical integrity of the compact. Three of the compacts were broken, as first observed during extraction from the graphite bodies during disassembly, but six broke into two pieces during subsequent (gentle) handling. The weakness of the bond between compact constituents may have contributed to the observed expansion.

The 12 compacts from the lower graphite fuel body were individually placed into graphite crucibles and transported to GA in the Sugarman Cask so that TRIGA R/B measurements could be made. The TRIGA fission gas release measurements were carried out at GA, and the compacts were then returned to ORNL. The fission gas release measured by TRIGA activation ranged by over two orders of magnitude from the compacts with the minimum exposure to the compacts with maximum exposure. These data are still under examination because the measurements were not made under equilibrium fission gas release conditions, and corrections need to be made.

SEM was conducted on the fracture surface of fuel compact $3 \mathrm{C}$ using an Integrated Systems, Inc. (ISI) SEM. Compact $3 \mathrm{C}$ had a fast neutron exposure of $3 \times 10^{25} \mathrm{n} / \mathrm{m}^{2}$, and the burnup was 21 and $2 \%$ FIMA for fissile and fertile particles, respectively. The compact was observed to be fractured when it was removed from the graphite holder in which it was irradiated. A high fraction of failed PPyC coatings resulted in loss of compact strength so that it had to be handled very carefully to avoid further loss of integrity.

Low-magnification examination of the fracture surface with optical microscopes revealed that most of the PPyC coatings were failed at the fracture surface, and the matrix was very porous. With the low-magnification view, it was not possible to determine if exposed kernels were present at the fracture surface. The compact was submitted for SEM examination to obtain a higher magnification view of the surfaces. 
The SEM examination confirmed the high level of PPyC failure observed in metallography. Careful examination of the cracks and surfaces exposed by coatings which had spalled off did not reveal any exposed kernels. The SiC layers were not grossly failed. It appeared that the PPyC and OPyC coatings had failed and, in many cases, completely fallen off the SiC coating surface.

The inner surface of the fragments of the OPyC coatings could be examined. The surfaces appeared smooth with no features which could be linked to the failure that had taken place.

The fracture surface of PPyC and OPyC was examined. In most cases, the fracture surface went smoothly through the interface between the PPyC and OPyC coatings. However, there were some cases where the fracture was interrupted at the interface, which indicated that the PyC seal coat on the OPyC may have functioned as intended in those particles.

The SEM examination clearly showed that PPyC and OPyC failure was nearly $100 \%$, but the crack propagation did not proceed through the $\mathrm{SiC}$ coating. No examples of failed $\mathrm{SiC}$ could be found on the fracture surface of compact $3 \mathrm{C}$.

Ceramography can provide invaluable data regarding the particle microstructure and thermal effects such as kernel migration or $\mathrm{SiC}$ fission product reaction. However, it can be ambiguous in the determination of the cause of mechanical failure of the PyC or SiC coatings because the brittle ceramic coatings can be cracked during the grinding and polishing process used to prepare the ceramographic mount. After the mount is prepared, it is not possible to determine conclusively whether the coating was cracked during irradiation or during the grinding and polishing process. With regard to characterizing the coating failure fraction by ceramography, we can record the frequency of cracked coatings observed in the polished section and treat this information as an upper limit on what may have existed during irradiation.

Three compacts, 1C, 2B, and 4A, representing, respectively, minimum, intermediate, and maximum fast neutron exposure and burnup, were selected for examination by ceramography. The compacts were extremely fragile, and before sectioning, they were first impregnated with epoxy resin. After the resin cured, ceramographic samples were cut from the compact ends. The samples obtained were mounted in resin and polished so that a circular cross section representing each end of the compact was obtained for examination.

The polished surfaces were examined at 100,250, and $500 \times$ and the condition of the matrix, kernel, buffer, IPyC, SiC OPyC, and PPyC use documented in terms of mechanical integrity and signs of chemical reaction. The compact matrix consisted of $\mathrm{H}-451$ graphite shim particles and 
graphite flour bonded with carbonized petroleum pitch. The irradiated matrix had a large number of cracks and high porosity consistent with observations of prior irradiation of this material.

With regard to the fuel particles dispersed in the matrix, the type of particle being examined was determined from the appearance of the kernel. The UCO kernels were porous with gas voids and evidence of kernel swelling into cracks in the buffer. The $\mathrm{ThO}_{2}$ kernels were generally featureless with no sign of kernel swelling or distortion. This examination characterized about $500 \mathrm{ThO}_{2}$ and 200 UCO TRISO particles in the three compacts. The observations are summarized in the following paragraphs.

The low-density PPyC layer exhibited the highest failure of all the coatings at each exposure level. At the lowest fast-neutron exposure of about $1.5 \times 10^{25} \mathrm{n} / \mathrm{m}^{2}$, the PPyC failure fraction was about $70 \%$ in both fertile and fissile particles, while at exposures above $2 \times 10^{25} \mathrm{n} / \mathrm{m}^{2}$ to the peak exposure of $3.7 \times 10^{25} \mathrm{n} / \mathrm{m}^{2}$, the PPyC failure fraction was nearly $100 \%$. The cracks in the PPyC appeared to originate at the outer surface and propagate inward. Although at low exposure there was some evidence that crack propagation was impeded at the OPyC/PPyC interface, at high exposure, cracks in the PPyC propagated through the interface and the OPyC layer.

There was no significant difference between coating performance on the fertile and fissile particles. The failure fraction of the OPyC was about $5 \%$ at low fast-neutron fluence but was the same as PPyC failure (100\%) at high exposure.

Cracks were observed in the SiC layer in a low-fluence compact (compact 1C, $1.5 \mathrm{x}$ $10^{25} \mathrm{n} / \mathrm{m}^{2}$ ), but they were circumferential in the $\mathrm{SiC}$, and no through-coating radial cracks were observed. The cracks sometimes covered more than $90^{\circ}$ of the circumference with both crack ends connecting either to the inner or outer SiC coating surface. About $21 \%$ of the fertile particles examined showed the circumferential cracks, whereas only one fissile particle (1\%) of the group examined had a cracked $\mathrm{SiC}$ layer.

At higher fast-neutron exposure and burnup, the few cracks observed in the $\mathrm{SiC}$ were radial and not circumferential. Like the lower exposure condition, the cracked SiC coatings were more numerous in the fertile than in the fissile particles. The tendency observed was a decrease in fissile particle $\mathrm{SiC}$ cracks with increasing fast-neutron exposure and an increase in fertile particle $\mathrm{SiC}$ cracks with increasing fast-neutron exposure.

It seems unlikely that the observed cracks in low-exposure samples were present during irradiation since they were not present in specimens irradiated to high exposure. It is probable that many of the cracked SiC coatings were an artifact of the grinding and polishing process, 
interacting with material that had been preconditioned by fabrication and/or irradiation. Perhaps residual stress in the $\mathrm{SiC}$ made low-exposure specimens more prone to failure during mount preparation. Irradiation-induced creep may have relieved stress at the higher fluence.

Fission product attack or corrosion of the $\mathrm{SiC}$ was observed in the ceramographic sections to be less than $10 \mu \mathrm{m}$ in depth. From 2 to $3 \%$ of the particles in compacts $2 \mathrm{~B}$ and $4 \mathrm{~A}$ showed evidence of fission product reaction with the SiC inner surface. No reaction was observed in compact 1C. The reaction of fission products with the $\mathrm{SiC}$ was usually associated with a crack in the IPyC near the reaction site. The opening in the IPyC apparently facilitated fission product transport to the $\mathrm{SiC}$.

The IPyC coating showed a rapid increase in failure fractions at fast-neutron fluence greater than $2.3 \times 10^{25} \mathrm{n} / \mathrm{m}^{2}$. The cracks did not propagate into the SiC. However, as discussed above, evidence of fission product attack of the SiC was usually found near a crack in the IPyC.

The IPyC coating was strongly bonded to the SiC. During irradiation, the IPyC tends to contract in the radial and circumferential directions due to radiation damage. If the bond between the IPyC and $\mathrm{SiC}$ is weak, the IPyC will pull away from the $\mathrm{SiC}$, and a gap will develop between the IPyC and SiC. Such a gap was not observed in the metallography of particles in the HRB-21 fuel compacts. Some examples could be found where the IPyC separated from the SiC when the IPyC had cracked, but, usually, the failed IPyC stayed bonded to the SiC. As the fast-neutron exposure increased from $2.3 \times 10^{25} \mathrm{n} / \mathrm{m}^{2}$ to $3.5 \times 10^{25} \mathrm{n} / \mathrm{m}^{2}$, the fraction of failed IPyC increased by a factor of three. The increase in IPyC failure fraction coincided with a similar reduction in the observed fraction of cracked SiC. Although the incidence of SiC failure decreased significantly as IPyC failure fraction increased, there was no causal relationship observed. In fact, at high exposure, nearly all of the cracked $\mathrm{SiC}$ coatings were in particles which had cracked IPyC. Based on observations of metallographic mounts, failure of the IPyC had not precluded the occurrence of failed SiC.

The buffer coating was deposited as a $50 \%$ dense PyC that provided a void volume for accumulation of fission gases during irradiation and a non-load-bearing compliant layer to prevent mechanical interaction between the kernel and the structural coating layers. During irradiation, the buffer coating shrunk in both the radial and circumferential directions as it densified. Usually, the buffer coating would pull away from the IPyC along a portion of the circumference and leave a 10- to 20- $\mu \mathrm{m}$-wide gap. The PyC seal coating, which was applied to the buffer outer surface 
during manufacture, appeared to remain attached to the IPyC coat as the buffer underwent radial shrinkage so that a 5- to $10-\mu$ m-thick band of seal coat and buffer PyC remained with the IPyC.

In about $10 \%$ of the fissile UCO particles, the buffer layer experienced radial cracking and circumferential shrinkage, which widened the cracks. In these instances, the kernel material usually expanded into the radial cracks which developed in the buffer.

The $\mathrm{ThO}_{2}$ kernel heavy metal burnup ranged between $0.5 \%$ FIMA at the ends of the capsule and 2.2\% FIMA at the middle of the capsule, which was near the HFIR core midplane. The 2.2\% FIMA is $80 \%$ of the maximum burnup expected in MHTGR service. The $\mathrm{ThO}_{2}$ kernel microstructure was relatively featureless in the metallographic cross sections. There was a fine porosity that made it possible to distinguish angular-shaped grains in some kernels. The kernels retained their spherical shape as evidenced by the circular cross section which was obtained in the metallographic section.

The UCO kernel heavy metal burnup ranged between 14\% FIMA at the ends of the capsule and $22.5 \%$ FIMA at the middle of the capsule, which was near the HFIR core midplane. The 22.5\% FIMA attained is beyond the 22\% FIMA maximum burnup expected in the NE-MHTGR.

In three particles in compact $4 \mathrm{~A}$, which had the highest exposure, there was what appeared to be a carbon deposit at the kernel-buffer interface. The deposit showed optical activity in polarized light, which is typical for the carbon rejected on the cool side of $\mathrm{UO}_{2}$ and $\mathrm{UC}_{2}$ kernels heated in a thermal gradient. The rejection of the carbon on the cool side is associated with migration of the kernel up the temperature gradient in what has been called the "amoeba effect." These observations in HRB-21 represent the first evidence of the amoeba effect in UCO kernels.

The kernel migration coefficient (KMC) was calculated for the three kernels with observed migration, using the thickness of the rejected carbon as a measure of kernel migration. The particle temperature was estimated at $1225 \mathrm{~K}, \Delta \mathrm{T} / \Delta \mathrm{d}$ at $1.5 \times 10^{4} \mathrm{~K} / \mathrm{m}$, and $\mathrm{t}$ at $10^{7} \mathrm{~s}(120 \mathrm{~d})$.

The estimated KMC for the three particles was about $10^{-10} \mathrm{~m}^{2} \mathrm{~K} / \mathrm{s}$, which is three orders of magnitude larger than the design value for $\mathrm{UCO}$ at the irradiation temperature $\left(950^{\circ} \mathrm{C}\right)$ but a factor of 30 less than the design value for pure $\mathrm{UO}_{2}$ kernels. The fact that only three kernels in the most highly exposed compact showed kernel migration, and the intermediate value of KMC between $\mathrm{UO}_{2}$ and $\mathrm{UCO}$ design curves, may indicate that the kernels exhibiting migration contained excessive amounts of $\mathrm{UO}_{2}$. The nominal composition of the unirradiated UCO was $15 \% \mathrm{UC}_{2}$ and $85 \% \mathrm{UO}_{2}$, but results of characterization work on the NP-MHTGR Program for highly enriched uranium (HEU) UCO kernels showed that the distribution of kernel composition 
ratios can be relatively wide. Kernel composition measurements have not yet been made in the LEU UCO of HRB-21, but there may have been much less than $15 \% \mathrm{UC}_{2}$ in several percent of the HRB 21 kernels if they were similar to the HEU UCO fuel. A low $\mathrm{UC}_{2}$ initial content could lead to kernel migration similar to that in pure $\mathrm{UO}_{2}$.

At the lowest burnup, the fission gas bubbles were very small $(<5 \mu \mathrm{m})$, with the larger voids tending to concentrate at the center of the kernel. The kernels with low burnup (14\% FIMA) retained their spherical shape. At the highest burnup experienced, fission gas bubbles, 10 to $50 \mu \mathrm{m}$ in major diameter, were present and dispersed throughout the UCO kernels. No grain structure could be discerned in the metallographic view of the kernel cross section. Where there was a crack in the buffer, the kernel tended to swell into the void created by the crack. The migration of kernel material by swelling into cracks in the buffer resulted in much greater movement of kernel material than observed in the amoeba effect discussed previously. However, the protrusion of the kernel terminated at the IPyC and, in no case, was the kernel material seen in contact with the SiC coating. Kernel swelling represents a significant mechanism for movement of kernel material toward the coating in UCO, and even though it doesn't appear to have caused failure under HRB 21 conditions, it should be treated in the fuel performance model.

IMGA is a technique for characterizing the fission product content of individual coated particles to determine if the coating system has been retentive. Detection of a deficiency of a mobile fission product, such as Cs-137 relative to immobile Ce-144, is taken as an indication that the coatings have lost integrity.

For examination of particles that have been irradiated in compacts, the particles must first be debonded from the compact so that they can be handled individually. The debonding is accomplished by subjecting the compact to room-temperature nitric acid with a low-voltage difference imposed between the compact and the acid solution. The carbonaceous bonding material between particles is preferentially oxidized in this procedure, and the particles are freed from the compact.

Compact deconsolidation was performed for four HRB-21 compacts: $5 \mathrm{C}, 6 \mathrm{~B}, 7 \mathrm{~A}$, and $8 \mathrm{~A}$. The remnants from $5 \mathrm{C}$ and $8 \mathrm{~A}$ were run through the deconsolidation process a second time to increase the particle recovery fraction. Liquid electrolyte samples from compact $8 \mathrm{~A}$ were transported to the Analytical Chemistry hot cells for analysis of heavy metal content. The radioactivity level of the electrolyte sample from compact $7 \mathrm{~A}$ was too high due to failed particles 
to transport it directly to Analytical Chemistry; the paperwork has been completed to allow shipments of hot samples to commence.

The Analytical Chemistry hot cells had an incident shortly after delivery of the first samples (late December 1992) and have not reopened for operation and sample analysis. As a result, none of our electrolyte samples have been analyzed. We are presently exploring the possibility of having diluted electrolyte samples analyzed for heavy metal content by another group in ORNL. We are awaiting results to determine the practicality of this effort.

In compact $8 \mathrm{~A}$, the PPyC coatings were intact, and the rubble consisted primarily of graphite shim particles. For compact 5C, the PPyC and OPyC coatings were nearly all fractured, and they spalled off during deconsolidation to become part of the rubble separated from the particles. In addition, compact $5 \mathrm{C}$ rubble contained about $60 \%$ of the coated particles in agglomerates consisting of many particles which had not been fully deconsolidated by exposure to the electrolytic acid treatment.

The exposure conditions and number of particles subjected to IMGA from compacts $5 \mathrm{C}$ and $8 \mathrm{~A}$ are summarized below:

\begin{tabular}{cccccc}
$\begin{array}{c}\text { Fuel } \\
\text { compact }\end{array}$ & $\begin{array}{c}\text { Irradiation } \\
\text { temperature }{ }^{\circ} \mathrm{C}\end{array}$ & $\begin{array}{c}\text { Burnup } \\
\text { (\% FIMA) }\end{array}$ & \multicolumn{2}{c}{$\begin{array}{c}\text { Neutron fluence } \\
\left(\mathrm{n} / \mathrm{m}^{2} \mathrm{E} .29 \mathrm{fJ}\right)\end{array}$} & \multicolumn{2}{c}{$\begin{array}{c}\text { No. particles examined } \\
\text { Fertile }\end{array}$} & Fissile \\
$8 \mathrm{~A}$ & $500-1100$ & $\begin{array}{c}\text { 0.5 fertile } \\
\text { 12.6 Fissile }\end{array}$ & $1.5 \times 10^{25}$ & 925 & 1759 \\
$5 \mathrm{C}$ & $500-1100$ & 2.2 Fertile & $3.5 \times 10^{25}$ & 1785 & 372
\end{tabular}

At the time of this writing, a total of 1763 fissile particles from compact $8 \mathrm{~A}$ had been examined by IMGA, and 926 fertile particles were examined. The particles that were examined represented about 70 and $20 \%$ of the total $\mathrm{UCO}$ and $\mathrm{ThO}_{2}$ particles, respectively, which had been in the compact. The unexamined particles remained in the rubble as intact or broken particles, and additional deconsolidation and separation treatment will be needed to extract them.

Only the IMGA data from the fissile particles were analyzed during the report period. The fission product activity ratios were used, instead of absolute measured values for individual isotopes, in order to remove the inventory variability that would result from the difference in the kernel size and which would not be an indicator of coating retention. 
The analysis of the gamma spectrometry data was based on comparison of the theoretical and measured activity ratios for mobile and immobile fission products. The ratios used were Cs-137/Ce-144 and Cs-137/Zr-95. The cesium is known to be mobile while cerium and zirconium are retained, even in particles with failed coatings. The theoretical ratio of these isotopes was calculated based on the burnup of the fissionable material. A measured ratio smaller than the calculated ratio was taken as indication of a particle that had released cesium through a failed coating.

The gamma counting results have inherent variability, but because large numbers of particles are examined, the results can be analyzed by statistical methods to yield quantitative results. The IMGA results were analyzed by comparison of measured fission product activity ratios with:

- Measured mean activity ratios for the whole population

- Calculated activity ratios based on burnup

- Calculated activity ratios based on the assumption that fission product Ce-144 was retained

Several observations can be made from the IMGA of compact $8 \mathrm{~A}$ fissile particles. The distribution of activity ratios follows a normal distribution and shows a low standard deviation (all were $<2.4 \%$ different from the mean). There were no particles that were off the normal distribution or far from the mean. Distributions based on comparison of measured activity ratios with calculated ratios were within the error associated with the burnup calculations.

Performance assessment based on Ce-144 retention is that none of the UCO particles in compact $8 \mathrm{~A}$ were deficient in cesium (the Ce-144-to-cesium ratios were consistent); thus, they were retentive of their metallic fission products. Although analysis of the $\mathrm{ThO}_{2}$ data was not completed, the preliminary indication was that none of the $\mathrm{ThO}_{2}$ particles were deficient in cesium.

Because of the relatively low burnup and exposure conditions of compact $8 \mathrm{~A}$, it is possible that the kernel and intact PyC coatings may have been able to retain $\mathrm{Cs}$ even if the $\mathrm{SiC}$ coating was failed. In that case, the IMGA results from compact $8 \mathrm{~A}$, showing retention of $\mathrm{Cs}$, would not provide conclusive evidence for intact $\mathrm{SiC}$. However, measured loss of $\mathrm{Cs}$ from unbonded piggyback samples discussed later in this report indicated that it may be possible for particles in HRB-21 to release Cs through what appeared to be unbroken coatings. This issue will receive further attention as the PIE progresses. 
Compact 5C was deconsolidated and particles obtained similar to compact 8A. Nearly all the particles had lost the PPyC and OPyC coatings, so the particles were processed as bare SiC-coated particles. Since the fertile particles had more burnup than in compact $8 \mathrm{~A}$, the fission product inventory could be measured more quickly, so unlike $8 \mathrm{~A}$, the decision was made to obtain inventory data from fertile, as well as fissile, particles.

The analysis of IMGA data from compact $5 \mathrm{C}$ is in progress. Preliminary results indicated that 1 failed $\mathrm{ThO}_{2}$ coating (out of 1350) and 14 failed UCO coatings (out of 384) were detected through low-Cs inventory. Fissile particles with indicated Cs loss, and particles that were retentive, were selected and submitted for metallography to determine if microstructural differences exist.

Irradiated unbonded fertile and fissile particles with 5- and 7-layer standard and defective TRISO coatings were irradiated in capsule HRB-21 with 32 particles in each container (piggyback). The defective particles were those in which the buffer coating was intentionally missing. In this report period, the standard (non-defective) particles were obtained from piggyback samples. During irradiation, the graphite crucibles that held the particles became bonded to the walls of the niobium tube containment so that disassembly was difficult. Samples were obtained for examination, but many particles were lost during the process. A summary of the piggyback identification and exposure conditions is given below:

\begin{tabular}{|c|c|c|c|c|c|}
\hline $\begin{array}{l}\text { Specimen } \\
\text { number }\end{array}$ & Particle type & $\begin{array}{l}\text { Irrad. } \\
\text { Temp. } \\
\left.{ }^{\circ} \mathrm{C}\right) \\
\end{array}$ & $\begin{array}{l}\text { Burnup } \\
\frac{(\%}{\text { FIMA })}\end{array}$ & $\begin{array}{l}\text { Fast fluence } \\
\left(10^{25} \mathrm{n} / \mathrm{m}^{2}\right. \\
\mathrm{E}>29 \mathrm{fJ})\end{array}$ & $\begin{array}{c}\text { No. } \\
\text { particles } \\
\text { examined }^{a}\end{array}$ \\
\hline $2 \mathrm{~A}$ & UCO 7-layer TRISO & $\mathrm{TBD}^{b}$ & 21 & 2.2 & 28 \\
\hline $3 \mathrm{~A}$ & UCO 5-layer TRISO & $\mathrm{TBD}^{b}$ & 18 & 3.1 & 28 \\
\hline $6 \mathrm{~A}$ & $\mathrm{ThO}_{2}$ 5-layer TRISO & $\mathrm{TBD}^{b}$ & 2 & 3.0 & 19 \\
\hline $7 \mathrm{~A}$ & $\mathrm{ThO}_{2}$ 7-layer TRISO & $\mathrm{TBE}^{b}$ & 1 & 2.2 & 15 \\
\hline
\end{tabular}

${ }^{a}$ There were 32 particles in each container, and some were lost during disassembly. All retrieved particles were examined.

${ }^{b} \mathrm{TBD}=$ to be determined. 
All of the fissile and fertile piggyback particles were examined visually, and two had cracked PPyC coatings. Those two were $\mathrm{ThO}_{2}$ 7-layer TRISO from specimen number 7A. All other unbonded piggyback particles showed no cracked coatings. The fact that unbonded piggyback particles showed almost no PPyC cracks, while particles in compacts had cracked PPyC in nearly all particles, indicated that compact features, such as higher temperatures or matrix-particle interactions, may contribute to coating failures in compacts.

The piggyback particles were measured by IMGA, and the release of Cs was detected from the fertile, but not from the fissile, particles. For the fertile particles, 1 of the 17 five-layer TRISO particles and 2 of the 15 seven-layer TRISO particles were deficient in Cs. The 5 to $13 \%$ failure fraction in piggyback fertile particles indicated by these results is not consistent with the absence of no failure in the 1350 fertile particles from compact 5C examined by IMGA and discussed above. In order to provide additional evidence for fission product release from the fertile particles, one of the graphite crucibles containing the fertile particles (7A) was scanned to determine if fission products had been sorbed. Cesium activity at the microcurie level, equivalent to $10 \%$ of a fertile kernel inventory, and cerium activity, equivalent to about $2 \%$ of a particle inventory, were detected in the graphite crucible. Scans of both graphite crucibles containing the fissile particles showed one to two orders of magnitude more fission product contamination than the crucible with the fertile particles, and the amount detected was $10^{-2}$ to $10^{-4}$ fraction of a fissile particle inventory.

In view of the difficulty experienced in piggyback sample disassembly, the fact that coated particles were lost, and the detection of a normally immobile fission product like cerium in the graphite crucible, it is possible that fertile particles were damaged, and some fission product activity from damaged particles contaminated the fertile particle graphite crucible. In that case, the presence of fission products in the graphite would not provide information on fission product release during irradiation. This issue will receive further evaluation.

An unirradiated archive HRB-21 compact was put through the entire leach-burn-leach experimental procedure. A standard operating procedure for the initial leach step in the hot cells has been written and approved. The operating procedure for the subsequent burn-leach step is presently in draft form. The equipment stand for the hot cell has been designed and is currently being fabricated, with completion expected shortly.

Analysis of the fission gas release during irradiation of HRB-21 is under way. Fission gas release depends inversely on the radioactive decay constant of the gas under study raised to some 
power, $n$. The values of $n$ in diffusive release are normally in the range of 0.3 to 0.5 . During the release of stored fission gas, however, the values of $n$ are larger, in the range of 1.0 to 1.5. The discovery has been made that large values of $\mathrm{n}$ are found when $\mathrm{Ne}$ is added to the He carrier gas and that only smaller values are found when He alone is present. Furthermore, in the presence of the $\mathrm{Ne}-\mathrm{He}$ mixture, additional noise appears on the record of the ionization gauge signal used to monitor sudden releases of fission gas following the failure of a coated fuel particle.

\subsubsection{Modeling}

\subsubsection{Fuel Modeling - R. C. Martin and B. F. Myers}

For accident-condition models of fission product release, efforts at ORNL over the last several years focussed on the German HTGR fuel data base pending obtaining significant hightemperature data from the latest U.S. fuel variants. Compilation of the German data and analysis of metallic fission product release via diffusive transport, with emphasis on cesium, were pursued in several reports and presented at an International Atomic Energy Agency (IAEA) Specialists Meeting in November $1990 .^{13-15}$ The need for more detailed microstructural characterization of the SiC and understanding of the effects of irradiation on its microstructural integrity were also emphasized. A detailed diffusion model for high-temperature cesium release was presented in which a fast-fluence-dependent diffusion coefficient (similar to a German analysis) was used to reproduce the cesium release from German sphere heating tests with less error than the existing Goodin-Nabielek model. ${ }^{16}$

Relevant accident-condition data from U.S. particles were obtained from one CCCTF heating test at $1600^{\circ} \mathrm{C}$ for $100 \mathrm{~h}$ on HRB-17 piggyback particles. Although several particles showed significant but variable cesium release, the average release corresponded to a diffusion coefficient determined by B. F. Myers in 1984 to represent columnar-like SiC structure. ${ }^{17}$ The German data correspond to a second, lower diffusion coefficient which represents a laminar-like structure. These results generally correlate with the observed larger, columnar grains in the U.S. SiC and the smaller German SiC grains and also indicate that U.S. SiC, as presently fabricated, will be less successful at retaining cesium at high temperatures than the German material.

K. Röllig of Germany used a log-normal distribution of diffusion coefficients in $\mathrm{SiC}$ to reproduce the cesium release data from German sphere R2-K13/1 (ref. 18). His results suggest that a distribution of diffusion coefficients around the average is the most promising approach to modeling metallic fission product release from particles and correlating transport to variations in 
$\mathrm{SiC}$ microstructure. This approach is consistent with the cesium distributions obtained from the HRB-17 CCCTF test.

A major effort was undertaken to document the current NE fuel performance and fission product transport models, their background and the assumptions used in their derivation, and the data base supporting their development. ${ }^{19}$

Collaboration with German personnel continued under the U.S./FRG Umbrella Agreement for Cooperation in GCR Development. On a technical exchange to ORNL, K. Verfondern of KFA Jülich compared the German and Japanese reference accident-condition fuel performance models $^{20}$ and analyzed the IMGA data for cesium release from German fuel sphere HFR-K3/3 after heating. ${ }^{21}$ These heating results were unique in the resultant bimodal cesium distribution, and Verfondern postulated an additional failure mechanism resulting from rapid furnace and fuel cooldown. R. C. Martin of ORNL continued Verfondern's analysis of German sphere HFR-K3/3, comparing the predictive capabilities of several models (Goodin-Nabielek, MartinGoodin-Nabielek, and diffusion models). ${ }^{2}$ During another technical exchange, the current reference German fuel performance and fission product transport models were documented and compared to the models used in the U.S., Japanese, Russian, etc., national programs and issued as a KFA Jülich report. ${ }^{23}$

A computerized bibliography system used to tabulate and retrieve HTGR document references by category was developed at ORNL, and reference entry was initiated. ${ }^{24}$

The modeling of fission product behavior in the gas turbine-modular high-temperature gascooled reactor (GT-MHTGR) was addressed (Myers, 1991). The goal of the effort was to compare the prismatic steam cycle, the prismatic GT, and the pebble-bed core reactors in terms of fission product behavior. In particular, attention was directed to: (1) the effect of higher fuel temperatures under normal operating conditions and under severe-accident conditions on the release of fission products from the coated fuel particles, (2) the effect of higher core temperatures under normal operating conditions and under severe-accident conditions on the release of fission products from the graphite materials, (3) the diffusion of fission products into turbine blades, (4) the deposition of fission products in the primary system, and (5) the effects of dust on fission product transport and on the turbomachinery.

The analysis led to the following conclusions:

1. Based on a particle defect fraction of $10^{-4}$, calculations indicate that higher fuel temperatures in the prismatic GT reactor can lead to unacceptable releases of fission 
products from particles during normal operation and in a loss-of-coolant accident for the current particle design. For the pebble bed reactor, the releases appear to be smaller.

2. Higher core temperatures in the prismatic and pebble-bed GT reactor can lead to unacceptable increases in the quantities of some fission products reaching the primary system. The absolute releases for the pebble-bed GT reactor are smaller than for the prismatic GT reactor.

3. When the defect fraction is reduced to $10^{-5}$ and the time-average fuel temperature is kept below $1200^{\circ} \mathrm{C}$, the releases and depositions of fission products are significantly reduced to acceptable levels, except possibly for silver.

4. The reduction in the fraction of defective coated particles must be lowered from $10^{-4}$ to perhaps $10^{-5}$. A second requirement is that the peak fuel temperature be limited to about $1200^{\circ} \mathrm{C}$ if present fuel technology is to be employed. If a significant fraction of fuel is at temperatures above $1200^{\circ} \mathrm{C}$ for long periods, fission products will diffuse through the fuel coating even if the fuel defect fraction is extremely low.

5. If $\mathrm{ZrC}$ replaces $\mathrm{SiC}$ as the primary barrier to fission products, the acceptable maximum fuel temperature during normal operating conditions is estimated to increase by $300^{\circ} \mathrm{C}$, to $1500^{\circ} \mathrm{C}$.

6. The interaction of dust with fission products and with the turbomachinery needs careful examination, as does the extent of diffusion of fission products into the turbine blades at high temperatures.

\subsubsection{Modeling of Fission Gas Release - B. F. Myers and F. C. Montgomery}

The description of diffusively released fission gas release generally adopted internationally is given in the "equivalent sphere model." The fractional fission gas release in this model is:

$$
\begin{gathered}
R / B=3 \operatorname{SCALESYM200}\left[\frac{1}{\sqrt{\mu}} \operatorname{Coth}(\sqrt{\mu})-\frac{1}{\mu} \operatorname{SCALESYM2} 00\right] \\
-6 S C A L E S Y M 150 e^{-\lambda t}-S C A L E S Y M 150 \sum_{n=1}^{n=\infty} \frac{S C A L E S Y M 150 e^{-\frac{n^{2} \pi^{2} D t}{a^{2}}}}{\left(n^{2} \pi^{2}+\mu\right)}
\end{gathered}
$$


where

$$
\begin{aligned}
\mu & =\gamma \mathrm{a}^{2} / \mathrm{D} \text { (dimensionless), } \\
\gamma & =\text { radioactive decay constant }(1 / \mathrm{s}), \\
\mathrm{a} & =\text { radius of equivalent sphere }(\mathrm{m}), \\
\mathrm{D} & =\text { diffusion coefficient }\left(\mathrm{m}^{2} / \mathrm{s}\right), \\
\mathrm{t} & =\text { time }(\mathrm{s}), \\
\mathrm{n} & =\text { summation index. }
\end{aligned}
$$

This model is applied strictly to a system of a single material, such as $\mathrm{UO}_{2}$. In the MHTGR applications, the system is not simple but consists of a fuel kernel and surrounding coatings. If the coatings are broken, the kernel is exposed and fission gas is released from the system. There are two materials from which the fission products escape by diffusion: diffusion from the kernel and diffusion from the buffer and inner pyrocarbon layer. In the latter case, the diffusion is by the fission products that recoil out of the kernel and stop in the buffer or, to a lesser extent, the inner pyrocarbon. This suggests the need for a model with a distribution of equivalent sphere radii, the "Distribution Model of Equivalent Sphere Radii. "25 This model will apply to the release of fission gas from exposed kernels, from powders, from hydrolyzed fuel kernels, and possibly other configurations.

The equivalent sphere model couples the parameters $\lambda, a$, and $D$ as the dimensionless variable, $\lambda \mathrm{a}^{2} / \mathrm{D}$. By taking into account a distribution of sphere sizes, the parameters $\lambda$ and $\mathrm{a}^{2} / \mathrm{D}$ are decoupled, which is clearly needed when the particle sizes vary. The model is applied, in a first-order calculation, to two powdered materials: one is a uranyl/barium stearate powder used for calibration in a standard fission gas release measurement, and the other is a fully hyrdolyzed $\mathrm{UC}_{2}$ kernel that undergoes densification under continued heating. In both cases, the assumption of a two-size group distribution (small grains and large grains) is made. The releases from both populations are combined as:

$$
R / B=(R / B)_{1} f_{V 1}+(R / B)_{2} f_{V 2}
$$

where

$(R / B)_{i}=$ the $R / B$ for grains of size group $i=1$ or 2 ,

$f_{v i}=$ volume fraction of size group $i=1$ or 2 . 
The comparison of the R/B time profile with experimental data in the uranyl/barium stearate case is shown in Figure 2-8 for the two isotopes ${ }^{85 \mathrm{~m}} \mathrm{Kr}$ and ${ }^{87} \mathrm{Kr}$. There is good agreement. Only the distribution model of equivalent sphere radii can fit the data. The equivalent sphere model cannot be made to fit the data; the coupling of $\lambda$, a, and $D$ via the quanity $\lambda a^{2} / D$ prevents this. Also notable is the agreement with the half-life dependence for the two isotopes shown based on the distribution model of equivalent sphere radii. Again, agreement could not be obtained with the equivalent sphere model.

The comparison of the R/B time profile with experimental data in the hydrolyzed $\mathrm{UC}_{2}$ case is shown in Figure 2-9 for the two isotopes ${ }^{85 \mathrm{~m}} \mathrm{Kr}$ and ${ }^{87} \mathrm{Kr}$. There is good agreement. Only the distribution model of equivalent sphere radii can fit the data. Furthermore, the densification of the hydrolyzed fuel can be accurately taken into account for both isotopes if three points for the ${ }^{85 \mathrm{~m}} \mathrm{Kr}$ were fitted. The increasing values for $\mathrm{a}^{2} / \mathrm{D}$ indicate that the values of " $\mathrm{a}$ " are increasing as expected during sintering of the small particles.

\subsubsection{Burnup Modeling - R. N. Morris}

Determination by radiochemical methods of the burnup of MHTGR fissile and fertile particles can be an expensive and laborious process that creates a significant amount of hazardous waste if more than a few particles are to be analyzed. Since large numbers of particles are required to develop a significant statistical basis under some conditions, a fast method that requires little operator intervention and generates little or no waste is desired. One way that this can be accomplished is by measuring the inventory of several gamma-emitting fission products in the particle. Once the inventory of several key isotopes is known, the burnup can be determined by making use of the radionuclide's decay constant and fission yield.

Rapid determination of a particle's inventory of several gamma-emitting fission products can be accomplished by using the IMGA device. Typically, a particle's inventory of ${ }^{95} \mathrm{Zr},{ }^{103} \mathrm{Ru}$, ${ }^{106} \mathrm{Ru},{ }^{137} \mathrm{Cs},{ }^{141} \mathrm{Ce}$, and ${ }^{144} \mathrm{Ce}$ can be determined in several minutes using this device.

Furthermore, the device operates in an automatic mode so that scores of particles can be counted in a few hours. Burnup determinations based on data collected in this fashion can make efficient use of resources and can allow burnup determination on a particle-by-particle basis or on an aggregate basis.

A single-group neutronics model is used to determine a set of equations that relates the endof-irradiation radionuclide inventory to the number of fissions that have taken place during the course of the irradiation. ${ }^{26}$ A least-squares minimization technique is used to find the best 


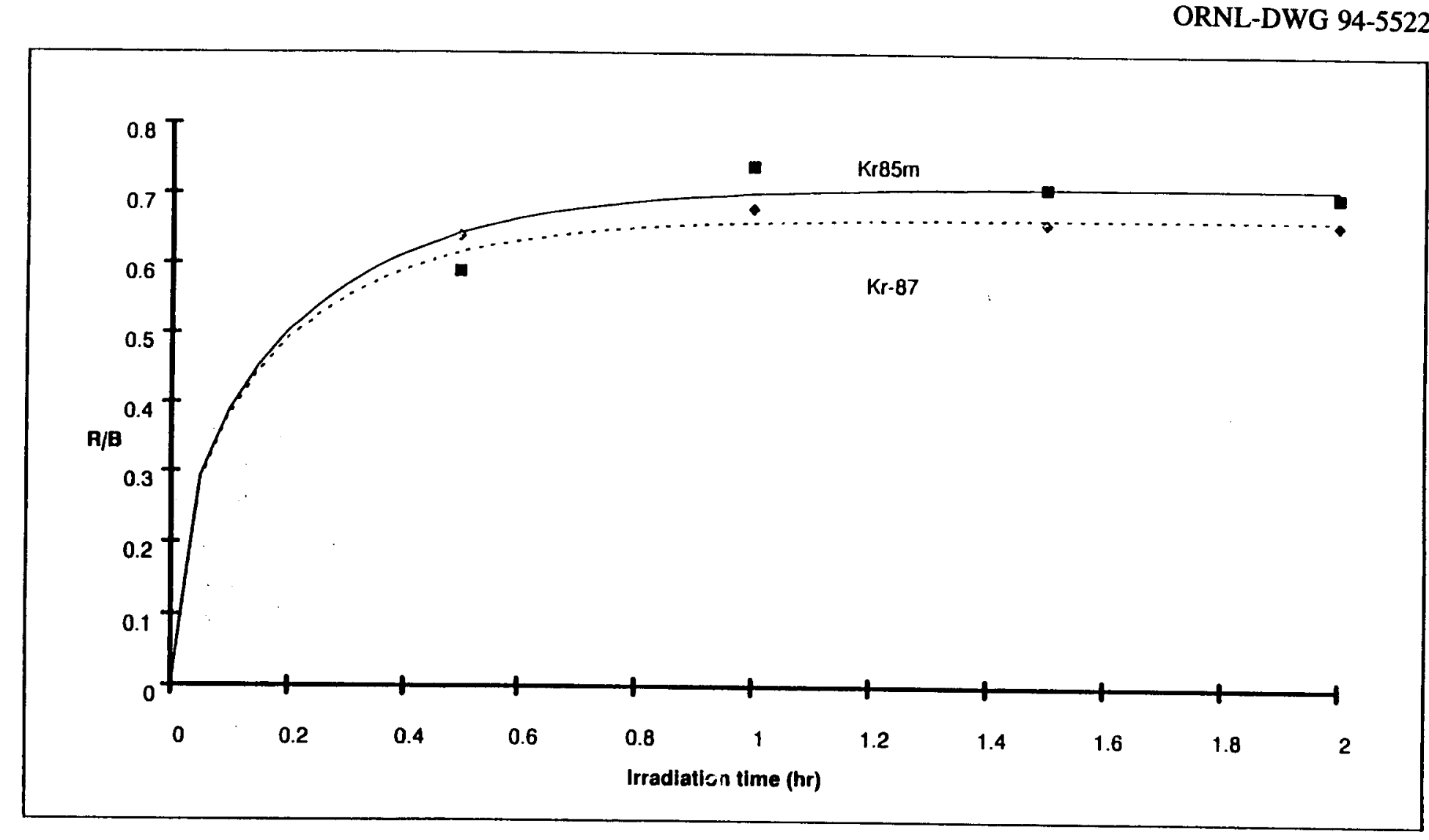

Figure 2-8.

COMPARISON OF THE DISTRIBUTION SPHERE MODEL CALCULATIONS WITH MEASUREMENTS OF R/B $\left({ }^{85 \mathrm{~m}} \mathrm{Kr}\right.$ AND ${ }^{87} \mathrm{Kr}$ ) FOR AN IRRADIATED

URANYL/BARIUM STEARATE-GRAPHITE SYSTEM 


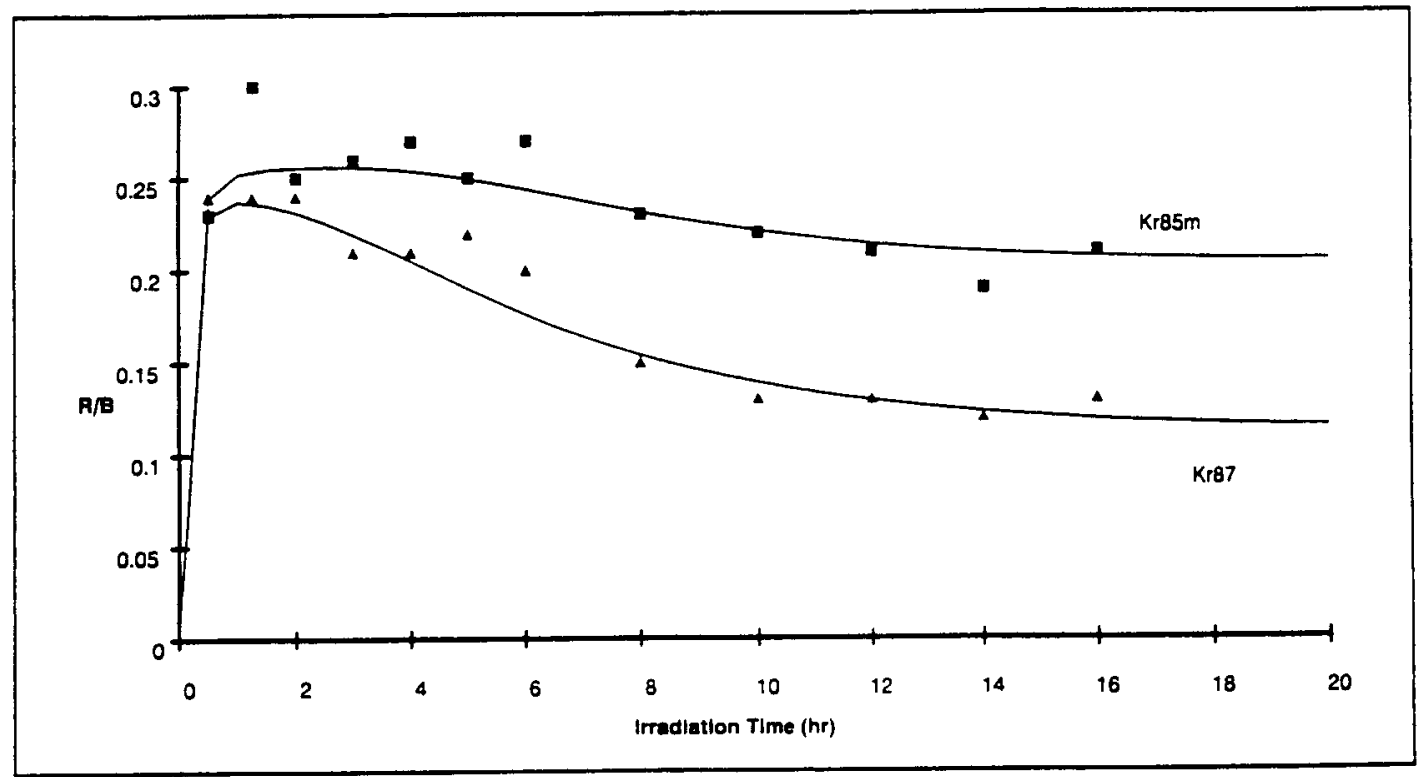

\begin{tabular}{c|c|c} 
TIME $(H r)$ & $\begin{array}{c}D / a^{2 *} \\
(1 / 5)\end{array}$ & $\begin{array}{c}\text { volume } \\
\text { fraction in } \\
\text { small grains }\end{array}$ \\
\hline 1 & $1 \times 10^{-4}$ & 0.26 \\
\hline 8 & $4 \times 10^{-6}$ & 0.37 \\
\hline 16 & $8 \times 10^{-7}$ & 0.59
\end{tabular}

${ }^{*} D / a^{2}$ for large grain group $=4 \times 10^{-10}$

Figure 2-9.

COMPARISON OF THE DISTRIBUTION SPHERE MODEL CALCULATIONS WITH MEASUREMENTS OF R/B $\left({ }^{85 \mathrm{~m}} \mathrm{Kr}\right.$ AND $\left.{ }^{87} \mathrm{Kr}\right)$ FOR AN

IRRADIATED SYSTEM OF HYDROLYZED UC ${ }_{2}$ 
estimate for the burnup based on the use of all the collected data-both the radionuclide inventory and its standard deviation. Finally, the standard deviation of the burnup is estimated. The technique can also determine the burnup as a function of time during the irradiation, subject to the limitations of the model.

\subsubsection{Equipment Development and Maintenance}

\subsubsection{Fission Gas Sampling Station - L. C. Emerson}

As part of a program to modernize and upgrade data acquisition from HFIR fuel irradiation experiments, a fission gas sampling station was fabricated and tested. This station must be capable of the quantitative measurement of radionuclide gas release from coated particle fuel during irradiation, rapidly and frequently. The capability of this device makes it possible to routinely measure the effect of rapid changes in temperature or moisture level on fission gas release. These measurements have been possible in the past only at the expense of laborious sample taking and multiple handling during gamma counting. In the new device, the sample taking and analysis can be accomplished by relatively simple control panel manipulation and automatic methods. Progress in the design, assembly, and testing of this device is described below.

The fission gas sampling station was originally designed to provide a cooling system to take each charcoal trap to liquid nitrogen temperatures $\left(-196^{\circ} \mathrm{C}\right)$ and to then purge the traps by heating to approximately $+175^{\circ} \mathrm{C}$. During this report period, additional information was obtained from associates at GA indicating that more uniform and better counting efficiencies could be obtained by cooling to intermediate temperatures, i.e., nearer to the boiling points of krypton and xenon, which are -152 and $-107^{\circ} \mathrm{C}$, respectively. The purpose of this was to ensure that the gases were deposited internally in the trap rather than freezing out in the adjoining plumbing and on the mechanical supporting structures. Since the physical arrangement of the traps was optimized for one particular location of the solid state detector, any deviation from this location could result in lowered counting efficiency as well as an additional uncertainty in the results obtained.

In an attempt to design traps for these intermediate temperatures, a series of experiments was carried out that involved both heating and cooling the traps simultaneously. Here, the idea was to balance the heating and cooling rates in such a way that any desired trap temperature could be obtained. In principle, this method is feasible, but long thermal lag times created a control problem. The location of the heating jacket is such that there is a significant time lag between 
changing the input heating power and the resulting change in the trap temperature. Part of this problem results from the inability to maintain a constant flow rate of the liquid nitrogen through the system. The flow rate is critically sensitive on a number of factors including the liquid level within the Dewar, the overpressure of the gas blanket, and the setting of the various valves within the supply system. Constant operator attention was required to maintain a reasonably constant trap temperature. The addition of a complex control system was not feasible at this point in the project.

To eliminate the control problem created by the long thermal lag times, the experimental heating arrangement was modified to apply heat directly to the nitrogen supply line rather than attempt to heat the trap itself. A series of heating elements were fabricated and tested using one trap from each of the two banks. The results of these tests were encouraging, and it was decided to modify the sampling station and the control system by adding a separate supply line heater to each trap. The final design consists of a flexible, stainless-steel-jacketed heater wound, using a bifilar technique, around the liquid nitrogen supply line adjacent to each trap. The jacket diameter is 0.040 in. and contains a 30 -gauge Nicrome $\mathrm{V}$ heating element insulated from the sheath by magnesium oxide. It was found that trap temperatures between liquid nitrogen temperatures and $-120^{\circ} \mathrm{C}$ can be reached and held with input power levels ranging up to $100 \mathrm{~W}$. These power levels are well within the capabilities of the variable transformers used to provide the heating jacket power.

Concern regarding a possible pressure buildup in portions of the liquid nitrogen supply header has dictated several minor modifications in the piping. In the original design, it was possible to isolate short sections of the supply header if there was simultaneous closure of adjacent valves in the header. If this were to happen, the liquid nitrogen, upon evaporation, would generate significant pressures within the confined volume. This problem was circumvented by modifying each of the six plug valves with a steel pin inserted into the valve body in a position that eliminates the possibility of the valve being fully closed. To protect the main supply header, two pressure-relief valves, with the cracking pressure set at 10 psi, were installed, in parallel, between the supply Dewar shutoff valve and the six solenoid supply line valves.

The design of the new $\mathrm{LN}_{2}$ supply line heaters and control panel was completed, and the control panel was fabricated. The control panel was installed on the front surface of the gas 
sampling station. Final drawings of the electrical and piping details have also been completed and accepted by the safety committees.

The fission gas sampling station also provides for positioning of a gamma detector to measure individual trap activity precisely and rapidly.

Measurement of the hysteresis in the mechanism of the gamma detector drive system was determined for the horizontal movement and was found to vary from 0.7 to $0.8 \mathrm{~mm}$ between adjacent sampling positions. This results from the backlash present in the horizontal lead screw and cannot be eliminated. This distance is small compared to the source-detector distance of approximately $38 \mathrm{~mm}$ and will not be a problem. The uncertainty introduced by backlash will be determined during the calibration process. If, indeed, it is a problem, then it can be accommodated either by approaching the counting positions from the same direction each time or with a correction factor obtained by calibration. This effect is presumably also present in the vertical drive but will not present a problem as the final detector position will always be approached from the same direction. Approval was obtained to do a "live" calibration of the sampling station once the unit is moved to the HFIR site.

Calculations of the geometrical efficiency of the source-detector arrangement have now been completed. This procedure also took into account the self-shielding of the source. The cylindrical shape of the actual source was approximated by a more tractable shape, that of a truncated cone, which permitted an analytic solution for the photon flux at the detector position. The solution is expressed in terms of second-order exponential integrals. Using a recurrence relation, these were converted to first-order exponential integrals which were then expressed in terms of an infinite series. A number of terms sufficient to yield an accurate value for the function were then computer evaluated. When this was compared with a point source, which is normally used in calibration, an estimate was obtained for the quantity of xenon-127 necessary to provide a counting rate sufficiently high for good statistics. A value of $2.17 \mu \mathrm{Ci}$ of ${ }^{127} \mathrm{Xe}$ was obtained by this method.

Some concern was expressed by the Research Reactors Division review staff regarding the possibility of the simultaneous failure of the detector-positioning systems and the protective limit switches that could allow the detector: to be raised to a position against the beryllium window during operation of the station. While the likelihood of this is extremely remote, it was feared that if this should happen, it might be possible to rupture the window and breach the primary fission gas containment system. To alleviate these safety concerns, a 12.7 -mm-diam steel pin 
was inserted through the rear wall of the main support of the detector-positioning assembly at a location to mechanically impede the detector travel above the upper vertical limit switch.

In preparation for the calibration of the system using radioactive rare gas standards, final testing of each of the traps will be carried out. This entails taking each part of the system through a complete cooling and heating cycle. Calibration of the system will be done when the system is in its final configuration. This system was not used during the irradiation of the HRB21 capsule because shielding calculations need to be done and shielding material installed. This work is not likely to proceed in earnest until the next irradiation capsule is ready.

\subsubsection{Irradiated Component Dimensional Measurement (ICDM) - N. H. Packan and M. J. Kania}

PIE of fuel compacts, graphite crucibles, and other components of fuel irradiation tests requires accurate dimensional measurement. These measurements are difficult and time consuming if conventional micrometers are used with the remote manipulators of the hot cell. In order to provide upgraded capability for rapid and accurate dimensional measurements of fuel experiment components after irradiation, development of a postirradiation capsule component metrology device was initiated at ORNL. Progress on this device is described below.

Specifications were written and a design completed for a custom fixture that would hold cylindrical specimens in front of a scanning laser beam with rotation or translation computer controlled. Included in the design effort for this report period was a provision for shielding the laser micrometer against radiation from both the particular fuel component being measured and also from other potential sources in the hot cell. The shield design consists of $18 \mathrm{~mm}$ of tungsten within the measurement volume of the laser micrometer and 12-mm-thick depleted uranium used for external "armor."

A laser micrometer was obtained from LaserMike, Inc. This instrument will be able to measure dimensions up to $3 \mathrm{in}$. (76 mm) with a resolution and repeatability of 0.0002 in. $(0.005 \mathrm{~mm})$. Design and fabrication of a custom rotation/translation fixture was completed. The fixture will hold the cylindrical specimens in front of the scanning laser beam for determinations of both diameter and length. An evaluation by a member of the ORNL Laser Committee indicated that this apparatus can be regarded as extremely safe, with no warning signs required in its vicinity.

An IBM-XT personal computer with a 20-Mb "HardCard" fixed drive and dual floppy disk drives was set up for use with the laser micrometer in-cell dimensional measurement system. 
The LaserMike head and its computer interface "Smartbox" accessory were connected to the computer and shown to function properly. While dedicated software for specific fuel component measuring tasks will have to be written, the use of a terminal emulator program permitted elementary communication with the system. Calibration of the laser micrometer was easily accomplished using previously procured standard cylinders of "Class X" accuracy (one of $0.50000 \pm 0.00002 \mathrm{in}$. diam and the other of $2.49920 \mathrm{in}$. length). The LaserMike then provided continuous size (inches) measurements to five decimal places of any object placed within the beam.

Three shields were designed and fabricated to keep any loose fuel particles or debris away from the shafts, bearings, or gear train of the specimen-holding rotation/translation fixture. A removable, shallow pan was built to fill the central space under a specimen situated in the diametral measuring station. This pan will confine loose fuel particles and prevent their accumulation in less accessible parts of the apparatus.

Adjustable stops designed to align and retain the sliding base of the specimen-manipulating fixture at either the diameter- or the length-measuring stations were fabricated and installed. The stops incorporated strong, permanent magnets to prevent any unintended shifts of the fixture during measurements. The carrier and dust cover that will permit the ICDM apparatus to be hoisted and stored in the second level of the High-Radiation-Level Experimental Laboratory (HRLEL) facility were designed, and lifting hardware components were installed.

Bench testing was conducted with the assembled ICDM apparatus that will be installed in the HRLEL hot-cell facility. Rotation of a cylindrical specimen in front of the scanning laser beam was a smooth and precise motion provided by a stepping motor driver with microstepping capability (5000 pulses from the motion control computer board for $360^{\circ} \mathrm{C}$ rotation of a 12.7 mm-diam fuel compact). The capability of having a real-time oscilloscope display of the scan profile (a feature of the laser micrometer chosen for this system) provides an important supplement to visual sighting (through the hot-cell window) in adjusting the specimen position for length and ID measurements.

Due to a problem with a cable and its associated shielding, this device has not been installed in the hot cell, and so, it has been unavailable for PIE work to date. Because of the cancellation of the NP Program and the current uncertainties in the NE Program, it was decided not to pursue the installation of the device in the hot cell because of the likely contamination problem. The device is ready for service and can be installed in the hot cell once the proper cables and 
shielding become available. It is unlikely that this option will be pursued until a new irradiation capsule is disassembled.

\subsubsection{Scanning Electron Microprobe/Electron Microprobe Facility - L. G. Shrader}

The HRLEL facility at ORNL has a shielded scanning electron microprobe and electron microprobe facility for characterization of the microstructure and morphology of irradiated fuel components. During this report period, the following activity contributed to the operational readiness of the facility:

1. Technical staff attended the 19th Annual Short Course on Scanning Electron Microscopy and X-ray Microanalysis, $12-16,1989$, at Lehigh University, Bethelehem, Pennsylvania.

2. Service work was performed on the Tracor-Northern $5402 \mathrm{X}$-ray Analyzer, which is a part of the JEOL JXM-840A System.

3. Two electronic boards were replaced on a service contract repair/exchange basis.

The SEM system is now fully operational including the JEOL-840A SEM, Tracor 5600 Image Processing System, and the Tracor $5401 \mathrm{X}$-ray Analysis System.

\subsubsection{IMGA - C. A. Baldwin and M. J. Kania}

The IMGA is a unique facility that is part of the HRLEL at ORNL. The objective of IMGA is to isolate individual irradiated coated particles and measure the inventory of gamma-emitting radionuclides. The automatic features of IMGA permit the characterization of large numbers of particles from fuel spheres or compacts so that the fraction of particles releasing metallic fission products and their location in the fuel body can be established with high statistical confidence. During this report period, the following progress was made in maintaining IMGA capability at ORNL.

A fuel sphere deconsolidation apparatus (FSDA) based on the KFA and Harwell designs was designed and fabricated. A few minor modifications were made to the original design to provide a platform for holding fuel compacts and cylindrical samples. An additional rig was designed to aid in remotely mounting fuel spheres and fuel compacts to the electrode/arbor shaft.

The ORNL fuel deconsolidation apparatus was subsequently demonstrated at GA's new production reactor (NPR) target fabrication facility. The apparatus was fitted with an adapter to hold an annular NPR target compact above a beaker of $2 M \mathrm{HNO}_{4}$ electrolyte. A $10 \mathrm{~g}$ wire-mesh platinum electrode was suspended from the side of the beaker, and electrical connections were 
made to a variable dc power supply. Voltage-current settings were set by observing the residue of the deconsolidation process and adjusting so that large chunks of material did not fall off before the microspheres were separated. Although it was necessary to adjust the initial voltagecurrent setting and occasionally add makeup electrolyte, an equilibrium condition was eventually reached where the power supply was steady at $7.5 \mathrm{~V}$ and a current of $9 \mathrm{~A}$. The breaker height was adjusted so that only a small portion of the target compact's outer circumference was in contact with the surface of the electrolyte. The target compact itself was rotated at approximately one-half revolution per minute. In this way, it was possible to obtain microspheres free of matrix graphite from annular regions of the target compact.

Operation of the IMGA system was briefly hampered by a recurring problem with the singularizer. The stepping motor that operates the mechanism would randomly lose steps, often after many hours of flawless operation. The source of the problem was traced to the vacuum seal between the drum assembly and the drum arbor. The vacuum grease used to both seal and lubricate the interface had deteriorated. A thorough cleaning and reapplication of vacuum grease to the seal eliminated the problem.

New gamma-ray calibration sources were ordered from Amersham Corporation. The sources are in solution form and are supplied in 5-mL vials with a total source strength of approximately $5 \mu \mathrm{Ci}$ each. One of the sources is a mixed nuclide source containing ${ }^{241} \mathrm{Am},{ }^{109} \mathrm{Cd}$, ${ }^{57} \mathrm{Co},{ }^{139} \mathrm{Ce},{ }^{203} \mathrm{Hg},{ }^{113} \mathrm{Sn},{ }^{85} \mathrm{Sr},{ }^{137} \mathrm{Cs},{ }^{88} \mathrm{Y}$, and ${ }^{60} \mathrm{Co}$, and the two other sources contain ${ }^{125} \mathrm{Sb}$ and

${ }^{152} \mathrm{Eu}$, respectively. These solutions will be used to calibrate the IMGA device to permit more quantitative evaluation of particle fission product content.

The IMGA device was used for the HRB-21 PIE, and the results of that effort are reported in the HRB-21 PIE section.

2.1.4.5 CCCTF - W. A. Gabbard, M. J. Kania, R. N. Morris, W. L. Wright, C. A. Malone, B. F. Myers, and M. E. Peters, Jr.

The construction of the laboratory facility for conducting core conduction cooldown experiments at temperatures as high as $1800^{\circ} \mathrm{C}$ has been completed and demonstrated; this limit provides a comfortable margin above the maximum design temperature of about $1600^{\circ} \mathrm{C}$.

\subsection{CCCTF Overview}

The CCCTF allows the thermal testing of irradiated MHTGR fuel specimens under demanding off-normal conditions. The facility is capable of exposing irradiated fuel specimens to 
a variety of temperature-time histories with a maximum temperature of $1800^{\circ} \mathrm{C}$ and experiment duration times of up to $1000 \mathrm{~h}$. In addition, the test atmosphere can be adjusted to suit programmatic demands from completely inert to a variety of chemically active agents. The fission products released by the fuel specimen are collected and quantitatively analyzed. Specimen heating takes place in an instrumented graphite-resistance heated furnace with a computerized temperature control and data collection system. The fuel specimen is located in the central hot zone of the furnace, and a sweep gas of predetermined composition slowly flows past the specimen upwards toward the fission product collection systems. In its present configuration, the sweep gas is limited to helium, but modifications are currently under way so that water and air may be used. The furnace and some of its support systems are located in a hot cell during heating.

Two different and independent systems are available for the collection of the fission products released from the test specimen. The first is a cold finger assembly that is located within the furnace just above the fuel test specimen. This assembly is water cooled and provides a cool surface for the condensible fission products to plateout on. During furnace operation, the cold finger assembly can be withdrawn from the furnace, the deposition surface removed and replaced, and the cold finger assembly reinserted to the furnace. A combination of valves and purging systems prevents interruption of furnace operation or the introduction of contaminates. This capability provides information on the release history of the fuel in addition to the aggregate metallic fission product release. The second fission product collection system is an external cold trap assembly for the collection of the noble fission gases. The sweep gas from the furnace is routed through a cryogenically cooled charcoal trap that adsorbs the inert fission gases. The traps are constantly monitored for their activity, providing a time record of the total fission gas release. The traps are located in shielded containers outside the hot cell to keep the background radiation levels as low as possible.

The entire system is highly automated, with computer-controlled temperature data collection and furnace temperature control. The data collection times can be varied to suit the demands of the experiment, and the collected data are stored on a computer hard disk in a format that allows easy access to the information. After the completion of the experiment, the data are copied and stored outside the computer system to prevent possible loss of information due to later computer problems. Temperature control input can be selected from three different furnace temperature 
measuring devices. Two internal TCs of differing types and an external optical pyrometer are available for the control loop.

A system diagram of the CCCTF is shown in Figure 2-10. Note that the furnace is contained in the hot cell. The cold traps are located outside of the hot cell to aid in the reduction of the background radiation. The furnace and its sensors, along with the cold traps, are tied into the computer control and data collection system; the detectors have their own computer and storage system. The purge gas is a once-through system with the hot-cell ventilation system handling the exhaust from the traps.

The CCCTF furnace is a modified, commercially available, graphite-resistance heated furnace with an internal muffle tube to provide isolation between the furnace elements and the fuel test region. The axis of the furnace is vertical, allowing access to the heating region from both the top and bottom. In the present configuration, the fuel specimen is loaded from the bottom, and the cold finger assembly is inserted from the top. The basic furnace is capable of operation to as high as $3000^{\circ} \mathrm{C}$, but because of material limitations and the expected use of chemically active atmospheres, the modified version is limited to approximately $1800^{\circ} \mathrm{C}$ at the present time.

Two muffle tube designs were investigated in the development of the furnace: an impermeable aluminum oxide one-piece muffle tube and a two-piece muffle tube composed of a semipermeable outer graphite support tube and a loosely fitted tantalum liner tube. Both designs were tested for compatibility with the graphite furnace environment. The aluminum oxide tube underwent carbothermic reduction and failed near the high-temperature graphite heating elements. This result occurred during a high-temperature test that reached a peak temperature of over $1900^{\circ} \mathrm{C}$ at a helium pressure of $1 \mathrm{~atm}$ for a period of several hours. The failure of the muffle tube was due to the enhanced decomposition of aluminum oxide in a carbon-rich atmosphere (due to the graphite heating element). The released oxygen and aluminum attacked the heating elements, producing carbon dioxide and aluminum carbide. The oxygen concentration in the helium was 25 parts per million (ppm) and is not considered to be responsible for more than minor effects. Later operation of the furnace revealed than the aluminum oxide muffle tube would not be stable for long-term operation above approximately $1350^{\circ} \mathrm{C}$ in the desired test atmosphere. Investigators at KFA-Jülich also found that aluminum oxide was not a suitable material for their furnace design, even when they used tantalum instead of graphite heating elements. ${ }^{27}$ 


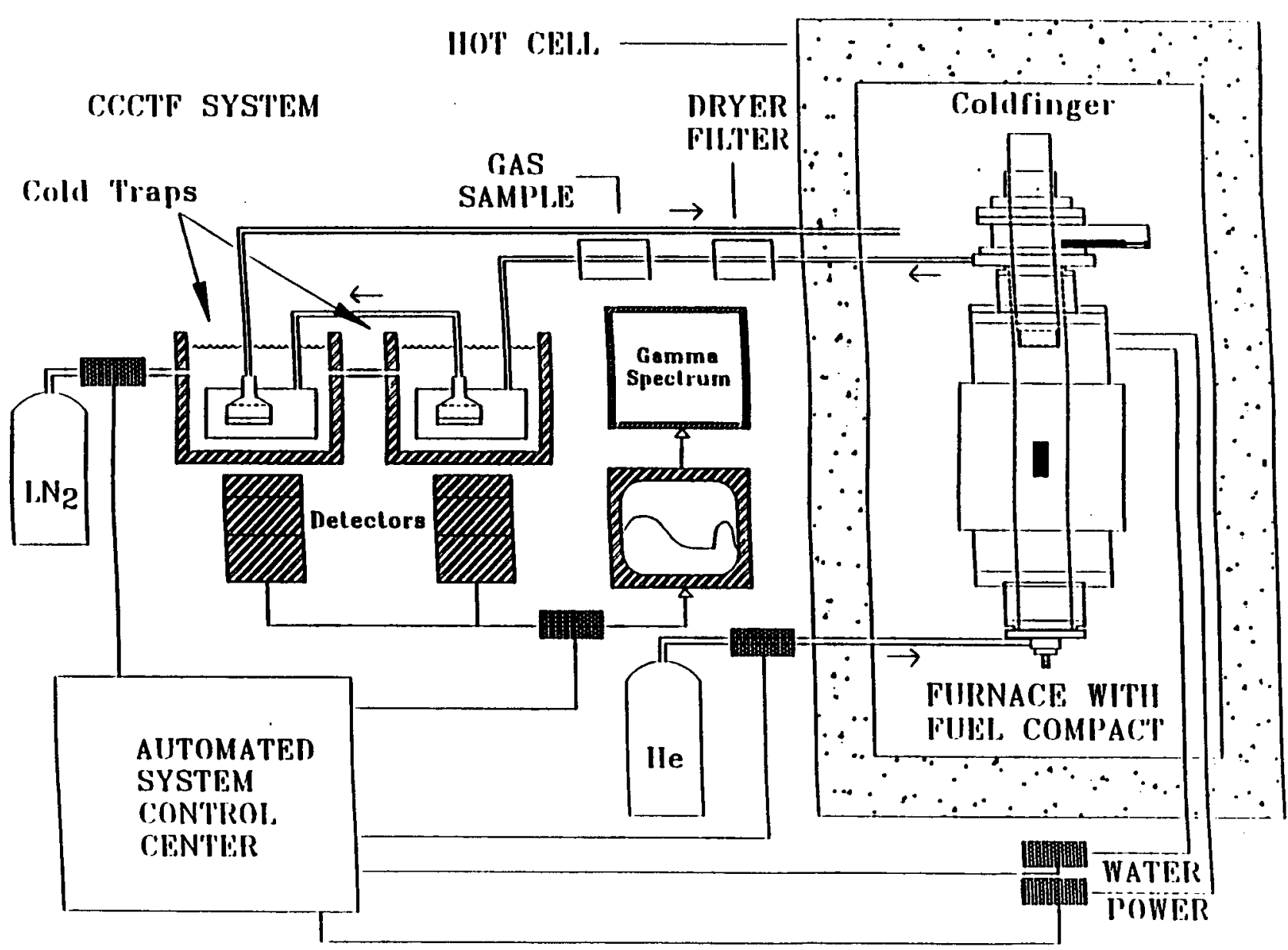

Figure 2-10.

SCHEMATIC DIAGRAM OF THE CCCTF. 
After the poor results with aluminum oxide, the two-piece graphite/tantalum muffle tube was tested. Tantalum has been used extensively in high-temperature furnace design, and graphite is a common refractory material, so major problems were not expected when operating in an inert atmosphere. The only concern was the rate of the tantalum/carbon reaction. Work by the investigators at KFA-Jülich indicated that the reaction rate was acceptable, although it was not quantified. After approximately $12 \mathrm{~h}$ of exposure at $1600^{\circ} \mathrm{C}$ in a helium atmosphere, in three heatup and cooldown cycles, no degradation of the graphite tube or tantalum liner was noted. A very light, golden layer of tantalum carbide was observed on the tantalum where it was in contact with the graphite in the high-temperature region. At the current time, this two-piece design is in use in the CCCTF. Another concept is under investigation, the "can-in-a-can" design that will provide better isolation between the furnace internal regions and the test specimen. This is of importance for the chemically active atmosphere tests.

The helium sweep gas circuit includes an upstream helium purifier to ensure that the oxygen concentration is held at very low levels, less than $1 \mathrm{ppm}$. Oxygen removal is achieved by passing the helium supply gas over a heated $\left(800^{\circ} \mathrm{C}\right)$ getter consisting of $425 \mathrm{~g}$ of titanium. Low oxygen levels are required to minimize material degradation, so that long experimental run times are possible. The helium purifier has a self-contained oxygen-monitoring gauge so that the quality of the sweep gas may be easily observed. Two mass flow transducers in the gas distribution and flow system monitor the flow rates into the furnace heating and muffle tube regions. Flow rates are approximately $0.4 \mathrm{~L} / \mathrm{min}$ through the muffle tube, $0.2 \mathrm{~L} / \mathrm{min}$ through the furnace heating element region, and $0.05 \mathrm{~L} / \mathrm{min}$ through the window region (so that the pyrometer window retains a clear view of the muffle tube).

The furnace temperature is controlled and monitored by the computerized control system, which represents a major modification to the stock furnace control system. This system consists of three major parts: a computerized controller and its data processing software, the temperaturesensing elements, and the power supply and its electronics. The computer subsystem is composed of a commercially available computer, digital controllers, and a flexible software package. ${ }^{28}$ In addition to controlling the furnace temperature, the computer controls the temperature of cold traps, logs the temperature history of the furnace, and controls the sweep gas inlet and exhaust valves. At the present time, the flow rates must be manually controlled. The system can be programmed to execute a range of furnace temperature-time histories and to $\log$ the data on an appropriate monitoring interval. Important operational information is constantly 
updated and displayed on the video monitor. The display and data formats are flexible and can be easily modified to include new variables as the experimental program develops.

Three independent temperature-sensing elements measure the furnace temperature. The muffle tube external temperature is monitored by a boron graphite thermocouple (BGT) and by an optical pyrometer through the furnace window. The fuel specimen temperature is monitored by a tantalum-clad type-C TC. The furnace control system can use any one or combination of these sensors as the control input. In practice, the BGT provides the most stable temperature control, although with any controlling element, the temperature fluctuations are only a few degrees. The temperature difference between the specimen holder and the exterior of the muffle tube is approximately $50^{\circ} \mathrm{C}$. All temperature readings are continuously logged, both in computed temperature and actual millivolt readings, so that back calculations and checks will be possible.

The cold finger assembly provides a cooled surface, within the furnace and near the fuel specimen, on which condensible fission products released from the fuel can deposit. The fission products of interest are the radioactive isotopes of $\mathrm{I}, \mathrm{Cs}, \mathrm{Sr}, \mathrm{Ag}$, and $\mathrm{Te}$. The cold finger assembly can be periodically withdrawn from the furnace, the deposition surface replaced, and the assembly reinserted into the furnace. A series of samples taken throughout the experiment duration can provide a release history.

The cold finger assembly consists of a water-cooled support cylinder, a TC, a motorized screw drive, and a deposition cup. See Figure 2-11 for a cross-sectional view of the assembly. The assembly is aligned vertically along the furnace axis and is lowered into and withdrawn from the furnace by a special remotely controlled elevator and slide assembly. A water-cooled gate valve, gas evacuation lines, and a series of "O"-ring seals that engage the support cylinder ensure furnace isolation during the oferation of the cold finger assembly. The motorized screw drive mechanism extends through the support cylinder and provides a way to attach and remove the deposition cup. The deposition cup is internally threaded to receive the screw drive shaft. Driving the motor in one direction engages the threads of the deposition cup and draws it firmly onto the support cylinder; driving the motor in the opposite direction releases the cup from the support cylinder. For installation, the deposition cup will be held in a jig by the hot-cell manipulators; for removal, the cup is dropped off into a special container.

The support cylinder is hollow and has chilled water flowing through it during operation. Its temperature, approximately $15^{\circ} \mathrm{C}$, is constantly monitored by a Type- $\mathrm{K} \mathrm{TC}$ and the reading logged in the data base. Heat transfer from the deposition cup to the support cylinder is through 


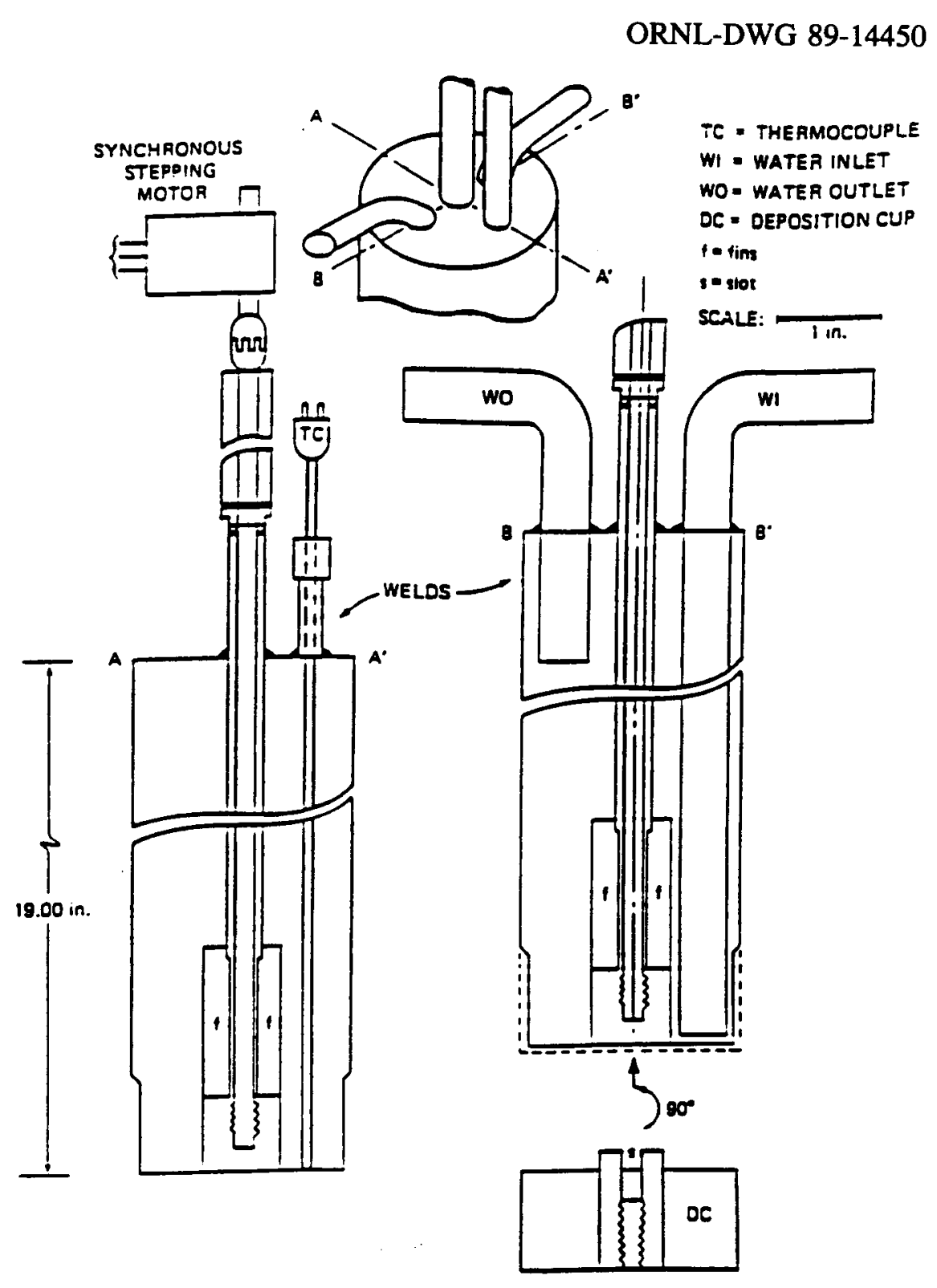

Figure 2-11.

COLD FINGER ASSEMBLY. 
the contact surfaces. The temperature of the surface of the deposition cup is determined by both the temperature of the furnace and the axial distance of the surface of the cup from the horizontal centerline of the furnace. Previous measurements of the cup surface temperature versus furnace peak temperature and axial distance allow the determination of the proper cup axial location for a specified temperature. The temperature of the cup is targeted at approximately $350^{\circ} \mathrm{C}$; the actual temperature will be a compromise between the amount of material collected by the cup and the amount that remains attached to the wall of the muffle tube and other furnace components. The deposition cup is copper plated to aid in the analytic leaching process; the reflective copper surface also aids in minimizing the radiative heat transfer. The fuel specimen is located within the muffle tube, near the geometric center of the tube. A volume approximately $10 \mathrm{~cm}$ in length and $7 \mathrm{~cm}$ in diameter, located near the geometric center of the muffle tube, forms the central heating region. The temperature variation over this region is small, approximately $0.013 * \mathrm{~T}_{\text {peak }}$, so an essentially isothermal region is available for the heating experiments. The irradiated fuel specimen is supported by an assembly that extends from the furnace, bottom up, into the central heating zone. This assembly consists of three parts: a lower support, a TC, and a fuel holder. The lower support component is, for the most part, a hollow graphite rod through which the sweep gas flows and the TC is routed. The TC is a tantalum-sheathed type $\mathrm{C}$, which is located as near the fuel sample as is practical, and provides the basis of the sample temperature measurement. The fuel holder is attached to the lower support and holds the fuel specimen in the central hot zone of the furnace. It is also designed to direct the flow of the sweep gas around the fuel sample. The fuel holder is a custom component that is different for each fuel specimen.

As with the muffle tube, the sorption of condensible fission products impacts the selection of materials for the fuel holder. An additional concern is possible chemical reactions between the fuel sample and the fuel holder. A significant chemical reaction could damage the fuel particle's coatings and result in spurious fission product releases. Thus, the two primary issues for design are fuel specimen/fuel holder chemical reactions and condensible fission product adsorption. The present reference design is a graphite holder because of the chemical compatibility issue, even though the graphite is known to adsorb many condensible fission products. The adsorption is mitigated to some extent by the fact that the holder is in the hottest part of the furnace. This location aids in driving off the fission products. Other designs have been and are being considered; these designs will be needed when chemically active materials are introduced into the furnace. 
The gaseous effluent from the furnace passes through a cryogenic trapping system to permit the removal of inert fission gases and the measurement of their radioactivity. The gases of interest for this facility are the radioactive isotopes of krypton and xenon. After exit from the furnace, the sweep gas is routed through a filter to remove the particulates and any elemental iodine. Next, the gas is routed to the cold trap assembly. The cold trap assembly consists of two separate charcoal trap systems with associated cooling, detectors, and electronics. The first trap is designed to do the bulk of the collection, and the second trap is used to estimate the collection efficiency of the trap system and to act as a backup in case of failure of the first trap. The trap system can also be reconfigured so that the first trap operates at a different temperature than the second trap. This configuration allows for the differential collection of xenon and krypton, with xenon captured in the warmer trap and krypton captured in the cooler trap. Xenon has the disadvantage that its isotopes are short lived and may not be available in sufficient quantities in the fuel specimens to be used in the testing.

Each cold trap consists of a small cylindrical charcoal bed retained in position by wire-mesh screens at each end. The charcoal bed is cooled with liquid nitrogen, and the temperature is monitored by an embedded TC. Beneath the trap assembly is a sodium iodide detector that monitors the gamma activity of collected gases. See Figure 2-12 for a cross-sectional view of the trap. In operation, the fission gas is continuously trapped, and the detector signal yields a time profile of the cumulative release of the fission gas from the test specimen. The detector signal is monitored by a dedicated computer that also provides the necessary computational effort required to decompose the energy spectrum. A strip chart recorder continuously records the detected trap activity and functions as a backup system. Together, these components form the heart of a multichannel analyzer that provides details of the observed spectrum. At the end of an experiment, a heating jacket surrounding the trap body is used to drive off the trapped gas in preparation for subsequent experiments.

The only problem noted in the operation of the trap system was plugging by moisture. The bulk of the moisture is believed to come from the furnace insulating material and not from the heating zone of the furnace (gas analysis revealed no water in the sweep gas from the furnace heating zone). The sweep gas from the insulation region is run through the trap system, as well as the sweep gas from the furnace hot zone, to ensure that no fission gas is lost because the muffle tube assembly is not gas tight. The insulation region is relatively cool and cannot be easily baked out, so it stores a small, but significant, amount of water that is slowly released 
ORNL-DWG 89-14458

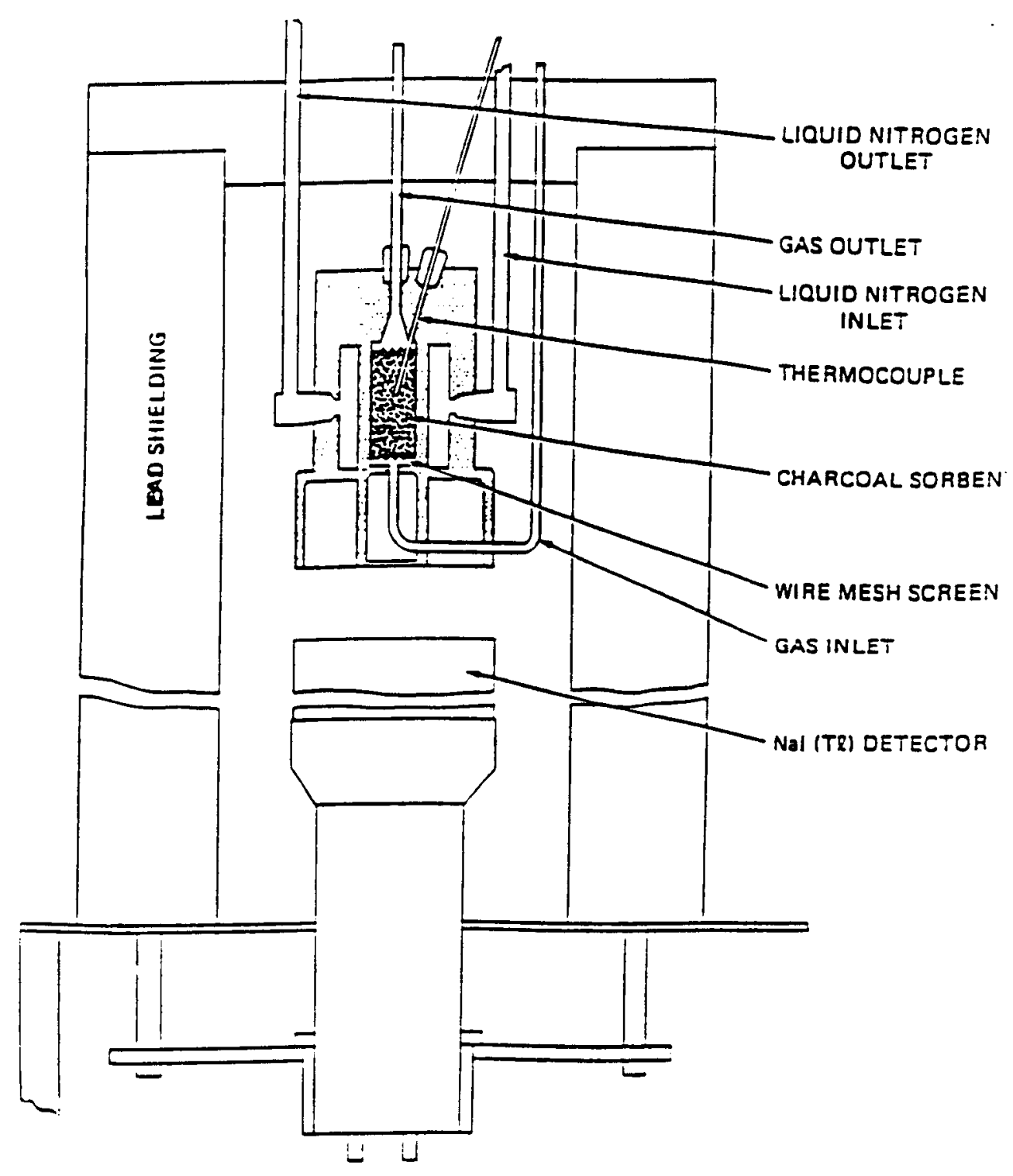

Figure 2-12.

COLD TRAP CROSS SECTION. 
during a heating cycle. The plugging problem was solved by the addition of a water condenser operating at approximately $-100^{\circ} \mathrm{C}$. The sweep gases from the furnace heating zone and insulation region are combined together and routed through the condenser and then into the trap system. This solved the bulk of the plugging problems.

Because the expected levels of fission gas release are small, care was taken in the location of the traps. The CCCTF has the trap system located just outside the hot cell in which the furnace is located. Both traps are located in individual lead pigs to provide a measure of shielding from local background radiation.

The CCCTF has been developed to provide real-time monitoring of the furnace temperatures and both programming and monitoring of the desired temperature ramp up, ramp down, and hold points. The data collection interval is programmable and can be tailored to the needs of the current experiment. A real-time display shows the current status of the furnace, its gas flow valves, and the temperatures of the various measuring devices. This information is constantly collected and stored in a hard-disk data base. At the termination of the experiment, this data base can be transferred to a floppy disk for use by other program participants and for storage. Portions of this information can be printed out by the system computer, as desired, or the entire data base can be entered into commonly used spreadsheet software for more detailed manipulation. The system is flexible and additional calculations, sensors, and functions are easily added.

Monitoring of the furnace atmosphere is by periodic mass spectrographic determination of impurities in the helium purge gas supply and periodic mass spectrographic determination of output carrier gas composition by the residual gas analyzer. This function is not automated at the present time; the data record consists of a series of log book entries.

Monitoring of specimen condensible fission product releases is by collection of metallic fission products on a cold finger deposition cup within the furnace as described previously. The collected material on the cup is gamma counted and may be leached off to determine if other nongamma-emitting fission products are present. Laboratory supporting services, under CCCTF guidance, provide analysis of the fission products collected by the cold finger and deposited within the furnace on the interior components.

The CCCTF is protected by several safety systems independent of its experimental program. The furnace power supply is automatically shut down, should the furnace body cooling water supply be interrupted or an overpressure condition occur in the furnace, and can only be 
manually reset. An "overcurrent" limit prevents excess furnace power supply current, should a fault occur. The upper gate valve is interlocked to prevent its opening without the cold finger in the proper position. The furnace specimen elevator cannot be operated with the locking jack in position. Check valves and shutoff valves are in the source gas and water lines to prevent backflows. The furnace can be quickly and safely shut down by the interruption of the main power supply or by a computer command. In addition to these "hard" limits, other monitoring and checks on furnace operation are possible and desirable. The furnace temperature is monitored by three separate sensors providing independent indications of furnace temperature. Both the gas flow to the furnace interior and exterior are monitored, along with the manifold pressure, to provide an indication of overall gas flow performance. Finally, the system software is capable of safety alarms and any special system shutdown needs as well. This function can be tailored to the needs of a specific experiment as necessary.

\subsection{CCCTF Characterization}

The CCCTF has been characterized by measuring furnace temperature profiles, deposition cup temperatures, fission product distributions in the furnace, and fission product collection efficiencies. $^{29}$ The former measurements define the range of the approximately isothermal region, peak temperature, the furnace temperature profile, and the cold finger temperature behavior. The latter measurements establish suitable locations for the cold finger, the components on which the fission products are distributed, system fission product collection efficiency, and the measurements necessary to achieve a mass accounting.

Initial characterization tests using the aluminum oxide muffle tube were conducted in which the axial temperature profiles in the furnace along the centerline were measured at furnace peak temperatures of $1200,1400,1600$, and $1920^{\circ} \mathrm{C}$. There was an approximately isothermal zone of $8 \mathrm{~cm}$, slightly offset from the furnace center. At $1550^{\circ} \mathrm{C}$, the zone is symmetric about the midpoint but is shifted slightly downward at lower temperatures; the cause of this shift is unknown, but it is minor and does not present any problems. Within this approximately isothermal zone, the variation in temperature is approximately $0.013^{*} \mathrm{~T}_{\max }$. Beyond this zone, the temperature declines symmetrically about the midplane. The temperature uniformity of the outer graphite muffle tube with the tantalum liner has not been examined to the same degree as the alumina muffle tube but appears to be similar. No differences in operation have been noted. Because of mechanical difficulties, it is not possible to measure the surface temperature of the deposition cup during an experiment; the surface temperature must be inferred from the 
characterization measurements. This issue will be readdressed in the future to ensure that the deposition cup collection efficiency is maximized and does not degrade with time. As experience is gained with the facility, the cup may be redesigned to take advantage of this experience.

Of importance for the control system is the stability of the TCs and the pyrometer. In general, the pyrometer has exhibited stable behavior. The type-C TC has also exhibited stable behavior as well, but in-operation failure has occurred for TCs cycled many times. The cause of this failure is not clear, but a new TC is used for each experiment. Finally, the BGT does exhibit some drift during the first 10 to $25 \mathrm{~h}$ of operation. The temperature drift has been estimated to be as much as $8 \%$. This device is calibrated before an experimental run.

The collection efficiency of the deposition cup and the fission product distribution within the furnace are both items that allow one to estimate the ability of the furnace to perform its intended task. In general, this is a complex problem to address because both items depend on the specific chemistry of the released fission products, on the furnace temperature, and the local temperature gradients. To begin to address this set of needs, a test involving a single element at a constant temperature was selected. This is consistent with the first part of the experimental program for the CCCTF, involving old fuel held at a constant temperature.

The methodology employed was to select a cesium compound that would decompose at a temperature above $1000^{\circ} \mathrm{C}$ and prepare this substance using ${ }^{137} \mathrm{Cs}$. The material would then be placed in the furnace and the furnace cycled through a short heating program. The cold finger would be inserted within the furnace and normally cooled. The compound selected for the test was cesium zirconate, and it was contained in a zirconia crucible with a platinum foil cover. A small hole was punched in the cover for the outward diffusion of the released cesium. The sample was supported by a fuel holder and a fuel holder support that were the same as those to be used in the upcoming series of experiments with the exception of a larger hole in the fuel holder to contain the crucible. The starting cesium inventory was $71 \mu \mathrm{Ci}( \pm 5 \%)$ of ${ }^{137} \mathrm{Cs}$. The majority of the cesium, $91 \%$, was accounted for after the test. The measurement error of up to $5 \%$ is due to the limited accuracy of the calibration of the gamma-counting system used for these measurements; the additional error due to geometric effects has not been included or quantified. The low activity and cumbersome geometry of the furnace components introduced some error because point source geometry could not be maintained for the gamma counting in all cases, and self-shielding effects were not accounted for. More detailed gamma counting and self-shielding estimates were not pursued because of time and resource limitations. However, a $91 \%$ 
accounting of material for an apparatus of this nature is considered to be quite good. Later estimates of the errors due to shielding and geometry were a few percent, so the overall errors and fission product accounting were good, well within the uncertainties of counting, shielding, and geometry. The location of the released cesium is shown in Figure 2-13. As can be seen, approximately half of the released material was collected by the deposition cup. The remainder of the material was located on the graphite parts or masked by the uncertainties. The tantalum liner had only a trace of material on it, as did the furnace bottom and cold finger support cylinder. Analysis from the tests run indicates that the collection efficiency of the cold finger is a function of the furnace temperature and the cold finger distance from the sample. Under actual experimental conditions, the cold finger efficiency was found to be near $90 \%$ for cesium release temperatures in the range of 1000 to $1400^{\circ} \mathrm{C}$ and about $35 \%$ for temperatures near $1600^{\circ} \mathrm{C}$. One reason for this may be that the cold finger is much farther away from the fuel specimen in the higher temperature tests.

Krypton collection efficiency and cold trap detector calibration were accomplished by heating and consequently breaking a glass vial containing a known amount of krypton-85 in the furnace and catching the released krypton in the cold trap system. A total of five tests were performed. The first three of these tests were conducted before the more efficient moisture condenser was installed; the first two of these tests were conducted before improvements in the trap temperature control system were made. These early tests were drivers for the development of the condenser.

The first two krypton tests, KR-1 and -2 , did not achieve their objectives. The first test (KR-1) was conducted with cold trap temperatures above $-160^{\circ} \mathrm{C}$ and resulted in considerable migration and some loss of the krypton. Preliminary tests with stable krypton had indicated that retention of the krypton was possible at these temperatures, but actual results at normal furnace flow rates proved otherwise. This test provided evidence that temperatures below the freezing point of krypton were necessary to retain it in the CCCTF trap system. An indication of the behavior of the krypton migration as a function of trap temperature is shown in Figure 2-14. The rate meter curve shows that the krypton is initially captured at the base of the trap and then migrates up through the trap to the exit. After this was observed, the trap temperature was lowered, and the results for two temperatures are shown on the graph. Low temperatures are required for even relatively short-term retention. One disadvantage of the trap system is the rather high flow rate through the trap system. This may enhance migration because solid krypton still has a substantial vapor pressure even at liquid nitrogen temperatures. 


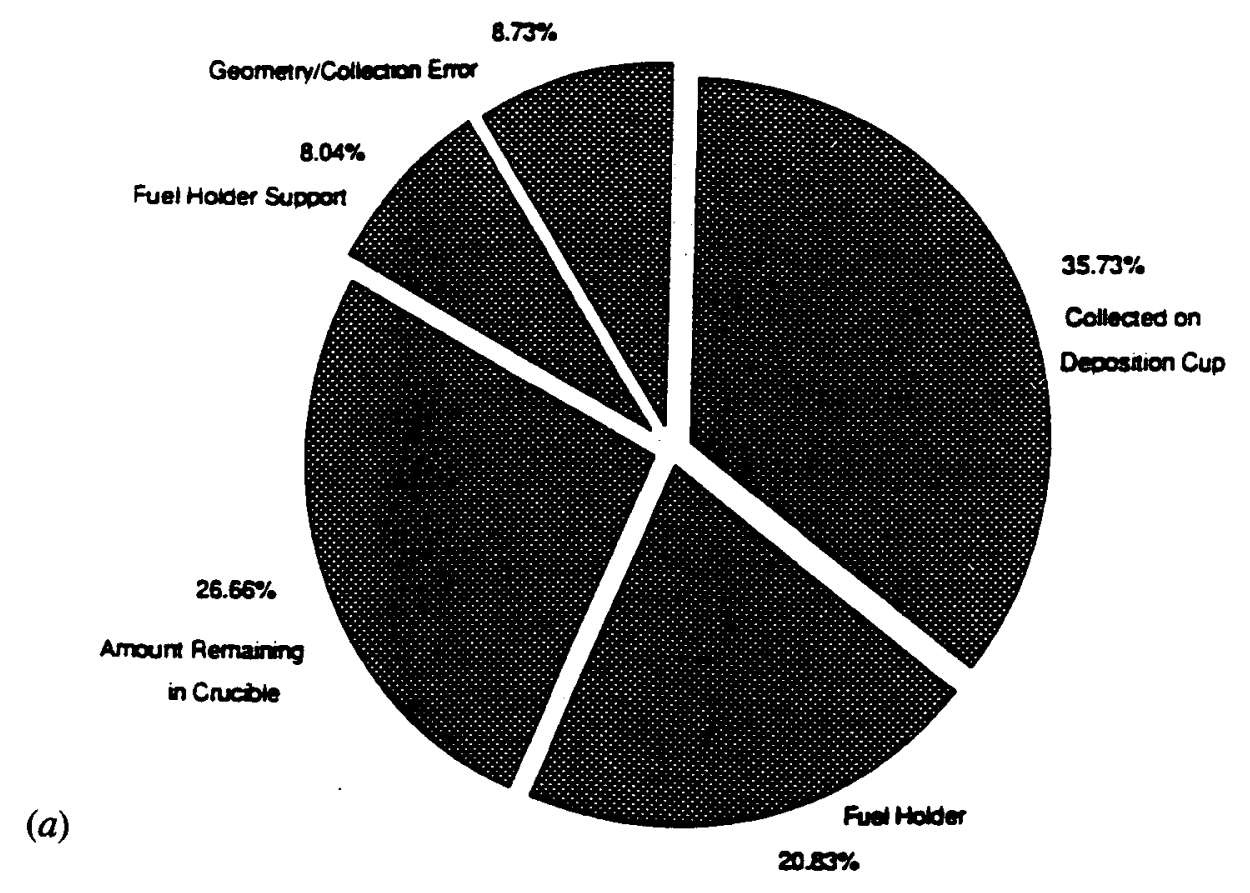

ORNL-DWG 92-5144

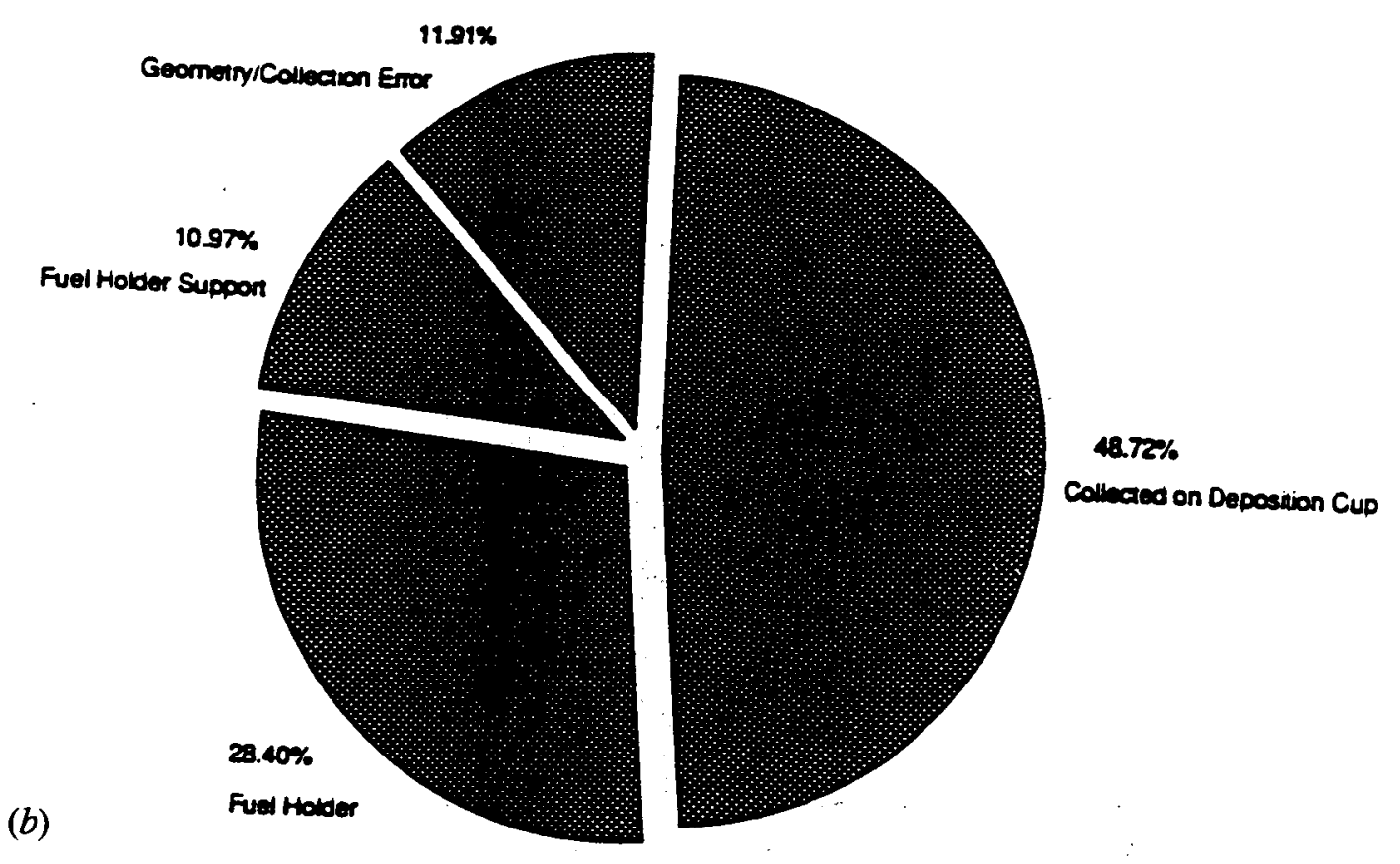

Figure 2-13:

(a)TOTAL CESIUM MASS BALANCE FOR CESIUM TRACER TEST. (b)RELEASED CESIUM LOCATION. 


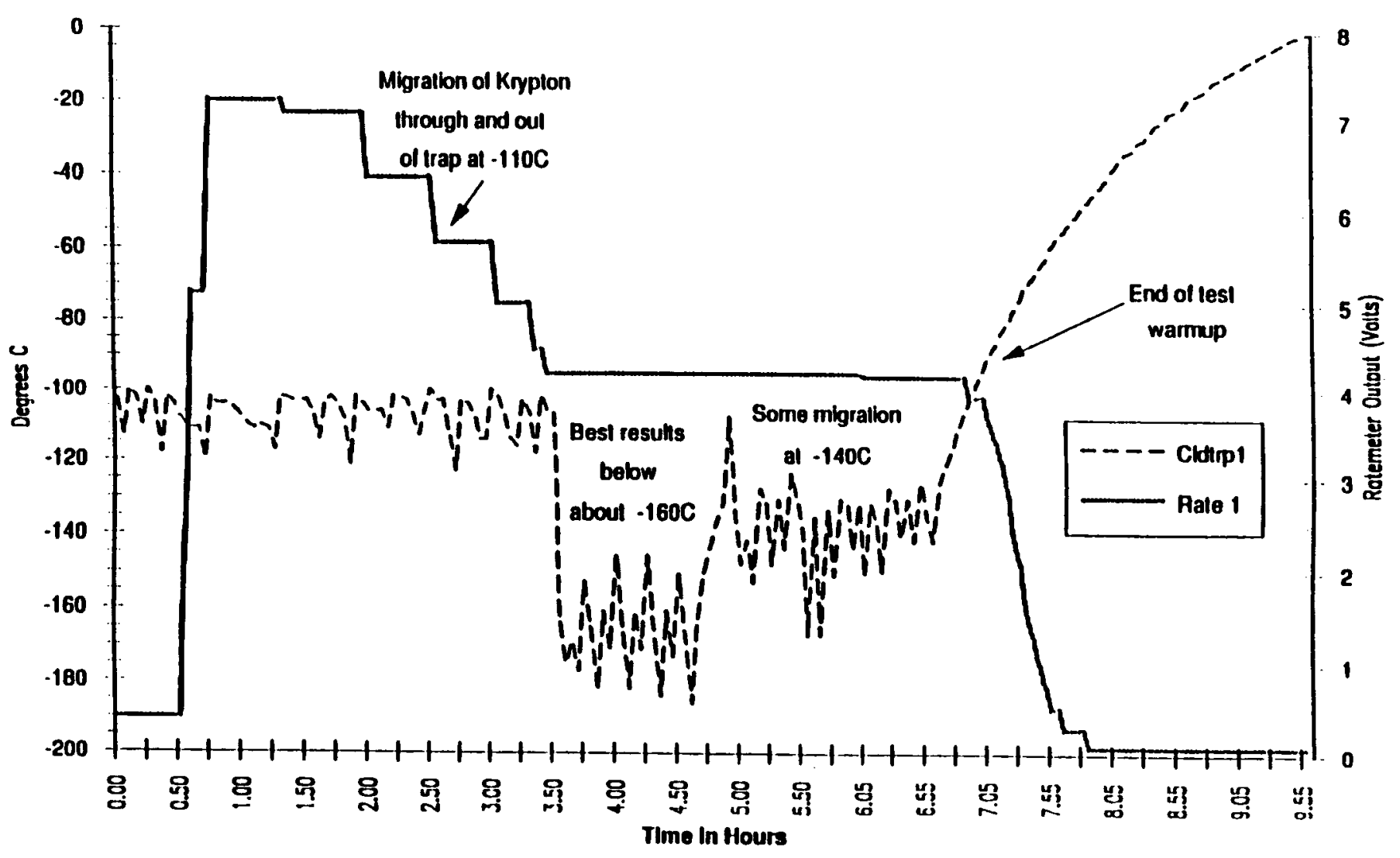

Figure 2-14.

EFFECT OF KRYPTON MIGRATION ON DETECTED ACTIVITY AS A FUNCTION OF TEMPERATURE. 
The second krypton test (KR-2) provided no useful information because of a leak in the water-trapping system that bled off about $90 \%$ of the flow. After this problem was detected, procedures were modified to check for this condition before starting an experimental run.

The third test (KR-3) resulted in the desired calibration information. This test was conducted with an initial inventory of $381 \mu \mathrm{Ci}( \pm 5 \%)$ of krypton contained in a small glass vial held by a fuel holder in the normal heating zone of the furnace. The furnace was in its normal configuration with both traps operational. The traps were operated just above liquid nitrogen temperature at $-180^{\circ} \mathrm{C}$. As the furnace was heated up, the vial containing the krypton broke in the neighborhood of 200 to $300^{\circ} \mathrm{C}$, and essentially all the krypton travelled to the first trap within $30 \mathrm{~min}$. The trapped krypton was measured approximately $1 \mathrm{~h}$ into the experiment and the trap inventory calculated to be $372 \mu \mathrm{Ci}( \pm 3.7 \%)$ using a point source model for the krypton deposition in the trap. The trap held the krypton until the liquid nitrogen supply ran out, for a total time of approximately $26 \mathrm{~h}$. At the time of the initial release of krypton from the first trap, the measured quantity in the first trap was $368 \mu \mathrm{Ci}$. The small difference between the first and final measurement appeared to be due to some migration within (but not through) the trap as indicated by the fact that no krypton was in the second trap. This measurement can be used to estimate the effect of the migration rate of the krypton within a trap, only a $1 \%$ difference in measured activity after $24 \mathrm{~h}$. A later test confirmed this estimate. During this time, the flow through the traps dropped off considerably due to icing; the final flow was about $40 \%$ of the beginning flow.

The final two tests, KR-4 and -5 , were conducted after the improved moisture condenser was installed in the system. Prior to the installation of the new condenser, it was not possible to run the trap system for long periods of time without some plugging due to moisture freezing. Cold furnace testing of the improved trap system gave confidence that the system could be run for long periods of time with no water freezing problems. The improved control system also provided stable trap temperatures.

Test four (KR-4) was a short-term test to provide further information about the detector calibration of the trap. The sample size for this test was $41.7 \mu \mathrm{Ci}( \pm 5 \%)$, and $39.5 \mu \mathrm{Ci}$ $( \pm 3.7 \%)$ were captured in trap 1 . This sample size is roughly the ${ }^{85} \mathrm{Kr}$ inventory of four highburnup HEU particles. After the krypton had been released, the flow began to decrease, indicating a blockage. To free the blockage, trap 1 was slowly warmed up. At approximately $-145^{\circ} \mathrm{C}$, nominal flow returned and normal trap cooling was then immediately resumed. After 
the brief warmup, the amount of krypton in the trap was then measured to be $37.2 \mu \mathrm{Ci}$, indicating that this operation had only a minor effect on detected krypton inventory due to migration of the krypton, and trap recovery during an experiment was feasible. The exact nature of the blockage was not determined.

The fifth krypton test (KR-5) was conducted with a $303-\mu \mathrm{Ci}( \pm 5 \%)$ krypton sample. The furnace was operated as in previous tests, and $284 \mu \mathrm{Ci}( \pm 3.7 \%)$ were measured in trap 1 about $2 \mathrm{~h}$ after the release. After about $50 \mathrm{~h}, 277 \mu \mathrm{Ci}$ were measured in trap 1. The overall test lasted approximately $85 \mathrm{~h}$. The trapped krypton measurement at the termination of the test was not available because the collection system had not been prepared for a run of this duration. However, rate meter data were collected for the duration of the test, and no large or sudden changes in inventory were observed. A summary of the last three krypton tracer test runs is:

\begin{tabular}{|c|c|c|c|}
\hline Test number & Sample size & Collected & Difference \\
\hline KR-3 & $381.0 \mu \mathrm{Ci}$ & $372.0 \mu \mathrm{Ci}$ & $2.4 \%$ \\
\hline $\mathrm{KR}-4$ & $41.7 \mu \mathrm{Ci}$ & $39.5 \mu \mathrm{Ci}$ & $5.3 \%$ \\
\hline KR-5 & $303.0 \mu \mathrm{Ci}$ & $284.0 \mu \mathrm{Ci}$ & $6.3 \%$ \\
\hline
\end{tabular}

The average uncertainty of $4.7 \%$ between the sample measurements and the collected krypton measurements, assuming a point source model, is considered to be quite good. The calibration of the detector system was examined both before and after the fourth test, and it was within $2 \%$ repeatability error indicating that the thermal cycling of the system, both detector cooldown and trap warmup, did not have any adverse effects. The root mean square uncertainty for this system would be approximately $8 \%$. If several days' migration of krypton is added to the uncertainty, the total uncertainty will still be within about $10 \%$.

\subsection{CCCTF Shakedown Run}

To date, four runs have been made with the CCCTF; three have been with unbonded particles and one with a small compact. ${ }^{30}$ Three of these runs have completed all or almost all of their experimental program; one run (the first attempt at the shakedown) had to be terminated early because of equipment problems. The duration of the runs varied from 100 to $1000 \mathrm{~h}$, and the temperature was held at either 1400 or $1600^{\circ} \mathrm{C}$. Significant fission product releases from the

particles were noted in all but one run. Cesium was by far the main fission product released, 
followed by small amounts of strontium, europium, and cerium. The shakedown test was the only test to release measurable amounts of krypton. The first two runs of the CCCTF were conducted for the NP Program and, in addition to providing data for the NP Program, demonstrated furnace performance for run times of almost $300 \mathrm{~h}$. These runs have been summarized in another document. ${ }^{31}$ Only the shakedown test will be discussed in this report.

The goals of the shakedown test were to demonstrate that the CCCTF could operate for extended periods of time while performing its functions of:

- Maintaining programmed specimen temperature

- Maintaining specified furnace atmosphere

- Collecting and monitoring released fission gases

- Collecting condensible fission products

- Collecting data on system functions

The original shakedown goal was to heat a small irradiated fuel compact from capsule HRB-18 for a period of $500 \mathrm{~h}$ at a temperature of $1600^{\circ} \mathrm{C}$. Due to software and mechanical problems, this test had to be aborted. The second shakedown program required the heating of $25 \mathrm{HEU}$ UCO particles, also from capsule HRB-18, for a period of $500 \mathrm{~h}$ at a temperature of $1600^{\circ} \mathrm{C}$. This attempt was successful and a decision was made to continue heating the fuel specimen, uninterrupted, for a period of $1000 \mathrm{~h}$. This extended goal was completed as well.

Prior to the beginning of the shakedown test, two largely successful tests had been conducted for the NP Program, one for a period of $259 \mathrm{~h}$ at a temperature of $1400^{\circ} \mathrm{C}$ and another for a period of $100 \mathrm{~h}$ at $1600^{\circ} \mathrm{C}$. The first test had been planned to last $300 \mathrm{~h}$, but a power supply safety switch problem resulted in the early termination of the run. Other than the switch problem, the CCCTF had functioned in the expected manner. The original goal of the shakedown test was to heat a small fuel compact, irradiated in capsule HRB-18, containing approximately 175 LEU UCO particles, 5 designed-to-fail (DTF) LEU UCO particles, and approximately $400 \mathrm{ThO}_{2}$ fertile particles, at a temperature of $1600^{\circ} \mathrm{C}$ for a period of $500 \mathrm{~h}$. The average burnup was $25 \%$ for the fissile particles and $4 \%$ for the fertile particles.

Unfortunately, a programming error resulted in a ramp up to $2000^{\circ} \mathrm{C}$ rather than the planned $1600^{\circ} \mathrm{C}$. The furnace operated at this temperature for approximately $3 \mathrm{~h}$ before the temperature was manually ramped down to $1600^{\circ} \mathrm{C}$. The furnace then operated at $1600^{\circ} \mathrm{C}$ for approximately $150 \mathrm{~h}$ before the cold finger airlock failed. The furnace was then shut down. In addition, the $\mathrm{LN}_{2}$ supply to the cold traps malfunctioned, and ${ }^{85} \mathrm{Kr}$ collection was lost for a period of about 
$5 \mathrm{~h}$. The ${ }^{85} \mathrm{Kr}$ release had begun to level off at the time of the malfunction, so the untrapped ${ }^{85} \mathrm{Kr}$ was probably small.

After the test was aborted, an examination of the CCCTF systems took place, and several changes and modifications were made to the facility. The cold finger airlock system is essential to the operation of the CCCTF, and its early failure required an examination and redesign of the system. This device is cycled many times during a run and must provide isolation between the furnace interior and the outside world. The original airlock mechanism failed due to excessive friction between the cold finger and the "O"-ring seals. This problem was eliminated by modifying the "O"-ring grooves for better clearance and by the use of "O" rings impregnated with a special lubricant. In addition, the airlock evacuation cycle was modified to incorporate a purge/evacuate cycle for better elimination of the air and moisture.

The overheating observed in the first attempt at the shakedown test was caused by an error in the computer data base. Before each test, calibration data for the BGT are manually entered into the data base, and a transcription error was made during this process as preparations were made for the test. This error resulted in the incorrect evaluation of the furnace temperature when the controlling TC (i.e., BGT) temperature exceeded approximately $1000^{\circ} \mathrm{C}$. Below $1000^{\circ} \mathrm{C}$, the system functioned normally, so the error was not apparent during the initial ramp-up phases of the test. Future problems of this nature will be prevented because the preoperational procedures have been modified to include a pretest simulation of the TC by a millivolt source. This test allows the examination of the data collection/computer data base system so that errors can be spotted before power is applied to the furnace.

A larger Dewar was incorporated in the $\mathrm{LN}_{2}$ system so that Dewar refilling could take place every 5 to $7 \mathrm{~d}$ rather than every day as previously required. This feature minimizes the likelihood of $\mathrm{LN}_{2}$ boilout. The problem that caused the interruption of the $\mathrm{LN}_{2}$ supply during the first attempt at the shakedown test was determined to be an improper pressure relief valve that allowed the $\mathrm{LN}_{2}$ supply to deliver nitrogen at a higher-than-designed pressure. This resulted in greater-than-anticipated nitrogen consumption that exhausted the small Dewar before the next scheduled supply replacement. The larger Dewar provides a larger operating margin so that more time is available to spot and correct problems.

The second attempt at the shakedown used unbonded irradiated particles instead of a compact. The particles were used because they had been well characterized, and fission product releases could be determined on an individual basis. The fuel specimen was composed of 
25 HEU UCO HRB-18 particles heated previously in a CCCTF test. These particles had not released fission products during their $259-\mathrm{h}, 1400^{\circ} \mathrm{C}$ test. One advantage of using these particles, in addition to their characterization, was that the previous heating had removed the surface contamination from the particles, so a complicating experimental factor had been removed.

The test was to be done at a temperature of $1600^{\circ} \mathrm{C}$ for a period of at least $500 \mathrm{~h}$ to provide a long-term checkout of the CCCTF. Both the krypton and cesium releases were monitored. At the 500-h point, CCCTF performance was reviewed and a decision was made to extend the test period to $1000 \mathrm{~h}$. Furnace performance was excellent and the heating proceeded for $1000 \mathrm{~h}$ at the test temperature. The furnace temperature history is shown in Figure 2-15. The fuel temperature is indicated by the type-C TC. Overall, the furnace performance was as expected. The BGT drifted a small amount during the run, about $28^{\circ} \mathrm{C}$ total, but this drift did not affect the test because it was compensated for during the run. The furnace control system has a built-in manual trim control that allows the operator to add a small temperature offset in the control loop to compensate for small BGT drifts. Small offsets were added in during the test at periodic intervals so that the fuel specimen temperature did not drift with the BGT.

Some problems due to trap plugging were encountered during the test. No loss in the ability to monitor krypton occurred during the plugging and clearing operations because the use of dual cold traps allows one trap to back up the other. In addition, the water condenser also plugged up late in the run; it also was cleared without loss of krypton monitoring ability. In fact, the plugging problems were overcome before the krypton release began. At this point, it should be noted that the source of the moisture is not the furnace heating region.

During the test, both cesium and krypton were collected. The deposition cup integrated cesium collection is shown in Figure 2-16, and the collection rate is shown in Figure 2-17. The cesium collection efficiency was approximately $35 \%$. The krypton collection is detailed in Figure $2-18$. Note that nearly $800 \mathrm{~h}$ at $1600^{\circ} \mathrm{C}$ were required (in addition to the previous $259 \mathrm{~h}$ at $1400^{\circ} \mathrm{C}$ ) for the krypton to break through. The particles have not yet had their postheating analysis performed, so a mass balance and particle coating performance details are not available at the present time. While the postheating inventory of the particles is not available, the inventories of the deposition cups and the furnace components are available and can be used to provide a preliminary estimate of the fuel performance. Table 2-2 itemizes the measured activity levels. 
ORNL-DWG 94-5525

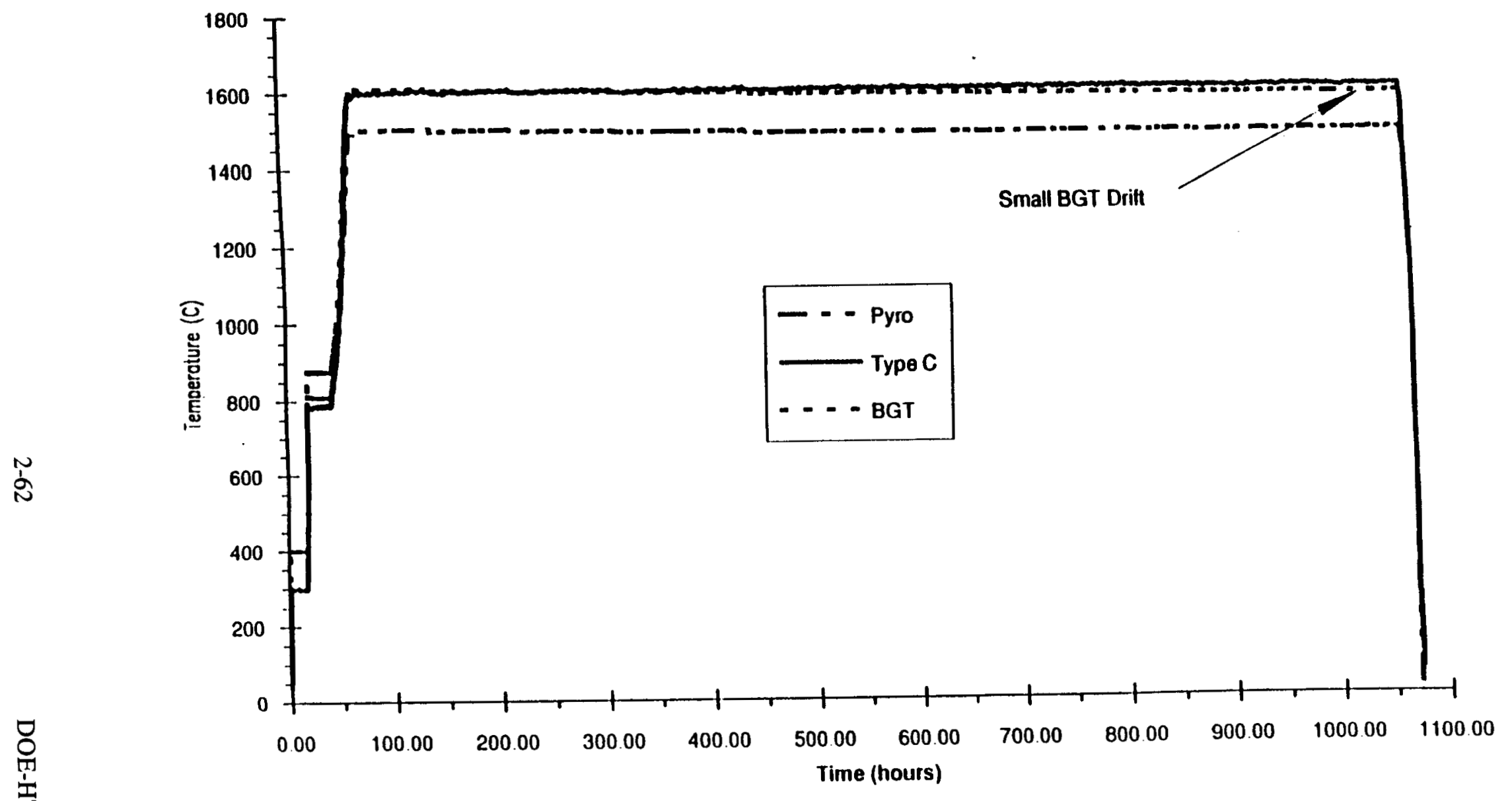

Figure 2-15.

FURNACE TEMPERATURE HISTORY FOR THE SHAKEDOWN TEST. 


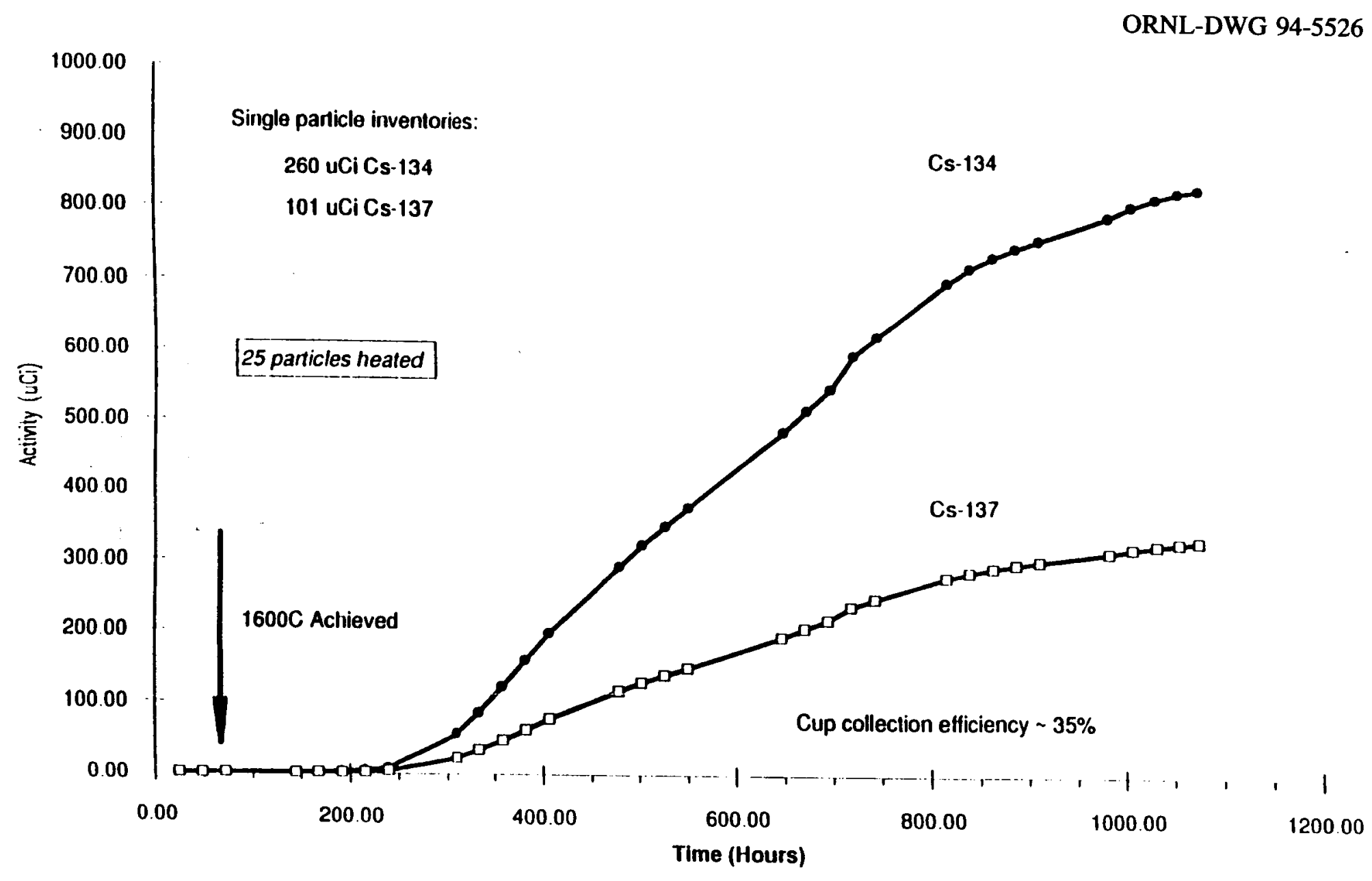

Figure 2-16.

INTEGRATED CESIUM RELEASE FOR THE SHAKEDOWN TEST. CORRECTED TO FEBRUARY 5, 1986. 


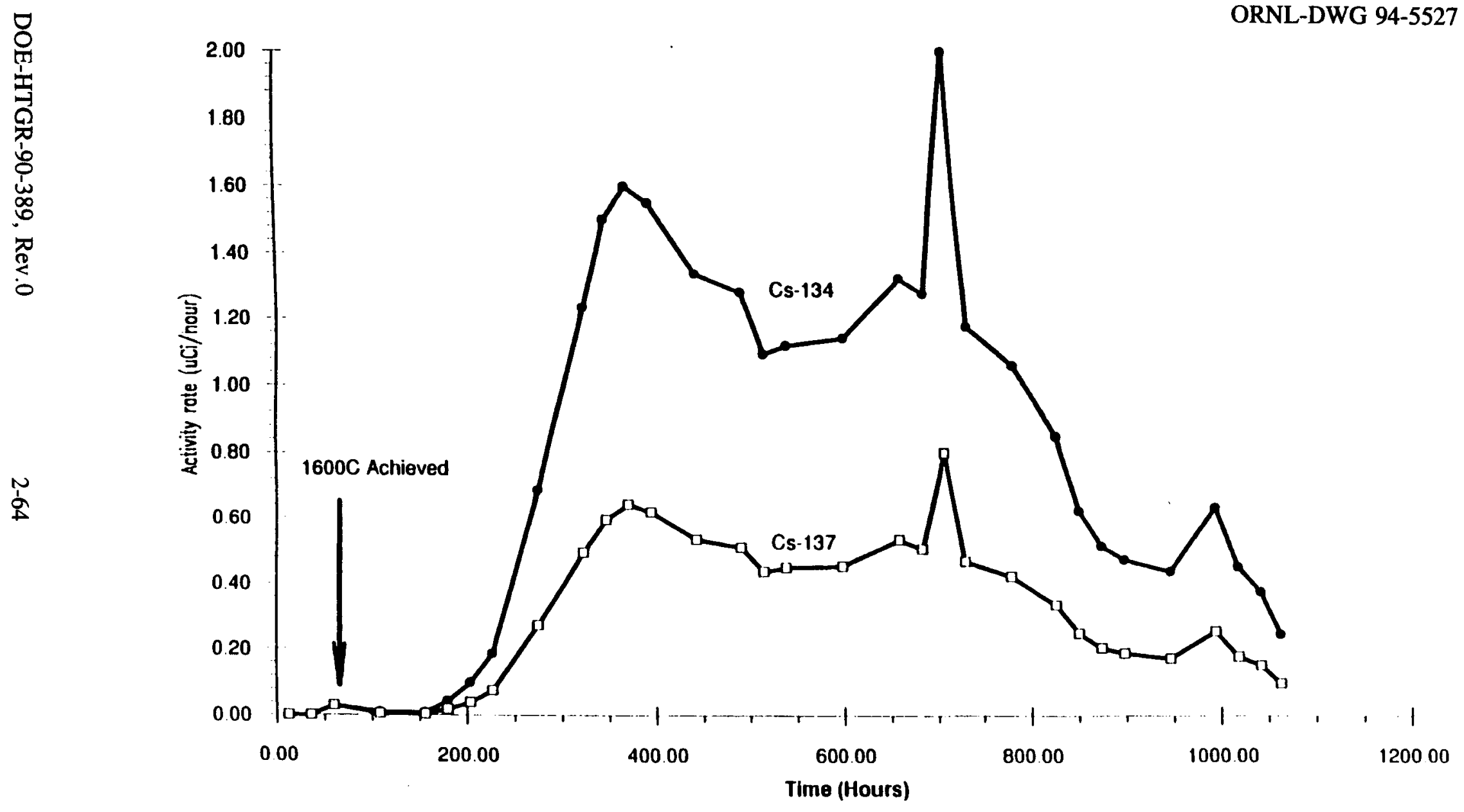

Figure 2-17.

DEPOSITION CUP COLLECTION RATE AS A FUNCTION OF TIME FOR THE SHAKEDOWN TEST. CORRECTED TO FEBRUARY 5, 1986. 


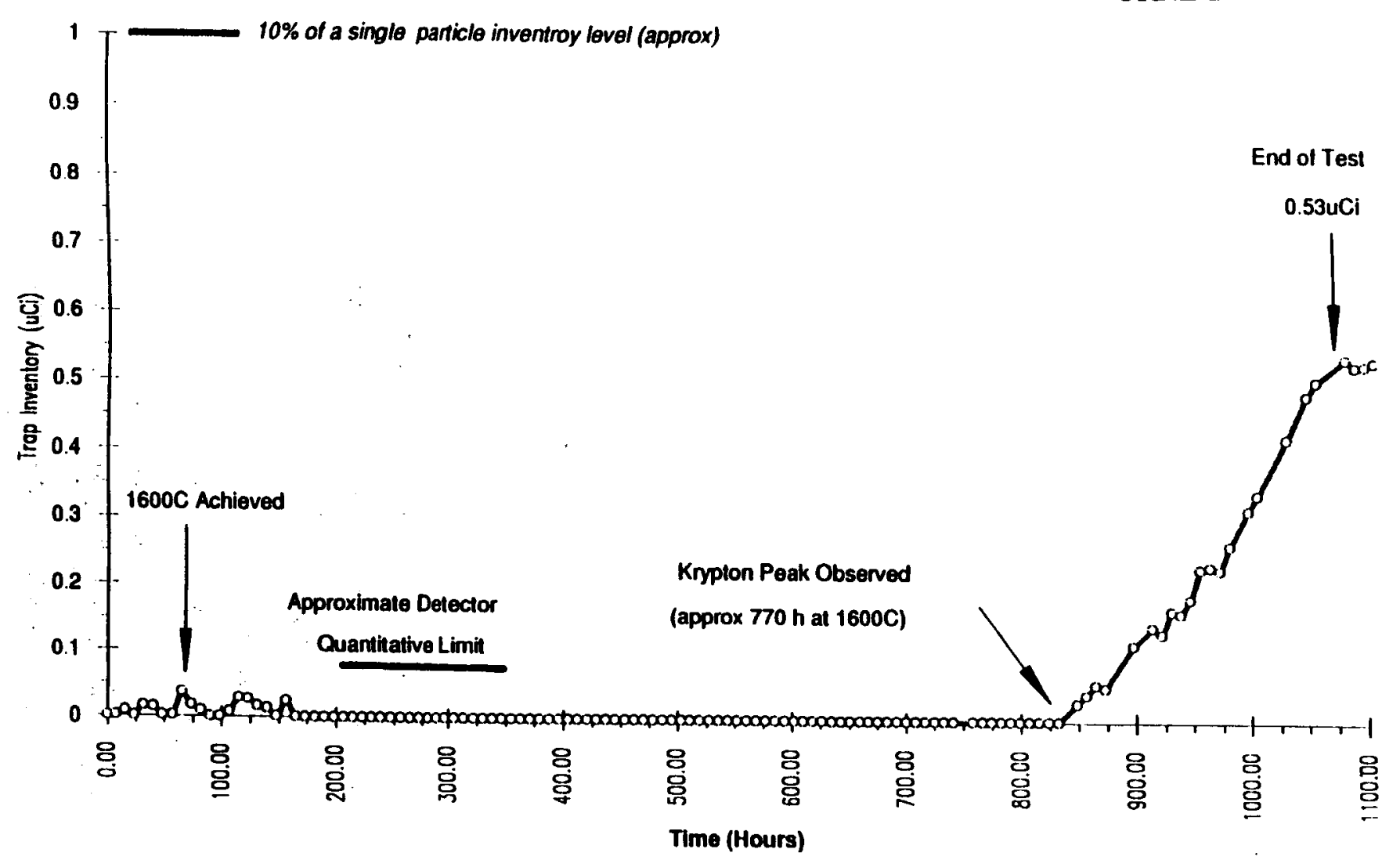

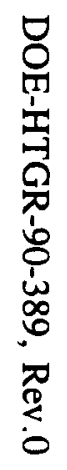

Figure 2-18.

KRYPTON COLLECTION FOR THE SHAKEDOWN TEST. CORRECTED TO MARCH 24, 1992. 
Table 2-2

ACTIVITIES IN MCI (CORRECTED TO 5 FEB 1986)

\begin{tabular}{|l|c|c|c|}
\hline Component & ${ }^{134} \mathrm{Cs}$ & ${ }^{137} \mathrm{C}$ & ${ }^{154} \mathbf{E u}$ \\
\hline \hline Furnace parts & 1500 & 600 & 16 \\
\hline Depositon cup & 830 & 330 & 0 \\
\hline Fuel holder & unknown at present & & \\
\hline Total & 2330 & 930 & 16 \\
\hline
\end{tabular}

The per-particle preheating inventory of ${ }^{134} \mathrm{Cs}$ was $260 \mu \mathrm{Ci}$ and of ${ }^{137} \mathrm{Cs}, 101 \mu \mathrm{Ci}$. The total fuel inventory of cesium was $6500 \mu \mathrm{Ci}$ of ${ }^{134} \mathrm{Cs}$ and $2525 \mu \mathrm{Ci}$ of ${ }^{137} \mathrm{Cs}$. Thus, the total fuel release fraction of cesium is at least $36 \%$. The ${ }^{85} \mathrm{Kr}$ release fraction is approximately $0.2 \%$. As the postheating particle inventories are not available, no mass balance calculations can be done at this time.

The performance of the CCCTF is good and has improved with time, with the most notable improvements being made to the cold finger airlock seals and purging method. Improvements in procedures and operational experience have increased the efficiency of the CCCTF and should eliminate the possibility of overheating and control problems. The one recurring difficulty with the system has been the plugging of the cold traps. It appears that small amounts of water, probably from the furnace insulation, get by the moisture trap and plug the traps after startup or after a few hundred hours of operation. The traps can be cleared without losing ${ }^{85} \mathrm{Kr}$ monitoring ability, so loss of data is not a problem, but the operation is inconvenient. Changes in the trap operation are being evaluated to see if this problem can be eliminated; a new trap system design is being examined to see if this problem can be completely eliminated.

Due to the projected cost increases in the operation of the hot cell housing the CCCTF during these tests, the furnace and support equipment were removed from the hot cell in the fall of 1992 and placed in storage. The closeout of the NP Program includes funds for the relocation of the facility in the IFEL building. A small, portable hot cell has been purchased for the purpose of containing the CCCTF, and this hot cell will be isolated from the main bank of hot cells so that contamination can be held to a minimum. Preparation of the building to receive the 
CCCTF began in the spring of 1993 , and the facility is expected to be operational by the end of CY 1993.

Some redesign of the facilty has taken place to simplify operation and decrease turnover time. The furnace liner has been modified so that it is easier and faster to change. In addition, it is now easier to disassemble the major parts of the furnace remotely, so that the risk of a long shutdown due to furnace contamination from a poorly performing fuel is greatly reduced. The trap and detector system have also been upgraded. The trap system now is better insulated so that liquid nitrogen consumption can be reduced, and a better computer system is now available for the detector system.

\subsubsection{Laser-Induced Fluorescence (LIF)}

An evaluation of LIF as a technique for measuring fission product sorptivities was completed. The project was undertaken in order to establish whether the technique and the available equipment could measure extremely low levels of fission products, especially iodine, in plateout experiments to determine isotherms under MHTGR conditions.

The detection limit for molecular iodine, using the dispersed LIF system, has been determined to be $10^{-9} \mathrm{~atm}$ at room temperature. The experimental determination was in agreement with calculated limits and was several orders of magnitude above what was required $\left(10^{-12}\right.$ to $\left.10^{-14} \mathrm{~atm}\right)$ for fission product sorptivity measurements. An improvement in sensitivity of 1 to 2 orders of magnitude could be obtained by measuring undispersed fluorescence; this improvement, however, would not be sufficient to overcome the decrease in sensitivity that results from $\mathrm{I}_{2}$ dissociation at elevated temperatures. The LIF technique typically possesses more sensitivity for atomic than for molecular species, but the wavelengths required for excitation of atomic iodine cannot be produced with the available laser equipment.

Although LIF may be sensitive enough for sorptivity measurements of atomic species, it is unlikely, given the highly reactive environment of the HTGR, that the atomic form is predominant for the fission product sorptivity measurements because completely different experimental arrangements, including different lasers and detectors, are required for each species of interest. There has, as yet, been no determination of the chemical form of fission product elements in the HTGR gas stream. In the absence of such a determination, it was concluded that LIF is an inappropriate technique for sorptivity measurements. 


\subsubsection{International Cooperation - M. J. Kania and O. M. Stansfield}

There are two international programs on high-temperature reactor (HTR) development: (1) the U.S./FRG Umbrella Agreement under Project Work Statement (PWS) FD-20 of the Fuels, Fission Products, and Graphite (FFPG) Subprogram (now expired); and (2) the U.S. DOE/JAERI Cooperation, under Annex 2, Collaboration on Fuel Performance Testing. Work in this report period has focused on the U.S./FRG Umbrella Agreement, PWS FD-20, in which the IMGA device at ORNL is used to characterize performance of FRG fuel irradiation in capsules and the AVR. The results are discussed below.

\subsubsection{IMGA - C. A. Baldwin and M. J. Kania}

Workers at ORNL examined and analyzed the data from 25,730 individual microspheres contained in spherical fuel elements HFR-K3/3. The parent spheres were irradiated in excess of end-of-life (EOL) exposure and subsequently subjected to simulated core-heating tests in a special high-temperature furnace at KFA. Following the heating tests, the spheres were electrolytically deconsolidated to obtain unbonded fuel particles for IMGA analysis. The coated particles making up these spheres were FRG reference $\mathrm{LEU} \mathrm{UO}_{2}$ TRISO coated particles, and they, along with the spherical fuel elements, were fabricated to HTR-Modul quality specifications by the FRG HTR fuel manufacturer, HOBEG, GmbH.

The HFR-K3 experiment assembly, specifically designed to test HTR spherical fuel elements, was irradiated in the High Flux Reactor (HFR) located at Petten, The Netherlands. ${ }^{32}$ The assembly contained three separate compartments, each with an independent sweep gas and temperature control system. Sphere HFR-K3/1 was irradiated in the upper compartment at an operating temperature ranging from 1020 to $1200^{\circ} \mathrm{C}$ and accumulated a fast-neutron fluence of $4 \times 10^{25}$ neutrons $/ \mathrm{m}^{2}(\mathrm{E} \geq 0.1 \mathrm{MeV})$. Spheres HFR-K3/2 and HFR-K3/3 were irradiated in the central compartment at an operating temperature ranging from 700 to $920^{\circ} \mathrm{C}$ and accumulated fast-neutron fluences of $4.9 \times 10^{25}$ neutrons $/ \mathrm{m}^{2}(\mathrm{E} \geq 0.1 \mathrm{MeV})$. After 359 full-power days in the HFR at a nominal 45-MW power level, the experiment was discharged from the reactor. At that time, spheres 1 through 4 had achieved average burnups of $7.5,10.0,10.6$, and $9.0 \%$ FIMA, respectively.

Following irradiation, the experiment was disassembled and the major components shipped to KFA for PIE. After the fuel spheres were recovered from their respective compartment, spheres HFR-K3/2 and HFR-K3/4 were placed in long-term storage, and spheres HFR-K3/1 and 
HFR-K3/3 were subjected to simulated core-heating tests in a specially designed high-temperature furnace located in the hot cells at KFA. ${ }^{33}$ Sphere HFR-K3/1 was tested for $500 \mathrm{~h}$ at $1600^{\circ} \mathrm{C}$, and sphere HFR-K3/3 was tested for a total of $100 \mathrm{~h}$ at $1800^{\circ} \mathrm{C}$. The latter test consisted of two separate runs of 25 and $75 \mathrm{~h}$. During the tests, the fission products released from the spheres were collected and analyzed. Following the simulated core-heating tests, the spheres were electrolytically deconsolidated to obtain unbonded fuel particles for IMGA analysis.

All particles free of overcoating material from the two HFR-K3 spheres were examined by the IMGA system. ${ }^{34}$ This represents 13,750 fuel particles from sphere HFR-K3/1 and 11,980 fuel particles from sphere HFR-K3/3. Of the 13,750 individual particles examined from sphere HFR-K3/1, four were identified as having peculiar characteristics and were segregated by the IMGA system. Their fission product inventories are given in Table 2-3.

Table 2-3

FISSION PRODUCT ACTIVITIES FOR FOUR PARTICLES ISOLATED DURING THE EXAMINATION OF SPHERE HFR-K3/1 ${ }^{a}$

\begin{tabular}{|c|c|c|c|c|c|}
\hline Particle & $\begin{array}{c}{ }^{106} \mathrm{Ru} \\
(622 \mathrm{keV}) \\
(\mathrm{Bq})\end{array}$ & $\begin{array}{c}{ }^{134} \mathrm{Cs} \\
(604 \mathrm{keV}) \\
(\mathrm{Bq})\end{array}$ & $\begin{array}{c}{ }^{137} \mathrm{Cs} \\
(622 \mathrm{keV}) \\
(\mathrm{Bq})\end{array}$ & $\begin{array}{c}{ }^{144} \mathrm{Ce} \\
(133 \mathrm{keV}) \\
(\mathrm{Bq})\end{array}$ & $\begin{array}{c}{ }^{154} \mathrm{Eu} \\
(1274 \mathrm{keV}) \\
(\mathrm{Bq})\end{array}$ \\
\hline \hline 3(a) Unknown & $1.80 \mathrm{E}+07$ & $1.03 \mathrm{E}+06$ & $1.28 \mathrm{E}+06$ & $2.03 \mathrm{E}+07$ & $4.98 \mathrm{E}+04$ \\
\hline 3(b) Fragment & $1.22 \mathrm{E}+07$ & $4.98 \mathrm{E}+06$ & $3.85 \mathrm{E}+06$ & $\mathrm{ND}^{b}$ & $3.21 \mathrm{E}+02$ \\
\hline 3(c) Fragment & $7.07 \mathrm{E}+06$ & $3.83 \mathrm{E}+06$ & $2.96 \mathrm{E}+06$ & $\mathrm{ND}^{b}$ & $\mathrm{ND}^{b}$ \\
\hline 3(d) Fragment & $\mathrm{ND}$ & $2.26 \mathrm{E}+06$ & $1.68 \mathrm{E}+06$ & $\mathrm{ND}^{b}$ & $2.16 \mathrm{E}+03$ \\
\hline Sphere Means & $2.31 \mathrm{E}+07$ & $5.45 \mathrm{E}+06$ & $4.82 \mathrm{E}+06$ & $9.14 \mathrm{E}+07$ & $1.57 \mathrm{E}+05$ \\
\hline
\end{tabular}

${ }^{a}$ Activities corrected to September 5, 1993.

${ }^{b} \mathrm{ND}$ - none dectected.

'Sphere means are based on the analysis of 13,746 individual particle records.

From the visible and analytical evidence, particles 3(b) through 3(d) appear to be TRISO coating fragments. Visual and analytical evidence for particle 3(a), however, is inconclusive and somewhat contradictory. Although the particle appears intact, its ${ }^{106} \mathrm{Ru}:{ }^{144} \mathrm{Ce}$ activity ratio is very 
low, usually indicating some loss of kernel material. For the HFR-K3/3 sphere, no visibly defective particles were found; however, analysis of mean activities and activity ratios revealed that essentially all particles from the sphere exhibited fission product release (cesium).

To determine how much of a given fission or activation product a particle has retained, it is necessary to know the inventory that should be present in the particle, assuming nothing has escaped. Normally, such information requires detailed calculations of the buildup, decay, and burnup of individual isotopes during the irradiation period and subsequent out-of-reactor hold time for the fuel. Unfortunately, for the HFR-K3 spheres, such detailed calculations were not available. As an approximation, the following assumption was made: during irradiation no loss of fission or activation products occurred from the spheres. This assumption is supported by the EOL fission gas $R / B$ values for the spheres. These values indicate that the $E O L{ }^{85 m} \mathrm{Kr} R / B$ was less than $2 \times 10^{-7}$. Using a gas release value for a failed $\mathrm{UO}_{2}$ particle $\left[(\mathrm{R} / \mathrm{B})_{\mathrm{f}}\right]$ of about $5 \times$ $10^{-3}$, the EOL capsule R/B data represent a $\leq 4 \times 10^{-5}$ failed particle fraction. Approximately 16,400 particles were contained in each spherical fuel element, so this activity represents $<66 \%$ of a single particle inventory. Therefore, the activity must be due to the heavy metal contaminations present in the sphere from fabrication. The low EOL R/B data are representative of no failed $\mathrm{UO}_{2}$ particles.

The mean particle activity value was obtained by dividing the sphere total activity reported by $\mathrm{KFA}^{35}$ by 16,400 (the number of particles per sphere). Note that two sets of data were reported by KFA for the sphere, and in most instances, they were in close agreement. The exception was the activity for ${ }^{144} \mathrm{Ce}$, where a discrepancy of approximately $15 \%$ exists between the measured and the calculated values. Because of their good agreement with IMGA measurements, the higher calculated values were used. Cerium in oxide kernels is known to form stable compounds even at high temperatures. The cerium inventories measured with IMGA are the most representative of the actual particle inventory because they are direct measurements performed on several thousand particles. Tables 2-4 and 2-5 compare mean particle activities before and after the HFR-K3 spheres were subjected to the simulated core-heating tests. 
Table 2-4

COMPARISON OF ORNL AND FRG FISSION-ACTIVATION PRODUCT ACTIVITIES FOR HFR-K3/SPHERE $3\left(1800^{\circ} \mathrm{C} \text { FOR } 100 \mathrm{~h}\right)^{a}$

\begin{tabular}{|c|c|c|c|c|c|c|}
\hline \multirow[b]{2}{*}{ Isotope } & \multicolumn{3}{|c|}{ After $500 \mathrm{~h} @ 1600^{\circ} \mathrm{C}^{b}$} & \multicolumn{3}{|c|}{ Before heating ${ }^{c}$} \\
\hline & $\begin{array}{l}\text { Photon } \\
\text { (keV) }\end{array}$ & $\begin{array}{c}\text { Particle } \\
\text { mean } \\
\text { (Bq) }\end{array}$ & $\begin{array}{c}\text { Std. } \\
\text { Dev. } \\
(\%)\end{array}$ & $\begin{array}{l}\text { Sphere } \\
\text { total } \\
(\mathrm{Bq}) \\
\end{array}$ & $\begin{array}{l}\text { Particle } \\
\text { mean } \\
\text { (Bq) }\end{array}$ & $\begin{array}{l}\text { After } \\
\text { Before }\end{array}$ \\
\hline${ }^{106} \mathrm{Ru}$ & 622 & $2.31 \mathrm{E}+07$ & 11.81 & $3.64 \mathrm{E}+11$ & $2.22 \mathrm{E}+07$ & 1.04 \\
\hline${ }^{134} \mathrm{Cs}$ & 604 & $5.45 \mathrm{E}+06$ & 9.95 & $9.21 \mathrm{E}+10$ & $5.62 \mathrm{E}+06$ & 0.97 \\
\hline${ }^{137} \mathrm{Cs}$ & 662 & $5.09 \mathrm{E}+06$ & 6.12 & $8.86 \mathrm{E}+10$ & $5.40 \mathrm{E}+06$ & 0.94 \\
\hline${ }^{144} \mathrm{Ce}$ & 133 & $9.14 \mathrm{E}+07$ & 7.46 & $1.52 \mathrm{E}+12$ & $9.27 \mathrm{E}+07$ & 0.99 \\
\hline${ }^{154} \mathrm{Eu}$ & 1247 & $1.57 \mathrm{E}+05$ & 10.99 & $2.86 \mathrm{E}+09$ & $1.74 \mathrm{E}+05$ & 0.90 \\
\hline
\end{tabular}

${ }^{2}$ Activities corrected to September 5, 1993.

${ }^{b}$ Based on measurements of 13,746 particles at ORNL.

'Based on measurement of the entire sphere at KFA. 
Table 2-5

\section{COMPARISON OF MEAN PARTICLE ACTIVITIES BEFORE AND AFTER HEATING} SPHERE HFR-K3/3 FOR $100 \mathrm{~h}$ AT $1800^{\circ} \mathrm{C}$

\begin{tabular}{|c|c|c|c|c|c|c|}
\hline \multirow[b]{2}{*}{ Isotope } & \multicolumn{3}{|c|}{ After $100 \mathrm{~h} @ 1800^{\circ} \mathrm{C}$} & \multicolumn{3}{|c|}{ Before heating ${ }^{\mathrm{c}}$} \\
\hline & $\begin{array}{l}\text { Photon } \\
(\mathrm{keV})\end{array}$ & $\begin{array}{c}\text { Particle } \\
\text { mean } \\
(\mathrm{Bq})\end{array}$ & $\begin{array}{c}\text { Std. Dev. } \\
(\%)\end{array}$ & $\begin{array}{c}\text { Sphere } \\
\text { total } \\
\text { (Bq) }\end{array}$ & $\begin{array}{c}\text { Particle } \\
\text { mean } \\
(\mathrm{Bq})\end{array}$ & $\begin{array}{l}\text { After } \\
\text { Before }\end{array}$ \\
\hline${ }^{106} \mathrm{Ru}$ & 622 & $4.00 \mathrm{E}+07$ & 8.91 & $6.14 \mathrm{E}+11$ & $3.74 \mathrm{E}+07$ & 1.07 \\
\hline${ }^{134} \mathrm{Cs}$ & 604 & $4.59 \mathrm{E}+06$ & 51.99 & $1.81 E+11$ & $1.10 \mathrm{E}+07$ & 0.42 \\
\hline${ }^{137} \mathrm{Cs}$ & 662 & $3.00 \mathrm{E}+06$ & 52.61 & $1.19 \mathrm{E}+11$ & $7.26 \mathrm{E}+06$ & 0.41 \\
\hline${ }^{144} \mathrm{Ce}$ & 133 & $1.19 E+08$ & 6.41 & $1.91 \mathrm{E}+12$ & $1.16 \mathrm{E}+08$ & 1.03 \\
\hline${ }^{154} \mathrm{Eu}$ & 1274 & $2.89 E+05$ & 7.56 & $5.24 \mathrm{E}+09$ & $3.20 \mathrm{E}+05$ & 0.90 \\
\hline
\end{tabular}

${ }^{a}$ Activities corrected to September 5, 1993.

bBased on measurements of 11,980 particles at ORNL.

'Based on: measurements of the entire sphere at KFA. 
The comparison indicates a sphere total release (cesium) for sphere HFR-K3/1 of approximately $5 \%$. For sphere HFR-K3/3, the comparison indicates a sphere total release (cesium) of approximately $60 \%$. Cesium escaping the individual microspheres should be retained in the matrix graphite or detected leaving the spherical element by the condensate plates placed in the high-temperature furnace. Table 2-6 summarizes integral release data for the condensate plates and the matrix graphite for the two spheres as reported by KFA (ref. 36) and by Harwell Laboratory, England. ${ }^{36}$ For the HFR-K3/1 sphere, less than $0.2 \%$ of the initial cesium inventory was detected, and for the HFR-K3/3 sphere, less than $15 \%$ was detected. Thus, a mass balance analysis fails to confirm the release of cesium implied by the ratios in Tables $2-4$ and 2-5.

If one assumes that individual particle failures are responsible for the release of fission products in the spherical elements, then it should be possible to distinguish these particles from a distribution of no-failed particles. For the purpose of this analysis, particle failure is defined as a significant release of fission products. A simple histogram method was employed to analyze the individual particle data. Examination of the individual particle data revealed no particles with abnormally high or low ratios for either sphere. This fact, along with the good absolute agreement with KFA preheating test data for ${ }^{106} \mathrm{Fu}$ and ${ }^{144} \mathrm{Ce}$, supports the assertion that all particles in the main distributions have retained their ${ }^{106} \mathrm{Ru}$ and ${ }^{144} \mathrm{Ce}$ inventories. A comparison of interior versus exterior particles reveals that particles from the sphere interior have, on the average, lower ratios. This is probably due to differences in fuel burnup caused by thermal neutron self-shielding.

For the HFR-K3/1 sphere, no particles with abnormally low ratios of ${ }^{137} \mathrm{Cs}:{ }^{144} \mathrm{Ce}$ were observed (excluding the four particles discussed earlier). For sphere HFR-K3/3, however, there appear to be two distributions of particles which overlap, each containing approximately half of the particles from the sphere. Both distributions are centered significantly lower than the 100th percentile; thus, these distributions probably represent particles with high- and medium-release characteristics. In other words, for sphere HFR-K3/3, there is no identifiable distribution of nonfailed particles based on cesium release. The data indicate that individual particle release for cesium varies from approximately $10 \%$ to as much as $90 \%$ of the mean particle inventory. On average, particles from the exterior exhibited higher cesium release than particles from the interior. 
Table 2-6

FRACTION OF CESIUM RELEASED TO MATRIX GRAPHITE AND CONDENSATE PLATES FOR SPHERES HFR-K3/1 AND HFR-K3/3

\begin{tabular}{|c|c|c|c|c|c|}
\hline \multirow[b]{2}{*}{ Sphere } & \multirow[b]{2}{*}{ Isotope } & \multicolumn{2}{|c|}{ Harwell } & \multicolumn{2}{|c|}{ KFA } \\
\hline & & $\begin{array}{c}\text { Matrix } \\
\text { graphite }\end{array}$ & $\begin{array}{l}\text { Condensate } \\
\text { plate }\end{array}$ & $\begin{array}{c}\text { Matrix } \\
\text { graphite }\end{array}$ & $\begin{array}{l}\text { Condensate } \\
\text { plate }\end{array}$ \\
\hline \multirow[t]{2}{*}{ HFR-K3/1 } & ${ }^{134} \mathrm{Cs}$ & 1.6E-03 & $1.4 \mathrm{E}-04$ & - & 1.3E-04 \\
\hline & ${ }^{137} \mathrm{Cs}$ & $1.8 \mathrm{E}-03$ & $1.2 \mathrm{E}-04$ & $1.2 \mathrm{E}-03$ & $1.1 \mathrm{E}-04$ \\
\hline \multirow[t]{2}{*}{ HFR-K3/3 } & ${ }^{134} \mathrm{Cs}$ & 8.7E-02 & $1.2 \mathrm{E}-01$ & -- & $6.4 \mathrm{E}-02$ \\
\hline & ${ }^{137} \mathrm{Cs}$ & 9.7E-02 & $1.3 \mathrm{E}-01$ & $8.2 \mathrm{E}-02$ & $5.9 \mathrm{E}-02$ \\
\hline
\end{tabular}

In conclusion, PIE of 25,730 microspheres taken from two FRG spherical fuel elements by the IMGA system has been completed. This represents the greatest number of individual particles from a single experiment ever analyzed by the system. The parent spheres from which the unbonded particles were obtained exceeded normal EOL irradiation conditions and were subsequently subjected to simulated core-heating tests in a special high-temperature furnace at KFA. The testing consisted of heating spherical element HFR-K3/1 for $500 \mathrm{~h}$ at $1600^{\circ} \mathrm{C}$ and spherical element HFR-K3/3 for $100 \mathrm{~h}$ at $1800^{\circ} \mathrm{C}$. After the heating test, the spheres were electrolytically deconsolidated to obtain unbonded fuel particles for IMGA examination. The EOL $R / B$ data support the assumption that no particles in the spheres failed during the irradiation period. Therefore, coupled measurements and calculations performed on the spheres before the heating test were used to estimate mean particle activities. These preheating test activities were compared directly with IMGA measurements made on the unbonded particles after the heating test. Although absolute comparisons with KFA preheating test activities indicated some fission product release (cesium) for sphere HFR-K3/1, a mass balance analysis was able to confirm only a small percentage of the loss. In addition, an examination of the distribution of individual particle data revealed no statistical evidence of individual particle failures in the main set of particles. This lack of evidence of individual particle failure does not rule out a uniform loss of cesium from all of the particles examined; however, a uniform loss on the order of $5 \%$ would 
however, a uniform loss on the order of $5 \%$ would surely have been detected in the analysis of the condensate plates and matrix graphite. For sphere HFR-K3/3, a significantly higher release of cesium was indicated from the analysis of the individual microspheres than was indicated from the analysis of the matrix graphite and the condensate plates. Individual particle release averaged ten times the KFA-measured integral spherical fuel element release value. The particle data also suggest that there may be two distinct modes of failure at fuel temperatures of $1800^{\circ} \mathrm{C}$ and above with significant differences in release characterisitics.

\subsubsection{U.S./FRG FFPG Subprogram Manager's Meeting - M. J. Kania}

On June 6-7, 1989, the Management Meeting for the FFPG Subprogram under the U.S./FRG Umbrella Agreement on HTR Development was held at ORNL. The meeting was attended by representatives from DOE Headquarters (HQ) and DOE Oak Ridge Operations (ORO), the HBK-Projekt, KFA-Jülich, FRG, GA, and ORNL. The highlights of the cooperative FFPG exchange were reviewed for the period from April 1988 through June 1989. Revision 13 of the subprogram plan was updated and approved by the U.S. and FRG subprogram managers by reviewing the active PWSs. A total of 15 PWSs remain active, 4 in the fuel development area, 5 in the fission product area, and 6 in the graphite area. One new draft PWS, GD-17, was proposed and discussed by the participants at the meeting. It will be included in Rev. 14 of the FFPG plan and considered for inclusion into the program at the next subprogram meeting.

Revision 14 of the U.S./FRG Umbrella Agreement - FFPG Subprogram, reflecting agreements of the June 6-7, 1989, meetings, was approved by the subprogram managers and sent to DOE-HQ and KFA for their approval (DOE-HTGR-88370 and ORNL/GCR-89/5) [FY 1989 M/S 1601.1.03]. Highlights of the report are summarized below:

1. There are nine active PWSs in the fuel and fission product area and six in the graphite development area.

2. A draft PWS for conducting a temperature-cycling creep experiment at KFA in the 1990-92 time frame is being considered for incorporation into the program.

3. A letter report on the "Oxidation Study of FRG ASR-1RG Graphite Specimens" was transmitted to KFA by ORNL (PWS GD-10, milestone 3).

4. A letter report on the second installment of probabilistic FRG design criteria was provided to ORNL and GA by KFA (PWS GD-5, milestone 9).

5. ORNL expressed interest in extending cooperation in the development and validation of HTGR fuel performance and fission product behavior models and codes. ORNL will 
propose new PWSs in this area prior to the next FFPG Subprogram Management Meeting.

\subsubsection{Proposed U.S./FRG Iodine Release Experiment}

A joint Petten-ORNL proposal was made for a reactor experiment in which the direct release of iodine from fuel elements, the formation of volatile species, and the formation of aerosols, including the contribution of particulates, plateout, and chemically induced liftoff, could be studied and measured. The direct measurement would eliminate the greatest uncertainty in the present knowledge of iodine behavior in the HTGR. The proposed HFR experiment will permit observing and measuring the behavior of iodine under conditions simulating release from the core and deposition and transport in the primary circuit. The experiment may offer advantages of improved definition, flexibility, and simplicity in the treatment of important phenomena relative to current large-scale experiments such as COMÉDIE. The proposal was submitted for consideration to the program managers of the U.S./FRG Umbrella Agreement for cooperation in HTGR work.

\subsubsection{Second Fuel Performance Experts Meeting}

The FFPG Subprogram Management Meeting was followed by the Second Experts Meeting on MHTGR/HTR Fuel Performance Under Accident Conditions on June 8-9, 1989, at ORNL. Representatives from DOE-HQ and DOE-ORO, KFA-Jülich, Interatom, HRB in the FRG, Massachusetts Institute of Technology (MIT), GA, and ORNL were present. Topics presented at the meeting included: the overall requirements for reactor design and fuel performance, accidentcondition testing and recent results, post-accident test characterization, fuel behavior and failure mechanisms, accident-condition fuel performance models, and fuel performance beyond accident conditions. A total of 14 pages were presented on these subjects with emphasis on a critique of the current models and directions for development of more appropriate models. This meeting provided the participants with a detailed update on the status of HTGR/HTR fuel performance and modelling efforts in the United States and FRG. All recent results and up-to-date modelling efforts were exchanged among the meeting participants.

\subsubsection{The HFR-B1 Experiment - B. F. Myers}

The reactor experiment, HFR-B1, was a joint undertaking of the KFA, FRG; GA (formerly GA Technologies, Inc.); and the Joint Research Centre, Petten (JRC Petten), of the Commission 
of European Communities, The Netherlands, under the U.S./FRG Umbrella Agreement of Cooperation in GCR Development. ORNL participated in the experiment and in the planning of the PIE and is responsible for the PIE and the analysis of results. The proposal and justification of the experiment, the fabrication of the fuel elements, and the design and safety of the reactor and experimental configuration have been reported elsewhere. ${ }^{38,39}$

The experiment was conducted at the JRC, The Petten Establishment of the Commission of European Communities, and the PIEs at the KFA. The experiments were designed to provide for measurement of fission gas release and metallic fission product transport in simulated, prismatic core fuel elements over the range of normal operating conditions and in the presence of significant quantities of water vapor. The Petten staff designed and assembled the irradiation rig using fuel elements and other samples fabricated by GA. The overall management was the responsibility of the KFA; the supervision and conduction of the experiments was the responsibility of the JRC. The irradiation was begun in April 1987 and ended in July 1989 during which 446 EFPDs were accumulated. After completion, the irradiation rig was disassembled and the contents sent to KFA in December 1991 for PIE..$^{40,41}$

The main objectives of the HFR-B1 experiments involved the transport of metallic fission products and the release of fission gas in fuel elements and under conditions simulating those of the HTGR in the presence and absence of water vapor. Experiments were conducted in three separate capsules contained within the irradiation rig. The temperature range was between 820 and $1230^{\circ} \mathrm{C}$, and in one capsule, water vapor was injected at partial pressures between 18 and $1060 \mathrm{~Pa}$.

The main objectives of the HFR-B1 experiments were as follows:

- Measurement of the transport and distribution of condensible fission products in a fuel element representative of the HTGR

- Measurement of the release of fission gases at temperatures near and above the upper limit of HTGR normal operating temperatures.

- Measurement of the effect of hydrolysis on coated fuel particles with exposed UCO kernels and on the surrounding fuel compact matrix material and graphite

- Measurement of fission product release from and distribution in coated fuel particles with different artificial defects encapsulated under a controlled atmosphere

- Provision of irradiated fuel compacts for use in postirradiation heating tests simulating accident conditions and of unbonded, coated fuel particles for postirradiation tests 
The writing of the final irradiation report is in progress. ${ }^{42}$ Following this, the analysis of the results from the three capsules will be addressed. The data to be analyzed consist of (1) data files, (2) laboratory recorded data, (3) graphics and associated data, (4) gas chromatographic data, and (5) postirradiation iodine decay data. The data files that contain most of the data to be used in the analysis are on magnetic tape and contain 1457 files and 270,464 blocks of data; these data represent the time histories of fission gas release, temperatures, power, process and sweeploop quantities, radioactivity, and capsule locations.

The data of experiment HFR-B1, obtained during the trip, are briefly described in the categories of (1) data files, (2) laboratory recorded data, (3) graphics and associated data, (4) gas chromatographic data, and (5) postirradiation iodine decay data as follows:

1. Data Files. A magnetic tape, generated in the HFR Vax-4300 System, was carried to ORNL by the traveler at the end of his assignment. This tape contains 1457 files and 270 to 464 blocks of data in 3 directories for the HFR-B1 experiment. The files include those with (a) the steady-state fission gas release values (e.g., R/B) for all capsules and cycles for both the tren fissile loading and for the loading in the DTF particles only; (b) the plots of these $\mathrm{K} / \mathrm{B}$ data as a function of time along with a reference temperature profile; (c) the vertical displacement history; (d) the activity history for the three capsules; (e) all TC temperature histories; (f) power and control rod histories; (g) shape factors (related to the axial distribution of neutron fluxes); (h) process data including flow, hygrometer, and pressure data; and (i) sweeploop data including gas composition, pressure, hygrometer, and reference temperature data.

2. Laboratory Recorded Data. Eleven ring-binder notebooks were obtained containing data recorded during the irradiation as well as associated data for all 20 cycles. Although these data are in loose-leaf form, they are equivalent to data that would be recorded in bound notebooks in the ORNL or GA system.

The principal data relate to the counting of the gaseous isotopes ${ }^{85 \mathrm{~m}} \mathrm{Kr},{ }^{87} \mathrm{Kr},{ }^{88} \mathrm{Kr},{ }^{89} \mathrm{Kr}$, ${ }^{90} \mathrm{Kr}$, ${ }^{133} \mathrm{Xe},{ }^{135} \mathrm{Xe},{ }^{135 \mathrm{~m}} \mathrm{Xe}$, and ${ }^{138} \mathrm{Xe}$. Associated with each counting are the specific capsule, date, spectrum number, sample collection time, start of counting time, reference temperature, flow rate and pressure, and the net number of counts for each isotope which is computing the steady-state fractional fission gas release, $R / B$. 
In addition, there are:

- Post-cycle calculations of the flux and fluence in seven energy groups, damage to activation ratios for graphite, damage fluence, equivalent DIDO nickel fluence, axial shape factors, and the number of full-power days (these data appear in the final irradiation report)

- HFR-Vax graphics for (per cycle per capsule): (a) temperature profiles; (b) gaseous activity; (c) vertical position; (d) neutron flux from the monitoring of the self-powered neutron (SPN) detectors, SPN1, SPN3, and SPN5; (e) flow histories; (f) downstream moisture profiles; and (g) upstream moisture profiles

- DACOS files consisting of: (a) temperature data from the 54 TCs; (b) process data including flow, hygrometer, activity, pressure and position data; and (c) sweeploop data including gas composition, pressure, hygrometer, and reference temperature data

- Weekly experimental data summaries (these reports are useful for an overall view but were not issued for all weeks)

- Operating instructions and data logger information

- Discussions by fax on the course of the experiments (GA, ORNL, and JRC Petten)

3. Graphics and Associated Data. The graphic displays and associated data obtained include (a) power profiles in fuel compacts and piggyback samples; (b) burnup profiles with separate contributions from ${ }^{235} \mathrm{U},{ }^{239} \mathrm{Pu},{ }^{241} \mathrm{Pu}$, and ${ }^{233} \mathrm{U}$ for fuel compacts and piggyback samples; (c) tabular power data and neutron fluxes; (d) tabular ORIGEN calculational data for each cycle for the profiles of (a) and (b) at nominal and maximum fluxes; (e) R/B profiles at 8.9 and $100 \%$ fissile power and corresponding reference temperature profiles for each cycle of each capsule; (f) profiles of the activity, pressure, hygrometer readings, and purge flow and the SPN detector outputs; (g) comparison profiles of the reference temperatures in capsules 1,2 , and 3 for each cycle; and (h) temperature profiles for each cycle associated with three fuel compacts and with each fueled graphite wedge in each capsule.

4. Gas Chromatographic Data. The gas chromatographic chart records of the time history of the products of hydrolysis of the carbonaceous components of the fuel elements in the three capsules, mainly $\mathrm{CO}, \mathrm{CO}_{2}, \mathrm{H}_{2}$, and $\mathrm{CH}_{4}$; selected temperatures; flow rates; and other process and sweeploop quantities accompanied the gas chromatographic records. 
5. Postirradiation Iodine Decay Data. The postirradiation measurements of the xenon isotopes resulting from the radioactive decay of iodine released from exposed kernels during irradiation, and the corresponding spectral analyses leading to the net area counts for the xenon isotopes ${ }^{133} \mathrm{Xe},{ }^{135} \mathrm{Xe}$, and ${ }^{135 \mathrm{~m}} \mathrm{Xe}$, were obtained in the form of computer printouts. These data covered the measurements of the xenon isotopes after the termination of irradiation in cycles $88.10,89.02,89.04,89.05$, and 89.06.

The PIE of capsules 2 and 3 has been conducted by the KFA, and a final report will be issued..$^{41}$ A plan for the postirradiation of capsule 1 has been written in collaboration with the staff of the KFA hot cell staff and will be conducted at the KFA provided ORNL and DOE management approve; otherwise, it is unlikely that the examination will be conducted at all. ${ }^{40}$ This would be most unfortunate as the data from capsule 1 are unique and provide the most stringent test of the models on the transport of condensible fission products to date in the HTGR Program. The data from the PIE of capsule 1 will consist of a 3-D concentration field of the fission products in the fuel element; the fuel element is closely modeled on the reactor fuel element configuration and, in addition, has both oxidized and unoxidized graphite wedges containing the stacked fuel compacts.

\subsubsection{U.S./Japan Cooperation}

The U.S./Japan cooperation in fuels development consists of the irradiation of JAERI fuel in the HRB-22 irradiation capsule and characterization of performance along with that of U.S. MHTGR quality fuel irradiated in capsule HRB-21. Both capsules have been described elsewhere. ${ }^{43}$ The HFIR remained in a shutdown condition in CY 1989 so that no irradiation or other reportable activity took place during this report period.

\subsubsection{IAEA Coordinated Research Program (CRP)-2 - B. F. Myers}

A consultants' meeting, sponsored by the IAEA and attended by B. F. Myers of ORNL, was held at the KFA in Jülich, Germany, on March 23-25, 1992. The goal of the meeting was establishment of a CRP under the sponsorship of the IAEA, leading to the validation of predictions for fuel and fission product behavior in GCRs.

The development of CRPs by the IAEA was described by its representative, Mr. John Cleveland. This would involve primarily the validation of fuel and fission product behavior predictive codes and review of adequacy of experimental data and models. The results of the work would be published and made available without restriction. 
Discussion of the needs of the participants' countries led to the following form for the CRP. The agreed-upon CRP-2 will consist of the following four tasks:

1. This task is based on a status report (Verfondern et al., 1992) containing data and models for fuel performance and fission product transport in the core and primary circuit of GCRs. ${ }^{44}$ The KFA will distribute the complete draft of the status report by May 1992. The participants in the CRP are to review this report and provide comments on its contents. The participants are also encouraged to provide detailed papers on data and models that, in their opinion, should be added to the status report. The comments and papers are to be submitted as early as possible within the period preceding (by two months) the next research coordinating meeting (RCM).

2. The contribution of the participants to the status report will be critically reviewed. This review will consist of a discussion of the discrepancies in the contributions, an assessment of the adequacy of the experimental data, and improvements in the modeling techniques.

3. Following the completion of task 2 , a comparison of model predictions with experimental data will be made. In the event of significant discrepancies, reassessment of the model will be undertaken and the comparison with experimental data repeated. The improved model will then be used to compare predictions with new data.

4. The predictions of the codes incorporating the various models will be compared, following completion of task 3 , with experimental data derived from integral tests such as irradiation capsules, accident-condition tests, and so forth. Significant discrepancies in these comparisons will require a study of the complex of models, of the assumptions in the construction of the codes, and of possible omissions.

In addition, the participants agreed to the following tasks and agenda proposed for the RCM to be held in early 1993 :

1. Report on the activities under task 1 , and provide a more detailed plan for task 2 .

2. Exchange reports on current and future tests in the following areas, by country, as indicated:

- Irradiation test of high-quality fuel (Germany, Japan)

- Dependence of fission gas diffusion coefficients on water vapor concentration (United Kingdom)

- Variation of the melting point of $\mathrm{UO}_{2 \mathrm{x}}$ as a function of $\mathrm{x}$ (United Kingdom) 
- Review of irradiation tests (United States, Russia)

- Fission gas release under moisture ingress (Germany)

- Summary of ZrC-coated particle performance: heating tests and irradiation performance (Japan)

- Report on the experimental results from HFR-B1 (United States, Germany)

- Pulse tests of fuel elements (Russia)

- Results from COMÉDIE (United States, France) and SPAREX (Germany) experiments

The United States will participate in CRP-2; a nonbinding agreement has been reached between ORNL and the IAEA (in May 1993). A meeting is planned in Vienna on June 23-25, 1993.

\subsection{FISSION PRODUCT BEHAVIOR (WBS 1601.03)}

\subsubsection{Fission Product Transport}

\subsubsection{Determination of Defect or Failed Fractions - B. F. Myers}

The determination of the fraction of defective or failed coated fuel particles is very im $\operatorname{tant}$ in assessing the quality of the particles and, consequently, the acceptability of the fuel com: xs and their irradiation performance. ${ }^{45}$ The methods for determining the defect fraction are critically analyzed. The burn-leach, gaseous acid leach, and intrusion methods are addressed; for the intrusion method, both wetting and nonwetting intrusants are discussed. The burn-leach method is used routinely to determine the fraction of defective or failed SiC layers, and the gaseous acid leach method is used to determine the fraction of exposed kernels as well as uranium and thorium contamination in the compact. In both methods, the final step is the extraction of the kernel by leaching.

The evaluation of these methods reveals that (1) the efficacy of the burn-leach and gaseous acid leach methods is limited by access through the defect to the fuel kernel of the defective or failed particle; (2) the burn step of the burn-leach method can aggravate the problem of access through $\mathrm{SiC}$ by inducing the growth of oxide layers over defects; and (3) the defects of the particles can be characterized, on the basis of the results of the intrusion method, in terms of pores through which the interiors of the particles are accessible.

Characterization of the defects in terms of pores is used to further evaluate the methods for determining defect fraction. Central to this evaluation is the quantitative description of gaseous 
and liquid transport through pores within the range of radii between 10 and $10,000 \mathrm{~nm}$. The mechanisms of transport treated are (1) capillary flow in unfilled pores, (2) viscous flow of fluids, (3) molecular flow of gases, and (4) diffusional transport of fluid components.

Quantitative evaluation of gas transport in the burn-leach and gaseous acid leach methods indicates that within periods of $<50 \mathrm{~h}$, only defective or failed particles having pore radii larger than several hundred nanometers are fully detected by these methods. A similar conclusion is reached for the liquid leach portion of the burn-leach method. A quantitative evaluation of the intrusion method using mercury as the intrusant is ambiguous in accounting for the detection of pores of the smallest radii associated with observed cumulative defect fractions.

The main conclusions drawn from the analyses of the methods for determining defect fractions are that (1) a population of defective or failed $\mathrm{SiC}$ layers can be characterized by a distribution of effective pore radii and (2) currently used methods for detecting defective or failed $\mathrm{SiC}$ layers or exposed kernels are limited to layers or particles with pore radii larger than a minimum, whose precise value remains to be determined.

The pore radius distributions peak in the range 6 to $8 \mathrm{~nm}$ and fall to lower frequencies for radii less than $5 \mathrm{~nm}$ and greater than $15 \mathrm{~nm}$. The distribution of radii have long tails extending to hundreds of nanometers. The question of the importance of the various subranges on the scale of pore radius is addressed for three events: (1) release of fission gas under HTGR normal operating conditions, (2) release of fission gas under accident simulation conditions, and (3) release of cesium.

Analysis of fission gas release under normal conditions in the presence of larger radius pores (>50 nm) when particle interior and exterior gas pressures are equalized shows that: (1) stable fission gas release from the particles is the same as the release from the kernel and (2) the steady-state release of radioactive gases depends on the response of the buffer to irradiation (a) reaching a maximum value for an undensified buffer and (b) falling to low or even negligible values for a densified buffer and the associated void volume.

The steady-state fission gas release from a small-radius pore $(<25 \mathrm{~nm})$ is negligible compared with that from a larger radius pore, but given the distribution of pore radii, the contribution of a collection of small-radius pores to the total steady-state fission gas release cannot be neglected.

Under accident-simulation conditions and with good-quality particles, the gas release may be governed by transport through small-radius pores as demonstrated with sphere 1 of the German 
capsule in reactor experiment R2-K13. For cesium release under these conditions, the smallradius pores may also contribute significantly to release.

Analyses of the burn-leach and gaseous acid leach methods and of the three events specified above indicate that (1) these methods will not detect defective or failed particles that have effective pore radii significantly less than several hundred nanometers and (2) pores of effective radii less than several hundred nanometers can contribute to fission product release. If the quality of the $\mathrm{SiC}$ layers or the fuel particles is represented by the range of the distribution of pore radii and the cumulative defect fraction, then as the range narrows and the fraction decreases, the quality of SiC layer or the particle increases, but the burn-leach and gaseous acid leach methods become less effective and useful. Thus, the application of these current methods for determining defect levels leaves a lingering question as to the true quality of the coated fuel particles.

Better methods of detecting defective and failed particles than the burn-leach and the gaseous acid leach methods are conceivable. The recommendation is made to formulate and evaluate these methods, drawing upon related work in a variety of scientific disciplines.

\subsubsection{The Effect of Water Vapor on the Release of Gaseous Fission Products - B. F. Myers}

Two irradiation experiments were conducted to determine the effect of water vapor on the release of fission gases. One experiment was conducted in the HFIR at Oak Ridge, experiment HRB-17 and -18, and one in the HFR at Petten, The Netherlands, experiment HFR-B. ${ }^{46-49}$ For the former experiment, the summary is as follows.

Measurements of the effect of water vapor on fission gas release in reactor experiments with HTGR UCO fuel led to three significant observations:

1. In response to water-vapor addition, an initial transient release of stored fission gas occurs. The mode is consistent with the possibility of significant release of stored fission gas during water ingress under accident conditions.

2. Continued addition of water vapor induces a subsequent, much smaller, steady release of fission gas. This release is, however, larger than the release in the absence of water vapor.

3. Removal of the water vapor leads to a decline of the fission gas release to prehydrolysis values. The decline is attributed to the sintering of the fuel.

The probability of the release of a large fraction of the stored fission gas, including radioactive iodine, the principal safety concern, depends on extrapolations and assumptions that 
have yet to be evaluated. The extrapolations involve the dependence of stored fission gas release on water-vapor concentrations and hydrolysis times; the assumptions concern the retentivity of reactor materials such as the fuel compact matrix material, core graphite, and, in the primary circuit, metallic surfaces.

The hydrolysis of the reference fissile fuel, UCO, was studied in two irradiation experiments, HRB-17 and HRB-18, by injecting water vapor into a capsule containing a fuel element which had a known number of HTGR-coated particles with exposed fuel kernels. The experiments were conducted in the HFIR at a nominal system pressure of $200 \mathrm{kPa}$ and temperatures between 200 and $1000^{\circ} \mathrm{C}$. The partial pressures of water vapor were between 20 and $1850 \mathrm{~Pa}$ [100 and 10,000 parts per million by volume (ppmv)].

For the prehydrolysis phase of the experiments, the dependence of fission gas release from the exposed kernels on fission rate density was evaluated. This led to a model modification with which fission gas release can now be more accurately predicted in normally operating HTGRs. Also, in this phase, under the high-flux conditions of the HFIR, the release of long-lived gaseous isotopes was found to be unexpectedly large, an observation attributed to the opening of gas-filled voids by the high fission-fragment flux.

In experiment HRB-17, four hydrolysis tests were conducted at fractional water-vapor concentrations of 100,300 , and $1000 \mathrm{ppmv}$ ( 2 tests) and temperatures between 700 and $1000^{\circ} \mathrm{C}$. The general sequential response of the exposed fuel kernels to water-vapor addition consisted of (1) a rapid release of stored fission gas with a concomitant increase in the steady-state release, (2) a period of constant steady-state release, and upon removal of the water-vapor source, (3) a decline in the release to prehydrolysis values except where configuration changes occurred in the particles with exposed kernels.

There were differences in the responses of the carbide and oxide portions of the UCO $\left(\mathrm{UO}_{2}+\mathrm{UC}_{2}\right)$ kernel to water vapor. After water vapor had been in contact with the carbide portion for a short time, stored fission gas was released over a period of $2 \mathrm{~min}$, whereas with the oxide portion, the release continued for $2 \mathrm{~h}$. This difference reflects the nature of the processes: hydrolysis of $\mathrm{UC}_{2}$, involving reaction of the carbon in the lattice; and hydrolysis of $\mathrm{UO}_{2}$, involving only a distortion of the lattice via a relatively slow insertion of oxygen atoms.

The release of stored fission gas was dependent on the square of the partial pressure of water vapor. This is consistent with the stoichiometry of a reaction of $\mathrm{H}_{2} \mathrm{O}$ with $\mathrm{UC}_{2}$ or $\mathrm{UO}_{2}$ molecules, but in the latter case, only for the preliminary stages, because the extent of hydrolysis during the release of stored gas was exceedingly small, both absolutely and with respect to the fraction of 
stored fission gas released. The fractional release of stored fission gas was, for example, 0.04 at a fractional water-vapor concentration of 1000 ppmv.

The ratio of the steady-state fission gas release in the period of constant release to the prehydrolysis value was independent of the partial pressure of water vapor and was of order 2 , with one exception. The independence was attributable to a lattice distortion of the surface layers after hydrolysis to a depth beyond which fission gases decayed before reaching the surface. Equilibrium among reactants and products of hydrolysis need not have been established according to this attribution. The absence of a significant difference where carbide hydrolysis predominated was probably the result of the small magnitude of the carbide portion of the fuel compared to that of the oxide portion at the time of the tests.

The period of steady-state release during carbide hydrolysis was independent of the presence of water vapor, but for oxide hydrolysis, it only ended when the water vapor was removed. The decline in release following these periods was attributed to sintering. When the water vapor was removed, presumbly oxygen atoms left the lattice in the oxide portion of the kernel, and the sintering then proceeded. The time constant for the general decline in the steady-state fission gas release after the cessation of water-vapor injection for oxide or after a fixed delay for carbide portions of the fuel was the same in all of the hydrolysis tests.

After completion of the sintering in the first 1000-ppmv water-vapor injection tesi, the steady-state fission gas release was larger than the prehydrolysis value, contrasting with observations in the subsequent hydrolysis tests. This persisting change in release was attributed to enlargement of fractures in the coating surrounding the exposed kernels. These enlarged fractures may have resulted from a large increase in gas pressure on the coating following the rapid release of gas during hydrolysis.

In experiment HRB-18, a large water ingress in an operating reactor was simulated by the injection of 10,000 ppmv of water vapor. Shortly after beginning the water-vapor $i_{n}$, the capsule was removed from the reactor and held for $29.3 \mathrm{~d}$ at $200^{\circ} \mathrm{C}$; during this tims, ajection continued except for the last $1.7 \mathrm{~d}$. Afterward, the capsule was reinserted in the reactor. The prehydrolysis and posthydrolysis fission gas release was the same; the extent of hydrolysis during the low-temperature period was small, and no sintering of fuel was observed.

During the course of HRB-17 and -18 experiments, the temperature was varied by changing the sweep-gas composition. The higher temperature led to an increased rate and the change in the composition to a lowered rate of fission gas release. The former effect was immediate and larger; the latter effect required about $3 \mathrm{~d}$ to fully develop. The change in sweep-gas 
composition was manifest through reduction in viscous flow and diffusion of fission gases in the pores of the fuel. In the HRB-17 and -18 experiments, the release of fission gas was only weakly dependent on burnup.

In hydrolysis tests, water vapor moved slowly as a front radially inward through the pores of the fuel compact and sequentially reached and hydrolyzed the exposed kernels; the slow movement, about $0.5 \mathrm{~mm} / \mathrm{h}$, was attributed to retardation of diffusion of reaction of the water vapor with the carbonaceous pore walls of the fuel-compact matrix material.

A phenomenological model was developed to describe the time profiles of krypton, xenon, and iodine isotopes. The phenomenological model was in good agreement with the measured steady-state fission gas release values except for ${ }^{133} \mathrm{Xe}$ and ${ }^{135} \mathrm{Xe}$; the releases of the latter were in excess of the model predictions. This excess was attributed to the opening of pores induced by high-neutron fluxes and by the migration of water-derived species in the fuel lattice. The excess was consistent among the hydrolysis tests. Predominantly, the pores contained the relatively long-lived ${ }^{133} \mathrm{Xe}$ and ${ }^{133} \mathrm{I}$ isotopes.

A new diffusion parameter for xenon was derived, and the first direct determination of this parameter for iodine was made. A model for the contribution to the release of xenon by iodine, which was initially stored in pores, was in good agreement with the measurements.

Evidence for a change in the structure of the surface layers of the fuel kernel during cooling of the fuel at reactor shutdown was manifest by a change in the strength of the dependence of the steady-state fission gas release on the decay constants. The cooling apparently led to cracking of the fuel kernel surfaces, and a change in the distance fission gas had to diffuse before escaping from the fuel. As stated previously, the reactor experiment, HFR-B1, was a joint undertaking of a number of foreign and domestic organizations. ORNL participated in the experiment and in the planning of the postirradiation PIE and is responsible for the PIE and the analysis of results.

The experiment involved three capsules irradiated concurrently, capsules 1,2 , and 3 . For capsule 1 , the main objectives were:

- Measurement of transport and distribution of condensible fission products in a fuel element representative of the HTGR

- Measurement of the release of fission gas during irradiation

- Provision of irradiated fuel compacts for use in postirradiation heating tests simulating accident conditions and of unbonded coated fuel particles for postirradiation tests 
The irradiation of HFR-B1 is completed. The PIE of capsules 2 and 3 is near completion, and the PIE of capsule 1 is in the planning stage..$^{40,50}$ A preliminary analysis of the results from capsule 3 has been made. ${ }^{49}$ The summary of this analysis is as follows:

A preliminary analysis of selected aspects of the water-vapor injection tests in capsule 3 of experiment HFR-BI has been completed. The release of fission gas stored in bubbles and the diffusive release of fission-gas atoms are distinguished. The dependence of the release of storedfission gas $\left.{ }^{85 m} \mathrm{Kr}\right)$ on water-vapor pressure, $\mathrm{P}\left(\mathrm{H}_{2} \mathrm{O}\right)$, and temperature were established taking into account the contributing mechanisms of gaseous release, the effect of graphite hydrolysis, and the requirement of consistency with experiment $H R B-17$ in which similar water-vapor injection tests were conducted. The dependence on $\mathrm{P}\left(\mathrm{H}_{2} \mathrm{O}\right)$ becomes weaker as temperatures increase above $770^{\circ} \mathrm{C}$; the activation energy for release of stored-fission gas is $393 \mathrm{~kJ} / \mathrm{mol}$. Isorelease curves for the pressure-temperature plane were deduced from a derived functional relation. The storedfission gas releases as a function of $P\left(H_{2} \mathrm{O}\right)$ at a common temperature for experiments $H F R-B 1$ and HRB-17 differ by a factor of four; this discrepancy could be attributed to the differences in fission-rate density and neutron flux between the two experiments. Diffusive release of fission gas occurred during and after the release of stored gas. The ratio of diffusive release during watervapor injection to that prior to injection varied in contrast to the results from HRB-17. The variation was attributed to the practice of injecting water vapor into HFR-BI before sintering of the fuel, hydrolyzed in the previous test, was completed. The derived activation energy for diffusive release is $23.6 \mathrm{~kJ} / \mathrm{mol}$.

2.2.1.3 Transport of Iodine - S. D. Clinton, J. C. Mailen, S. A. Sherrow, T. V. Dinsmore, and L. G. Shrader

The objectives and apparatus used for fission product transport characterization have been described previously. ${ }^{51}$ A series of four tests were completed this report period to characterize the effect of exposure of the alloy to a simulated HTGR gas mixture on the transport of iodine at HTGR conditions. Two T22 alloy samples for the first two tests were exposed at $400^{\circ} \mathrm{C}$ to a flowing helium atmosphere containing 130 ppmv $\mathrm{H}_{2} 0,130 \mathrm{ppmv} \mathrm{CO}_{2}, 320 \mathrm{ppmv} \mathrm{CO}$, and $630 \mathrm{ppmv} \mathrm{H}_{2}$ for 16 and $32 \mathrm{~d}$. The desorption-equilibrium data were obtained at temperatures from 400 to $700^{\circ} \mathrm{C}$ with average iodine loadings on the metal samples $\left(25.8 \mathrm{~cm}^{2}\right.$ each) varying from 2 to $46 \times 10^{-5} \mu \mathrm{g} / \mathrm{cm}^{2}$. The iodine vapor pressures ranged from $2 \times 10^{-13}$ to $2 \times 10^{-10} \mathrm{~atm}$ and were calculated from the radioactivity decrease on the alloy, the specific activity of the 
tracer, the helium flow rate, and the experimental time. The least-squares equation for the 12 experimental data values is:

$$
\ln (\mathrm{L} / \mathrm{P})=0.385+13,200 / \mathrm{T}
$$

where

$\mathrm{L}=$ average iodine loading on alloy, $\mu \mathrm{g} / \mathrm{cm}^{2}$,

$\mathbf{P}=$ iodine vapor pressure, atm,

$\mathrm{T}=$ absolute temperature, $\mathrm{K}$.

The correlation coefficient for the desorption-equilibrium data is 0.928 . This expression is very similar to that obtained for the alloy exposed to helium containing a small concentration of hydrogen reported in the September 1988 monthly report (constant of -2.26 and coefficient of 15,480). The constant and coefficient in the above expression for the alloy specimens exposed to the simulated HTGR gas mixture become 3.54 and 16,650, respectively, when the three data values at $400^{\circ} \mathrm{C}$ are eliminated. Examination of the thermodynamics for the gas mixture in contact with iron indicates that the mixture (and the mixture currently recommended which contains lower quantities of impurities) used is also reducing; thus, the agreement of the data for the two types of experiments indicates that there are no unforeseen effects of the impurities on iodine adsorption and desorption.

The third liftoff test examined the removal of iodine from $2.25 \mathrm{Cr}-1 \mathrm{Mo}$ tubing exposed to the simulated HTGR gas mixture at $300^{\circ} \mathrm{C}$. During the startup period, a flow of $\sim 110 \mathrm{~cm}^{3} / \mathrm{min}$ of clean helium was maintained through the tube. An exterior count of the filter housing before the high-flow tests were begun showed a significant amount of iodine had been transferred from the tube to the filter even at that low flow; the Reynolds number was only about two. It is likely that the iodine transferred was a highly. volatile species such as methyl iodide; highly volatile species are sometimes observed when initially transferring iodine from the palladium source to alloy strips. After the test with a Reynolds number of 5500 was completed, the exterior count of the filter assembly was still about the same, indicating that the iodine transferred on dust particles was insignificant compared to the volatile iodine species. About $16 \%$ of the iodine was removed and collected on the dust filter at flows up to a Reynolds number of 5500; this material would be removed from the surface at the normal reactor operating conditions. Helium flowing with a Reynolds number of 13,800 (to simulate accident conditions) removed an additional $0.9 \%$ of the iodine. A scan of the tube after the completed test showed that $44 \%$ of the iodine was removed by both liftoff of dust and desorption of iodine into the helium stream. Iodine not accounted for 
probably adsorbed on apparatus surfaces or was trapped in the silver-plated mesh trap in the gasexit line. Future tests will use a modified procedure to avoid the problem of highly volatile species. The available data are being examined to determine if the highly volatile iodine species became evident only after starting the use of the gas mixture.

The fourth liftoff test examined the removal of iodine from $2.25 \mathrm{Cr}-1 \mathrm{Mo}$ tubing that had been exposed to the simulated HTGR gas mixture for extended periods at $300^{\circ} \mathrm{C}$. The alloy tube was prepared by reducing for $4 \mathrm{~h}$ at $500^{\circ} \mathrm{C}$ with $4 \% \mathrm{H}_{2}$ in $\mathrm{He}$ and then contacting with a slightly reducing gas mixture containing $630 \mu \mathrm{m}$ atm $\mathrm{H}_{2}, 320 \mu \mathrm{m}$ atm $\mathrm{CO}, 130 \mu \mathrm{m}$ atm $\mathrm{CO}_{2}$, and $256 \mu \mathrm{m}$ atm $\mathrm{H}_{2} \mathrm{O}$ for $18 \mathrm{~d}$ with the deposition area of the tube at $400^{\circ} \mathrm{C}$ over the first few inches and the temperature decreasing to room temperature at the gas outlet. The radioactive iodine was then deposited on the interior surface of the tube from a slow flow of helium. During and after the movement of the tube to the liftoff apparatus, a slow flow of helium was maintained through it. About $21 \%$ of the iodine was removed and collected on the dust filter at flows up to a Reynolds number of 5500 (a major fraction of this material was volatilized during the initial heating up and consisted of unknown, highly volatile iodine species); this material would be removed from the surface at the normal reactor operating conditions. Helium flowing with a Reynolds number of 13,800 (to simulate accident conditions) removed an additional $0.6 \%$ of the iodine. A scan of the tube after the complete test showed that $54 \%$ of the iodine was removed by both liftoff of dust and desorption of iodine into the helium stream. Iodine not accounted for probably adsorbed on apparatus surfaces or was trapped in the silver-plated mesh trap in the gas-exit line.

The results of the work discussed above can be summarized as follows: Adsorption coefficients for iodine on $2.25 \mathrm{Cr}-1$ Mo at temperatures of $400,500,600$, and $700^{\circ} \mathrm{C}$ were determined under a reducing gas phase of helium, either containing hydrogen or a mixture of $\mathrm{H}_{2}$, $\mathrm{CO}, \mathrm{CO}_{2}$, and $\mathrm{H}_{2} \mathrm{O}$ simulating the gas in an HTGR. The average iodine loadings in these tests were $\sim 1 \times 10^{-4} \mu \mathrm{g} / \mathrm{cm}^{2}$ of geometric surface area; these loadings are lower by approximately three orders of magnitude than those previously examined. A semi-theoretical equation was fitted to these data to allow calculation of the iodine adsorption isotherms over the entire region of interest for the MHTGR. Liftoff experiments showed that the bulk of any dust particles which carried iodine were removed from the surface at Reynolds numbers of $\leq 5000$, a condition present in the heat exchangers during normal operating conditions. Very small quantities, a maximum of about $1 \%$ additional, were removed by the higher flows simulating accident conditions. 
Additional adsorption studies were conducted with iodine and the results compared with those reported for the first flow tests discussed above. Samples of $2.25 \mathrm{Cr}-1$ Mo metal alloy strip were reduced, in helium- $4 \%$ hydrogen at $500^{\circ} \mathrm{C}$. The alloy $\left(25.8 \mathrm{~cm}^{2}\right)$ was then initially loaded with iodine to $1 \times 10^{-3} \mu \mathrm{g}$ per $\mathrm{cm}^{2}$. The calculated adsorption coefficient ( $\mu \mathrm{g}$ per $\mathrm{cm}^{2}$-atm) was about a factor of two higher than expected from prior work at $500^{\circ} \mathrm{C}$ and about a factor of two lower than expected at $700^{\circ} \mathrm{C}$. During these runs, the iodine loading on the $2.25 \mathrm{Cr}-1 \mathrm{Mo}$ alloy was reduced to $2 \times 10^{-4} \mu \mathrm{g}$ per $\mathrm{cm}^{2}$. Additional data will be required to determine whether these discrepancies are the results of experimental error or a change in the iodine chemical form due to a palladium loading modification.

Subsequent desorption measurements were made at alloy temperatures from 300 to $600^{\circ} \mathrm{C}$ with the helium-256 ppmv hydrogen flow $\left(10 \mathrm{~cm}^{3} / \mathrm{min}\right)$ saturated with water vapor at ambient room temperature. At $300^{\circ} \mathrm{C}$, the adsorption coefficient was about three orders of magnitude less than expected from extrapolation of higher temperature data with dry helium; approximately $10 \%$ of the iodine on the alloy strip was removed by this treatment. Apparently, the presence of water vapor at $300^{\circ} \mathrm{C}$ enhanced the desorption of iodine from the $2.25 \mathrm{Cr}-1 \mathrm{Mo}$ metal alloy. The effective vapor pressure of iodine with water vapor present was equivalent to a temperature of 500 to $550^{\circ} \mathrm{C}$ with dry helium. Desorption of iodine with water vapor at temperatures of 400 , 500 , and $600^{\circ} \mathrm{C}$ was unexpected. Although the iodine loading on the alloy was between 1.7 and $1.8 \times 10^{-4} \mu \mathrm{g}$ per $\mathrm{cm}^{2}$, no significant decrease in ${ }^{131} \mathrm{I}$ activity could be measured after the system had been at $300^{\circ} \mathrm{C}$ for $21.6 \mathrm{~h}$. It is possible that the oxide layer formed by exposure to steam prevented additional vaporization of iodine.

Additional iodine adsorption/desorption studies with moist helium showed that, below $-500^{\circ} \mathrm{C}$, the distribution (gas phase concentration divided by surface concentration) of iodine to the gas phase from $2.25 \mathrm{Cr}-1 \mathrm{Mo}$ is greater in the presence of moisture than in the absence of moisture, and at $\geq 500^{\circ} \mathrm{C}$, the distribution is about the same in either case. These distributions are based on iodine loadings in mass per unit of geometric surface area. However, at the higher temperatures, a nonadherent oxide scale is formed that gives a greater actual surface area. Thus, even at the higher temperatures, the distribution coefficient, where the loading on the alloy (including the oxide scale) is expressed as mass per unit of true surface area, would be greater. Note, however, that the actual release of iodine to the gas phase is still greatly retarded by adsorption on the metallic or metal oxide surfaces. Gamma counting of the loose scale and the alloy showed that $20 \%$ of the iodine was on the loose scale $(0.03 \mathrm{~g})$, and $80 \%$ was on the alloy 
$(2.2 \mathrm{~g})$. This demonstrates that significant iodine can be associated with loose scale formed under oxidizing conditions.

The iodine adsorption experiments have shown that care must be taken to ensure that the molecular species of iodine are known and appropriate for simulating the MHTGR coolant environment. For example, occasionally, iodine was not sorbed onto the alloy as expected. The discrepancy was traced to a source of hydrocarbon in the experimental apparatus that led to the formation of organic iodine, which does not sorb readily. Because of this experience, the molecular form of the iodine is routinely determined in the adsorption work. Thermochemical evaluation of the iodine speciation in the iodine adsorption/desorption tests indicates that $\mathrm{HI}$ should be the predominant chemical form. The conditions of interest for the MHTGR are in a temperature range of about 573 to $973 \mathrm{~K}$ and $\mathrm{H}_{2}$ and/or $\mathrm{H}_{2} \mathrm{O}$ pressures of about $3.0 \times 10^{-5}$ to 6.3 $\mathrm{x} 10^{-4} \mathrm{~atm}$ with total iodine gaseous concentrations of $<10^{-10} \mathrm{~g}$-at $\mathrm{I} / \mathrm{L}$. The very low iodine concentrations and limited stability of $I_{2}$ relative to $I$ mean that $I_{2}$ is not likely to exist.

The relationship between $\mathrm{HI}$ and $\mathrm{I}$ can be derived from standard free energies of formation as:

$$
\left.P_{\mathrm{HI}} / P_{\mathrm{I}}=\left(\mathrm{P}_{\mathrm{H} 2}\right)^{1 / 2} \cdot \exp \left[\left(10^{4} / \mathrm{T}\right)-5.45\right)\right]
$$

\subsubsection{Transport of Cesium - S. D. Clinton, J. C. Mailen, S. A. Sherrow, and}

T. V. Dinsmore

An apparatus for determining cesium adsorption isotherms has been designed. Tre apparatus is similar to that used successfully for the determination of iodine isotherms but will be constructed of platinum tubing. The tubing has been procured and the fabrication started. The ${ }^{134} \mathrm{Cs}$ tracer is furnished in $0.5 \mathrm{M} \mathrm{HCl}$. A possible preparation method is to load the cesium onto cation exchange resin and desorb it with nitric acid. The solution would then be evaporated and the cesium nitrate decomposed by heating. The cesium oxide would convert rapidly to carbonate upon exposure to air. This could then be used as the source of cesium or could have tracerlabeled iodine added to it to examine the behavior of mixtures of cesium and iodine. The initial testing of the apparatus and techniques can use the existing counting system used for the iodine tests. To reach the low surface concentrations desired for most of the tests, the counting system will have to be redesigned. 


\subsubsection{The Effect of Neutrons on the Uptake of Fission Product by the SiC Coating -}

B. F. Myers

Experiments were conducted with the objective of determining, under a wide range of irradiation conditions, whether fission products reach and enter the $\mathrm{SiC}$ layer and to measure the amounts within the $\mathrm{SiC}$ layer if fission products have entered it. ${ }^{52}$ Irradiated fuel particles were selected from several irradiation experiments. The particles were laser drilled, the carbonaceous coatings removed by burning, and the kernel removed by leaching. The remaining $\mathrm{SiC}$ shell was repeatedly leached until the leach solution gave no evidence of fission products. The SiC shells were then gamma counted. The fractional retention of fission products by the SiC shells is given in Table 2-7. The large values of the fractional retention for $\mathrm{Ru}$ and $\mathrm{Sb}$ are attributed to compound or phase formation in the interior of the $\mathrm{SiC}$ layer.

Table 2-7

\section{ELEMENT RANGE OF FRACTIONAL RETENTION OF FISSION PRODUCTS IN SiC AFTER REPEATED LEACHING}

\begin{tabular}{|c|c|}
\hline Element & $\begin{array}{c}\text { Range of fractional retention of fission } \\
\text { products in SiC after repeated leaching }\end{array}$ \\
\hline \hline $\mathrm{Cs}$ & $4 \times 10^{-4}$ to $8 \times 10^{-3}$ \\
\hline $\mathrm{Ce}$ & $3 \times 10^{-3}$ to $2 \times 10^{-2}$ \\
\hline $\mathrm{Eu}$ & $2 \times 10^{-3}$ to $1 \times 10^{-1}$ \\
\hline $\mathrm{Ru}, \mathrm{Sb}$ & $1 \times 10^{-1}$ to 1.0 \\
\hline
\end{tabular}

No dependence of the $\mathrm{SiC}$ fission product content on time, burnup, temperature, or kernel enrichment was found. The amount of fission product found was dependent on the fast-neutron fluence, the neutron spectral distribution, and the kernel composition. The latter dependence is undoubtedly a consequence of the lower fractional release from $\mathrm{ThO}_{2}$ than from $\mathrm{UCO}$ or $\mathrm{UC}_{2}$ kernels under a common set of irradiation conditions: Thus, the fluence and spectral distribution are the important variables for the study reported here.

In the case of cesium, a simple model consists of the two following hypotheses:

1. Structural damage in the $\mathrm{SiC}$ coating from the slowing down of fast neutrons creates sites at which cesium binds, or paths by which the cesium may enter, the SiC coating. 
2. The cesium atoms move into the SiC coating to occupy these sites and perhaps along the paths generated by fast neutrons.

The first element of the model implies that the cesium atom concentration in the $\mathrm{SiC}$ is proportional to the number of sites created during the slowing down of fast neutrons. If the cesium content of the $\mathrm{SiC}$ is proportional to the number of damage sites in the irradiated $\mathrm{SiC}$, then an estimate of the probability of neutron damage (with respect to sites favorable to cesium binding) can be made. When the number of atoms in the SiC shells is normalized with respect to the damage probability as defined, the number of atoms is found to be proportional to the neutron fluence as shown in Figure 2-19.

The second element of the model implies a time dependence for transport of the fast-neutron flux. As no time dependence was uncovered, the time to reach the proposed damage rate may be very small and not attachable with the data presented.

\subsubsection{Washoff Studies - S. D. Clinton, J. C. Mailen, S. A. Sherrow, and T. V. Dinsmore}

No data exist for washoff of fission products where the loading is realistically low. Consequently, some simple initial experiments will be conducted in which loaded specimens of 2.25 $\mathrm{Cr}-1 \mathrm{Mo}$ and Alloy $800 \mathrm{H}$ will be exposed to heated water. The specimens to be tested may, in most cases, have to be specially prepared for the tests. However, some specimens from the tests to determine adsorption isotherms and effects of moisture may be used.

It appears that the most desirable washoff test will not involve actual boiling and condensing of steam. It will be much easier to control and quantify a system in which water is heated to the desired temperature and pressure and dispensed by controlled displacement by helium. The water would then flow over the specimen and be collected and sampled. This displacement and sampling would be repeated until all the water had been displaced. A significant, but feasible, modification of the apparatus would allow exposing the specimen to steam at elevated temperature and pressure and sampling the steam phase.

The experimental conditions for these tests are still to be determined. The conditions stated in Modular HTGR Plant Fuel/Fission Product Technology Development Plan, DOE-HTGR-86027, Rev. 1, April 1987, are not reasonable since they call for temperatures above the critical temperature of water $\left(374.2^{\circ} \mathrm{C}\right)$ and indicate a $\mathrm{pH}$ range that is difficult to justify for the reactor system (4 to 10). The pressure range specified indicates only $>10 \mathrm{~atm}$ to $1 \mathrm{~atm}$. In these tests, the full 60 atm will not be difficult in the autoclave we plan to use. Before experiments are 
ORNL-DWG 94-5529

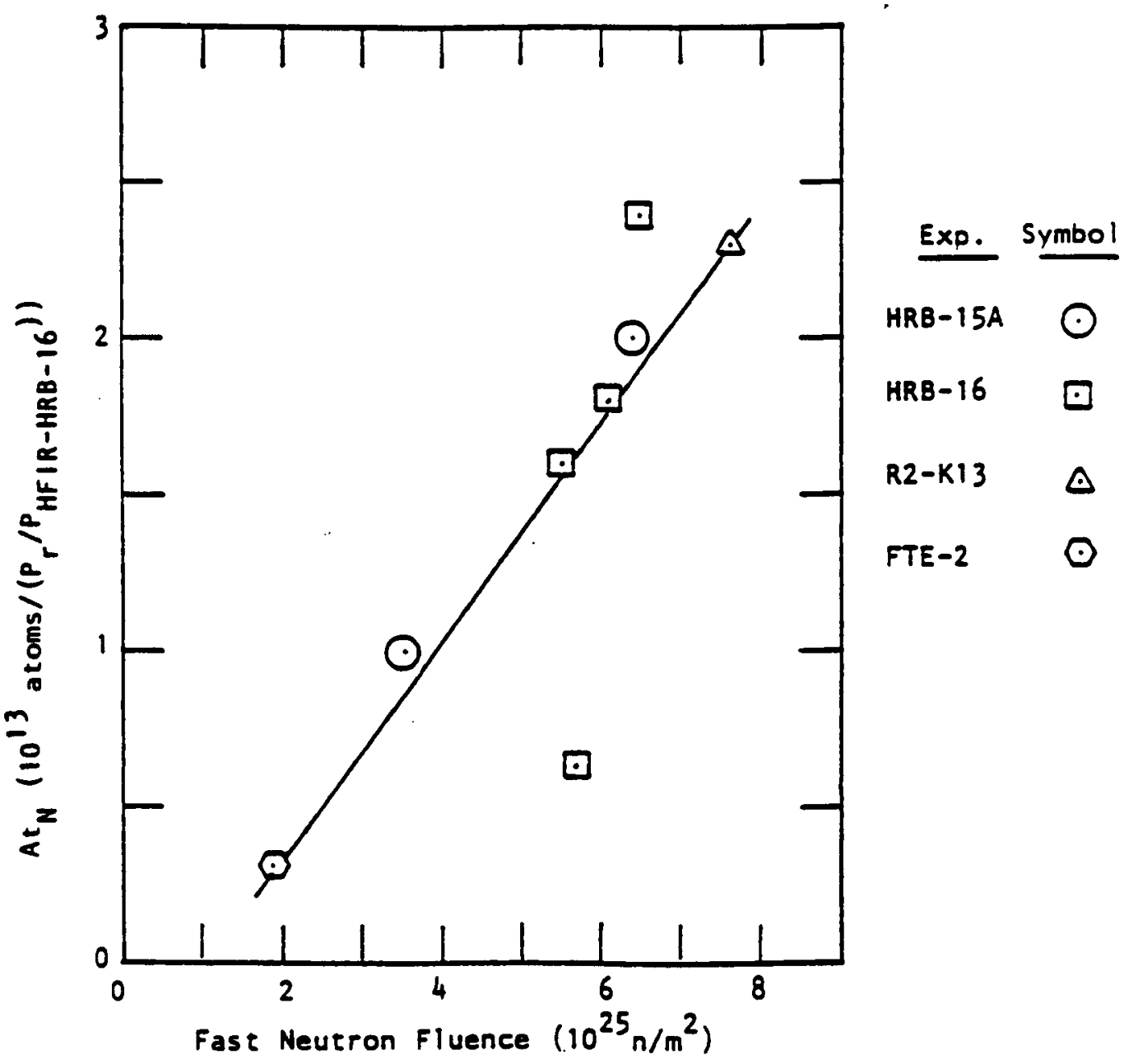

Figure 2-19.

THE DEPENDENCE OF THE CESIUM CONTENT OF THE SIC LAYER, NORMALIZED TO THE EQUIVALENT NEUTRON DAMAGE, ON THE FAST NEUTRON FLUENCE 
initiated, the range of experimental parameters needs to be specified through consultations with the designers.

The specimens to be studied in the washoff apparatus will be sections of 0.375 -in. outside diameter (OD), 0.25 -in. ID tubing loaded on the interior and exterior with iodine and/or cesium in our standard isotope transport apparatuses. In some cases, the tubing can be subjected to conditions designed to generate particulates to examine the washoff of material under these conditions. If desired, the system could be equipped with a filter to prevent the particulates from exiting the autoclave with the water samples.

The water from the washoff tests can be extracted, using various extraction agents, to evaluate the fraction of iodine as organic iodide, $\mathrm{I}^{-} \mathrm{IO}_{3}^{-}$, and $\mathrm{I}_{2}$.

Most of the equipment required for the washoff studies is now available. The fission product (initially iodine) will be deposited on pieces of 0.375 -in. OD, 0.25 -in. ID tubing. These will then be loaded into a holding fixture which will cause the water to pass through the inside of the tubing and over the outside of the tubing to ensure, as nearly as possible, complete contact of the deposited fission product with the flowing water. A holding fixture has been designed, fabricated, and will be tested by injecting dye into the flowing water and observing its path over a tubing specimen.

\subsubsection{Fort St. Vrain Reactor (FSVR) Dust Characterization - J. C. Mailen}

Dust samples were obtained from the hub of a helium circulator removed from the FSVR, and the activity of the samples was reported previously. During this report period, plans were made to determine the quantitative composition of the dust by X-ray diffraction (XRD) and size by SEM or settling methods (stokes diameter).

\subsubsection{Dust Characterization Studies - D. F. Wilson, P. S. Bishop, and J. R. DiStefano}

The objective of this work is to characterize the reaction mechanisms, rate of production, and surface corrosion products, commonly referred to as "dust," that form on materials exposed to simulated coolant gas compositions under: (1) isothermal, (2) thermal cyclic, and (3) thermal cyclic and mechanical impact conditions.

The exposures will be performed in a continuous recirculating gas flow loop located in the Metals and Ceramics Division. The chemical composition of the gas will be monitored at the inlet and outlet of the high-temperature retort. The chemical composition of the inlet gas will be adjusted so that the outlet composition is within $25 \%$ of the inlet. The inlet gases will be 
preheated by flowing them down the outside of the tube containing the structural material specimens within the constant temperature zone of the furnace. The materials of primary interest are $2.25 \mathrm{Cr}-1 \mathrm{Mo}$ and Alloy $800 \mathrm{H}$. The gas compositions will be chosen so as to simulate the proposed MHTGR coolant gas compositions.

CY 1989 efforts have been concentrated on remodelling and reconditioning the recirculating gas flow loop. Components of the system have been modified to allow for collection and removal of spalled particulates. A Panametrics 2100 hygrometer system and system pressure regulators are being serviced and calibrated. The molecular sieve column of the Bendix gas chromatograph has been reconditioned. Concurrent with these activities, samples of Alloy $800 \mathrm{H}$ are being chemically analyzed for their constituent composition.

\subsubsection{COMÉDIE Test Program - B. F. Myers, T. S. Kress, O. M. Stansfield, and O. F. Kimball}

The COMÉDIE Program is an experimental program being performed for the DOE by the Commissariat a l'Energie Atomique (CEA) in the SILOE reactor pool at the Centre d'Etudes Nuclearies de Grenoble (CENG). The primary purpose of the COMÉDIE test program is to obtain an independent data base that can be used to validate MHTGR fission product distribution codes developed by GA. The object of the experiments to be performed is the simulation of fission product release, transport, deposition, and re-entrainment as affected by steady-state operation, liftoff (due to depressurization events), and washoff (due to moisture ingress events). The facility and test program have been described in detail elsewhere. ${ }^{39}$

The COMÉDIE loop is a complex system that is operated in-reactor at representative MHTGR conditions for primary coolant chemistry, flow rate, and pressure with representative components. The in-reactor section contains a section of a fuel block, with a fraction of DTF fuel particles, a graphite block representing the lower reflector, and a counter-flow heat exchanger (gas to gas) with three parallel tube bundles. It contains a depressurization section that is used to produce blowdowns simulating possible depressurization events in the MHTGR. The system contains the equipment required to make on-line measurements of gaseous fission products and for on-line measurement and control of test gas temperatures, pressures, and flow rates; component temperatures; and required impurities in the test gas. Postirradiation determinations of fission product distributions will be made at the CENG and at ORNL. The COMÉDIE Program is being performed under a subcontract from ORNL for the DOE NE-HTGR Program. ORNL manages this program with technical input from ORNL and GA. 
During CY 1989, refurbishment of the COMÉDIE loop and blowdown system was continued; this included procurement of major components such as the heat exchanger, the "inpile" heater, and the filter assembly for the depressurization section. Delay in the manufacture of components caused a month's delay in the test program so that the BD-0 and BD-1 tests were rescheduled for CY 1990.

A calculation was made to determine the time for complete failure of the DTF particles to be used in the source elements of the COMÉDIE experiments. From this calculation, the best estimate of the time was $22 \mathrm{~d}$ at a temperature of $800^{\circ} \mathrm{C}$; to this estimate must be added an unknown uncertainty associated with the higher temperature $\left(\sim 1250^{\circ} \mathrm{C}\right)$ of the COMÉDIE experiments. A previous estimate of a few days, published in the Specification for COMÉDIE Test $B D-1$, DOE-HTGR-87-095, is probably too small. ${ }^{53}$ A fuel characterization test was proposed by the CEA to establish the failure rate and cesium transport rate in the loop prior to the first in-pile test, BD-1.

A COMÉDIE technical review meeting was held at ORNL on April 18-20, 1989, and was attended by representatives of the CEA, GA, and ORNL. During the meeting, reviews were conducted of the COMÉDIE loop refurbishment; the design and performance analysis of the loop with emphasis on fuel elements, heat exchangers, and the depressurization train; and the specifications for the BD-0 and BD-1 tests. In addition, discussions were held on the fuel characterization test, PIEs, and specifications for the heat exchanger tube fabrication. A set of agreements and commitments was generated governing the course of the efforts on preparing and conducting the planned, aforementioned experiments from the present until the middle of 1990. It was agreed that a decision on whether or not to conduct the fuel characterization test would be made after the first liftoff test, BD-1. (During the BD-1 test, the performance of the DTF fuel particles was quite satisfactory, precluding the necessity for a fuel characterization test.)

The primary activities involved in the COMÉDIE Program during CY 1990 were concentrated on completing component and system designs, fabrication of components, and preparation of required documents. During FY 1990, design of the gas circuitry was completed, and the necessary components were ordered. The helium and other gas supplies, vacuum and pressure balance systems, gas additives panel, and the main circuit panel were fabricated and delivered.

Prior to 1990 , the other components were designed; during this year, fabrication activities continued on the fuel/reflector section, the heat exchanger, the in-pile heater, and the 
depressurization section. The graphite block for the BD-1 test was completed and delivered to GA for fuel loading. The in-pile heater fabrication was completed as was fabrication of the heat exchanger tubes. Design of the in-reactor upper section of the outer (primary) containment was completed, and fabrication was started. The BD-0 and BD-1 experimental procedures, the COMÉDIE Program quality assurance (QA) plan, and seven (of 26) loop operating modes were completed.

During 1990, there was one program review meeting on February 27-28 (with participants from the DOE, ORNL, and the CEA); one technical review meeting on July 16-20 (with participants from the DOE, ORNL, GA, and the CEA); one financial audit of the CEA proposal, SEREME 90.19, on March 5-6, by the Defense Contract Audit Agency; and one QA audit, on May 14-18.

The QA audit team consisted of a chairman, a lead auditor from ORNL, a representative from the PDCO, a technical specialist in PIE, an ORNL consultant, and a translator/interpreter. The team issued a report on June 5, 1990, that was a generally favorable review of the test facility and the QA procedures and documentation, with ten findings. By the start of the BD-0 test, most of these findings were resolved; the rest were resolved by the start of the BD-1 test.

During 1990, considerable progress was made in completing test loop design and component fabrication. Considerable required documentation was prepared, and a financial audit and a QA audit were completed satisfactorily. However, due to previous underestimates of the time and cost required to refurbish the test loop, increased documentation and increased QA requirements, and inadequate manpower throughout the year, the start of the mockup test (the BD-0 test) and the first irradiation test (the BD-1 test) slipped by about 8 months.

The primary accomplishments during CY 1991 were completion of component fabrication for the BD-0 test, installation of the components in the loop, qualification testing of components, training and document preparation for the test; successful completion of the test, and analysis of test results for this mockup test. More details of these activities are given below.

Fabrication of the following components was completed during this year: the fuel/reflector section (without fuel), the heat exchanger, and the depressurization section for the BD-0 test. These components and the in-pile heater were installed in the in-pile section of the loop for the BD-0 test. Fabrication and installation of the upper in-pile section of the loop and the out-of-pile integral filter also were completed. A second gas chromatograph, for test gas analysis, was purchased, installed, and checked out with the signal integrator and data recorder. The main 
circuit flow meter was installed in the loop. All connections of all data readouts to the PEGASE computer were completed, and the system was checked out prior to the start of the BD-0 test.

The fuel compacts for the BD-1 test were completed by GA and shipped to CENG. The compacts were installed in the fuel block for the BD-1 test. The BD-1 fuel and reflector blocks and the depressurization section for the BD1 tests were completed and delivered to the CENG. The neutron mockup test system was fabricated, assembled, and completed.

Considerable qualification testing needed for the BD-0 and BD-1 tests was completed during 1991. Included were successful short-term qualification tests for the heat exchanger bundle isolation valve, check tests of the prototype depressurization section valves, the 2000 -h hot $\left(800^{\circ} \mathrm{C}\right)$ test of the heat exchanger module isolation valve, and the loop-in-bypass circulator characterization and depressurization system tests.

During the loop-in-bypass test, two blower failures occurred. The first failure was due to imbalance of the rotor that was first observed in the tests in the mid-70s when a 9000 -rpm (revolutions per minute) limit was placed on the circulator speed to minimize vibrations. The vendor guarantees the circulator, properly balanced, to $12,000 \mathrm{rpm}$. The second circulator failure was caused by a short circuit in the stator. Each failure caused a 3-month delay in the program. A spare stator was procured, and reviews with the vendor resulted in additional operating and storage conditions and restrictions that, combined with complete inspections after each test, resulted in much more reliable circulator operation (no additional blower failures occurred). The depressurization system test before the first blower failure indicated that it was not possible to guarantee that the blowdown section filter isolation valves closed completely, which they must, during the $84 \mathrm{~d}$ of steady-state irradiation. This necessitated redesign of the filter isolation valves. The neutron mockup test, primarily designed to determine flux suppression caused by the fuel, was also completed.

The following safety-related pressure tests were satisfactorily completed prior to the start of the BD0 test:

- High-pressure in-pile circuit test at 105 bars (75\% overpressure) for $1 \mathrm{~h}$

- Low-pressure in-pile containment test at 2 bars (50\% overpressure) for $1 \mathrm{~h}$

- High-pressure main circuit test at 105 bars (75\% overpressure) for $2 \mathrm{~h}$

- Leak-tightness test for $24 \mathrm{~h}$ at 60 bars (operating pressure)

- Overpressure test of the flow meter at 105 bars (75\% overpressure) for $1 \mathrm{~h}$

- Overpressure test of the depressurization tanks at 125 bars (50\% overpressure) for $1 \mathrm{~h}$ 
The COMÉDIE QA plan, Rev. E, was completed by the CENG; it was reviewed by GA and ORNL QA specialists and by the program manager. Our comments, questions, and required revisions were formally transmitted to the CENG and discussed with them at the April 1991 Program Review Meeting. CENG incorporated the required changes in their Rev. F, which was reviewed and provisionally approved.

All experimental procedures and operating modes for the BD-0 and BD-1 tests were completed by the CENG. These documents were reviewed by the ORNL program manager and by GA thermal/hydraulic and fission product specialists. Our comments, questions, and required changes were given to the CENG at the April 1991 Program Review Meeting and formally transmitted by the end of June 1991. The CENG revised the BD-0 experimental procedure and the operating modes required for the BD-0 test. These documents were provisionally approved prior to the start of the BD-0 test phases for which they were required.

The BD-0 and BD-1 PIE procedures and eight operating modes for PIE or postirradiation disassembly (PID) were completed by the CENG and reviewed by ORNL and GA. Our comments, questions, and required changes were formally transmitted to the CENG by the end of June 1991. All PIE work was put on hold between April and July 1991 by the CENG until the CY 1991 contract was completed and they were assured that adequate funds for PIE equipment purchase and further work on documents would be provided.

Prior to the start of the BD-0 test, considerable training was completed on all loop systems. Training sessions on the following systems were completed:

- The in-pile heater, the heat exchanger, and the depressurization system

- The upper part of the in-pile system

- The circulator, the out-of-pile filter, and the auxiliary heater

- The gas purification systems

- The test gas analysis system and equipment

- The gas addition, vacuum, depressurization, pressure balance, cooler systems, and the helium and other gas supply systems

Final training on all loop systems was part of the BD-0 test.

The unfueled, no irradiation, mockup test (the BD-0 test) was started on August 1, 1991, and was completed on August 30, 1991. The steady-state portion of the test (to simulate conditions during the irradiation periods of the BD-1 test) was from August 14-26, 1991. Three series of four blowdowns each were completed between August 26-30, 1991. The ORNL 
program manager was present during the first 3 weeks, and a thermal/hydraulics expert from GA was present during the blowdown tests (the last week).

Disassembly of the in-pile components and the full-flow (out-of-pile) filter was completed during September 1991, and the components (fuel and reflector block, heat exchanger, and depressurization section) were transferred to the hot cells. A complete test description, the test results, and analyses of the results are given in the CENG BD0 reports, LIDI/91/NT/7484 (BDO Test Results - General), LIDI/91/NT/7453 (Thermohydraulic Interpretation of the BD-O Results), and LIDI/91/NT/7450 (Chemistry of the BD-0 Tests).

Seven hold points for this test, three associated with the loading of components into the inpile section, three with various phases of the test, and one at the end of the test, were processed expeditiously in conformance with the requirements of the BD-0 test specification.

The BD-0 test was very successful. As a mockup test for the BD-1 test, all of the test objectives were achieved, and all of the test specifications were satisfied with the exceptions of (1) the heat exchanger inlet temperature and (2) the specified test gas chemistry, which was within the required range for all controlled impurities for only a few hours. The loop was run satisfactorily for the 4-week period with no significant problems for any component. The test also was an excellent shakedown test, as several problems and their solutions were identified. Examples include: (1) several minor changes in the gas chemistry system, such as increasing the $\mathrm{H}_{2}$ concentration in the $\mathrm{H}_{2}$ addition cylinder from 0.1 to $1 \%$ to improve the $\mathrm{H}_{2}$ injection efficiency, and (2) a slight increase in the initial blowdown rate to decrease the total time required to reach equilibrium.

Three significant problems were discovered during this test. The major technical problem discovered was the inability to achieve the specified gas temperature at the heat exchanger inlet. This is a serious problem because it means the fuel temperature in the BD-1 test could be considerably (as much as $200^{\circ} \mathrm{C}$ ) below the temperature required to obtain adequate fission product release.

The second problem was that the depressurization filters isolation valves design used in the BD-0 test will not be that used in the BD-1 test. For the BD-1 test, the valves will be "backed up" with rupture diaphragms to ensure complete closure during the irradiation phase of the test. Test gas must flow through the filters only during the blowdown part of the test. Because of the design change without any information about the new design form the mockup test, GA and ORNL needed additional information to convince them that the rupture disks would not fail 
prematurely and would rupture when required. This information was provided by performance tests of the new depressurization filters isolation valves performed early in CY 1992.

The third problem had to do with the possibility that difficulties would be encountered in achieving the specified test gas chemistry for the BD-1 test within the time CENG was allowing (less than 2 weeks). The BD-1 test specification requires that the $\mathrm{H}_{2} \mathrm{O}$ concentration be kept below $6 \mathrm{ppmv}$ during the entire outgassing period. The restriction, which is applied because meaningful measurements on graphite burnoff are required to validate the design code for this parameter, is a severe restriction and may result in several weeks being needed to get to the test temperature.

Action plans to resolve these issues involving CENG, GA, and ORNL were developed. All issues were successfully resolved in the October 1991 COMÉDIE Technical Review Meeting.

Several meetings and audits to review this program were held during CY 1991. The program was reviewed and accepted, for the BD-0 test, by the CEA Quality and Safety Group (GQSE) in March 1991. An internal (CEA) audit of the test program was carried out in March 1991, with satisfactory results. A technical and programmatic review meeting was held from April 22-26, 1991. Several technical and contractual issues were reviewed and resolved by CENG, DOE, GA, and ORNL representatives. A new and revised list of agreements and commitments was issued. Complete reports on this meeting can be found in the following foreign trip reports: ORNL/FTR-3911, GA S\&R:016:GJC/DH:91, and ORNL/FTR-3909.

In summary, 1991 was a year of significant accomplishments culminating, in August, with the successful completion of the mockup, shakedown test, BD-0. The refurbishment of the COMÉDIE loop was completed, which was the end product of 3 years of work. The loop operating team was staffed up to the full compliment of three engineers and four technicians. Training for the BD0 and BD1 tests and documentation required for these tests were completed (for the BD1 test, some document revisions are in-process). The BD0 test was an excellent mockup and shakedown test; all of the test objectives were achieved and most of the test specifications were met. Those test specifications not met led to the identification and solution of three very important problems. The test also led to implementation of several system or operating changes that will be very helpful for the BD1 test. Because of two circulator failures, the start of the BD-0 and BD-1 tests slipped an additional 6 months.

After a very extensive safety review by the French nuclear safety authorities, which required considerable analysis and some minor, safety-related changes to the loop and its controls, the first 
irradiation test in the SILOE reactor pool was approved on August 27, 1992. The loop was installed in the SILOE pool on August 20,1992; outgassing of the loop was completed by the start of irradiation on September 3, 1992. The specified steady-state thermal and hydraulic conditions were achieved with $4 \mathrm{~d}$ after the start of irradiation. The steady-state test gas chemistry required nearly 2 weeks to be achieved. For the start of subsequent irradiation cycles, the required thermal and hydraulic conditions were achieved within 1 to $2 \mathrm{~h}$ and the required gas chemistry conditions within $1 \mathrm{~d}$.

The first irradiation cycle was completed on September 25, 1992, with the scheduled shutdown of SILOE for $6 \mathrm{~d}$. The second irradiation cycle of $21 \mathrm{~d}$ was completed on October 22, 1992. The irradiation phase of the BD-1 test ( 3 cycles) was completed on November 1992, for a total irradiation time of $64 \mathrm{~d}$. Between November 24 and 26, 1992, four blowdowns at shear ratios of $0.72,1.79,2.69$, and 5.58 , each through different blowdown filters, were successfully completed.

Since November 1992, the PIE work for the BD-1 test has been under way at CENG. This work involves the removal of the major components from the COMÉDIE test loop, PIE of the components at CENG, and transport of the fuel block (including the fuel compacts) and reflector blocks to ORNL for additional PIE work. Currently, the PIE work at CENG is three-fourths complete. The fuel and reflector blocks have not yet been shipped to ORNL.

\subsubsection{MIT Subcontract (DABLE Loop) - B. F. Myers, T. S. Kress, and O. M. Stansfield}

A high-pressure helium circulation loop (the DABLE Loop) is being designed and constructed at the MIT. Studies with the DABLE Loop will include the plate out and liftoff behavior of fission products and the effects of dust and moisture ingress on fission product release during tests at simulated accident conditions. The primary purpose of tests in the DABLE Loop facility is to provide basic knowledge for model development.

During CY 1990, the helium circulator was received from the vendor, and the design of the facility was completed. Shakedown tests and data acquisition tests will be conducted in CY 1990.

A visit to MIT was made by ORNL and GA representatives on April 8, 1990. The main parts of the discussion involved the institutional position of MIT as expressed by Professor Lidsky, the relevance of the test specification as written by GA, and the planned experiments on deposition and liftoff. In brief, Professor Lidsky takes the position that the test specifications provide guidance but are not binding if MIT workers consider alternate or additional tests or procedures more useful in characterization of fission product plateout on liftoff. Cooperation 
between ORNL and MIT regarding fission product sources, analysis or radioactive samples, and surface characterization studies was planned.

An important experimental procedure for the DABLE Loop is the insertion of a known amount of fission product into the circulating helium during a test. The first requirement will be for insertion of iodine with a radioactive tracer isotope of iodine. In order to assist MIT, a safe, efficient technique is being developed at ORNL to inject the iodine under controlled conditions. One method examined was to volatilize the iodine form a nitric acid solution containing a small amount of nitrite and adsorb the iodine on the inner surface of a piece of Alloy $800 \mathrm{H}$ tubing. The iodine would be subsequently desorbed by heating to $\sim 650^{\circ} \mathrm{C}$. These results indicated that the iodine could be desorbed at the lower temperature with modest helium flow rates. This procedure and other potential methods will be evaluated before the optimum technique is delivered to MIT for use in DABLE. 


\section{SECTION 3}

\section{GRAPHITES}

Graphite technology development was expanded considerably under the NP-MHTGR Program, and several tasks were added that were not previously funded by the commercial MHTGR Program. The vast majority of the graphite technology development activity reported here was supported by the NP-MHTGR Program but can be considered as generic to both MHTGR Programs.

Significant progress has been made since MHTGR graphite technology work was last reported. The extent of the $\mathrm{H}-451$ design data base has been dramatically increased, particularly with respect to mechanical, fracture, and thermal physical properties. Our understanding of graphite oxidation mechanisms and kinetics has been advanced. Significantly, the first biaxial strength tests on H-451 graphite have been performed. Prototype high-temperature control rods (C/C composite material) have been developed. Our international collaborations have continued to be fruitful and beneficial to the U.S. DOE MHTGR Program. Under the auspices of the NPMHTGR Program, the graphite technology program was subjected to a "peer review. "54 This chapter reports progress in the graphite technology development program.

\subsection{IRRADIATION BEHAVIOR - T. D. Burchell, D. F. Pedraza, J M Robbins, and} J. P. Strizak

Several irradiation experiments have been performed since the last MHTGR summary report was published. The irradiation conditions, purpose, and status of these experiments are summarized in Table 3-1.

\subsubsection{Irradiation Capsule HTK-7}

HTK-7 was a high-fluence "turn-around" experiment, i.e., irradiation continued to a point sufficient to cause the graphite to begin irradiation-induced volume expansion. Two graphites of interest to the U.S. program were included in HTK-7, grades $\mathrm{H}-451$ and 2020 . Additional graphites were included under our ongoing international collaborations, and they are discussed in Sect. 3.8 of this document.

Preirradiation data for HTK-7 specimens are reported elsewhere. ${ }^{55}$ HTK-7 completed irradiation on January 18, 1992, having been installed for 16 cycles in the HFIR and having 
Table 3-1

SUMMARY OF GRAPHTE IRRADIATION EXPERIMENTS DURING PERIOD 1989 ONWARD

\begin{tabular}{|l|c|c|l|l|}
\hline $\begin{array}{c}\text { Capsule } \\
\text { designation }\end{array}$ & $\begin{array}{c}\text { Irradiation } \\
\text { temperature } \\
\left({ }^{\circ} \mathrm{C}\right)\end{array}$ & $\begin{array}{c}\text { Peak fluence } 10^{26} \mathrm{n} / \mathrm{m}^{2} \\
\text { [E }>50 \mathrm{keV}]\end{array}$ & \multicolumn{1}{|c|}{ Purpose of experiment } & \multicolumn{1}{|c|}{ Status } \\
\hline HTN-1 & 900 & 0.975 & $\begin{array}{l}\text { To examine a series of graphites } \\
\text { manufactured from various cokes } \\
\text { and identify a replacement coke } \\
\text { for continued production of grade } \\
\text { H-451 graphite }\end{array}$ & $\begin{array}{l}\text { Irradiation complete. PIE data } \\
\text { reported in ORNL/NPR-91/35 } \\
\text { (December 1991). }\end{array}$ \\
\hline HTN-2 & 600 & 3.83 & Same as HTN-1 & $\begin{array}{l}\text { Irradiation complete. PIE } \\
\text { partially completed. Report } \\
\text { anticipated September 1993. }\end{array}$ \\
\hline HTN-3 & 900 & 2.18 & Same as HTN-1 & $\begin{array}{l}\text { Irradiation complete. PIE } \\
\text { partially completed. Report } \\
\text { anticipated September 1993. }\end{array}$ \\
\hline HTN-4 & 900 & 2.2 & $\begin{array}{l}\text { To assess behavior of alternate } \\
\text { MHTGR core graphites }\end{array}$ & $\begin{array}{l}\text { Specimens machined and } \\
\text { preirradiation testing } \\
\text { completed. }\end{array}$ \\
\hline HTN-5 & 600 & 3.8 & Same as HTN-4 & $\begin{array}{l}\text { Specimens machined and } \\
\text { preirradiation testing } \\
\text { completed. }\end{array}$ \\
\hline HTK-7 & 600 & 3.8 & $\begin{array}{l}\text { Graphite lifetime experiment } \\
\text { (international collaboration) }\end{array}$ & $\begin{array}{l}\text { Irradiation complete. PIE data } \\
\text { reported (DOE-HTGR-88511) } \\
\text { [ORNL/TM-11666] September } \\
\text { 1990. Interim PIE letter report } \\
\text { published October 1992. }\end{array}$ \\
\hline
\end{tabular}


attained a peak fluence of $3.8 \times 10^{26} \mathrm{n} / \mathrm{cm}^{2}[\mathrm{E}>50 \mathrm{keV}]$ or $2.89 \times 10^{26} \mathrm{n} / \mathrm{cm}^{2}[\mathrm{E}>18 \mathrm{keV}]$ at an irradiation temperature of $600^{\circ} \mathrm{C}$. Irradiation-induced dimensional changes of the graphite specimens included in HTK-7 have been reported previously. ${ }^{56}$ Figure 3-1 summarizes the dimensional change data for grades H-451 and 2020. H-451 showed very anisotropic dimensional changes, the minimum shrinkage being approximately twice as large in the specimen length (axial or with grain) as the specimen diameter (radial or against-grain) directions. This degree of anisotropy is expected because of preferential alignment of the filler coke particles during extrusion. Both $\mathrm{H}-451$ data sets show the turnaround phenomena. Fast neutrons cause the displacement of carbon atoms from their equilibrium lattice positions. This causes a shrinkage in the crystal $\langle\mathrm{a}\rangle$ directions (parallel to basal planes) and a growth in the crystal $\langle\mathrm{c}\rangle$ direction (perpendicular to the basal planes). During manufacture, thermal cracks form between the basal planes. Consequently, the $\langle c\rangle$ axis growth is initially accommodated, and the graphite's behavior is dominated by the $\langle a\rangle$ direction shrinkage. In an extruded graphite, there is a preferential alignment of $\langle a\rangle$ directions on the extrusion axis. Thus, shrinkage occurs more rapidly in the axial direction. With increasing fluence, a greater amount of the basal plane thermal cracks are closed due to $\langle c\rangle$ direction swelling, and the $\langle c\rangle$ axis expansion becomes apparent in the bulk dimensional changes. Hence, the graphite "turns around" in expansion. Turnaround occurs more rapidly in the perpendicular-to-extrusion direction because $\langle c\rangle$ axis growth is predominantly in the radial direction. Consequently, the maximum amount of shrinkage is less in the perpendicular-to-extrusion (against-grain) direction of an extruded graphite.

For $\mathrm{H}-451$, the maximum shrinkage in the with-grain direction was $\sim 4.25 \%$ at a fluence of $-2.5 \times 10^{26} \mathrm{n} / \mathrm{m}^{2}[\mathrm{E}>0.18 \mathrm{MeV}]$ or $-3.25 \times 10^{26} \mathrm{n} / \mathrm{m}^{2}[\mathrm{E}>50 \mathrm{keV}]$. This compares favorably with data from a previous turnaround experiment.

Figure 3-1 also shows the irradiation-induced dimensional changes of 2020 graphite. Grade 2020 is more isotropic in its dimensional changes compared to $\mathrm{H}-451$, yet still displays some anisotropy at the very high fluences reported here. The behavior of 2020 is fairly typical of the fine-grained isotropic graphites in that the maximum shrinkage is small, and the turnaround occurs at lower fluences compared to the coarser grained, extruded graphites such as $\mathbf{H}-451$.

\subsubsection{Irradiation Capsule HTN-1}

Capsule HTN-1 was the first in a series of three irradiation capsules whose purpose was to examine the behavior of several graphites, manufactured with different isotropic petroleum cokes, and irradiated to determine their suitability as replacements for grade $\mathrm{H}-451$ graphite, the current 
ORNL-DWG 93-11953

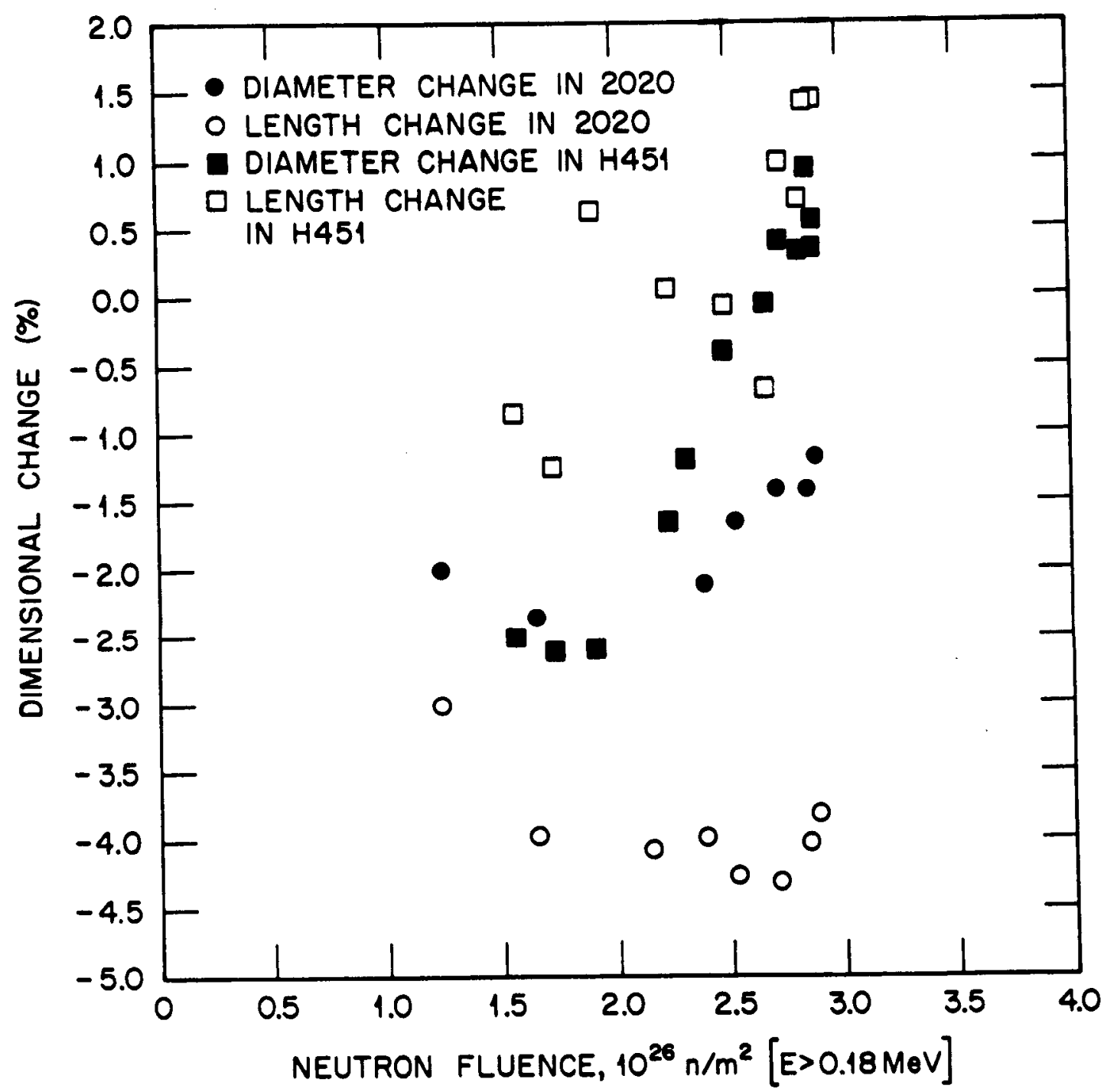

Figure 3-1.

IRRADIATION INDUCED DIMENSIONAL CHANGES

IN GRADES H-451 AND 2020 GRAPHICS

IRRADIATED AT $\sim 600^{\circ} \mathrm{C}$ IN

CAPSULE HTK-7. 
reference material for the replaceable core components of the NP-MHTGR and commercial MHTGR. Full accounts of the preirradiation examination and postirradiation of HTN-1 specimens are reported elsewhere. ${ }^{57,58}$ HTN-1 was installed in the HFIR for four operating cycles (294 to 297) and accumulated a peak dose of $9.75 \times 10^{25} \mathrm{n} / \mathrm{m}^{2}[\mathrm{E}>50 \mathrm{keV}]$ or $7.41 \times$ $10^{25} \mathrm{n} / \mathrm{m}^{2}[\mathrm{E}>0.18 \mathrm{MeV}]$. Analysis of the capsule temperature monitors indicated the irradiation temperature was $-800^{\circ} \mathrm{C}$. The HTN series of irradiations contains specimens of six graphites: production H-451 specimens from billet number 58/394; a UCAR Carbon Company grade, TS-1507; and specimens from pilot-scale graphite billets ( 6 in. diam by 6 in. length) manufactured from the existing grade H-451 coke (referred to as FSV or C-coke) and three candidate replacement cokes designated A-, D-, and G-coke.

PIE of the HTN-1 specimens included volume and dimensional changes, elastic constants, strength, electrical resistivity, and thermal conductivity (room temperature). Assessment of the volume and dimensional change data showed differences between the behavior of the pilot-scale billets and the production-size $\mathrm{H}-451$ made from the same C-coke blend. A comparison of the behavior of the candidate coke graphites showed that D- and G-coke are promising candidates for replacing FSV coke in the production of $\mathrm{H}-451$ graphite. The effect of irradiation on the elastic constants was largely as expected. However, the data for C-coke, which indicated a decreasing modulus with increasing fluence, were considered anomalous.

The strength of the pilot-scale C-coke graphite showed essentially the same irradiationinduced strength changes as the production H-451. Moreover, the behavior of A-, D-, and G-coke graphites was similar to C-coke graphite, except that A- and G-coke graphites exhibited a lower rate of strength increase. The irradiation responses of the production graphites $\mathrm{H}-451$ and TS-1507 were quite different. TS-1507 was significantly weaker than H-451 and did not exhibit further increases in strength after the initial rapid rise at low fluence. This behavior was also observed for TS-1507 elastic moduli.

Thermal conductivity and electrical resistivity behavior for the production $\mathrm{H}-451$ and pilotscale graphites were comparable. TS-1507, however, showed markedly different behavior. This was attributed to the more isotropic nature of grade TS-1507. These observations, and the lower density of TS-1507 compared with H-451, suggest that it will not be a candidate replacement for $\mathrm{H}-451$. 


\subsubsection{Irradiation Capsule HTN-2}

HTN-2 was the second irradiation experiment in our series of coke examination irradiations. Its layout was similar to HTN-1, and it contained specimens of the same graphites [H-451, TS1507, A-, C- (FSV), D-, and G-coke graphites] as HTN-1. Preirradiation examination of HTN-2 specimens is reported elsewhere. ${ }^{57}$ HTN-2 was installed in the HFIR reactor for 16 cycles (294 to 309) and completed irradiation on August 1, 1992, having accumulated a peak neutron irradiation dose of $3.83 \times 10^{26} \mathrm{n} / \mathrm{m}^{2}[\mathrm{E}>50 \mathrm{keV}]$ or $2.91 \times 10^{26} \mathrm{n} / \mathrm{m}^{2}[\mathrm{E}>0.18 \mathrm{MeV}]$ at a design temperature of $600^{\circ} \mathrm{C}$.

Assessment of the postirradiation data from capsule HTN-2 is in progress at the time of writing this report. However, HTN-2 dimensional change data were available and are summarized in Figures 3-2 through 3-7. HTN-1 dimensional change data are also shown in Figures 3-2 through 3-7 for comparison, although it must be noted that HTN-2 specimens were irradiated at a lower temperature than the HTN-1 specimens $\left(600\right.$ vs $\left.800^{\circ} \mathrm{C}\right)$.

The dimensional change data for $\mathrm{H}-451$ (Figure 3-2) are in good agreement with previously reported data ${ }^{56}$ for $600^{\circ} \mathrm{C}$ irradiations. The minimum in the axial, or with-grain, dimensional change curve is $--4.0 \%$ at a fluence of $3 \times 10^{22} \mathrm{n} / \mathrm{m}^{2}$ [E $\left.>50 \mathrm{keV}\right]$. As previously noted, TS-1507 should not be considered as a replacement graphite for $\mathrm{H}-451$ because of its low density. However, the two graphites identified from the HTN-1 data, ${ }^{58}$ namely D- and G-coke graphite, are strong candidates on the basis of the HTN-2 dimensional change data (Figures 3-6 and 3-7, respectively). Both graphites show minima in their dimensional change curves at $\sim 3 \times$ $10^{22} \mathrm{n} / \mathrm{cm}^{2}[\mathrm{E}>50 \mathrm{keV}]$ (axial or with-grain direction) of $\sim-4.0 \%$. A comparison of the D- and G-coke graphite dimensional change data from HTN-2 indicates that G-coke graphite is slightly more isotropic than D-coke graphite. All of the PIE data from HTN-2 (and HTN-3) specimens will be reported in the PIE report currently in preparation. ${ }^{59}$

\subsubsection{Capsule HTN-3}

HTN-3 was the final capsule in the coke examinations irradiation series. It contained specimens of the same six graphites as HTN-1 and -2. The capsule was installed in the HFIR for a total of 9 cycles (304 to 312) completing irradiation on November 14, 1992, having attained a peak capsule dose of $2.18 \times 10^{26} \mathrm{n} / \mathrm{m}^{2}$ [E $>50 \mathrm{keV}$ ] at a design temperature of $900^{\circ} \mathrm{C}$.

The irradiation-induced dimensional change data for the graphites in capsule HTN-3 are shown in Figures 3-8 through 3-13. The H-451 data are in reasonable agreement with previous data. ${ }^{56}$ The TS- 1507 data indicate that the graphite behaves reasonably isotropically, but its low 
ORNL-DWG 93-9577

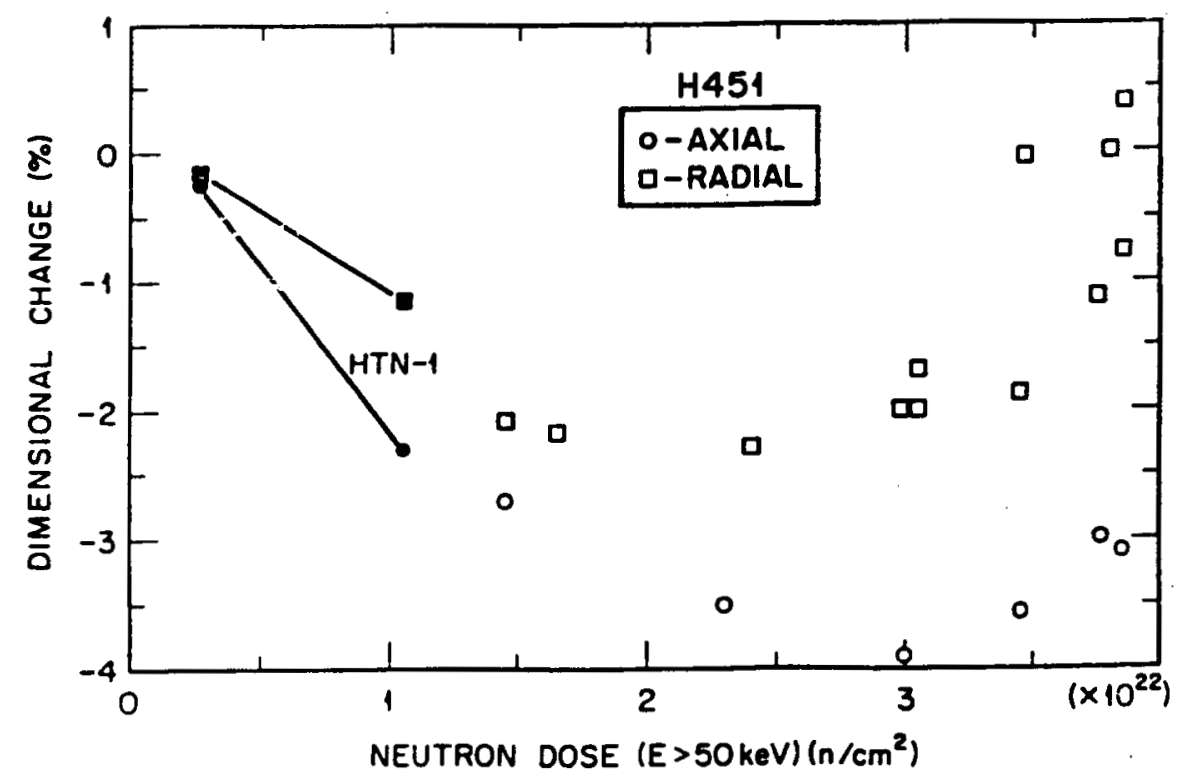

Figure 3-2.

IRRADIATION-INDUCED DIMENSIONAL CHANGES IN GRADE H-451 GRAPHITE IRRADIATED AT $\sim 600^{\circ} \mathrm{C}$ IN HFIR CAPSULE HTN-2.

ORNL-DWG 93-9578

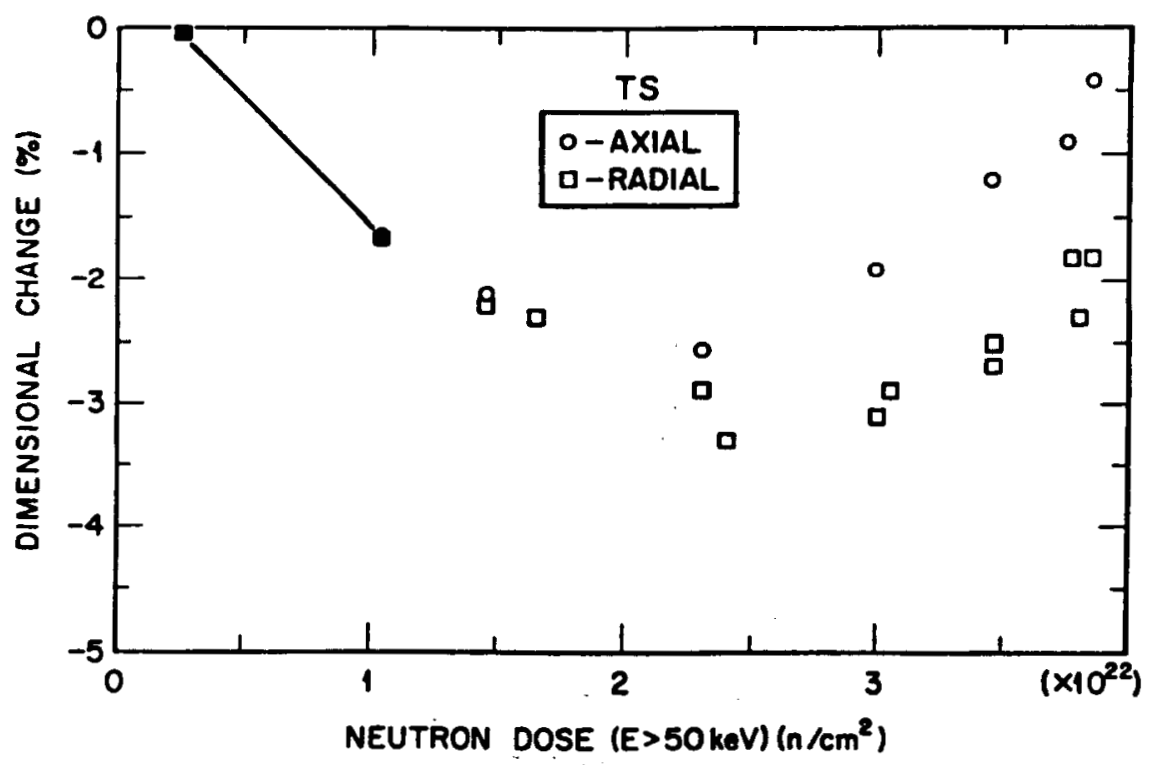

Figure 3-3.

IRRADIATION-INDUCED DIMENSIONAL CHANGES IN

GRADE TS-1507 GRAPHITE IRRADIATED AT $\sim 600^{\circ} \mathrm{C}$ IN HFIR CAPSULE HTN-2. 
ORNL-DWG 93-10099

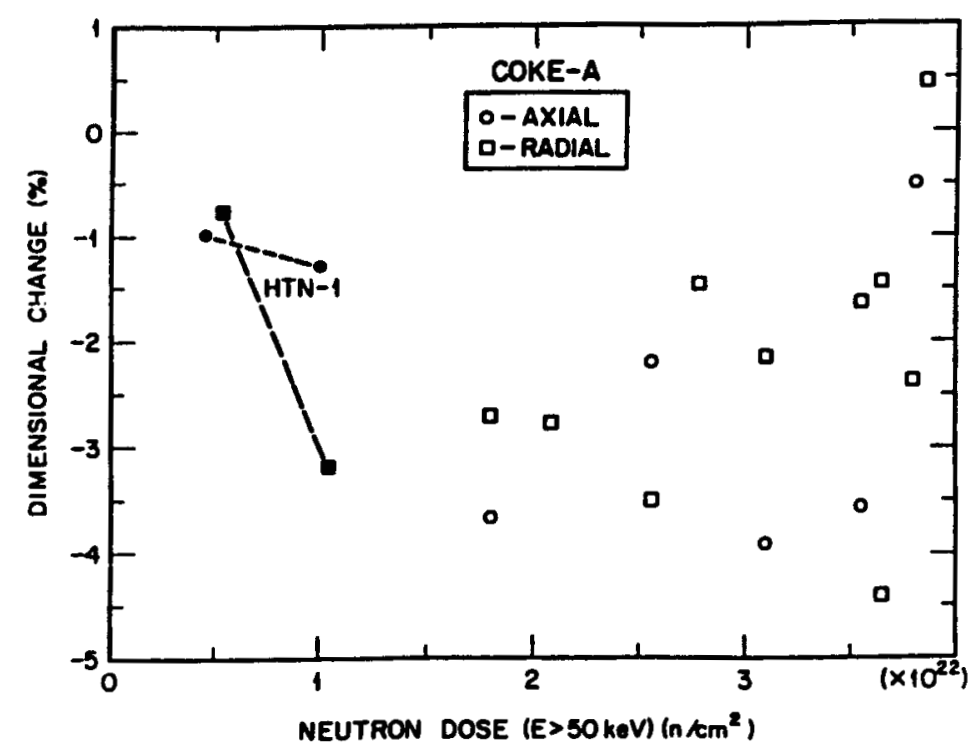

Figure 3-4.

IRRADIATION-INDUCED DIMENSIONAL CHANGES

IN A-COKE GRAPHITE IRRADIATED AT $\sim 600^{\circ} \mathrm{C}$ IN HFIR CAPSULE HTN-2.

ORNL-DWG 93-10100

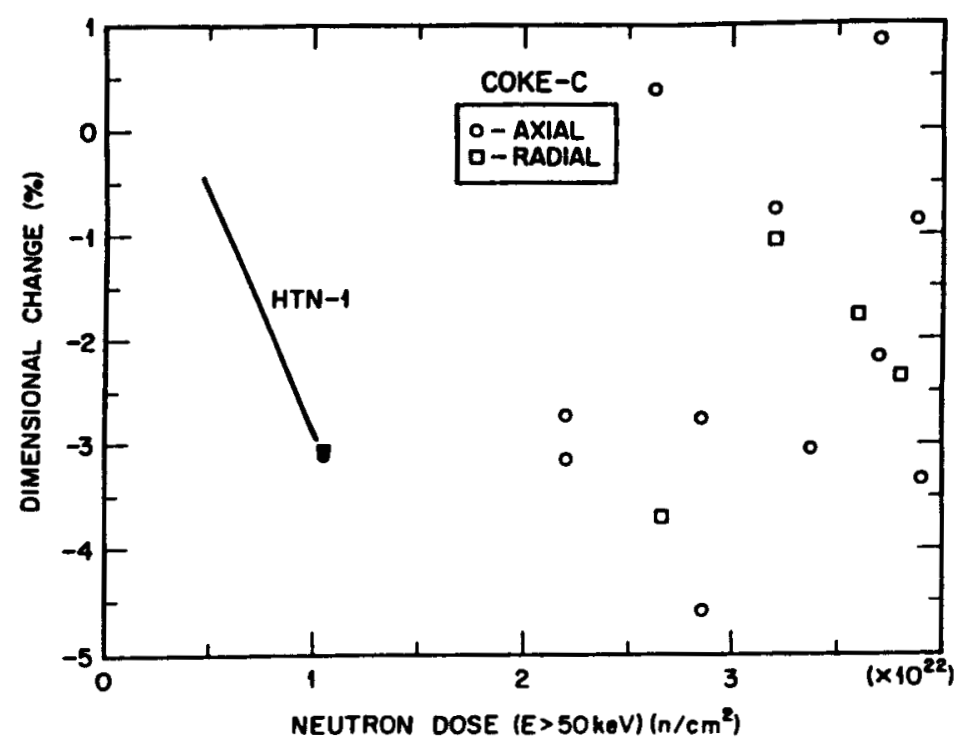

Figure 3-5.

IRRADIATION-INDUCED DIMENSIONAL CHANGES IN C-COKE (FSV) GRAPHITE IRRADIATED AT $\sim 600^{\circ} \mathrm{C}$ IN HFIR CAPSULE HTN-2. 
ORNL-DWG 93-9589

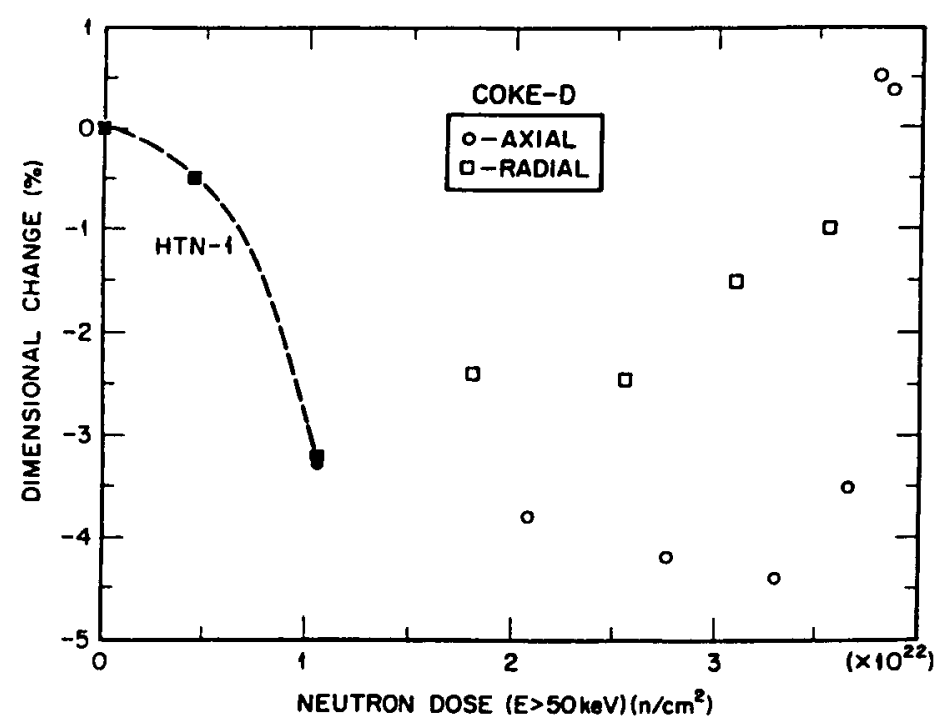

Figure 3-6.

IRRADIATION-INDUCED DIMENSIONAL CHANGES

IN D-COKE GRAPHITE IRRADIATED AT $\sim 600^{\circ} \mathrm{C}$ IN HFIR CAPSULE HTN-2.

ORNL-DWG 93-9590

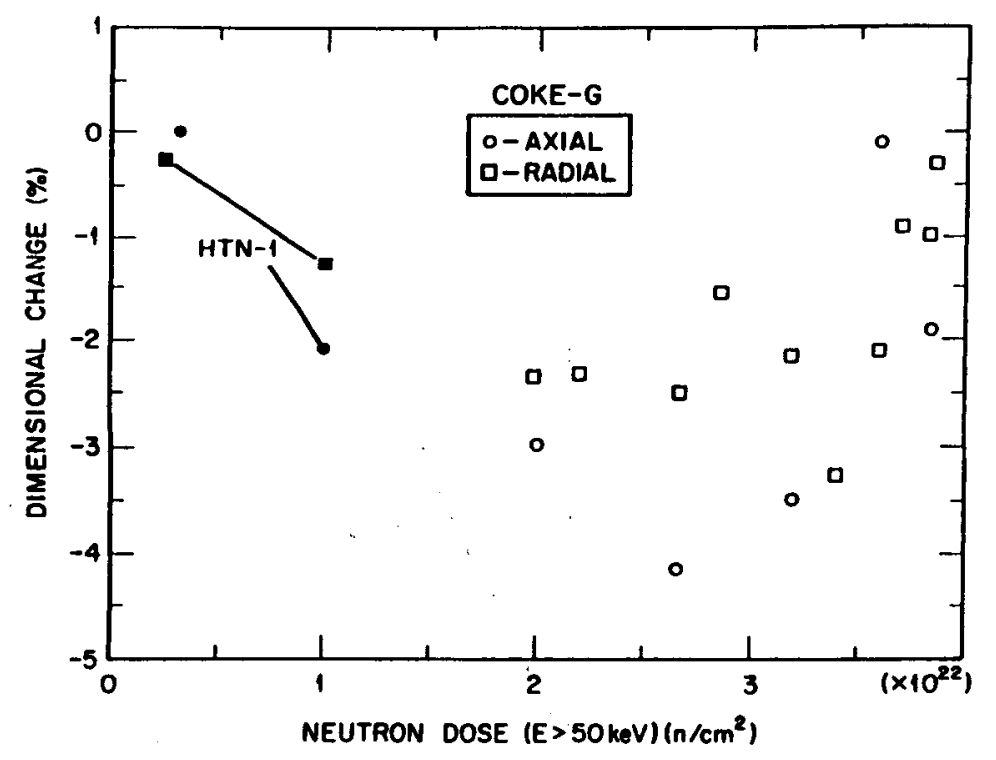

Figure 3-7.

IRRADIATION-INDUCED DIMENSIONAL CHANGES IN G-COKE GRAPHITE IRRADIATED AT $\sim 600^{\circ} \mathrm{C}$ IN HFIR CAPSULE HTN-2 CAPSULE HTK-7. 
ORNL-DWG 93-12000

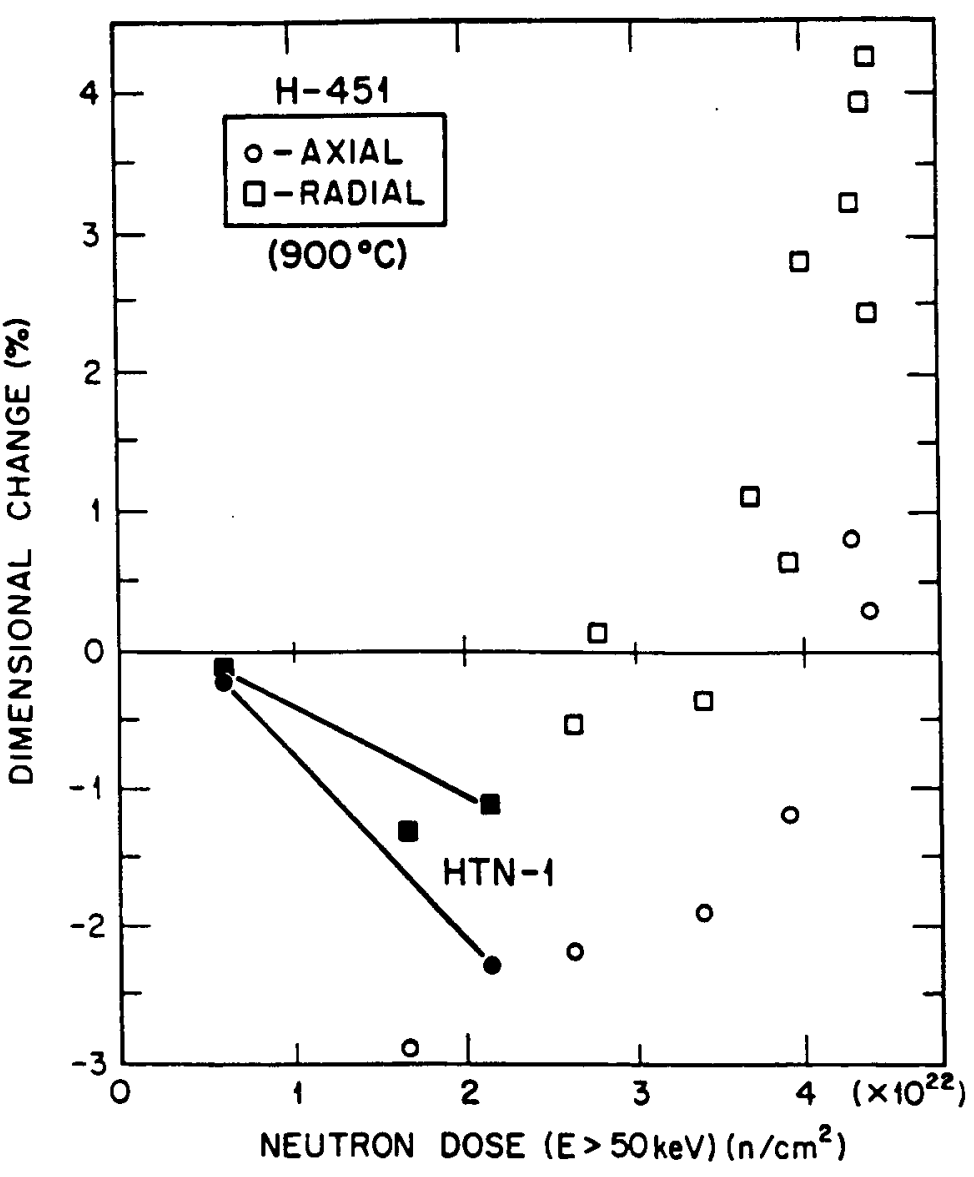

Figure 3-8.

IRRADIATION-INDUCED DIMENSIONAL CHANGES IN GRADE H-451 GRAPHITE IRRADIATED AT $\sim 900^{\circ} \mathrm{C}$ IN HFIR CAPSULE HTN-3.

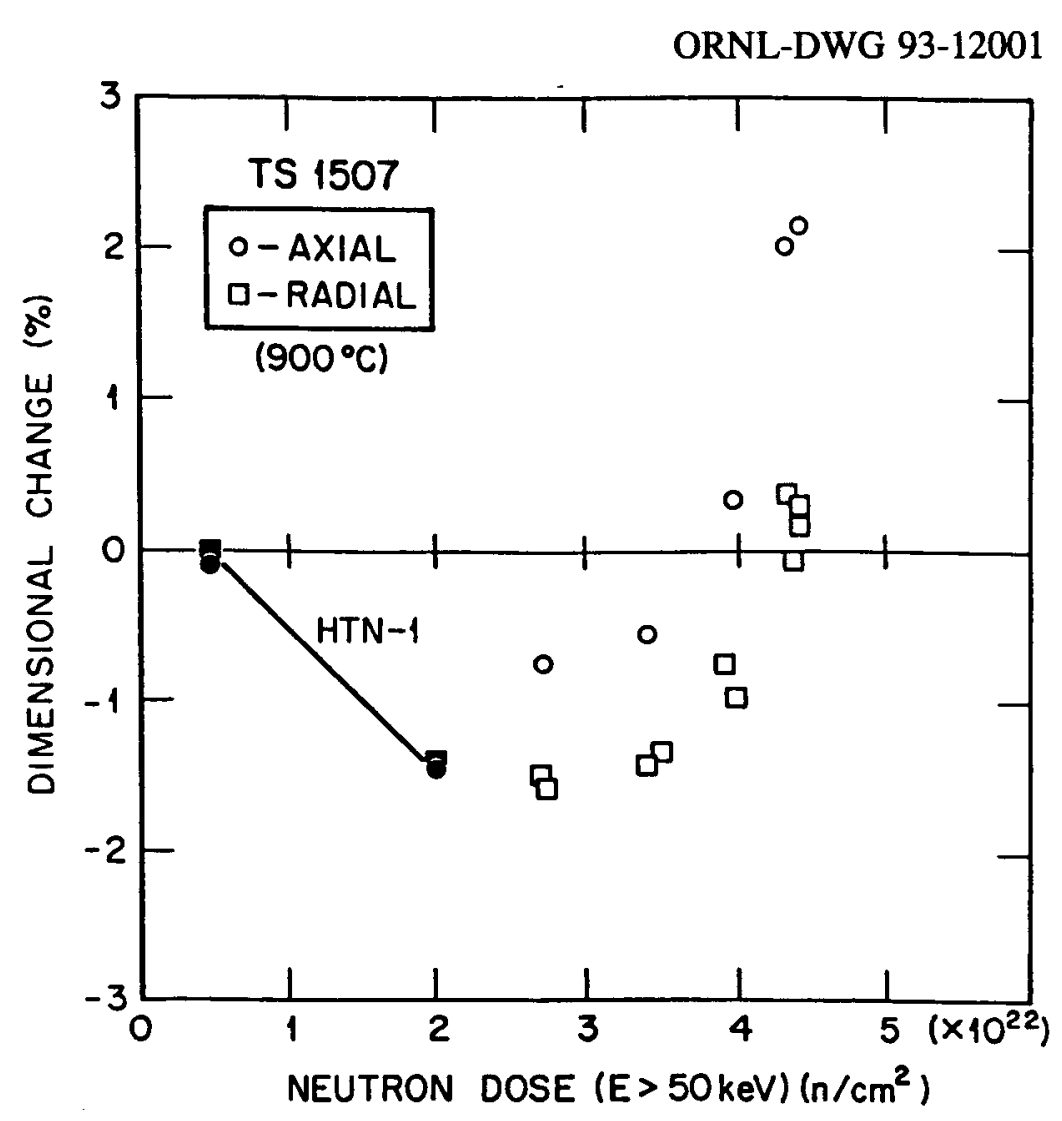

Figure 3-9.

IRRADIATION-INDUCED DIMENSIONAL CHANGES IN GRADE TS-1507 GRAPHITE IRRADIATED AT $\sim 900^{\circ} \mathrm{C}$ IN HFIR CAPSULE HTN-3. 
ORNL-DWG 93-12002

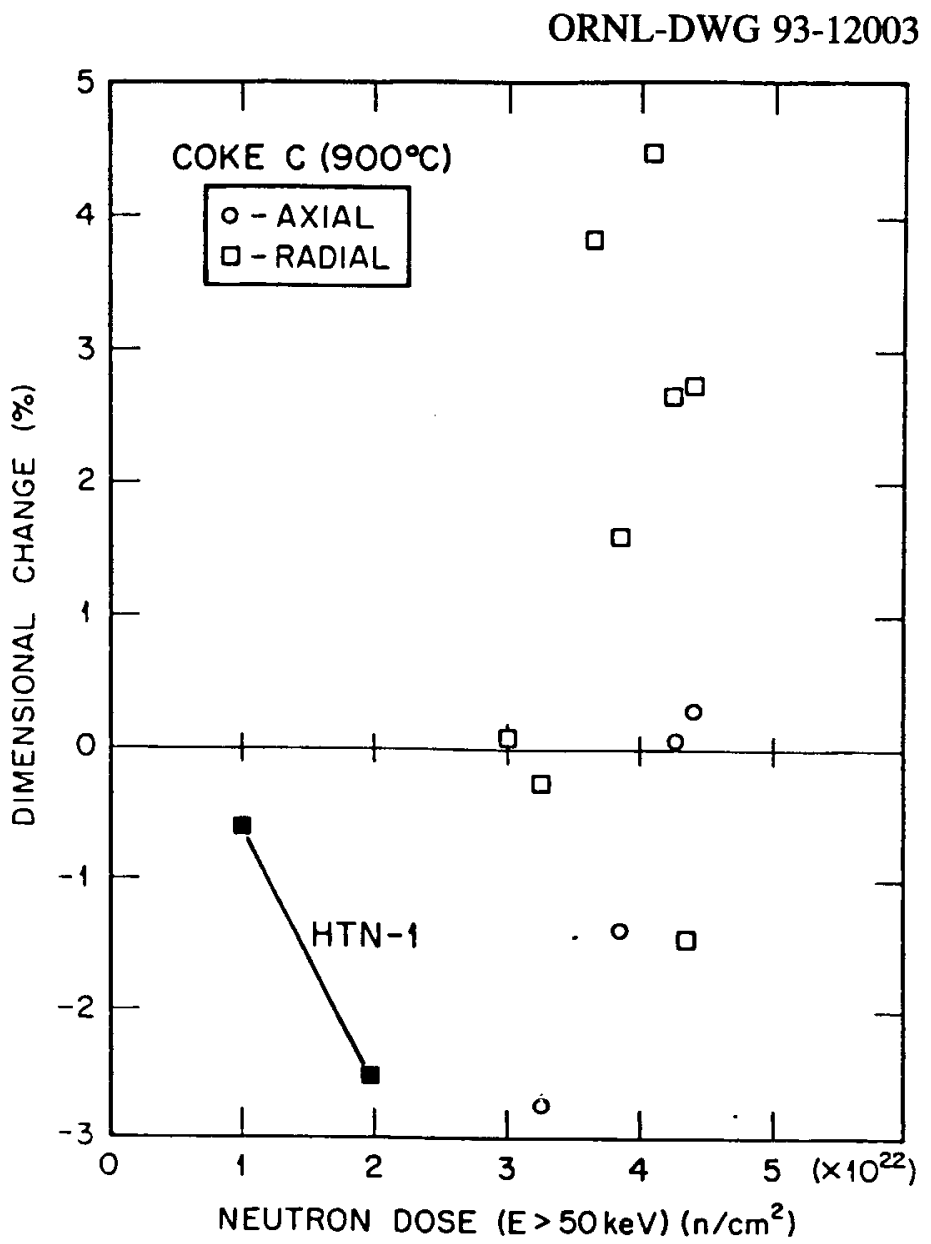

Figure 3-10.

Figure 3-11.

IRRADIATION-INDUCED DIMENSIONAL CHANGES

IN A-COKE GRAPHITE IRRADIATED AT $\sim 900^{\circ} \mathrm{C}$ IN HFIR CAPSULE HTN-3.

IRRADIATION-INDUCED DIMENSIONAL CHANGES IN C-COKE GRAPHITE IRRADIATED AT $\sim 900^{\circ} \mathrm{C}$ IN HFIR CAPSULE HTN-3. 
ORNL-DWG 93-12004

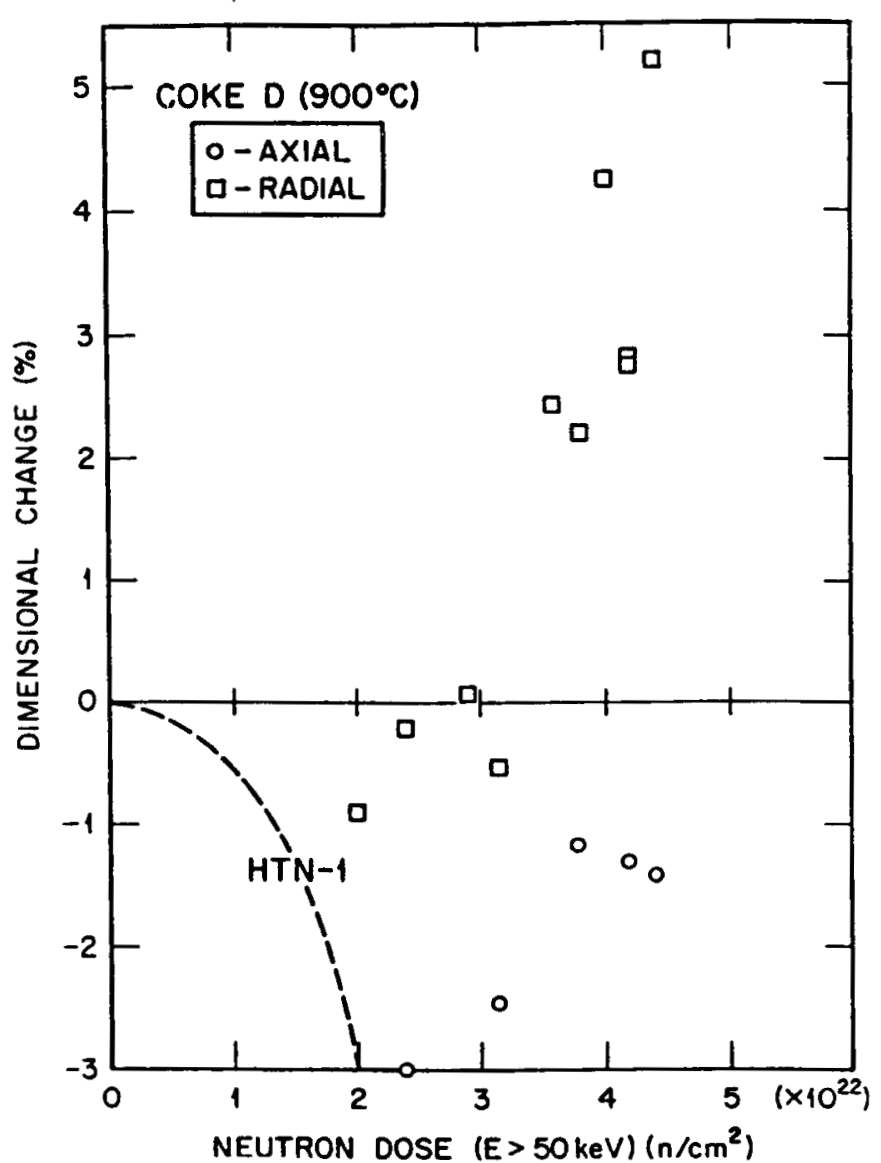

Figure 3-12.

IRRADIATION-INDUCED DIMENSIONAL CHANGES

IN D-COKE GRAPHITE IRRADIATED AT $\sim 900^{\circ} \mathrm{C}$ IN HFIR CAPSULE HTN-3.

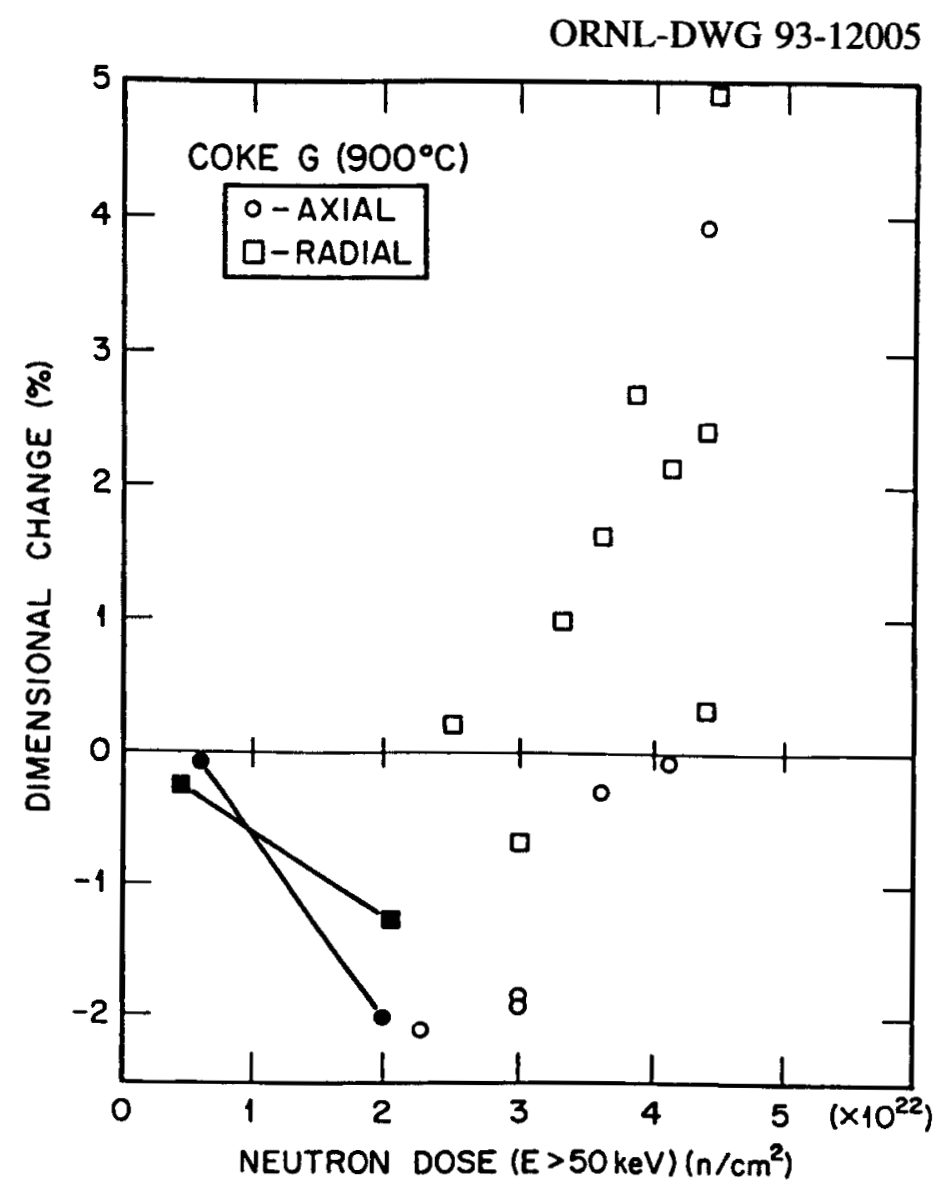

Figure 3-13.

IRRADIATION-INDUCED DIMENSIONAL CHANGES IN G-COKE GRAPHITE IRRADIATED AT $\sim 900^{\circ} \mathrm{C}$ IN HFIR CAPSULE HTN-3. 
density excludes it from use in the NP-MHTGR. D- and G-coke graphites were the two strongest candidates based upon data from HTN-1 and -2 . The data from HTN-3 support this finding.

However, D-coke exhibits a larger dimensional shrinkage than does G-coke, suggesting that G-coke would be the best candidate coke to replace the coke previously used in the production of H-451 graphite for the FSVRs.

\subsubsection{Capsules HTN-4 and -5}

HFIR irradiation capsules HTN-4 and -5 were planned to screen a set of graphites from alternate vendors for preliminary acceptability as $\mathrm{H}-451$ graphite substitutes. The irradiations were planned in response to the DOE Office of New Production Reactors (ONPR) and Combustion Engineering General Atomic's (CEGA's) alternate graphite strategy. The capsules were to have been turnaround experiments, HTN-4 being a $900^{\circ} \mathrm{C}$ irradiation and HTN-5 a $600^{\circ} \mathrm{C}$ irradiation. Regrettably, the closure of the NP-MHTGR Program led to the decision not to complete the assembly of these capsules. However, preparation of the specimens and their preirradiation examination were completed. The specimens will be archived for possible future use.

Capsules HTN-4 and -5 contained seven graphites as summarized in Table 3-2.

Preirradiation examination included nondestructive examination, specimen dimensions, mass,

Table 3-2

\section{HFIR CAPSULES HTN-4 AND -5 CONTENTS}

\begin{tabular}{|l|l|c|c|}
\hline \multicolumn{1}{|c|}{ Graphite grade } & \multicolumn{1}{|c|}{ Supplier } & $\begin{array}{c}\text { Number of } \\
\text { specimens per } \\
\text { capsule }\end{array}$ & $\begin{array}{c}\text { Specimen } \\
\text { designation code }\end{array}$ \\
\hline \hline H-451 (Production) & Sigri-Great Lakes Carbon & 8 & H \\
\hline H-451 (C-coke) & Sigri-Great Lakes Carbon & 10 & C \\
\hline S-1840 & $\begin{array}{l}\text { Carbon-Graphite Group, } \\
\text { Inc. }\end{array}$ & 10 & S \\
\hline EX-50-1 & Poco Graphite, Inc. & 6 & P \\
\hline TS-5102 & UCAR Carbon Co. & 10 & T \\
\hline TS-5099 & UCAR Carbon Co. & 10 & U \\
\hline TS-5116 & UCAR Carbon Co. & 10 & X \\
\hline
\end{tabular}


moduli, strength, electrical resistivity, and thermal conductivity. A full account of the preirradiation examination of HTN-4 and -5 specimens can be found elsewhere. ${ }^{60}$

\subsubsection{Fundamental Irradiation Studies}

In addition to the "engineering" studies of neutron irradiation, a fundamental study of the mechanisms of neutron irradiation damage in graphites has been ongoing. Techniques employed have included electron and ion beam irradiation, and analysis of the irradiation displacement damage has been carried out using a range of techniques including scanning and transmission electron microscopy (TEMs), high-resolution transmission electron microscopy (HRTEM), electron energy loss spectroscopy (EELS), Raman spectroscopy, XRD and electron diffraction analysis, and scanning-tunnelling microscopy (STM). The results of this work have been reported elsewhere. ${ }^{61-68}$

The fundamental graphite irradiation work performed for the NP-MHTGR Program was directed toward two major goals. First, a computer model was developed to simulate the behavior of self-interstitials. ${ }^{61}$ Experimental data were required to underpin our modelling efforts. Because of the layer structure of graphite, atomistic simulations of neutron damage can be performed using a large, parallelepipedic supercell containing a few layers. In particular, interstitial clustering was studied using a supercell that contained only two basal planes. Frenkel pairs were randomly produced. Interstitials were placed on sites between the crystal planes while vacancies were distributed in the two crystal planes. The size of the computational cell was 20,000 atoms, and periodic boundary conditions were used in two dimensions. Vacancies were assumed immobile whereas interstitials were given a certain degree of mobility. Two point defect sinks were considered, direct recombination of Frenkel pairs and interstitial clustering. The clusters were assumed to be mobile, up to a certain size, where they are assumed to become loop nuclei. Clusters could shrink by emission of singly bonded interstitials or by recombination of a peripheral interstitial with a neighboring vacancy. The conditions under which clustering occurs were determined, and it was shown that the cluster size population gradually shifts toward the largest size cluster.

Our second goal was to establish that "amorphization" did not occur in graphite during neutron irradiation. Studies performed in $\operatorname{Japan}^{69}$ had suggested that the graphite crystal structure was destroyed (amorphitized) by neutron irradiation. Much of the evidence was based upon Raman spectroscopy data taken from irradiated graphites. However, the argument of amorphization was countered by $\mathrm{Kelly}^{70}$ for the case of neutron irradiation in fission reactors on 
the basis of the highly anisotropic dimensional changes experienced by irradiated graphite. Our fundamental research performed using electron-irradiated pyrolytic graphite and HRTEM and EELS showed that the graphite c-axis periodicity was maintained, but long range ordering was destroyed. ${ }^{64}$

\subsubsection{Irradiation Creep Studies}

An assessment of graphite irradiation creep data from past experiments, capsules OC 3 and 4 (ref. 71), was performed by Prof. Brian Kelly under subcontract at ORNL. The data were analyzed and a new graphite irradiation creep model proposed based upon a previous United Kingdom graphite irradiation creep model. The new graphite irradiation creep behavior model is reported in detail elsewhere. ${ }^{2-74}$ Moreover, considerable progress has been made in the development of a graphite irradiation model that relates graphite structural changes (irradiation induced) to property changes. ${ }^{75}$

\subsection{MECHANICAL PROPERTIES - J. P. Strizak}

\subsubsection{Tensile Properties}

An in-depth experimental program has been under way for characterizing the roomtemperature tensile properties of $\mathrm{H}-451$ graphite to support the design of NP-MHTGR graphite reactor core components, including fuel elements, replaceable reflector elements, and core support posts. The status of the experimental effort is summarized in Table 3-3. Over 1,700 tensile tests have been conducted on specimens from 7 billets of $\mathrm{H}-451$ graphite. Analysis of the data is now under way to evaluate the effects of specimen size; specimen orientation and spatial location within the billet; and variabilities from billet to billet, class to class, and lot to lot. Initial observations are summarized below.

The billet selected for the initial work on spatial and stress volume (specimen size) effects was number 58-293. Four specimen sizes having gauge diameters of $6.35,9.53,15.88$, and $25.40 \mathrm{~mm}$ were machined such that the specimens were axially aligned with the longitudinal axis of the graphite billet. Schematic diagrams summarizing the specimen sampling plan are shown in Figures 3-14 and 3-15. The locations of the different size specimens taken from the billet are indicated in the sampling plan (Figure 3-14) by the relative sizes.

The results of the tensile tests on billet 58-293 illustrate that grade H-451 nuclear graphite exhibits a dependence on location within the billet. Generally, the strength near the edge of the 
Table 3-3

H-451 TENSILE TESTING EFFORT

\begin{tabular}{|c|c|c|l|}
\hline $\begin{array}{c}\text { Billet } \\
\text { number }\end{array}$ & $\begin{array}{c}\text { Lot } \\
\text { number }\end{array}$ & $\begin{array}{c}\text { Strength } \\
\text { class }\end{array}$ & \multicolumn{1}{|c|}{ Comments } \\
\hline \hline $58-293$ & 58 & 2 & $\begin{array}{l}\text { Specimen sizes 6.35 to 25.4mm diam; all } \\
\text { axially oriented. Assess spatial variabilicy } \\
\text { and volume effect. Tests completed (380). }\end{array}$ \\
\hline $58-357$ & 58 & 1 & $\begin{array}{l}\text { Axial, radial, and tangential orientations } \\
\text { throughout billet to assess orientation and } \\
\text { spatial variability. Specimens from center } \\
\text { slab to assess billet strength classification } \\
\text { procedure. Tests completed (228). }\end{array}$ \\
\hline $58-29$ & 58 & 2 & $\begin{array}{l}\text { Assess orientation, spatial variability and } \\
\text { class-to-class effects, and strength } \\
\text { classification. Tests completed (228). }\end{array}$ \\
\hline $58-892$ & 58 & 3 & $\begin{array}{l}\text { Assess orientation, spatial variability and } \\
\text { class-to-class effects, and strength } \\
\text { classification. Tests completed (228). }\end{array}$ \\
\hline $58-18$ & 58 & 4 & $\begin{array}{l}\text { Assess orientation, spatial variability and } \\
\text { class-to-class effects, and strength } \\
\text { classification. Tests completed (228). }\end{array}$ \\
\hline $472-16$ & 472 & 1 & $\begin{array}{l}\text { Assess orientation, spatial variability and } \\
\text { lot-to-lot effects, and strength classification. } \\
\text { Tests completed (228). }\end{array}$ \\
\hline $44-72$ & 474 & 1 & $\begin{array}{l}\text { Assess orientation, spatial variability and } \\
\text { lot-to-lot effects, and strength classification. } \\
\text { Tests completed (228). }\end{array}$ \\
\hline
\end{tabular}



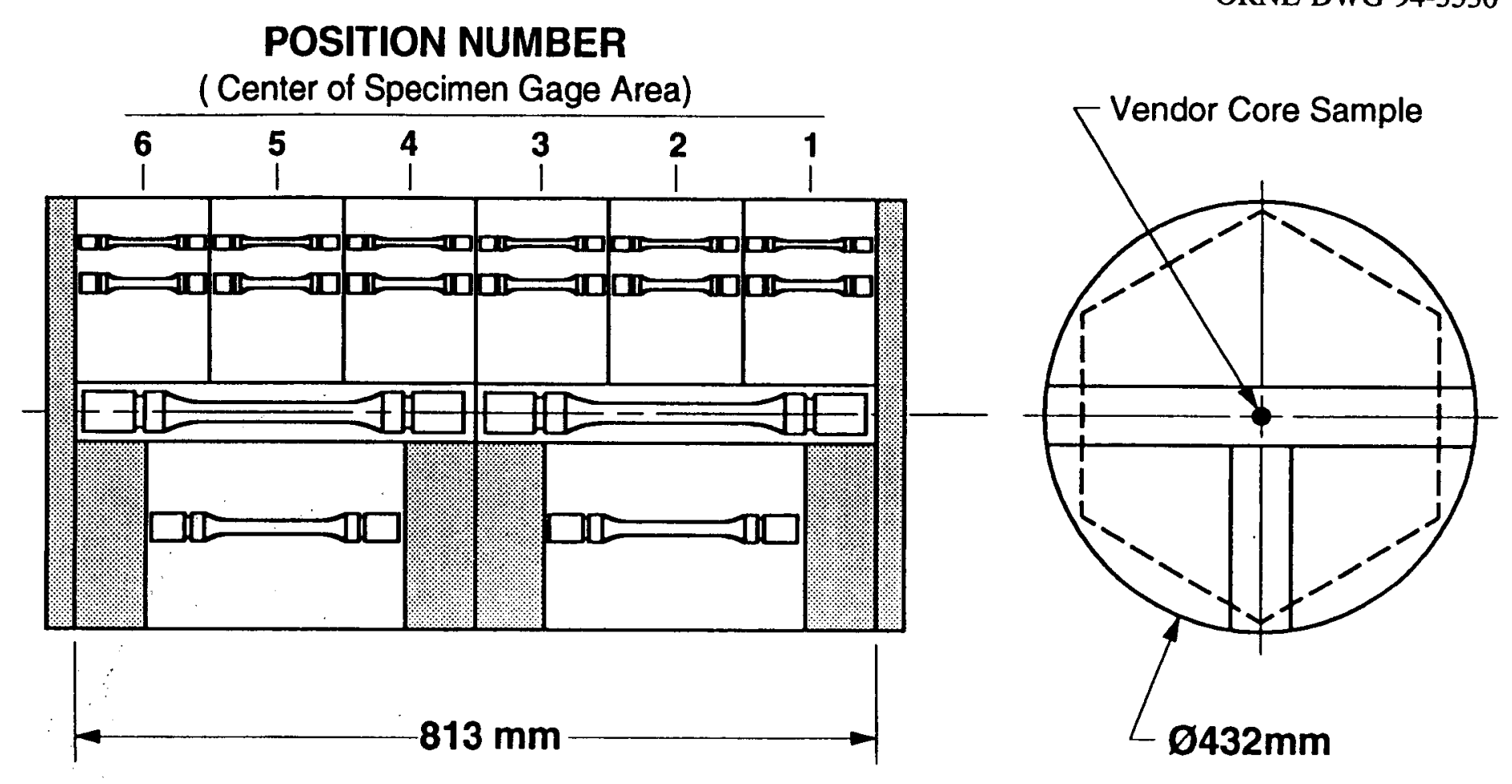

Figure 3-14. 


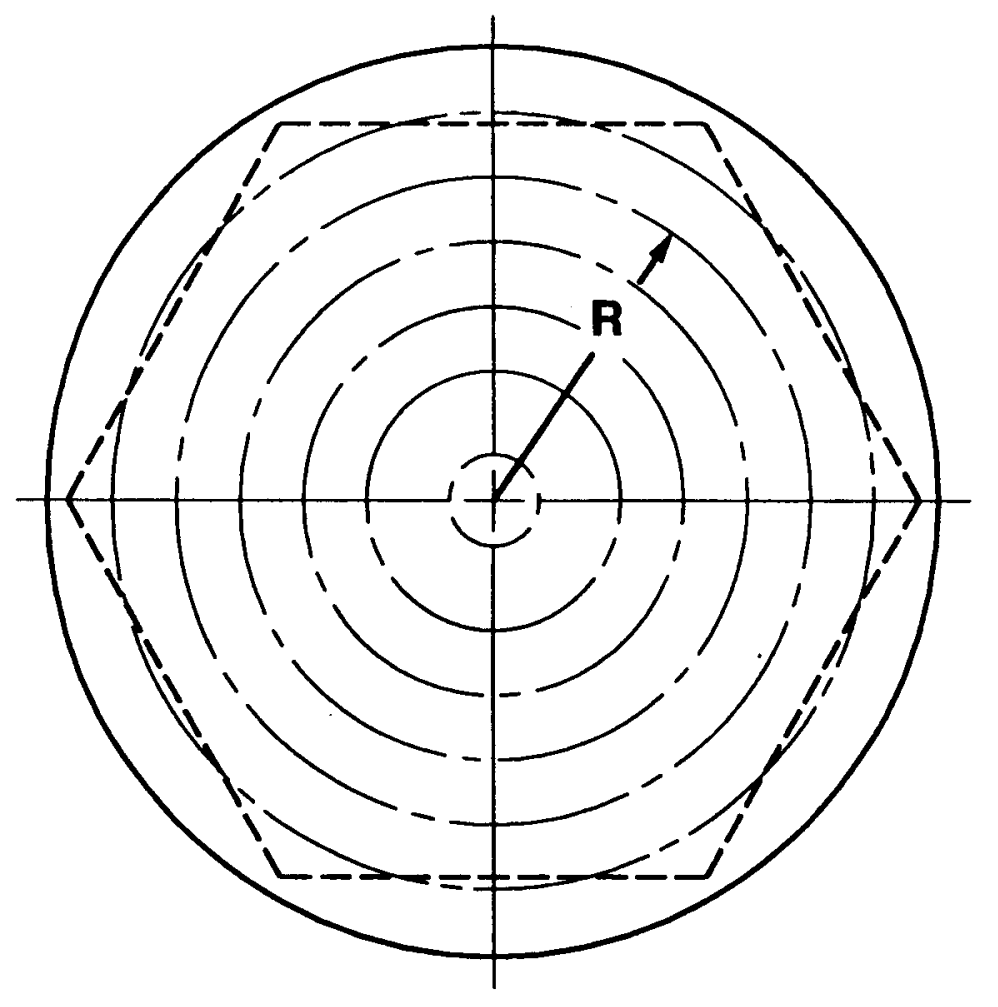

ORNL-DWG 94-5531

\begin{tabular}{|cc|cccc|}
\hline \multicolumn{4}{|c|}{ Radius } & \multicolumn{5}{|c|}{ Specimen Diameter, $\mathrm{mm}$} \\
\hline & $\mathrm{mm}$ & 6.35 & 9.53 & 15.88 & 25.4 \\
\hline R1 & 22 & $\mathrm{X}$ & $\mathrm{X}$ & & \\
R2 & 61 & $\mathrm{X}$ & $\mathrm{X}$ & $\mathrm{X}$ & $\mathrm{X}$ \\
R3 & 91 & $\mathrm{X}$ & $\mathrm{X}$ & & \\
R4 & 121 & $\mathrm{X}$ & $\mathrm{X}$ & $\mathrm{X}$ & $\mathrm{X}$ \\
R5 & 151 & $\mathrm{X}$ & $\mathrm{X}$ & & \\
R6 & 181 & $\mathrm{X}$ & $\mathrm{X}$ & $\mathrm{X}$ & $\mathrm{X}$ \\
\hline
\end{tabular}

$\underset{\omega}{\stackrel{\omega}{\infty}}$

Figure 3-15.

RADIAL LOCATIONS FOR TENSILE SPECIMENS IN BILLET 58-293. 
billet was greater than within the central area of the billet. Further, the strength was found to progressively increase from one end of the billet to the other. See Figures 3-16 and 3-17.

Grade H-451 graphite also exhibits a dependence on specimen size. Generally, the strength increased with increasing specimen size. However, the popular Weibull theory relating the strength to the stressed volume of material predicted behavior to the contrary. See Figure 3-18. On the other hand, strength has been observed to decrease rapidly as the specimen size approaches the grain size of the graphite. A modified Weibull model introduced by Fu Ho at GA attempted to reconcile the grain size effect but does not currently provide for spatial variations in $\mathrm{H}-451$ graphite, as evidenced in comparing Figure 3-19 with Figure 3-18.

H-451 graphite billets are classified as being class $1,2,3$, or 4 , based on the mean strength of four tensile specimens machined from a core sample of material very near the billet axis and located near the mid-length of the billet. Billet 58-293 was classified by Great Lakes Carbon Company (GLCC) as a class 2 billet. In this study, strength data were determined for a small core of material surrounding that employed for determining the billet strength classification. As shown in Figure 3-20, the bulk of these data lies below the class 2 strength range (11.5 to 13.5 $\mathrm{MPa}$ ) raising some question as to the utility of the current billet strength classification approach. As noted in Table 3-3, additional data have been generated in order to further investigate this matter.

A new fracture model introduced by Burchell ${ }^{76}$ incorporating microstructural elements in addition to grain size, as well as the fracture toughness of the material, showed good agreement with the experimental data for H-451 (refs. 76-78); see Figure 3-21. Microstructural image analysis was employed to obtain input data (Table 3-4) for the model.

A detailed discussion of the tensile data for billet 58-293 can be found in refs. 79-83.

Test specimens (all of which had 9.35-mm-diam test sections) were taken from the other six billets of H-451 graphite using a common slabbing plan (Figure 3-22). Similar to 58-293, over half of the specimens were machined such that the longitudinal axis of the specimen was aligned with the axis of the billet. The remainder had radial or tangential orientations with respect to the billet axis. Data analysis is just under way, but a few initial comments can be made. As shown in Figure 3-23, billet 58-29 also shows a strength gradient through the cross section of the billet. The strength decreases from the billet perimeter toward the axis of the billet. Figure 3-23 also suggests that radial and axial orientations of the test specimens may have nearly the same tensile strength. On the other hand, the tangential specimens (Figure 3-24) appear to be as strong as the 


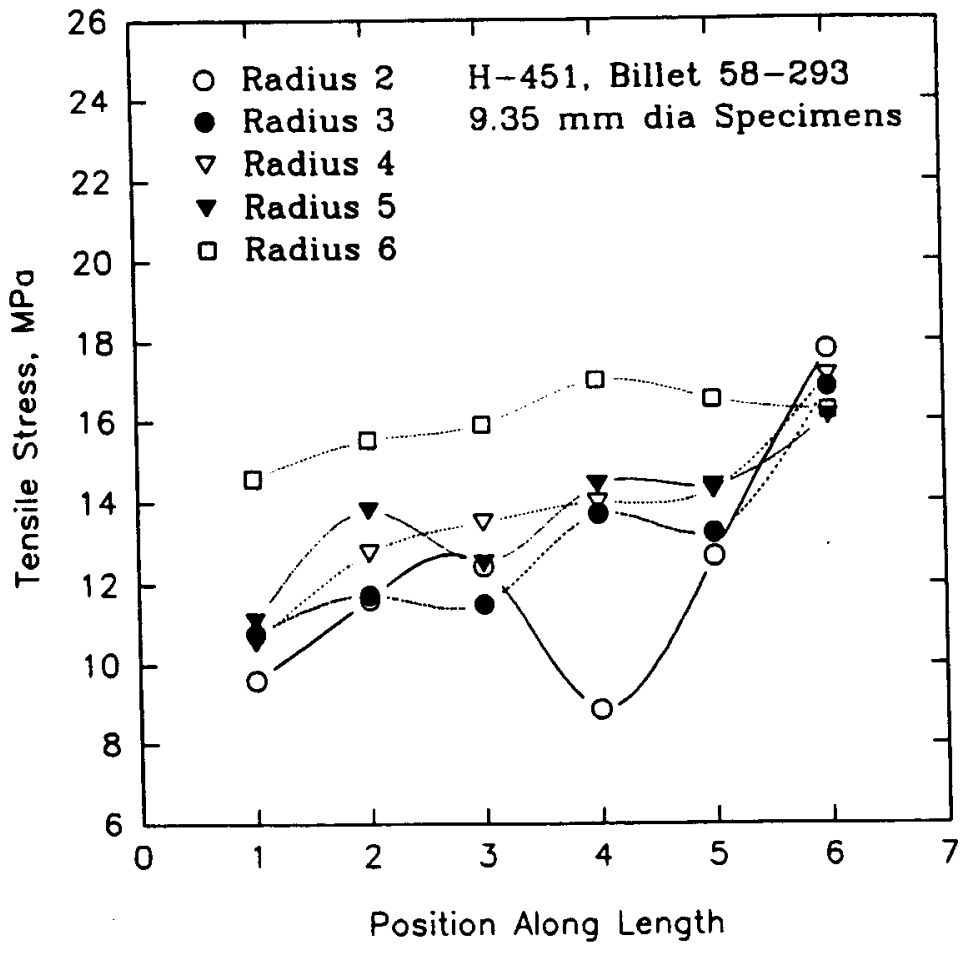

Figure 3-16.

MEAN TENSILE STRENGTH VERSUS POSITION ALONG THE LENGTH OF BILLET 58-293.

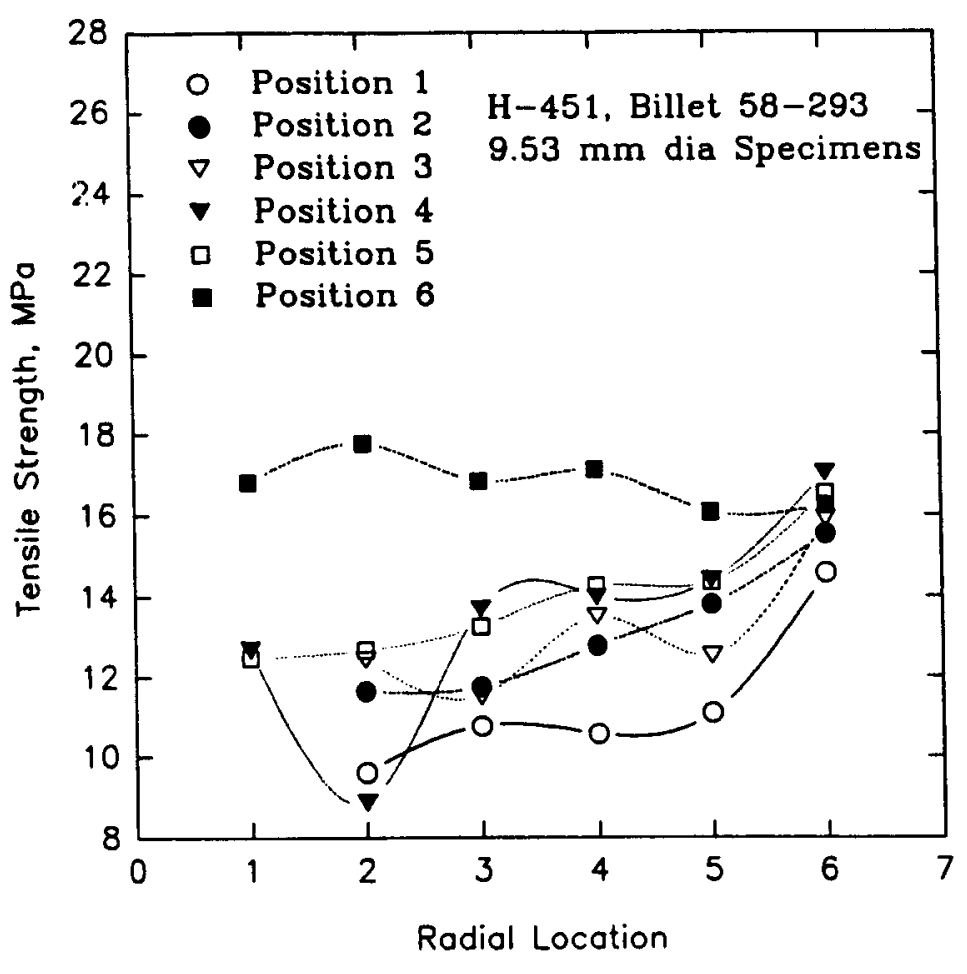

Figure 3-17.

MEAN TENSILE STRENGTH VERSUS RADIAL LOCATION THROUGH THE CROSS-SECTION OF BILLET 58-293. 
ORNL-DWG 94-5534

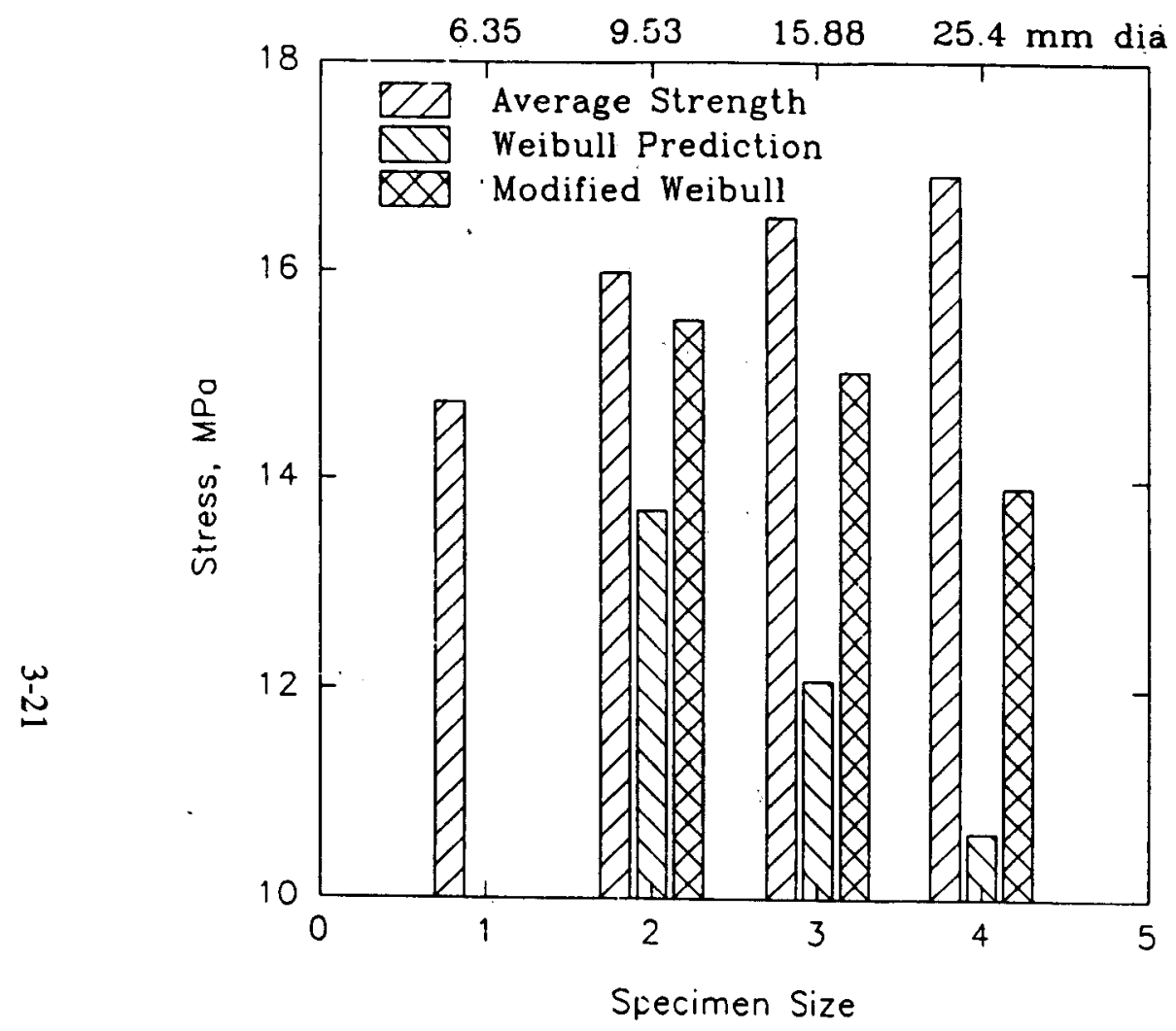

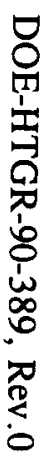

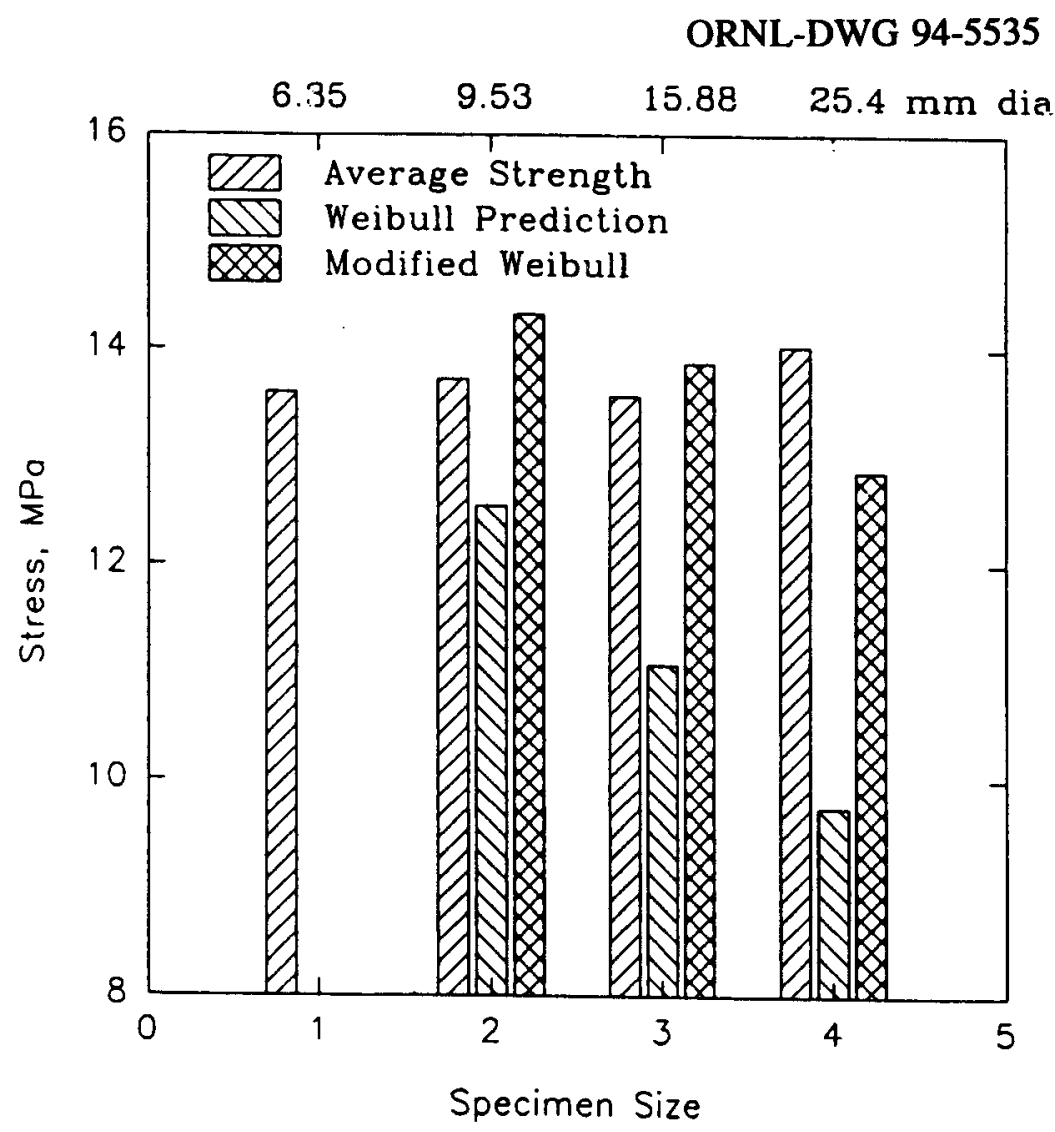

Figure 3-19.

MEAN TENSILE STRENGTHS OF THE FOUR SPECIMEN SIZES OF RADIAL LOCATION 4 IN BILLET 58-293 COMPARED WITH WEIBULL PREDICTIONS. 


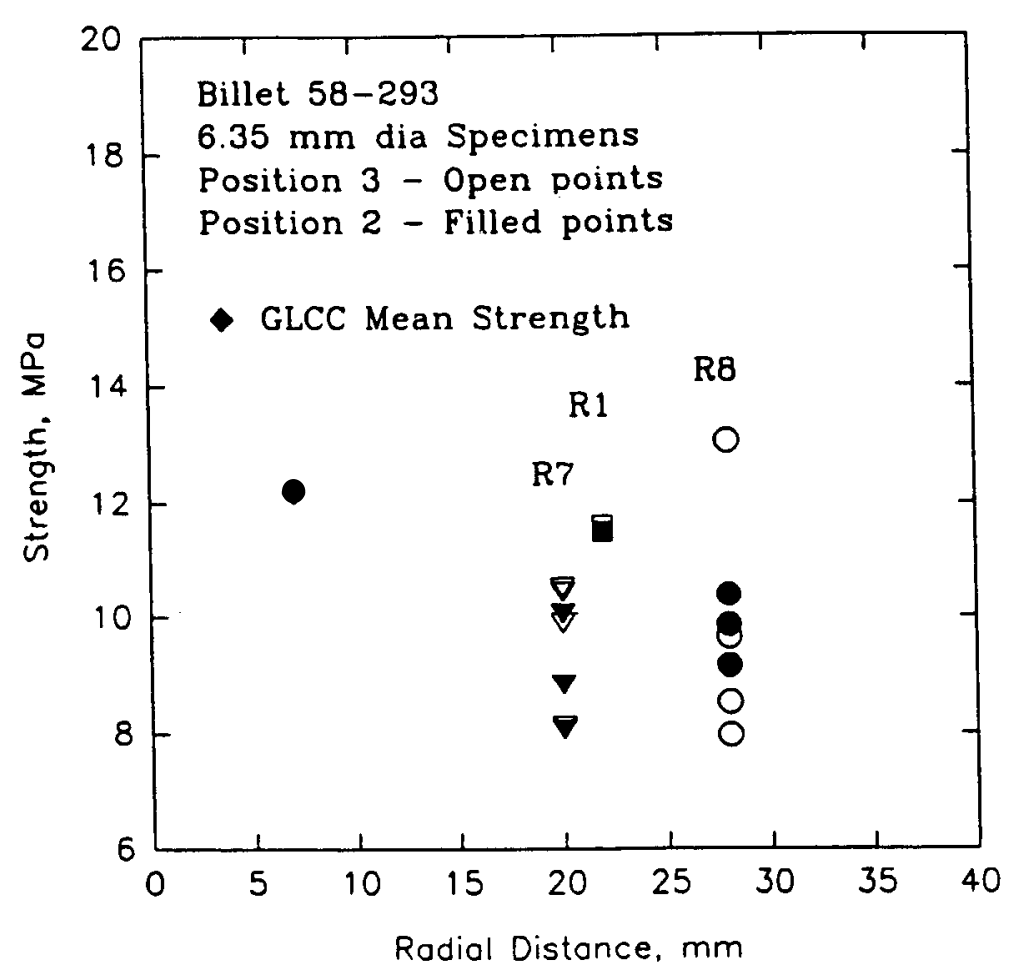

Figure 3-20.

TENSILE DATA FOR 6.36-MM DIAMETER SPECIMENS LYING NEAR GLCC SPECIMENS FORM THE SAMPLE CYLINDER REMOVED FROM BILLET 58-293.

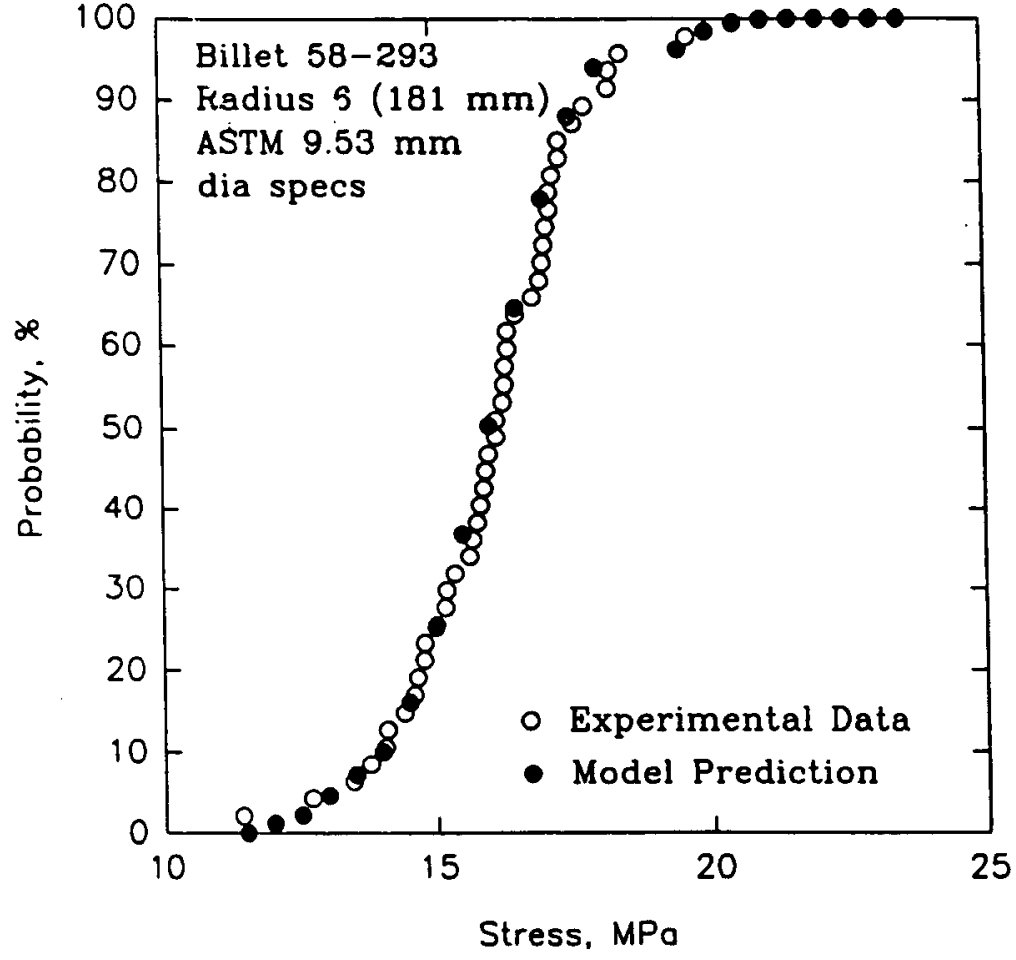

Figure 3-21.

TENSILE DATA FOR BILLET 58-293 COMPARED WITH BURCHELL MODEL PREDICTIONS. 
Table 3-4

MODEL INPUT PARAMETERS FOR GRADE H-451 GRAPHITE

\begin{tabular}{|l|c|}
\hline Model input parameters & Grade $\mathrm{H}-451$ \\
\hline \hline Particle critical stress intensity factor, $\mathrm{K}_{\mathrm{ic}}\left(\mathrm{MN} \mathrm{m}^{3 / 2}\right)$ & 0.285 \\
\hline Mean filler particle size, a $(\mathrm{mm})$ & 0.5 \\
\hline Density, $\rho\left(\mathrm{g} \mathrm{cm}^{3}\right)$ & 1.79 \\
\hline Mean pore size, $\mathrm{S}_{\mathrm{o}}(\mu \mathrm{m})$ & 42 \\
\hline Standard deviation, $\mathrm{S}_{\mathrm{d}}$ & 1.9 \\
\hline Mean pore area, $\mathrm{p}_{\mathrm{o}}\left(\mu \mathrm{m}^{2}\right)$ & 700 \\
\hline Number of pores per $\mathrm{m}^{3}, \mathrm{~N}\left(\mathrm{~m}^{-3}\right)$ & $2.97 \times 10^{8}$ \\
\hline Specimen breadth, $\mathrm{b}\left(\mathrm{mm}^{\prime}\right)$ & 8.44 \\
\hline Specimen volume, $\mathrm{V}\left(\mathrm{m}^{3}\right)$ & $3.17 \times 10^{-6}$ \\
\hline
\end{tabular}




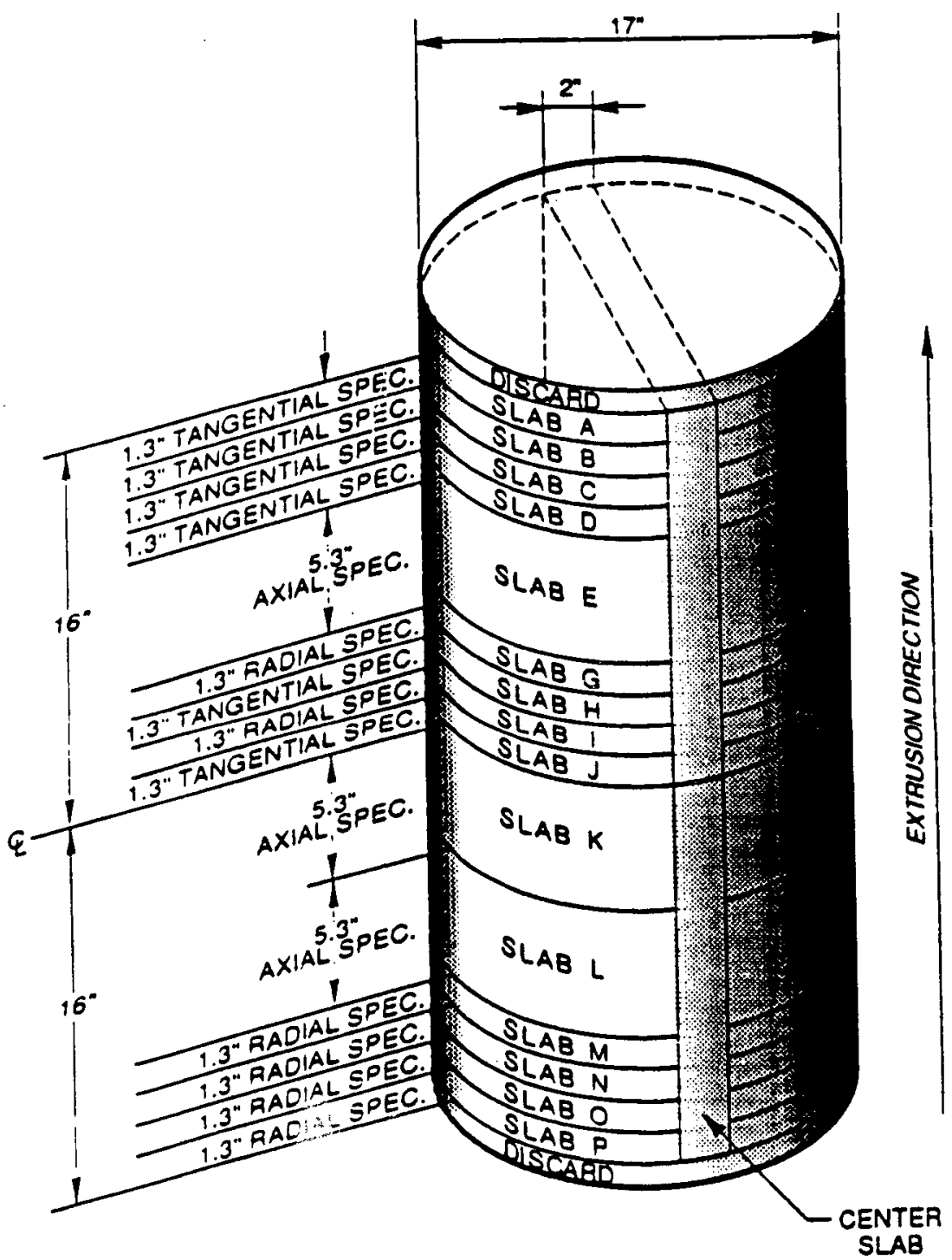

Figure 3-22.

H-451 GRAPHITE BILLET SLABBING PLAN FOR DETERMINATION OF MATERIAL VARIABILITY, I.E., CLASS-TO-CLASS, LOT-TO-LOT, AND BILLET-TO-BILLET. 


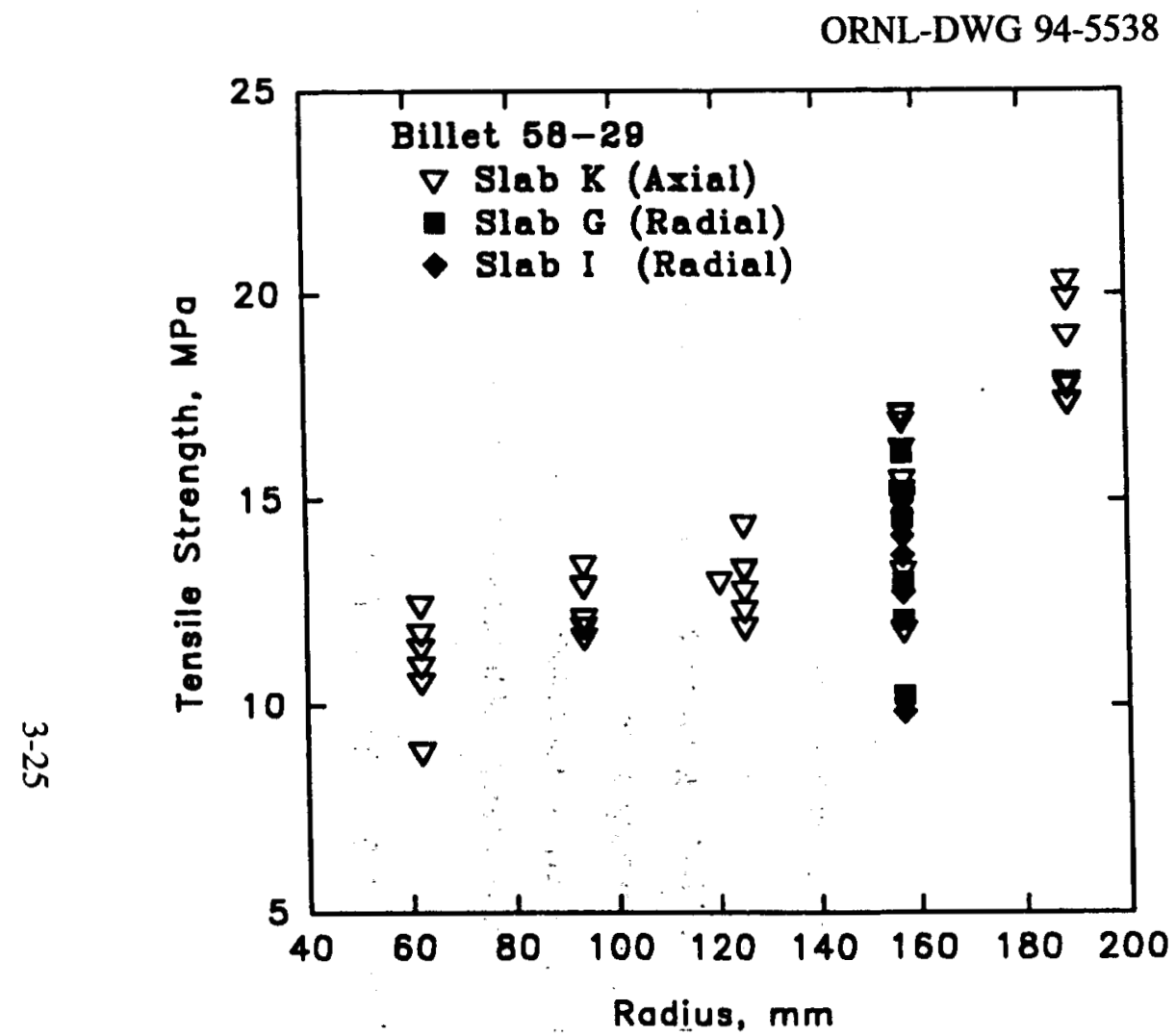

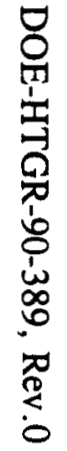

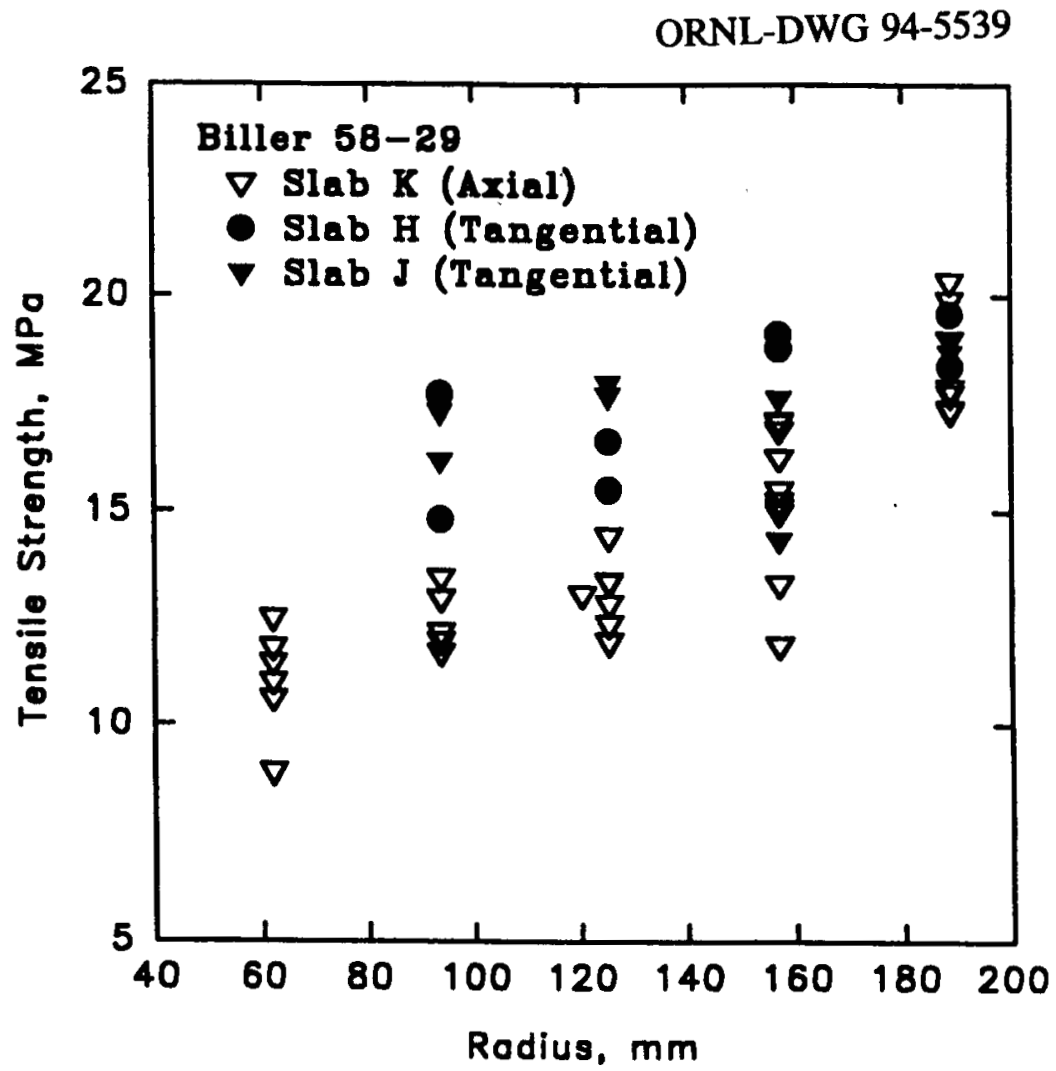

Figure 3-24.

COMPARISON OF TANGENTIAL AND AXIAL SPECIMEN ORIENTATIONS IN BILLET 58-29. 
axial specimens at the perimeter of the billet, but the stress gradient is not as steep, resulting in generally higher tensile strengths for the tangential orientation in the central portion of the billet cross section.

Compilation of the data from the remaining billets is under way, so analysis can proceed to determine spatial and specimen orientation effects and variations between billets, class to class and lot to lot.

\subsubsection{Fatigue Behavior}

Graphite core components in MHTGRs are subject to cyclic stresses from power cycling, flow-induced vibrations, and, possibly, seismic events. Mechanical design of NP-MHTGR components requires that the fatigue behavior of $\mathrm{H}-451$ graphite be taken into account. The data base must be sufficient to determine the mean fatigue strength with $95 \%$ confidence and to establish a specified minimum fatigue life in accordance with Subsection CE of the American Society of Mechanical Engineers (ASME) Code. ${ }^{84}$

In response to NPR-DDN-11.02 (ref. 85) and test specification CEGA-001916 (ref. 86), a fatigue data testing program was developed. Fatigue life over the range of $10^{2}$ to $10^{5}$ cycles will be determined as a function of stress amplitude under constant amplitude cyclic loading at room temperature. The effect of stress ratio, $R$ (minimum stress/maximum stress during a fatigue cycle), on cyclic life will be determined over the range $R=-1$ to $R=+1$ with the maximum stress ranging from 65 to $100 \%$ of the mean ultimate tensile strength. Further, since H-451 graphite billets are generally inhomogeneous and exhibit significant variations in properties, test matrices have been designed to expose any gradient in fatigue properties. The effects of specimen orientation and spatial location within the billet, as well as billet-to-billet and lot-to-lot variations, will be determined. The test plan ${ }^{86}$ includes: (1) the test objectives; (2) a summary of previous findings on the fatigue behavior of H-451 graphite; and (3) experimental details giving the basic approach, test matrices, and billet cutting plans.

Fatigue testing has not begun yet, but specimens have been machined from six entire billets of $\mathrm{H}-451$ graphite. The inventory of nearly 1,600 test specimens is summarized in Table 3-5.

3.3 MULTIAXIAL TESTING - G. T. Yahr, R. L. Battiste, D. T. Godwin, C. R. Luttrell, and W. F. Swinson

A test specimen and test facility have been developed for testing $\mathrm{H}-451$ graphite under internal pressure and axial load to determine fracture behavior under biaxial states of stress. The 
Table 3-5

INVENTORY OF H-451 GRAPHITE FATIGUE SPECIMENS

\begin{tabular}{|c|c|c|c|c|}
\hline $\begin{array}{c}\text { Billet } \\
\text { number }\end{array}$ & $\begin{array}{c}\text { Lot } \\
\text { number }\end{array}$ & $\begin{array}{l}\text { Strength } \\
\text { class }\end{array}$ & $\begin{array}{l}\text { Specimen } \\
\text { quantity }\end{array}$ & Comments \\
\hline $58-357$ & 58 & 1 & $\begin{array}{l}\text { Axial } 180 \\
\text { Radial } 36 \\
\text { Tangential } 48 \\
\text { Subtotal } 264\end{array}$ & $\begin{array}{l}\text { Axial, radial, and tangential specimen } \\
\text { orientations throughout billet to assess } \\
\text { orientation effects and spatial } \\
\text { variability }\end{array}$ \\
\hline $58-29$ & 58 & 2 & $\begin{array}{l}\text { Axial } 180 \\
\text { Radial } 36 \\
\text { Tangential } 48 \\
\text { Subtotal } 264\end{array}$ & $\begin{array}{l}\text { Assess orientation and spatial } \\
\text { variability effects and evaluate strength } \\
\text { classification }\end{array}$ \\
\hline $58-892$ & 58 & 3 & $\begin{array}{l}\text { Axial } 180 \\
\text { Radial } 36 \\
\text { Tangential } 48 \\
\text { Subtotal } 264 \\
\end{array}$ & $\begin{array}{l}\text { Assess orientation and spatial } \\
\text { variability effects and evaluate strength } \\
\text { classification }\end{array}$ \\
\hline $58-18$ & 58 & 4 & $\begin{array}{l}\text { Axial } 180 \\
\text { Radial } 36 \\
\text { Tangential } 48 \\
\text { Subtotal } 264\end{array}$ & $\begin{array}{l}\text { Assess orientation and spatial } \\
\text { variability and evaluate strength } \\
\text { classification }\end{array}$ \\
\hline $472-16$ & 472 & 1 & $\begin{array}{l}\text { Axial } 180 \\
\text { Radial } 36 \\
\text { Tangential } 48 \\
\text { Subtotal } 264\end{array}$ & $\begin{array}{l}\text { Assess orientation, spatial variability, } \\
\text { and lot-to-lot effects }\end{array}$ \\
\hline $474-72$ & 474 & 1 & $\begin{array}{l}\text { Axial } 180 \\
\text { Radial } 36 \\
\text { Tangential } 48 \\
\text { Subtotal } 264\end{array}$ & $\begin{array}{l}\text { Assess orientation, spatial variability, } \\
\text { and lot-to-lot effects }\end{array}$ \\
\hline & \multicolumn{2}{|c|}{ Grand Total } & 1,584 & \\
\hline
\end{tabular}


facility incorporates a carefully aligned rigid load train to minimize extraneous bending that might result from any large flaws in the specimen. The specimen is shown in Figure 3-25. The hydraulic mandrels are used to grip the specimen and are rigidly mounted on the load train. The relatively large specimen size is necessary because of the maximum particle size of $\mathbf{H}-451$ graphite. The same specimen geometry is also being used for testing IG-110 graphite.

Material strength is usually characterized by measuring the uniaxial strength. In real applications, however, materials are usually subjected to multiaxial stress conditions. Therefore, a multiaxial failure criterion is necessary so that the uniaxial strength data can be applied to component design. There are two general approaches to multiaxial failure criteria. One is a mechanistic approach, wherein the failure criterion is developed on the basis of the fundamental mechanisms that cause fracture. An example of this approach is the Griffith-Irwin fracture mechanics approach. The other approach is phenomenological in which a surface is developed in stress-space that fits the available data and meets certain geometrical requirements as well. Examples of the phenomenological approach include the maximum stress theory, the maximum strain theory, the modified Coulomb-Mohr theory with tension-cutoffs, and the Tsai-Wu tensor theory. The advantage of the phenomenological approach is that, with enough constants, the available data can always be accurately described. However, care must be used to make sure it is not applied to conditions that have not been tested, as it is strictly a mathematical curve-fitting procedure. Thus, interpolation between known conditions is reasonable, but extrapolation is dangerous.

The test of any multiaxial failure theory is how well it compares to multiaxial test data. Failure data from statically determinate tests are most useful for testing failure criteria because the stress at failure can be determined without using the constitutive equations. A number of investigators have run failure tests on thin-walled tubes. Some investigators ${ }^{87}$ have concentrated on the tension-tension quadrant. Many investigators ${ }^{88-96}$ have run tests where the axial stress was compressive to obtain data in the tension-compression quadrant as well as in the tension-tension quadrant. Data from thin-walled tube tests ${ }^{97}$ on RAXM graphite are compared with several of the multiaxial stress theories in Figure 3-26.

Difficulties are often encountered with buckling when high compressive loads are applied to the thin-wall tubes. Therefore, although several investigators ${ }^{98-107}$ have tried to obtain failure data in the compression-compression quadrant, premature failure, due to buckling, has usually been 


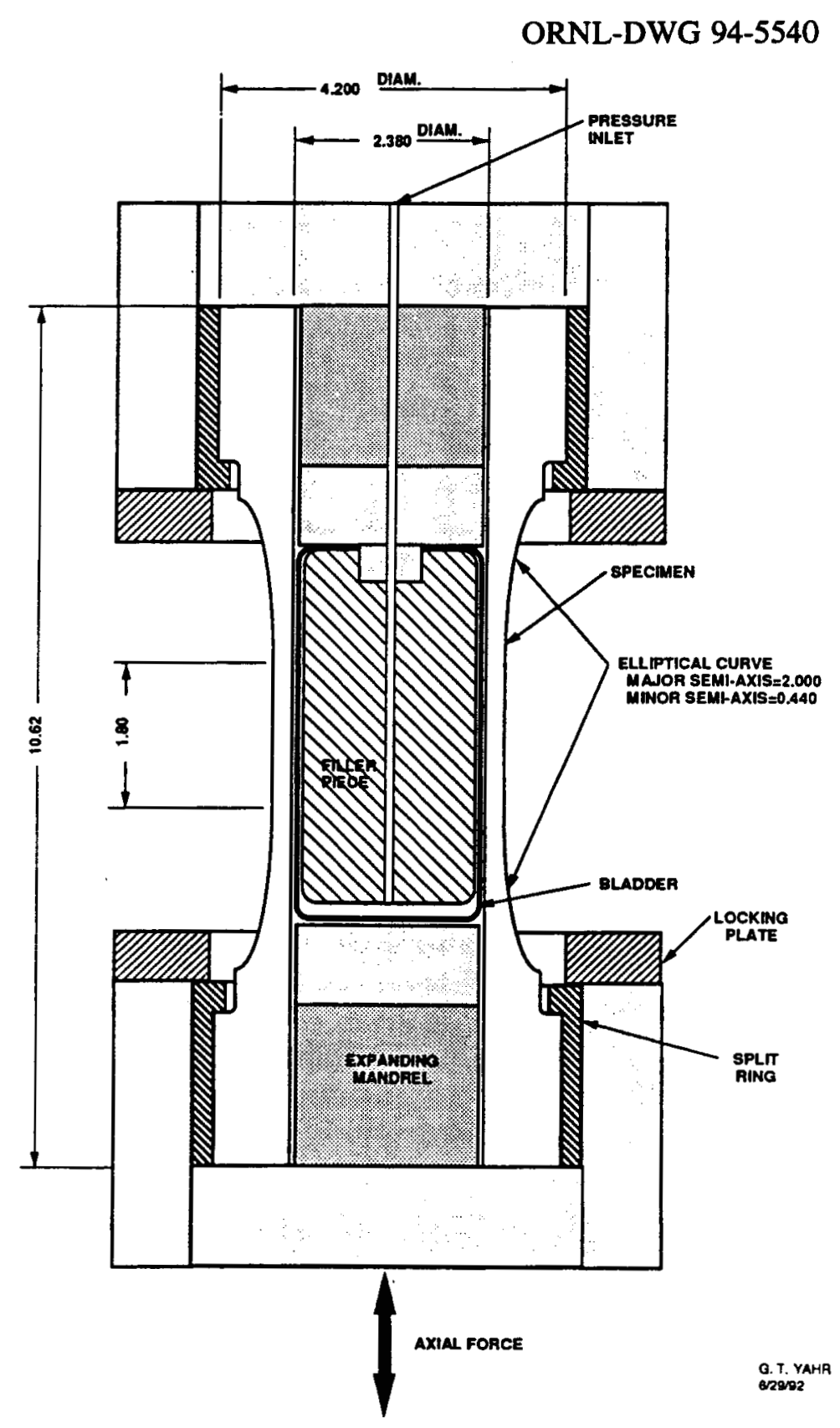

Figure 3-25.

MULTIAXIAL GRAPHITE LOADING ARRANGEMENT. 
ORNL-DWG 94-5541

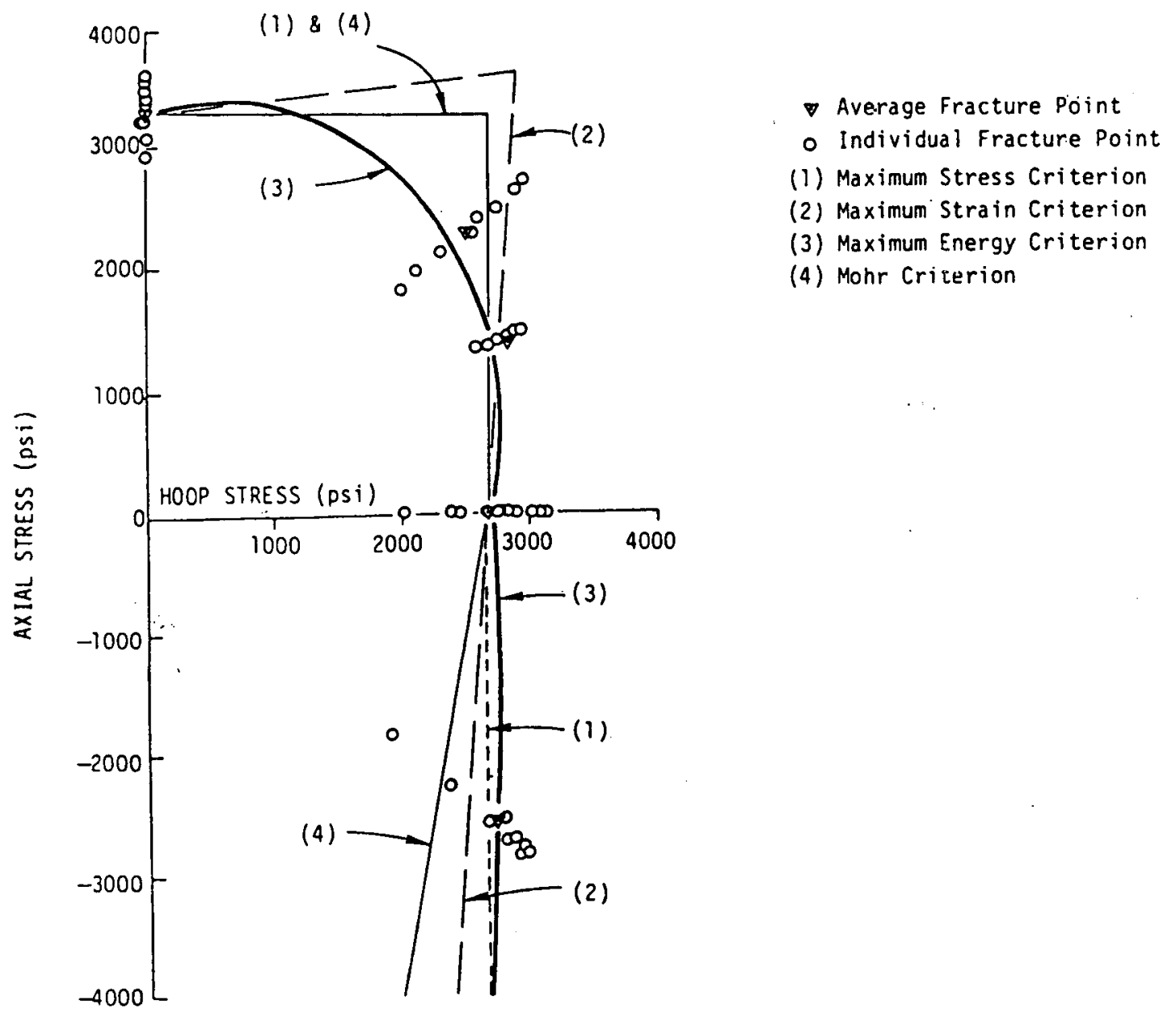

Figure 3-26.

COMPARISON OF FRACTURE DATA FROM RAXM THIN-WALLED TUBES WITH THEORIES OF FAILURE. 
suspected. Recent tests by Hackerott ${ }^{108}$ in the compression-compression quadrant appear to have minimized premature failure due to buckling.

Unfortunately, buckling is not the only problem experienced with thin-walled tube tests. Although the stresses are very nearly statically determinate in a thin-walled tube, the ends of the specimens are usually thicker than the gage section, which results in discontinuity stresses.

Although careful design can minimize this discontinuity, it can never be totally eliminated.

Another problem is encountered with testing thin-walled tubes when an axial tensile load is applied; if a conventional flexible load train is used, any flaw causes an effectively eccentric axial load, which will lower the apparent failure stress. A very accurately aligned, rigid load train must be used to overcome this problem.

In the paragraph above, we considered the relative fit of multiaxial failure theories to the average data from biaxial tests. However, for the design of MHTGR graphite core components, we are interested in precluding failure; therefore, we are most interested in the best fit to the lower bound of the failure data. Jortner ${ }^{104}$ decided in 1971 that the lower bound of biaxial tube data on ATJ-S graphite fitted the maximum principal stress criterion quite well.

Biaxial tests on thin-walled graphite tubes provide good data for comparing the relative merits of the phenomenological failure criteria. However, more prototypic test data are required to evaluate the relative merits of both the mechanistic and phenomenological theories. Analysis of the more prototypic tests requires the use of constitutive equations to determine the stresses and strains. More prototypic tests were run on splitting tensile specimens ${ }^{109}$ and flat-headed, thickwalled pressure vessels. ${ }^{110}$ Good failure predictions were achieved for both tests using linear elastic fracture mechanics (LEFM) when machined flaws were introduced into the specimens. Promising results were achieved on the specimen. without machined flaws, but there was an indication that the LEFM approach needed additional investigation.

A considerable amount of work was done under sponsorship of the Air Force Materials Laboratory (AFML) to develop design methods for application to graphite nosetips for re-entry vehicles. Just as with the MHTGR core, thermal stresses play a key role in nosetips for re-entry vehicles. Therefore, instrumented thermal stress tests were developed at TRW ${ }^{111-113}$ and Southern Research Institute ${ }^{114}$ that could be used as a proof test for design methods. Instrumented graphite nosecones were tested under realistic conditions ${ }^{115}$ in the Air Force Flight Dynamic Laboratory 50-MW facility. Deformations were monitored in the AFML tests. Comparisons of elastic analyses and elastic-plastic analyses using different constitutive equations showed that similar 
strain predictions were obtained regardless of the constitutive equations used. Predicted deformations were in reasonable agreement with measured deformations. Stress predictions were found to vary considerably depending on the constitutive equations used. The maximum strain theory of failure was used and found to be in reasonable agreement with the data. ${ }^{115}$ Plasticity analyses were done for a thermal shock test that was developed at ORNL ${ }^{116}$ in 1965 , and the maximum stress theory of failure gave reasonable agreement with the test data. ${ }^{117}$

The proposed ASME Boiler and Pressure Vessel Code design requirements for graphite core supports ${ }^{118}$ specify the use of the maximum stress theory of failure. A test program is being conducted to provide data to confirm the applicability of the maximum stress theory to $\mathrm{H}-451$ graphite and IG-110 graphite. Primary emphasis will be on the tension-tension quadrant (quadrant 1). Tests will also be done in the tension-compression quadrant (quadrant 4).

The objective of this work is to produce data that can be used to evaluate the adequacy of the maximum principal stress theory for describing the fracture behavior of H-451 and IG-110 graphite over the range of stress states relevant to the graphite core supports. A thin-walled cylindrical specimen under various combinations of axial tensile or compressive load and internal pressure is being used because it best meets the following requirements:

1. A significant volume of graphite must be under a homogeneous state of stress to minimize strain gradient and grain size effects.

2. Primary failure must start in the gage section of the specimen.

3. The state of stress/strain must be directly measurable to avoid analytical determination of the stress-strain state.

4. It must be possible to vary the three in-plane stress components independently.

An LEFM approach was used to determine the minimum wall thickness for tubular specimens that will be used to establish the biaxial fracture behavior of H-451 graphite. Data from 26 American Society for Testing and Materials (ASTM) tensile specimens with a gage diameter of 1.00 in. were used as the basis for establishing the flaw distribution in H-451 graphite. Two different fracture mechanics correlations were used. The first one, which was for a single-edge notch under uniform tension, is:

$$
K_{I C}=\sigma_{f} \sqrt{\pi a} f\left(\frac{a}{b}\right)
$$


where:

$$
f\left(\frac{a}{b}\right)=1.12-0.23\left(\frac{a}{b}\right)+10.6\left(\frac{a}{b}\right)^{2}-21.7\left(\frac{a}{b}\right)^{3}+30.4\left(\frac{a}{b}\right)^{4},
$$

where $f\left(\frac{a}{b}\right)$ is a geometric factor calculated by Gross ${ }^{119}$ et al., a is the notch depth, $\mathrm{b}$ is the specimen width, and $\sigma_{\mathrm{f}}$ is the fracture strength. The second correlation was for a penny-shaped crack in the center of a round bar under uniform tension given in Figure 161 of Rooke and Cartwright's Compendium of Stress Intensity Factors. ${ }^{20}$

A fracture toughness, $K_{I C}$, value of

$$
1.0 M P a \sqrt{m}(0.91 k s i \sqrt{i n})
$$

was used.

The calculated flaw distributions in the 1-in. tensile specimens are tabulated in Table 3-6 along with the measured strengths. The values of notch depth for the assumed through-thickness surface flaw varied from 0.50 to $2.52 \mathrm{~mm}$. The radius of the centered penny-shaped crack varied from 1.60 to $5.83 \mathrm{~mm}$. The small dimensions of the furnace cracks are indicative of the fact that surface cracks are more deleterious than internal flaws. The radii of the internal flaws are approximately three times the depth of the surface flaws.

The fracture mechanics relationships for the tube wall were obtained from Article A-3000 of Section XI of the ASME Boiler and Pressure Vessel Code. A semielliptical flaw was assumed on the inside surface with a total length six times the flaw depth. The distribution of flaw depths used corresponds to the values of " $a$ " tabulated in Table 3-6. Strength distributions were calculated for wall thicknesses of $3.18,4.83,6.35,10.16$, and $254 \mathrm{~mm}$. The $254-\mathrm{mm}$ wall is a limiting case, and the mean and standard deviations calculated for this case were taken as the ideal values. The values were $17.5 \mathrm{MPa}(2.54 \mathrm{ksi})$ and $4.8 \mathrm{MPa}(0.70 \mathrm{ksi})$, respectively. The calculated mean and standard deviations for the other four thicknesses were divided by the value for the 254-mm wall and plotted in Figure 3-27. A wall thickness of $5.6 \mathrm{~mm}$ was selected as a reasonable compromise. According to the LEFM analysis, specimens with this wall thickness will have an average axial strength that is $95 \%$ of an effectively infinite wall thickness, and the standard deviation will be $14 \%$ higher than the limiting value. No account was taken of Weibull size effects.

Ideally, the inside radius of the tubular specimen should be large compared to the wall thickness so that the stresses are statically determinate and uniform. As the ratio of inner radius 
Table 3-6

ESTIMATED CRACK SIZE DISTRIBUTION IN

LARGE H-451 TENSILE SPECIMENS

\begin{tabular}{|c|c|c|c|}
\hline & $\begin{array}{l}\text { Strength } \\
\text { (MPa) }\end{array}$ & $\begin{array}{l}\text { Crack depth } \\
(\mathrm{a}, \mathrm{mm})\end{array}$ & $\begin{array}{c}\text { Crack radius } \\
(1 / 2, \mathrm{~mm})\end{array}$ \\
\hline & $\begin{array}{l}22.07 \\
21.85 \\
21.72 \\
21.46 \\
20.93 \\
20.58 \\
19.66 \\
19.09 \\
18.96 \\
16.41 \\
15.35 \\
14.70 \\
14.00 \\
13.91 \\
12.90 \\
12.64 \\
12.51 \\
12.42 \\
12.38 \\
12.29 \\
11.67 \\
11.19 \\
11.19 \\
10.49 \\
10.44 \\
09.87\end{array}$ & $\begin{array}{l}0.50 \\
0.51 \\
0.52 \\
0.53 \\
0.56 \\
0.58 \\
0.63 \\
0.67 \\
0.68 \\
0.91 \\
1.04 \\
1.14 \\
1.25 \\
1.27 \\
1.47 \\
1.54 \\
1.57 \\
1.59 \\
1.60 \\
1.62 \\
1.80 \\
1.96 \\
1.96 \\
2.23 \\
2.25 \\
2.52 \\
\end{array}$ & $\begin{array}{l}1.60 \\
1.64 \\
1.66 \\
1.70 \\
1.78 \\
1.84 \\
2.01 \\
2.13 \\
2.16 \\
2.86 \\
3.26 \\
3.54 \\
3.86 \\
3.90 \\
4.45 \\
4.62 \\
4.69 \\
4.74 \\
4.77 \\
4.82 \\
5.19 \\
5.47 \\
5.47 \\
5.79 \\
5.81 \\
5.83 \\
\end{array}$ \\
\hline $\begin{array}{l}\text { MEAN } \\
\text { STD. DEV. }\end{array}$ & $\begin{array}{l}15.41 \\
04.24\end{array}$ & $\begin{array}{l}1.27 \\
0.62\end{array}$ & $\begin{array}{l}3.68 \\
1.55\end{array}$ \\
\hline
\end{tabular}




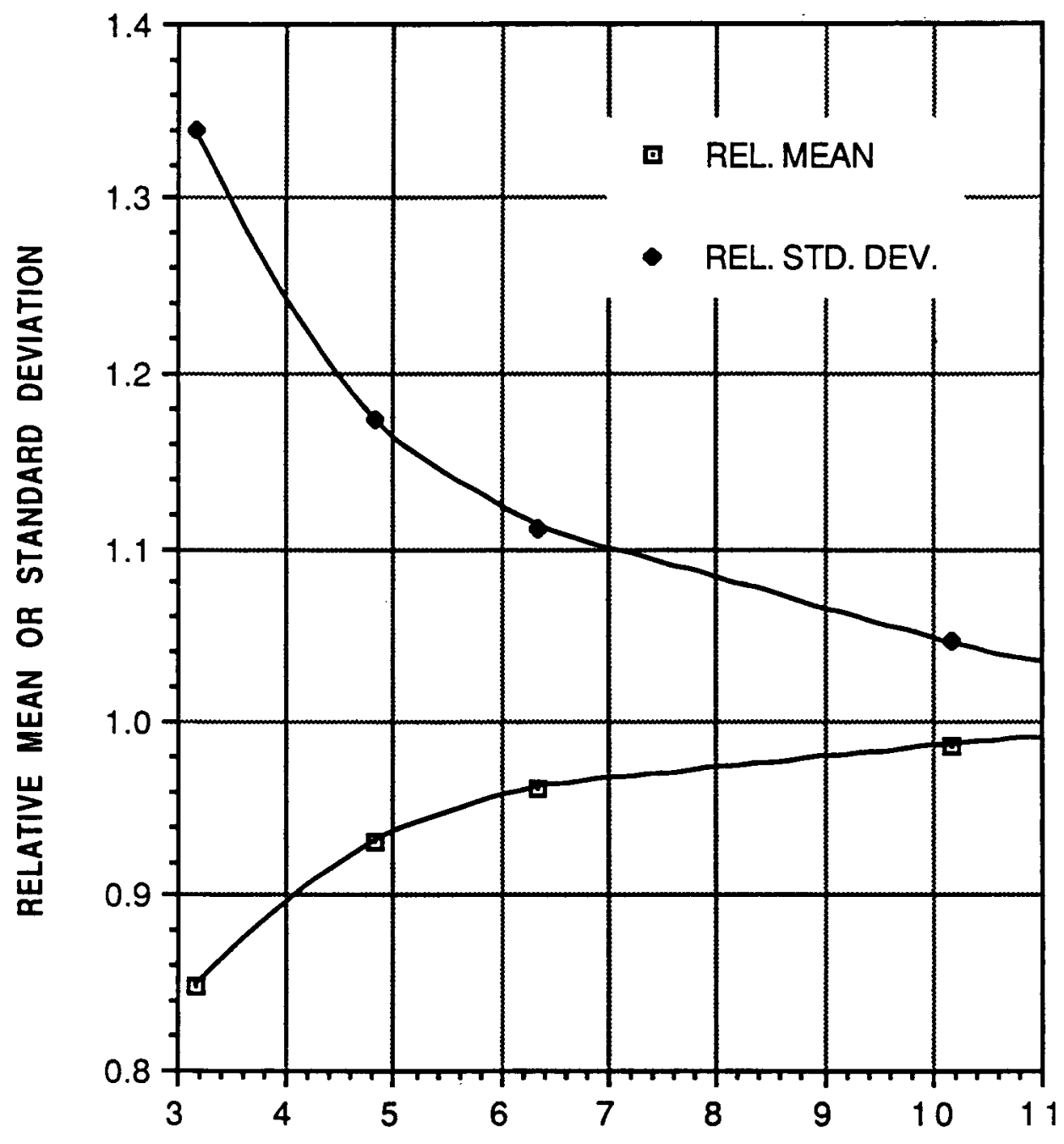

WALL THICKNESS $(\mathrm{mm})$

Figure 3-27.

LEFM PREDICTION OF EFFECT OF WALL THICKNESS ON MEAN STRENGTH AND STANDARD DEVIATION. 
to wall thickness decreases, the circumferential stress distribution through the wall caused by internal pressure loading becomes more and more nonuniform. The phenomenon is illustrated in Figure 3-28 where the peak circumferential stress divided by the nominal stress calculated by the equation:

$$
\sigma_{n o m}=\frac{p R_{i}}{l},
$$

(where $p$ is the internal pressure, $R_{i}$ is the inner radius, and $t$ is the wall thickness) is plotted versus the ratio of the inner radius to the wall thickness. An inside radius 5.4 times the wall thickness is selected for our specimens so that the elastically calculated peak stress will be no more than $10 \%$ higher than the nominal stress. The actual peak stress will be somewhat lower because of the nonlinear stress-strain response of graphite. Thus, our tubular specimen has an ID of $60.4 \mathrm{~mm}$ and an OD of $71.6 \mathrm{~mm}$. The area of the gage cross section is $1161 \mathrm{~mm}^{2}$. The complete preliminary tubular specimen design developed using elastic finite element analysis is shown in Figure 3-29. The elliptical transition region is designed to minimize discontinuity stresses so that failures will occur in the gage section. This specimen is designed to be aligned using expanding mandrels inserted in both ends, which will be connected to external clam-shells so that axial tensile load can be introduced at the stepped diameter.

Analyses were done to examine the axial, circumferential, and radial stresses in the specimen and to determine if the highest stress will occur in the gage section. Analyses were also performed to determine the buckling load of the specimen under axial compression. Several different designs of the specimen were analyzed to determine the best specimen for the test. The specimen had to be designed to accommodate an internal pressure and an axial force applied to the specimen. It also had to withstand an expansion due to the expanding mandrel used to align the specimen.

PATRAN-G, release 2.5, was used to develop the finite element models of the graphite specimen, and the finite element code ADINA was used to do the analyses. Due to symmetry, it was necessary to model only a quarter of the specimen. The elements used in the model were 20-node, solid 3-D elements. In the experiment, an expanding mandrel is used in the top and bottom of the specimen for aligning the specimen. To model this extsion of the steel mandrel, prescribed displacements were applied inside the end of the specimen model. The test specimen is loaded with a combination of circumferential and axial loads. These were modeled by applying 


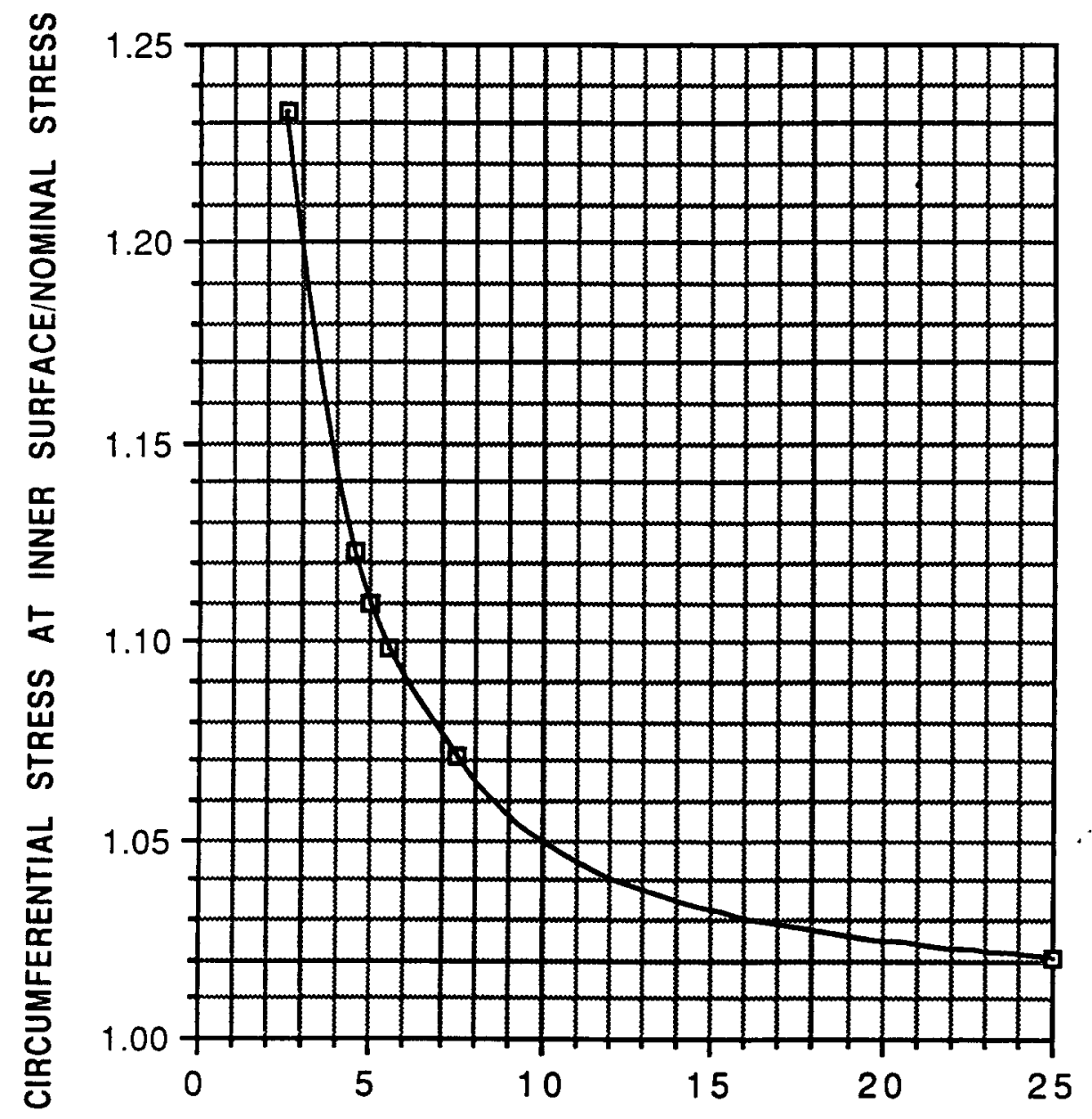

RATIO OF INNER RADIUS TO WALL THICKNESS

Figure 3-28.

THE RATIO OF THE PEAK CIRCUMFERENTIAL STRESS

ON THE INSIDE OF PRESSURIZED CYLINDER TO

THE NOMINAL STRESS INCREASES AS THE

RATIO OF THE INSIDE RADIUS TO THE

WALL THICKNESS DECREASES. 


\section{ORNL-DWG 94-5544}

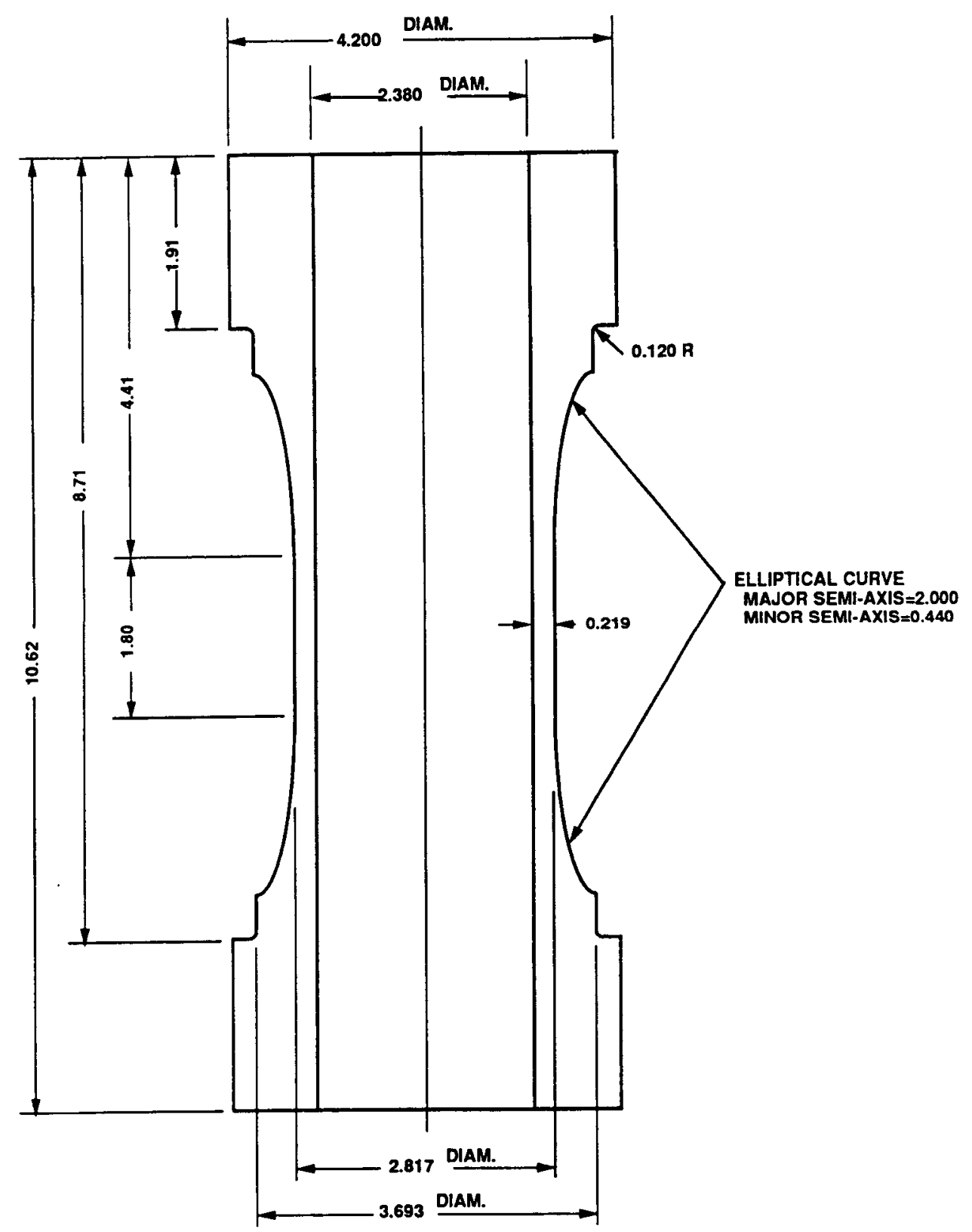

NOTE: DIMENSIONS IN INCHES.

Figure 3-29.

TEST SPECIMEN GEOMETRY AND DIMENSIONS. 
an internal pressure in the central part of the specimen and by applying an axial load on the step in the specimen.

Various models with different lengths and outer contours were developed to analyze several designs of the test specimen. The final design has a total length of $10.62 \mathrm{in}$. This specimen has a gage length of 1.80 in. and a grip length of 1.91 in. as Figure 3-25 shows. An elastomeric bladder was developed to prevent leakage of the pressurizing medium. This bladder exerts a pressure over the middle 4.62 in. of the specimen. This was modeled by applying a pressure over this area in the finite element model. The finite element model and loading are shown in Figure 3-30. The type of material model used was an orthotopic linear elastic model. The material constants used were:

$$
\begin{gathered}
E_{r}=E_{\theta}=1.12 E+06 \\
E_{x}=1.29 E+06 \\
v=0.13 .
\end{gathered}
$$

The finite element model was analyzed with seven different ratios of circumferential-to-axial stress to determine the stress levels in the specimen. The seven ratios of circumferential-to-axial stress used were $0: 1,1: 0,1: 1,1: 1.3,1: 2,2: 1$, and $0:-1$.

Figures 3-31 and 3-32 show the stresses on the inside and outside surfaces for the 0:1 case, which has an axial load of $4000 \mathrm{lb}$ and no pressure applied. For this case, the maximum stress is the axial stress and is on the inside surface of the specimen. The calculated value for the axial stress at the center of the specimen is:

$$
\sigma_{x}=F / A=2229 p s i
$$

The peak stress is less than $2 \%$ higher than the calculated axial stress. The axial stresses at the center on the inside and outside surfaces determined in the finite element analysis were $2261 \mathrm{psi}$ on the inside surface and $2197 \mathrm{psi}$ on the outside surface. The bending at the center of the specimen is less than $2 \%$.

The stresses on the inside and outside surfaces of the 1:0 case are shown in Figures 3-33 and 3-34. For this case, the specimen is loaded with an internal pressure of 412 psi and no axial load. Figure 3-28 shows that the maximum stress for this case is a circumferential stress of 2474 psi located $0.65 \mathrm{in}$. from the center on the inside surface. The circumferential stress at the center of 
ORNL-DWG 94-5545

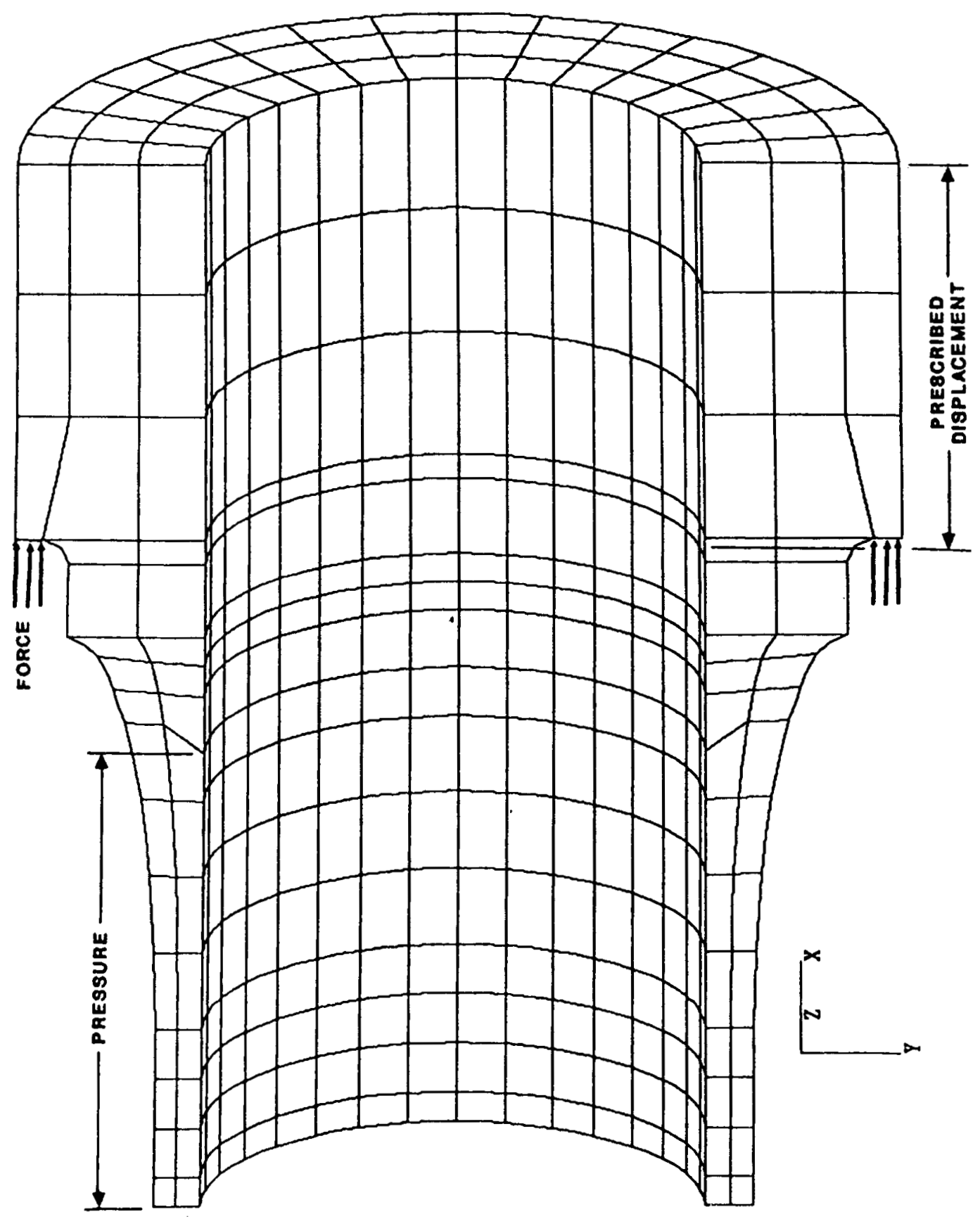

Figure 3-30.

FINITE ELEMENT MODEL. 
ORNL-DWG 94-5546

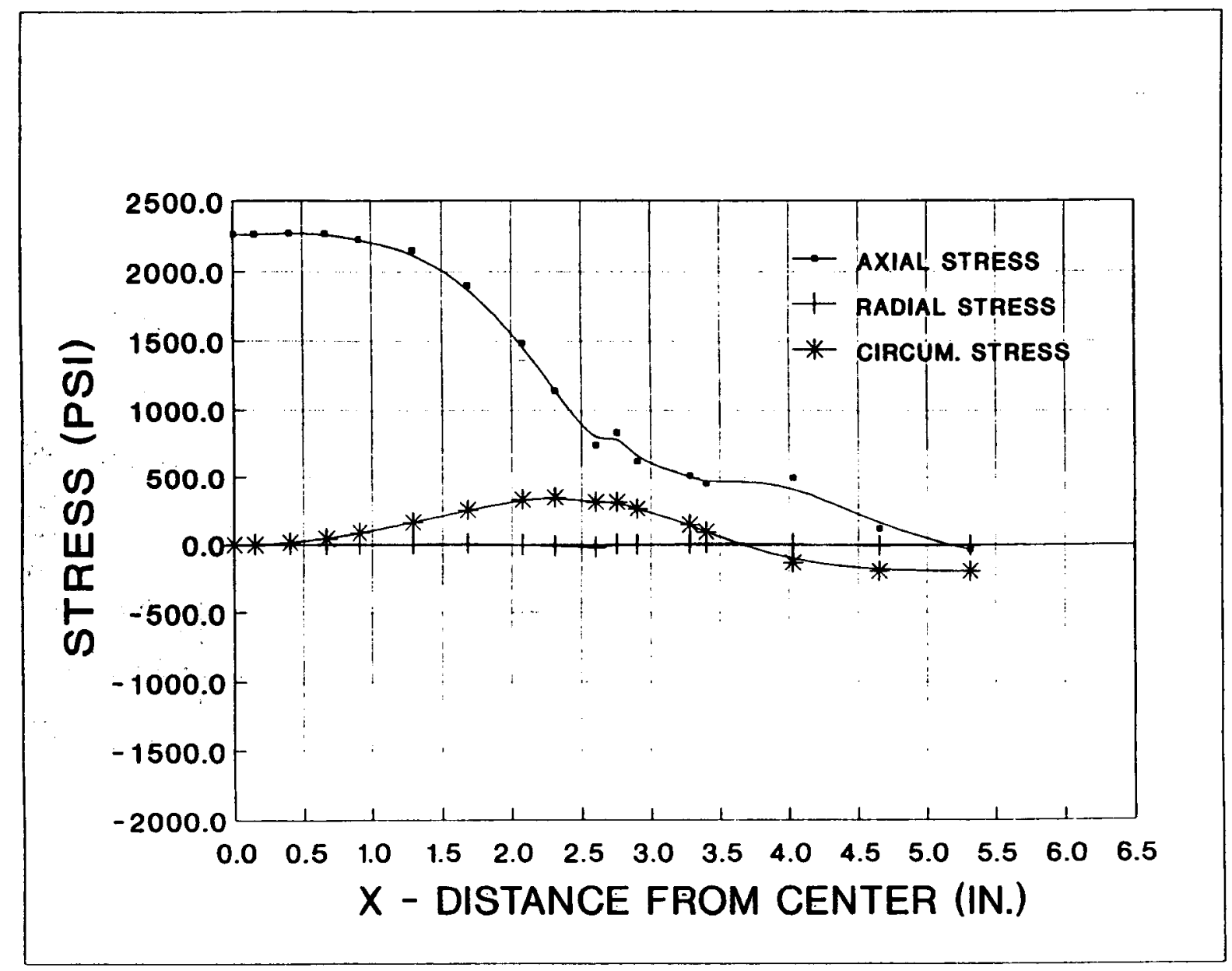

Figure 3-31.

STRESS ON INSIDE SURFACE 0:1 RATIO, F=4,000 LB. 
ORNL-DWG 94-5547

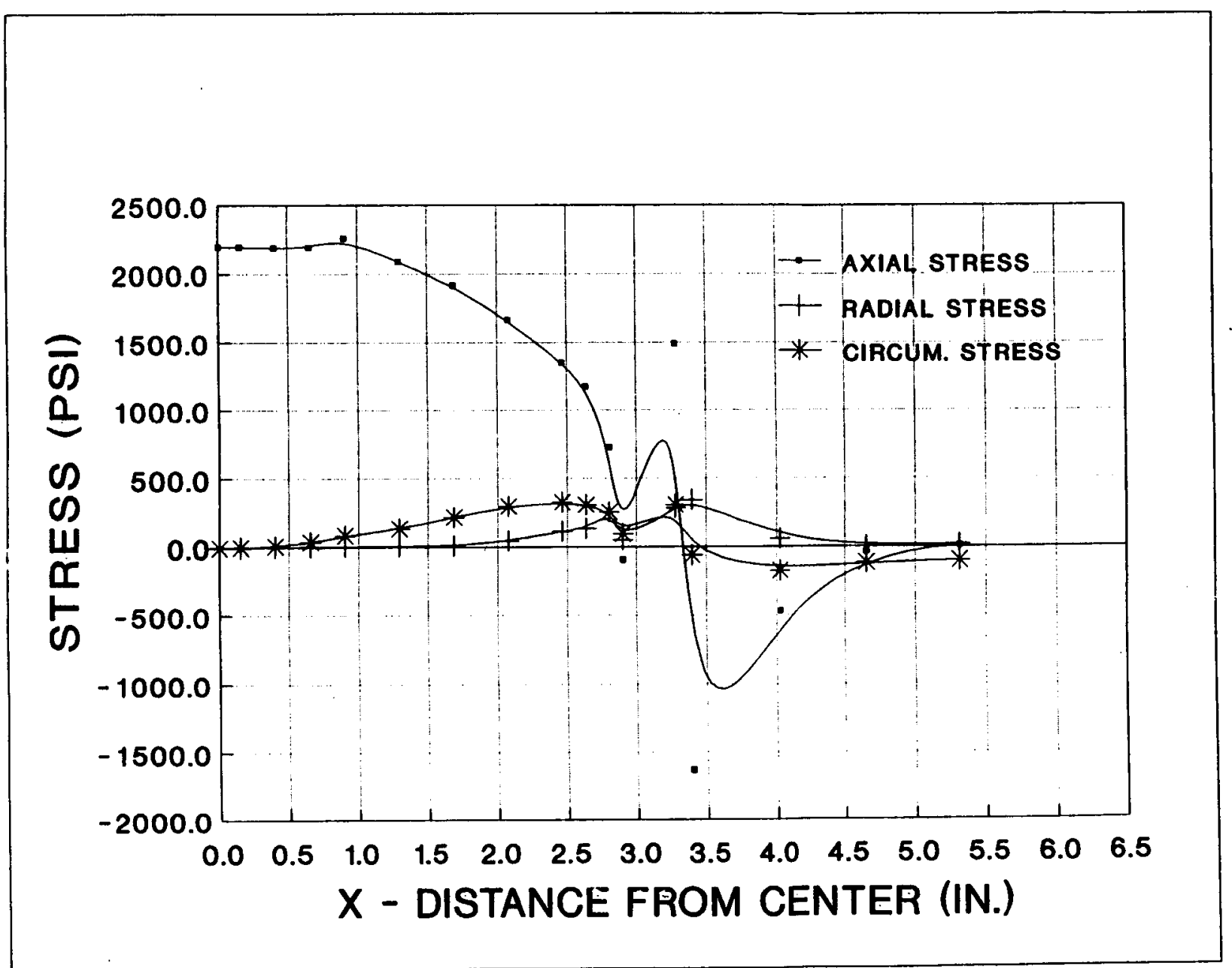

Figure 3-32.

STRESS ON OUTSIDE SURFACE 0:1 RATIO, $F=4,000$ LB. 
ORNL-DWG 94-5548

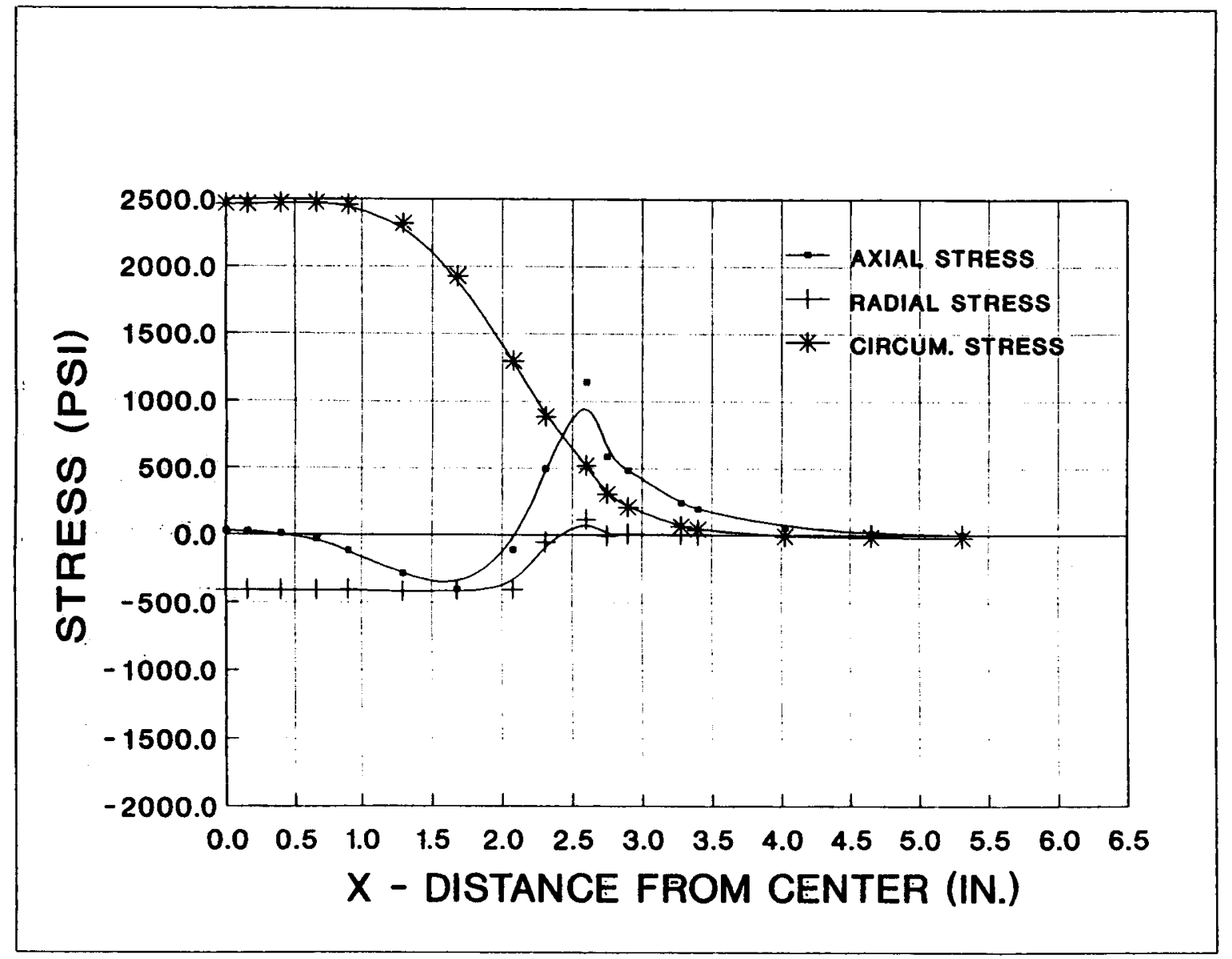

Figure 3-33.

STRESS ON INSIDE SURFACE 1:0 RATIO, $\mathrm{P}=412$ PSI. 


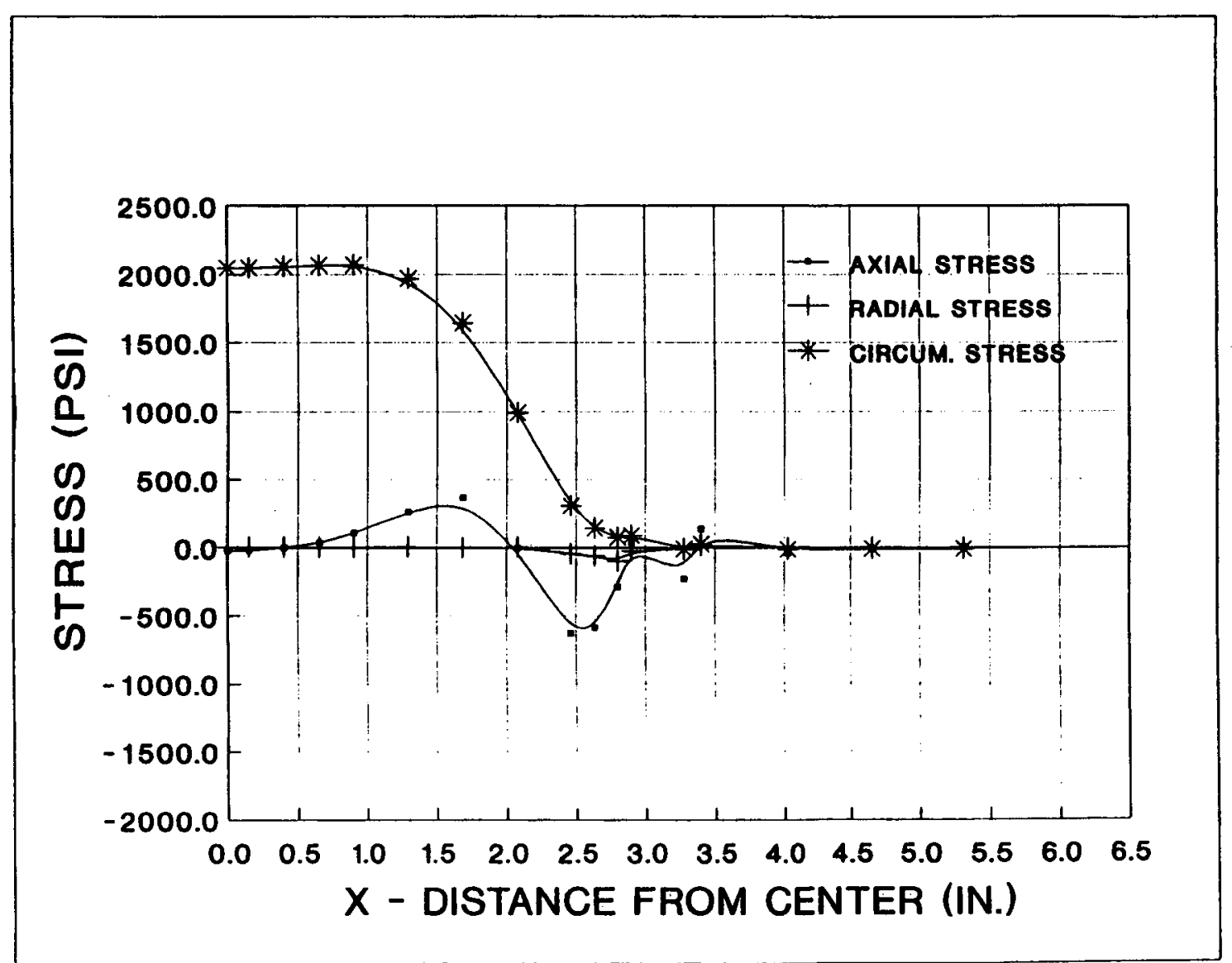

Figure 3-34.

STRESS ON OUTSIDE SURFACE 1:0 RATIO, $\mathrm{P}=412$ PSI. 
the specimen on the inside surface is $2464 \mathrm{psi}$. The Lamé stress on the inside surface of the specimen is:

$$
\sigma_{\theta}=\frac{P a^{2}}{b^{2}-a^{2}}\left(1+\frac{b^{2}}{r^{2}}\right)=2457 \text { psi . }
$$

where " $a$ " is the inside radius, and " $b$ " is the outside radius. For this case, the peak stress is only slightly higher than the Lamé stress.

The third case, which has equal amounts of axial and circumferential stress, is loaded with $4000 \mathrm{lb}$ of force and $412 \mathrm{psi}$ of pressure. Figures 3-35 and 3-36 show the stresses on the inside and outside surfaces for this case. Figure 3-30 shows that the maximum stress is the circumferential stress on the inside surface. This stress peaks to $2542 \mathrm{psi} 0.9$ in. from the center. The circumferential stress at the center of the specimen is 2458 psi. The peak stress is less than $4 \%$ higher than the Lamé stress of 2457 psi. The peak axial stress on the outside surface is 2369 psi, which is less than the Lamé stress on the inside.

The stresses for the fourth case, with 1.3 times more axial stress than circumferential stress, are plotted in Figures 3-37 and 3-38. This case has an axial load of 4,000 lb and a circumferential load of 317 psi. The maximum stress is the axial stress on the outside surface. This stress at the center on the outside surface is $2181 \mathrm{psi}$, and the stress at the center of the inside surface is $2281 \mathrm{psi}$. The bending in the specimen for the case is slightly over $2 \%$. The peak stress for this case is about $5 \%$ higher than the calculated stress of F/A $=2229 \mathrm{psi}$.

The next case analyzed was the case with twice as much axial stress as circumferential stress. To achieve this ratio, an axial load of $4000 \mathrm{lb}$ was applied, and a circumferential load of $206 \mathrm{psi}$ was applied. For this case, the maximum stress of $2314 \mathrm{psi}$ is the axial stress on the outside surface 0.9 in. from the center. The maximum axial stress at the center is 2274 psi, which is on the inside surface of the specimen. The bending at the center of the specimen for this case is less than 2\%. The stresses on the inside and outside surfaces can be seen in Figures 3-39 and 3-40. For this case, the stress away from the center peaks less than $4 \%$ above the calculated axial stress of $\mathrm{F} / \mathrm{A}=2229 \mathrm{psi}$.

The sixth case analyzed was the case with twice as much circumferential stress as axial stress. Figures 3-41 and 3-42 show the stresses for this case. For this case, the maximum stress is a 
ORNL-DWG 94-5550

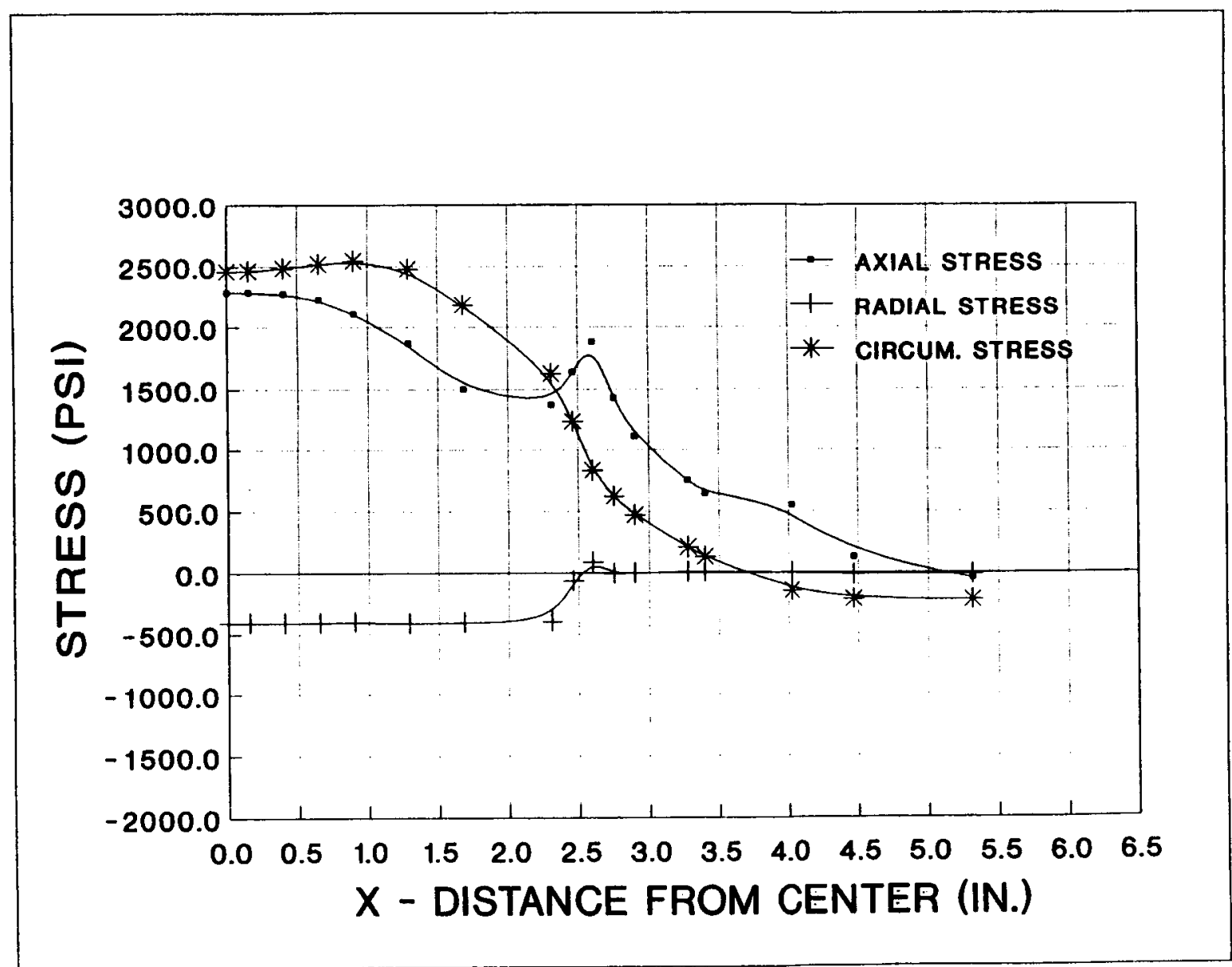

Figure 3-35.

STRESS ON INSIDE SURFACE 1:1 RATIO, $P=412$ PSI, F=4,000 LB. 
ORNL-DWG 94-5551

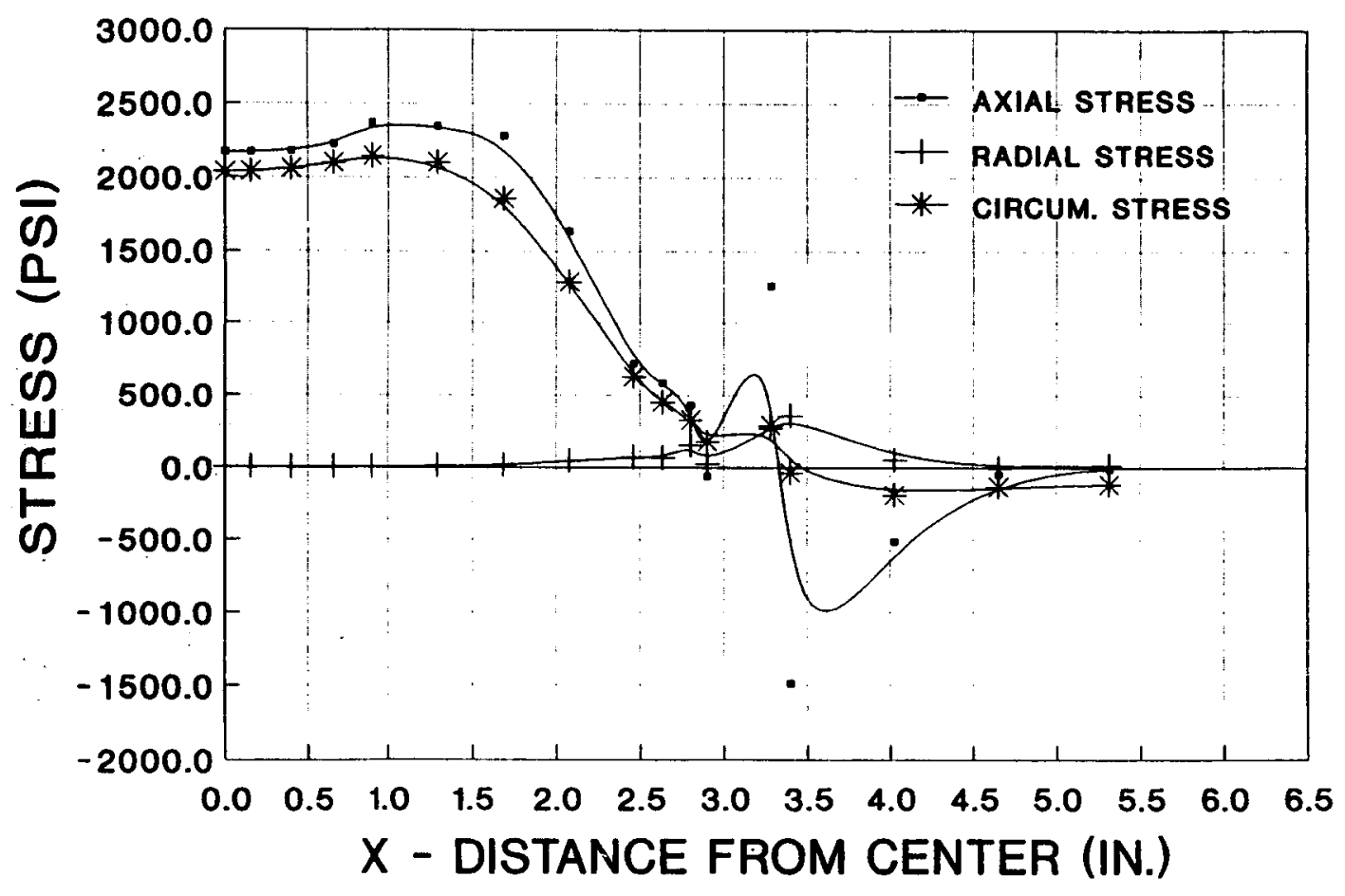

Figure 3-36.

STRESS ON OUTSIDE SURFACE 1:1 RATIO, $\mathrm{P}=412 \mathrm{PSI}, \mathrm{F}=4,000 \mathrm{LB}$. 
ORNL-DWG 94-5552

$\underset{\infty}{\omega}$

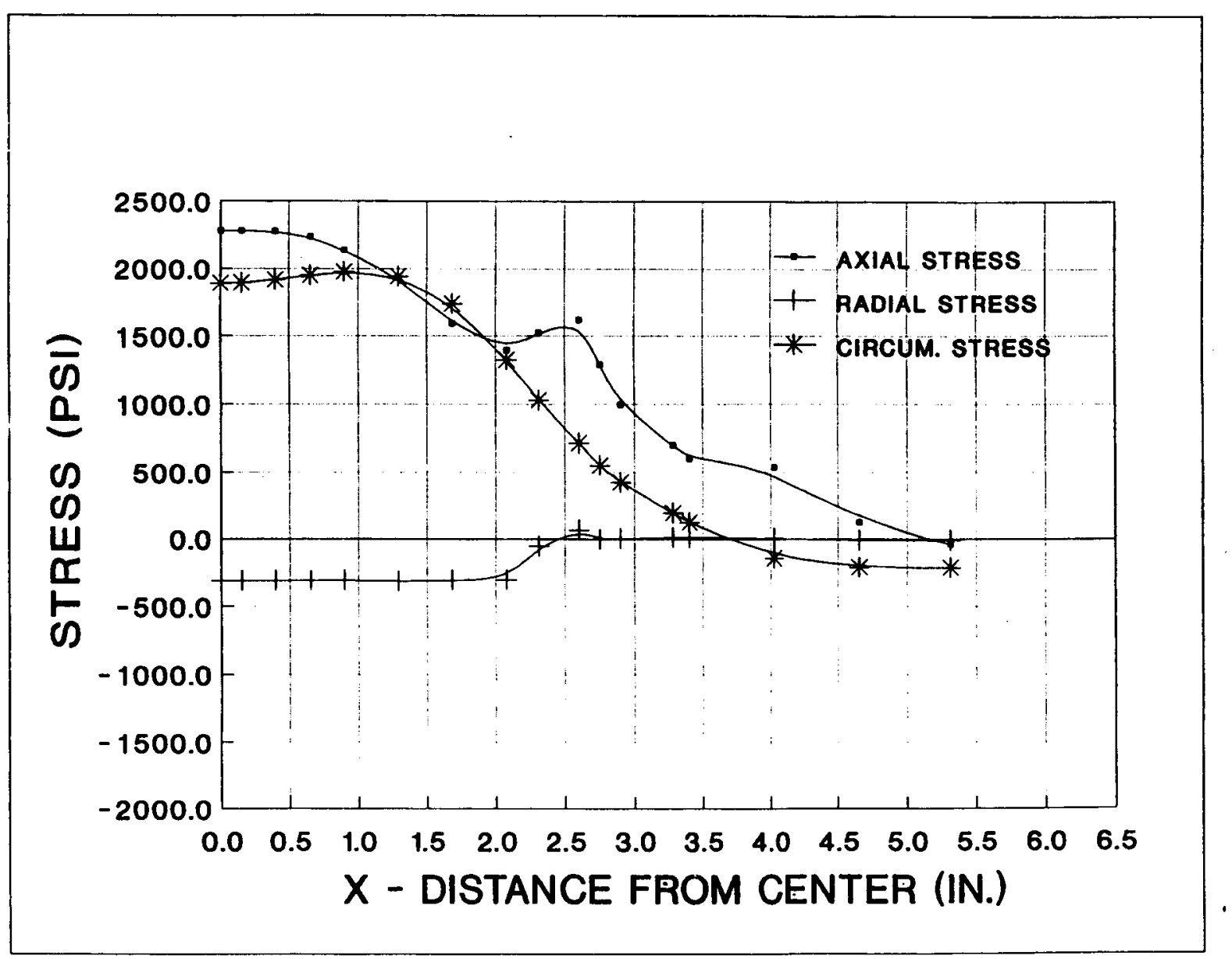

Figure 3-37.

STRESS ON INSIDE SURFACE 1:1.3 RATIO, $\mathrm{P}=317$ PSI, $\mathrm{F}=4,000$ LB. 
ORNL-DWG 94-5553

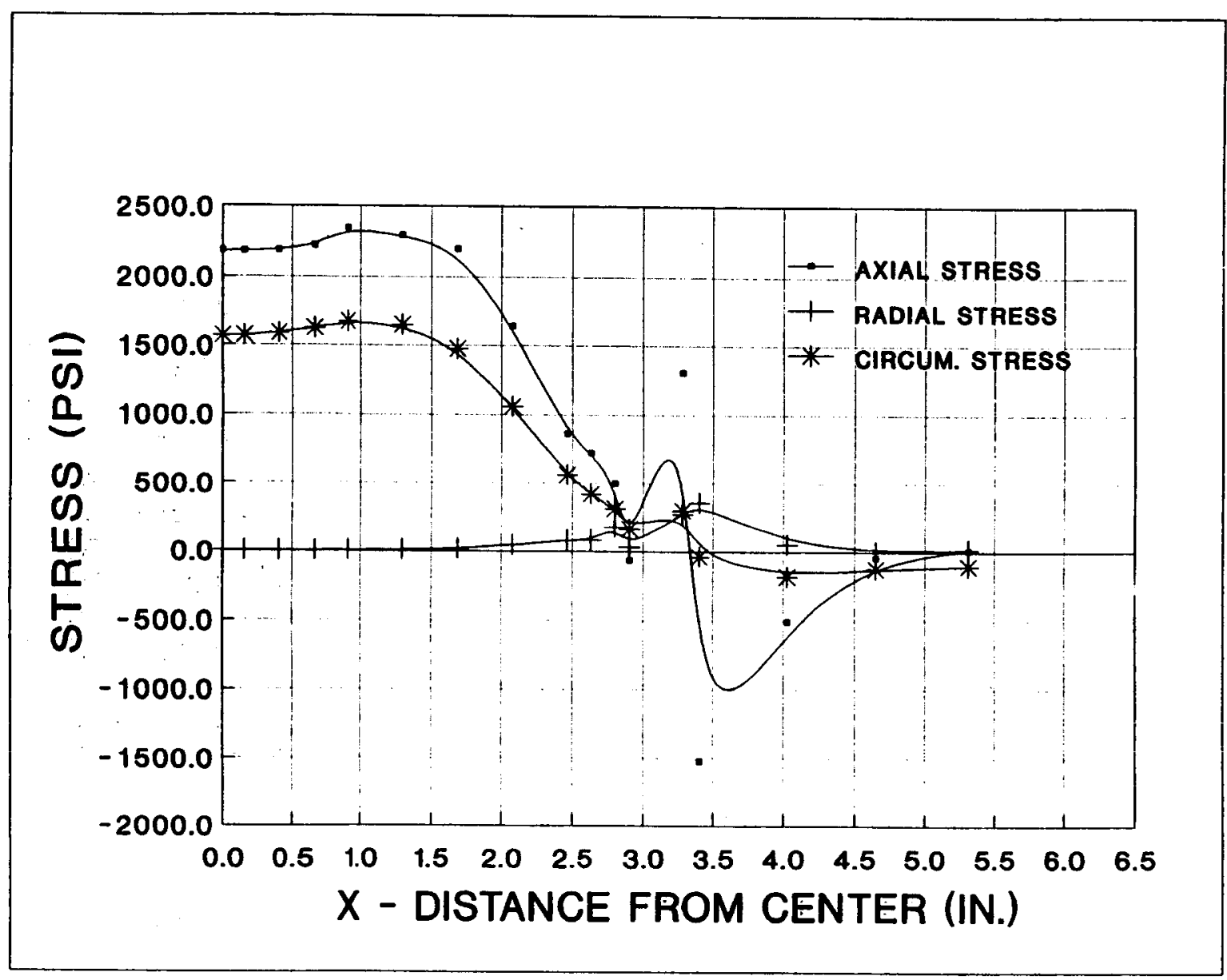

Figure 3-38.

STRESS ON OUTSIDE SURFACE 1:1.3 RATIO, $\mathrm{P}=317$ PSI, $\mathrm{F}=4,000$ LB. 


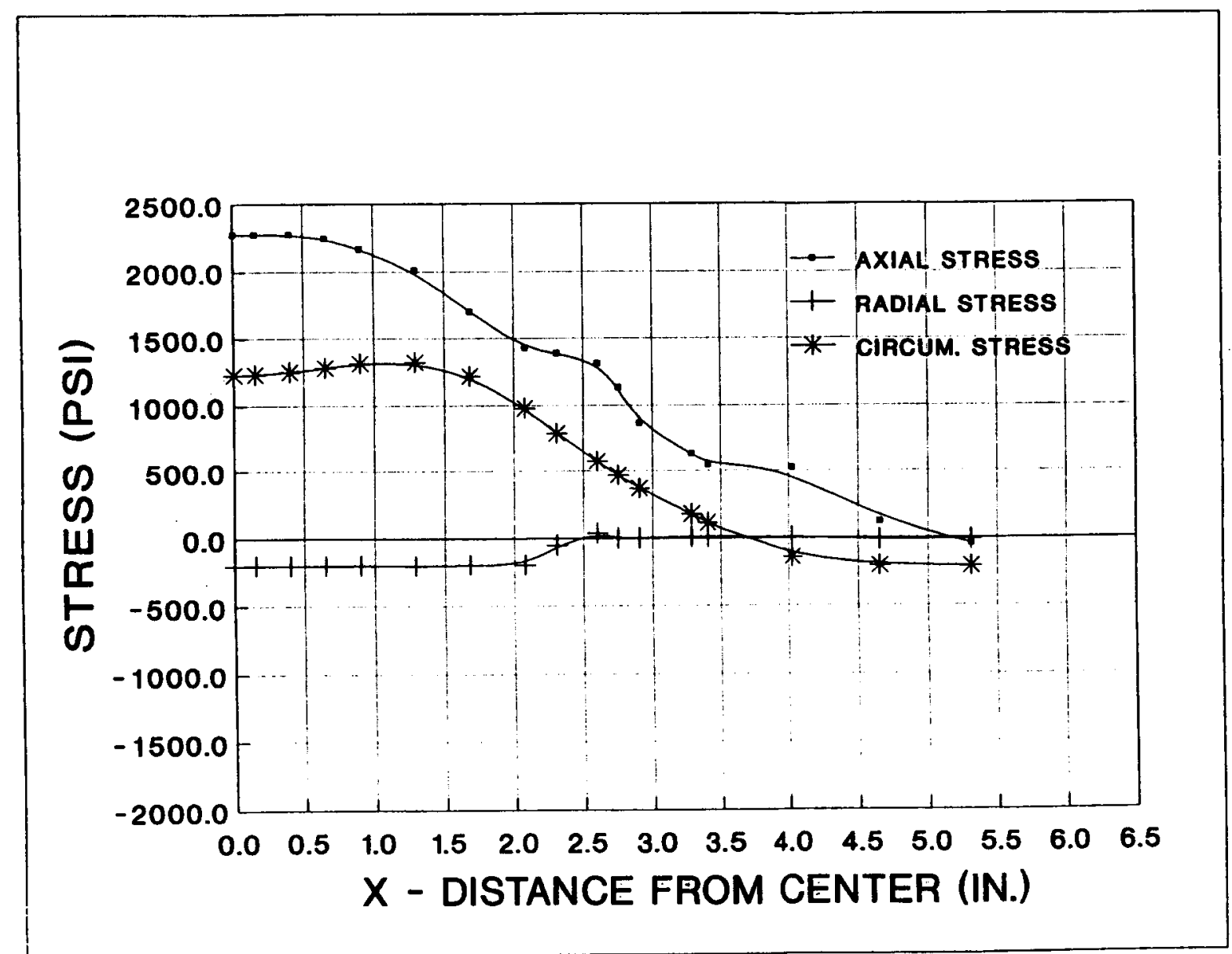

Figure 3-39.

STRESS ON INSIDE SURFACE 1:2 RATIO, P=206 PSI, F=4,000 LB. 
ORNL-DWG 94-5555

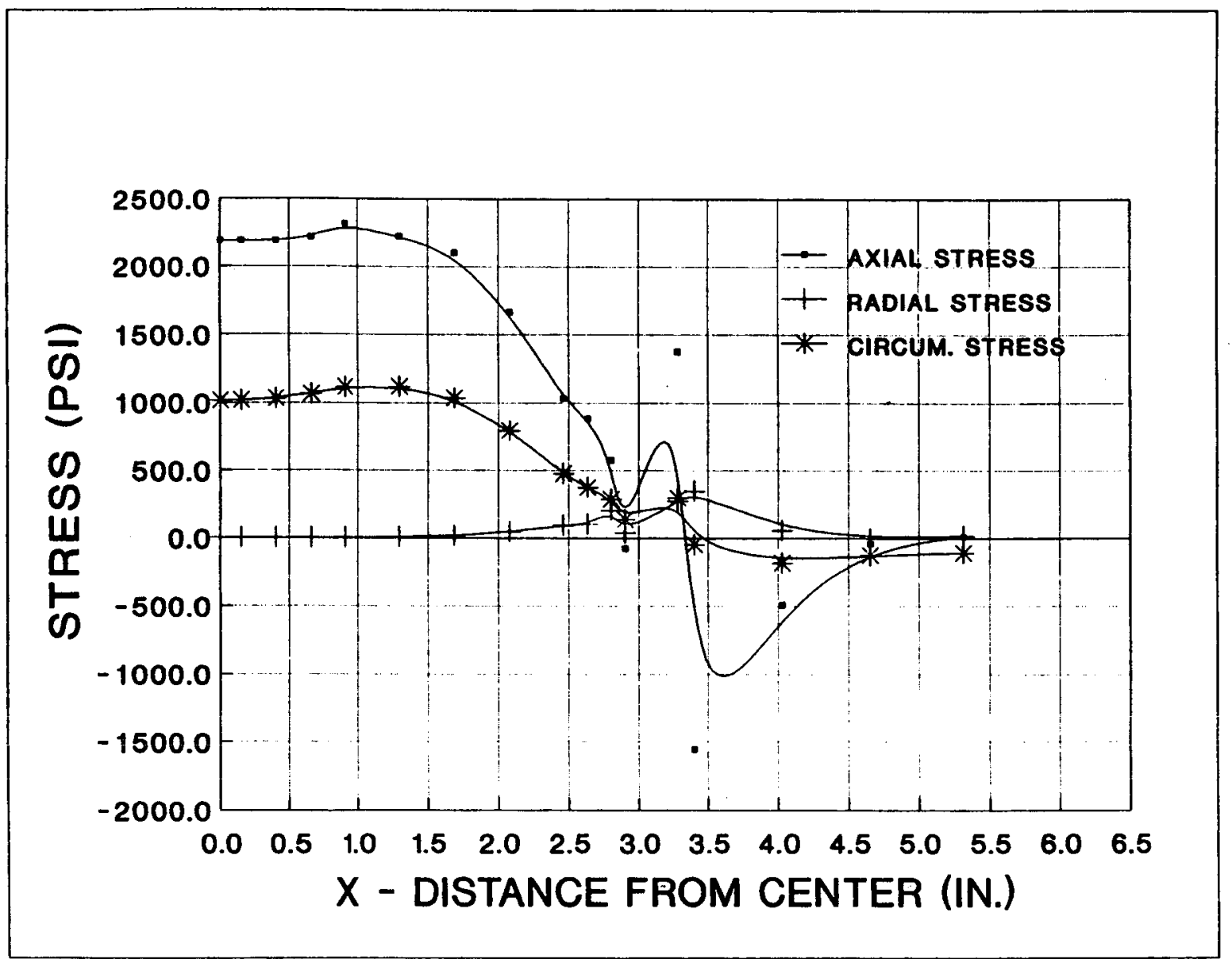

Figure 3-40.

STRESS ON OUTSIDE SURFACE 1:2 RATIO, P=206 PSI, F=4,000 LB. 


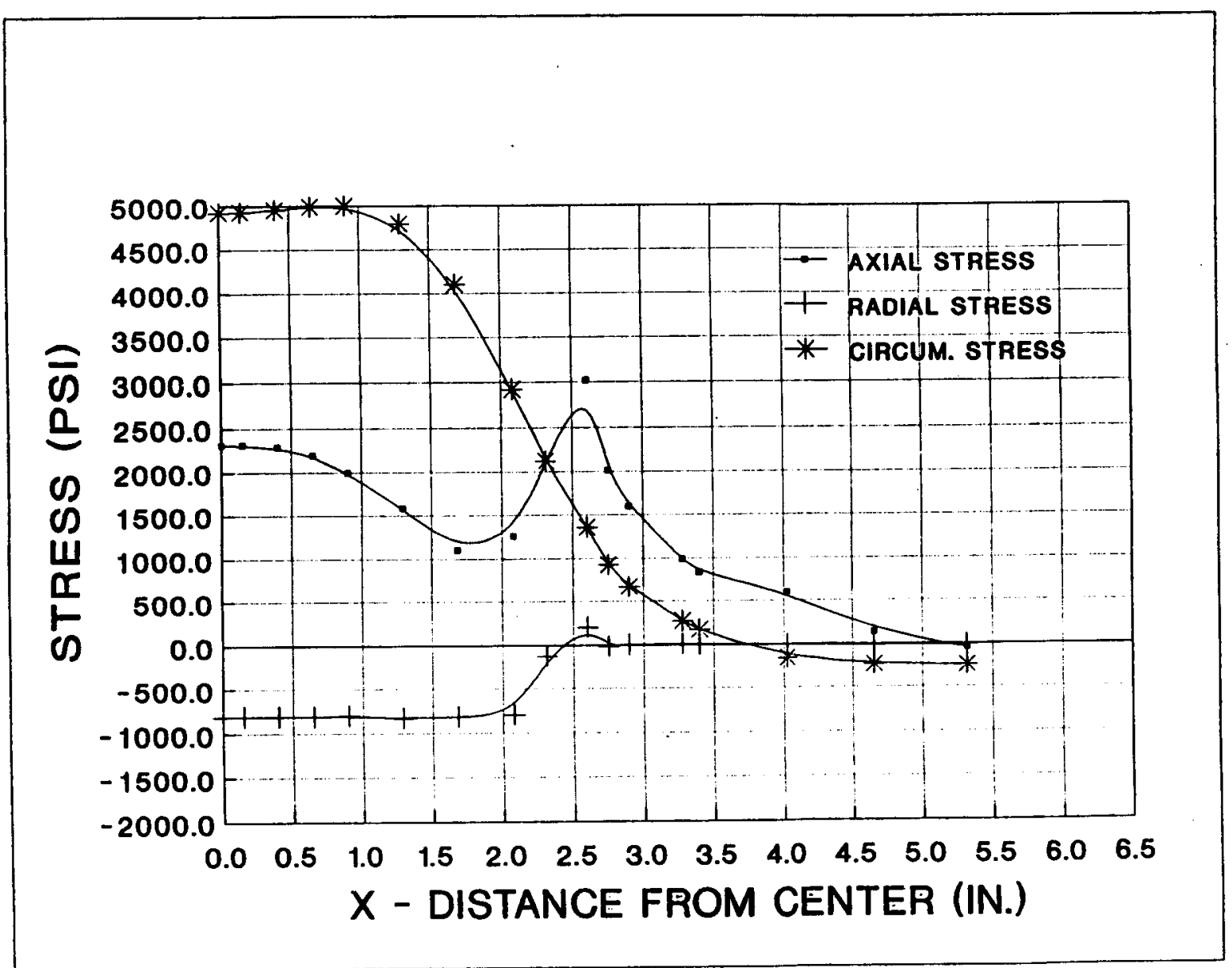

Figure 3-41.

STRESS ON INSIDE SURFACE 2:1 RATIO, P=824 PSI, F=4,000 LB. 
ORNL-DWG 94-5557

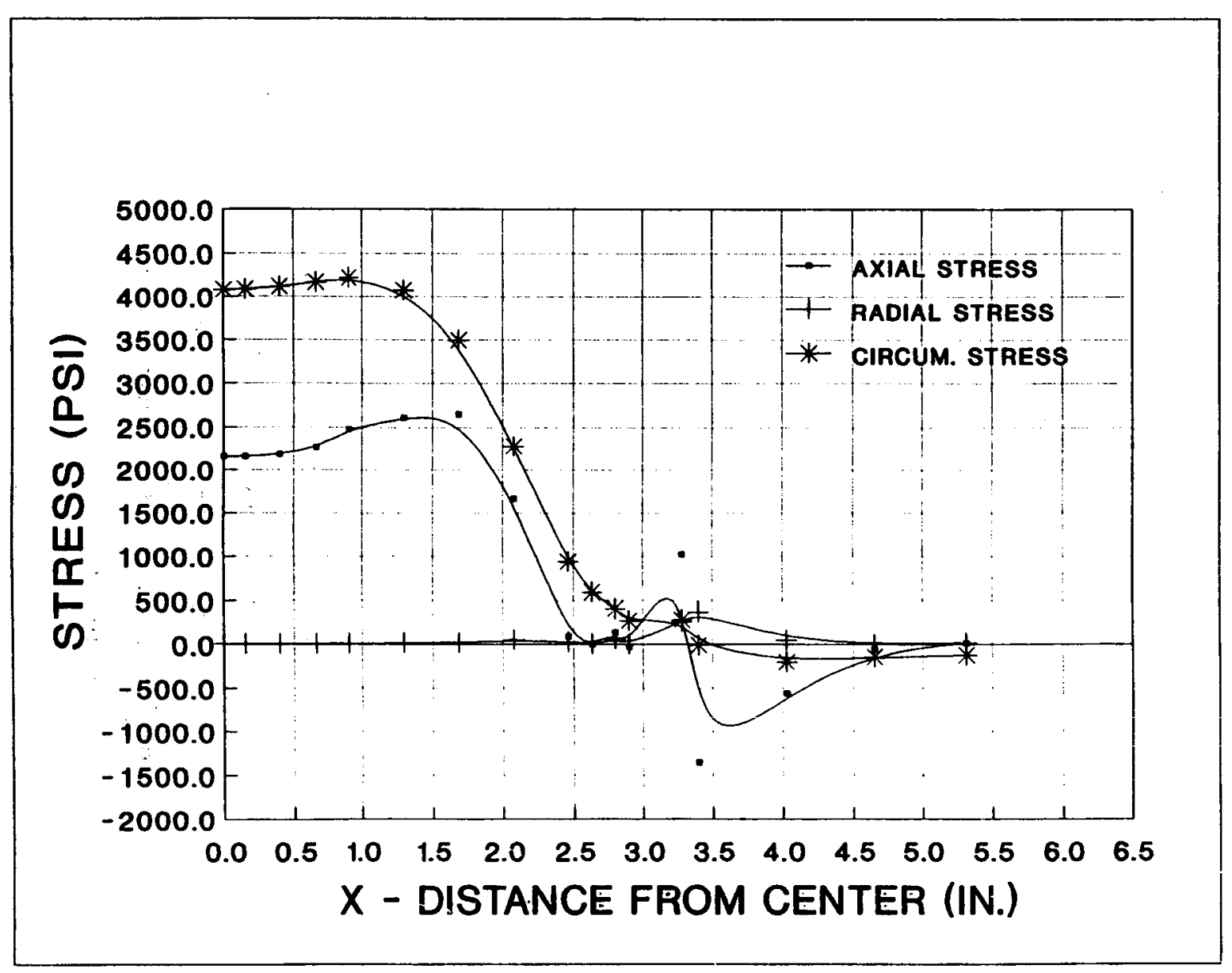

Figure 3-42.

STRESS ON OUTSIDE SURFACE 2:1 RATIO, $\mathrm{P}=824$ PSI, $\mathrm{F}=4,000$ LB. 
circumferential stress of $4997 \mathrm{psi}$ located $0.9 \mathrm{in}$. from the center on the inside surface. The stress at the center of the inside surface is 4921 psi. The Lamé stress on the inside for this case is:

$$
\sigma_{\theta}=\frac{P_{i} a^{2}}{b^{2}-a^{2}}\left(1+\frac{b^{2}}{r^{2}}\right)=4915 \text { psi . }
$$

The peak stress is less than $2 \%$ higher than the Lamé stress.

The last case analyzed was the case with an axial compression load of $4000 \mathrm{lb}$. Figures 3-43 and 3-44 show stresses for this case. For this case, the stresses to be concerned about are the minimum stresses. The minimum stress for this case was a stress of -2270 psi, which was located 0.4 in. from the center. The calculated value for the axial stress at the center of the specimen is:

$$
\sigma_{x}=F / A=-2,229 p s i
$$

The peak stress is less than $2 \%$ higher than the calculated axial stress. The finite element analysis gave the axial stresses at the center of the specimen as -2261 psi on the inside and -2197 psi on the outside. This means the bending at the center of the specimen is less than $2 \%$.

For all of these cases, the difference between the peak stress away from the center of the specimen and the calculated axial of Lamé stress for the specimen is less than $5 \%$. Several other designs of the specimen were also analyzed, but it was determined that this was the best design.

A buckling analysis was performed on the test specimen under an axial compressive load. A finite element buckling analysis was done on the specimen using a compressive load of $4000 \mathrm{lb}$. First, the analysis was run using the modulus of elasticity used for the other analyses. From this analysis, it was determined that the critical load for the specimen is $156,117 \mathrm{lb}$. Hand calculations of the buckling load for a cylinder with the same inside and outside radius as the specimen at the center were done to compare to the finite element analysis. A calculation was done using the same modulus of elasticity as the finite element analysis. For this calculation, the equation used to calculate the critical stress was:

$$
\sigma_{c r}=\frac{E h}{a \sqrt{3\left(1-v^{2}\right)}} .
$$

This equation can be found in the book by Timoshenko and Gere. ${ }^{121}$ From this equation, the critical load can be determined. For this calculation, the critical load was $198,328 \mathrm{lb}$. 
ORNL-DWG 94-5558

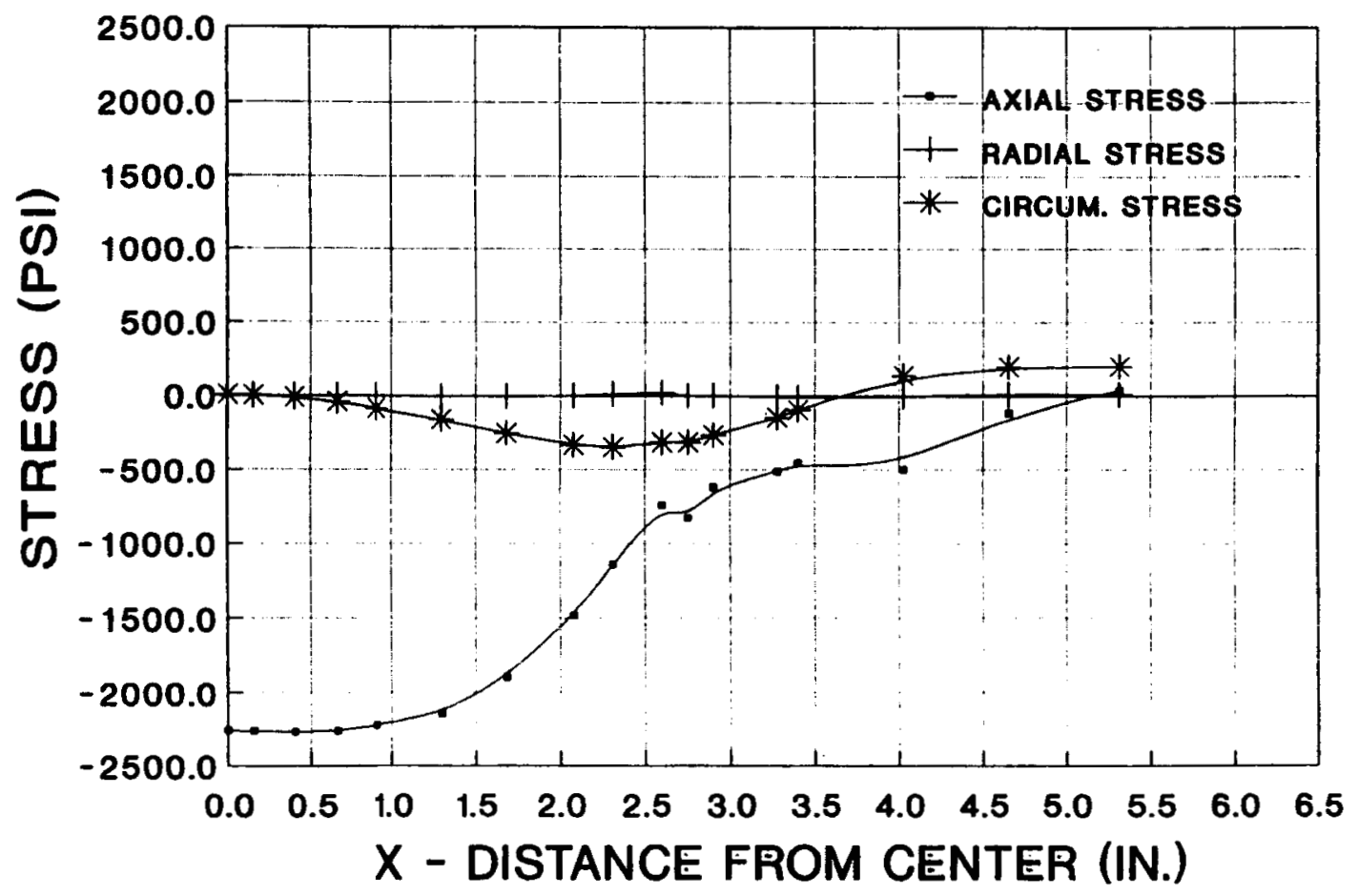

Figure 3-43.

STRESS ON INSIDE SURFACE 0:-1 RATIO, F=4,000 LB. 
ORNL-DWG 94-5559

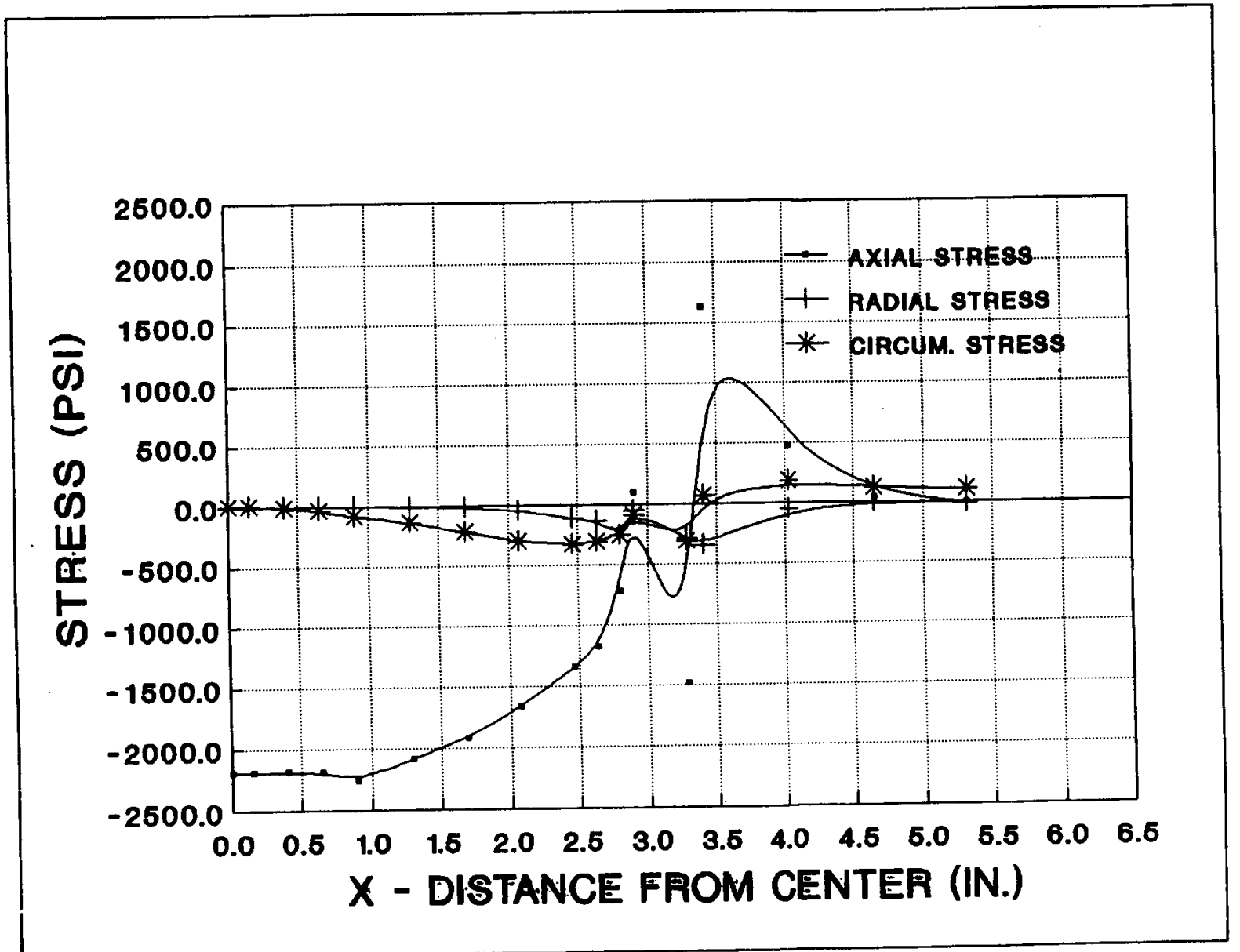

Figure 3-44.

STRESS ON OUTSIDE SURFACE 0:-1 RATIO, $F=4,000$ LB. 
Timoshenko and Gere indicate that the tangent modulus should be used instead of the modulus of elasticity. For this calculation, the equation becomes:

$$
\sigma_{c r}=\frac{E / h}{a \sqrt{3\left(1-v^{2}\right)}} .
$$

The tangent modulus used for this calculation was $0.3063 \mathrm{E}+06$. The results of this calculation for a cylinder give the critical load as $54,239 \mathrm{lb}$. The finite element analysis was also done using the tangent modulus, and the results give a critical load of $47,320 \mathrm{lb}$. The hand calculations of the cylinder are within $15 \%$ of the finite element results, which indicates that the finite element results are reliable. The load required to fail the specimen in compression is about $12,000 \mathrm{lb}$. The buckling load of $47,320 \mathrm{lb}$ is about 4 times this load.

After analyzing various models of the graphite test specimen for the multiaxial test, a final design was developed. The analyses showed that, in the final design, the highest stresses are located in the gage section. For the seven cases analyzed, the peak stress in the specimen is less than $5 \%$ greater than the stress at the center of the specimen. The buckling analysis shows that the test specimen will not buckle under a compressive load. All of the analyses performed on the graphite test specimen indicate that the final design of the specimen will fail in the gage section under the combinations of axial and circumferential loads that will be applied. These analytical results were validated by strain-gage measurements on an aluminum tube as shown in Figure 3-45.

A rigid load train facility for applying axial tension and compression loads to an internally pressurized, thin-walled cylinder is used. A 489-kN (110-kip) four-post MTS load frame is employed to maintain rigidity. Hydrostatic bearings, stud preloaders, and special shear web design 111-kN (25-kip) load cell are used to eñsure rigidity. The load cell allows monitoring of any extraneous moments. A precise load train alignment device facilitates accurate load train alignment to within $\pm .008 \mathrm{~mm}$ ( $\pm .0003 \mathrm{in}$.). Hydraulic expansion grips ensure accurate alignment of the specimen. Internal pressurization of $6.9 \mathrm{MPa}(1,000 \mathrm{psi})$ will use water as the pressurization medium. The facility is shown in Figure 3-46.

An MTS 442 control system is used to maintain the desired ratio of internal pressure to axial load, and a Hewlett-Packard (HP) 3565S system is used to record load, pressure, and strain gage data. Axial and circumferential strain in the uniform gage section are monitored with strain gages on the outer surface of each specimen. 


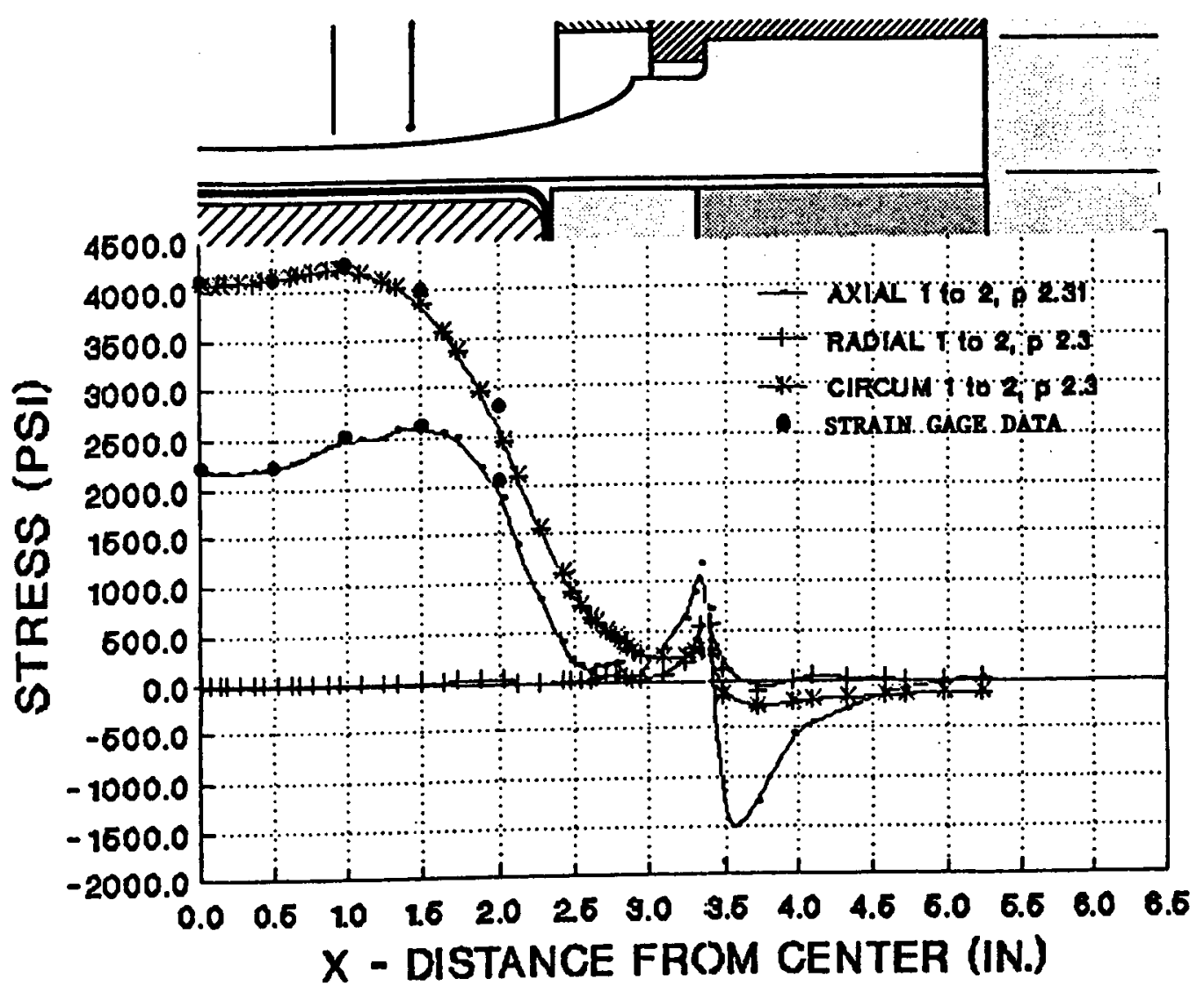

Maximum variation within $74 \mathrm{~mm}$ (2.91) gage section is $\pm 7.8 \%$.

Figure 3-45.
STRAIN-GAGED ALUMINUM TUBE VERIFIED UNIFORMITY OF STRAIN DISTRIBUTION PREDICTED BY ELASTIC FINITE ELEMENT ANALYSIS.




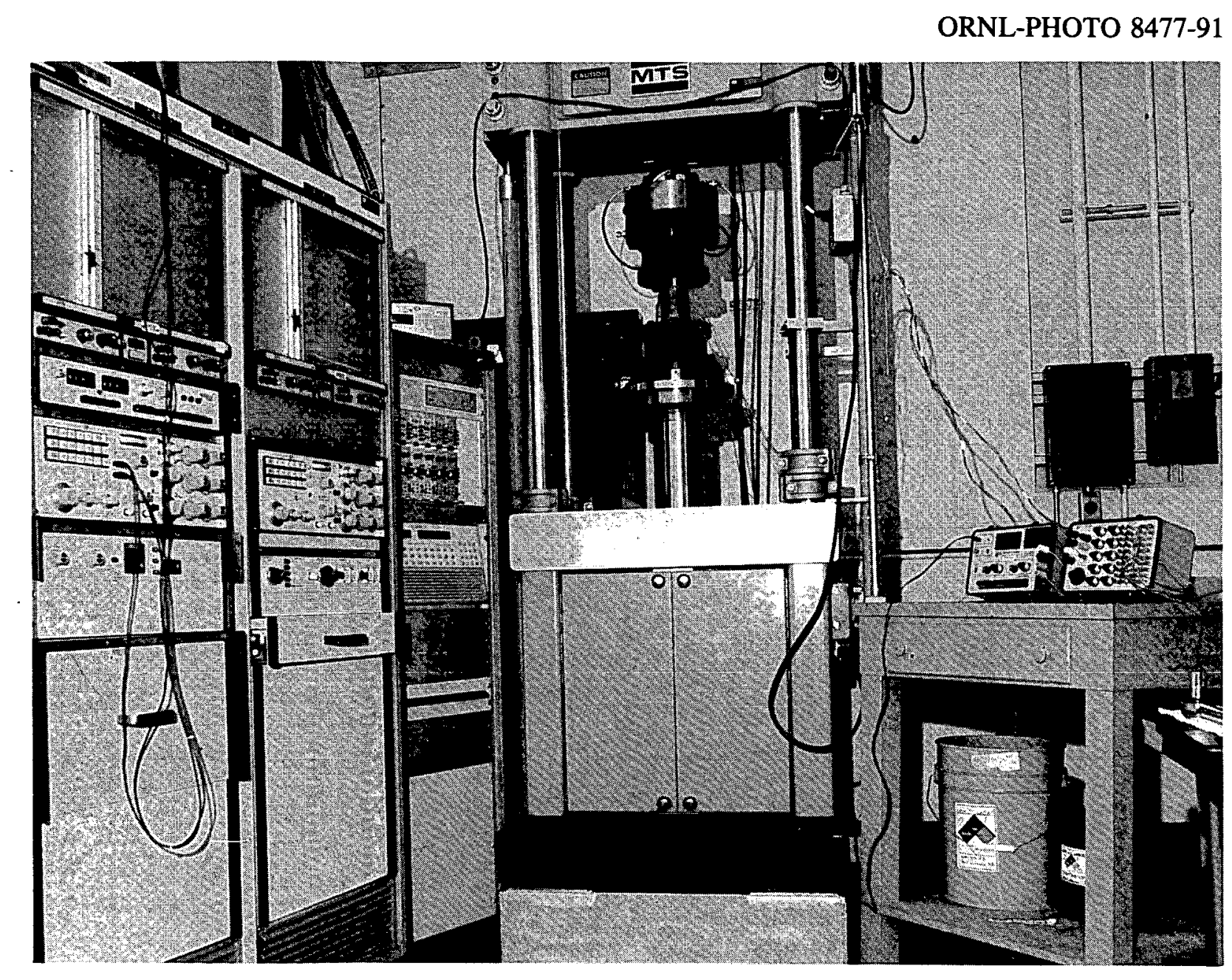

Figure 3-46. MULTIAXIAL GRAPHITE TEST FACILITY. 
The test matrices are illustrated in Tables 3-7 and 3-8. These tables list the principal stress ratio, the quadrant of the failure envelope where data are being collected, and the number of specimens being tested.

The circumferential stress is maintained by a specially designed hydraulic system that uses water as the pressurizing fluid and will be controlled by an MTS system. The axial load stress is maintained by the same MTS system. By controlling both principal stresses from the same control system, the desired principal stress ratio can be maintained.

The H-451 cutting plan is shown in Figure 3-47. A total of 15 specimens were obtained from each of four $0.43-\mathrm{m}$-diam by $0.84-\mathrm{m}$-long billets. The specimens for each stress ratio will be selected at random using a table of random numbers.

The axial load on the 489-kN MTS machine is monitored with an interface load cell, which is a compact shear web design. The load cell has four sensors, two axial load sensors and two moment sensors perpendicular to each other, calibrated accurate to better than $\pm .05 \%$ in the expected test load ranges. The load is set with an MTS 442 controller and can be set to the nearest $0.5 \mathrm{~N}$.

The pressure to the test piece is sensed with a calibrated Heise gage $( \pm 2 \mathrm{KPa})$ and controlled with an MTS 442 controller.

The ratio between the two loads (axial and pressure) is maintained through an MTS 410 Digital Function Generator. Strain gage signals are conditioned with Vishay 2310 signalconditioning amplifiers. All of the data are managed with an HP 3565 S data acquisition/control unit and are stored on disk for record.

Results from preliminary tests during facility shakedown and the tests conducted to date on the reference set of specimens are shown in Figure 3-48. Data from preliminary tests are shown as circles. These specimens were taken from near the edge of a billet. The data from tests using the cutting plan shown in Figure 3-47 are shown as Xs. They are all uniaxial tests. They were tested first to define the ratio of axial stress to hoop stress for tests in the corners of the maximum stress theory drawn in Figure 3-48; in quadrant 1, the tensile axial stress is 1.5 times the hoop stress, and in quadrant 4 , the compressive axial stress is 5 times the hoop stress.

The only biaxial data obtained thus far are from the preliminary tests. They fall outside the maximum principal stress failure envelope based on the average uniaxial data from the current tests. It should be noted though that $\mathrm{H}-451$ graphite is usually stronger near the outside of a billet. 
Table 3-7

H-451 GRAPHITE MULTIAXIAL TEST MATRIX

\begin{tabular}{|c|c|c|c|}
\hline \multicolumn{2}{|c|}{ Principal stress ratio } & & \\
\hline $\begin{array}{c}\text { Circumferential } \\
\text { stress }\end{array}$ & $\begin{array}{c}\text { Axial } \\
\text { stress }\end{array}$ & $\begin{array}{c}\text { Stress } \\
\text { quadrant }\end{array}$ & $\begin{array}{c}\text { Number of } \\
\text { specimens }\end{array}$ \\
\hline \hline 0 & 1 & uniaxial & 6 \\
0 & -1 & uniaxial & 6 \\
1 & 0 & uniaxial & 6 \\
1 & 1.5 & 1 & 9 \\
1 & 2 & 1 & 6 \\
2 & 1 & 1 & 6 \\
1 & -1 & 4 & 6 \\
1 & -2 & 4 & 6 \\
1 & -5 & 4 & 9 \\
\hline
\end{tabular}

Table 3-8

IG-110 GRAPHTE MULTIAXIAL TEST MATRIX

\begin{tabular}{|c|c|c|c|}
\hline \multicolumn{2}{|c|}{ Principal stress ratio } & & \\
\hline $\begin{array}{c}\text { Hoop } \\
\text { stress }\end{array}$ & $\begin{array}{l}\text { Axial } \\
\text { stress }\end{array}$ & $\begin{array}{c}\text { Stress } \\
\text { quadrant }\end{array}$ & $\begin{array}{c}\text { Number of } \\
\text { specimens }\end{array}$ \\
\hline \hline 0 & 1 & uniaxial & 4 \\
1 & 0 & uniaxial & 4 \\
1 & 2 & 1 & 4 \\
1 & 1 & 1 & 6 \\
2 & 1 & 1 & 4 \\
1 & -1 & 4 & 3 \\
1 & -3 & 4 & 2 \\
\hline
\end{tabular}


ORNL-DWG 94-5561

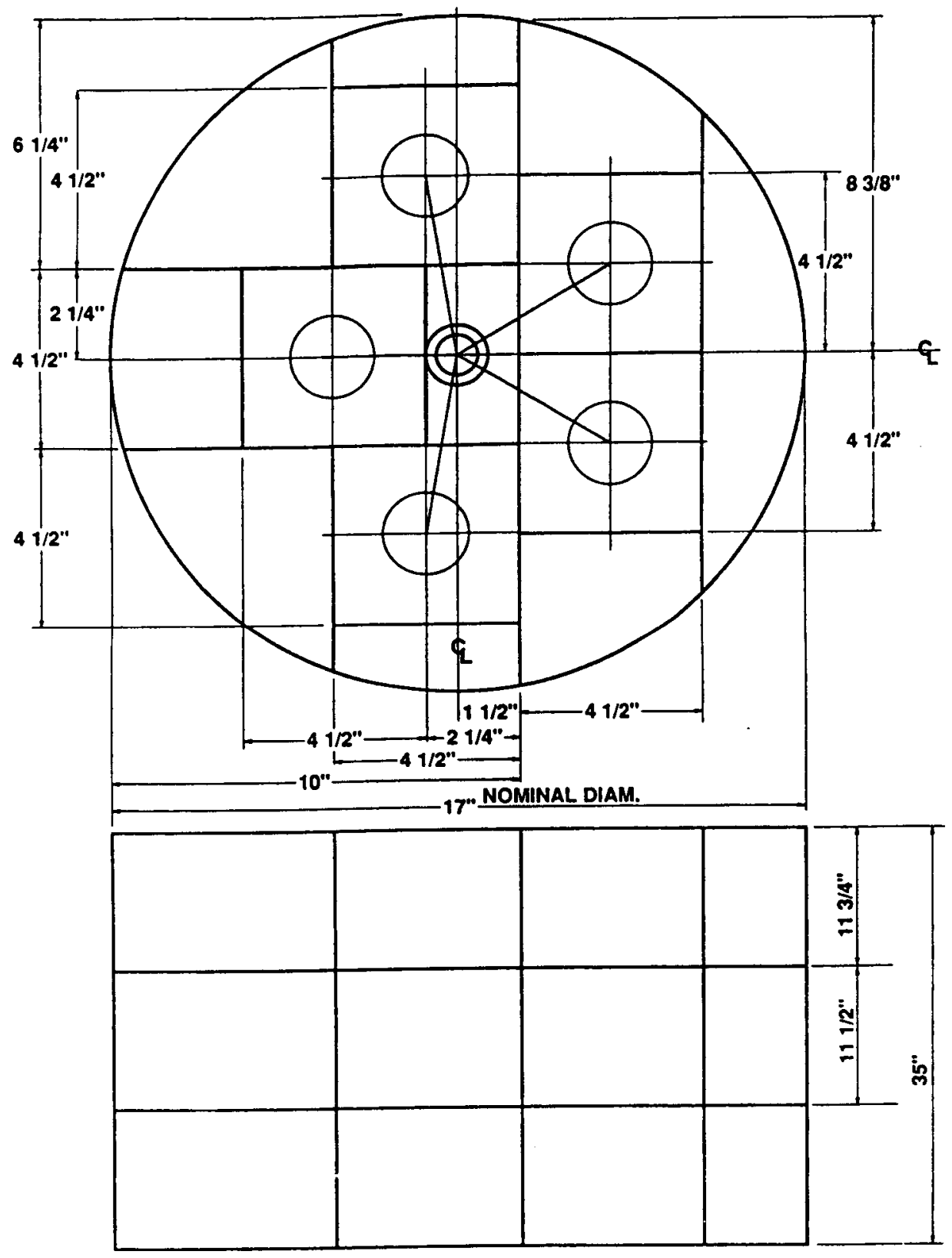

Figure 3-47.

H-451 BILLET CUTTING PLAN. 


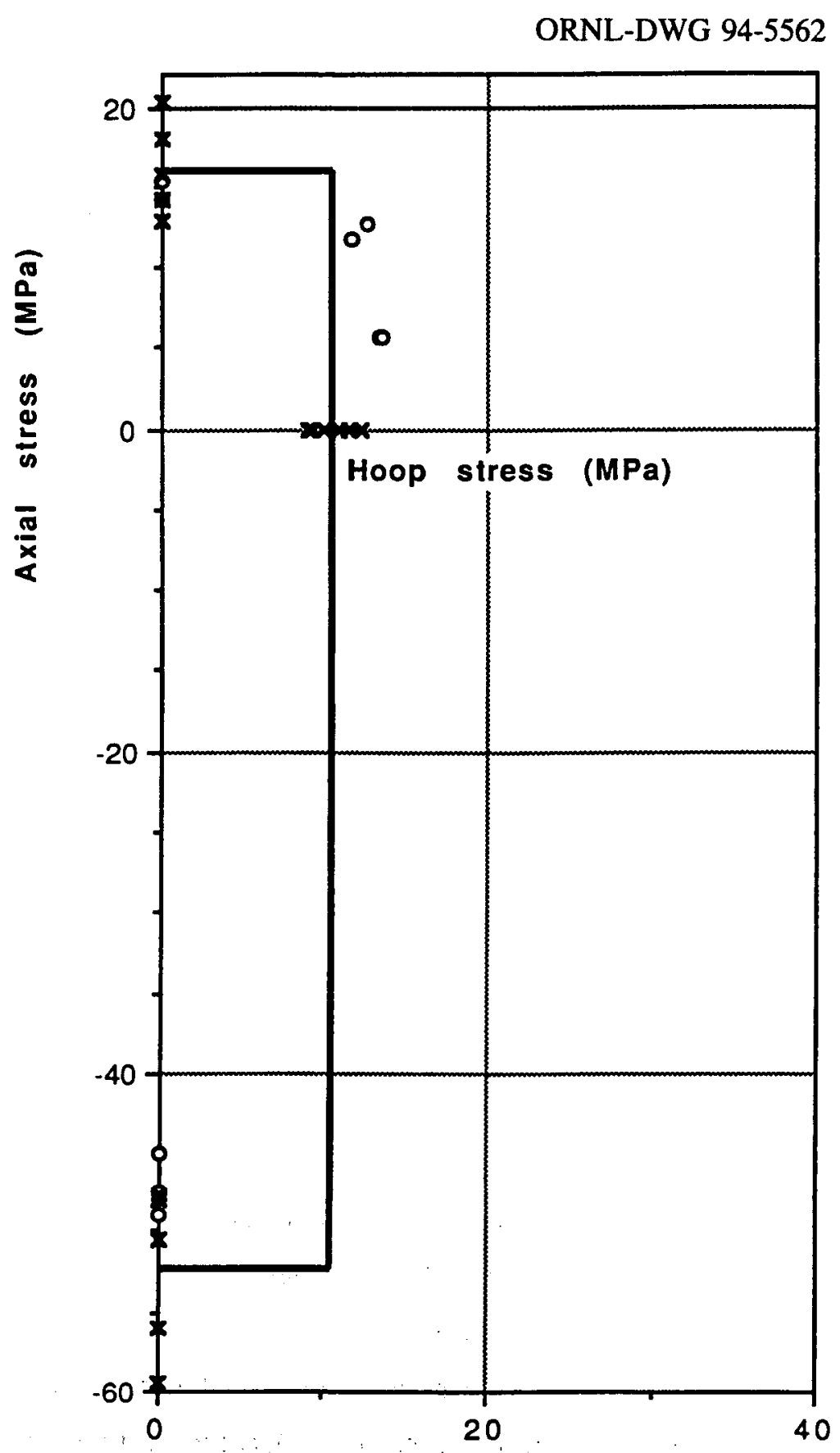

Figure 3-48.

FAILURE DATA OBTAINED IN MULTIAXIAL GRAPHITE TEST FACILITY. 


\subsection{FRACTURE MECHANICS - G. R. Romanoski}

Graphite core components in MHTGRs are subject to static and dynamic loads during assembly and operation. Although design is based on a maximum principal stress failure criterion, additional fracture mechanics analysis is needed to assess defect tolerance and inspection requirements. Data are required for critical stress-intensity factors and strain energy release rates for crack initiation, stable crack growth, and crack arrest in core graphite under ambient conditions. Important material variables include: orientation, within billet location, and lot-to-lot and billet-to-billet variation. A limited amount of additional data is needed to determine the effects of: neutron irradiation, oxidation degradation, pressurized helium atmospheres, and elevated temperatures. The chevron-notched short-rod (CNSR) test method per ASTM E1304-89 was chosen to provide fracture toughness data addressing material variables. The principal advantage of this technique is the small specimen size, which permits a significant number of specimens to be taken from a small volume at any chosen orientation. Furthermore, the 12.7-mm-diam short-rod (SR) specimen is compatible with the present limitations on specimen size defined by the HFIR irradiation capsules. The CNSR specimen geometry is shown in Figure 3-49.

A scoping study was conducted to demonstrate the suitability of the CNSR specimen and test method. ${ }^{122,123}$ Fracture toughness measurements were made on unirradiated $\mathrm{H}-451$, Stackpole 2020, and IG-110 nuclear graphites under ambient conditions. Specimen diameters of $12.7,19$, and $25.4 \mathrm{~mm}$ were tested. The results are given in Figure 3-50. Fracture toughness increased with increasing specimen size for all three graphites. This result was attributed to rising R-curve behavior. Fracture paths followed an array of large pores and filler coke cleavage planes resulting in nonideal fracture behavior. The CNSR test method provided a conservative and reproducible measure of fracture toughness.

In a joint ORNL/JAERI study, ${ }^{124}$ various fracture toughness test methods were applied to IG-110 graphite to establish if specimen geometry influenced fracture toughness. The geometries investigated included: compact tension (CT), disc compact tension (DCT), short rod (SR), CNSR, cylindrical bend specimen (BS), and centrally slotted disc (CSD). The results are shown in Table 3-9. Specimen geometries which allow slow crack propagation, such as the CNSR and $\mathrm{CT}$, yielded higher fracture toughness values than those where fracture is very rapid, e.g., the CSD. This result was again attributed to rising R-curve behavior. 
ORNL-DWG 91M-7001R
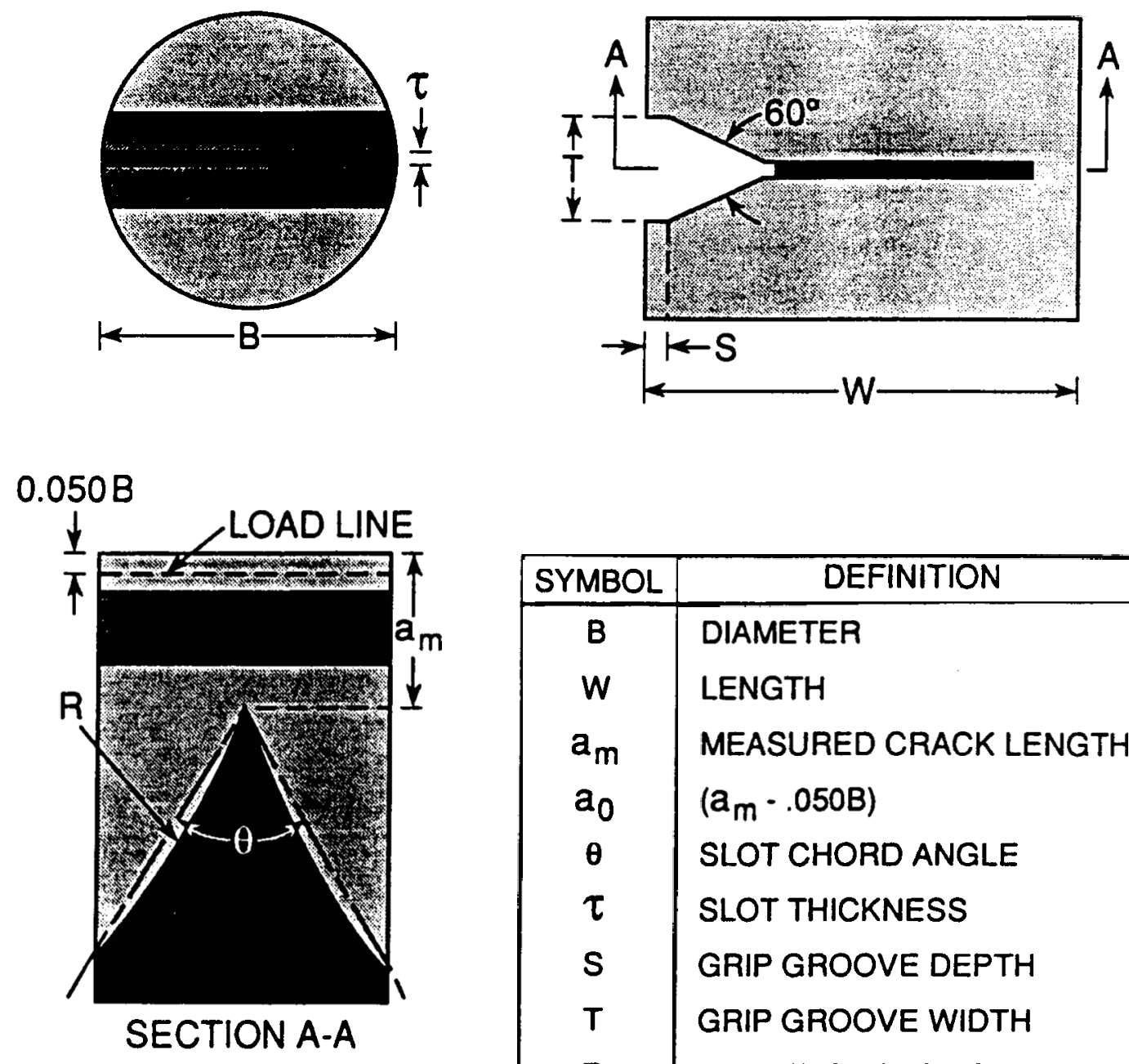

\begin{tabular}{|c|l|}
\hline SYMBOL & \multicolumn{1}{|c|}{ DEFINITION } \\
\hline$B$ & DIAMETER \\
$w$ & LENGTH \\
$a_{m}$ & MEASURED CRACK LENGTH \\
$a_{0}$ & $\left(a_{m} \cdot\right.$. O5OB $)$ \\
$\theta$ & SLOT CHORD ANGLE \\
$\tau$ & SLOT THICKNESS \\
$S$ & GRIP GROOVE DEPTH \\
$T$ & GRIP GROOVE WIDTH \\
$R$ & RADIUS OF SLOT CUT \\
\hline
\end{tabular}

Figure 3-49.

THE CHEVRON-NOTCHED SHORT-ROD SPECIMEN GEOMETRY. 


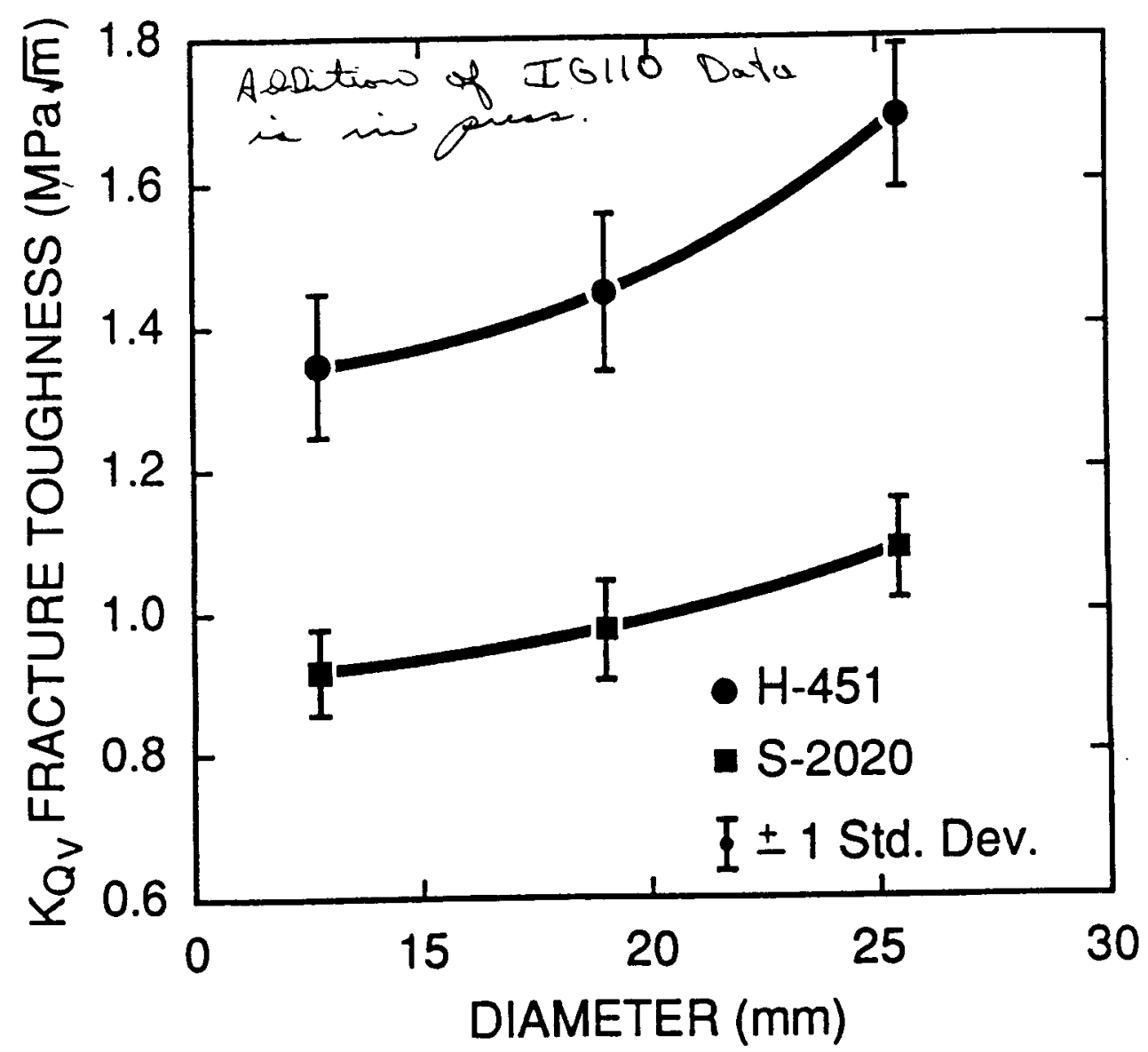

Figure 3-50.

CHEVRON-NOTCHED SHORT-ROD FRACTURE TOUGHNESS VERSUS SPECIMEN SIZE FOR UNIRRADIATED H-451, STACKPOLE

2020 AND IG110 NUCLEAR GRAPHITES UNDER AMBIENT CONDITIONS. 
Table 3-9

FRACTURE TOUGHNESS OF IG-110

\begin{tabular}{|c|c|c|}
\hline Specimen geometry & $\begin{array}{c}\text { Fracture toughness } \\
(\mathrm{MPa} / \mathrm{m})\end{array}$ & Laboratory \\
\hline \hline CNSR & 1.16 & ORNL \\
\hline DCT & 1.12 & JAERI \\
\hline BS & 1.07 & JAERI \\
\hline SR & 0.94 & JAERI \\
\hline CT & 0.92 & JAERI \\
\hline CSD & 0.83 & ORNL \\
\hline
\end{tabular}

In response to NPR-DDN-11.07 (ref. 84) and test specification CEGA-001915 (ref. 125), a test plan $^{126}$ was developed that addresses the need for fracture toughness characterization of 32-in.long by 17-in.-diam billets of H-451 graphite. To assess the spatial and orientational variability within an extruded graphite billet, a sampling plan was developed based on the assumption that physical and mechanical properties vary symmetrically about the longitudinal axis. If a central slab is cut (51 mm in thickness) symmetrically about a diametral plane and parallel to the billet axis, then this slab fully represents all volume elements within the billet. Graphite billets examined in the overall assessment of material variability on design properties employed the spatial cutting plan shown in Figure 3-51. The central slab was apportioned into 128 segments and identified using matrix notation. Half of the segments, designated $\mathrm{PTO}_{\mathrm{x}}$, were allocated for physical, thermophysical, and oxidation characterization. The remaining segments were allocated for fracture mechanics characterization. Four CNSR specimens were taken from each of these segments. The CNSR specimen geometry is shown schematically in Figure 3-51 depicting the orientation of the crack plane and direction of crack propagation. The orientation of the crack plane is defined by the direction perpendicular to it.

The scope of fracture toughness characterization of $\mathrm{H}-451$ graphite completed to date includes a within-billet evaluation of specimen orientation and spatial location as well as a billet-to-billet comparison of four billets representing the four minimum-strength classifications of $\mathrm{H}-451$ graphite according to Table 3-10. 


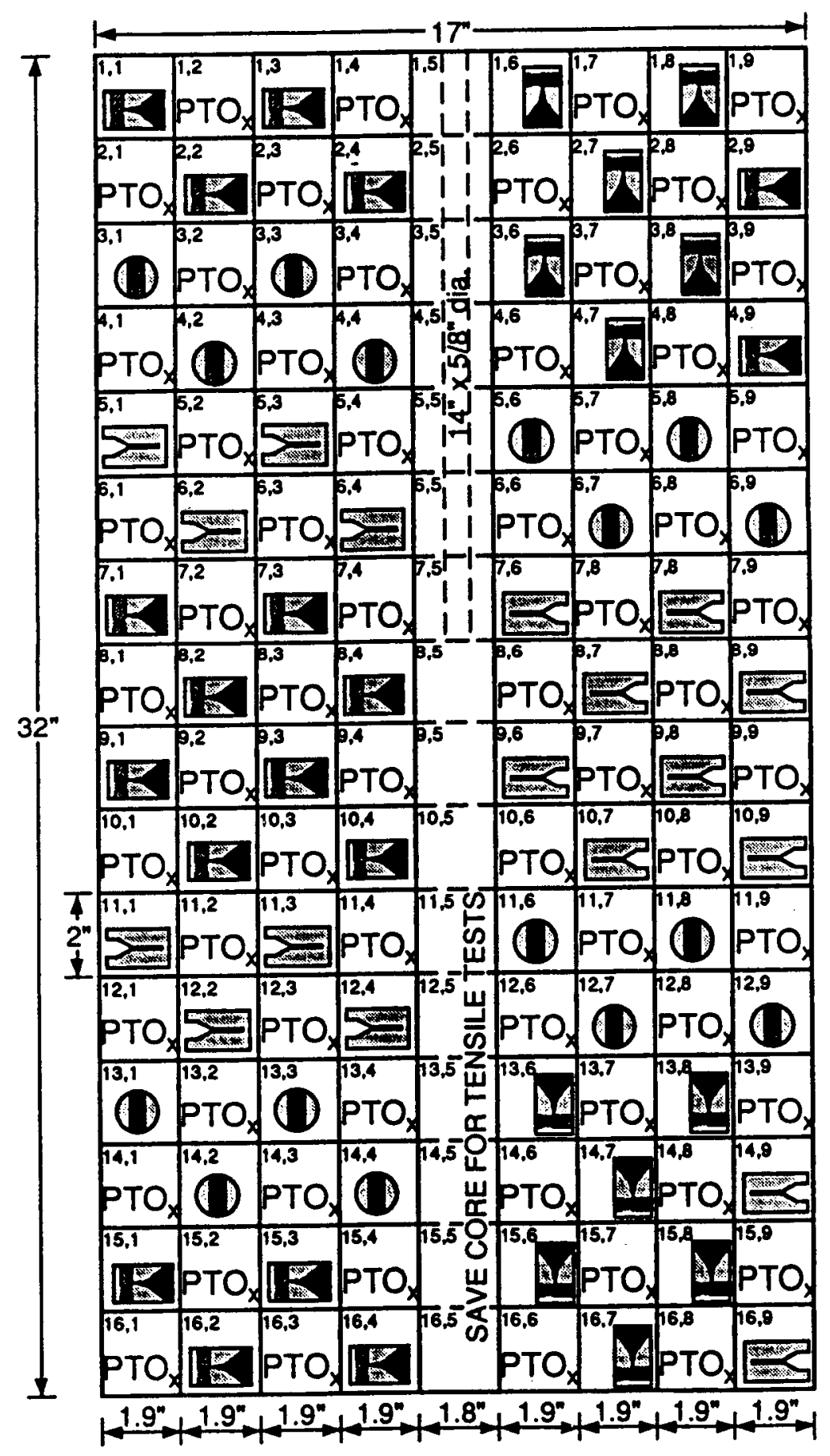

Figure 3-51.

CENTER SLAB CUTTING PLAN. 
Table 3-10

\section{H-451 GRAPHITE CHARACTERIZATION}

\begin{tabular}{|c|c|c|c|}
\hline Billet & Class & $\begin{array}{c}\text { Min. strength } \\
(\mathrm{MPa})\end{array}$ & $\begin{array}{c}\text { Avg. toughness } \\
(\mathrm{Mpa} V \mathrm{~m})\end{array}$ \\
\hline \hline $58-357$ & I & 15.6 & 1.52 \\
\hline $58-029$ & II & 12.3 & 1.26 \\
\hline $58-892$ & III & 10.8 & 1.47 \\
\hline $58-018$ & IV & 9.2 & 1.48 \\
\hline
\end{tabular}

Additional details of the test plans and procedures may be found in refs. 126 and 127 . The following conclusions can be drawn from these tests:

1. Fracture toughness is dependent on crack orientation; for example, in billet 58-357:

$\mathrm{K}_{\mathrm{Qv}}($ axial $)=1.56 \mathrm{MPa} / \mathrm{m}, \mathrm{K}_{\mathrm{Qv}}($ tangential $)=1.52 \mathrm{MPa} / \mathrm{m}$, and $\mathrm{K}_{\mathrm{Qv}}($ radial $)=$ $1.47 \mathrm{MPa} / \mathrm{m}$.

2. Fracture toughness showed some dependence on radial position but no dependence on axial position; for example, in billet $58-357 \mathrm{~K}_{\mathrm{QV}}(\mathrm{R}=48 \mathrm{~mm})=1.48 \mathrm{MPa} / \mathrm{m}, \mathrm{K}_{\mathrm{QV}}(\mathrm{R}=$ $97 \mathrm{~mm})=1.51 \mathrm{MPa} / \mathrm{m}, \mathrm{K}_{\mathrm{Qv}}(\mathrm{R}=145 \mathrm{~mm})=1.52 \mathrm{MPa} \vee \mathrm{m}$, and $\mathrm{K}_{\mathrm{Qv}}(\mathrm{R}=193 \mathrm{~mm})$ $=1.57 \mathrm{MPa} / \mathrm{m}$.

3. Fracture toughness showed little dependence on billet strength classification. A complete presentation of data and analysis can be found in the NPR closeout report. ${ }^{128}$

\subsection{OXIDATION BEHAVIOR' - E. L. Fuller, Jr.}

\subsubsection{Air Oxidation of H-451}

Current designs for the NP-MHTGR utilize H-451 graphite as a moderator. Very few data exist related to the intrinsic rate:constants for the reaction of air and/or oxygen with this material. These data are needed for design codes for trace levels of impurities in coolant (helium) streams in normal operation, and for air ingress accident scenarios. This report is an initial microgravimetric evaluation of the intrinsic reaction parameters for air reactions with $\mathrm{H}-451$ graphite. The studies were made over a temperature range of 375 to $850^{\circ} \mathrm{C}$ at atmospheric pressure and for water contents from 0 to 2 vol \% water vapor. Microscopic analyses were 
performed to show the heterogeneous nature of the graphite and the consequential variation of reaction rate as the samples are etched and roughened in the corrosion processes. Initial attack is upon the impregnate around the primary grains of the "near-isotropic" filler material. The reaction rate increases approximately twofold to a near-constant value and subsequently approaches zero as the remnant skeletal matrix is consumed. There appears to be no significant rate effect (neither catalytic nor impedimental) due to the presence of water vapor in the concentrations used. We conclude that the design data values used for $\mathrm{H}-327$ (currently employed) are comparable to those for $\mathrm{H}-451$-rates are about fivefold less for $\mathrm{H}-451$ due to its higher purity and lower porosity. Smooth trends are noted over the entire temperature regime, with no indication of any hazardous condition that might result during a "worst case" air ingress accident scenario for the MHTGR operation. Additional work is suggested to supply further validation of predictions related to normal operation and accident scenarios for the MHTGR. This report is a synopsis of much more detailed accounts of developmental and exploratory studies. ${ }^{29}$

Although the number of samples we were able to analyze using dry, purified air and dry, purified air saturated with $\mathrm{H}_{2} \mathrm{O}$ at different temperatures was limited, several important phenomena are noted:

1. Surface Preparation. The effects of surface preparation (machining) are relatively minor and probably do not persist beyond $25 \%$ mass loss (if that far). The original surface was progressively removed during oxidation, while at the same time, oxidation was also proceeded to enlarge and lengthen the pores below the surface within the carbonaceous substrate.

2. Roughening. The presence of large numbers of pores, many of which are interconnected, exerts a strong influence on the oxidation of this graphite because such openings permit oxidation to proceed within the material as well as on the outer surface. Initial attack involves complex geometric penetration into the substrate, by one or more mechanisms:

- Enlargement by gasification of material in very small pores that are not resolved by our microscopic analyses; these may be the result of incomplete impregnation during the original preparation of $\mathrm{H}-451$

- Chemical attack at the sites of incipient pores; these regions probably exist due to the ultimate filling process of impregnation (this last-in/first-out phenomenon is due to the lattice strains associated with the shrinkage on cooling of this material in the rigid filler/binder matrix after graphitization) 
- Preferential attack of impregnate/binder material; the material is all relatively pure carbon from a chemical standpoint, but variations in crystallinity and crystal morphology lead to etching around the more inert grains

- Etching and pitting (these phenomena are known to proceed with marked roughening of well-formed graphite substrates, ${ }^{130}$ and very small amounts of inorganic contaminates are known to accelerate these reactions)

3. Water Vapor. In addition to important experimental parameters such as temperature and gas flow rate, oxidation is controlled by the nature of the gas used. The amount of $\mathrm{H}_{2} \mathrm{O}$ introduced with the dry, purified air results in perceptible differences in the nature of the oxidized surface, including the surface texture (roughness or graininess) and development of pore shapes. A very distinct textural change can be related to the amount of $\mathrm{H}_{2} \mathrm{O}$ added to the purified air.

In spite of these morphological differences, the water vapor content has no statistically significant effect on the chemical kinetics of the air oxidation of $\mathrm{H}-451$ over the concentration regions studied here. The striking morphological effects must arise due to the interaction of sorbed water at the sites where oxygen attack occurs. The net result is production of a more uniform, grainy surface structure as compared to the rougher, more localized pitting in dry air.

4. Spallation. The loss of mass appears to occur through both chemical processes involved in oxidation and through the loss of particulate matter by a physical spalling process.

Based on the limited number of samples in this study, the rate of spalling increases as oxidation becomes more extensive; however, the amount (mass) of material involved in the spalling process is minute under our experimental conditions. At higher flow rates (greater turbulence), this may become a significant problem, where the weak interparticulate forces can be overcome, especially in the case of extensive removal of the "glue" that holds the graphite grains together.

5. Kinetic Constants. Evaluation of the rate constants in terms of the activation energy, $\mathrm{E}(\mathrm{a})$, shows that there is no appreciable variation with respect to sample and/or burnoff over the range studied here. The numerical value of $168 \pm 6 \mathrm{~kJ} / \mathrm{mole}$ is approximately one-half of that found for oxygen attack on more crystalline materials (230 to $270 \mathrm{~kJ} / \mathrm{mol}$ ). ${ }^{131}$ This is to be anticipated for these porous materials in accord with the observations of others ${ }^{130}$ where the apparent activation energy approaches one-half of the true activation energy for reactions limited by diffusion in pores. The intercept value is a 
measure of the reactivity (and possibly the porosity) of the H-451 samples and is reported as $\ln (\mathrm{A})=21.7+/-0.9$, with no obvious variation with respect to sample source or degree of burnoff. This value is for a single billet, and additional work is under way to study the production lot variations and variations with respect to chemical impurities.

6. Burnoff Effects. The reaction rates of $\mathrm{H}-451$ graphite with air follow the almost universal trend, i.e., "gasification rate increased with burn-up to a maximum value at $20-30 \%$ of complete burn-up and then decreased with further burn-up. ${ }^{132,133}$ In the case of nuclear graphites, which initially have intergranular porosity, finite initial reactivity is noted. This behavior is enhanced for very porous material, such as Saran chars, where the initially high reaction rate is maintained until the inevitable rate decrease is noted due to consumption of the residual skeletal substrate. ${ }^{132} \mathrm{H}-451$ has approximately $21 \%$ initial porosity, the external portion giving rise to initial finite rates.

Considerable interest exists concerning the size and shape of pores in carbonaceous materials and in modifications that occur during heterogeneous reactions (corrosion, activation, gasification, combustion, etching, pitting, channelling, etc). In general, these processes are controlled by diffusion, or percolation, through channels that can be defined in terms of their fractal dimensions, D. ${ }^{134-136}$ In general, Equation 3-12 contains a geometric term measuring the amount of reactive sites (surface area, pore area, total surface area, active surface area, etc.). The magnitude of the surface area is definitely changing as a function of time of exposure. Chemical rates vary as the amount of porosity changes as a function of time. The reactivity is related to the specific surface area, $\Sigma$, as:

$$
k(\text { air })=k(i) P^{m} \Sigma(0) t^{h}
$$

where $h$ is an adjustable parameter related to the fractal dimensions of the pores per se. At fixed reactant concentration and temperature, Equation 3-12 can be rewritten for any given time, $t$, as:

$$
\text { REACTION RATE }=\frac{-d m}{d t}=k(i) P^{m} \Sigma(0) t^{h}
$$

which can be expressed in rectilinear form as:

$$
\log \left(\frac{-d m}{d t}\right)=A+h \log (t)
$$


such that the slope of a $\log / \log$ plot will have a slope equal to $h$. This functionality defines the reactivity enhancement in the early stages of graphite oxidation up to the limiting (maximum) cutoff rate. The coefficient, $h$, is evaluated by linear regression as 0.385 with a standard deviation of 0.009 and $A$ (the intercept at $t=1 \mathrm{~min}$ ) is $0.166 \pm 0.011$, with an overall $\mathrm{R}^{2}=$ 0.9934. This is quite comparable to quoted values, "Typical for fractals are around $h=1 / 3$."136 The limiting cutoff rate noted is probably less than the ultimate rate one would expect for an infinitely thick sample. The samples used here are small enough that the etched surfaces overlap, and skeletal disintegration is enhanced. Samples of increasing size will be used for additional elucidation of the effective length of penetration that will be encountered for large billets. Density gradient studies will be used to further define the nature of the fractal structure formed during oxidation of nuclear graphites.

If, in accord with our micrographic and kinetic observations, one considers the complex initiation and development of pores in the substrate as the mode of generation of new reaction sites, the following relationship prevails: ${ }^{137}$

$$
\frac{R A T E}{R A T E(0)}=\frac{\Sigma}{\Sigma(0)}=(1-b)[1-\Psi \ln (1-b)]^{0.5}
$$

with a singular adjustable parameter, $\Psi$. No maximum rate is noted for the lower values of $\Psi$ (less than approximately 5), depicting: (1) the state of external surface attack only with virtually no new pore generation, or (2) a very high value for $\Sigma(0)$ such that all additional consumption involves intersection and consumption of skeletal walls. The maximum value (without a measurable "plateau" region) can only prevail for sample sizes less than the "effective" depth of the steady-state reaction (density) profile. Only for larger samples are the steady-state (burnoffindependent) rates achieved, and all rates for smaller samples are less than this maximum value. Additional work is under way to evaluate the reaction rates on larger samples applicable to MHTGR billets.

The results of a least-squares fit of the data are excellent for $\mathrm{H}-451$ samples. The adherence of the curve to the data is quite good considering the use of only two (one parameter, if the initial 
Table 3-11

DERIVED VALUES RELATED TO THE RATE VARIATION WITH DEGREE OF CONSUMPTION OF H-451 IN AIR AT $750^{\circ} \mathrm{C}$

\begin{tabular}{|c|c|c|}
\hline Sample & K018 & K022 \\
\hline \hline Rate $(0)(\mathrm{mg} / \mathrm{min})$ & 1.65 & 3.04 \\
\hline Standard deviation $(\mathrm{mg} / \mathrm{min})$ & 0.05 & 0.12 \\
\hline$\Psi$ & 128 & 377 \\
\hline Standard deviation & 8 & 3 \\
\hline $\mathrm{R}^{2}$ & 0.996 & 0.985 \\
\hline
\end{tabular}

rate is known) adjustable parameters, $\operatorname{Rate}(0)$ and $\Psi$. The optimum values and relevant statistics are presented in Table 3-11. Several points of interest are noted:

- The midrange data are more disparate from the smooth fit. This may be due to the opening of closed porosity within $\mathrm{H}-451$, which involves new reactivity, and localized accelerated rates of reaction.

- The fit to the data is not as good in the later stages of reaction. This is possibly due to the interruptions from the isothermal state for the evaluation of the temperature coefficients of the reaction rates. It is entirely feasible that reactions at lower temperatures generate an appreciably different morphology, altering the course of the subsequent reactions at $750^{\circ} \mathrm{C}$.

- There is a twofold variation in behavior for the two samples analyzed. This can arise due to inherent differences in the samples, to some undetermined sample preparation factor, or simply to the inherent chaotic nature of such processes under diffusion control.

- This methodology is an excellent means of evaluating the initial rate of the reaction.

Even though the control TC is embedded in the samples, there is some lag in establishing the isothermal state. There is thermal lag within the sample, and the furnace can only be heated at a finite rate (approximately $20^{\circ} \mathrm{C} / \mathrm{min}$ maximum in the current configuration). Examination of the data log affords an estimate, but the parameter optimization provides a value more consistent with the entire data base over the time of the experiments. 
- These data and analyses reveal that the small samples used in this study do not accurately measure the steady-state conditions that will prevail for larger samples. The rates of reaction noted here can be considered only an approximation of rates to be found for larger samples.

- Independent of the magnitude of the parameters involved, the maximum rate of reaction is approximately $8.0 \mathrm{mg} / \mathrm{min}$ for these small samples from this specific billet. This maximum rate may be an excellent means for comparison of samples to quickly screen production lots for variations related to trace concentration of catalytic material and for morphological variances.

7. Nuclear Reactor Considerations. Several workers have defined distinct changes in air oxidation mechanisms near $650^{\circ} \mathrm{C}$ (ref. 138). Most workers claim the reaction to be "kinetically controlled" below the transition temperature and "in pore diffusion regime, wherein volumetric oxidation of graphite was limited by diffusion of oxygen," 139 above the transition temperature. Our studies have shown that the entire reaction involves diffusion within the pores, over the entire temperature range, for sufficiently adequate delivery of reactants. This condition is met by concerted control of oxygen concentration, flow rates, and/or orifice size of the pores at any given temperature. The reactant concentration and flow rates are controlled by the operator and/or accident scenario, and the pore orifices are unavoidably increased with the degree of consumption. Similar conclusions were deduced from water corrosion studies: ${ }^{131}$

The transition temperature cannot be assumed to be a fixed parameter for any given type of graphite! There is absolutely no indication of "runaway conditions above a minimum temperature of $700^{\circ} \mathrm{C} "$ since the reactions are not self-supporting. The reactions are quenched immediately when any external source of heat is removed and/or decreased (resistance heat to the furnace in the case of our laboratory studies).

When a transition temperature is observed of the corrosion of $\mathrm{H}-451$, it is undoubtedly due to the diffusional depletion of the gas phase reactant concentration at the macroscopic boundary of the substrate. The diffusional limitation is in the bulk gas phase, not within the pores per se.

At the low flow rates (convection flow) encountered in most accident scenarios, the reaction rates will be very slow due to the gas-gas diffusion control. Additional studies 
are under way to study the air corrosion as a function of helium diluent to more closely approximate the conditions of an air ingress into the helium coolant stream.

The reaction mechanisms seem to be different for different temperatures. This is noted in the different reaction rates at high temperature, depending upon the temperature of the preceding burnoff. There is strong evidence that the corrosion rate at high temperatures may depend upon the history of the given H-451. Additional work is under way to study the influence of temperature cycles, concentration cycles, flow cycles, etc., on the rates of air corrosion.

The synergetic effect of water in altering the morphology of the air-corroded surfaces of H-451 needs further investigation. If the penetration depth (pitting) is decreased by the presence of water, the resultant loss of strength may also be less severe. Studies are planned to measure the strength of $\mathrm{H}-451$ as a function of degree of consumption under both dry and humid conditions. Additional studies will measure the density profiles of corroded samples under both sets of conditions.

The rate data reported here are for sample sizes smaller than the steady-state reaction depth for air corrosion. The maximum rate will be somewhat greater for larger samples. Future studies with larger samples will aid in evaluation of the maximum rate (normalized to macroscopic area) to be used for very large billets of H-451. The existing data may be directly relevant to the corrosion of the thin walls between channels in fuel blocks.

\subsubsection{Dimensional Changes Associated with Air Oxidation of H-451 Graphite}

Optimum use of graphite as a structural member and moderator in MHTGRs requires detailed understanding of the kinetics and mechanisms of reactions with oxidizing gases. Normal operation involves trace amounts $(<10 \mathrm{ppm}$ ) of water, oxygen, and/or carbon dioxide in the helium coolant gas. Ingress scenarios involve higher concentrations (percent levels) of these reactive vapors. This program addresses both situations over a wide temperature range $(25$ to $1600^{\circ} \mathrm{C}$ ). The results will be used in design and operation codes for the MHTGR. This report describes the development of methodology using dry air as a reactant over the temperature range of 350 to $750^{\circ} \mathrm{C}$. This report covers results discussed elsewhere. ${ }^{140}$ 
In general, the reaction rates can be represented as:

$$
\text { REACTION RATE }=\frac{-d m}{d t}=k(\text { air }) \Sigma P^{n}
$$

where $\mathrm{P}$ is the pressure of the reactive component (oxygen in this case). The mass, $\mathrm{n}$, change is related to the reaction order, $\mathrm{m}$, and reaction rate constant, $\mathrm{k}$. At fixed reactant concentration (as implemented by gas flow to the microgravimetric reactor chamber):

$$
\text { REACTION RATE }=A e^{-E(a) / R T},
$$

which can be presented in logarithmic form:

$$
\ln (R E A C T I O N R A T E)=\ln (A)-\frac{E(a)}{R T},
$$

with respect to temperature, T. Activation energy, E(a), can be evaluated from a plot of reaction rate versus the reciprocal of the absolute temperature as shown in Figure 3-52. The linear behavior is assurance that a singular reaction mechanism is in play over the noted temperature range. The excellence of the microgravimetric technique is noted for the $4+$ orders of reaction rate.

Corrosion of this material has been shown to proceed primarily by etching and pitting mechanisms. ${ }^{141}$ Analyses based upon the random generation of porosity in the consumption

$$
C(\text { solid })+\mathrm{O}_{2}(\text { gas })=\mathrm{CO}_{2}(\text { gas })
$$

lead to the relationship relating the rate to the degree of burnoff, $b$ :

$$
\frac{R A T E}{\operatorname{RATE}(0)}=(1-b)[1-\Psi \ln (1-b)]^{0.5}
$$

process where $\Psi$ is defined as a structural parameter related to the pore sizes and distribution. Our data are presented in this format in Figure 3-53. In this context, the results should be well described with the optimization of the single adjustable parameter, $\Psi$.

The missing data ranges correspond to the nonisothermal excursions to evaluate activation energies. Over the range for the $750^{\circ} \mathrm{C}$ isothermal, a nonlinear least-squares optimal fit is quite good. The initial rate of about $1.65 \mathrm{mg} / \mathrm{min}$ is due to the approximately $20 \%$ porosity of the original material and the surface area therein. 
ORNL-DWG 94-5563

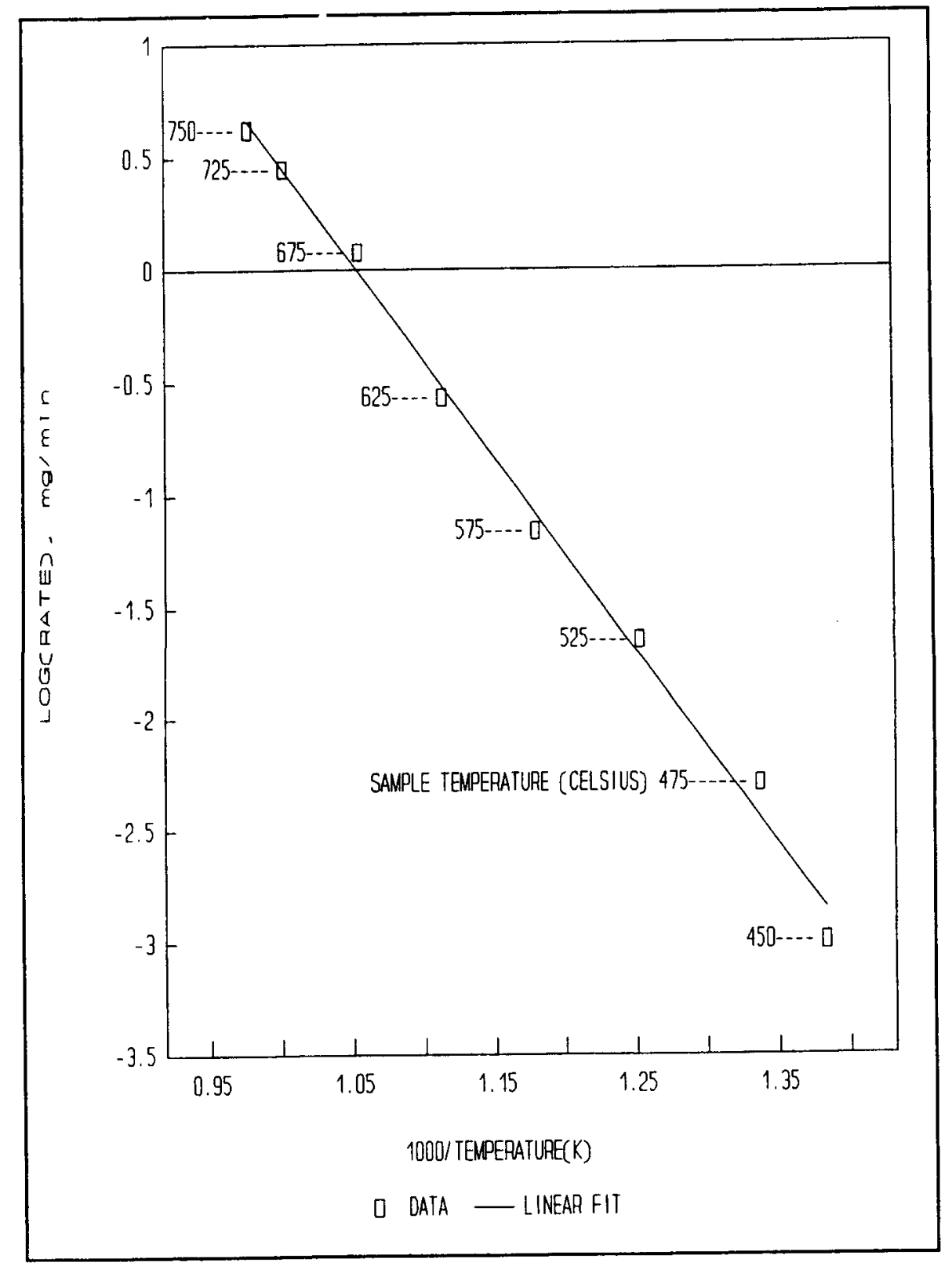

Figure 3-52.

TEMPERATURE VARIATION OF AIR CORROSION RATE WITH H-451 GRAPHITE. 


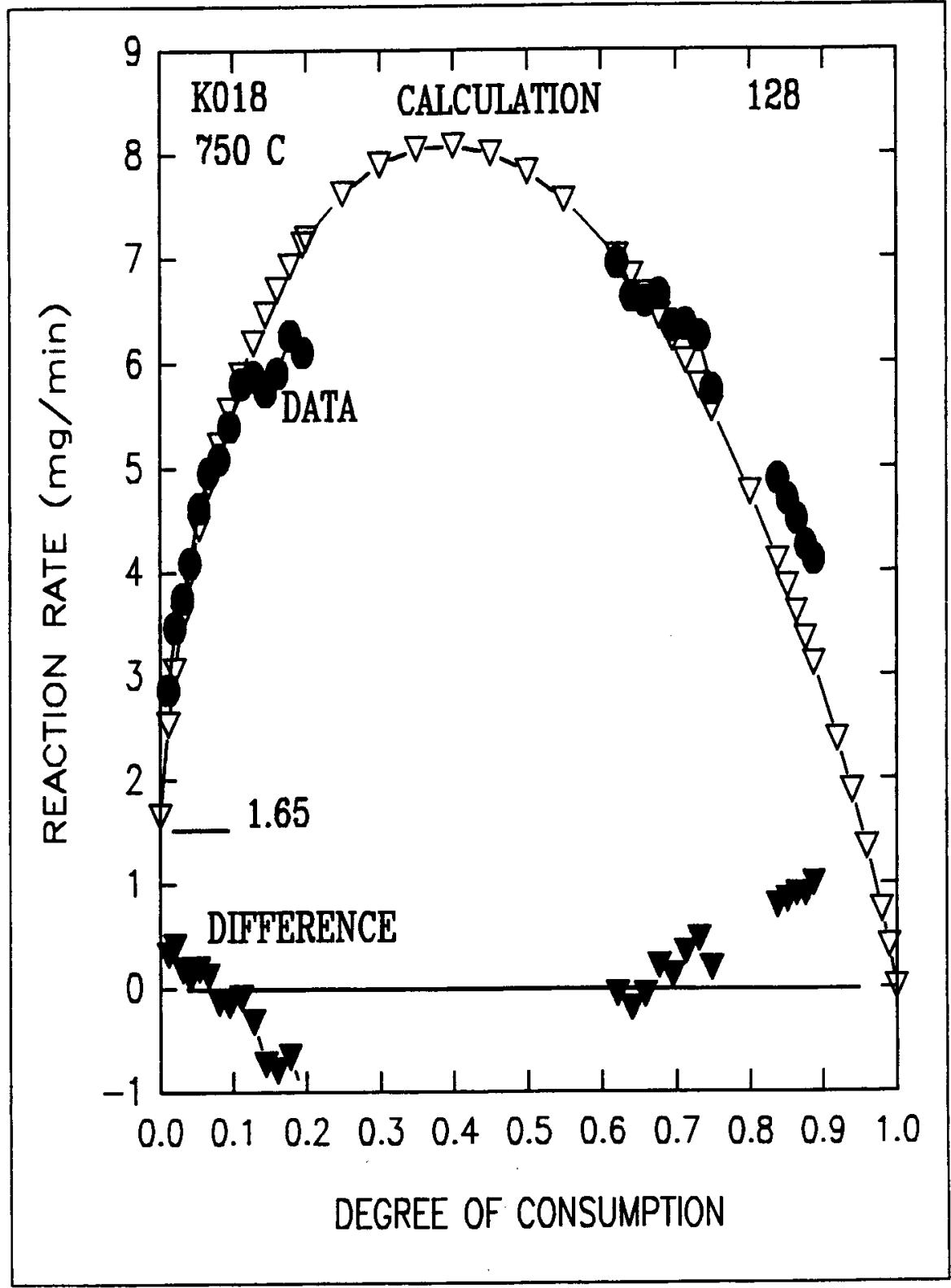

Figure 3-53.

PARAMETER EVALUATION FOR THE REACTION RATE OF AIR WITH H-451 GRAPHITE (SAMPLE K018). 
Additional information regarding the oxidation pathways is afforded by photographic examination of the cylindrical graphite samples after various degrees of consumption. Both the diameter and the length of the cylinders were measured and tabulated as noted in the graphical presentation of Figure 3-54. The external dimensions of the cylinders are seen to decrease only very slowly over the first $80 \%$ of mass loss. The carbon loss is virtually all within the inner reaches of the sample. A pure surface attack (shrinking core) would be described by a straight line from the original size to zero at $100 \%$ mass loss. Such behavior is not noted until the residual skeletal material is finally consumed at $>90 \%$ mass loss.

The oxidation of graphite has been shown to proceed by etching and pitting processes. This is indicated by macroscopic and microscopic observations. Modelling of microgravimetric reaction data is described well by pore generation-consumption assumptions.

\subsubsection{Water Vapor Reactions}

Preliminary evaluations show that vacuum microbalance techniques can supply valuable information related to the oxidation (corrosion) of nuclear-grade graphites by coolant impurities found in HTGR environments. Laboratory-scale tests simulate the MHTGR operating environment: temperatures up to $1600^{\circ} \mathrm{C}$, up to $15 \%$ water in helium, and oxygen concentrations up to those found in air. Evaluations of the response and applicability over the range of conditions have been completed, and all instruments have been calibrated and certified. ${ }^{142}$ Techniques and apparatuses have been developed to provide rate data as a function of temperature, consumption (burnoff), reactant concentration, gas flow rates, sample configuration, etc. Additional structure-specific techniques such as surface spectroscopy, elemental analyses, and microscopy are used to supplement the mass loss data. In this manner, a minimum number of assumptions are required for definition of kinetics and mechanisms of the corrosion processes encountered in normal operation and accident scenarios for HTGR modeling.

Little conclusive modeling is included at this writing since the program is in the developmental stage, and no verification of singular results has been accrued. Future work would refine the analyses, verify the results (for both this sample and other production lots), develop models for kinetics and mechanisms on a molecular scale, and validate and verify existing corrosion models. The results reported here are not definitive of the reaction mechanisms involved in graphite corrosion. 


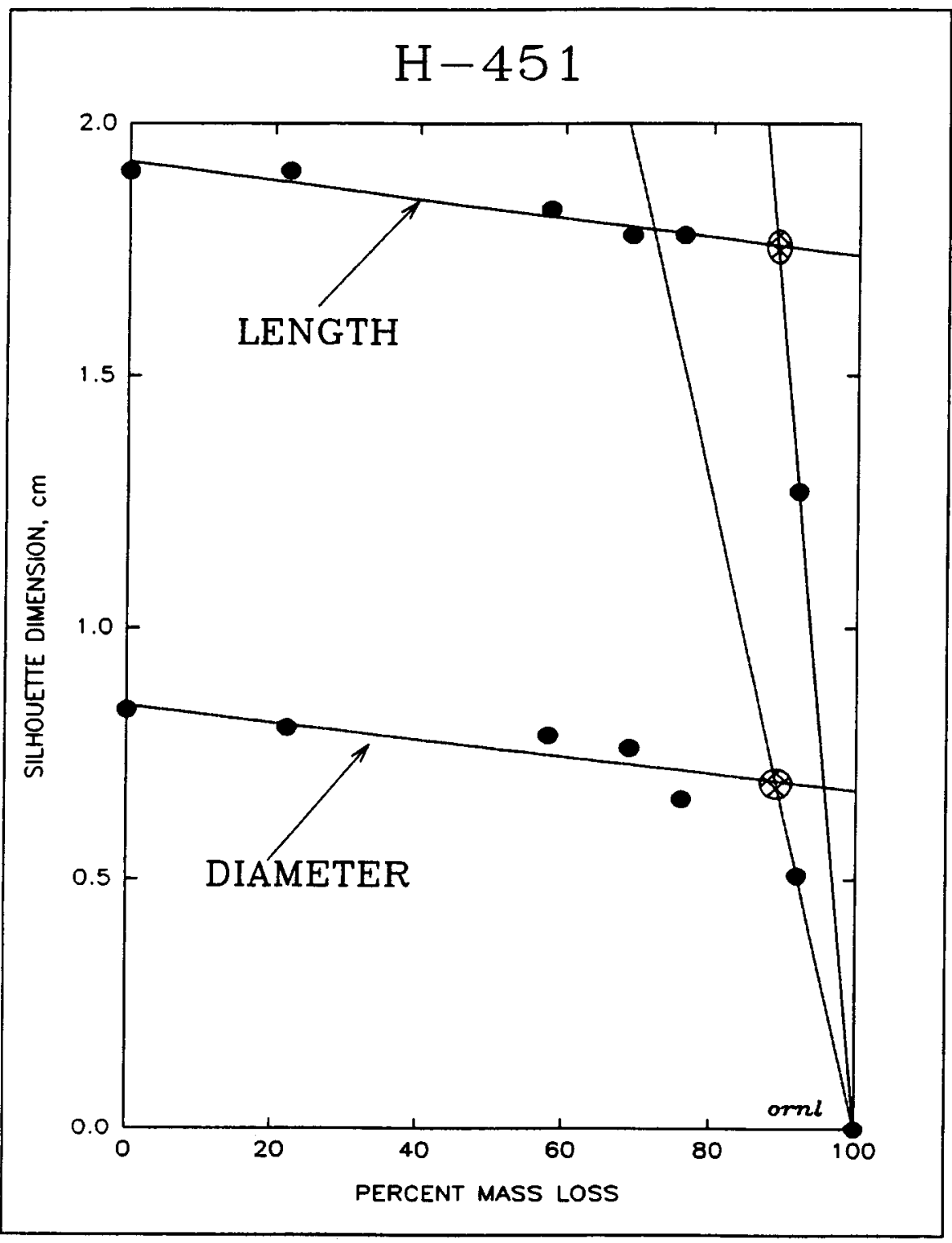

Figure 3-54.

DIMENSIONAL CHANGES OCCURRING ON OXIDATION OF GRAPHITE. 


\subsubsection{Spectroscopic Analyses}

Survey electron spectroscopy for chemical analysis (ESCA) scans of the air-oxidized surface of $\mathrm{H}-451$ graphite were obtained at 10,45 , and $90^{\circ}$ take-off angles and showed identical concentrations of impurities (silicon, chlorine, sulfur, etc.). Since the surface is enriched in oxygenated species, the impurity bands are more prominent in the spectra obtained at the higher take-off angle. This indicates that the impurities are rather homogeneously distributed in the bulk of the sample (at least over the range of about $150 \mu \mathrm{m}$ of the excitation/sensing region of the ESCA in the plane of the surface). The detailed ESCA scans can be used to note the intermediate states of the oxidation processes. The spectrum of the $\mathrm{C}(1 \mathrm{~S})$ region is noted, and band-fitting techniques were used to estimate relative concentration and number of species present. The band assignments agree well with those for other oxidized carbon surfaces prepared in other laboratories. Additional information related to the nature of the oxygen/surface complexes is obtained from the $\mathrm{O}(1 \mathrm{~S})$ spectrum of $\mathrm{H}-451$. The interpretation is not unequivocally well defined, and other diagnostic experiments are required. At this writing, we can only note that there are two, if not three, different forms of oxygen-containing groups on the surface of this graphite sample.

\subsubsection{Microscopic Analyses}

The nature of morphological changes is noted quite well in the optical microscopy photographs. Greater detail of the oxidized surfaces of sample K007 (after $85 \%$ burnoff) was afforded by the electron micrographs. Several degrees of magnification were utilized to show the various effects accompanying the oxidation process. These data indicate that there is considerable preferential etching of this material:

1. Deep pore etching forms a turbostratic structure that is penetrated by deep channels, possibly due to channeling from flaw to flaw through interconnecting faults or pores. Reorientation of the sample shows that these etch pores are very deep (greater than the depth of focus, several micrometers, of the electron microscope). In many instances, no termination could be found.

2. At higher magnification, an appreciable amount of preferential etching of the matrix is noted. The residual leaflets are quite thin, which is indicative of removal of intercrystalline materials of relatively higher reactivity. The white region is amorphous 
silica adjacent to a typical flat region showing considerable "dimpling" probably due to catalysis by impurity metals.

3. At even higher magnification, the amorphous agglomerates of the silica [identified as silicon by energy-dispersive spectroscopy (EDS)]-rich mineral matter are noted adhering to the carbonaceous substrate. This material exists as patches on the surface, either inherently or by a migratory accrual during oxidation.

4. A detailed examination of carbonaceous regions reveals the filamentous nature of the residual turbostratic regions. This sort of morphology is commensurate with the preferential attack on the faces of the graphite crystallites with more stability (less reactivity) associated with the edge atoms comprising the individual graphite residues.

For comparison purposes, detailed photomicrographs of an unreacted sample were examined in regions to highlight the nature of the highly dispersed surface flaws that exist in this material. Most of the freshly machined surface is free of flaws and appears virtually identical to the matrix material. There is some indication that hard crystals within the matrix may have been dislodged in the machining process. Enlarged views show the interparticulate voids that comprise $20 \%$ porosity of this material prior to oxidation.

\subsubsection{Water Vapor Reactions}

These results are preliminary and singular in nature. Additional work is required to determine the reproducibility, statistical significance, and general applicability to all samples of $\mathrm{H}-451$ graphite in general.

\subsubsection{Temperature Effects}

The Arrhenius plots of reaction rates for $\mathrm{H}-451$ with water vapor are described at lower temperatures $\left(<1050^{\circ} \mathrm{C}\right)$ as a parallel set of curves consistent with a constant activation energy, independent of reactant (water) concentration. At higher temperatures, the slopes are much less, indicating that either another reaction mechanism is in play or that the reaction is limited due to the rate of delivery of the reactant to the surface of the sample.

\subsubsection{Flow-Rate Effects}

For this study, the water content was fixed at $0.67 \mathrm{~mol} \%$ in helium, and the temperature and flow-rate effects were evaluated for the K011 sample of H-451 graphite. The following mode of 
operation was implemented to allow the evaluation of both the flow variation and temperature effects on the reaction rate:

1. Temperatures were held constant long enough to allow evaluation of the reaction rates and then increased to the next chosen value.

2. At $1000^{\circ} \mathrm{C}$, the flow rates were incrementally increased, as noted in inserts $A$ and $B$, where the reaction rates are presented on logarithmic and linear scales, respectively.

3. Temperatures were incremented again to evaluate the reaction rates at the increased flow rates.

4. Flow rates were again incremented at $1300^{\circ} \mathrm{C}$ to evaluate the additional dependence of reaction rate on flow rate, with the results shown in inserts $C$ and $D$ for the logarithmic and linear scaling, respectively.

5. Additional temperature increases were to evaluate variations to $1600^{\circ} \mathrm{C}$.

6. Sample temperatures were decrementally decreased (with adequate isothermal control) to trace the temperature effects at the highest flow rates.

It is quite evident that the reaction rate increases asymptotically to a maximum value as the delivery rate (flow rate) of the reactants is increased. The results show quite conclusively that there is reactant depletion (at least near the surface of the graphite) at the higher temperatures. This depletion is due, in part, to the actual consumption of the reactant and, in part, to diffusion limitations, since the turbulence is not great enough to ensure that the surface regime is kept at a constant chemical potential. A steady-state condition was achieved after the first flow-rate increase (at $1000^{\circ} \mathrm{C}$ ). Thus, Arrhenius methodology may be employed for evaluation of the chemical reaction energetics. In contrast, the data acquired at $1300^{\circ} \mathrm{C}$ show that the limiting reaction rate was not achieved (independent of gas flow rate). It is worthy of note that the ultimate rates achieved at this low moisture loading $(0.67 \%)$ exceeded the rates measured for high loading $(1.8 \%)$. To a first approximation, this shows that the rate of delivery of reactants \{moles $\left(\mathrm{H}_{2} \mathrm{O}\right) / \mathrm{min}$, measured as the product of flow rate [slpm] times the loading factor [moles $\left(\mathrm{H}_{2} \mathrm{O}\right) /$ mole (gas mixture)] $\}$ is the limiting factor. Even with this normalization factor, diffusional limitations prevail at high temperatures.

\subsubsection{Burnoff Effects}

One sample was completely consumed by exposure to $1.72 \%$ water vapor in helium gas delivered. The microgravimetric system was left in operation ( $2 \mathrm{~d}$, including pre- and post-period 
for stability determinations) for the entire reaction period, accruing data continuously. The results show the variation of the reaction rate as the reaction (burnoff) proceeds. The initial reaction rate is zero, by definition, and rises asymptotically to a rather constant rate, about $0.900 \mathrm{mg} / \mathrm{min}$ (20 to $50 \%$ burnoff). A slower, somewhat erratic rate is noted in the latter stages of the process. No data are available for the last $5 \%$ of reaction, since the supporting material was consumed and the remaining unreacted sample (approximately 5\%) fell from the TC support. This residual piece was recovered and weighed on a separate balance to verify data of the dedicated microbalance. These data are selected intermediate values evaluated from the strip chart recorder. Additional refinements of the computerized data management system will allow future evaluation of the nature of the rate fluctuations. The more complete data set will aid in determining the number and topochemical nature of the intermediate morphological configurations that occur in the corrosion process.

Microgravimetric techniques serve as excellent means for evaluating the amount of reaction that has occurred and the temporal variation under simulated conditions of MHTGR operation. The data allow evaluation of the global kinetics of reaction with water vapor and/or oxygen. The mechanisms of these reactions can be evaluated using additional extensive analyses such as surface spectroscopy, microscopic examination, and gas composition analyses. This preliminary work shows that the corrosion program will be able to supply detailed and statistically significant information required for prediction of corrosion and for design purposes. The laboratory simulation of design operation conditions and/or accident scenarios appears to be adequate and comprehensive.

\subsubsection{The Effect of Trace Elements on the Surface Oxidation of H-451 Graphite ${ }^{143}$}

Graphite is the highest temperature-stable elemental solid known, but it is highly reactive with gases that contain free oxygen at elevated temperatures. The surface oxidation of nucleargrade (H-451) graphite was observed to take place nonuniformly at pre-existing, and perhaps newly formed, pits. SEM and energy-dispersive X-ray analyses (EDAX) of areas that appear to have oxidized at different rates reveal that those areas which are deeply pitted have aluminum-tosilicon (Al:Si) ratios that are ten times greater than those areas which are less deeply pitted ( $\mathrm{Al}: \mathrm{Si}=13$ to $24 \mathrm{vs} \mathrm{Al}: \mathrm{Si}=1.3$ to 2.4 ). Evidence was found for the presence of relatively large grains of calcium sulfate (anhydrite) and clay minerals within the graphite. Small, residual masses exposed on the oxidized surface were found to be composed primarily of aluminum, which may be present as an oxide. 
Although the data presented here should be considered preliminary in nature, they suggest that rapid oxidation (and the concomitant development of deep pits) may be influenced by the trace element composition of the graphite. With one exception, roughly equal amounts of aluminum and silicon were found to be present in graphite which underlies surfaces that have undergone only low-to-intermediate degrees of oxidation. In those cases where there was heavy oxidation, the amount of silicon appears to be very low compared with the amount of aluminum and the Al:Si ratio relatively high. This strongly suggests that the presence of silicon may act to reduce the rate at which graphite oxidizes. In addition, the EDAX spectra also suggest that the presence of trace amounts of $\mathrm{Fe}$ and/or $\mathrm{V}$ may contribute to the increased rate of oxidation.

Residual masses of material, which stand out in relief above the surface of the graphite after oxidation, were shown to be very rich in aluminum. The aluminum peak areas are so large that these residual masses may contain little or no graphite per se and may be composed primarily of aluminum oxide.

Further study of these relationships (including additional EDAX analyses using an instrument capable of detecting elements lighter than sodium and electron diffraction of specific grains to determine the phases present) is warranted.

\subsubsection{Trace Inorganic Components in Nuclear Graphites ${ }^{144}$}

Graphite is used for structural elements and as a moderator in nuclear reactors. Few data exist concerning nongraphitic, solid phases that may be present within graphite which might influence its properties or be left behind as residues (or ashes) if the graphite should be oxidized. In the present study, two cylinders of 2020 nuclear-grade graphite were oxidized at an elevated temperature $\left(750^{\circ} \mathrm{C}\right)$ and at a low temperature $\left(<200^{\circ} \mathrm{C}\right)$, respectively. The residues were examined optically and using XRD. The interlocking nature of the very fine-grained residues suggests that these solids pre-existed as particles dispersed throughout the graphite as well as within individual graphite grains. Although the XRD patterns are similar in most respects, the low-temperature residue appears to contain a significant amount of amorphous (or poorly

crystallized) material as evidenced by a broad peak at about $4.8 \dot{A}$. Anhydrite $\left(\mathrm{CaSO}_{4}\right)$, gehlenite $\left(\mathrm{Ca}_{2} \mathrm{Al}_{2} \mathrm{SiO}_{7}\right)$, jasmundite $\left\{\mathrm{Ca}_{11}\left(\mathrm{SiO}_{4}\right)_{4} \mathrm{O}_{2} \mathrm{~S}\right\}$, and larnite $\left(\beta-\mathrm{CaSiO}_{4}\right)$ were tentatively identified in the diffraction patterns from both residues.

The results of XRD analyses of the residues obtained by oxidizing nuclear-grade graphite (2020) at both an elevated temperature $\left(750^{\circ} \mathrm{C}\right)$ and a lower temperature $\left(<200^{\circ} \mathrm{C}\right)$ suggest that 
many of the phases found in the high-temperature residue were already present in the graphite prior to oxidation. The procedure for manufacturing graphite involves heating to a temperature in the vicinity of $2700^{\circ} \mathrm{C}$. Note that the graphitization process takes place under reducing conditions, while the samples examined here were oxidized to remove as much carbon as possible.

Two major differences in the X-ray patterns were observed: (1) the sample oxidized at temperatures below $200^{\circ} \mathrm{C}$ appears to contain amorphous (or poorly crystallized) material based on the presence of a broad peak in the range 14 to $23^{\circ} 2 \theta$ and (2) the relative intensities for several of the stronger peaks are different for the two residues analyzed. These observations could be explained by slight differences in the original compositions of two adjacent cylinders, the effects of recrystallization of the amorphous material, or by other factors that are not known at this time.

Based on the interlocking network of very fine-grained material (with larger clusters of white to slightly yellowish grains on the surface and embedded within the oxidized material) observed for both residues, it appears that the trace elements contained within 2020 graphite are not randomly dispersed throughout the graphite. At least some of these elements may be present in the form of pre-existing particles, some of which may be dispersed between graphite grains as well as contained within individual graphitic particles.

Whether the small amount of non-carbon material present in 2020 graphite $(<0.3$ wt \%) has any significant influence on properties such as the mechanical strength, thermal conductivity, electrical conductivity, etc., of the polycrystalline graphite is not known at this time; however, their presence should not be ignored. In a large reactor, very gradual oxidation may result in the accumulation of residual material upon exposed surfaces, causing a change in thermal conductivity locally, or if dislodged, the fine-grained particles may become entrained in the flowing coolant and be deposited in some unintended locations as the result of local fluctuations in the coolant velocity.

\subsubsection{High-Pressure Test Loop}

The high-pressure test loop ${ }^{145}$ has been upgraded, calibrated, and tested at temperatures up to $1000^{\circ} \mathrm{C}$ and to pressures up to $1000 \mathrm{psi}$. The stainless steel sample holder has been found to catalytically accelerate the corrosion of $\mathrm{H}-451$ graphite. A new sample holder has been fabricated entirely of ceramic high-density alumina. Initial tests show no preferential corrosion attributed to the sample holder. Operations are completely automated with continuous data acquisition under the control of a dedicated computer. All calibrations, operating procedures, and QA documents are complete and documented for this program. 


\subsection{HIGH-TEMPERATURE MHTGR CONTROL RODS - J. P. Strizak and T. D. Burchell}

The reference design for the MHTGR control rods uses a series of alloy $800 \mathrm{H}$ canisters along an alloy $800 \mathrm{H}$ support spine as illustrated in Figure 3-55. Each canister contains neutron absorber compacts comprised of natural boron in a graphite matrix. During $100 \%$ power operation modes, the inner six alloy $800 \mathrm{H}$ control rods are locked out of the core so as to prevent damage caused by overheating should a conduction cooldown event occur. An alternative would be to use control rods made of materials that would sustain temperatures of up to $1600^{\circ} \mathrm{C}$.

The desire for high-temperature control rods for use in the inner reflector region of the MHTGR was first reported by Vollman et al. ${ }^{146}$ in January 1989. Vollman advocated the use of graphite or C/C composite material for the high-temperature control rod. ORNL was requested to recommend suitable graphite or composite materials. In June 1990, ORNL published a report ${ }^{147}$ that reviewed the properties of carbon materials suitable for MHTGR control rods. It was recommended that $\mathrm{C} / \mathrm{C}$ composite materials be considered rather than graphites because of their greater strength and toughness (resistance to impact). It was also recommended that ORNL develop a design data base for $\mathrm{C} / \mathrm{C}$ control rod materials. Consequently, a $\mathrm{C} / \mathrm{C}$ composite task was included in the annual operating plan beginning in FY 1991. A confirmatory development need (CDN) document was written for $\mathrm{C} / \mathrm{C}$ composite control rod materials design; the latest issue of the CDN was in January 1992 (ref. 148). Technical details of the control rod operating environment, including the anticipated neutron fluences and service temperatures, were available from a recently published GA report on $450 \mathrm{MW}(\mathrm{t})$ control rod material selection. ${ }^{149}$

A technical plan ${ }^{150}$ describing a technology program for high-temperature control rods manufactured from $\mathrm{C} / \mathrm{C}$ composites was published in January 1992. The plan presents a development strategy along with arguments for the selected materials, carbon fibers, architectures, and processing details. A prototype control rod design based upon GA's conceptual drawings and the CDN is presented. The required program of irradiation, mechanical, thermal-physical, and oxidation testing is briefly outlined.

The initial prototype high-temperature $\mathrm{C} / \mathrm{C}$ control rod consists of a number of tubular elements connected together as illustrated in Figure 3-56. The tubes are constructed from multilayer, braided $\mathrm{C} / \mathrm{C}$ composites with radial reinforcement in the thick section for maximum thread strength. Details on the selected fiber, composite architecture, and processing details for the control rod tubes are given in ORNL purchase specification MET-CMT-PS-16, which appears as Appendix 2 of ref. 150. The swivels and connectors are machined from a solid block of 
ORNL-DWG 92M-13315

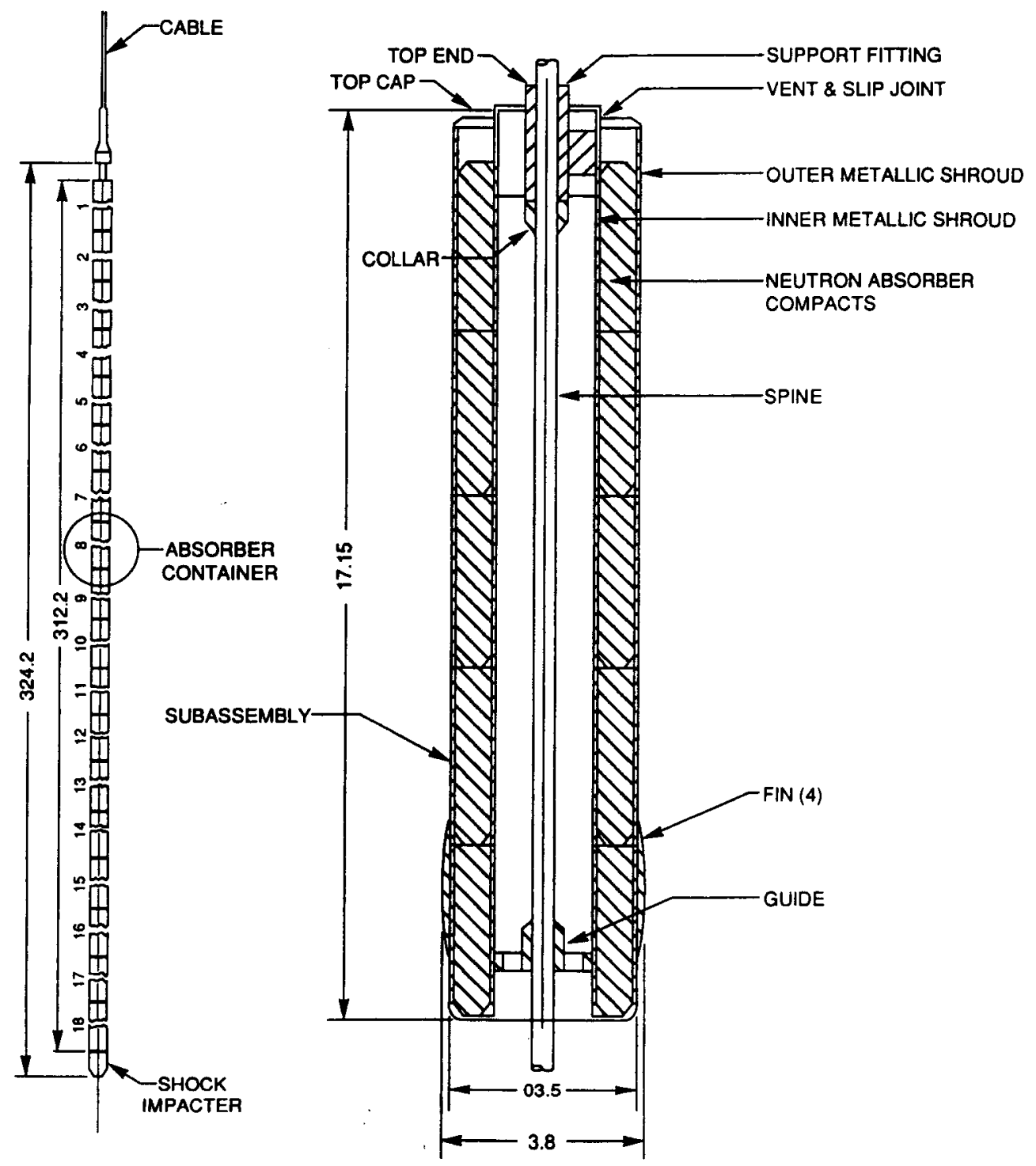

Figure 3-55.

REFERENCE MHTGR CONTROL ROD DESIGN. 


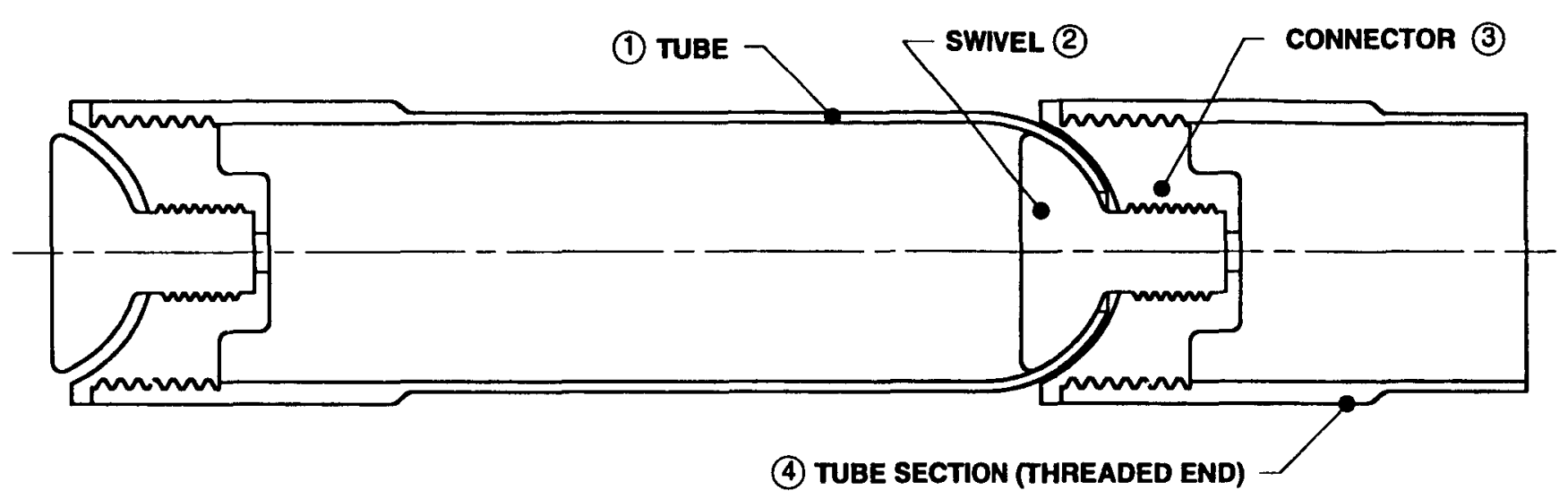

(1) TUBE, Dwg. GRA-NP-93-341, Qty. 1

(2) SWIVEL - TYPE A, Dwg. GRA-NP-93-337, Qty. 2

(3) CONNECTOR - TYPE A, Dwg. GRA-NP-93-336, Qty. 2

(4) TUBE SECTION (THREADED END), Dwg. GRA-NP-93-342, Qty. 1

\begin{tabular}{|lll|}
\hline Job & \multicolumn{3}{l|}{ C/C CONTROL ROD CONCEPT } \\
\hline Part & TYPE A ASSEMBLY & CROSS SECTION \\
\hline Drawing no. GRA-NP-93-343 & Revision no. & O \\
\hline \hline NPR P.I. Approval & Date \\
\hline & & \\
\hline
\end{tabular}

Figure 3-56.

TYPE A PROTOTYPE C/C CONTROL ROD ASSEMBLY. 
orthogonal, three-directional $\mathrm{C} / \mathrm{C}$ composite, i.e., commercially available type 222 manufactured by Fiber Materials, Inc. (FMI).

In February 1992, a purchase order was placed with FMI for: (1) one block of FMI 222 3-D $\mathrm{C} / \mathrm{C}$ composite, $191 \times 191 \times 305 \mathrm{~mm}$; (2) six unidirectional composite rods, $19 \mathrm{~mm}$ diam by $102 \mathrm{~mm}$ long; and (3) eight control rod tube elements meeting ORNL specification MET-CMT-PS-16. Currently, two demonstration prototype control rod assemblies (Figures 3-56 and 3-57) are being machined by FMI. Note that in Figure 3-57, the connectors and swivels are joined using a unidirectional composite pin. The remaining materials will be employed for mechanical, thermal-physical, and oxidation studies as funding becomes available.

\subsection{THERMAL-PHYSICAL PROPERTIES - T. D. Burchell}

Thermal-physical properties data were taken to validate thermal-physical design codes that may be used to predict peak temperatures, thermal gradients, and thermal stresses. Thermalphysical property data acquired included: thermal diffusivity, thermal conductivity, specific heat, and thermal expansivity. Experimental measurements have been performed to assess the effects of specimen orientation and within-billet property variations. Specimens from a single class I billet of H-451 (number R58-357) were tested, although a number of specimens were additionally machined from a class II $\mathrm{H}-451$ billet (R58-29).

Preliminary thermal-physical property data for $\mathrm{H}-451$ have been reported previously. ${ }^{151}$ Figures 3-58 through 3-60 show the billet slabbing plan and thermal-physical property specimens and locations. The major emphasis of our thermal-physical properties testing during the NP-MHTGR closeout period was to determine the extent of spatial variability of thermal conductivity. This was achieved by measuring the room-temperature thermal conductivity from specimens cut throughout a graphite billet center slab. The data are shown on three-axis spatial plots in Figures 3-61 through 3-63. We are unable to detect any systematic spatial variation from these data. Figures 3-64 through 3-66 show the axial, radial, and tangential orientation data, respectively, drawn as probability plots. The good fit to a straight line shows that the data are normally distributed, the mean conductivity ( $50 \%$ probability) being greater in the axial direction $(\sim 150 \mathrm{~W} / \mathrm{m} \cdot \mathrm{K})$ than in either the tangential $(\sim 137 \mathrm{~W} / \mathrm{m} \cdot \mathrm{K})$ or the radial direction $(\sim 135 \mathrm{~W} / \mathrm{m} \cdot \mathrm{K})$.

High-temperature thermal conductivity data have been taken for specimens in the axial, tangential, and radial orientation using the laser flash diffusivity method. Some high-temperature conductivity data have already been published, ${ }^{151}$ and a full account of our thermal conductivity 


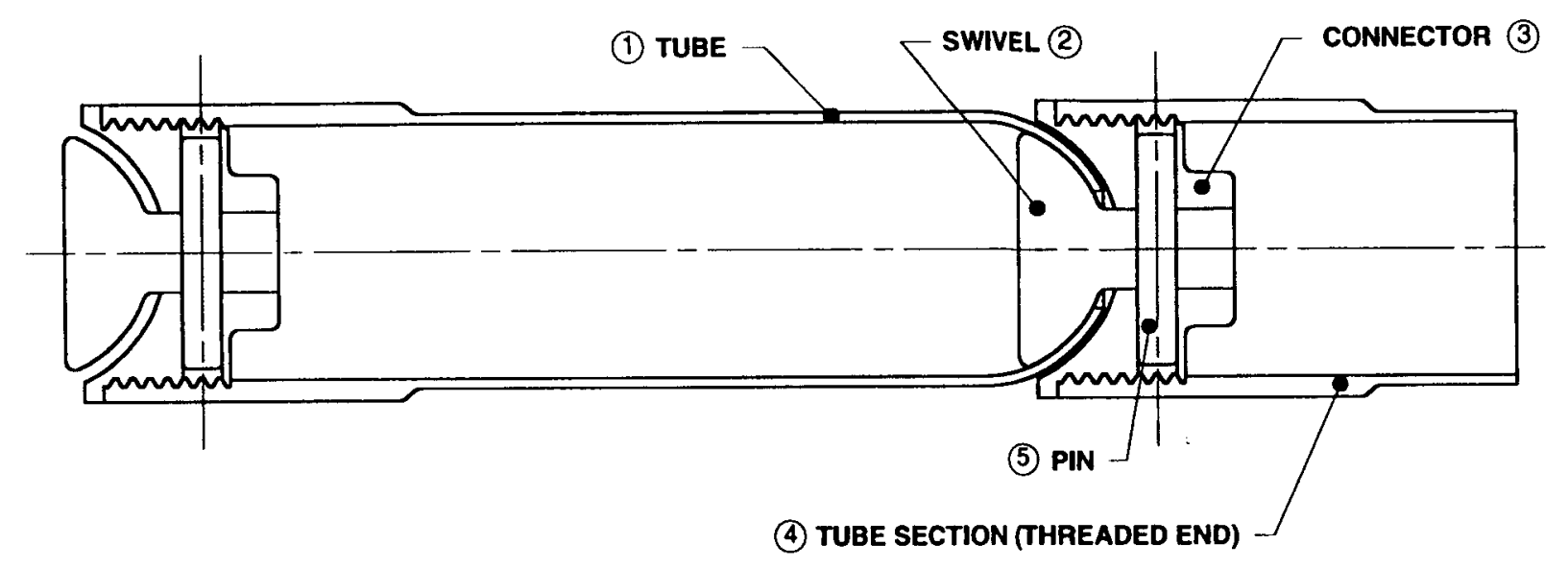

\section{PARTS LIST}

(1) TUBE, Dwg. GRA-NP-93-341, Oty. 1

(2) SWIVEL - TYPE B, Dwg. GRA-NP-93-339, Oty. 2

(3) CONNECTOR - TYPE B, Dwg. GRA-NP-93-338, Qty. 2

(4) TUBE SECTION (THREADED END). Dwg. GRA-NP-93-342, Oty. 1

(5) PIN, Dwg. GRA-NP-93-340, Oty 2

\begin{tabular}{|ll|}
\hline Job & \multicolumn{3}{l|}{ C/C CONTROL ROD CONCEPT } \\
\hline Pan & TYPE B ASSEMBLY - CROSS SECTION \\
\hline Drawing no. GRA-NP-93-344 & Aevision no. $\quad 0$ \\
\hline \hline NPR P.I. Approval & \multicolumn{2}{|c|}{ Dato } \\
\hline & \\
\hline
\end{tabular}

Figure 3-57.

TYPE B PROTOTYPE C/C CONTROL ROD ASSEMBLY. 


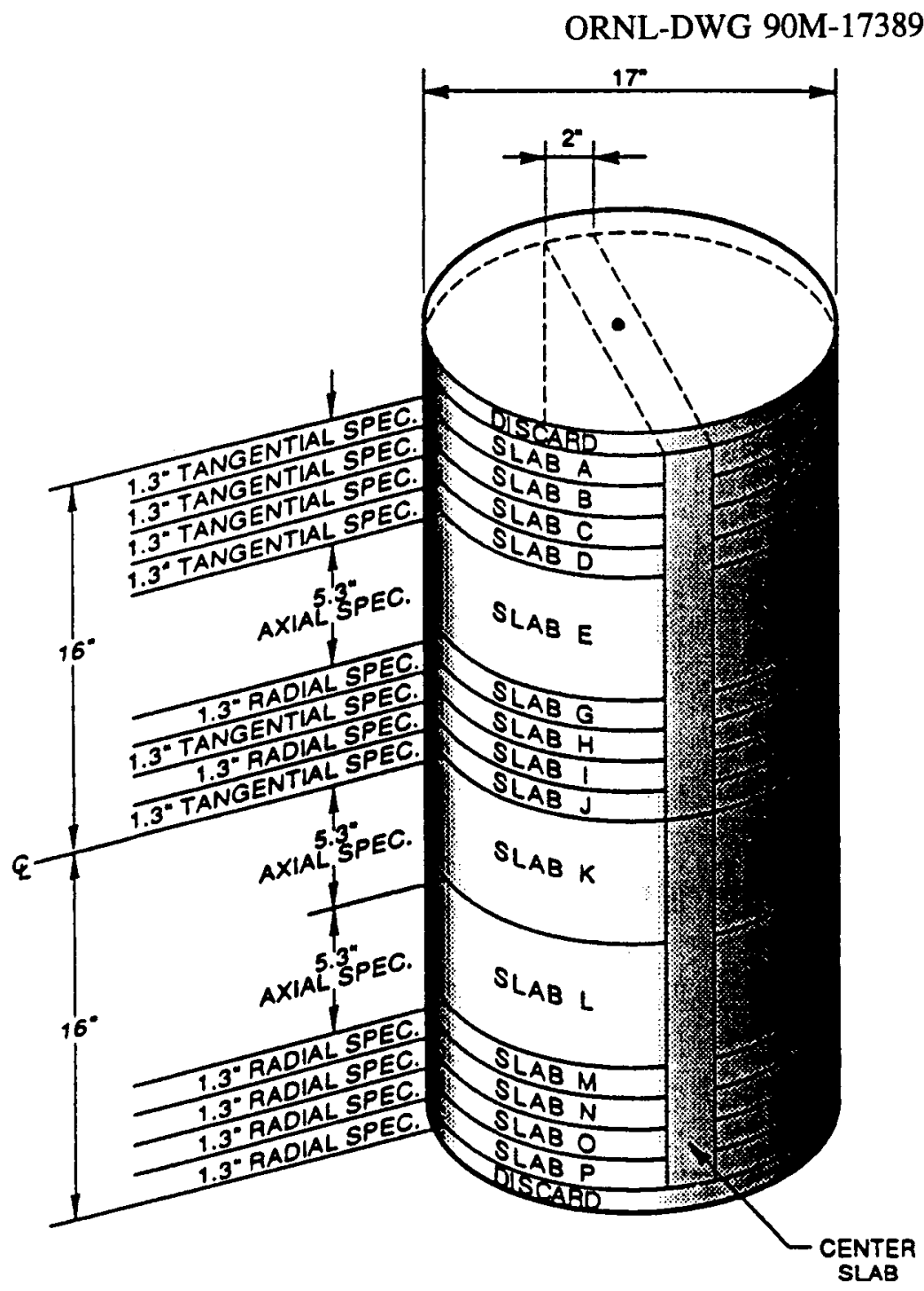

Figure 3-58.

H-451 GRAPHITE BILLET CUTTING DIAGRAM. 
ORNL-DWG 90M-17802R

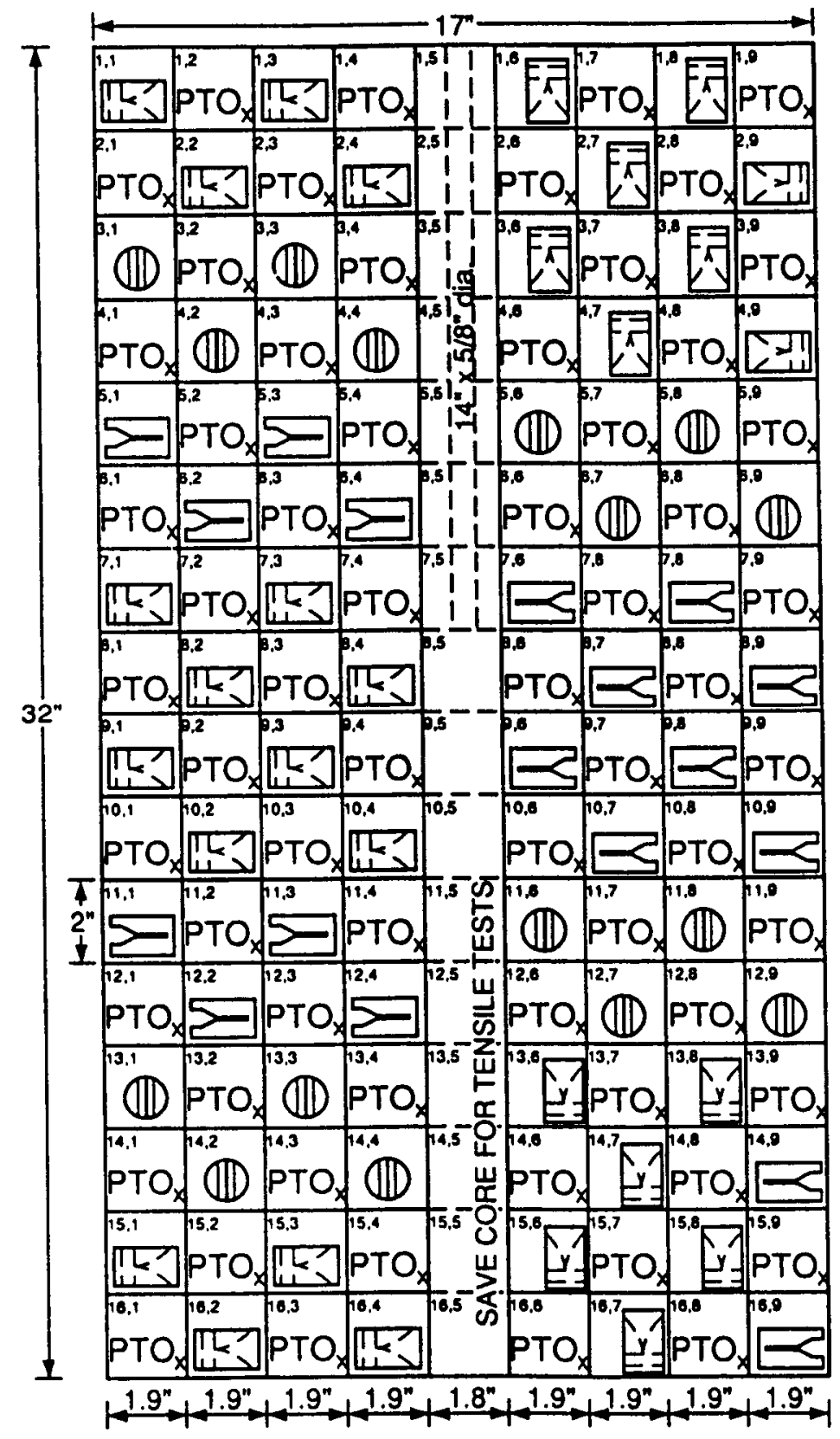

Figure 3-59.

H-451 GRAPHITE BILLET CENTER SLAB CUTTING DIAGRAM. 

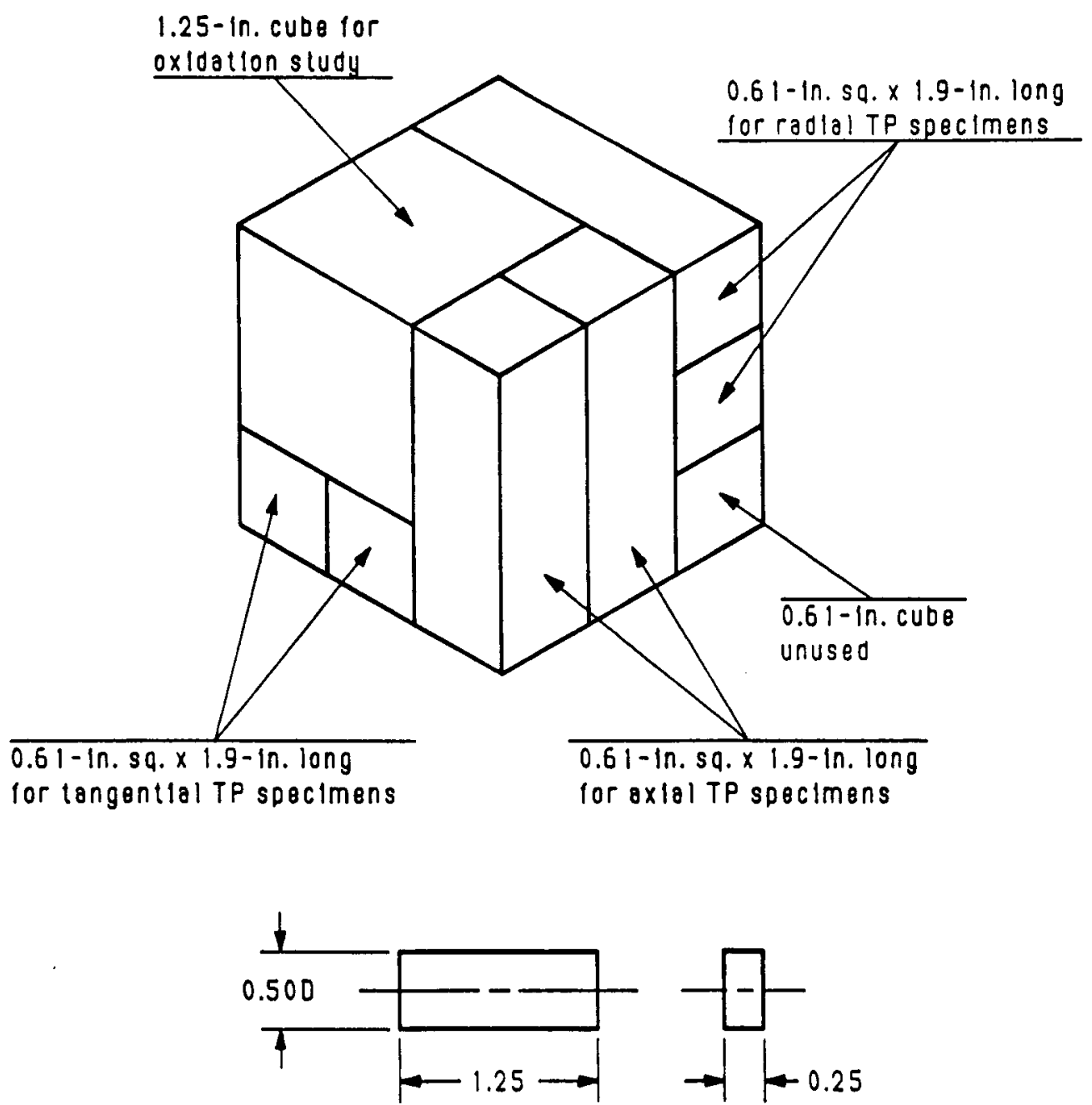

Inermal Properves (TP) Specimens

Figure 3-60.

H-451 GRAPHITE THERMAL PHYSICAL

PROPERTIES SPECIMEN DETAILS. 


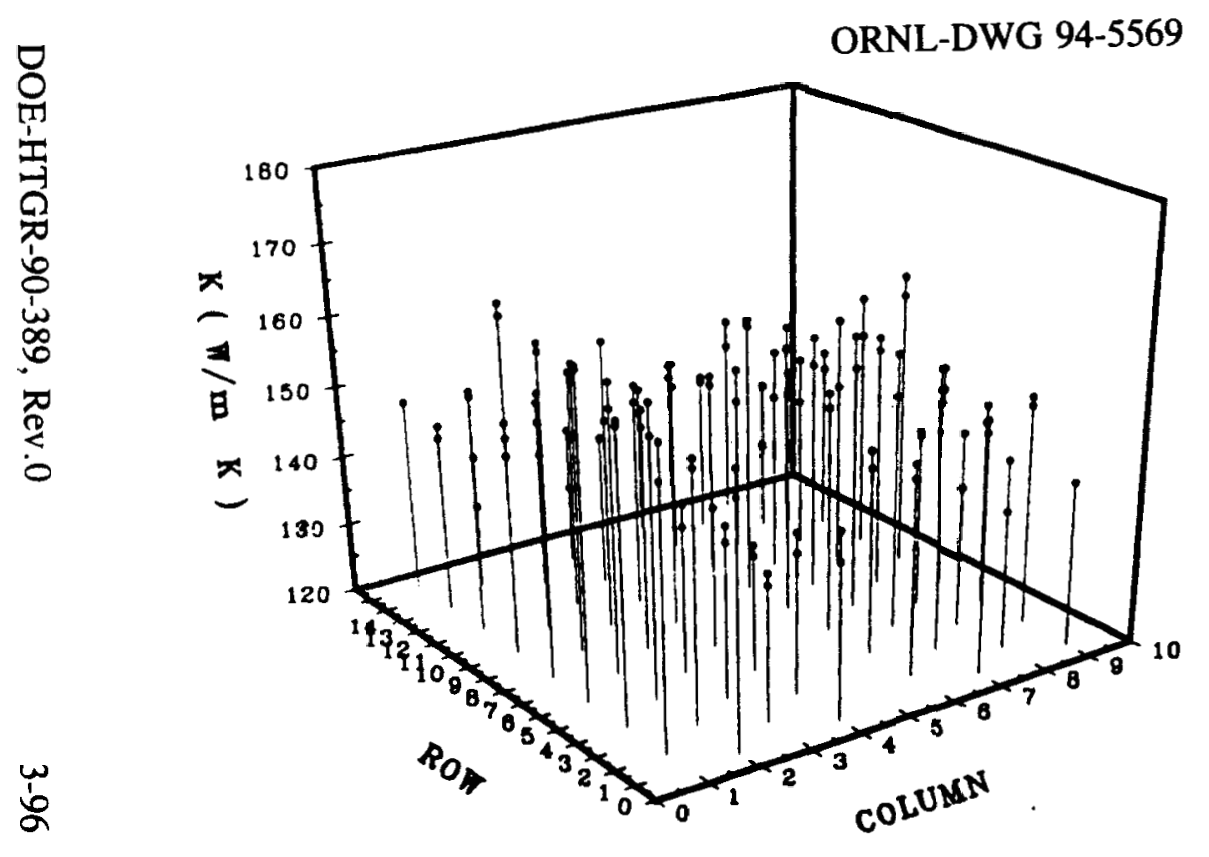

Figure 3-61.

ROOM-TEMPERATURE THERMAL CONDUCTIVITY DATA FOR H-451 GRAPHITE (AXIAL ORIENTATION) SHOWING SPATIAL DISTRIBUTION.

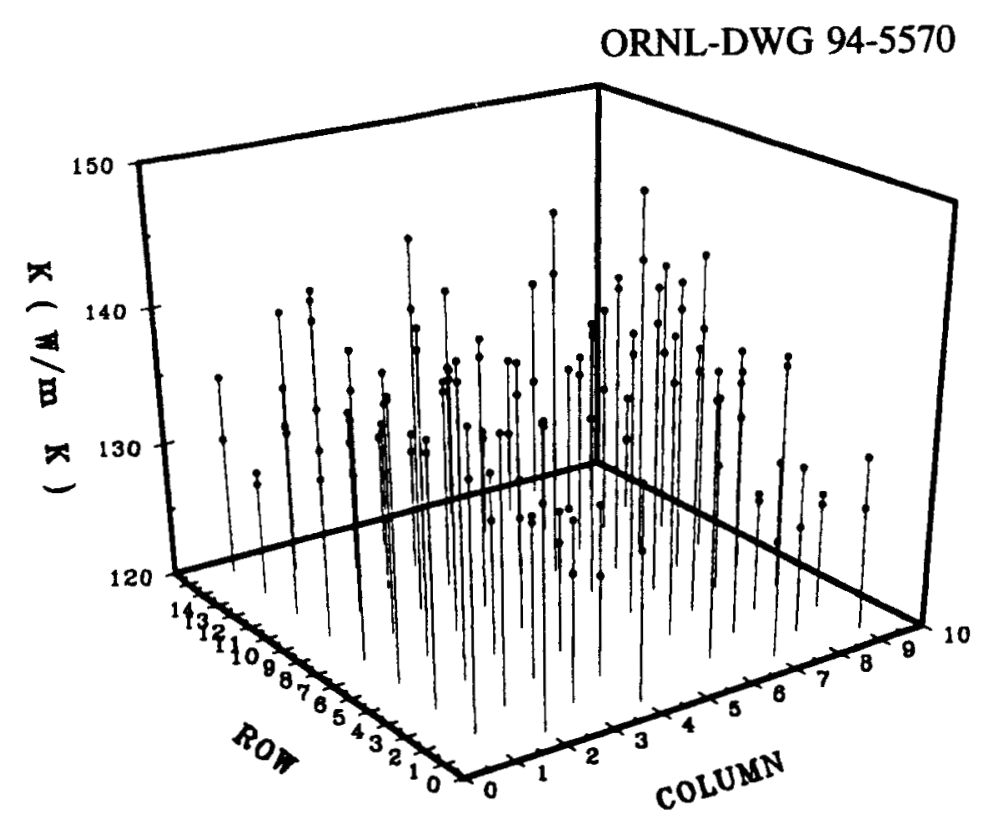

Figure 3-62.

ROOM-TEMPERATURE THERMAL CONDUCTIVITY DATA FOR H-451 GRAPHITE (RADIAL ORIENTATION) SHOWING SPATIAL DISTRIBUTION. 


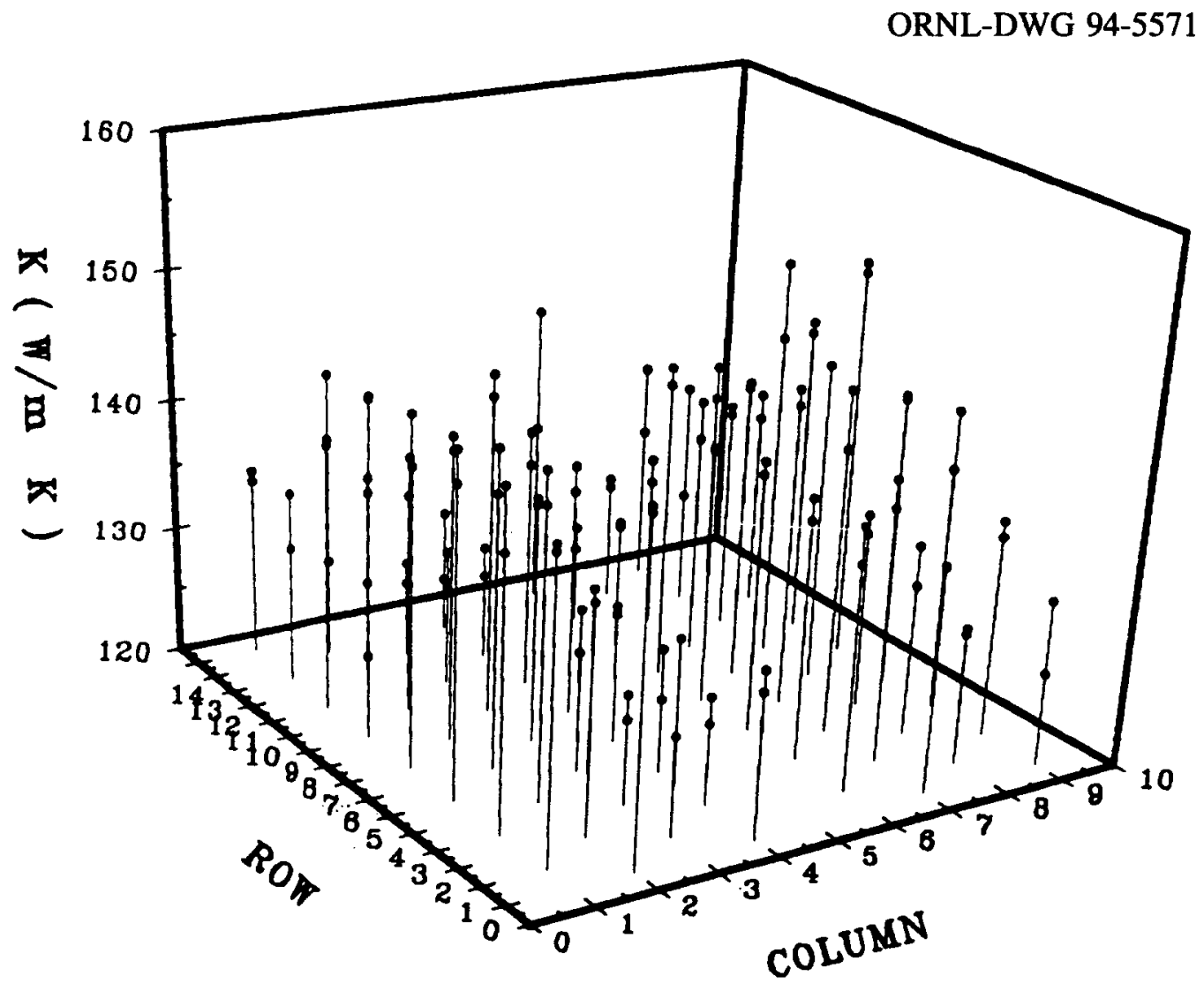

$\forall$
0
11
1
7
0
07
0
0
0
0
0
0
0
0
0

Figure 3-63.

ROOM-TEMPERATURE THERMAL CONDUCTIVITY DATA FOR H-451 GRAPHITE (TANGENTIAL ORIENTATION) SHOWING SPATIAL DISTRIBUTION. 


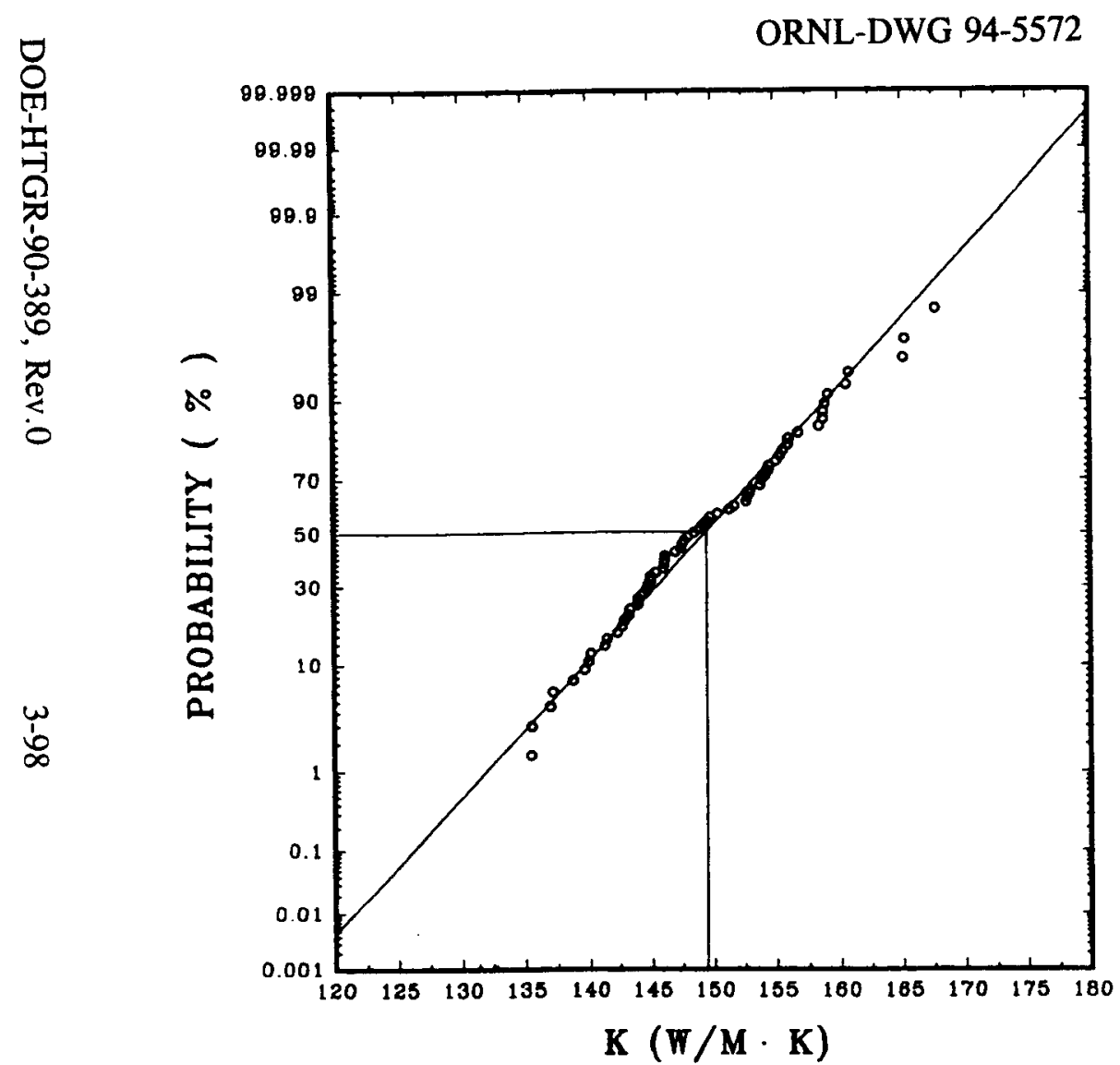

Figure 3-64.

PROBABILITY PLOT OF H-451 GRAPHITE

ROOM-TEMPERATURE THERMAL

CONDUCTIVITY DATA (AXIAL

ORIENTATION).

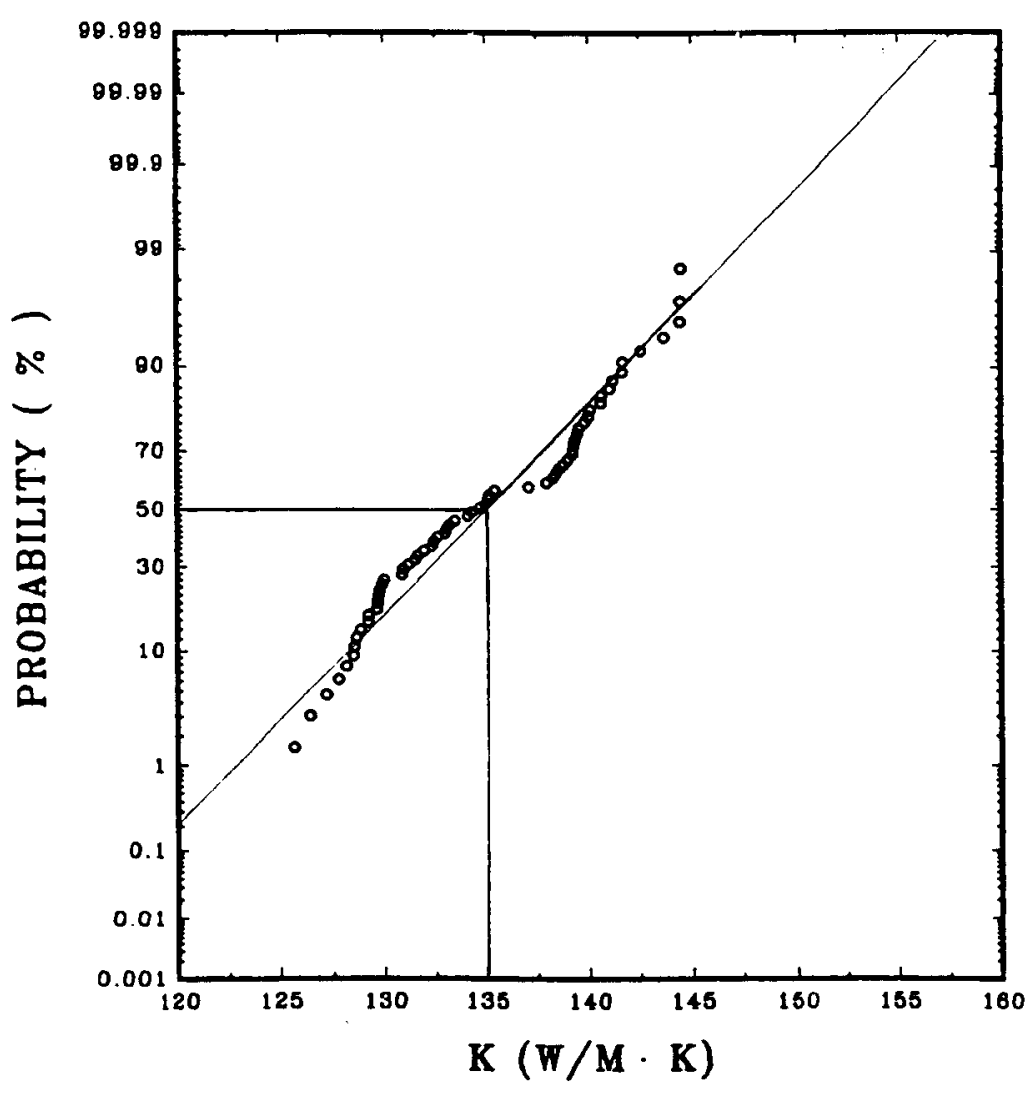

Figure 3-65.

PROBABILITY PLOT OF H-451 GRAPHITE ROOM-TEMPERATURE THERMAL CONDUCTIVITY DATA (RADIAL ORIENTATION). 
ORNL-DWG 94-5574

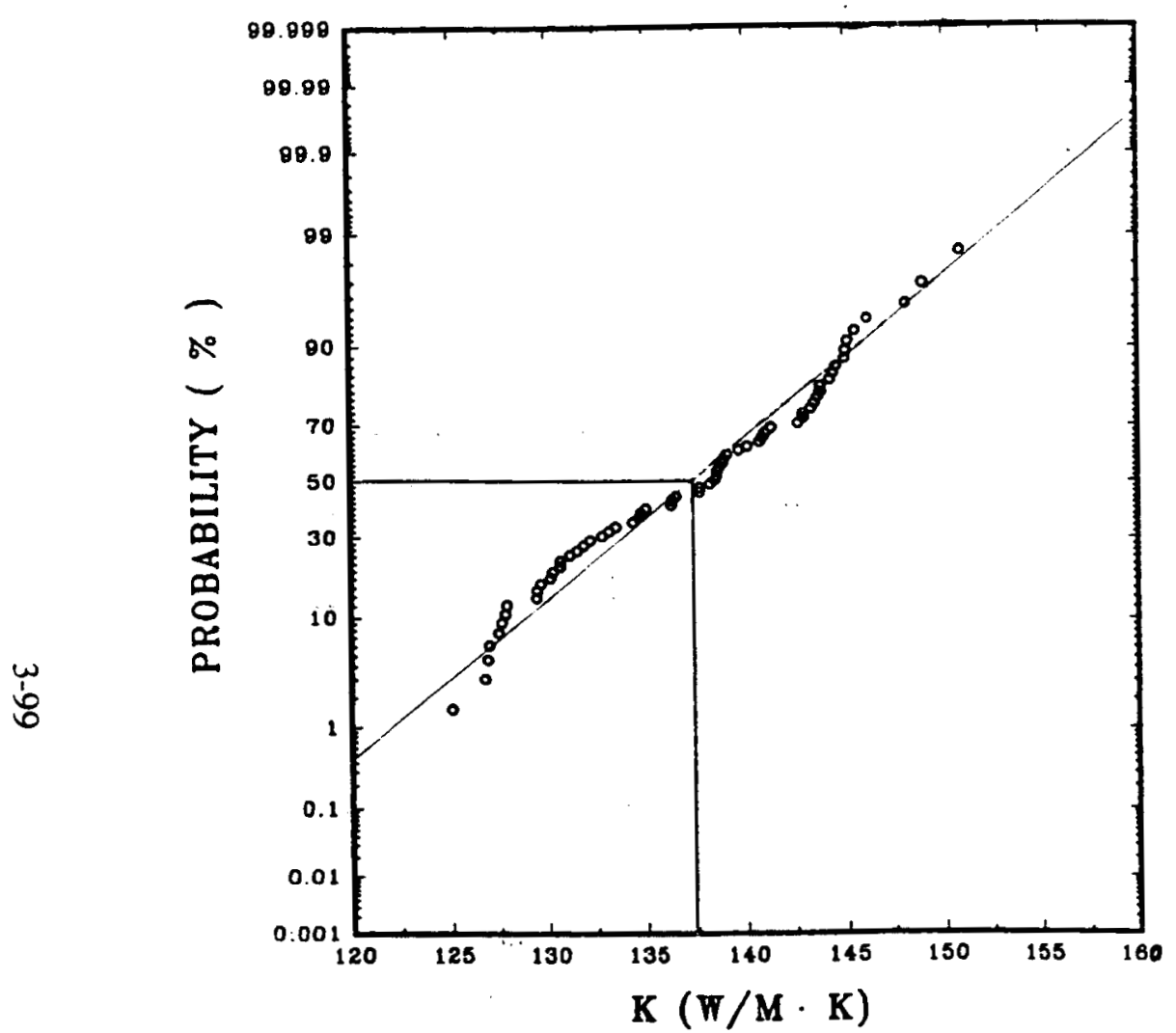

$Ð$
0
1
1
1
0
0
0
0
0
$\dot{0}$
0
0
0
0
0
0

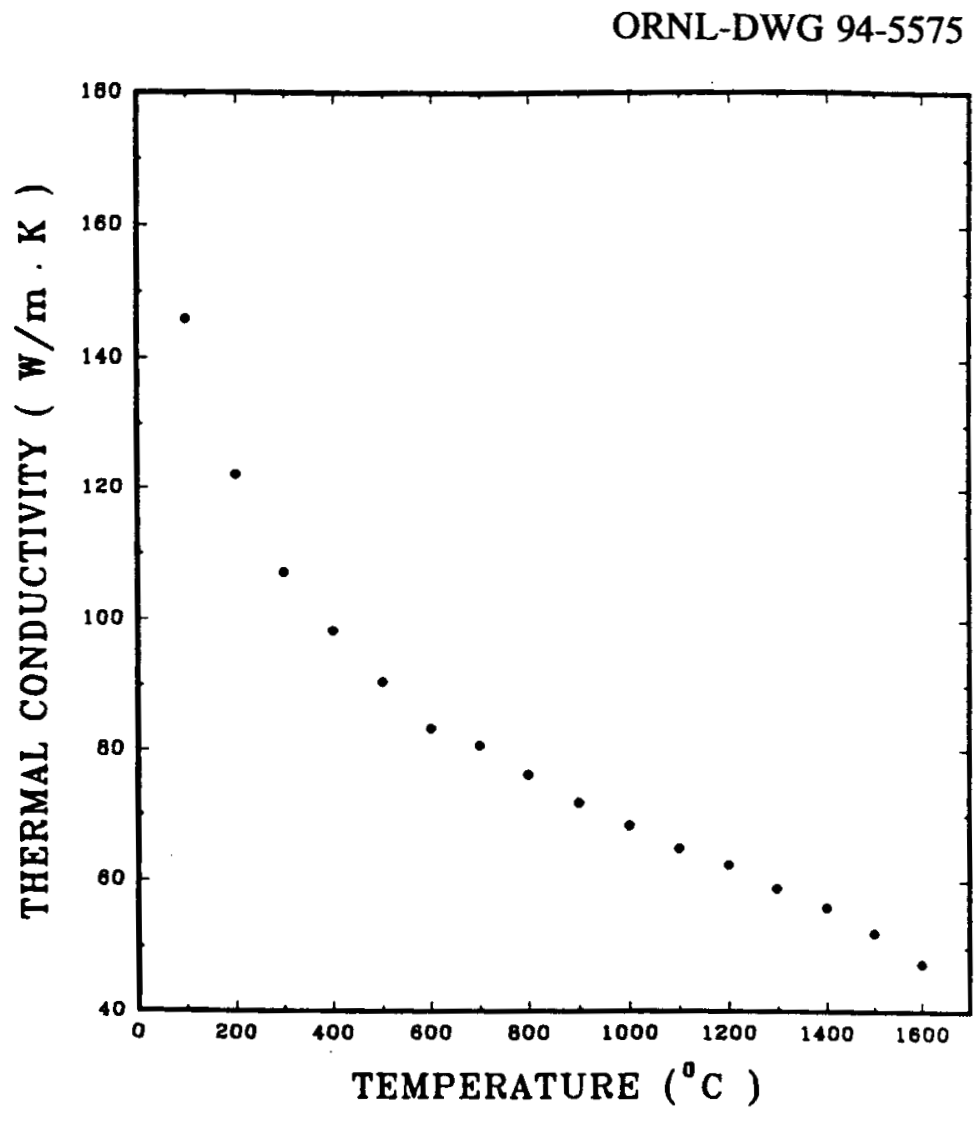

Figure 3-67.

TEMPERATURE DEPENDENCE OF H-451 GRAPHITE THERMAL CONDUCTIVITY (AXIAL ORIENTATION). 


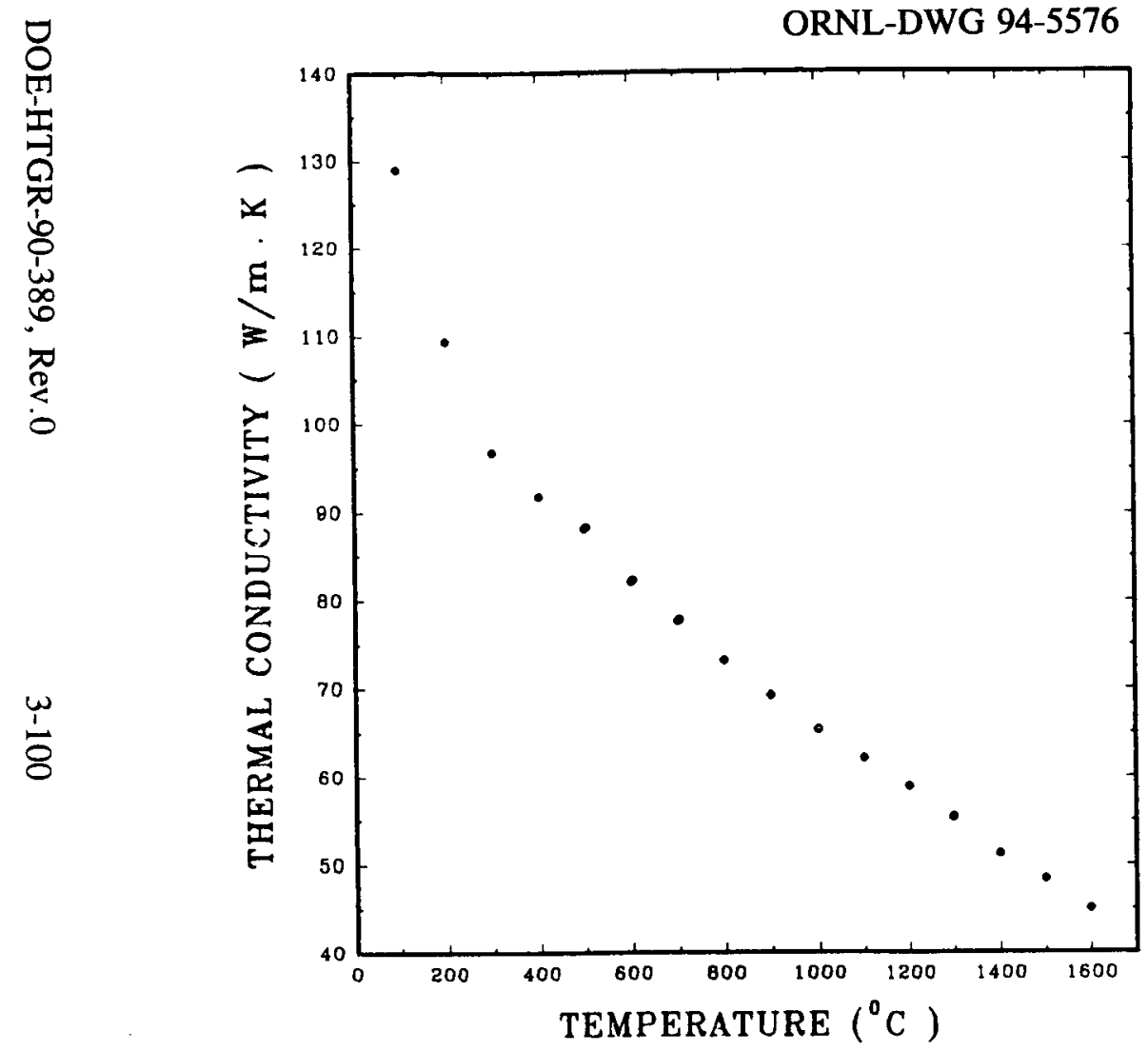

Figure 3-68.

TEMPERATURE DEPENDENCE OF H-451 GRAPHITE THERMAL CONDUCTIVITY (RADIAL ORIENTATION).

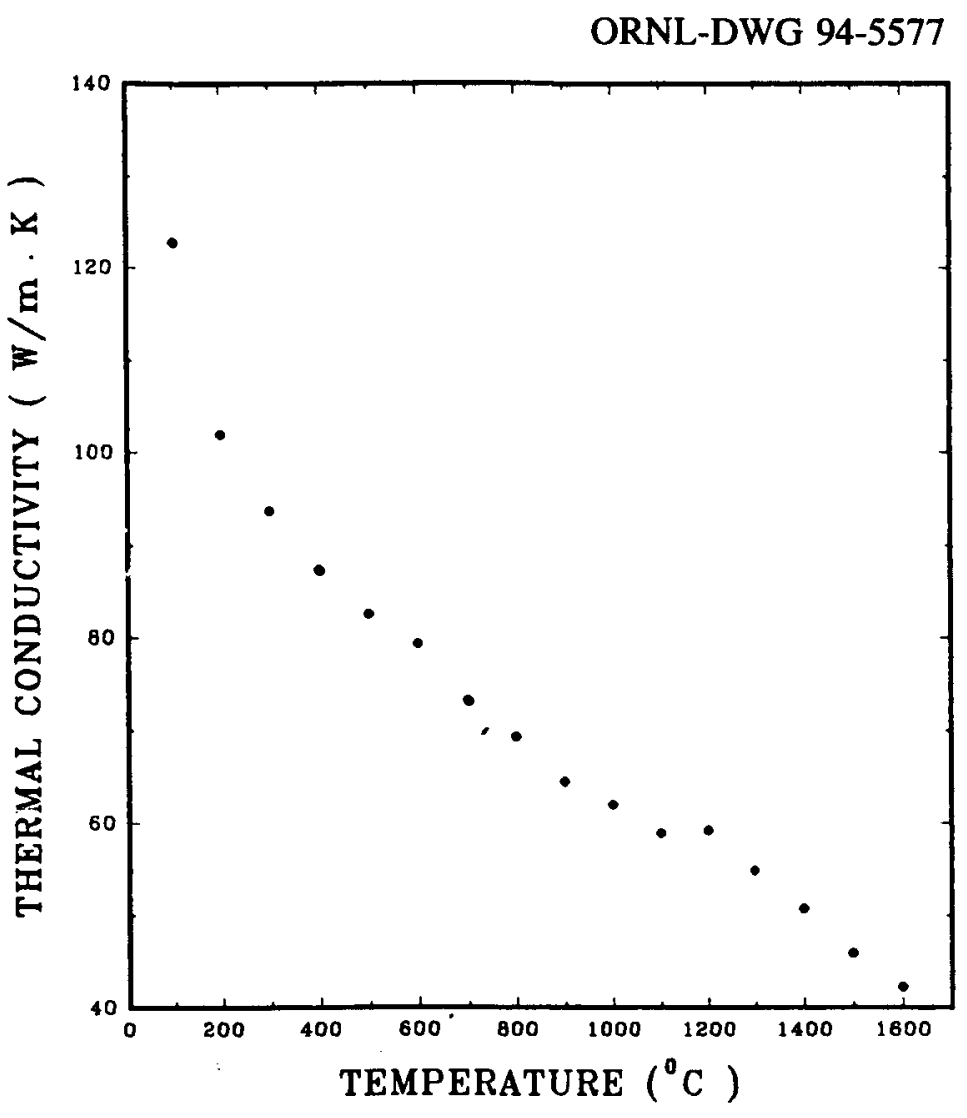

Figure 3-69.

TEMPERATURE DEPENDENCE OF H-451 GRAPHITE THERMAL CONDUCTIVITY (TANGENTIAL ORIENTATION). 
Table 3-12

HIGH TEMPERATURE THERMAL CONDUCTIVITY OF H-451 GRAPHITE IN THE AXIAL ORIENTATION. (Billet R58-357, 2-6-AIX)

\begin{tabular}{|c|c|c|c|c|c|}
\hline $\begin{array}{c}\text { TEMP } \\
\left({ }^{\circ} \mathrm{C}\right)\end{array}$ & $\begin{array}{c}\text { DIFF } \\
\mathrm{cm}^{2} / \mathrm{sec}\end{array}$ & LOSS & $\begin{array}{c}\text { DENSITY } \\
\mathrm{g} / \mathrm{cm}^{3}\end{array}$ & $\begin{array}{c}\mathrm{Cp} \\
\mathrm{J} / \mathrm{Kg} \bullet \mathrm{K}\end{array}$ & $\begin{array}{c}\mathrm{TC} \\
\mathrm{W} / \mathrm{m} \bullet \mathrm{K}\end{array}$ \\
\hline \hline 100 & & & & & \\
\hline 200 & 0.8876 & 0.0131 & 1.7666 & 930.304 & 145.8765 \\
\hline 301 & 0.4535 & 0.0081 & 1.7666 & 1338.221 & 107.2049 \\
\hline 400 & 0.3749 & 0.0484 & 1.7666 & 1484.545 & 98.3238 \\
\hline 500 & 0.3200 & 0.0182 & 1.7666 & 1601.598 & 90.5403 \\
\hline 600 & 0.2785 & 0.0394 & 1.7666 & 1695.948 & 83.4313 \\
\hline 700 & 0.2578 & 0.0109 & 1.7666 & 1772.334 & 80.7017 \\
\hline 800 & 0.2350 & 0.0303 & 1.7666 & 1834.765 & 76.1769 \\
\hline 900 & 0.2157 & 0.0487 & 1.7666 & 1886.234 & 71.8860 \\
\hline 1000 & 0.2012 & 0.0651 & 1.7666 & 1929.027 & 68.5619 \\
\hline 1100 & 0.1878 & 0.0975 & 1.7666 & 1964.892 & 65.1714 \\
\hline 1200 & 0.1774 & 0.0668 & 1.7666 & 1995.178 & 62.5419 \\
\hline 1299 & 0.1650 & 0.0000 & 1.7666 & 2020.932 & 58.9222 \\
\hline 1400 & 0.1549 & 0.0000 & 1.7666 & 2042.973 & 55.9225 \\
\hline 1500 & 0.1432 & 0.0000 & 1.7666 & 2061.950 & 52.1553 \\
\hline 1600 & 0.1297 & 0.0000 & 1.7666 & 2078.376 & 47.6185 \\
\hline & & & & & 1155.588 \\
\hline
\end{tabular}


Table 3-13

HIGH TEMPERATURE THERMAL CONDUCTIVITY OF H-451 GRAPHTE IN THE RADIAL ORIENTATION. (Billet R58-357, 2-6-RIX).

\begin{tabular}{|c|c|c|c|c|}
\hline $\begin{array}{l}\text { TEMP } \\
\left({ }^{\circ} \mathrm{C}\right)\end{array}$ & $\begin{array}{c}\text { DIFF } \\
\mathrm{cm}^{2} / \mathrm{sec}\end{array}$ & $\begin{array}{l}\text { DENSITY } \\
\mathrm{g} / \mathrm{cm}^{3}\end{array}$ & $\begin{array}{c}\mathrm{Cp} \\
\mathrm{J} / \mathrm{Kg} \bullet \mathrm{K}\end{array}$ & $\begin{array}{c}\mathrm{TC} \\
\mathrm{W} / \mathrm{m} \bullet \mathrm{K}\end{array}$ \\
\hline 100 & 0.7868 & 1.7624 & 930.304 & 129.0028 \\
\hline 200 & 0.5372 & 1.7624 & 1155.588 & 109.4107 \\
\hline 300 & 0.4103 & 1.7624 & 1338.221 & 96.7590 \\
\hline 400 & 0.3508 & 1.7624 & 1484.545 & 91.7715 \\
\hline 500 & 0.3123 & 1.7624 & 1601.598 & 88.1459 \\
\hline 600 & 0.2747 & 1.7624 & 1695.948 & 82.1032 \\
\hline 700 & 0.2485 & 1.7624 & 1772.334 & 77.6143 \\
\hline 800 & 0.2265 & 1.7624 & 1834.765 & 73.2505 \\
\hline 900 & 0.2083 & 1.7624 & 1886.234 & 69.2584 \\
\hline 1000 & 0.1925 & 1.7624 & 1929.027 & 65.4344 \\
\hline 1100 & 0.1796 & 1.7624 & 1964.892 & 62.1803 \\
\hline 1200 & 0.1676 & 1.7624 & 1995.178 & 58.9156 \\
\hline 1299 & 0.1554 & 1.7624 & 2020.932 & 55.3522 \\
\hline 1400 & 0.1424 & 1.7624 & 2042.973 & 51.2572 \\
\hline 1500 & 0.1333 & 1.7624 & 2061.950 & 48.4446 \\
\hline 1600 & 0.1230 & 1.7624 & 2078.376 & 45.0357 \\
\hline
\end{tabular}


Table 3-14

HIGH TEMPERATURE THERMAL CONDUCTIVITY OF H-451 GRAPHITE IN THE TANGENTIAL ORIENTATION. (Billet R58-357, 2-6-TIX).

\begin{tabular}{|c|c|c|c|c|c|}
\hline $\begin{array}{c}\text { TEMP } \\
\left({ }^{\circ} \mathrm{C}\right)\end{array}$ & $\begin{array}{c}\text { DIFF } \\
\mathrm{cm}^{2} / \mathrm{sec}\end{array}$ & LOSS & $\begin{array}{c}\text { DENSITY } \\
\mathrm{g} / \mathrm{cm}^{3}\end{array}$ & $\begin{array}{c}\mathrm{Cp} \\
\mathrm{J} / \mathrm{Kg} \bullet \mathrm{K}\end{array}$ & $\begin{array}{c}\mathrm{TC} \\
\mathrm{W} / \mathrm{m} \bullet \mathrm{K}\end{array}$ \\
\hline \hline 100 & 0.7432 & 0.0144 & 1.7763 & 930.304 & 122.8088 \\
\hline 200 & 0.4965 & 0.0162 & 1.7763 & 1155.588 & 101.9213 \\
\hline 300 & 0.3944 & 0.0203 & 1.7763 & 1338.221 & 93.7497 \\
\hline 400 & 0.3313 & 0.0511 & 1.7763 & 1484.545 & 87.3611 \\
\hline 500 & 0.2904 & 0.0339 & 1.7763 & 1601.598 & 82.6022 \\
\hline 600 & 0.2635 & 0.0407 & 1.7763 & 1695.948 & 79.3887 \\
\hline 700 & 0.2329 & 0.0211 & 1.7763 & 1772.334 & 73.3215 \\
\hline 800 & 0.2127 & 0.0333 & 1.7763 & 1834.765 & 69.3274 \\
\hline 900 & 0.1926 & 0.0793 & 1.7763 & 1886.234 & 64.5243 \\
\hline 1000 & 0.1811 & 0.0793 & 1.7763 & 1929.027 & 62.0579 \\
\hline 1100 & 0.1690 & 0.1101 & 1.7763 & 1964.892 & 58.9745 \\
\hline 1200 & 0.1674 & 0.0000 & 1.7763 & 1995.178 & 59.3286 \\
\hline 1299 & 0.1528 & 0.0000 & 1.7763 & 2020.932 & 54.8425 \\
\hline 1400 & 0.1399 & 0.0000 & 1.7763 & 2042.973 & 50.7586 \\
\hline 1500 & 0.1255 & 0.0000 & 1.7763 & 2061.950 & 45.9673 \\
\hline 1600 & 0.1147 & 0.0000 & 1.7763 & 2078.376 & 42.3393 \\
\hline
\end{tabular}


data (and other thermal-physical properties data) will be published. ${ }^{152}$ Typical high-temperature thermal conductivity curves (room temperature to $1600^{\circ} \mathrm{C}$ ) for $\mathrm{H}-451$ graphite in the axial, radial, and tangential directions are shown in Figures 3-67, 3-68, and 3-69 respectively, and the data are reported in Tables 3-12 through 3-14.

3.8 INTERNATIONAL COLLABORATION - T. D. Burchell, E. L. Fuller, Jr., J M Robbins, G. R. Romanoski, and J. P. Strizak

Collaborative graphite technology development activities have been ongoing with two international partners, Germany and Japan. The collaborative agreement between the DOE and JAERI remains active; however, the agreement with Germany is no longer active. The results of our collaborative studies are summarized below.

\subsubsection{Collaboration with Germany}

Our collaborative activities with Germany centered on the inclusion of German graphites in a HFIR target irradiation capsule (HTK-7). This work was performed under PWS GD-1 of the subprogram on FFPG. Capsule HTK-7 was a high-fluence "turnaround" experiment and contained a total of 64 specimens, representing six grades of graphite. Three of these graphites were supplied by Germany (see Table 3-15). Capsule HTK-7 completed irradiation on January 18, 1992, having been installed for 16 operating cycles, and attained a peak fluence of $3.8 \times 10^{26} \mathrm{n} / \mathrm{m}^{2}[\mathrm{E}>50 \mathrm{keV}]$ or $2.89 \times 10^{26} \mathrm{n} / \mathrm{m}^{2}[\mathrm{E}>0.18 \mathrm{MeV}]$ at an estimated irradiation temperature of $600^{\circ} \mathrm{C}$. Pre-irradiation examination of the graphite specimens irradiated in HTK-7

Table 3-15

CAPSULE HTK-7 CONTENTS

\begin{tabular}{|l|l|l|c|}
\hline \multicolumn{1}{|c|}{ Graphite } & \multicolumn{1}{|c|}{ Details } & \multicolumn{1}{c|}{ Manufacturer } & $\begin{array}{c}\text { Number of } \\
\text { Specimens }\end{array}$ \\
\hline \hline H-451 & $\begin{array}{l}\text { Petroleum coke, near- } \\
\text { isotropic extruded }\end{array}$ & $\begin{array}{l}\text { Sigri-Great Lakes Carbon, } \\
\text { United States }\end{array}$ & 8 \\
\hline 2020 & $\begin{array}{l}\text { Petroleum coke, isotropic, } \\
\text { isostatically molded }\end{array}$ & $\begin{array}{l}\text { Carbone-Lorraine North } \\
\text { America, United States }\end{array}$ & 14 \\
\hline IG-110 & $\begin{array}{l}\text { Petroleum coke, isotropic, } \\
\text { isostatically molded }\end{array}$ & $\begin{array}{l}\text { Toyo-Tanso Company, } \\
\text { Japan }\end{array}$ & 7 \\
\hline ASR-1RS & $\begin{array}{l}\text { Pitch coke, isotropic } \\
\text { molded }\end{array}$ & Sigri GmbH, Germany & 13 \\
\hline
\end{tabular}

DOE-HTGR-90-389, Rev.0 
Table 3-15 cont.

\begin{tabular}{|l|l|l|c|}
\hline ASR-2RS & Sis6 & $\begin{array}{l}\text { Pitch coke, isotropic } \\
\text { molded }\end{array}$ & Sigri GmbH, Germany \\
\hline ASR-2E & $\begin{array}{l}\text { Pitch coke, near-isotropic } \\
\text { extruded }\end{array}$ & Sigri GmbH, Germany & 8 \\
\hline
\end{tabular}

is reported elsewhere. ${ }^{153}$ Moreover, an assessment of the irradiation-induced dimensional changes of the graphites irradiated in HTK-7 has been published..$^{154}$

The dimensional changes of the three German grades of graphite irradiated in HTK-7 are shown in Figure 3-70. Grades ASR-1RS and -2RS are essentially identical. Both are coalderived coke (pitch coke) graphites formed by vibrational molding. ${ }^{155}$ However, ASR-2RS has undergone one additional densification cycle to increase its strength and density. Our data (Figure 3-70) for the dimensional changes of ASR-1RS and -2RS indicated the two behaved in an identical fashion and that the additional densification cycle had little effect upon the irradiationinduced dimensional changes. Both grades develop significant anisotropy at fluences $>1.0 \times$ $10^{26} \mathrm{n} / \mathrm{m}^{2}$ [E $\left.>0.18 \mathrm{MeV}\right]$. Haag ${ }^{155}$ has reported the irradiation-induced dimensional changes of ASR-1RS at $600^{\circ} \mathrm{C}$. Turnaround was reported at a fluence of $\sim 1.3 \times 10^{26} \mathrm{n} \cdot \mathrm{m}^{2}[\mathrm{E}>0.18$ $\mathrm{MeV}]$, and the maximum shrinkages were $\sim 1.75 \%$ (across grain) and $-2.5 \%$ (with grain). The ASR specimens irradiated in HTK-7 were machined with their length in the against-grain directions. Examination of Figure 3-70 shows that our data are in reasonable agreement with those reported by Haag. The HTK-7 data for the ASR graphites show a turnaround in dimensional change at $\sim 1.25-1.5 \times 10^{26} \mathrm{n} / \mathrm{m}^{2}[\mathrm{E}>0.18 \mathrm{MeV}]$ and maximum shrinkages of $\sim 1.5$ and $\sim 1.75 \%$ in the across-grain and with-grain directions, respectively. The greater observed shrinkage in the with-grain orientation is a result of the preferred orientation of the filler coke (and hence graphite crystal basal planes) during the molding operation.

Grade ATR-2E is an extruded grade. Consequently, its preferred orientation is opposite to that of the molded ASR grades. Higher shrinkages would thus be expected in the extrusion direction (specimen length) than in the perpendicular-to-extrusion (specimen diameter) direction, as shown by our data (Figure 3-70). In comparison to H-451, which is also an extruded graphite, ATR-2E undergoes less shrinkage and exhibits turnaround at a lower fluence. 


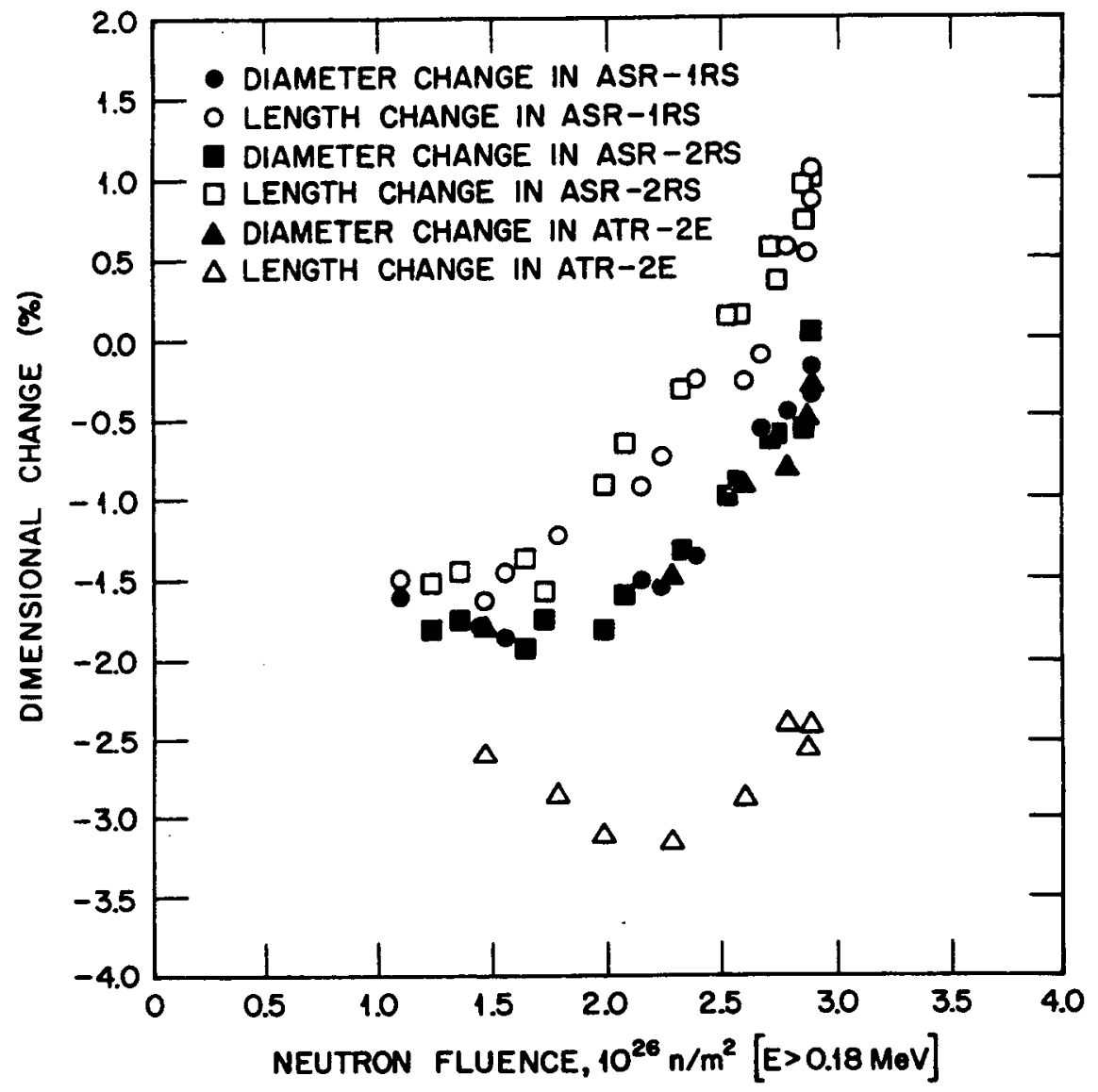

Figure 3-70.

IRRADIATION-INDUCED DIMENSIONAL CHANGES IN AS̀-1RS, ARS-2RS, AND ATR-2E GRADE GRAPHITES IRRADIATED AT $\sim 600^{\circ} \mathrm{C}$ IN CAPSULE HTK-7. 


\subsubsection{Collaboration with Japan}

Our collaborations with Japan are performed in accordance with Annex 3 - Graphite, of the U.S. DOE/JAERI Agreement on the Development of HTRs. Currently, there are seven test project plans (TTPs) active under Annex 3. Here, we report on our collaborative studies in four specific areas: fracture mechanics studies, fracture modelling, irradiation effects, and graphite oxidation.

\subsubsection{Fracture Mechanics Studies}

Various fracture-toughness (critical stress-intensity factor, or $\mathrm{K}_{\mathrm{tc}}$ ) measurement techniques were applied to IG-110, a fine-grained, isostatically molded, high-strength graphite manufactured by Toyo Tanso Company. IG-110 is the designated graphite for the fuel elements and core support structure in the Japanese HTTR. Two fracture toughness specimen geometries were evaluated at ORNL and four at JAERI. Detailed accounts of this work are published elsewhere. ${ }^{157}$ Table 3-16 summarizes the data obtained in this study.

Table 3-16

A COMPARISON OF $\mathrm{K}_{\mathrm{IC}}$ OBTAINED FROM DIFFERENT TEST GEOMETRIES OF IG-110 GRAPHITE

\begin{tabular}{|c|c|c|c|}
\hline \multirow[b]{2}{*}{ Specimen geometry } & \multicolumn{2}{|c|}{$\mathrm{K}_{\mathrm{Ic}}\left(\mathrm{MNm}^{-3 / 2}\right)$} & \multirow[b]{2}{*}{$\begin{array}{l}\text { Laboratory where } \\
\text { tests performed }\end{array}$} \\
\hline & Mean & Std. Dev. & \\
\hline Chevron-notched short rod & 1.16 & 0.05 & ORNL \\
\hline Disc compact tension & 1.12 & - & JAERI \\
\hline Cylindrical bend specimen & 1.07 & - & JAERI \\
\hline Short rod & 0.94 & -- & JAERI \\
\hline Compact tension & 0.92 & 0.04 & JAERI \\
\hline Centrally slotted disc & 0.83 & 0.03 & ORNL \\
\hline
\end{tabular}

The $\mathrm{K}_{\mathrm{lc}}$ values obtained from tests on six different specimen geometries range from $1.16 \mathrm{MNm}^{-3 / 2}$ using CNSR to $0.83 \mathrm{MNm}^{-3 / 2}$ from the CSD. The latter value is in reasonable agreement with that previously obtained by Sato et al. ${ }^{158}$ of $\mathrm{K}_{\mathrm{lc}}=0.78 \mathrm{MNm}^{-3 / 2}$. The smaller 
value obtained by Sato et al. may be attributable to the thinner specimen width $(2 \mathrm{~mm})$ they employed. Earlier work by Oku et al. ${ }^{159}$ using CT specimens has shown an effect of specimen thickness on fracture toughness.

The CNSR and DCT are the methods preferred by ORNL and JAERI, respectively. The $\mathrm{K}_{\mathrm{Ic}}$ values reported here for IG-110 graphite from these two methods (Table 3-16) are in very good agreement. Critical stress-intensity factors $\left(\mathrm{K}_{\mathrm{Ic}}\right)$ obtained from the CBS, SR, and CT ranged from 1.07 to $0.92 \mathrm{MNm}^{-3 / 2}$.

The differences in the fracture toughness values obtained in this study were attributed to a true specimen size effect caused by the tendency for crack growth resistance to increase with increasing crack extension in graphites.

In a further study, ${ }^{160}$ the size effect on fracture toughness in IG-110 and two U.S. graphites (H-451 and 2020) was investigated using the CNSR specimen geometry. The experimental data are summarized in Table 3-17. There is a marked increase in the fracture toughness with specimen size for all three graphites reported here. This behavior is attributed to rising R-curve behavior in graphites and is more dominant in graphites that exhibit increased amounts of inelastic fracture processes, such as $\mathrm{H}-451$, during deformation and failure.

Our fracture mechanics studies are reported in more detail in Sect. 3.4 of this document.

Table 3-17

CNSR FRACTURE-TOUGHNESS TEST RESULTS

\begin{tabular}{|c|c|c|c|}
\hline \multirow{2}{*}{ Graphite } & \multirow{2}{*}{ Diam $(\mathrm{mm})$} & \multicolumn{2}{|c|}{$\mathrm{K}_{\mathrm{Qv}_{\mathrm{v}}}\left(\mathrm{MNm}^{-3 / 2}\right)$} \\
\cline { 3 - 4 } & Mean & Std. Dev. \\
\hline \hline \multirow{2}{*}{$\mathrm{H}-451$} & 12.7 & 1.35 & 0.055 \\
& 19.0 & 1.44 & 0.095 \\
& 25.4 & 1.68 & 0.078 \\
\hline \multirow{2}{*}{ S-2020 } & 12.7 & 0.91 & 0.058 \\
& 19.0 & 0.98 & 0.035 \\
& 25.4 & 1.10 & 0.025 \\
\hline \multirow{2}{*}{ IG-110 } & 12.7 & 0.98 & 0.032 \\
& 19.0 & 1.07 & 0.036 \\
& 25.4 & 1.19 & 0.040 \\
\hline
\end{tabular}




\subsubsection{Graphite Fracture Modelling}

A fracture model ${ }^{161}$ has been successfully applied to two nuclear graphites. The physical basis of, and assumptions behind, the fracture model for nuclear graphites are reported elsewhere. ${ }^{162}$

Microstructurally related inputs, such as filler particle size, filler particle fracture toughness $\left(\mathrm{K}_{\mathrm{Ic}}\right)$, density, pore size distribution, number of pores, and specimen geometry (size and volume), are utilized in the model. The model was applied to two graphites, GLCC grade H-451 and Toyo Tanso grade IG-110. For each graphite, the predicted tensile failure probabilities were compared with experimental data generated using ASTM Standard C-749 tensile test specimens. The predicted failure probabilities were in close agreement with the experimental data, particularly in the case of the H-451. The model was also shown to qualitatively predict the influence on the failure probabilities of changes in filler particle size, density, pore size, pore size distribution, number of pores, and specimen geometry (stressed volume). The good performance is attributed to the sound physical basis of the model, which recognizes the dominant role of porosity in controlling crack initiation and propagation during graphite fracture. The performance of the fracture model is shown in Figures 3-71 and 3-72 for grades H-451 and IG-110, respectively.

In the case of $\mathrm{H}-451$ (Figure 3-71), the prediction of the failure probability distribution is excellent. The very close agreement of the predicted and experimental mean (50\% failure probability) tensile strength of the graphite is particularly encouraging. Moreover, the shape of the distribution is correctly predicted for this graphite grade. However, the agreement between experimental data and model prediction is less good in the case of IG-110 graphite (Figure 3-72). This is perhaps evidence that the failure mechanism assumed in the model is less applicable to fine-grained graphites such as IG-110. Indeed, it has been shown that fine-grained graphites exhibit much less subcritical cracking, or process-zone activity, during fracture than do coarser-

grained graphites. ${ }^{163}$ Quantitatively, this is shown by the lower bulk $\mathrm{K}_{\mathrm{Ic}}$ of IG-110 compared with that of H-451. ${ }^{160}$ Despite the poorer performance in the latter case, the model does display considerable versatility in being able to predict the behavior of two graphites with significantly different microstructures.

More recently, ${ }^{164}$ the fracture model has been revised and improved microstructural data used to model the tensile fracture probability of $\mathbf{H}-451$. Table 3-18 reports the microstructural input value used in the model, and Figure 3-73 shows the model performance. The model still closely predicts the mean strength ( $50 \%$ failure probability) of H-451. Moreover, the microstructural 


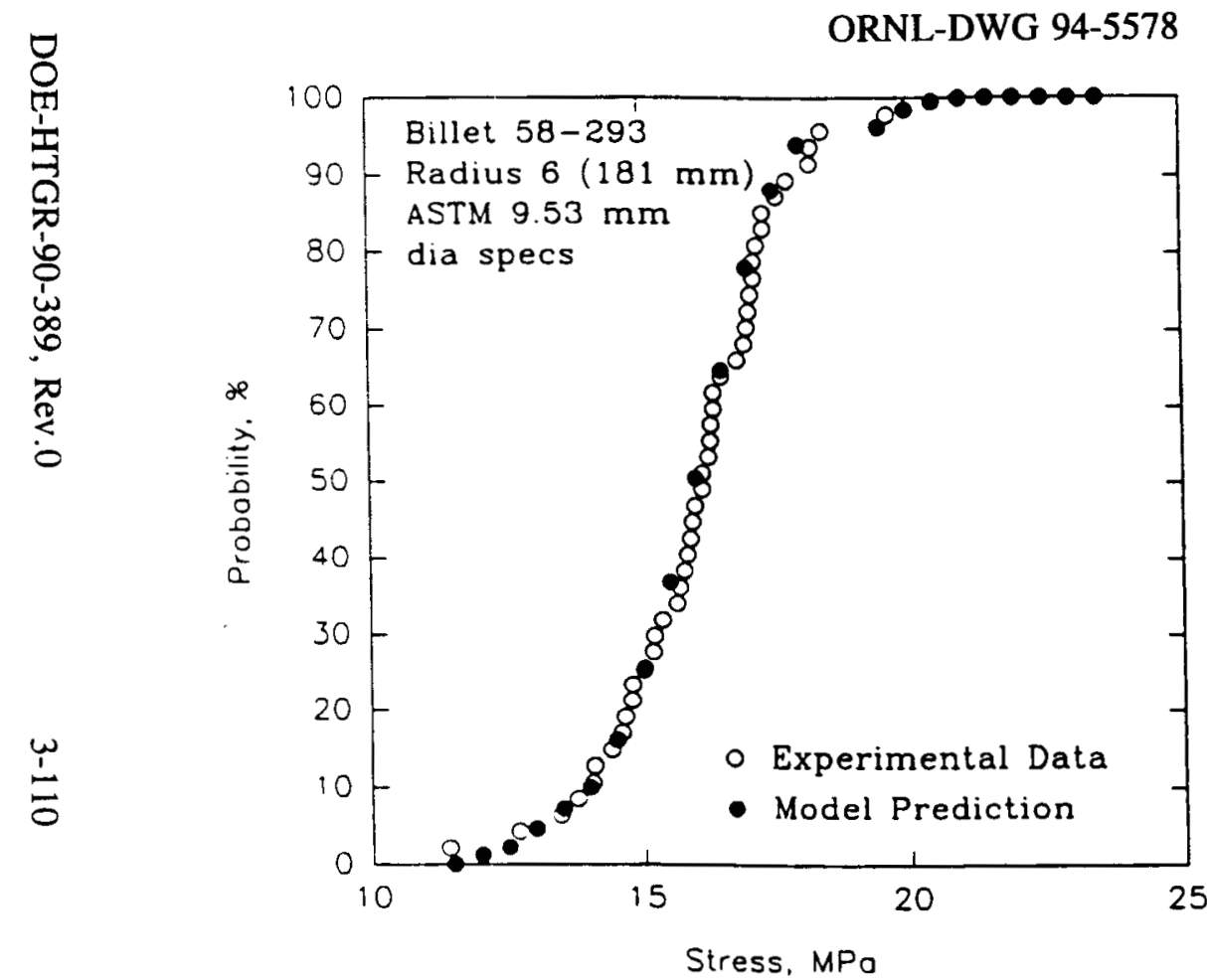

Figure 3-71.

FAILURE PROBABILITIES FOR GRADE H-451 GRAPHITE COMPARISON OF MODEL PREDICTIONS AND EXPERIMENTAL DATA.

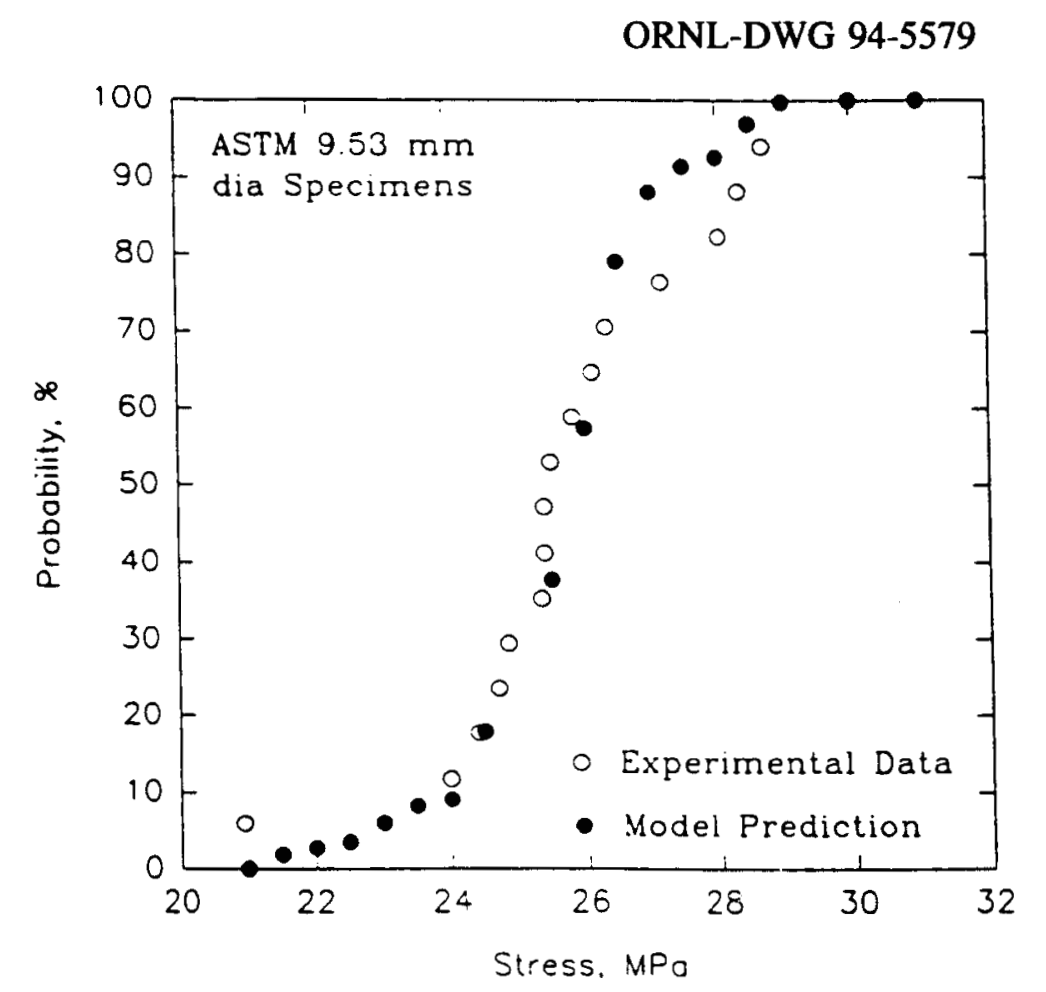

Figure 3-72.

FAILURE PROBABILITIES FOR GRADE IG-110 GRAPHITE COMPARISON OF MODEL PREDICTIONS AND EXPERIMENTAL DATA. 
Table 3-18

MODEL INPUT PARAMETERS FOR GRADE H-451 GRAPHITE

\begin{tabular}{|l|c|}
\hline \multicolumn{1}{|c|}{ Model input parameters } & Grade $\mathrm{H}-451$ \\
\hline \hline Particle critical stress-intensity factor, $\mathrm{K}_{\mathrm{lc}}\left(\mathrm{MN} \bullet \mathrm{m}^{-3 / 2}\right)$ & 0.285 \\
\hline Mean filler particle size, a $(\mathrm{mm})$ & 0.5 \\
\hline Density, $\rho\left(\mathrm{g} \bullet \mathrm{cm}^{-3}\right)$ & 1.79 \\
\hline Mean pore size, $\mathrm{S}_{\mathrm{o}}(\mu \mathrm{m})$ & 42 \\
\hline Standard deviation, $\mathrm{S}_{\mathrm{d}}$ & 1.9 \\
\hline Mean pore area, $\mathrm{P}_{\mathrm{o}}\left(\mu \mathrm{m}^{2}\right)$ & 700 \\
\hline Number of pores per $\mathrm{m}^{3}, \mathrm{~N}\left(\mathrm{~m}^{-3}\right)$ & $2.97 \times 10^{8}$ \\
\hline Specimen breadth, $\mathrm{b}\left(\mathrm{mm}^{\prime}\right)$ & 8.44 \\
\hline Specimen volume, $\mathrm{V}\left(\mathrm{m}^{3}\right)$ & $3.17 \times 10^{-6}$ \\
\hline
\end{tabular}




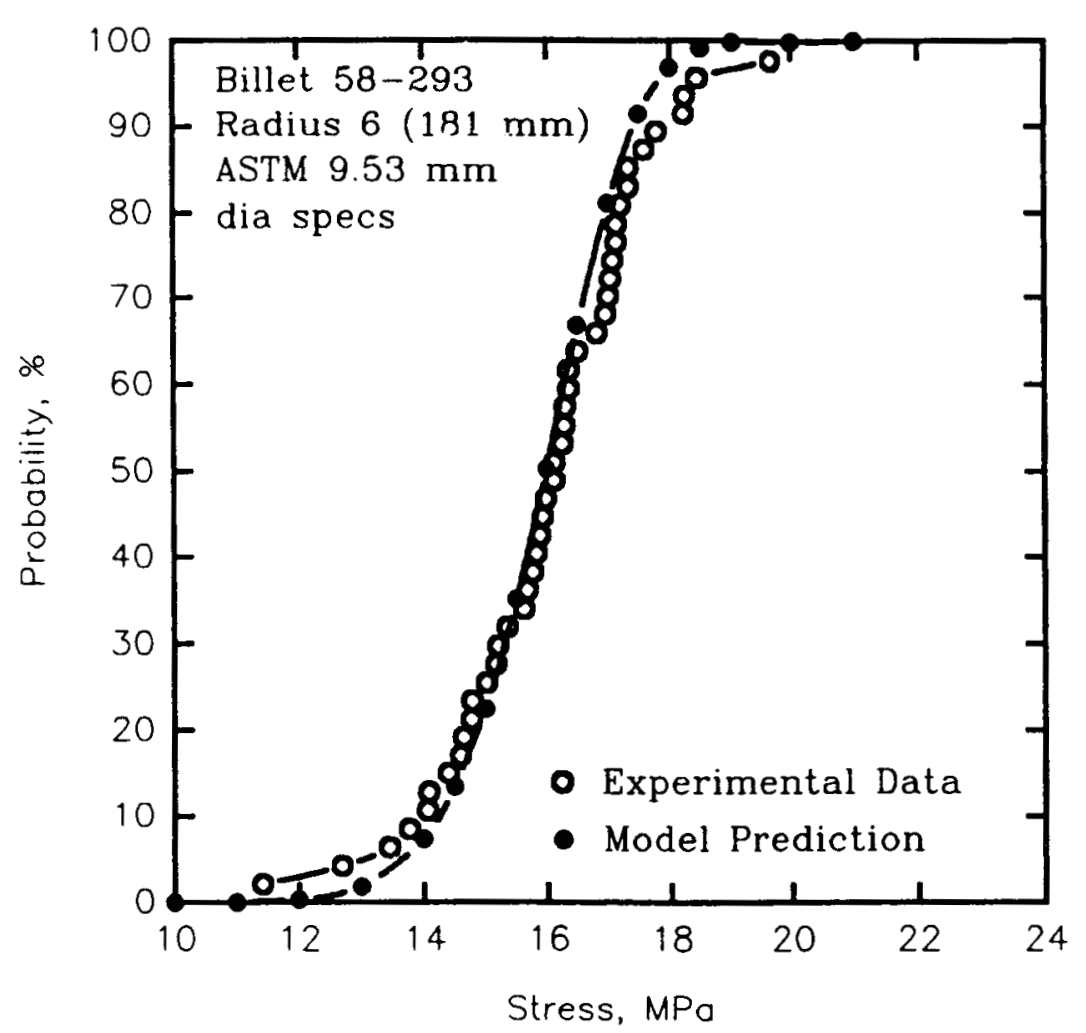

Figure 3-73.

FAILURE PROBABILITIES FOR GRADE H-451 GRAPHITE; COMPARISON OF MODEL PREDICTIONS

AND EXPERIMENTAL DATA. 
inputs to the model, particularly the mean pore size and particle $\mathrm{K}_{\mathrm{lc}}$, are well founded.

Figure 3-74 shows a typical pore size distribution for $\mathrm{H}-451$, obtained using image analysis, as used in the fracture model. Detailed image analysis studies of H-451 microstructure are currently under way at ORNL.

\subsubsection{Irradiation Effects}

Specimens of grade IG-110 graphite were included in HFIR irradiation capsule HTK-7 (ref. 156) [details of capsule content and irradiation history are given in Sect. 3.8.1]. The irradiation-induced dimensional changes of IG-110 are shown in Figure 3-75. Also included in Figure 3-75 are data for grade 2020 graphite.

Toyo Tanso grade IG-110 develops less anisotropy than grade 2020 when irradiated to high fluences, as seen in Figure 3-75, where the IG-110 dimensional change data fall between the data for grade 2020. However, a marked anisotropy can be detected in IG-110 at fluences $>2.0 \times$ $10^{26} \mathrm{n} / \mathrm{m}^{2}[\mathrm{E}>0.18 \mathrm{MeV}]$.

\subsubsection{Graphite Oxidation}

A study of the air-graphite reaction kinetics for IG-110 graphite over the temperature range 450 to $750^{\circ} \mathrm{C}$ has been performed. The activation energy, $E_{2}$, for the graphite-air reaction was found to be $187.9 \mathrm{~kJ} / \mathrm{mol}$, which indicated the reaction is occurring under kinetic control. The reaction rate increased with burnoff to a maximum value of $1.35 \times 10^{3} \mathrm{~g} / \mathrm{m}^{2} \mathrm{~s}$ at $34 \%$ burnoff. A full account of this work is currently in preparation. 


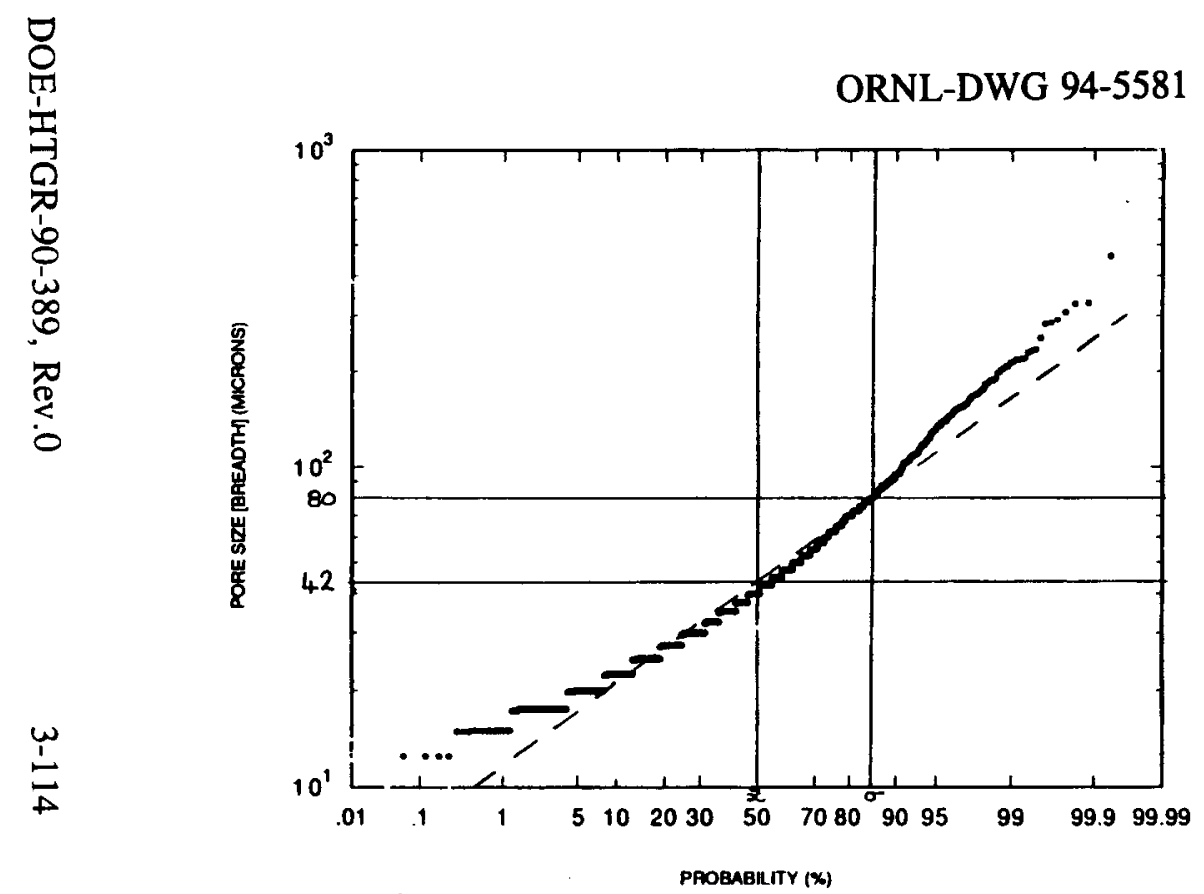

Figure 3-74.

PORE SIZE DISTRIBUTION FOR H-451 GRAPHITE (SPECIMEN 92 0751, 10 FIELDS @ $\times 5,1673$ PORES).
ORNL-DWG 93-11952

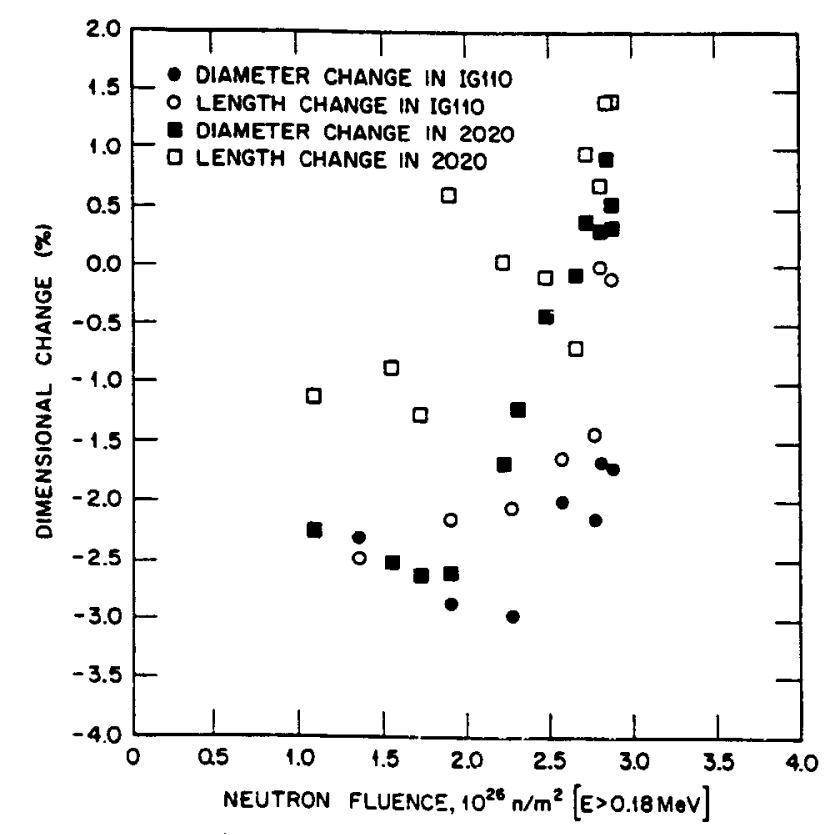

Figure 3-75.

IRRADIATION-INDUCED DIMENSIONAL CHANGES IN IG-110 AND 2020 GRADE GRAPHITES

IRRADIATED

$$
\text { AT } \sim 600 \text {. }
$$




\section{SECTION 4}

\section{METALS}

Metals technology development work during this report period, funded almost entirely by the NP Program, centered on a number of alloys for the various parts of the reactor system. Type A 533, grade B, class 1 plate; A 508, class 3 forgings; and weldments of those materials were studied for the pressure vessel. Alloy $800 \mathrm{H}$ and its weldments were studied for the reactor structural internals, and Alloy $800 \mathrm{H}$ and $2.25 \mathrm{Cr}-1 \mathrm{Mo}(\mathrm{T}-22)$ tubing were the subjects for study for the heat-transfer (steam generator) system. At the inception of the NP Program, a number of the structural materials subtasks were scheduled to last up to 6 years. These long time spans included thermal aging periods of 1,2 , and 4 years, to be followed by the required testing activities. With the termination of the NP Program last year, all of the test plans were reevaluated to determine what could be salvaged during the closeout year. In many instances, testing continued with scaled-down test matrices that could still yield useful information.

\subsection{IRRADIATION TESTING OF PRESSURE-VESSEL STEELS - F. M. Haggag}

\subsubsection{Introduction}

The need for MHTGR design data on the nil-ductility-transition temperature (NDT) shift necessitated the irradiation at different temperatures of A 533, grade B, class 1 plate; A 508, class 3 forging; and welds used for the vessel shell, vessel closure head, and vessel flange. The original irradiation plan, which included 14 capsules, addressed the effects of irradiation temperature; neutron flux spectrum; neutron flux; and thermal aging on base plate, forging, and weld materials. The mechanical property evaluation include drop-weight, Charpy V-notch (CVN) impact, standard tensile, and mini-tensile test specimens. Other material characterization included metallography, fractography, chemical analysis, and other miniature specimen and/or nondestructive test techniques [e.g., automated ball indentation (ABI) tests conducted on broken halves of previously tested CVN specimens]. Because of the different irradiation conditions, various test materials, and limited irradiation volume in each capsule, miniature tensile specimens were included in each capsule. Furthermore, due to the small volume of these mini-tensile specimens (24 specimens are packaged to the equivalent size of one standard CVN specimen), 
more materials were included in every capsule in addition to the MHTGR specimens. Results from five irradiation capsules are discussed.

\subsubsection{Irradiation Matrix and Experimental Procedure}

The current irradiation plan, which included 14 capsules described in Table 4-1, addressed the effects of irradiation temperature, neutron flux spectrum, neutron flux (damage rate), and thermal aging (not shown in Table 4-1) on base plate, forging, and weld materials. Table 4-1 shows the two materials irradiated in each capsule, irradiation temperature, equivalent fast ( $>1 \mathrm{MeV}$ ) fluence, and the objective and relationship of each capsule to others in the matrix. CVN, standard (regular-size) tensile, and mini-tensile specimens from two heats of A 533, grade $\mathrm{B}$, class 1 plate (containing 0.07 and $0.14 \% \mathrm{Cu}$ ) were included in each capsule. In Table 4-1, the first capsule number is the ORNL designation (ORNL-1 through -14), while the second number is the capsule designation by reactor facility where UBR and FNR represent the University of Buffalo Reactor and Ford Nuclear Reactor, respectively. The first four capsules (ORNL-1 through -4) were irradiated by Materials Engineering Associates (MEA) in the UBR to an effective fast fluence of $1.1 \times 10^{18}$ neutrons $/ \mathrm{cm}^{2}\left[0.68 \times 10^{18}\right.$ neutrons $\left./ \mathrm{cm}^{2}(>1 \mathrm{MeV})\right]$ at temperatures of $288,204,163$, and $121^{\circ} \mathrm{C}\left(550,400,325\right.$, and $\left.250^{\circ} \mathrm{F}\right)$, respectively (Figure 4-1). The irradiation temperature was controlled to within $\pm 8^{\circ} \mathrm{C}\left(15^{\circ} \mathrm{F}\right)$. The MEA designation for these four capsules was UBR-81A, $-81 \mathrm{~B},-82 \mathrm{~A}$, and $-82 \mathrm{~B}$. The effective fast ( $>1 \mathrm{MeV})$ neutron fluence was determined using the weighing factors given in Table 4-2. Capsule ORNL-7 was irradiated by MEA in the FNR to an effective fast fluence of $1.3 \times 10^{18}$ neutrons $/ \mathrm{cm}^{2}[0.80 \mathrm{x}$ $10^{18}$ neutrons $\left./ \mathrm{cm}^{2}(>1 \mathrm{MeV})\right]$ at $60^{\circ} \mathrm{C}\left(140^{\circ} \mathrm{F}\right)$. The purpose of this capsule (designated by MEA as FNR-3A) was to investigate low-temperature irradiation similar to the HFIR vessel operating temperature and applicable to vessel structural support components. The MHTGR flux spectrum is also shown in Table 4-2. The effect of flux spectrum on mechanical property degradation was to have been investigated in later capsules where the neutron spectrum would be tailored, by using specially designed shielded capsules, to match that shown in Table 4-2. These capsules (ORNL-6, -9 through -11) were to have been irradiated in the FNR at the University of Michigan. Capsules ORNL-5, -8 , and -12 were also irradiated by MEA in the FNR facility under MEA's designation FNR-3B, $-6 \mathrm{~B}$, and $-6 \mathrm{~A}$, respectively. However, irradiated specimen testing for these capsules is not completed at this time. The test results of specimens from these capsules will be published later. 
Table 4-1

SUMMARY OF IRRADIATION MATRIX FOR MHTGR REACTOR VESSEL MATERIALS

\begin{tabular}{|c|c|c|c|c|}
\hline $\begin{array}{l}\text { Capsule } \\
\text { nubmer }^{a}\end{array}$ & Material & $\begin{array}{c}\text { Temperature } \\
\left({ }^{\circ} \mathrm{C}\right)\end{array}$ & $\begin{array}{c}\text { Effective } \\
\text { fast fluence } \\
\text { (neutrons } / \mathrm{cm}^{2} \text { ) }\end{array}$ & $\begin{array}{l}\text { Objective and } \\
\text { relation to } \\
\text { other capsules }\end{array}$ \\
\hline $\begin{array}{l}\text { ORNL-1 } \\
\text { (UBR- } \\
81 \mathrm{~A})\end{array}$ & $\begin{array}{l}\text { A 533-B-1 (low Cu) } \\
\text { A 533-B-1 (med. } \\
\text { Cu) }\end{array}$ & 288 & $1 \times 10^{18}$ & $\begin{array}{l}\text { Relate to LWR data } \\
\text { base at } 288^{\circ} \mathrm{C} \text {; } \\
\text { capsules } 2,3,4,7\end{array}$ \\
\hline $\begin{array}{l}\text { ORNL-2 } \\
\text { (UBR- } \\
81 B)\end{array}$ & $\begin{array}{l}\text { A 533-B-1 (low Cu) } \\
\text { A 533-B-1 (med. } \\
\text { Cu) }\end{array}$ & 204 & $1 \times 10^{18}$ & $\begin{array}{l}\text { Upper range of vessel } \\
\text { operating } \\
\text { temperature; capsules } \\
1,3,4,7\end{array}$ \\
\hline $\begin{array}{l}\text { ORNL-3 } \\
\text { (UBR- } \\
82 \mathrm{~A})\end{array}$ & $\begin{array}{l}\text { A 533-B-1 (low Cu) } \\
\text { A 533-B-1 (med. } \\
\text { Cu) }\end{array}$ & 163 & $1 \times 10^{18}$ & $\begin{array}{l}\text { Middle range of } \\
\text { vessel operating } \\
\text { temperature; capsules } \\
1,2,4,7\end{array}$ \\
\hline $\begin{array}{l}\text { ORNL-4 } \\
\text { (UBR- } \\
82 B)\end{array}$ & $\begin{array}{l}\text { A 533-B-1 (low Cu) } \\
\text { A 533-B-1 (med. } \\
\text { Cu) }\end{array}$ & 121 & $1 \times 10^{18}$ & $\begin{array}{l}\text { Lower range of vessel } \\
\text { operating } \\
\text { temperature; capsules } \\
1,2,3,7\end{array}$ \\
\hline $\begin{array}{l}\text { ORNL-5 } \\
\text { (FNR-3B) }\end{array}$ & $\begin{array}{l}\text { A 508-3 } \\
\text { SAW (low Cu) }\end{array}$ & 163 & $1 \times 10^{18}$ & $\begin{array}{l}\text { Relate forging and } \\
\text { weld with plates, } \\
\text { capsule } 3\end{array}$ \\
\hline ORNL-6 & $\begin{array}{l}\text { A 508-3 } \\
\text { SAW (low Cu) }\end{array}$ & 163 & $1 \times 10^{17}$ & $\begin{array}{l}\text { Effect of HTGR } \\
\text { spectrum at low } \\
\text { fluence; capsule } 9\end{array}$ \\
\hline $\begin{array}{l}\text { ORNL-7 } \\
\text { (FNR-3A) }\end{array}$ & $\begin{array}{l}\text { A 533-B-1 (low Cu) } \\
\text { A 533-B-1 (med. } \\
\text { Cu) }\end{array}$ & 60 & $1 \times 10^{18}$ & $\begin{array}{l}\text { Effect of fluence at } \\
\text { low temperature } \\
\text { (HFIR); capsules } \\
1,2,3,4\end{array}$ \\
\hline $\begin{array}{l}\text { ORNL-8 } \\
\text { (FNR-6B) }\end{array}$ & $\begin{array}{l}\text { SAW (low } \mathrm{Cu} \text { ) } \\
\text { SAW (high } \mathrm{Cu} \text { ) }\end{array}$ & 163 & $1 \times 10^{18}$ & $\begin{array}{l}\text { Relate welds to } \\
\text { plates; capsule } 3\end{array}$ \\
\hline ORNL-9 & $\begin{array}{l}\text { A 533-B-1 (low Cu) } \\
\text { SAW (low Cu) }\end{array}$ & 163 & $1 \times 10^{18}$ & $\begin{array}{l}\text { Effect of HTGR } \\
\text { spectrum; capsules } \\
3,5\end{array}$ \\
\hline
\end{tabular}


Table 4-1 cont.

\begin{tabular}{|c|l|c|c|c|}
\hline $\begin{array}{c}\text { Capsule } \\
\text { nubmer }\end{array}$ & \multicolumn{1}{|c|}{ Material } & $\begin{array}{c}\text { Temperature } \\
\left({ }^{\circ} \mathrm{C}\right)\end{array}$ & $\begin{array}{c}\text { Effective } \\
\text { fast fluence } \\
\text { (neutrons/cm }{ }^{2}\end{array}$ & $\begin{array}{c}\text { Objective and } \\
\text { relation to } \\
\text { other capsules }\end{array}$ \\
\hline \hline ORNL-10 & $\begin{array}{l}\text { A 533-B-1 (low Cu) } \\
\text { SAW (low Cu) }\end{array}$ & 163 & $1 \times 10^{17}$ & $\begin{array}{l}\text { 3-year irradiation with } \\
\text { GTGR spectrum to } \\
\text { low fluence; capsule 6 }\end{array}$ \\
\hline ORNL-11 & $\begin{array}{l}\text { A 533-B-1 (low Cu) } \\
\text { SAW (low Cu) }\end{array}$ & 163 & $1 \times 10^{18}$ & $\begin{array}{l}\text { 3-year irradiation with } \\
\text { HTGR spectrum to } \\
\text { higher fluence for } \\
\text { dose rate effects; } \\
\text { capsules 9,10 }\end{array}$ \\
\hline $\begin{array}{l}\text { ORNL-12 } \\
\text { (FNR-6A) }\end{array}$ & $\begin{array}{l}\text { A 533-B-1 (med. } \\
\text { A 533-B-1 (med. } \\
\text { Cu) }\end{array}$ & 121 & $1 \times 10^{18}$ & $\begin{array}{l}\text { Address repeatability } \\
\text { and accuracy; capsule } \\
4\end{array}$ \\
\hline ORNL-13 & $\begin{array}{l}\text { A 508-3 } \\
\text { A 533-B-1 (low Cu) }\end{array}$ & 163 & $1 \times 10^{19}$ & $\begin{array}{l}\text { Effect of temperature } \\
\text { and percent copper at } \\
\text { high fluence; capsules } \\
\text { 3,5,14 }\end{array}$ \\
\hline ORNL-14 & $\begin{array}{l}\text { A 508-3 } \\
\text { A 533-B-1 (low Cu) }\end{array}$ & 288 & $1 \times 10^{19}$ & $\begin{array}{l}\text { Compare results to } \\
\text { capsules 1,13 and to } \\
\text { LWR surveillance } \\
\text { data }\end{array}$ \\
\hline
\end{tabular}


ORNL-DWG 94-5582

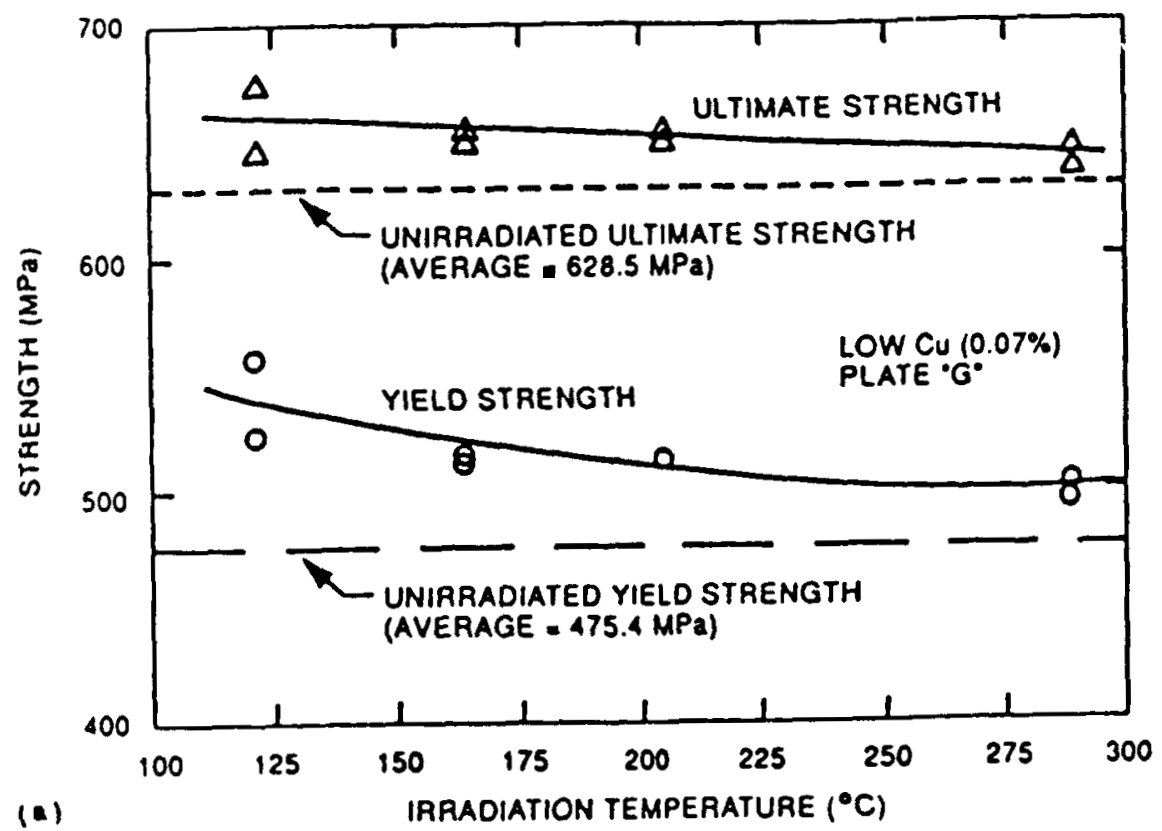

ORNL-DWG 94-5583

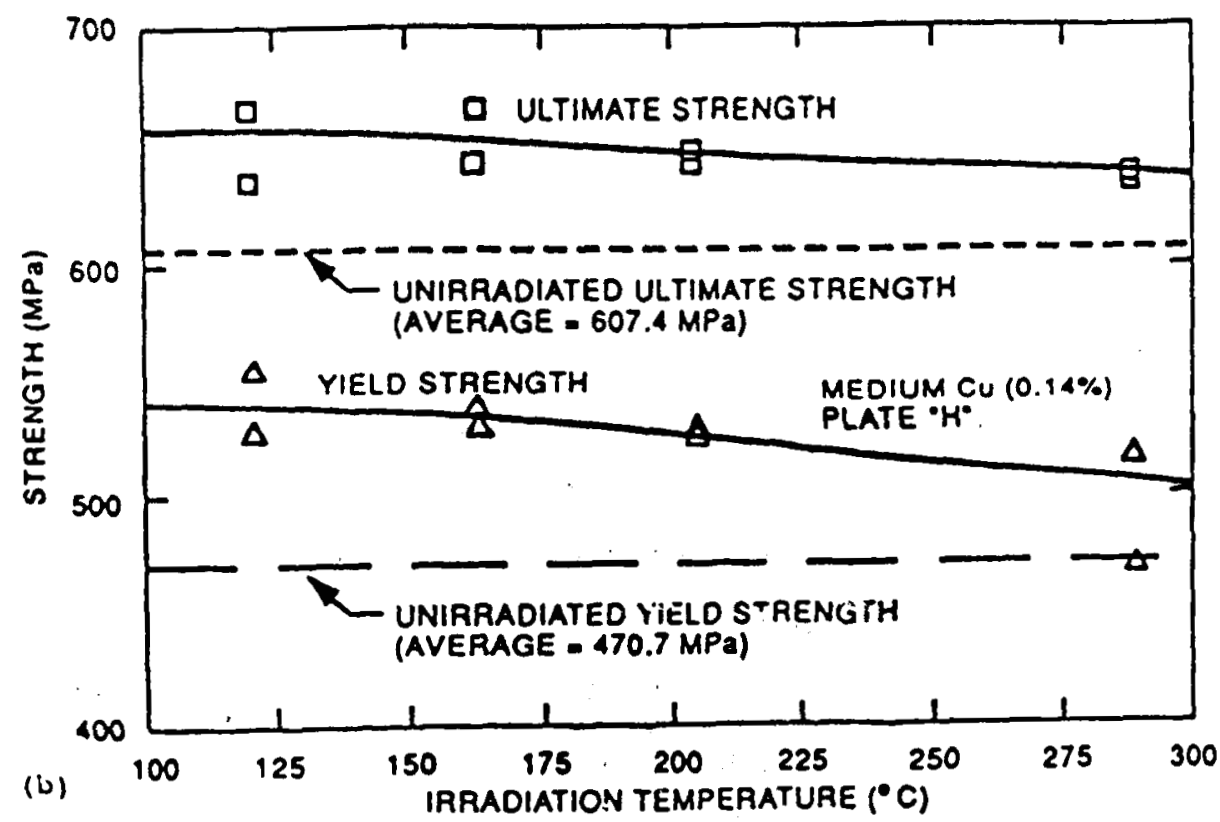

Figure 4-1.

EFFECT OF IRRADIATION TEMPERATURE ON TENSILE PROPERTIES

OF A 533 GRADE B CLASS 1 PLATES [FLUENCE OF $0.7 \times 10^{18}$ NEUTRONS/CM ${ }^{2}$ ( $\left.>1 \mathrm{MEV}\right)$ ]. (a) PLATE G, $0.07 \%$ CU, (b) PLATE H, 0.14\% CU. 
Table 4-2

MHTGR FLUX SPECTRUM AND WEIGHING FACTORS FOR CALCULATING THE EFFECTIVE FAST $(>1 \mathrm{MeV})$ FLUENCE

\begin{tabular}{|l|c|c|}
\hline \multicolumn{1}{|c|}{ Neutron energies } & $\begin{array}{c}\text { MHTGR spectrum } \\
(\%)\end{array}$ & $\begin{array}{c}\text { Weighing } \\
\text { factor }\end{array}$ \\
\hline \hline $\mathrm{E}>1.0 \mathrm{Ne} / \mathrm{v}$ & 4 & 1.0 \\
$0.1 \mathrm{MeV}>\mathrm{E}>1.0 \mathrm{MeV}$ & 21 & 0.5 \\
$0.4 \mathrm{eV}>\mathrm{E}>0.1 \mathrm{MeV}$ & 65 & 0.0025 \\
$\mathrm{E}<0.4 \mathrm{eV}$ & 10 & 0.07 \\
\hline
\end{tabular}

\subsubsection{Results and Discussion}

Chemical analyses of the two heats of A 533, grade B, class 1 plates are shown in Table 4-3. The drop-weight and upper-shelf energy (USE) test results of the unirradiated steels, conducted according to ASTM Standards E 208 and E 23, respectively, are shown in Table 4-4. The tensile test results from regular-size test specimens are shown in Figures 4-1(a) and $(b)$. The yield and ultimate strengths of both A 533, grade B, class 1 steel plate materials increased with decreasing irradiation temperature.

The 41-J CVN transition temperature shift increased with decreasing irradiation temperature (in agreement with the increase in yield strength). The CVN impact energy and fracture appearance test results from the two heats are shown in Figures 4-2 through 4-5, respectively. Sample test results of the CVN impact energy curves with the individual data points are shown in Figures 4-6 and 4-7 (one curve in the unirradiated condition and a curve at one irradiation temperature are shown for each heat of the material). The CVN test results are also summarized in Table 4-5. Furthermore, the measured 41-J transition temperature shifts $\left(\Delta \mathrm{T}_{41}\right)$ were compared to those predicted using the Nuclear Regulatory Commission (NRC) Regulatory Guide 1.99, Rev. 2 (ref. 165) for irradiation at $288^{\circ} \mathrm{C}$. Table $4-5$ shows that the predicted values of the $C V N \Delta T_{41}$ were consistently conservative or higher than the measured shifts. For the high-copper plate $(0.14 \% \mathrm{Cu})$ of capsule ORNL-4 in Table 4-1, the measured CVN 41-J transition temperature shift at $121^{\circ} \mathrm{C}\left(250^{\circ} \mathrm{F}\right)$ is $-1.6^{\circ} \mathrm{C}$, which is not consistent with the increase in yield strength. This discrepancy will be investigated by repeating the irradiation capsule (see capsule ORNL-12 in Table 4-1 of the irradiation test matrix). Capsule ORNL-12 is just completed, and the results from double the number of the CVN specimens will be reported elsewhere. Also, some 
Table 4-3

CHEMICAL ANALYSIS OF MHTGR PRESSURE-VESSEL STEEL PLATES (A 533, GRADE B, CLASS 1)

\begin{tabular}{|c|c|c|}
\hline \multirow[b]{2}{*}{ Element } & \multicolumn{2}{|c|}{$\begin{array}{c}\text { Plate } \\
(w t \%)\end{array}$} \\
\hline & $G$ & $H$ \\
\hline $\mathrm{C}$ & 0.22 & 0.20 \\
\hline $\mathrm{Mn}$ & 1.35 & 1.47 \\
\hline $\mathbf{P}$ & 0.007 & 0.005 \\
\hline$S$ & 0.016 & 0.004 \\
\hline $\mathrm{Si}$ & 0.24 & 0.23 \\
\hline $\mathrm{Ni}$ & 0.64 & 0.58 \\
\hline $\mathrm{Cr}$ & 0.07 & 0.14 \\
\hline Mo & 0.53 & 0.48 \\
\hline V & 0.003 & 0.002 \\
\hline $\mathrm{Cb} / \mathrm{Ta}$ & 0.003 & 0.002 \\
\hline $\mathrm{Ti}$ & $<0.001$ & 0.001 \\
\hline Co & 0.015 & 0.024 \\
\hline $\mathrm{Cu}$ & 0.07 & 0.14 \\
\hline $\mathrm{Al}$ & 0.021 & 0.022 \\
\hline B & $<0.001$ & $<0.001$ \\
\hline W & $<0.01$ & $<0.01$ \\
\hline As & 0.010 & 0.027 \\
\hline $\mathrm{Sn}$ & 0.004 & 0.010 \\
\hline $\mathrm{Zr}$ & $<0.001$ & $<0.001$ \\
\hline $\mathrm{N}$ & 0.010 & 0.010 \\
\hline $\mathrm{O}$ & 0.002 & 0.002 \\
\hline $\mathrm{Fe}$ & Balance & Balance \\
\hline
\end{tabular}


Table 4-4

UNIRRADIATED PROPERTIES OF A 533, GRADE B, CLASS 1 PRESSURE-VESSEL STEEL PLATES

\begin{tabular}{|l|l|l|}
\hline \multicolumn{1}{|c|}{$\begin{array}{c}\text { Plate } \\
(0.07 \% \mathrm{Cu})\end{array}$} & \multicolumn{1}{c|}{$\begin{array}{c}\text { Plate } \mathrm{H} \\
(0.14 \% \mathrm{Cu})\end{array}$} \\
\hline \hline $\mathrm{RT}_{\mathrm{NDT}}=-20^{\circ} \mathrm{C}\left(-4^{\circ} \mathrm{F}\right)$ & & $\mathrm{RT}_{\mathrm{NDT}}=-45^{\circ} \mathrm{C}\left(-49^{\circ} \mathrm{F}\right)$ \\
\hline $\mathrm{T}_{41}=-25^{\circ} \mathrm{C}\left(-13^{\circ} \mathrm{F}\right)$ & & $\mathrm{T}_{41}=-54^{\circ} \mathrm{C}\left(-66^{\circ} \mathrm{F}\right)$ \\
\hline & Upper-shelf energy & \\
\hline $114 \mathrm{~J}(84 \mathrm{ft}-\mathrm{lb})$ & & $162 \mathrm{~J}(119 \mathrm{ft}-\mathrm{lb})$ \\
\hline
\end{tabular}

Table 4-5

MEASURED AND PREDICTED TRANSITION TEMPERATURE SHIFTS FROM

CHARPY IMPACT TESTS ON A 533, GRADE B, CLASS 1 STEEL

AFTER IRRADIATION TO $0.7 \times 10^{18}$ NEUTRONS/CM ${ }^{2}$

$(>1 \mathrm{Mev})$

\begin{tabular}{|c|c|c|c|c|c|c|}
\hline \multirow{3}{*}{$\begin{array}{l}\text { Irradiation } \\
\text { temperature } \\
\quad\left({ }^{\circ} \mathrm{C}\right)\end{array}$} & \multicolumn{3}{|c|}{$\begin{array}{l}\text { Plate "G" } \\
(0.07 \% \mathrm{Cu})\end{array}$} & \multicolumn{3}{|c|}{$\begin{array}{l}\text { Plate "H" } \\
(0.14 \% \mathrm{Cu})\end{array}$} \\
\hline & $\Delta \mathrm{T}_{41}$ & & $\Delta \mathrm{T}_{\mathrm{Reg}}$ & $\Delta \mathrm{T}_{41}$ & & $\Delta \mathrm{T}_{\mathrm{Reg}}$ \\
\hline & & $\left({ }^{\circ} \mathrm{C}\right)$ & & & $\left({ }^{\circ} \mathrm{C}\right)$ & \\
\hline $\begin{array}{c}288 \\
204 \\
163 \\
121 \\
60\end{array}$ & $\begin{array}{c}2.2 \\
24.1 \\
20.7 \\
19.6 \\
24.6\end{array}$ & & 7.0 & $\begin{array}{c}6.5 \\
15.0 \\
15.7 \\
-1.6 \\
18.4\end{array}$ & & 12.0 \\
\hline
\end{tabular}




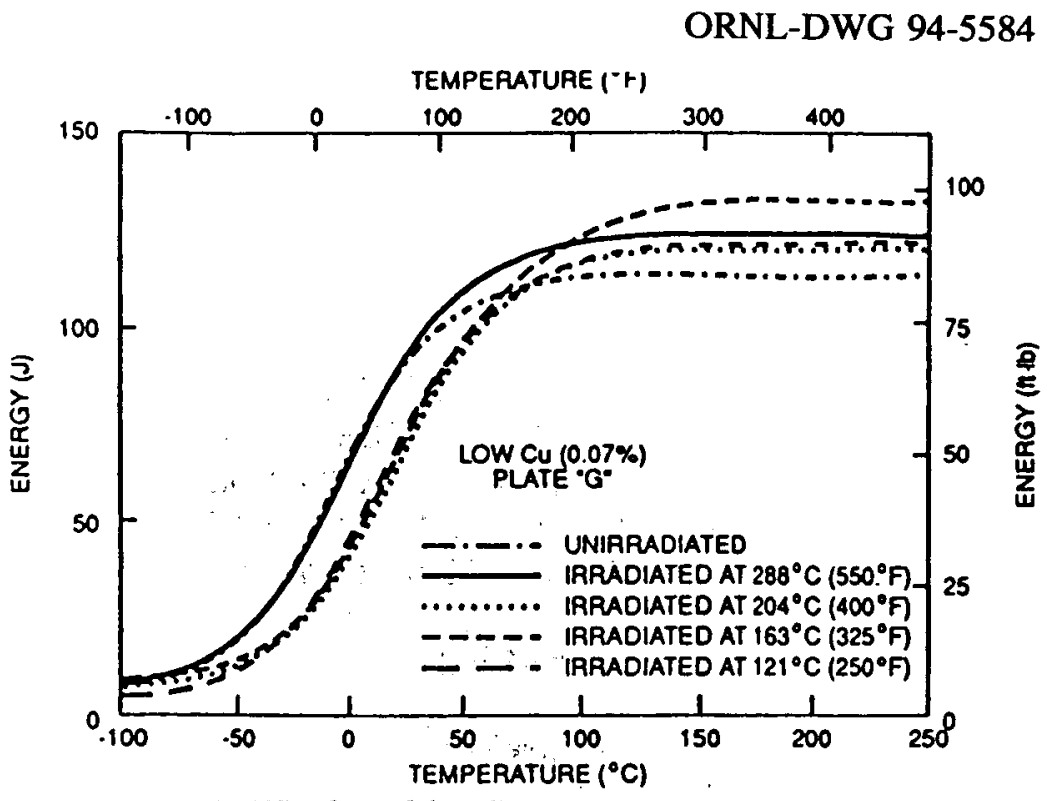

Figure 4-2.

EFFECT OF IRRADIATION TEMPERATURE ON THE CHARPY IMPACT ENERGY AND THE 41-J TRANSITION TEMPERATURE SHIFT $\mathrm{V}\left(\Delta \mathrm{T}_{41}\right)$ FOR A 533 GRADE B CLASS 1

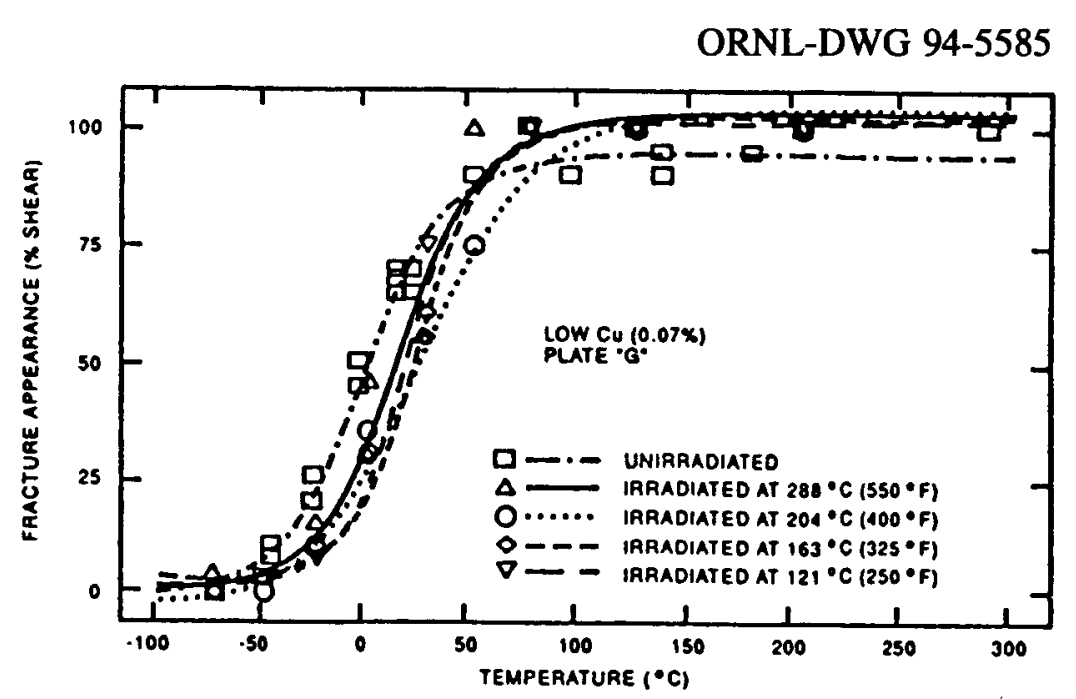

Figure 4-3.

EFFECT OF IRRADIATION TEMPERATURE ON THE CHARPY FRACTURE APPEARANCE AND THE 50\% SHEAR TRANSITION TEMPERATURE SHIFT FOR A 533 GRADE B CLASS 1 STEEL, PLATE G, $0.07 \%$ CU. 


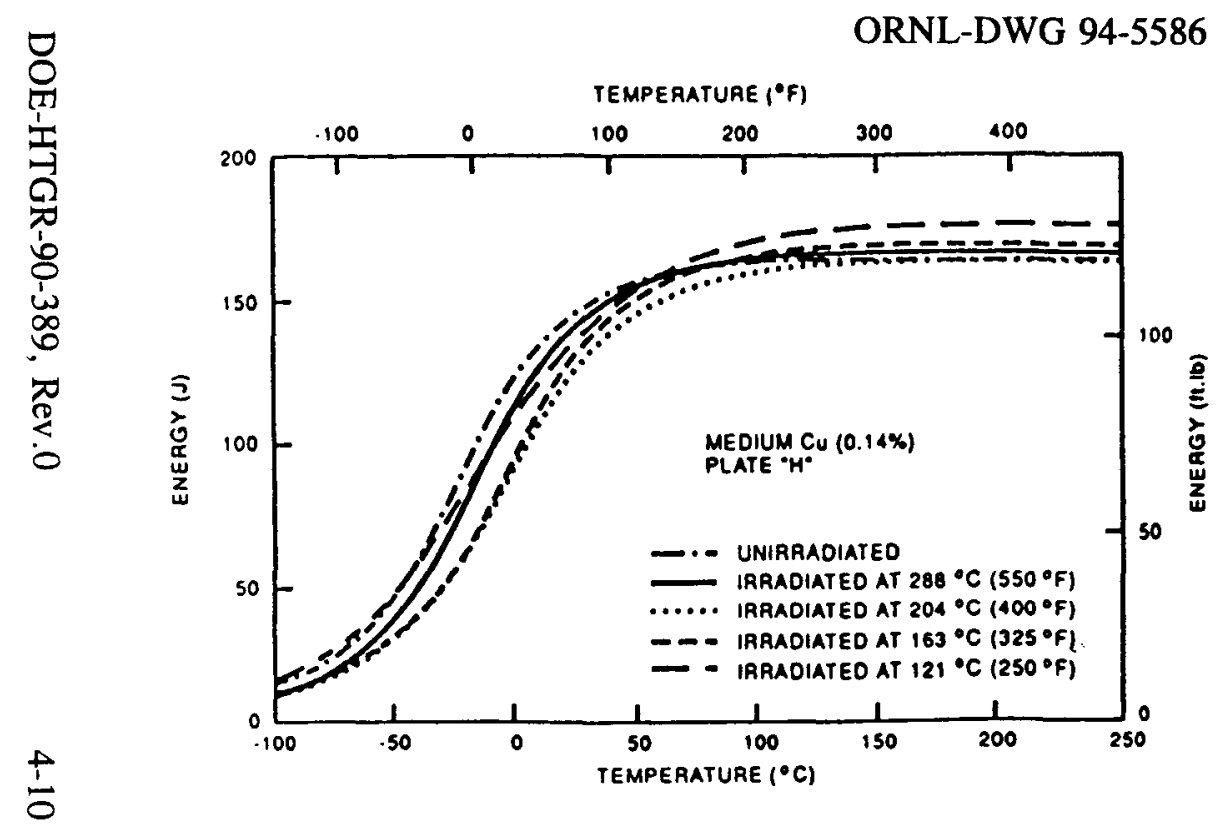

Figure 4-4.

EFFECT OF IRRADIATION TEMPERATURE ON THE CHARPY IMPACT ENERGY AND THE 41-J TRANSITION TEMPERATURE SHIFT $\left(\triangle T^{41}\right)$ FOR A 533 GRADE B CLASS 1 STEEL, PLATE H, $0.14 \% \mathrm{CU}$.
ORNL-DWG 94-5587

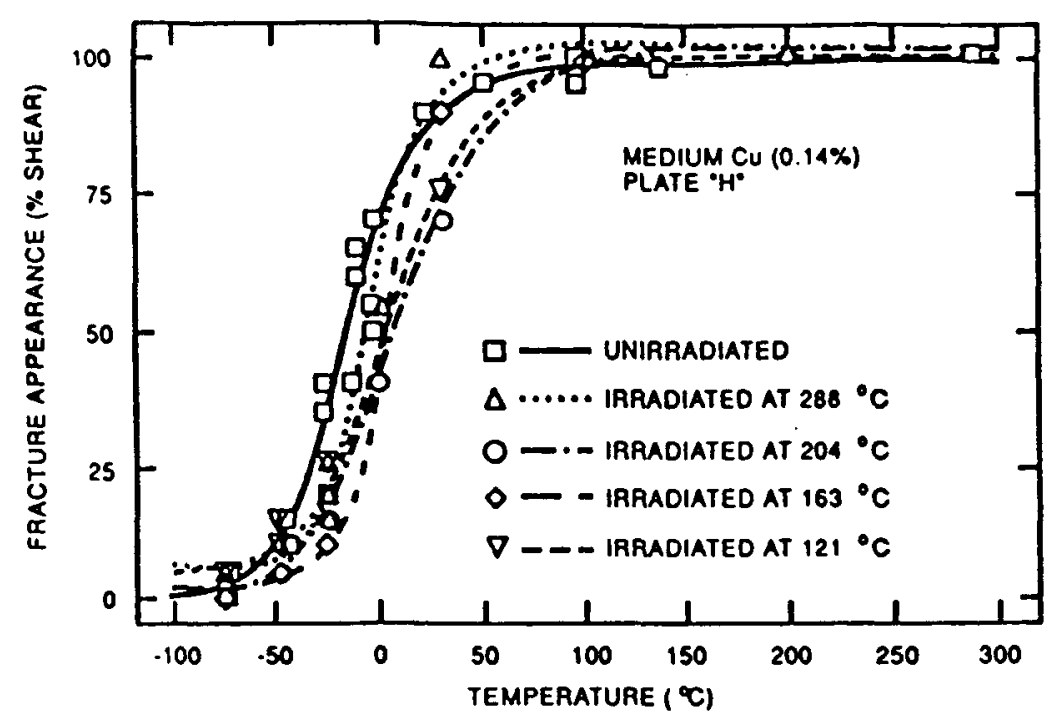

Figure 4-5.

EFFECT OF IRRADIATION TEMPERATURE ON THE CHARPY FRACTURE APPEARANCE AND THE 50\% SHEAR TRANSITION TEMPERATURE SHIFT FOR A 533 GRADE B CLASS 1 STEEL, PLATE $\mathrm{H}, 0.14 \% \mathrm{CU}$. 


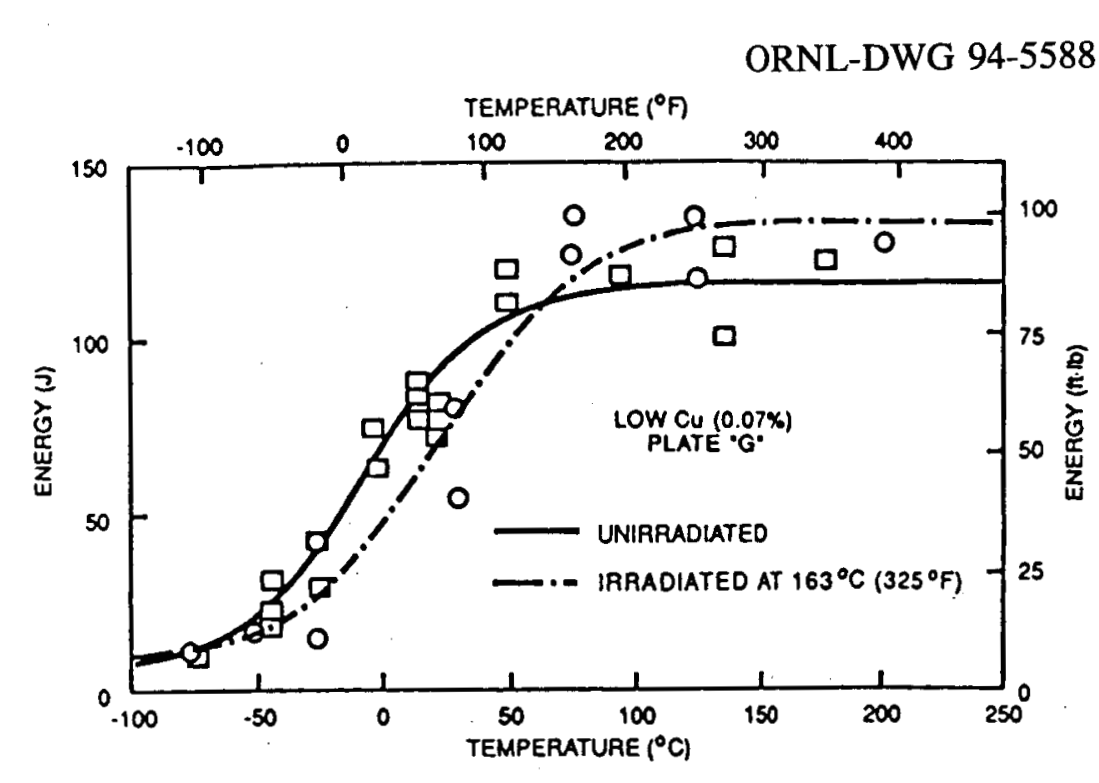

$\stackrel{t}{E}$

Figure 4-6.

CHARPY V-NOTCH IMPACT ENERGY OF A 533 GRADE B CLASS 1 PRESSURE VESSEL STEEL, PLATE G, $0.07 \%$ CU, UNIRRADIATED, AND $163^{\circ} \mathrm{C}$ IRRADIATION DATA.
ORNL-DWG 94-5589

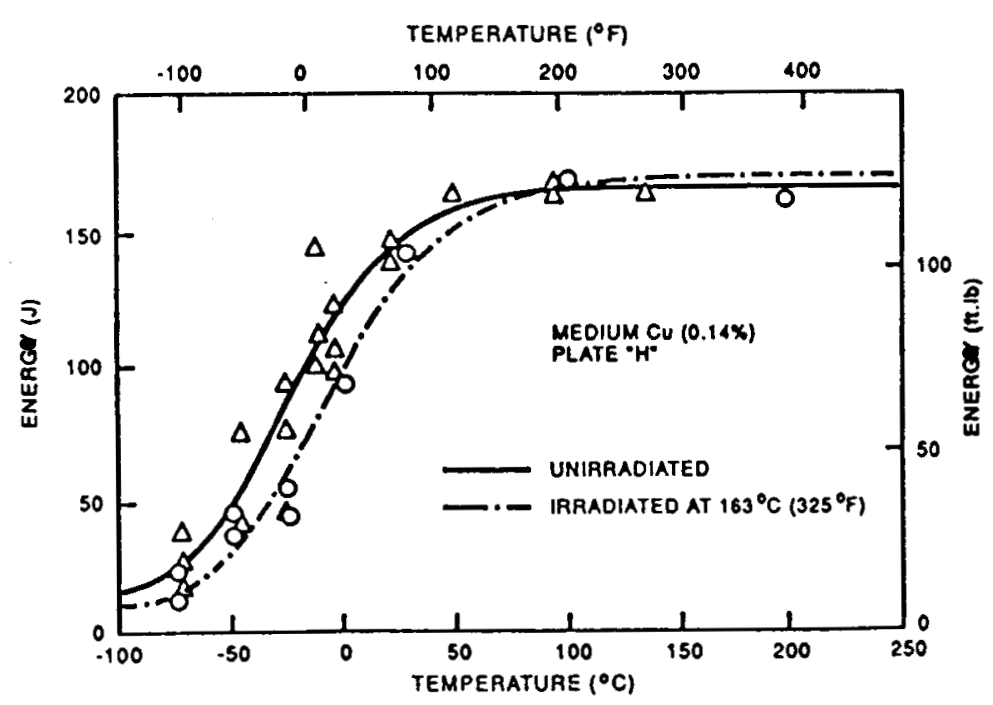

Figure 4-7.

CHARPY V-NOTCH IMPACT ENERGY OF A 533 GRADE B CLASS 1 PRESSURE VESSEL

STEEL, PLATE H, $0.14 \%$ CU, UNIRRADIATED, AND $163^{\circ} \mathrm{C}$ IRRADIATION DATA. 
additional analyses are being conducted on the load-time trace of the CVN test specimens from capsule ORNL-4.

Twenty-four (24) miniature tensile specimens were packed to an equivalent size of one CVN specimen as shown in Figure 4-8. The room-temperature test results from the miniature tensile specimens of the yield and ultimate strengths from all specimens (both unirradiated and irradiated in the four capsules ORNL-1 through 4) for the two heats of the A 533, grade B, class 1 materials were in excellent agreement with those from the regular-size specimens as shown in Figure 4-9. Uniform elongation slightly decreased with decreasing irradiation temperature. The increase in yield strength was found to correlate with the increase in the 41-J CVN transition temperature shift as shown in Figure 4-10. Also, in this figure, a single point from two ABI test results on A 212 , grade $B$, class 1 steel $^{166}$ is in agreement with the miniature tensile data. Details of the ABI test technique and results on various materials and welds (including materials with different irradiation levels) are given in refs. 167 through 171. Figure 4-11 shows several specimens where $\mathrm{ABI}$ tests were conducted on their surfaces, including irradiated ones (in two vials). The slope of the linear fit in Figure 4-10 is 0.45 , which is slightly smaller than that reported in ref. $165(\sim 0.65)$. However, it should be mentioned here that the correlation in ref. 165 was

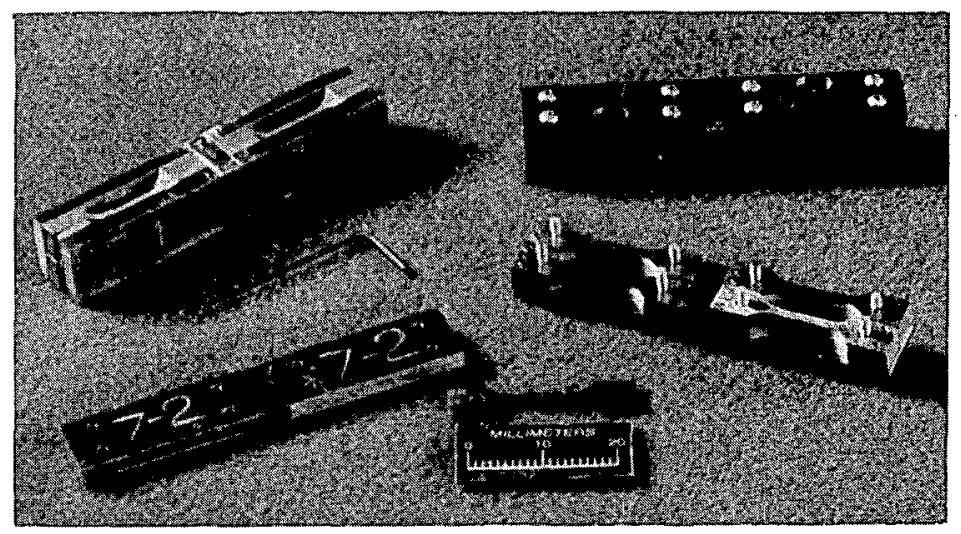

Figure 4-8.

\section{MINIATURE TENSILE SPECIMENS [24 SPECIMENS PACKAGED EQUIVALENT TO ONE CHARPY V-NOTCH SPECIMEN}

$(1 \times 1 \times 5.5 \mathrm{~cm})]$. 
ORNL-DWG 94-5590

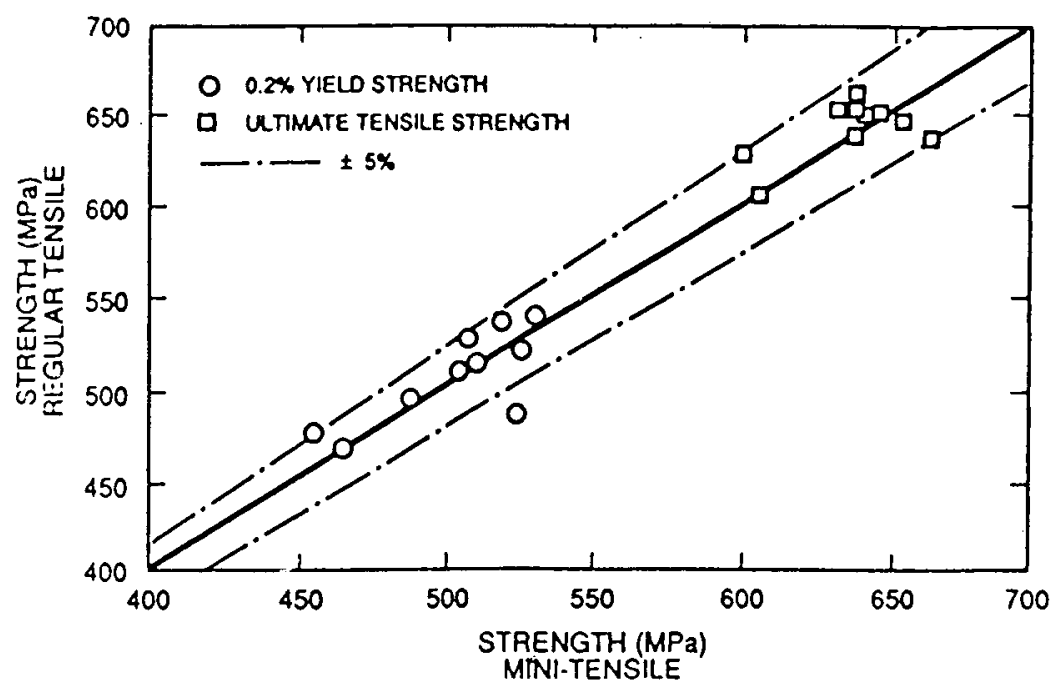

Figure 4-9.

\section{COMPARISON BETWEEN REGULAR SIZE AND MINIATURE TENSILE SPECIMENS OF A533 GRADE B CLASS 1 PRESSURE VESSEL STEEL.}

ORNL-DWG 94-5591

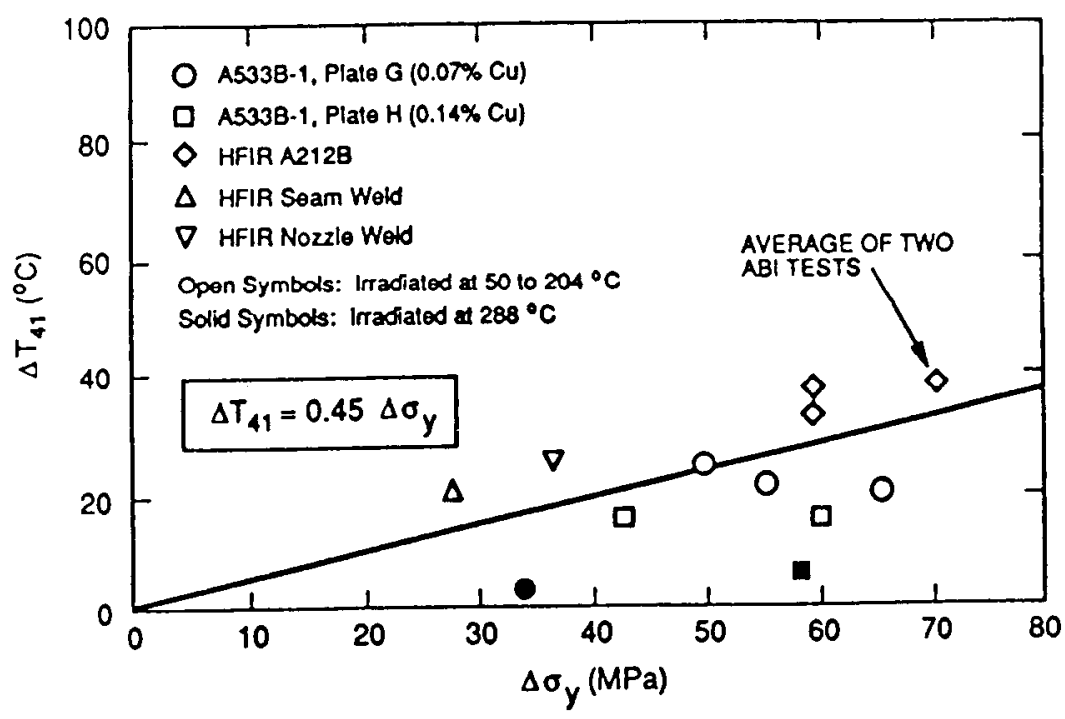

Figure 4-10.

CORRELATION BETWEEN TRANSITION TEMPERATURE SHIFT $\left(\triangle T^{41}\right)$ AND THE CHANGE IN YIELD STRENGTH DUE TO NEUTRON IRRADIATION. 


\section{YP7057}

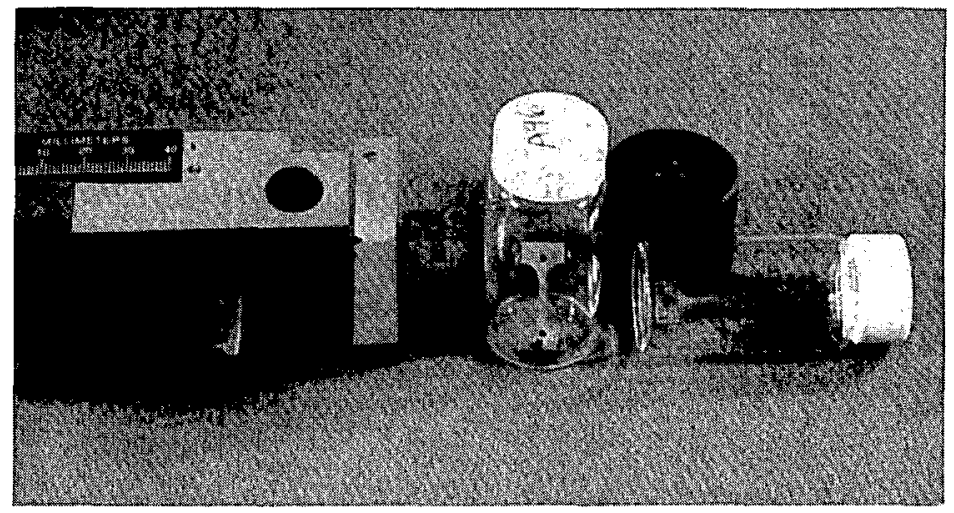

Figure 4-11.

\section{SPECIMEN GEOMETRIES USED IN A AUTOMATED BALL INDENTATION (ABI) TESTS.}

developed from surveillance data from light-water reactors (LWRs) where the irradiation was conducted at $288^{\circ} \mathrm{C}\left(550^{\circ} \mathrm{F}\right)$ and to higher fluences than our MHTGR specimens. Also in ref. 165 , test reactor data were presented where the correlation coefficient ranged from 0.43 to 0.65 .

At the completion of this program and when tensile and ABI test results from specimens irradiated in all 14 capsules are obtained, a better correlation between changes in yield strength and/or other flow properties and transition temperature shifts might be developed. Furthermore, the large amount of test results from several nuclear pressure-vessel materials (plates, welds, and forgings) will improve our understanding of radiation damage mechanisms. Also, thermal aging of CVN impact and tensile specimens to the same length of irradiation times will aid in separating the effects of thermal aging from the neutron irradiation at the corresponding temperatures.

\subsubsection{Summary and Conclusions}

For the low-copper, A 533, grade B, class 1 plate $(0.07 \% \mathrm{Cu})$, the $41-\mathrm{J}, 68-\mathrm{J}$, and $50 \%$ shear transition temperature shifts increased by reducing the irradiation temperature from 288 to $204^{\circ} \mathrm{C}$ but did not change with further decrease of temperature to 163 or to 121 or to $60^{\circ} \mathrm{C}$. The maximum transition temperature shift was $25^{\circ} \mathrm{C}$. 
Specimens from the medium copper plate $(0.14 \% \mathrm{Cu})$ showed behavior similar to the lowcopper plate.

Regulatory Guide 1.99, Rev. 2, predictions of the 41-J transition temperature shift for the $288^{\circ} \mathrm{C}$ irradiation temperature were conservative for both A 533, grade B, class 1 materials.

The yield and ultimate tensile strength of two heats of A 533, grade B, class 1 pressurevessel steel increased with decreasing irradiation temperature. Uniform elongation slightly decreased with decreasing irradiation temperature.

Miniature tensile and ABI test results were in agreement with standard (regular-size) tensile data for various pressure-vessel steels and welds in the as-received and irradiated conditions.

The 41-J transition temperature shifts were correlated with changes in the yield strength for all irradiation temperatures. The correlation coefficient of 0.45 is within the range of 0.43 to 0.80 reported in ref. 166 for specimens irradiated in power and test reactors for relatively higher neutron fluences.

Miniature tensile and ABI test techniques could be useful in measuring yield strength and flow properties and understanding radiation damage mechanisms. However, the ABI test technique is particularly advantageous for localized testing [e.g., welds and heat-affected zones (HAZs)]; for efficient use of test material and providing more test results for statistical analyses; and, finally, more suitable for in situ nondestructive applications.

Effects of neutron spectrum and thermal aging on several nuclear pressure-vessel materials are being investigated, and the results will be published as they become available.

\subsection{IN-REACTOR METALS}

\subsubsection{Tensile and Creep Properties - H. E. McCoy}

Several 0.5 -in.-thick plates of Alloy $800 \mathrm{H}$ were obtained from a single heat for mechanical property studies for the MHTGR Program. A procedure for joining his alloy with ERNiCr-3 filler metal using the gas tungsten arc (GTA) process was developed. Test specimens were prepared of base metal, weld metal, and transverse across the weld. Tensile tests over the temperature range of 24 to $871^{\circ} \mathrm{C}$ ( $\left(75\right.$ to, $\left.1600^{\circ} \mathrm{F}\right)$ showed that the procured heat of Alloy $800 \mathrm{H}$ had tensile properties in excess of the minimum values specified in Sect. II, Part D, of the $A S M E$ Boiler and Pressure Vessel Code. The limited creep results form this heat were compared with those for a large data set and were found to exceed the average stress-rupture properties. The 
weld deposit was stronger than the base metal, so all failures of transverse weld specimens failed $i$ the base metal.

The details of this study were presented elsewhere. ${ }^{172}$

\subsubsection{Fracture Mechanics Properties of Alloy $800 \mathrm{H}$ for the NP-MHTGR Reactor}

\subsubsection{Introduction}

This fracture mechanics task addresses the DDNs defined in Combustion Engineering General Atomics (CEGA) Test Specification 001910, "Primary Coolant Helium Impurities and Thermal Aging Effects on Alloy $800 \mathrm{H}$ Design Properties for NP-MHTGR Hot Duct Components." The proposed test matrix has the objective of defining the degradation of material toughness and subcritical crack growth characteristics as a function of exposure time in the hot duct application. Fracture toughness properties are needed for exposure in primary coolant helium at temperatures ranging from room temperature to $870^{\circ} \mathrm{C}\left(1600^{\circ} \mathrm{F}\right)$. Service conditions were to be simulated by exposure in contaminated primary coolant helium for times ranging from 1 to 4 years. It is expected that thermally induced aging effects and chemically activated carburization will contribute to changes in fracture toughness properties. Carburization and thermal aging effects are expected to act synergistically to degrade fracture toughness. The study was to be made on Alloy $800 \mathrm{H}$ base metal, Inconel 82 weld filler metal, and the HAZ. The test matrix was jointly developed with CEGA to address the CEGA test specifications, and this is shown in Table 4-6. The material was to be evaluated by fracture toughness in the form of $J_{R^{-}}$ curves (with $\mathrm{J}_{\mathrm{IC}}$ identified therefrom), fatigue crack growth rate in the form of da/dN versus $\Delta \mathrm{K}_{\mathrm{I}}$ plots," and creep crack growth rate characterized as da/dt versus crack drive, quantified by stressintensity factor.

In addition to the fracture mechanics-related data, the plan was to test CVN impact specimens. The Charpy test are most useful for materials screening work. The test practice has its greatest utility for following trends of toughness properties such as in surveillance capsule work in operating commercial reactors. Correlations to fracture mechanics-related performance can be developed, provided there is adequate data plus experience in the use of the correlation. The test matrix for these CVN tests is shown in Table 4-7.

${ }^{*} \mathrm{da} / \mathrm{dN}$ is crack growth per fatigue cycle (in./cycles), da/dt is crack growth rate per unit of time, (in. $/ \mathrm{h}$ ) and $\mathrm{K}_{\mathrm{l}}$ is stress-intensity factor (lesi $\sqrt{\text { in. }}$ ) 
Table 4-6

FRACTURE MECHANICS TEST MATRIX FOR ALLOY 800H REACTOR INTERNALS [1TC(T) COMPACT SPECIMENS, 0.48 IN-THICK WITH 20\% SIDE GROOVES; SPECIMENS TO BE AGED]

\begin{tabular}{|c|c|c|c|c|c|c|c|c|c|c|c|}
\hline \multicolumn{2}{|c|}{ Aging condition ${ }^{(a)}$} & \multirow[b]{2}{*}{$\begin{array}{c}\text { Test } \\
\text { temperature } \\
\left({ }^{\circ} \mathrm{F}\right)\end{array}$} & \multicolumn{3}{|c|}{$\mathrm{J}_{\mathrm{Ic}}^{(b)}$} & \multicolumn{3}{|c|}{$\mathrm{da} / \mathrm{dN}^{(c)}$} & \multicolumn{3}{|c|}{$\mathrm{da} / \mathrm{dt}$} \\
\hline Time (h) & $\begin{array}{c}\text { Temperature } \\
\left({ }^{\circ} \mathrm{F}\right)\end{array}$ & & BM & WM & HAZ & BM & WM & HAZ & $\mathrm{BM}$ & WM & HAZ \\
\hline unaged & unaged & room & $\mathbf{x}$ & $\mathrm{X}$ & $\mathrm{X}$ & $\mathbf{X}$ & $\mathbf{X}$ & $\mathrm{X}$ & & & \\
\hline unaged & unaged & 1100 & $\mathbf{X}$ & $\mathrm{X}$ & $\mathbf{X}$ & $\mathbf{X}$ & $\mathbf{X}$ & $\mathbf{X}$ & $\mathbf{X}$ & $\mathrm{X}$ & $\mathrm{X}$ \\
\hline unaged & .. unaged & 1300 & $\mathrm{X}$ & $\mathrm{X}$ & $X$ & $\mathrm{X}$ & $\mathrm{X}$ & $X$ & $\mathrm{X}$ & $\mathrm{X}$ & $\mathrm{X}$ \\
\hline 8,750 & 1100 & 1100 & $\mathrm{X}$ & $\mathbf{X}$ & $\mathbf{X}$ & $\mathbf{X}$ & $\mathbf{X}$ & $\mathrm{X}$ & $\mathrm{X}$ & $\mathrm{X}$ & $\mathrm{X}$ \\
\hline 17,500 & 1100 & 1100 & $\mathrm{X}$ & $\mathrm{X}$ & $\mathbf{X}$ & $\mathrm{X}$ & $\mathrm{X}$ & $\mathrm{X}$ & $\mathrm{X}$ & $\mathbf{X}$ & $\mathrm{X}$ \\
\hline 35,000 & 1100 & 1100 & $\mathrm{X}$ & $\mathrm{X}$ & $\mathbf{X}$ & $\mathrm{X}$ & $\mathrm{X}$ & $\mathrm{X}$ & $X$ & $\mathrm{X}$ & $\mathrm{X}$ \\
\hline 8,750 & 1300 & 1300 & $\mathbf{X}$ & $\mathrm{X}$ & $\mathbf{X}$ & $\mathbf{X}$ & $X$ & $\mathrm{X}$ & $\mathrm{X}$ & $\mathrm{X}$ & $\mathrm{X}$ \\
\hline 17,500 & 1300 & 1300 & $\mathrm{X}$ & $\mathrm{X}$ & $X$ & $\mathrm{X}$ & $\mathrm{X}$ & $X$ & $\mathrm{X}$ & $\mathrm{X}$ & $\mathrm{X}$ \\
\hline 35,000 & 1300 & 1300 & $X$ & $\mathrm{X}$ & $X$ & $\mathrm{X}$ & $X$ & $\mathrm{X}$ & $\mathrm{X}$ & $\mathrm{X}$ & $\mathrm{X}$ \\
\hline 8,750 & 1600 & 1100 & $\mathrm{X}$ & $\mathrm{X}$ & $\mathrm{X}$ & $\mathrm{X}$ & $\mathrm{X}$ & $\mathrm{X}$ & $\mathrm{X}$ & $\mathrm{X}$ & $\mathrm{X}$ \\
\hline 17,500 & 1600 & 1100 & $\mathrm{X}$ & $\mathrm{X}$ & $\mathrm{X}$ & $\mathrm{X}$ & $\mathbf{X}$ & $\mathrm{X}$ & $\mathrm{X}$ & $\mathrm{X}$ & $\mathrm{X}$ \\
\hline 35,000 & 1600 & 1100 & $\mathrm{X}$ & $\mathbf{X}$ & $X$ & $\mathrm{X}$ & $\mathbf{X}$ & $X$ & $\mathbf{X}$ & $\mathrm{X}$ & $\mathrm{X}$ \\
\hline 8,750 & 1600 & 1300 & $X$ & $\mathrm{X}$ & $\mathrm{X}$ & $\mathrm{X}$ & $\mathrm{X}$ & $\mathrm{X}$ & $\mathrm{X}$ & $\mathrm{X}$ & $\mathrm{X}$ \\
\hline 17,500 & 1600 & 1300 & $\mathrm{X}$ & $\mathrm{X}$ & $\mathrm{X}$ & $\mathrm{X}$ & $\mathrm{X}$ & $\mathbf{X}$ & $X$ & $\mathrm{X}$ & $\mathrm{X}$ \\
\hline 35,000 & 1600 & 1300 & $\mathrm{X}$ & $\mathrm{X}$ & $X$ & $\mathrm{X}$ & $\mathrm{X}$ & $\mathrm{X}$ & $\mathrm{X}$ & $\mathrm{X}$ & $\mathrm{X}$ \\
\hline
\end{tabular}

${ }^{(a)}$ All aging in controlled impurity environment. Helium impurity levels defined in test specification 001910 . Two duplicate specimens per test condition.

${ }^{(b)}$ See example data treatment, Attachment 1.

(c) Load ratio (min. to $\max$.) $=0.1$. 
Table 4-7

CHARPY TESTS (ALL TESTING AT ROOM TEMPERATURE UNLESS OTHERWISE NOTED)

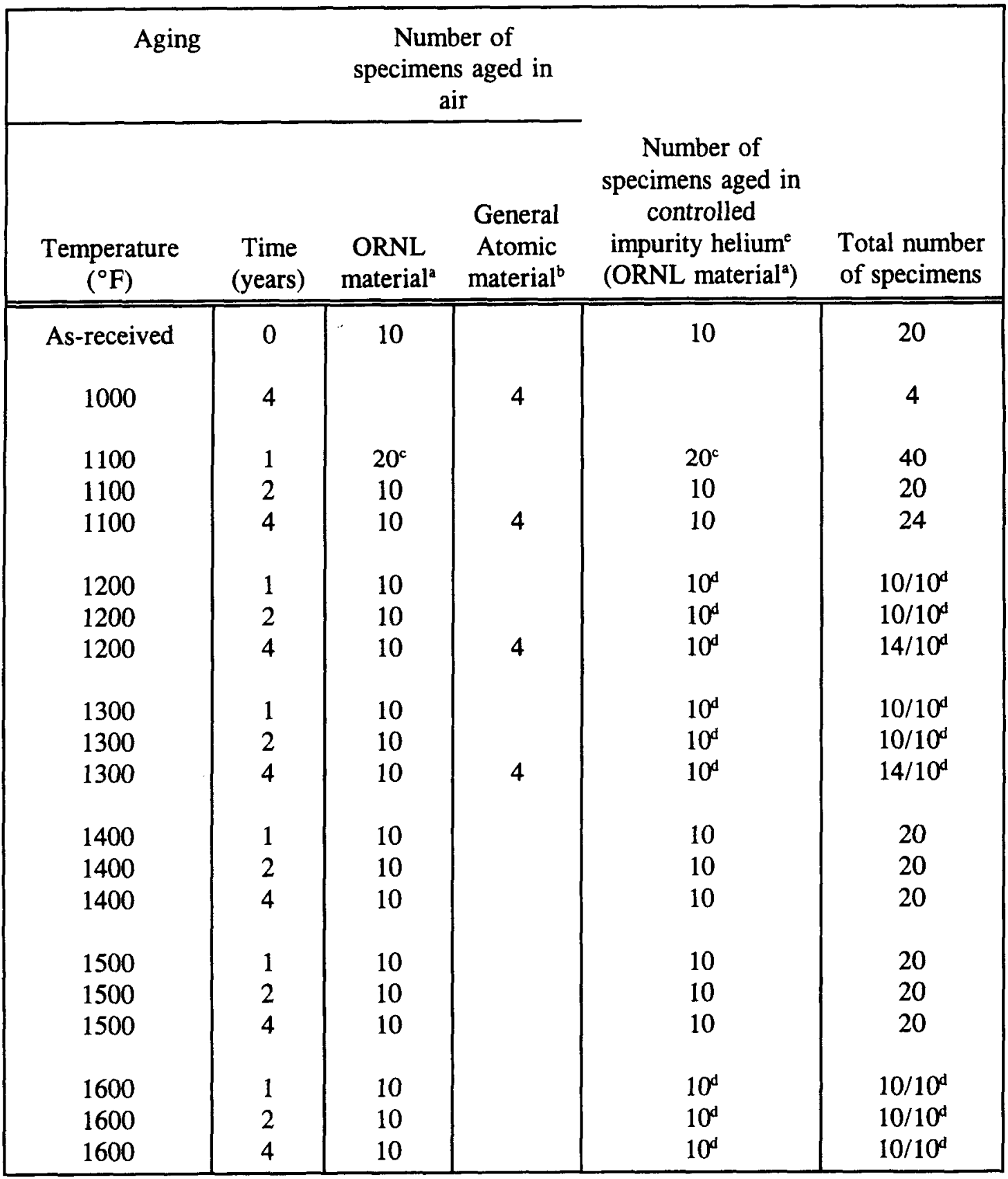

aFor ten specimens: four base metal, four weld metal, and two heat-affected zone.

bBase metal only.

'Two sets of specimens, one set to be tested at $1100^{\circ} \mathrm{F}$ (total of 20 specimens: eight base metal, eight weld metal, and four heat-affected zone).

'Precracked.

'Impurity levels defined in CEFA Test Specification 001910. 


\subsubsection{Material Preparation}

Alloy $800 \mathrm{H}$ plate material of 0.5 -in. thickness was purchased through a commercial source specified to meet ASME SB409 chemistry and grain size requirements. An ample supply of Inconel 82 weld wire was also purchased to American Welding Society (AWS) ERNiCr-3 specifications. Weld metal specimens were fabricated from a single-V weld prep, and HAZ specimens were made from half-K weld, prep joint. Each of the aforementioned three fracture mechanics test specimen types has a unique design, but all used the basic compact specimen proportionality. About 189 compact specimens for the Table 4-6 test matrix have been made, and the balance of the specimens ( 77 more) remain to be machined to complete the matrix. These are currently in the form of blanks ready for specimen machining.

Specimens needed to satisfy the test matrix of Table 4-7 have been prepared, and all are ready for aging treatments if continued work were authorized.

\subsubsection{Equipment and Facilities}

The conduct of fracture mechanics tests at high temperatures and in contaminated gaseous environments is a specialized type of test that requires considerable equipment development. Two test frames of 20-kip capacity have been prepared for this work. Each frame has an instrument panel equipped with MTS 458 controller, signal generator, etc., for servo-hydraulic control of load and/or displacement. A schematic of the chambers that are used for environment control is shown in Figure 4-12. Shown schematically are the special water-cooled chamber and pull rods. The cutaway view shows the specimen and the special extensometer built for the testing of hightemperature specimens. Also shown is a susceptor that surrounds the specimens. The susceptor is induction heated and, as such, is a local furnace for heating specimens. The susceptor is heated using a 7.5-kW Lepel power supply. Again, two such units were built for this work. Both are completely dedicated to data development for the present project. See Figure 4-13.

In addition to this, a facility has beén prepared for creep crack growth rate testing. These are generally long-term tests that involve sustained steady-state loading of specimens for weeks and/or months. For this work, 10 dead-weight creep machines of 10-kip loading capacity have been prepared. Each unit contains an Applied Test Systems, Inc. (ATS), 3-zone, clamshell-type furnace; temperature controllers; and environment control retort. See Figure 4-14. Displacement and crack growth are monitored continuously during the test. 
ORNL-DWG 93-6745

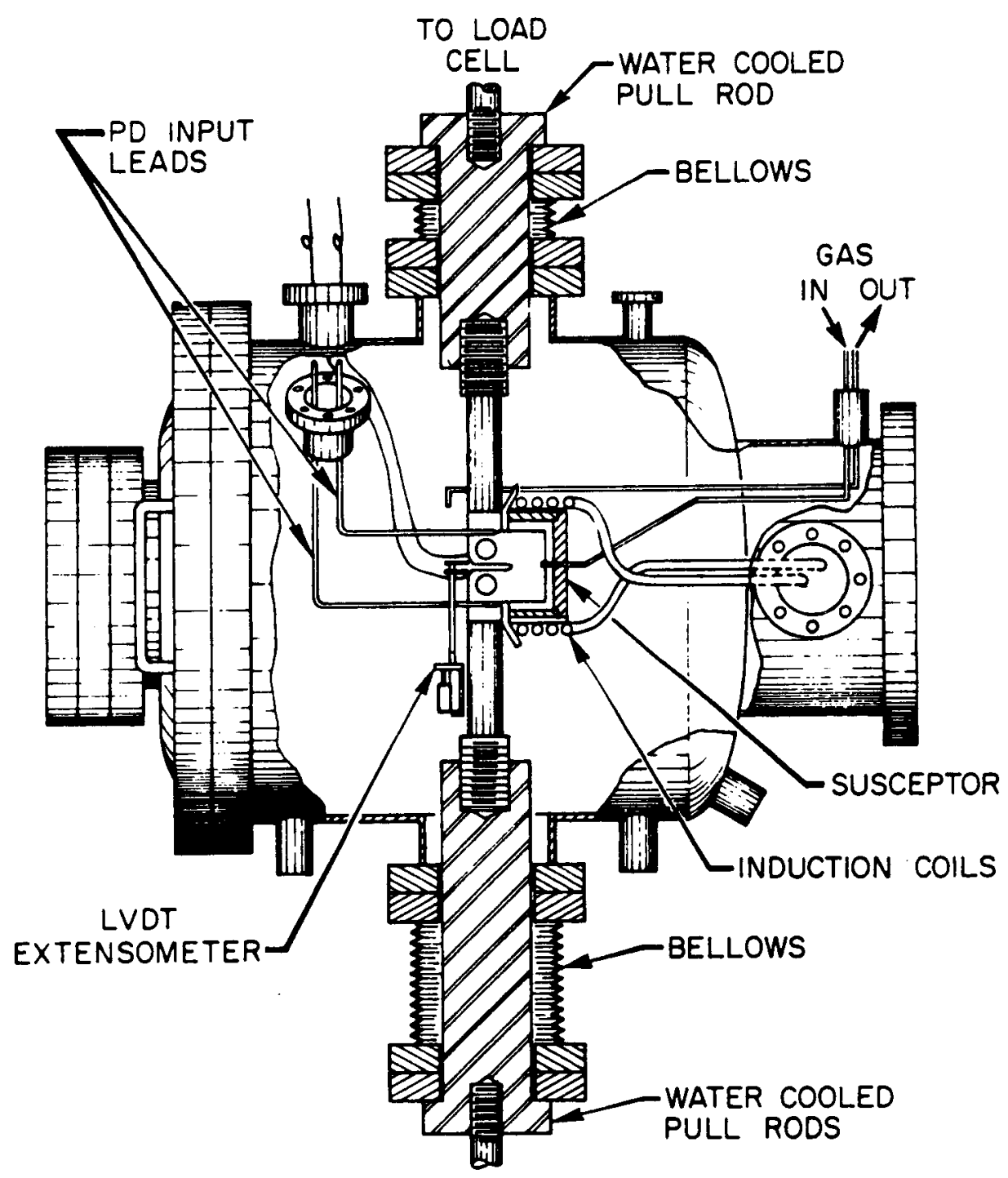

Figure 4-12.

\begin{abstract}
SCHEMATIC OF TEST SETUP FOR HELIUM ENVIRONMENT, HIGH-TEMPERATURE TESTS.
\end{abstract}




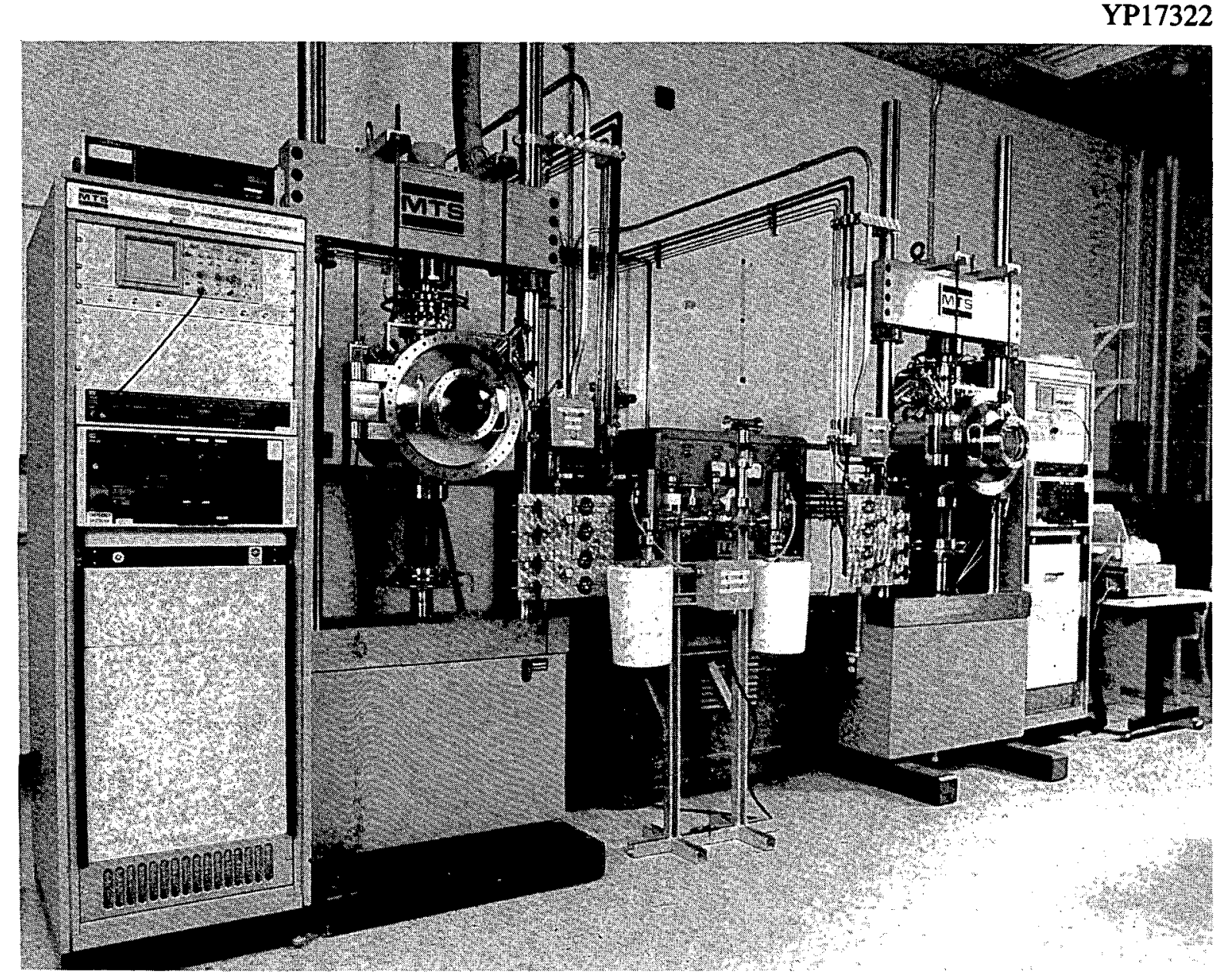

Figure 4-13.

PHOTO OF TEST SYSTEM EQUIPMENT ASSEMBLED FOR THE CURRENT PROJECT. 


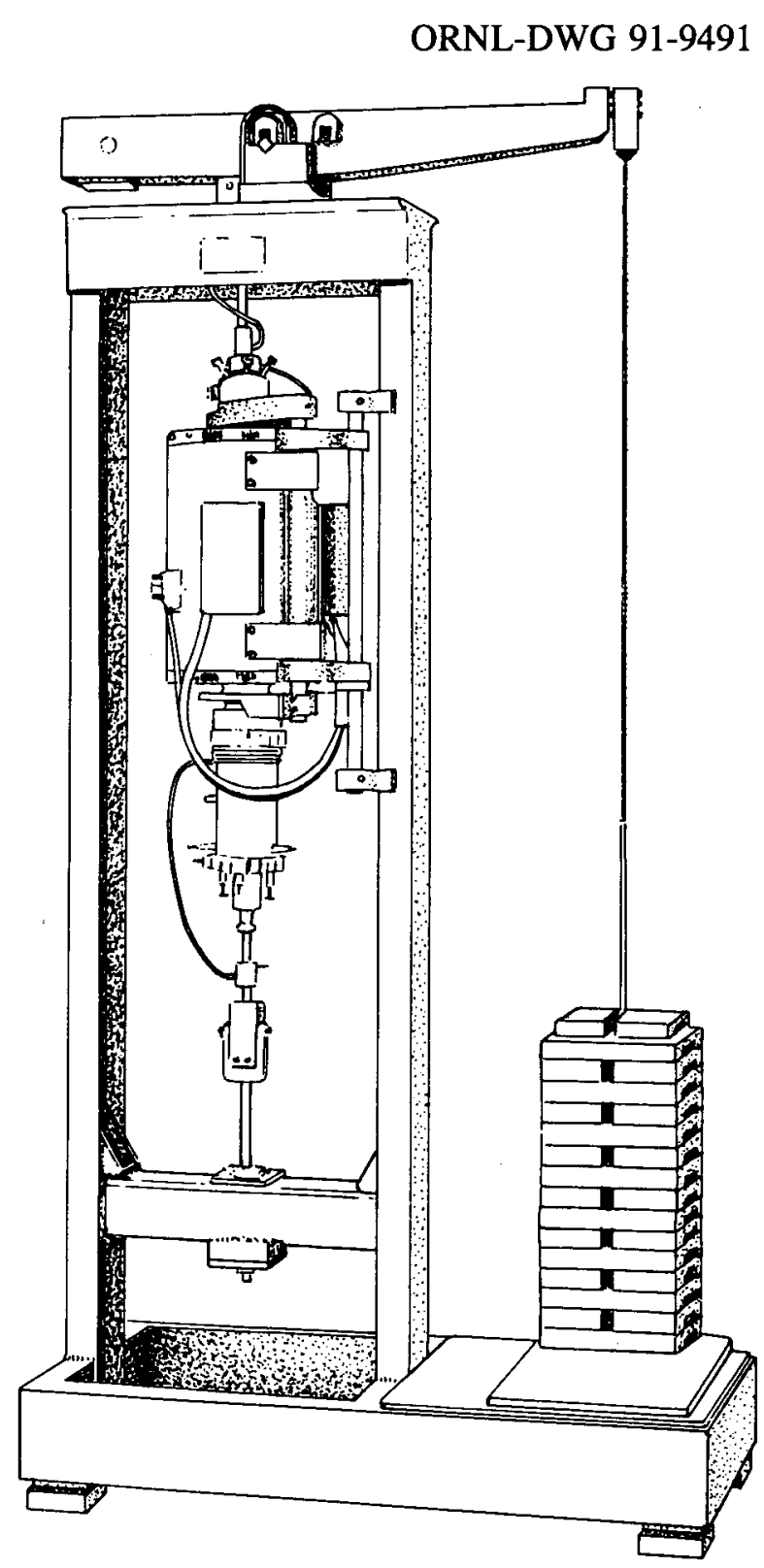

Figure 4-14.

\section{SCHEMATIC OF DEAD-WEIGHT LOADING OF CREEP CRACK GROWTH SPECIMENS.}




\subsubsection{Instrumentation and Control}

All fracture mechanics-type tests require the measurement of crack size and crack size change to very high precision. Displacement is also measured, but ultrahigh precision is needed only in cases where specimen compliance is used to monitor crack size. The equipment has been made and/or purchased for the data development. For fatigue crack growth rate testing, a Fracture Technology Associates (FTA) computer-controlled system with affiliated electronic control equipment has been obtained. Crack growth can be monitored by either potential drop or by compliance. This equipment is a high-quality system that is used by many of the top laboratories here and abroad that perform fatigue tests routinely. For R-curve development, an ORNLdeveloped system of quality comparable to that of the FTA system will be used. Again, both compliance and/or potential drop can be used for high-precision measurement of crack size. For creep crack growth, high-precision instrumentation is again used, but there is less complexity than the aforementioned two test practices. Displacement is measured with high precision using a new custom-designed extensometer. Crack growth is followed using electrical potential drop.

\subsubsection{Current Status}

The aforementioned equipment has been obtained, and an experience base in operating these systems has been developed prior to the official project termination date. Specimens and unmachined test blanks are being stored. Project records have been transferred to DOE storage.

\subsection{IRRADIATION PROPERTIES OF INCOLOY 800H - M. L. Grossbeck}

\subsubsection{Introduction}

The NPR design incorporates metallic core internals of Alloy $800 \mathrm{H}$. The upper core internals are expected to be exposed to low fluences, below $10^{25} \mathrm{n} / \mathrm{m}^{2}$, with the fast fluence a factor of 50 to 400 lower. In some regions of the core, where the thermal fluence is expected to remain below $10^{22} \mathrm{n} / \mathrm{m}^{2}$, the fast fluence is expected to be up to a factor of ten lower. The highest fast fluence is then not expected to exceed $2 \times 10^{23} \mathrm{n} / \mathrm{m}^{2}$. Normal service temperatures are expected to be in the range of 300 to $500^{\circ} \mathrm{C}$, but transient temperatures may reach $870^{\circ} \mathrm{C}$. As a result, scoping tests were conducted at elevated temperatures: 700 and $900^{\circ} \mathrm{C}$.

The most important consideration for application of any alloy in a neutron spectrum at high temperatures is high-temperature helium embrittlement. Helium is formed through thermal neutron interaction primarily with boron and nickel. Boron is the primary source of helium below 
a thermal fluence of $10^{25}$ neutrons $/ \mathrm{m}^{2}$. At fluences greater than this value, the primary source of helium is nickel. Since the goal fluence for the NPR is on the order of $10^{25} \mathrm{n} / \mathrm{m}^{2}$, boron is expected to be the primary contributor of helium, but nickel cannot be neglected. In addition, welds in Incoloy $800 \mathrm{H}$ are typically made with Inconel 82 as a filler metal. Since the Inconel 82 contains about $72 \%$ nickel, helium in the weld metal is even more of a concern than in the base metal. A literature search has revealed that welds in Alloy $800 \mathrm{H}$ have not been irradiated. For this reason, scoping experiments were felt to be necessary prior to initiating a very large irradiation experiment on this alloy.

\subsubsection{Experimental Methods}

Scoping irradiation experiments on Alloy $800 \mathrm{H}$ and welds were conducted in a rabbit tube facility of the HFIR. This facility permits irradiation in a neutron spectrum similar to that which would be experienced in a GCR similar to the NPR. It also permits elevated-temperature irradiation through nuclear heating in the specimens themselves. Limited space, however, allows irradiation of only a small number of specimens and does not permit active monitoring or control of the temperature.

A series of six sheet tensile specimens of Alloy $800 \mathrm{H}$ meeting the specifications of the NPR were irradiated at a temperature of $400^{\circ} \mathrm{C}$ in the rabbit facility of the HFIR. The neutron irradiation is predicted to produce helium in the alloy; however, the $400^{\circ} \mathrm{C}$ irradiation temperature is not sufficiently high for the helium to diffuse to grain boundaries where it can cause embrittlement. During a conduction cooldown, temperatures as high as $870^{\circ} \mathrm{C}$ might be expected. In the scoping tests, 700 and $900^{\circ} \mathrm{C}$ post-irradiation heat treatments were used, both of which are within the range of helium embrittlement. The specimens were exposed to the elevated temperatures for periods of 1 and $2 \mathrm{~h}$, both sufficient for migration of helium to grain boundaries.

Irradiation was conducted in the HFIR, in the Be reflector surrounding the core. A position containing a rabbit facility was used in order to be able to insert and retrieve the specimens as desired to obtain the low fluences required. The facility had a thermal flux of $4.9 \times 10^{18} \mathrm{n} / \mathrm{m}^{2}-\mathrm{s}$ and a fast flux of $1.94 \times 10^{17} \mathrm{n} / \mathrm{m}^{2}-\mathrm{s}(\mathrm{E}>0.1 \mathrm{MeV})$. The resulting thermal/fast flux ratio of 25 was within the range required for the NPR. The specimens were irradiated in an aluminum capsule as shown in Figure 4-15. Four specimens were accommodated in a single capsule and positioned in tight thermal contact with the holder in order to remove nuclear heat. The capsule contained cavities for melt indicator materials and dosimeters. The specimens were irradiated in two batches, each for $168 \mathrm{~h}$, to a measured thermal fluence of $3.0 \times 10^{24} \mathrm{n} / \mathrm{m}^{2}$ and a fast fluence 
ORNL-DWG 93-12064

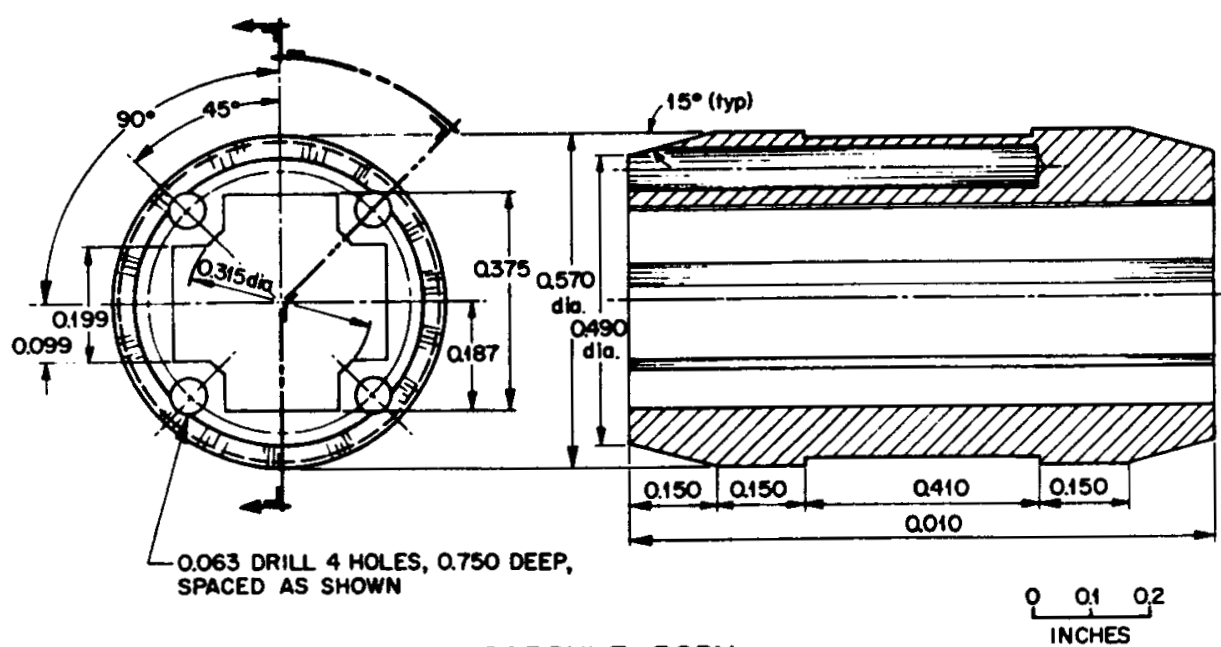

CAPSULE BODY

Figure 4-15(a).

\section{RABBIT BODY FOR IRRADIATION OF FOUR SHEET TENSILE SPECIMENS. FOUR HOLES ARE PROVIDED FOR DOSIMETERS AND MELTING TEMPERATURE MONITORS.}

ORNL-DWG 93-12065

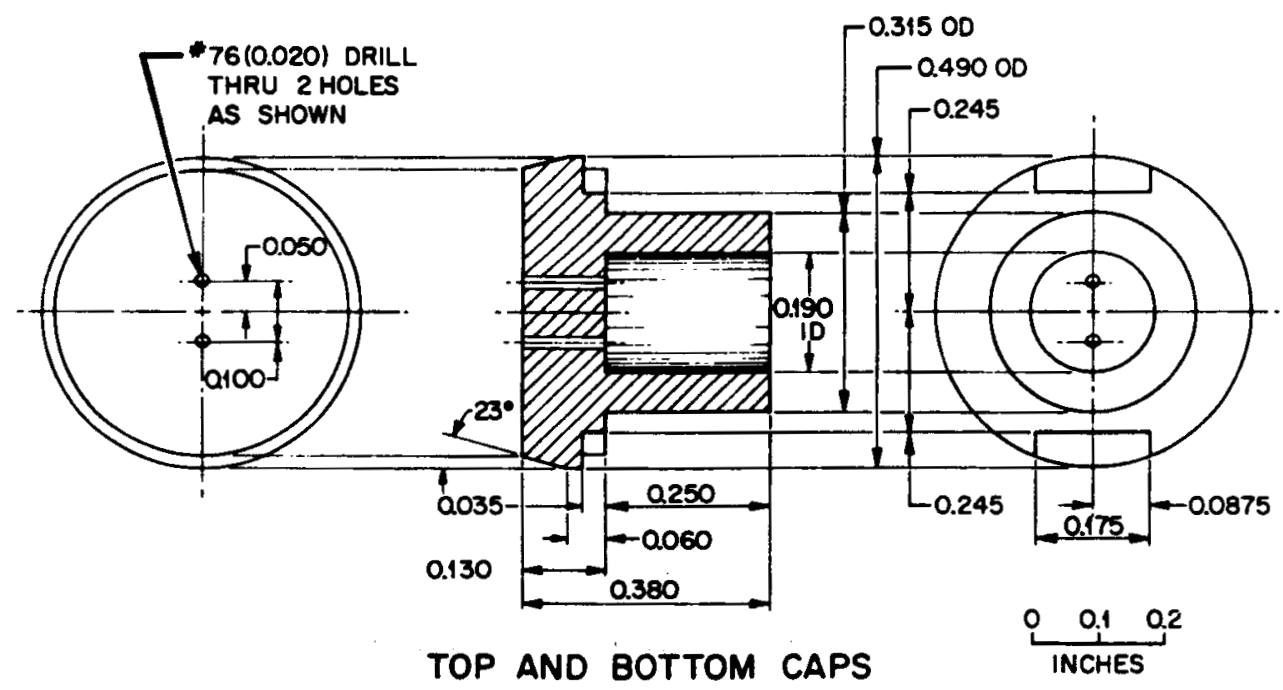

Figure 4-15(b).

END CAP FOR RABBIT. A SINGLE NICKEL WIRE IS THREADED THROUGH THE HOLES AND TWISTED TIGHT TO HOLD THE END CAPS IN PLACE IN CASE THEY LOOSEN. 
of $1.17 \times 10^{23} \mathrm{n} / \mathrm{m}^{2}$ ( $\mathrm{E}>0.1 \mathrm{MeV}$ ), producing an atomic displacement level of $0.014 \mathrm{dpa}$. The irradiation temperature was calculated from the results of the low-melting materials.

At such low fluence levels, the most important source of helium is transmutation of boron. Calculations based on chemical analyses for boron predict $7 \mathrm{appm} \mathrm{He}$ in the Alloy $800 \mathrm{H}$. The boron concentration in the Inconel 82 was below the limit of detectibility. Nickel is the next important source of helium at this fluence, producing $0.4 \mathrm{appm}$ in the Incoloy $800 \mathrm{H}$ and $0.9 \mathrm{appm}$ in the Inconel 82. Therefore, both alloys contained small concentrations of helium.

Testing was done in an Instron universal testing machine equipped with a high-vacuum system capable of pressures below $10^{-3} \mathrm{~Pa}\left(10^{-5}\right.$ torr $)$ at test temperature. A strain rate of $1.11 \times 10^{-4} \mathrm{~s}^{-1}$ was used for all tests. The specimens were machined from rolled $0.76-\mathrm{mm}$-thick sheet in the solution-annealed condition. They had a gage section $1.51 \mathrm{~mm}$ wide and $7.62 \mathrm{~mm}$ in length.

\subsubsection{Results and Discussion}

As shown in Table 4-8, tests of Alloy $800 \mathrm{H}$ were conducted at 700 and $900^{\circ} \mathrm{C}$, considerably higher than the irradiation temperature, in order to assess the effects of elevated temperatures following a loss of flow accident in an HTGR. Another reason for the elevated temperature is that helium embrittlement has not been observed in tensile and fatigue tests at temperatures below $500^{\circ} \mathrm{C} .{ }^{173}$

Figures 4-16 and 4-17 illustrate the effect of irradiation at a test temperature of $700^{\circ} \mathrm{C}$. No effect on strength was observed; however, the total elongation was diminished to $37 \%$ of its pre-irradiation value. The welded specimens, which included the fusion zone, HAZ, and base metal in the gage section, also showed no effect of irradiation on strength but, as with the base metal, suffered about a 50\% degradation in total elongation, as shown in Figures 4-18 and 4-19. The $900^{\circ} \mathrm{C}$ test results, shown in Figure 4-20, also showed no effect of irradiation on strength. However, total elongation of the irradiated material was only one-sixth of that for the unirradiated material.

Most unirradiated specimens showed no serrated yielding, but all irradiated specimens tested at $700^{\circ} \mathrm{C}$ demonstrated serrated yielding. At $900^{\circ} \mathrm{C}$, no serrated yielding was observed. This phenomenon, known as the Portevin-Le Chatelier effect, results from dislocation pinning by interstitial impurities. At higher temperatures, the interstitials diffuse sufficiently fast to remain with the dislocations and eliminate the breakaway load-drop effect. Although the reasons for the enhancement of this effect by irradiation are not completely understood, a few mechanisms are suggested. Interstitial impurities could have been introduced during the irradiation in air. 
Table 4-8

TENSILE PROPERTIES OF INCOLOY 800H (INCO HH 5132AG)

\begin{tabular}{|c|c|c|c|c|c|c|c|c|c|}
\hline Specimen & Alloy & $\begin{array}{c}\text { Exposure/type } \\
\text { (dpa) }\end{array}$ & $\begin{array}{c}\mathrm{He} \\
\text { (appm) }\end{array}$ & $\begin{array}{l}\text { Test temp } \\
\left({ }^{\circ} \mathrm{C}\right)\end{array}$ & $\begin{array}{l}\text { Soak } \\
\text { period } \\
\text { (h) }\end{array}$ & $\begin{array}{c}\text { Yield } \\
\text { strength } \\
(\mathrm{MPa})\end{array}$ & $\begin{array}{l}\text { Ultimate } \\
\text { tensile } \\
\text { strength } \\
(\mathrm{MPa})\end{array}$ & $\begin{array}{l}\text { Uniform } \\
\text { elongation } \\
(\%)\end{array}$ & $\begin{array}{c}\text { Total } \\
\text { elongation } \\
(\%)\end{array}$ \\
\hline $\begin{array}{c}\text { J33 } \\
\text { J39 } \\
\text { J21 } \\
\text { J29 } \\
\text { J13 } \\
\text { J2 } \\
\text { J5 } \\
\text { J10 } \\
\text { J31 } \\
\text { J22 } \\
\text { IN09 } \\
\text { IN04 } \\
\text { IN05 } \\
\text { IN02 }\end{array}$ & $\begin{array}{c}\text { Incoloy } \\
800 \mathrm{H} \\
\\
\text { Inconel } \\
690\end{array}$ & $\begin{array}{c}0 \\
0 \\
0.014 \\
0.014 \\
0 / \text { weld } \\
0 / \text { weld } \\
0.014 / \text { weld } \\
0.014 / \text { weld } \\
0 \\
0.014 \\
0 \\
0.014 \\
0 \\
0.014\end{array}$ & $\begin{array}{c}7 \\
7 \\
1 \\
1 \\
1 \\
1 \\
\\
7 \\
\\
2-3 \\
2-3\end{array}$ & $\begin{array}{c}700 \\
700 \\
700 \\
700 \\
700 \\
700 \\
700 \\
700 \\
900 \\
900 \\
22 \\
22 \\
400 \\
400\end{array}$ & $\begin{array}{l}1 \\
1 \\
1 \\
1 \\
1 \\
1 \\
1 \\
1 \\
2 \\
2\end{array}$ & $\begin{array}{c}133 \\
127 \\
130 \\
134 \\
123 \\
128 \\
130 \\
126 \\
70.7 \\
66.5 \\
470 \\
597 \\
443 \\
435\end{array}$ & $\begin{array}{c}300 \\
314 \\
291 \\
300 \\
281 \\
289 \\
293 \\
288 \\
87.5 \\
81.9 \\
728 \\
763 \\
639 \\
634\end{array}$ & $\begin{array}{c}20 \\
22 \\
14 \\
14 \\
18 \\
18 \\
14 \\
16 \\
42 \\
6.5 \\
32 \\
31 \\
29 \\
35\end{array}$ & $\begin{array}{l}46 \\
43 \\
16 \\
17 \\
43 \\
34 \\
16 \\
23 \\
81 \\
13 \\
38 \\
38 \\
37 \\
44\end{array}$ \\
\hline
\end{tabular}

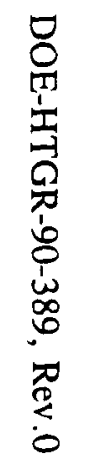




\section{ORNL-DWG 93-11627}

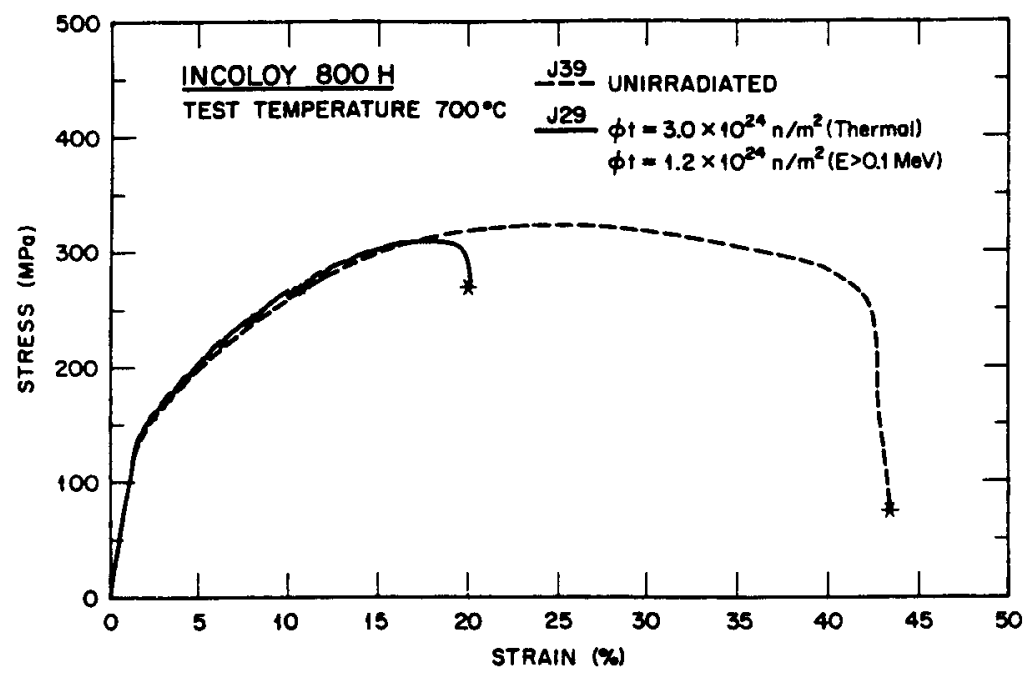

Figure 4-16.

STRESS VS STRAIN FOR INCOLOY $800 \mathrm{H}$ COMPARING IRRADIATED AT $400^{\circ} \mathrm{C}$ AND UNIRRADIATED SPECIMENS J29 AND J39, RESPECTIVELY.

ORNL-DWG 93-12060

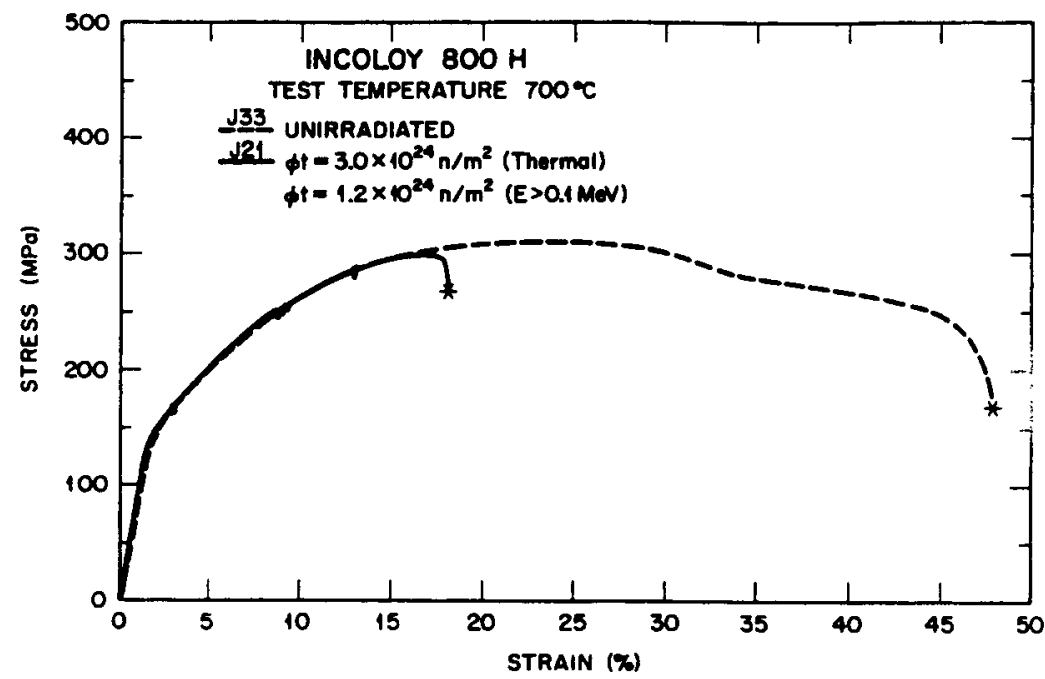

Figure 4-17.

STRESS VS STRAIN FOR INCOLOY 800H COMPARING IRRADIATED AT $400^{\circ} \mathrm{C}$ AND UNIRRADIATED SPECIMENS J21 AND J33, RESPECTIVELY. 
ORNL-DWG 93-12062

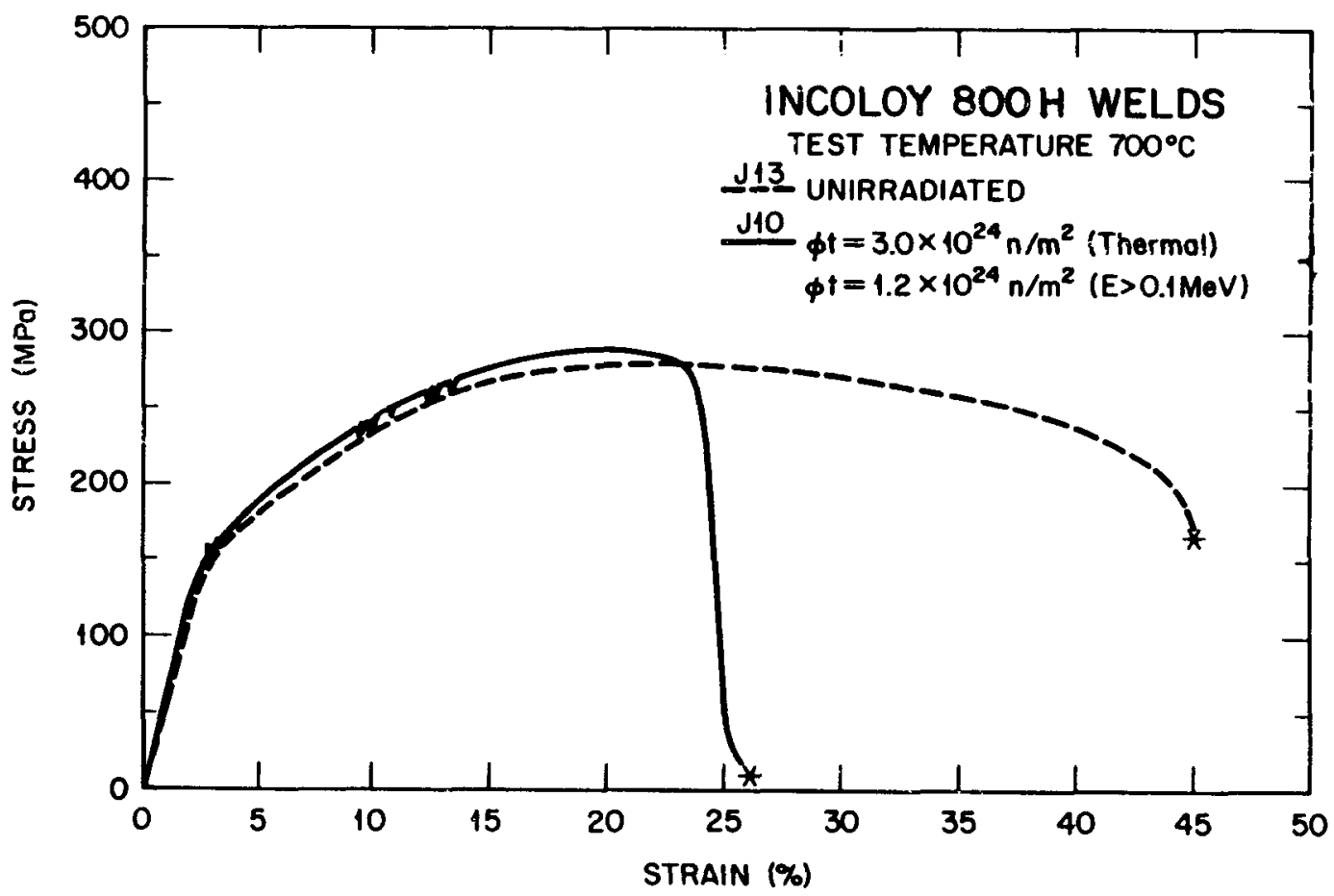

Figure 4-18.

STRESS VS STRAIN FOR INCOLOY $800 \mathrm{H}$ WELDED WITH INCONEL 82 FILLER METAL SHOWING THE EFFECT

OF IRRADIATION USING SPECIMENS J10 AND

J13 CONTAINING BASE METAL, HAZ, AND FUSION ZONE IN THE GAGE SECTION. 
ORNL-DWG 93-12061

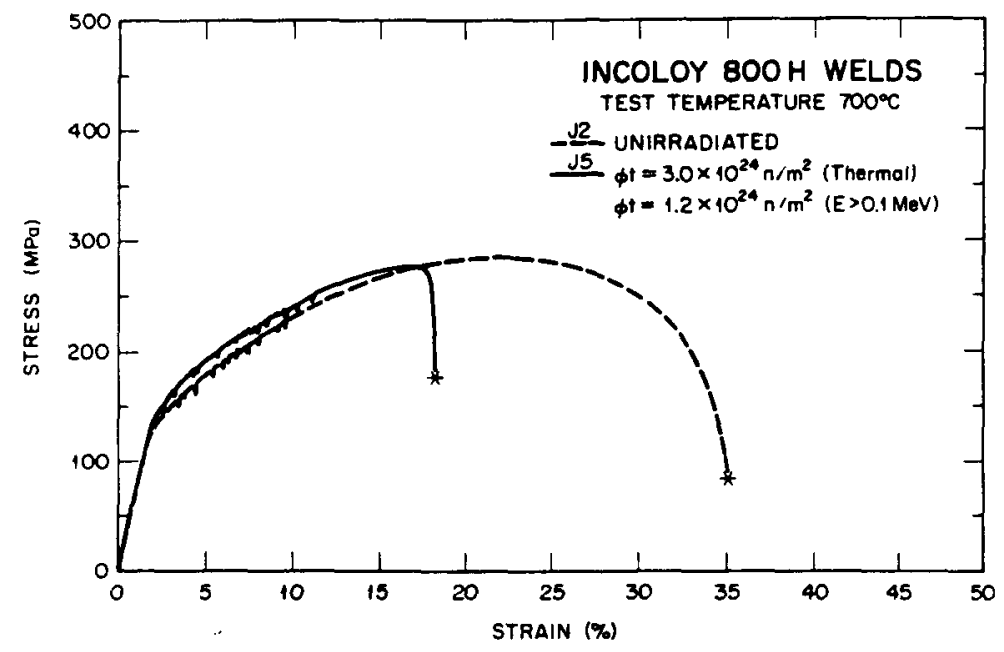

Figure 4-19.

STRESS VS STRAIN FOR INCOLOY 800H WELDED WITH INCONEL 82 FILLER METAL SHOWING THE EFFECT OF IRRADIATION USING SPECIMENS J5 AND J2 CONTAINING BASE METAL, HAZ, AND FUSION ZONE IN THE GAGE SECTION.

ORNL-DWG 93-12063

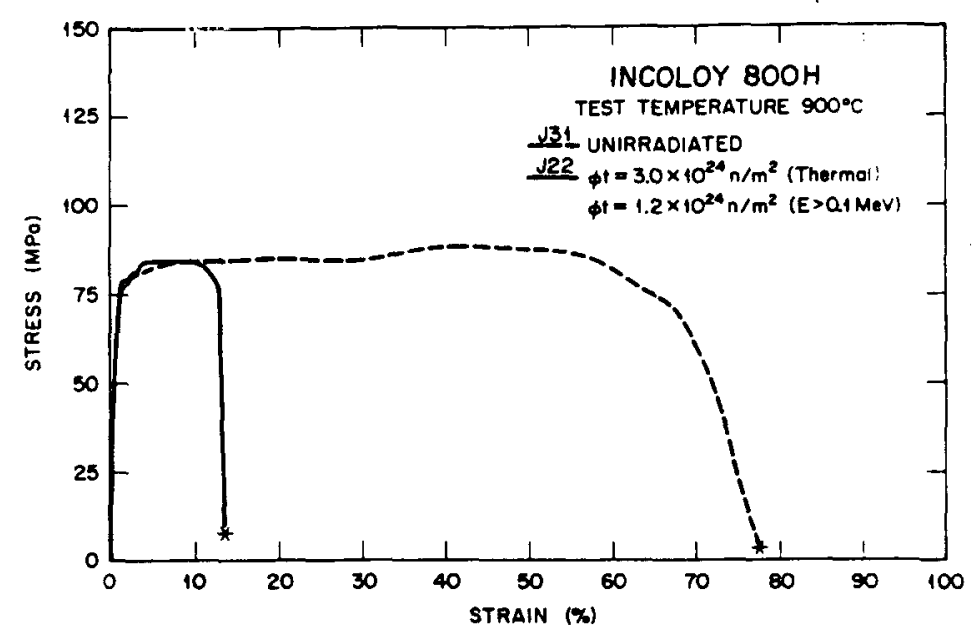

Figure 4-20.

STRESS VS STRAIN FOR INCOLOY $800 \mathrm{H}$ TESTED AT $900^{\circ} \mathrm{C}$ COMPARING IRRADIATED AT $400^{\circ} \mathrm{C}$ AND UNIRRADIATED SPECIMENS J22 AND J31, RESPECTIVELY. 
Precipitates may have dissolved during irradiation, thus increasing their concentration in the matrix. It is also possible that irradiation-induced defects that remain after the high-temperature soak period contribute to serrated yielding.

SEM fractography revealed the cause of the reduced elongation: in all cases of irradiated Alloy $800 \mathrm{H}$, the fracture mode was intergranular; see Figure 4-21. In the case of unirradiated material, the fracture mode was transgranular ductile rupture with a small amount of intergranular failure at $900^{\circ} \mathrm{C}$, see Figures 4-22 and 4-23. Figure 4-24 shows the fracture surface of an irradiated weld where the larger grain size indicates that at least part of the fracture was within weld metal or in the HAZ.

Although segregation of impurity elements, in general, to grain boundaries can induce hightemperature embrittlement of irradiated alloys, helium, in particular, has been shown to account for embrittlement more than any other element. ${ }^{174}$ Since high temperatures and longer times increase growth of bubbles and diffusivity of helium to grain boundaries, a single pair of tests was made at $900^{\circ} \mathrm{C}$ with a 2 -h soak period. As expected for helium embrittlement, the ductility was strongly affected, with total elongation reduced to one-sixth the pre-irradiation value.

\subsubsection{Conclusions}

Incoloy $800 \mathrm{H}$ base metal and welds irradiated at $400^{\circ} \mathrm{C}$ exhibited helium embrittlement at tensile test temperatures of $700^{\circ} \mathrm{C}$ and above. However, despite intergranular fracture, total elongations were greater than $10 \%$ in all cases. Because helium embrittlement is exacerbated by long periods and high temperatures, creep testing is essential to fully evaluate any alloy for HTGR application. Welds using Inconel 82 filler metal appear to be no worse than base metal, but welds also must be creep tested before conclusions can be drawn.

\subsection{PROPERTIES OF HEAT TRANSPORT MATERIALS}

The Minimum Commitment Method (MCM) ${ }^{175}$ of analyzing creep data was used to evaluate the effects of carbon, aluminum, and titanium on the average and minimum stress-rupture properties of Alloy $800 \mathrm{H}$ from 482 to $816^{\circ} \mathrm{C}$. The data set of 744 points from 69 heats was divided into 5 sets based on chemical composition. The details of this analysis are presented elsewhere $;{ }^{176}$ the conclusions based on this work are summarized here:

1. The MCM as developed by Manson ${ }^{175}$ and modified by Pepe ${ }^{177}$ was easy to use. The solutions were well behaved, and extrapolations were reasonable. 


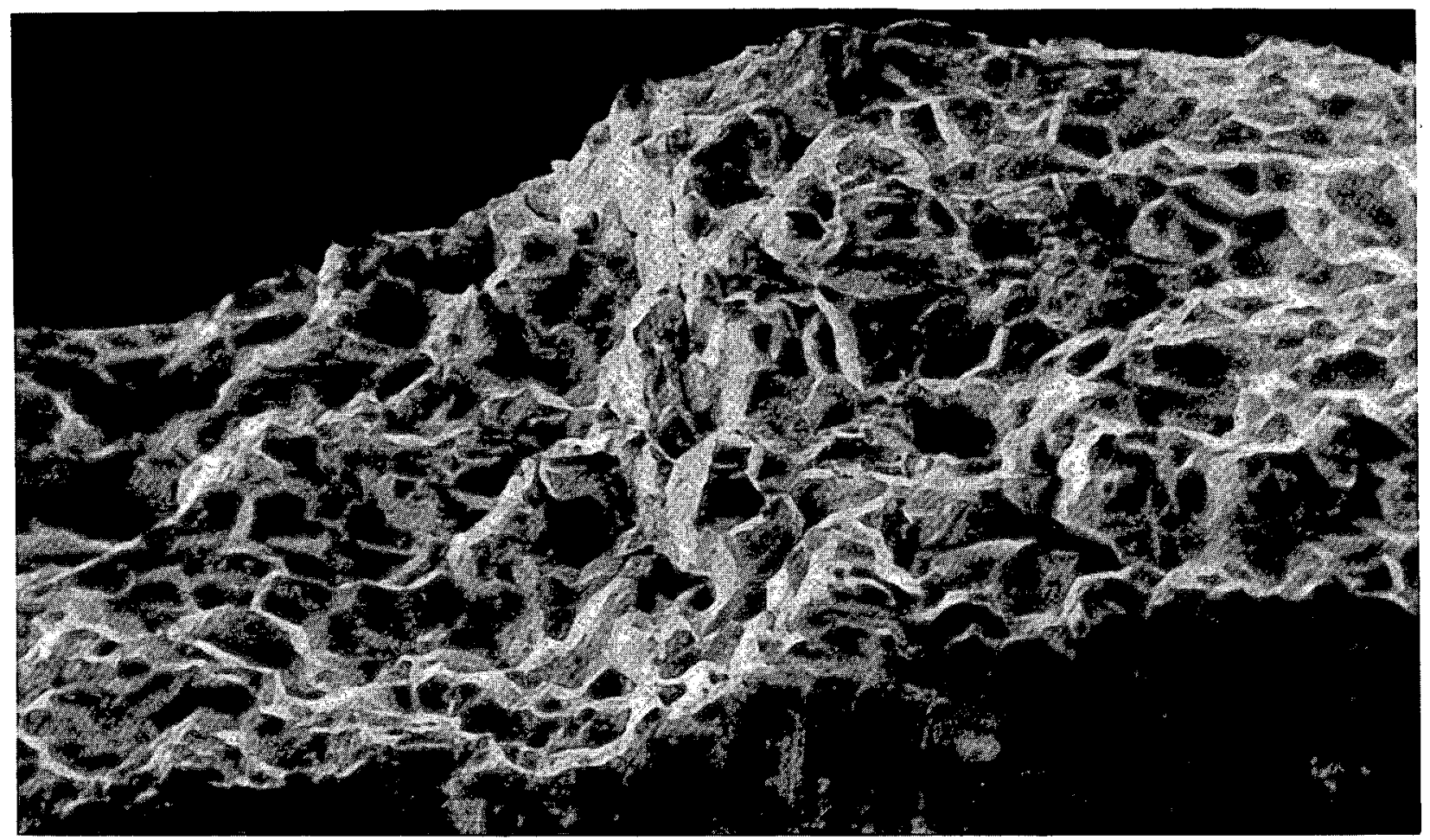

Figure 4-21.

FRACTURE SURFACE OF INCOLOY 800H SPECIMEN J29 IRRADIATED TO A THERMAL FLUENCE OF $3.0 \times$ $10^{24} \mathrm{~N} / \mathrm{M}^{2}$ AND 0.014 DPA AT $400^{\circ} \mathrm{C}$ AND TESTED AT $700^{\circ} \mathrm{C}$. 


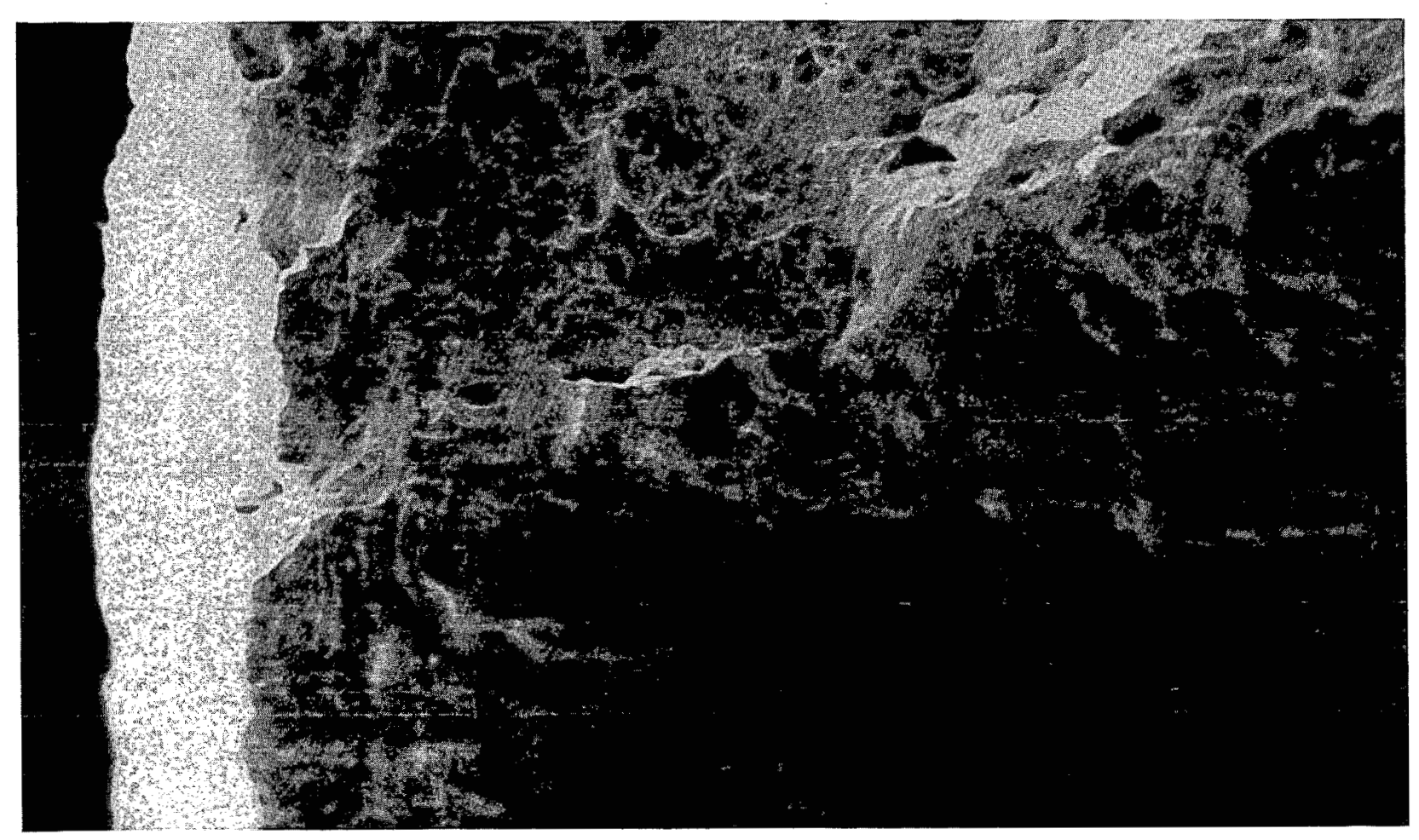

Figure 4-22.

0
0
1
1
0
0
0
0
0
4
0
0
0
0
0
0
0

FRACTURE SURFACE AND LATERAL SIDE OF INCOLOY 800H UNIRRADIATED SPECIMEN J39 TESTED AT $700^{\circ} \mathrm{C}$. 


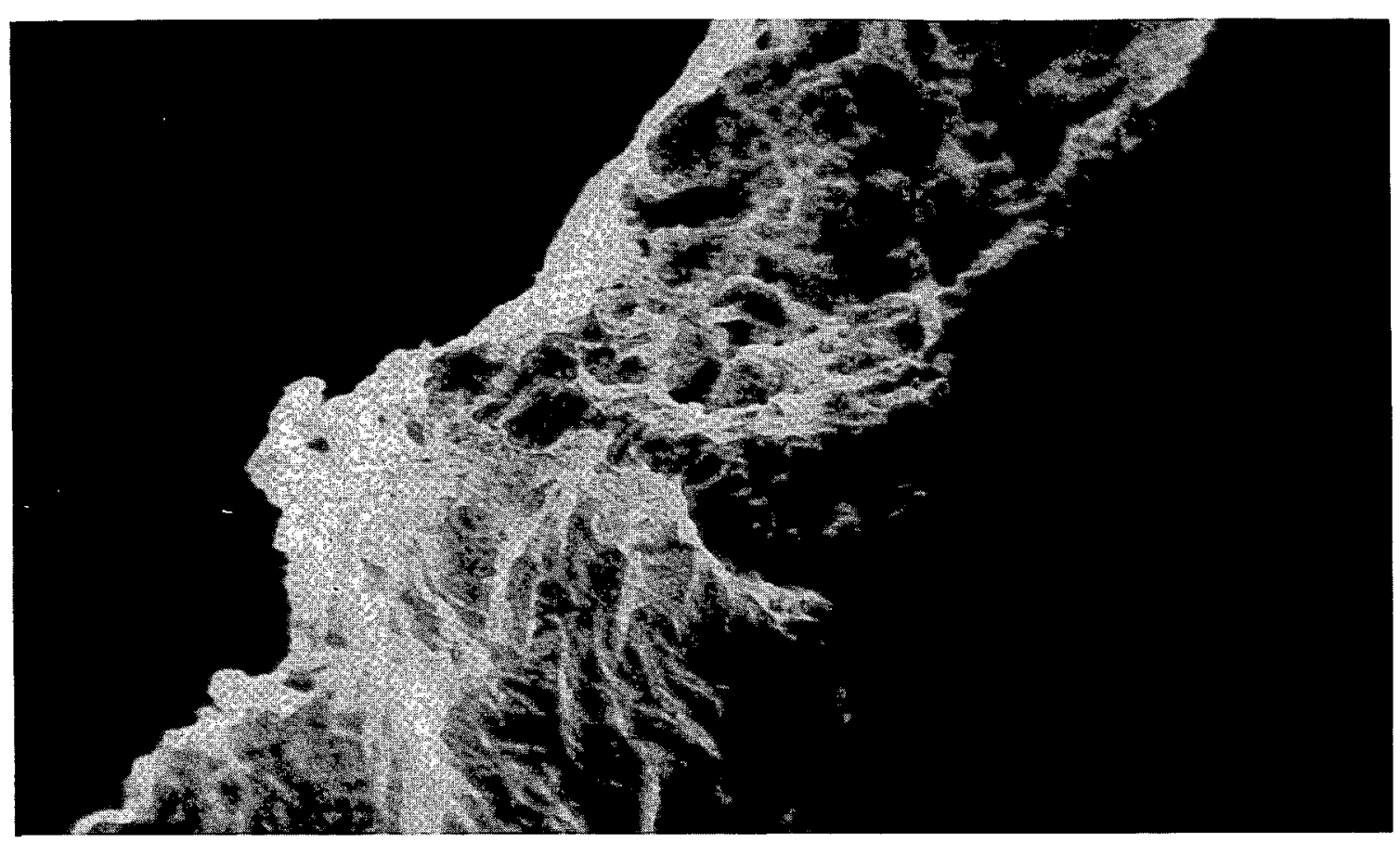

Figure 4-23.

FRACTURE SURFACE OF INCOLOY 800H UNIRRADIATED SPECIMEN J31 TESTED AT $900^{\circ} \mathrm{C}$. 


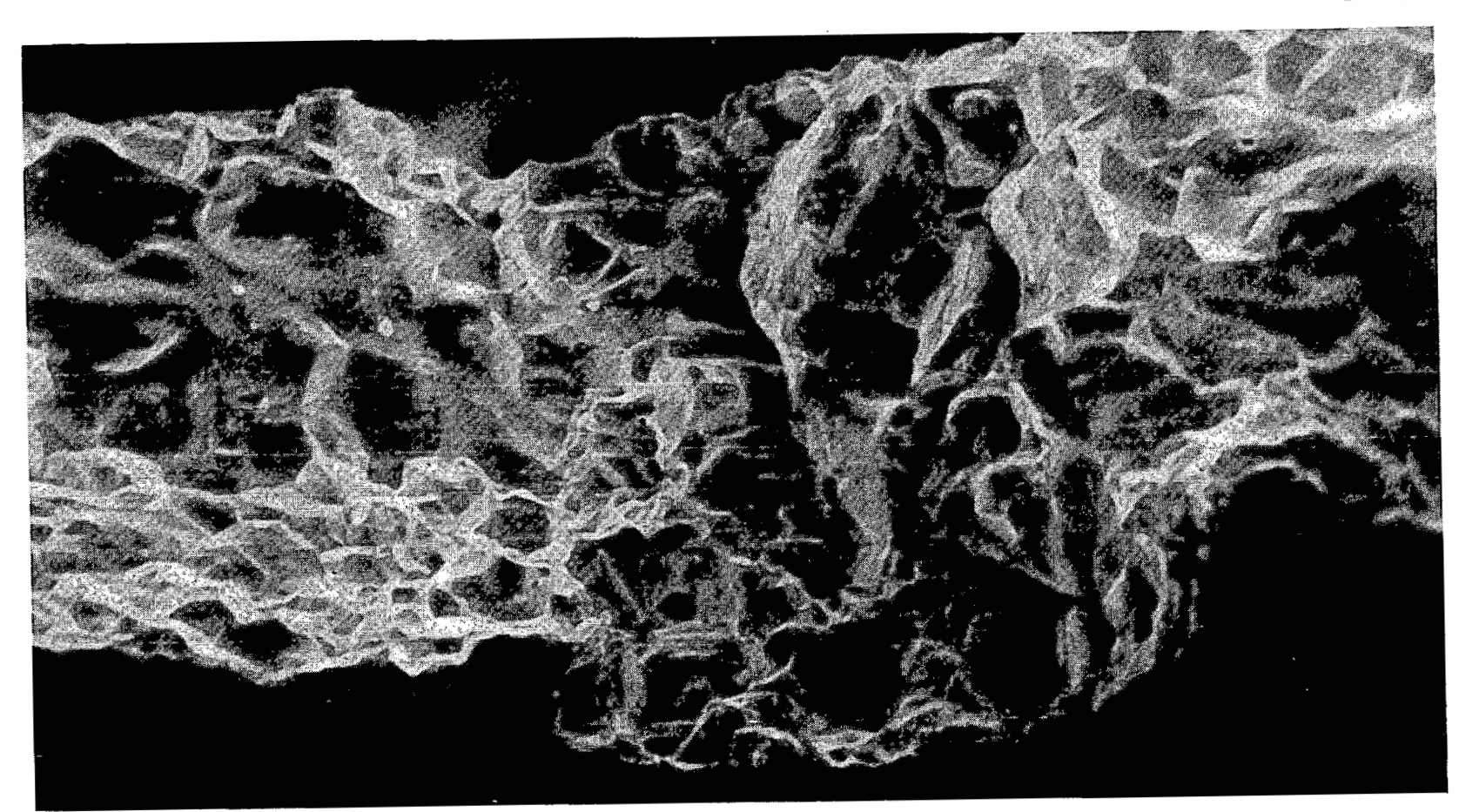

Figure 4-24.

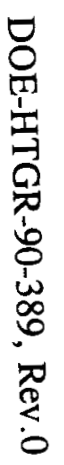

FRACTURE SURFACE OF INCOLOY 800H/INCONEL 82 WELD SPECIMEN J5 IRRADIATED TO A THERMAL FLUENCE OF $3.0 \times 10^{24} \mathrm{~N} / \mathrm{M}^{2}$ AND 0.014 DPA AT $400^{\circ} \mathrm{C}$ AND TESTED AT $700^{\circ} \mathrm{C}$. 
2. The results obtained by Pepe and ourselves using the MCM to analyze standard Alloy $800 \mathrm{H}$ are in good agreement considering the different temperature ranges of two data sets.

3. The chemical requirements of Alloy $800 \mathrm{HT}$ result in an alloy with creep strength superior to that of standard Alloy $800 \mathrm{H}$.

4. The ASME Code Case $\mathrm{N}-47$ supplemental requirement that the aluminum-plus-titanium content of 0.50 to $1.20 \%$, as opposed to the standard range of 0.30 to $1.20 \%$, leads to improvement in strength for an alloy with the standard carbon content of 0.04 to $0.06 \%$ carbon is not improved by the higher aluminum plus titanium.

5. Reducing the carbon concentration from 0.05 to $0.10 \%$ to 0.04 to $0.06 \%$ in standard Alloy $800 \mathrm{H}$ does not reduce the 100,000 -h rupture strength; however, reducing the carbon concentration to this level in Alloy $800 \mathrm{H}$ containing 0.5 to $1.2 \%$ aluminum plus titanium does reduce the rupture strength.

Creep tests were performed at ORNL on $2.25 \mathrm{Cr}-1$ Mo steel for times in excess of $100,000 \mathrm{~h}$. The temperature range was 482 to $649^{\circ} \mathrm{C}$, and the test environment was air or helium containing controlled impurities. The four test materials satisfied the chemical requirements of SA-387, grade 22, and all materials were isothermally annealed prior to testing.

The creep test results were analyzed using the $\mathrm{MCM},{ }^{175}$ and the details of this analysis were presented previously. ${ }^{178}$ In determining design stresses, the stresses to produce $1 \%$ strain, tertiary creep, and rupture are considered. The ORNL creep data were divided into several different sets for analysis.

The conclusions from this analysis were:

- The MCM was found to work well for $2.25 \mathrm{Cr}-1 \mathrm{Mo}$ steel in that the data were fit well by the correlations, and extrapolations of the correlations to reasonable times appeared reasonable

- Analysis of creep test results in air and helium by the MCM did not reveal any effect of environment to times of about $100,000 \mathrm{~h}$ on the test results

- The ORNL creep data set consisting of the results from four heats was analyzed by the MCM using the analytical methods on Code Case $\mathrm{N}-47$ at 538 through $649^{\circ} \mathrm{C}(1000$ through $1200^{\circ} \mathrm{F}$ )

- Room-temperature tensile tests of preaged specimens revealed that extended aging of some heats at 593 and $649^{\circ} \mathrm{C}\left(1100\right.$ and $\left.1200^{\circ} \mathrm{F}\right)$ decreased the yield strength below the 30-ksi minimum value specified by ASME for this material 
- The data were not sufficient to obtain quantitative values, but pretest aged specimens generally had lower creep strength than isothermally annealed material

\subsection{BIMETALLIC WELD STRUCTURAL INTEGRITY - J. Blass and R. L. Battiste}

\subsubsection{Introduction}

In the design of the NP-MHTGR steam generator, each of the 439 heat-transfer tubes is in the form of two vertical-axis helical coils connected by a vertical, straight section of tubing. The lower coil serves as the economizer, evaporator, and initial superheater (EES), and the upper coil serves as the finishing superheater (FSH). The EES tubing is of ferritic $2.25 \mathrm{Cr}-1 \mathrm{Mo}$ steel, whereas the FSH tubing is of austenitic $\mathrm{Ni}-\mathrm{Fe}-\mathrm{Cr}$ Alloy $800 \mathrm{H}$, for greater resistance to creep and oxidation at higher operating temperatures. The transition from one material to the other, consisting of a butt weld made with nickel-base Inconel 82 filler metal, is located in the straight section connecting the coils. ${ }^{179}$ The transition joint is referred to as a dissimilar metal weld or (ignoring the filler metal) a bimetallic weld (BMW). The relatively short, straight section of tubing is to be fabricated as a subassembly, referred to as a spool piece or "dutchman," under optimum conditions for welding and inspection. Since the primary helium coolant flows vertically downward through the FSH and EES, the coiled tubing is in cross flow, and the spool piece is in parallel flow. Consequently, the heat flux in the spool piece is lower than in the coiled tubing, and the steady-state operating temperature of the BMW is not expected to exceed $454^{\circ} \mathrm{C}\left(850^{\circ} \mathrm{F}\right)$.

The behavior of ferritic-to-austenitic BMWs in superheaters and reheaters of fossil-fuel power plants was the subject of an Electric Power Research Institute-Metal Properties Council (EPRI-MPC) joint study. ${ }^{180}$ In service and in tests at temperatures of $566^{\circ} \mathrm{C}\left(1050^{\circ} \mathrm{F}\right)$ and higher, under loading conditions that produced much more creep damage than fatigue damage, failures usually initiated in the HAZ of the ferritic steel at the interface with the weld metal. Voids or cracks initially formed at carbide precipitates within the wall of the tube. Growth and linkage of cracks then led to failure. To retard precipitation and growth of carbides, an upper limit on steady-state operating temperature of $482^{\circ} \mathrm{C}\left(900^{\circ} \mathrm{F}\right)$ was adopted for the BMWs in the NP-MHTGR steam-generator tubing. To confirm the adequacy of the temperature limit and to reduce the uncertainty and technical risk associated with the creep-fatigue behavior of the BMW under conditions relevant to NP-MHTGR operation, needs were identified in NPR-DDN-13.22 (ref. 181), and tests were specified in CEGA-002009 (ref. 182). The tests were to be conducted at ORNL. 
To supplement the generic design criteria of ASME Code Case N-47 (ref. 183), BMW-specific design criteria were proposed for HTGR applications. These criteria are a direct extension of the Prediction of Damage in Service (PODIS) life-assessment procedure. ${ }^{184}$ When conservatively applied to the BMWs in the NP-MHTGR steam-generator tubing, the PODIS procedure provides a rather high estimate of fatigue damage. ${ }^{179}$ Because the development of PODIS was based largely on failure data for temperatures and loading conditions that produced much more creep damage than fatigue damage, the high estimate of fatigue damage is considered unrealistic. The results of the tests specified in CEGA-002009 were to serve as a basis for refinement of certain features of the PODIS procedure to provide more realistic estimates of creep-fatigue damage for this application.

\subsubsection{Task Description}

To confirm the adequacy of the $482^{\circ} \mathrm{C}\left(900^{\circ} \mathrm{F}\right)$ limit on steady-state operating temperature adopted for the BMWs in the NP-MHTGR steam-generator tubing, prototypic tubular specimens containing BMWs, unaged and aged for periods of time at elevated temperatures, were to be destructively sampled and examined for evidence of metallurgical change, as specified in CEGA-002009. Results of the metallurgical examinations were to be used to establish, by extrapolation, the growth rates of carbides under conditions relevant to NP-MHTGR operation.

To reduce the uncertainty and technical risk associated with the creep-fatigue behavior of the BMWs in the NP-MHTGR steam-generator tubing, isothermal fatigue and creep-fatigue tests to failure of unaged and aged prototypic tubular specimens containing BMWs were to be conducted as specified in CEGA-002009. Fatigue tests of 500 to 50,000 cycles duration were to be conducted at $371,427,482$, and $538^{\circ} \mathrm{C}\left(700,800,900\right.$, and $\left.1000^{\circ} \mathrm{F}\right)$ under purely axial and

purely torsional constant-amplitude cyclic load. Creep-fatigue tests of up to 5000-h duration were to be conducted at 427,482 , and $538^{\circ} \mathrm{C}\left(800,900\right.$, and $\left.1000^{\circ} \mathrm{F}\right)$ under purely axial and purely torsional constant-amplitude cyclic load, with hold periods at maximum load, minimum load, or both. Some of the axial and torsional fatigue and creep-fatigue tests were to be conducted with a constant positive mean load equal to the amplitude of the cyclic load.

To provide confirmation of BMW design criteria and life-assessment methods under more representative loading conditions, fatigue and creep-fatigue tests of prototypic tubular specimens containing BMWs were also to be conducted under combined in-phase cycling of temperature, internal pressure, axial load, and torsional load. A maximum temperature of $482^{\circ} \mathrm{C}\left(900^{\circ} \mathrm{F}\right)$ and 
a maximum internal pressure of at least $11.03 \mathrm{MPa}(1600 \mathrm{psi})$, corresponding to the differential pressure at the BMWs in the NP-MHTGR steam-generator tubing, were to be used in these tests.

As specified in CEGA-002009, each BMW test specimen was to have an overall length of approximately $380 \mathrm{~mm}$ (15 in. vs about 60 in. for production spool pieces) and was to consist of equal straight lengths of prototypic Alloy 800H (ASME SB-163, UNS N08810) and $2.25 \mathrm{Cr}-1 \mathrm{Mo}$ (ASME SA-213, grade T22) tubing, with OD of $22.2 \mathrm{~mm}(0.875 \mathrm{in}$.) and wall thickness of $3.30 \mathrm{~mm}(0.130 \mathrm{in}$.), joined by a prototypic butt weld made with a weld insert and filler wire of Inconel 82 (ASME SFA-5.14, UNS N06082, AWS ERNiCr-3) using an automatic gas-tungsten-arc welding (GTAW) technique. Applicable requirements of the proposed specifications for production spool pieces ${ }^{185-187}$ were to be satisfied. However, stamping and thirdparty inspection were not required. Moreover, the tubing, weld inserts, and filler wire were purchased as commercial grade and were to be tested by an approved vendor so as to be dedicated for this use.

Although the BMW specimens are full-size structural components (except for length), a materials testing standard, ASTM Standard E 606 (ref. 188), was to be used as guidance for most aspects of the testing. The planned methods of gripping and applying loads to the specimen required that misalignment between the pieces of austenitic and ferritic tubing be reduced to a practical minimum. It was assumed that the geometrical and metallurgical nonuniformities in the vicinity of the weld and the elevated temperature of the test section would be sufficient to preclude failure at one of the grips used for load application.

Additional information needed for interpretation of results of the BMW tests was to be provided by tests of base-metal specimens fabricated from the austenitic and ferritic tubing.

\subsubsection{Preliminary Tests}

Because of the decision not to proceed with the NPR project, only a few preliminary axial fatigue tests of unaged specimens at $482^{\circ} \mathrm{C}\left(900^{\circ} \mathrm{F}\right)$ were conducted. The objectives of these tests were to establish the effectiveness of the planned testing techniques, identify any shortcomings, and obtain information needed for effective planning of future tests.

Six welded composite tubes [see Figure 4-25 (a)] were fabricated at ORNL, using the following materials obtained from ABB Combustion Engineering:

- Ferritic $2.25 \mathrm{Cr}-1$ Mo EES tubing, NPR No. 135

- $0.05 \mathrm{C}$ austenitic Alloy 800H FSH tubing, heat No. 80015, NPR No. 262

- Inconel 82 weld inserts, heat No. VF45-1, code No. J-9000-1 

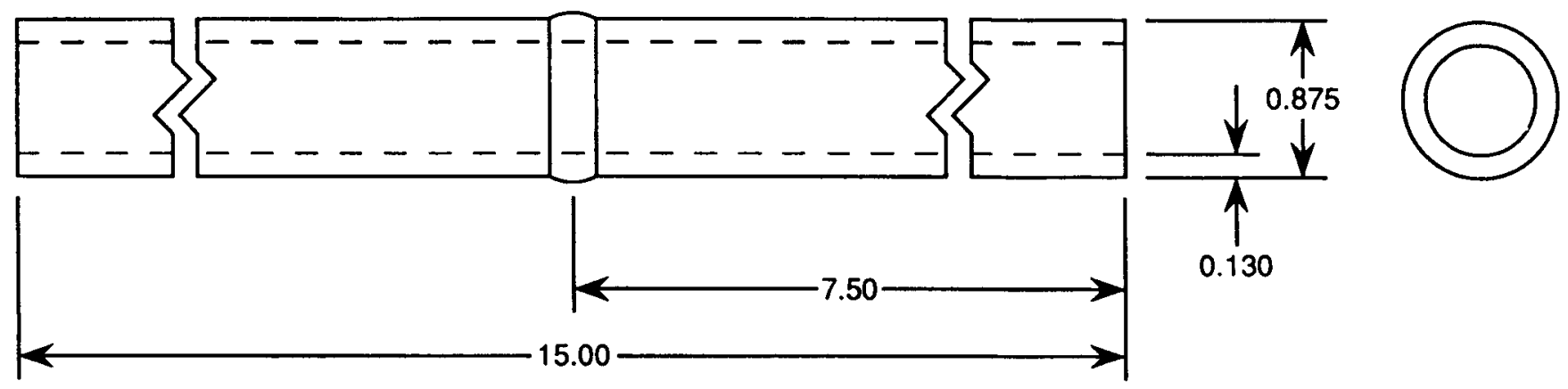

(a) Welded Composite Tube

$t$
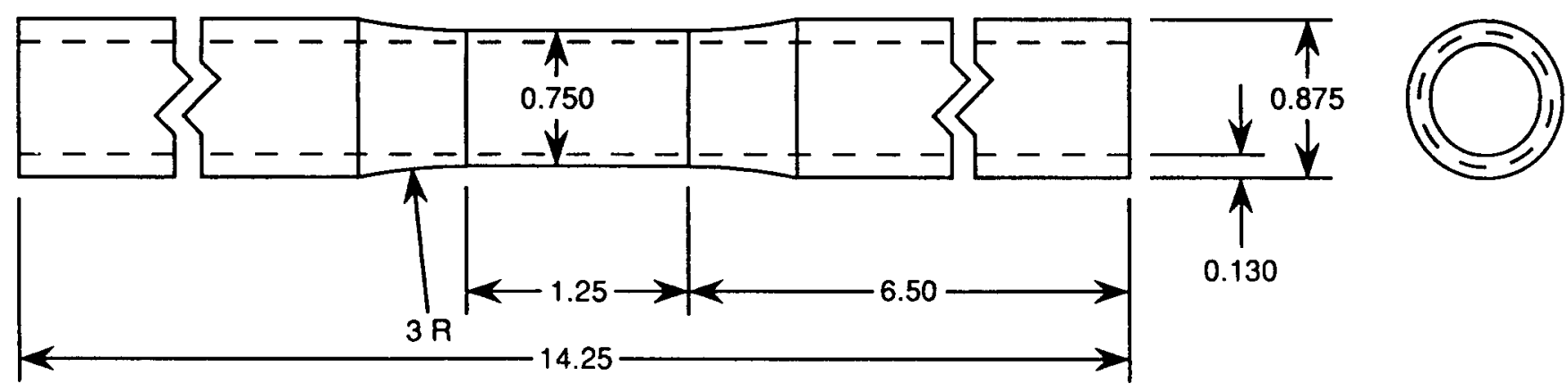

(b) Base Metal Specimen

Dimensions in Inches ( 1 in. $=25.4 \mathrm{~mm}$ )

Figure 4-25.

TEST SPECIMENS FABRICATED FROM PROTOTYPIC

STEAM-GENERATOR TUBING. 
- AWS ERNiCr-3 weld wire, 0.030 in. diam., heat No. FP-926

Welding specifications issued by ABB Combustion Engineering ${ }^{187}$ were used as guidance. Because of the small number of specimens, a manual rather than an automatic GTA technique was employed. Each weld was made in two passes. To reduce misalignment between the pieces of austenitic and ferritic tubing, each specimen was straightened after the root pass. It is assumed that residual stresses due to straightening were relieved in the final pass. Visual and liquid-penetrant inspections of each weld were performed after each pass. Radiographic inspection of each weld after the final pass indicated lack of penetration in the root pass of one weld.

Tests of the welded composite tubes were conducted under axial load control in an MTS axial-torsional testing machine with a digital control system and water-cooled, hydraulically operated collet grips. For a secure grip, the radial stiffness of each end of a specimen was increased by means of a solid internal plug. Cylinders of American Iron and Steel Institute (AISI) S7 tool steel, $57.50 \mathrm{~mm}$ (2.30 in.) long with a slight interference fit, were used for this purpose.

During each test, a uniform temperature of $482^{\circ} \mathrm{C}\left(900^{\circ} \mathrm{F}\right)$ was maintained for $25.4 \mathrm{~mm}$ (1.00 in.) above and below the weld by induction heating. Because of the differences in physical properties of the austenitic and ferritic tubing, two independent heating systems were used, one for each piece of tubing. Each heating system consisted of a helical induction coil with a diameter of $64 \mathrm{~mm}$ (2.5 in.), coaxial with the specimen; a control TC, spot welded to the outside surface of the specimen $12.7 \mathrm{~mm}(0.50 \mathrm{in}$.) from the weld; a radio-frequency power supply; and a temperature controller. Each water-cooled induction coil was formed from soft copper tubing with a nominal diameter of $5 \mathrm{~mm}(0.19 \mathrm{in}$.). The upper coil, consisting of four turns around the piece of austenitic tubing, was $44 \mathrm{~mm}$ (1.75 in.) long, and the lower coil, consisting of three turns around the piece of ferritic tubing, was $25 \mathrm{~mm}$ (1 in.) long.

Four sets of measuring TCs were spot welded to the outside surface of each welded specimen, two sets on each piece of tubing, one close to the weld, and the other $25.4 \mathrm{~mm}$ (1.00 in.) away from the weld. Each set consisted of three TCs spaced $120^{\circ}$ apart.

Two 25.4-mm (1.00-in.) MTS high-temperature extensometers were attached to the outside surface of each welded specimen, one on each piece of tubing, close to the weld, at $90^{\circ}$ to each other. Each was used to measure axial strain in half of the heated test section during each test.

Two sets of electrical resistance strain gages were bonded to the outside surface of each welded specimen, one set near each grip. These were used to determine the static bending stress 
at the weld due to gripping at room temperature prior to fatigue testing. The bending stress depends on the misalignment between the pieces of austenitic and ferritic tubing. Each set contained four axial gages spaced $90^{\circ}$ apart. For elastic values of strain, both orthogonal components of bending moment could be readily calculated at the location of each set of gages. Since these locations were equidistant from the weld, each component of bending moment at the weld was equal to the average of the corresponding components near the grips. The maximum bending stress at the weld was calculated from the resultant of the components.

Strain gage data were also recorded during the fatigue tests. Processing of these data, which was more difficult because higher stresses and temperatures preclude elastic calculation, has been deferred until additional resources become available. Since the adhesive used to bond the strain gages to the outside surface of the specimen had a temperature limit of $66^{\circ} \mathrm{C}\left(150^{\circ} \mathrm{F}\right)$, supplemental water cooling was necessary during the fatigue tests. For this purpose, a helical coil was formed by wrapping soft copper tubing, with a nominal diameter of $3 \mathrm{~mm}(0.13 \mathrm{in}$.), directly around the specimen near each set of gages, on the side closer to the weld. The upper coil had five closely spaced turns, and the lower coil had four. Each coil was secured to the specimen with a stainless steel hose clamp.

Techniques similar to the above were used to conduct supplementary tests of one austenitic and one ferritic base-metal specimen see [Figure 4-25(b)]. Two induction heaters were also used in each of these tests, providing two-zone temperature control; however, since each specimen was fabricated from a single piece of tubing, only one extensometer and no electrical resistance strain gages or surplemental cooling coils were used. Three sets of three measuring TCs were used in each test, one set at the center of the test section and the other sets $12.7 \mathrm{~mm}(0.50 \mathrm{in}$.) above and below the center.

\subsubsection{Test Results}

Listed in Table 4-9, in order of increasing number of cycles to failure, are principal results of the preliminary fatigue tests of bimetallic-weld specimens 1-6 and base-metal specimens 135 and 262.

For each BMW specimen, somewhat different values of static bending stress are listed for austenitic and ferritic tubing. Each was calculated from the same value of bending moment at the weld, using different values of ID and different values of OD. Similarly, different values of cyclic stress amplitude were calculated from the same value of axial load using different values of inside and outside diameters. In the footnotes to Table 4-9, the stress values are described as 


\section{Table 4-9}

PRINCIPAL RESULTS OF PRELIMINARY FATIGUE TESTS

\begin{tabular}{|c|c|c|c|c|c|c|c|c|c|}
\hline \multirow[t]{3}{*}{ Specimen } & \multicolumn{4}{|c|}{ Static bending stress ${ }^{\mathbf{a}}$} & \multicolumn{4}{|c|}{ Cyclic stress amplitude ${ }^{\mathrm{b}}$} & \multirow{3}{*}{$\begin{array}{l}\text { Cycles to } \\
\text { Failure }^{c}\end{array}$} \\
\hline & \multicolumn{2}{|c|}{ Austenitic } & \multicolumn{2}{|c|}{ Ferritic } & \multicolumn{2}{|c|}{ Austenitic } & \multicolumn{2}{|c|}{ Ferritic } & \\
\hline & $\mathrm{MPa}$ & ksi & $\mathrm{MPa}$ & ksi & $\mathrm{MPa}$ & ksi & $\mathrm{MPa}$ & ksi & \\
\hline $\begin{array}{l}4 \\
5 \\
2 \\
6 \\
3 \\
1\end{array}$ & $\begin{array}{r}91.6 \\
8.1 \\
21.0 \\
11.1 \\
4.1 \\
16.5\end{array}$ & $\begin{array}{r}13.29 \\
1.17 \\
3.05 \\
1.61 \\
0.59 \\
2.40\end{array}$ & $\begin{array}{r}90.3 \\
7.9 \\
20.6 \\
10.8 \\
4.0 \\
16.2\end{array}$ & $\begin{array}{r}13.09 \\
1.14 \\
2.99 \\
1.57 \\
0.58 \\
2.35\end{array}$ & $\begin{array}{l}322.8 \\
283.1 \\
260.3 \\
260.3 \\
227.5 \\
236.8\end{array}$ & $\begin{array}{l}46.82^{d} \\
41.06 \\
37.75^{d} \\
37.75^{d} \\
33.00^{d} \\
34.35\end{array}$ & $\begin{array}{l}315.6 \\
275.8 \\
253.5 \\
253.5 \\
221.7 \\
231.0\end{array}$ & $\begin{array}{l}45.77 \\
40.00^{d} \\
36.77 \\
36.77 \\
32.15 \\
33.50^{d}\end{array}$ & $\begin{array}{c}\mathrm{e} \\
4,242^{\mathrm{f}, \mathrm{g}} \\
10,365^{\mathrm{h}} \\
11,310^{\mathrm{i}} \\
19,340^{\mathrm{f}} \\
28,131^{\mathrm{f}, \mathrm{j}}\end{array}$ \\
\hline $\begin{array}{l}262 \\
135\end{array}$ & - & - & - & - & $\begin{array}{c}260.3 \\
-\end{array}$ & $\begin{array}{c}37.75^{\mathrm{d}} \\
-\end{array}$ & $\begin{array}{c}- \\
253.5\end{array}$ & $36.77^{d}$ & $\begin{array}{l}56,886^{k, 1} \\
182,741^{k}\end{array}$ \\
\hline
\end{tabular}

${ }^{a}$ Maximum nominal value at given weld interface due to gripping of misaligned specimen at room temperature prior to fatigue test.

${ }^{b}$ Nominal value in given piece of tubing during fatigue test at $482^{\circ} \mathrm{C}\left(900^{\circ} \mathrm{F}\right)$.

'Separation of specimen into two pieces.

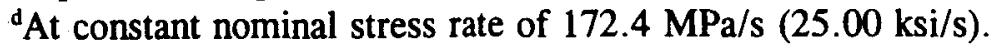

'Buckled in compression due to excessive misalignment between austenitic and ferritic tubing.

fSeparated at austenitic interface of weld.

${ }^{8}$ Initial twist of $10^{\circ}$ due to control malfunction.

hSeparated near lower end of cooling coil for upper strain gages.

iSeparated at ferritic interface and within weld with cracking at austenitic interface.

${ }^{j}$ Lack of penetration in root pass of weld.

'Base-metal specimen, separated at end of uniform test section.

'Temperature increase of $28^{\circ} \mathrm{C}\left(50^{\circ} \mathrm{F}\right)$ at upper end of test section for less than $13 \%$ of test due to control malfunction. 
nominal because geometrical and metallurgical nonuniformities in the vicinity of the weld were not taken into account. Similarly, for each base-metal specimen, the increase in stress at the ends of the uniform test section was not taken into account.

Specimens 1 and 5 were tested first, and for each the cyclic load amplitude was based on the stress in the ferritic tubing. Specimen 1 had a weld defect, and specimen 5 was given an initial twist due to a control malfunction. Neither shortcoming seems to have had a significant effect on the test result. Each of these specimens separated at the austenitic weld interface. In subsequent BMW tests, the cyclic load amplitude was therefore based on the stress in the austenitic tubing.

Specimen 4 buckled in compression after a few cycles, apparently due to excessive misalignment between austenitic and ferritic tubing, as indicated by the relatively high values of static bending stress. Specimen 2 separated in the austenitic tubing outside of the heated test section, near the lower end of the cooling coil for the upper set of strain gages. As a test of the weld, it is equivalent to a test lasting more than $10^{4}$ cycles and terminating prior to failure. Since the premature termination may have been due to thermal-gradient stresses, the cooling water was turned off well before the end of each subsequent test. Specimen 6, tested under the same cyclic stress as specimen 2 , lasted only $9 \%$ longer. Approximately half the separation in specimen 6 took place at the ferritic weld interface and half within the weld. However, there was also prominent secondary cracking along the austenitic weld interface. Specimen 3 separated at the austenitic weld interface after fewer cycles than specimen 1, tested at a higher cyclic stress.

Both base-metal specimens separated at one end of the uniform test section. As fabricated, the transition at each end of the test section was less gradual than called for in Figure 4-25(b). Furthermore, a control malfunction occurred at night, late in the test of the austenitic specimen, causing the temperature to increase by $28^{\circ} \mathrm{C}\left(50^{\circ} \mathrm{F}\right)$ at the end of the test section where separation took place.

\subsubsection{Discussion of Results}

For the BMW specimens in Table 4-9, the values of static bending stress at room temperature are not insignificant, especially for specimen 4 . However, the corresponding values would be less during the fatigue tests at $482^{\circ} \mathrm{C}\left(900^{\circ} \mathrm{F}\right)$, due to the effects of plastic cycling and the reduction in elastic moduli of the austenitic and ferritic tubing.

For the austenitic tubing, each value of cyclic stress amplitude in Table 4-9 is more than $186 \mathrm{MPa}(27.0 \mathrm{ksi})$, the estimated value of $0.2 \%$ offset yield strength at $482^{\circ} \mathrm{C}\left(900^{\circ} \mathrm{F}\right)$, obtained by multiplying the room-temperature value from the tubing vendor by the ratio of the value for 
the higher temperature in Table I-14.5 of ASME Code Case N-47 (ref. 183) to that for the lower temperature. For the ferritic tubing, each value of cyclic stress amplitude is less than the corresponding estimate of yield strength, $353 \mathrm{MPa}(51.1 \mathrm{ksi})$. Thus, considerably more plastic strain was to be expected in the austenitic tubing than in the ferritic tubing. It was because of differences in the expected behavior of the austenitic tubing, the ferritic tubing, and the weld metal that constant-amplitude cyclic load control was specified in CEGA-002009 (ref. 182).

The behavior of the austenitic tubing is illustrated in Figure 4-26, a plot of axial stress versus strain for the base-metal specimen during the initial loading and the next five complete stress cycles. Under constant-amplitude cyclic load control, a large initial strain is followed by cycles of decreasing strain amplitude. The stress amplitude and the elastic strain amplitude remain constant, and the plastic strain amplitude decreases due to cyclic hardening. In a more typical strain-controlled, low-cycle fatigue test, the mean strain is zero and the cyclic strain amplitude is constant. The stress amplitude and the elastic strain amplitude increase due to cyclic hardening, and the plastic strain amplitude decreases.

Stress amplitude versus cycles to failure is plotted on logarithmic coordinates in Figure 4-27. The symbols correspond to the results in Table 4-9 for the five BMW and two base-metal specimens that failed by fatigue. For the BMW specimens, the stress amplitude in the austenitic tubing is plotted. The result for specimen 2 , which did not fail at the weld, is included in the plot with an arrow pointing to the right.

The solid line and its dashed extrapolation in Figure 4-27 correspond to the model:

$$
\Delta \sigma / 2=A / N^{a}
$$

where $\Delta \sigma$ is stress range and $N$ is cycles to failure. Optimum values of the parameters, $A=$ 873.65 $\mathrm{MPa}(126.71 \mathrm{ksi})$ and $a=0.13153$, were obtained from a linear, least-squares fit to the $\log (N)$ vs $\log (\Delta \sigma / 2)$ results of the BMW fatigue tests. For this purpose, it seemed reasonable to assign to specimen 2 the same number of cycles to failure as specimen 6 .

The upper dashed line in Figure 4-27 corresponds to a simulation for small, solid-bar specimens of Alloy $800 \mathrm{H}$ tested under constant-amplitude cyclic load. The simulation is based on design values of strain range versus allowable cycles in Table T-1420-1C of ASME Code Case $\mathrm{N}-47$ (ref. 183). Design values of strain range for $482^{\circ} \mathrm{C}\left(900^{\circ} \mathrm{F}\right)$, obtained by taking the geometric mean of design values for 427 and $538^{\circ} \mathrm{C}\left(800\right.$ and $\left.1000^{\circ} \mathrm{F}\right)$, were transformed into 
ORNL-DWG 94-5593

$t$

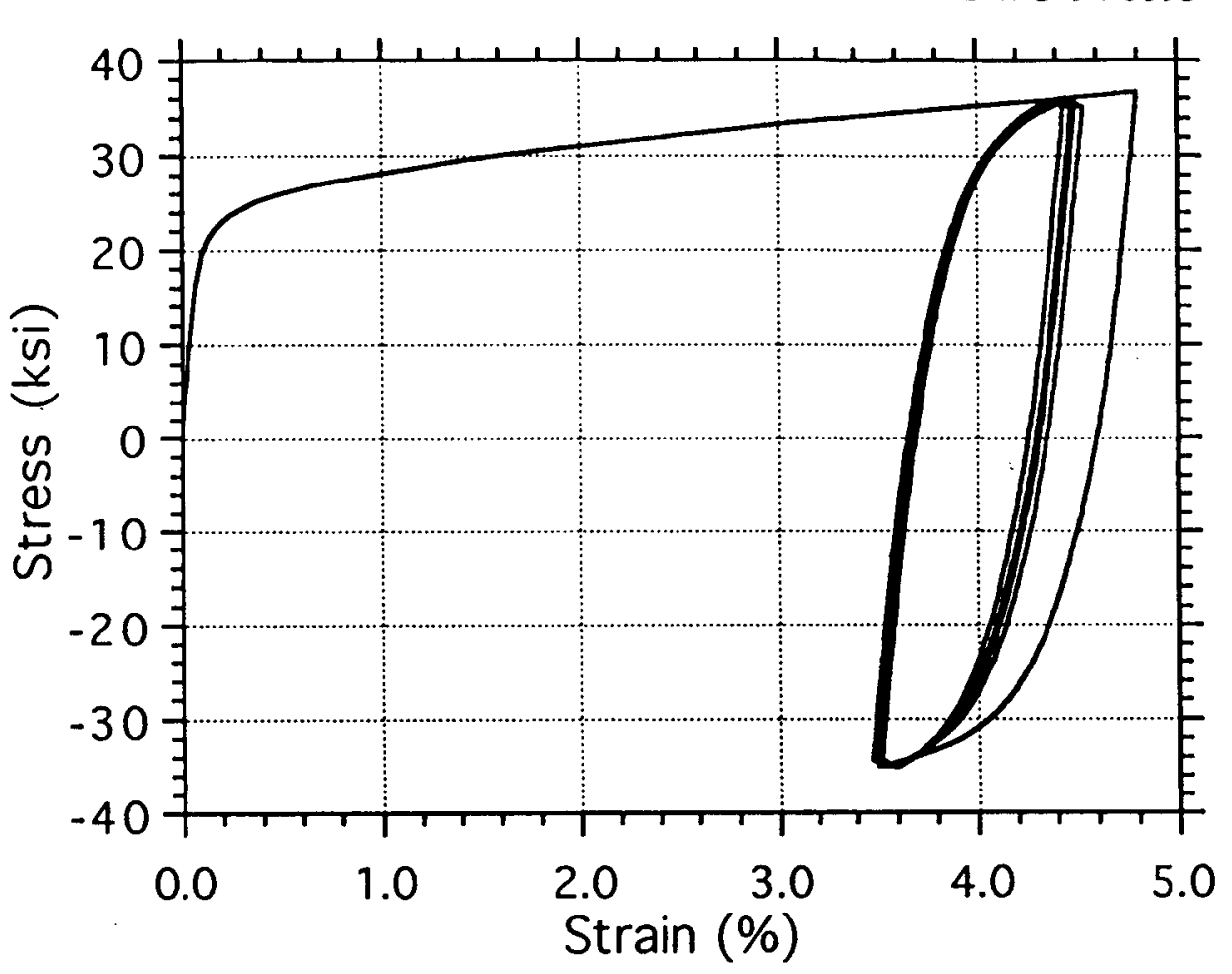

Figure 4-26.

AXIAL STRESS ( $1 \mathrm{KSI}=\mathbf{6 . 8 9 5} \mathrm{MPA})$ VS. AXIAL STRAIN FOR AUSTENITIC-TUBING SPECIMEN WITHOUT

WELD DURING INITIAL LOADING AND

NEXT FIVE COMPLETE STRESS

CYCLES AT $482^{\circ} \mathrm{C}$

$\left(900^{\circ} \mathrm{F}\right)$. 


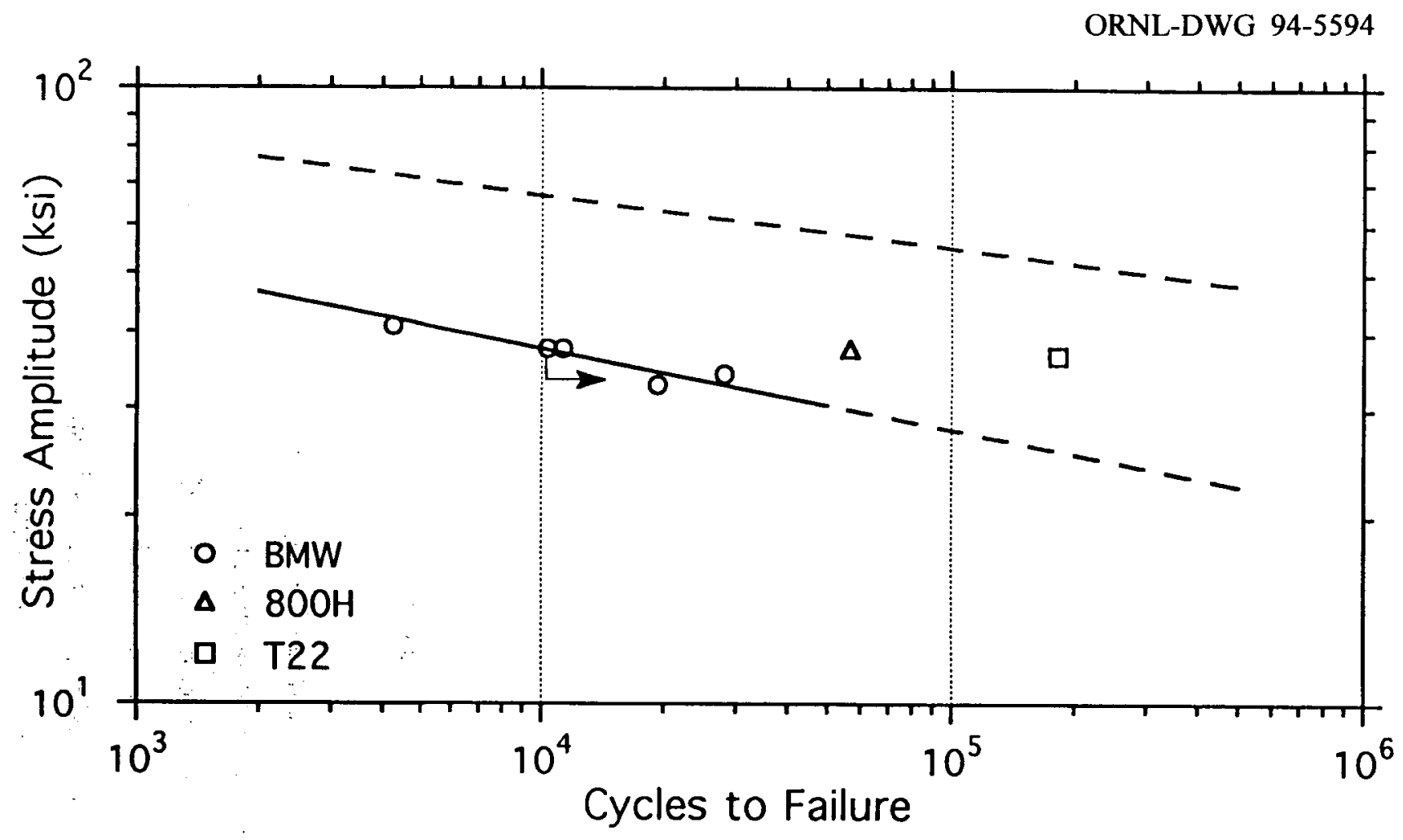

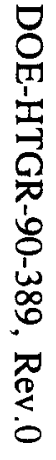

Figure 4-27.

STRESS AMPLITUDE ( $1 \mathrm{KSI}=6.895 \mathrm{MPA})$ VS. CYCLES TO FAILURE FOR FIVE BIMETALLIC-WELD AND TWO BASE-METAL SPECIMENS (SYMBOLS) AT $482^{\circ} \mathrm{C}\left(900^{\circ} \mathrm{F}\right)$. LOWER SOLID AND DASHED LINE CORRESPONDS TO BMW FATIGUE MODEL AND UPPER DASHED LINE TO FATIGUE MODEL FOR ALLOY $800 \mathrm{H}$. 
average values using a factor of 2 on strain or 20 on cycles. The average values of strain range were represented by the following model:

$$
\begin{gathered}
\Delta \varepsilon=\Delta \varepsilon_{e}+\Delta \varepsilon_{p} \\
\Delta \varepsilon_{e}=\Delta \sigma / E=B / N^{b} \\
\Delta \varepsilon_{p}=C / N^{c}
\end{gathered}
$$

where De is strain range, the subscripts $e$ and $p$ designate elastic and plastic components, respectively, and $E$ is the elastic modulus. Optimum values of the parameters, $B=1.1904 \%$, $b=0.085392, C=564.90 \%$ and $c=0.86892$, were obtained by iteration, minimizing the sum of squares of $\log \left[\Delta \varepsilon /\left(\mathrm{BN}^{-b}+\mathrm{CN}^{-c}\right)\right]$. The results are shown in Figure 4-28, where the symbols correspond to the transformed design values of strain range, the curved line corresponds to Eq. (4-2a), the straight line with the smaller slope corresponds to Eq. (4-2b), and the straight line with the larger slope corresponds to Eq. (4-2c).

Elimination of $N$ from Eqs. (4-2b) and (4-2c) results in the following relationship between strain range and stress range:

$$
\Delta \varepsilon=(\Delta \sigma / E)+C(\Delta \sigma / B E) c / b
$$

Cyclic stress amplitude is plotted versus cyclic strain amplitude in Figure 4-29. The curve was generated from Eq. (4-3), with $E=171 \mathrm{GPa}(24,800 \mathrm{ksi})$ from Table I-14.7 of ASME Code Case N-47 (ref. 183). Significant cyclic hardening is evident in the figure, compared to the initial cycles in Figure 4-26.

In the single test of a tubular specimen of Alloy $800 \mathrm{H}$ without a weld, the stress amplitude was a factor of 1.54 less than that of the fatigue model for Alloy $800 \mathrm{H}$ [Eq. (4-2b)], for the same number of cycles. Analogous factors on strain range of about 1.5 were found for tubular specimens of 316 stainless steel ${ }^{189}$ and modified $9 \mathrm{Cr}-1$ Mo steel ${ }^{190}$ without welds. This apparent reduction in fatigue strength, attributable to differences in specimen size and geometry, is comparable to the reduction due to effects of the weld. 


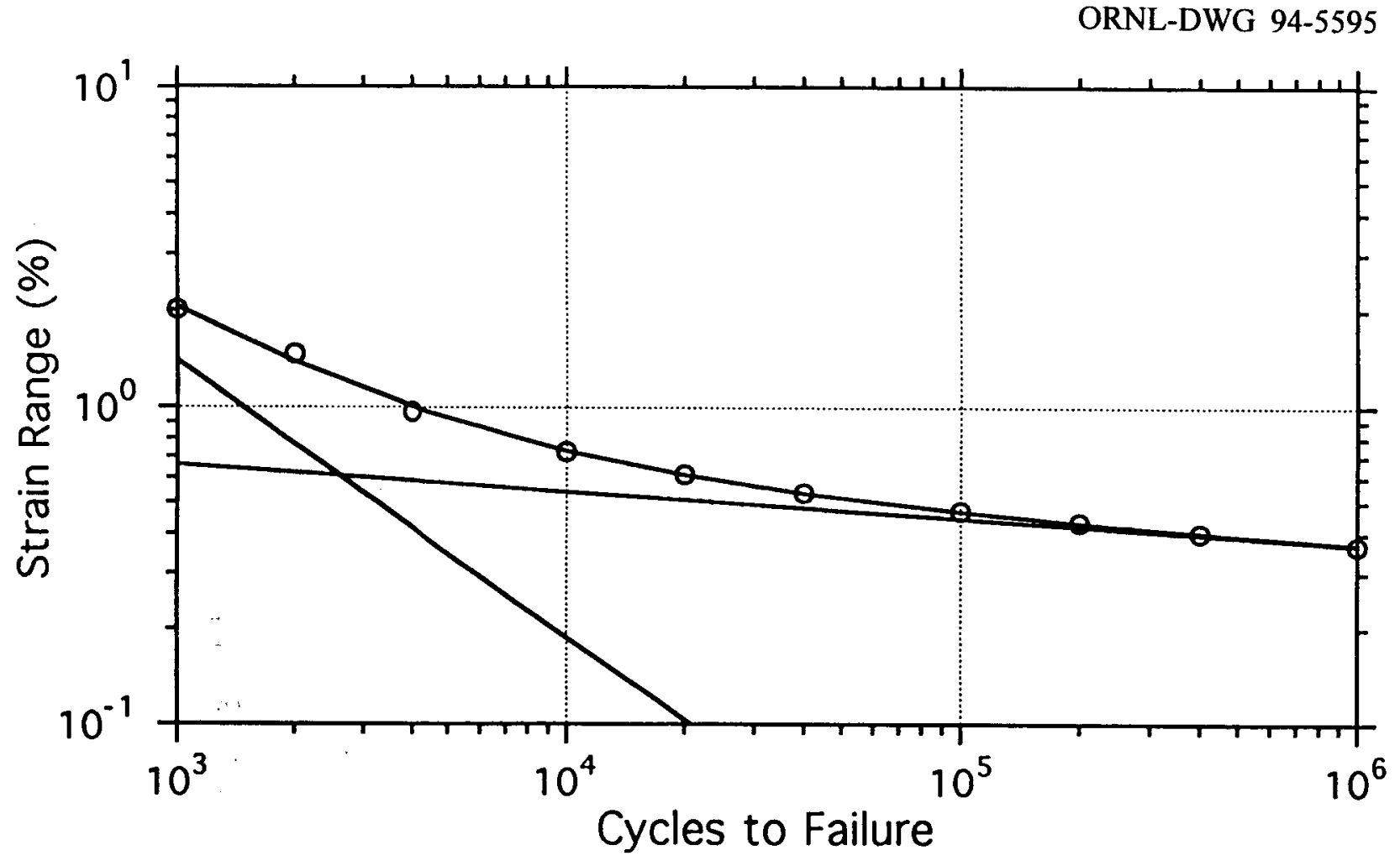

Figure 4-28.

AVERAGE VALUES OF STRAIN RANGE (SYMBOLS) VS. CYCLES TO FAILURE FOR ALLOY $800 \mathrm{H}$ AT $482^{\circ} \mathrm{C}\left(900^{\circ} \mathrm{F}\right)$. LINES CORRESPOND TO FATIGUE MODELS FOR ELASTIC, PLASTIC AND TOTAL STRAIN. 
ORNL-DWG 94-5596

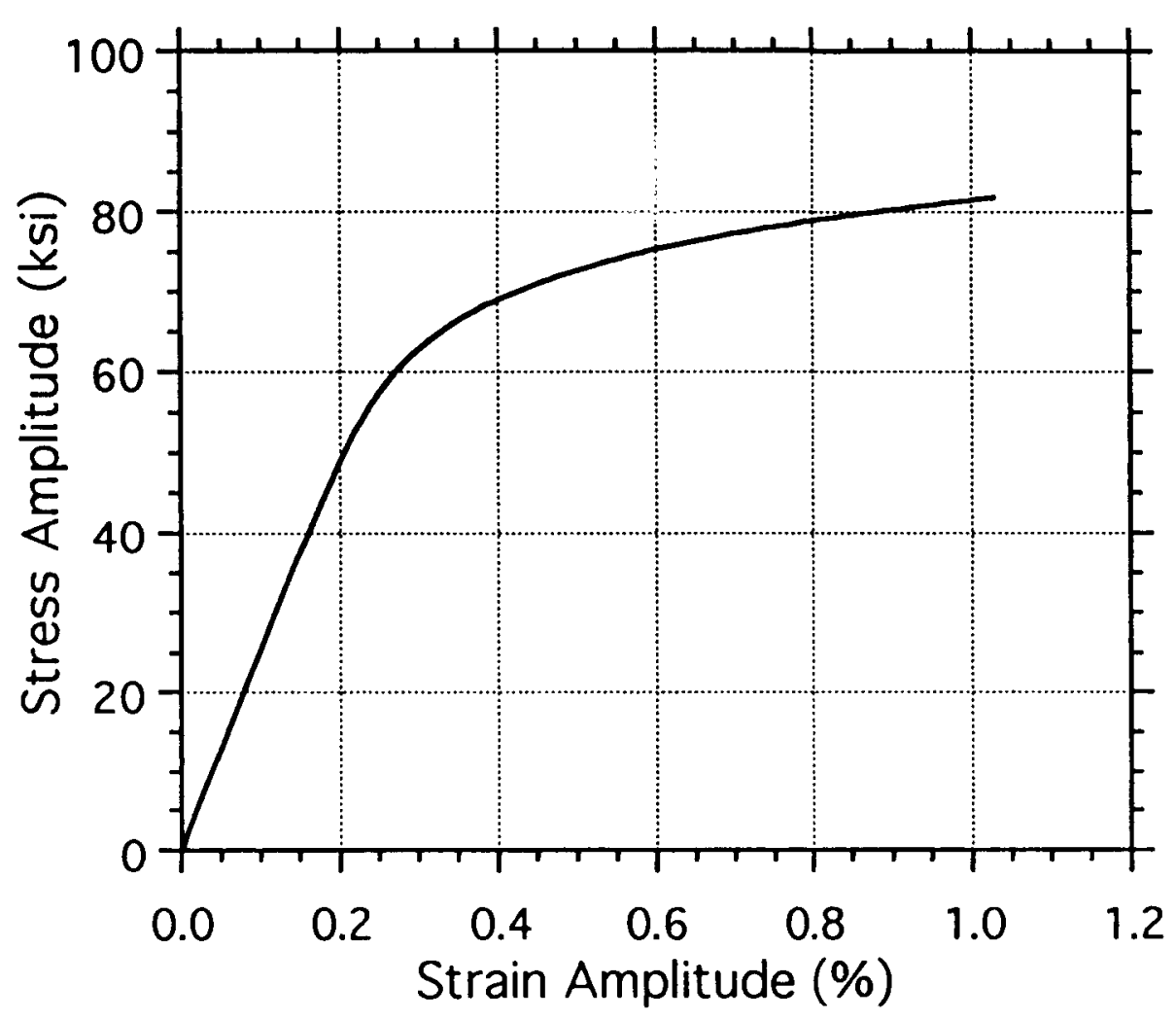

Figure 4-29.

CYCLIC STRESS AMPLITUDE $(1 \mathrm{KSI}=6.895 \mathrm{MPA})$ VS. CYCLIC STRAIN AMPLITUDE CORRESPONDING TO FATIGUE MODEL FOR ALLOY $800 \mathrm{H}$. 


\subsubsection{Conclusions and Recommendations}

The results of the preliminary axial fatigue tests have established the effectiveness of the planned testing techniques, including the methods of heating, gripping, and applying axial load to BMW and base-metal specimens fabricated from prototypic steam-generator (SG) tubing.

For the BMW specimen, the geometrical and metallurgical nonuniformities in the vicinity of the weld and the elevated temperature of the test section were sufficient to preclude failure at one of the grips. The requirement that misalignment between the pieces of austenitic and ferritic tubing be reduced to a practical minimum was confirmed. Additional effort is recommended to satisfy this requirement for welds made with an automatic GTA technique.

For the base-metal specimen, the reduced OD and the elevated temperature of the test section were sufficient to preclude failure at one of the grips. Use of a single induction heater is recommended in future tests of this specimen to obtain a slightly higher temperature at the center of the test section than at the ends. This has been sufficient in other tests ${ }^{189,190}$ to prevent failure at one end of the test section.

The fatigue model [Eq. (4-1)] based on the results of the preliminary BMW tests is considered very useful for effective planning of future tests. A more comprehensive model, based on the results of tests specified in CEGA-002009, is recommended for use in design.

\subsection{HEAT TRANSPORT SYSTEM - D. F. Wilson and G. E. C. Bell"}

\subsubsection{Steam-Side Corrosion}

\subsubsection{Introduction}

The objectives of this test program are to investigate water-side corrosion damage mechanisms of SG tubing materials and weldments (including BMWs) and to complement, support, and confirm results of the model boiler test [CEGA Corporation, "Test Specification for Secondary Side Corrosion Tests for NP-MHTGR Steam Generator," CEGA-002251, Rev. N/X, January 1993], which was to have been conducted at ABB-CE in Chattanooga, Tennessee.

\footnotetext{
${ }^{*}$ M. J. Schiff \& Associates, 1291 N. Indian Hill Blvd., Claremont, CA 91711-3897.
} 


\subsubsection{Procedures}

This test program addresses, in part, the DDNs identified in DDN No. 13.40, "Assess Secondary Side Corrosion Characteristics of Bimetallic Weld and Alloy 800 Base Metal and Weldments." These state that data are needed to assess the secondary side corrosion resistance of the BMW and the Alloy $800 \mathrm{H}$ base metal and weldments under long-term exposure to the feedwater specified for the MHTGR SG. Included within the work scope is the task "perform autoclave and/or isothermal capsule test on material and weldment samples."

The corrosion resistance of the SG materials is required in order to properly set the chemistry control requirements for the NP-MHTGR plant feedwater system. These requirements must be set so that there is an adequate margin at all times against known forms of corrosion damage. This requires that the possible damage mechanisms be known and quantified in terms of temperature, durations, and impurities causing the damage. The NP-MHTGR SG feedwater chemistry requirements are shown in Table 4-10. The greatest threats to the materials in the SG are (1) concentrations of impurities under boilout conditions and (2) during startup/shutdown or other conditions when secondary side feedwater (SSF) chemistry transients occur as the BMW and Alloy $800 \mathrm{H}$ are wetted. The test described herein will measure, with a statistically designed testing approach using mechanically loaded specimens in high-temperature water/steam environments, the SSF conditions under which stress-corrosion cracking (SCC) and other corrosion damage mechanisms [pitting, intergranular corrosion attack (IGCA), etc.] occur in these materials.

This work will quantify the sensitivity of Alloy $800 \mathrm{H}$ base materials and weldments, and BMWs of Alloy $800 \mathrm{H}$ to $2.25 \mathrm{Cr}-1 \mathrm{Mo}$ (T-22) steel, to corrosion damage due to the SSF in the NP-MHTGR SG. Alloy $800 \mathrm{H}$ base metals and its weldments are used in the FSH tubes of the SG. The EES is made from 2.25 Cr-1 Mo steel. The BMW forms the transition between the ferritic EES and the austenitic FSH materials.

Slow strain rate tensile (SSRT) tests in autoclaves with recirculating water will be employed to provide the maximum information in the limited amount of time available for testing. Tests will be performed on materials in both the as-received and the heat-treated (aged) conditions, and from weldments fabricated under conditions as close as possible to those anticipated for the NPMHTGR SG. Recirculating water, approximating the NP-MHTGR feedwater normal water chemistry (NWC) and expected off-normal water chemistry (ONWC), will be used during testing. 
Table 4-10

NP-MHTGR STEAM GENERATOR FEEDWATER CHEMISTRY REQUIREMENTS. MAXIMUM VALUES ${ }^{(a)}$ ATHE ECONOMIZER INLET.

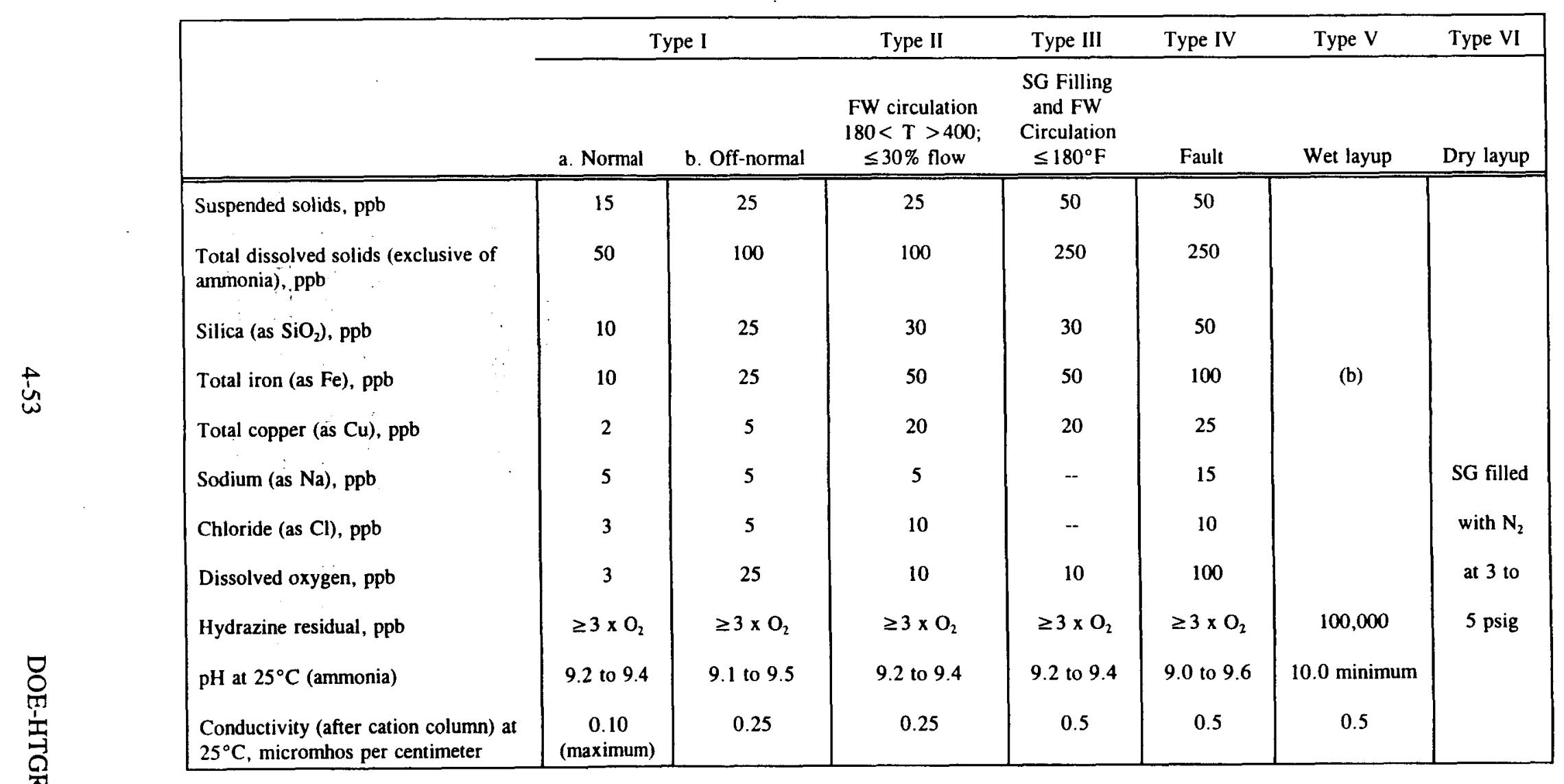

(a) Hydrazine residuals and $\mathrm{pH}$ should be as specified.

${ }^{(b)}$ SG initially filled with feedwater Type la chemistry. 


\subsubsection{Status}

\subsection{Systems}

A continuous recirculating water SSRT test facility was designed and is being implemented. The tensile test systems allow for strain rates in the range of $10^{-6}$ to $10^{-8} \mathrm{~s}^{-1}$.

The autoclaves, which have been used in the past for SSRT testing, are made of hastalloy and are capable of operating up to $4500 \mathrm{psi}$. These systems are fully instrumented and allow for control of temperature and strain rate, as well as continuous recording of strain, load, test temperature, and pressure. In its present configuration, the water is recirculated around the outside of the test specimen. While this arrangement does not exactly mimic the model boiler test system, this simpler test configuration was chosen to allow for completion of testing by the closeout date.

The recirculating water system is being supplied by CORTEST. This system, less the hastalloy pumps, has been received and connected to the autoclave for performance evaluation. This recirculating water system consists of two 12-gal water reservoirs, associated high-pressure valves, flow and pressure sensors, and preheaters. The systems can operate up to 3500 psi. This system can be operated so that two independent water chemistries are maintained through two different autocalves, or that the same chemistry is maintained through the two autoclaves.

Between the recirculating water system and the autoclaves are water purification, chemisty control, pH, conductivity, and oxygen content subsystems. These subsystems are located between the water return from the autoclaves and the return input to the storage tanks. The water purification systems consist of a prefilter, mixed beds for the removal of cationic and anionic impurities, and a carbon removal filter.

Water chemistry is monitored in the effluent return lines between the purification system and input to the storage tanks. The equipment used for this purpose is listed in Table 4-11.

\subsection{Specimens}

Tubing materials received from ABB-CE (Chattanooga) were used in the manufacture of 36 test specimens to allow for comparison of results of the model boiler test. The tubular $800 \mathrm{H}$ material, SB-163 Alloy 800, conforms to ABB-CENP Materials Specification 93789-CE-MS-017 [CEGA Corporation, NP-MHTGR QA Categorization Report, CEGA -000051, Rev. 3]. 
Table 4-11

CORROSION LOOP WATER CHEMISTRY MONITORS

\begin{tabular}{|c|c|c|c|c|c|}
\hline Quantity & Monitor & Vendor & Model & Range & $\begin{array}{c}\text { Accuracy/ } \\
\text { Precision }\end{array}$ \\
\hline \hline 2 & $\mathrm{pH}$ & Omega & PHCN-30 & 0 to 14 & \pm 0.01 \\
2 & Conductivity & Omega & CDCN-002 & 0 to $500 \mu \mathrm{S} / \mathrm{cm}$ & $\pm 2 \%$ \\
2 & Oxygen & Omega & PHDG-70 & 0 to $19.9 \mathrm{mg} / 1$ & $\pm 2 \%$ \\
\hline
\end{tabular}

Weldments were made in accordance with ABB-CENP General Requirements for Welding 93789CE-GR-003 and -004 [ABB-CENP, SB-409 Alloy UNS N08810 Alloy (800H) Nickel-IronChromium Alloy Plate for NP-MHTGR Steam Generator, 93789-CE-MS-002, Rev. 00, October 1991] with modifications and techniques documented. The geometry of the test specimen is shown in Figure 4-30. This is not a standard design specimen but allows for the results of this testing to be compared to those of the model boiler test.

The identities of all materials were maintained throughout the fabrication of the specimens. Three materials/configurations specimens were manufactured. These are $800 \mathrm{H}, 800 \mathrm{H}$ welded to $800 \mathrm{H}$, and $800 \mathrm{H}$ welded to $2.25 \mathrm{Cr}-1 \mathrm{Mo}$. Bar stock material, similar to the end to which it was to be welded, was welded to the ends of the specimens. All weldments were made in argon and inspected using dye penetrant and $\mathrm{x}$ rays. The guage length of and threads at the end of the specimens were machined so as to maintain alignment.

Aging of the test specimens shall be performed at $540^{\circ} \mathrm{C}$ for $100 \mathrm{~h}$ in evacuated quartz capsules. This short aging time was chosen so that all experimental work might be completed by closeout.

\subsection{Test Matrix}

Three materials/configurations will be subjected to strain testing at low and high levels of six environmental factors. Resources can only allow a total of 24 experimental runs. The strain to breakage for the metal/configuration specimens and the observed failure microstructure will be 


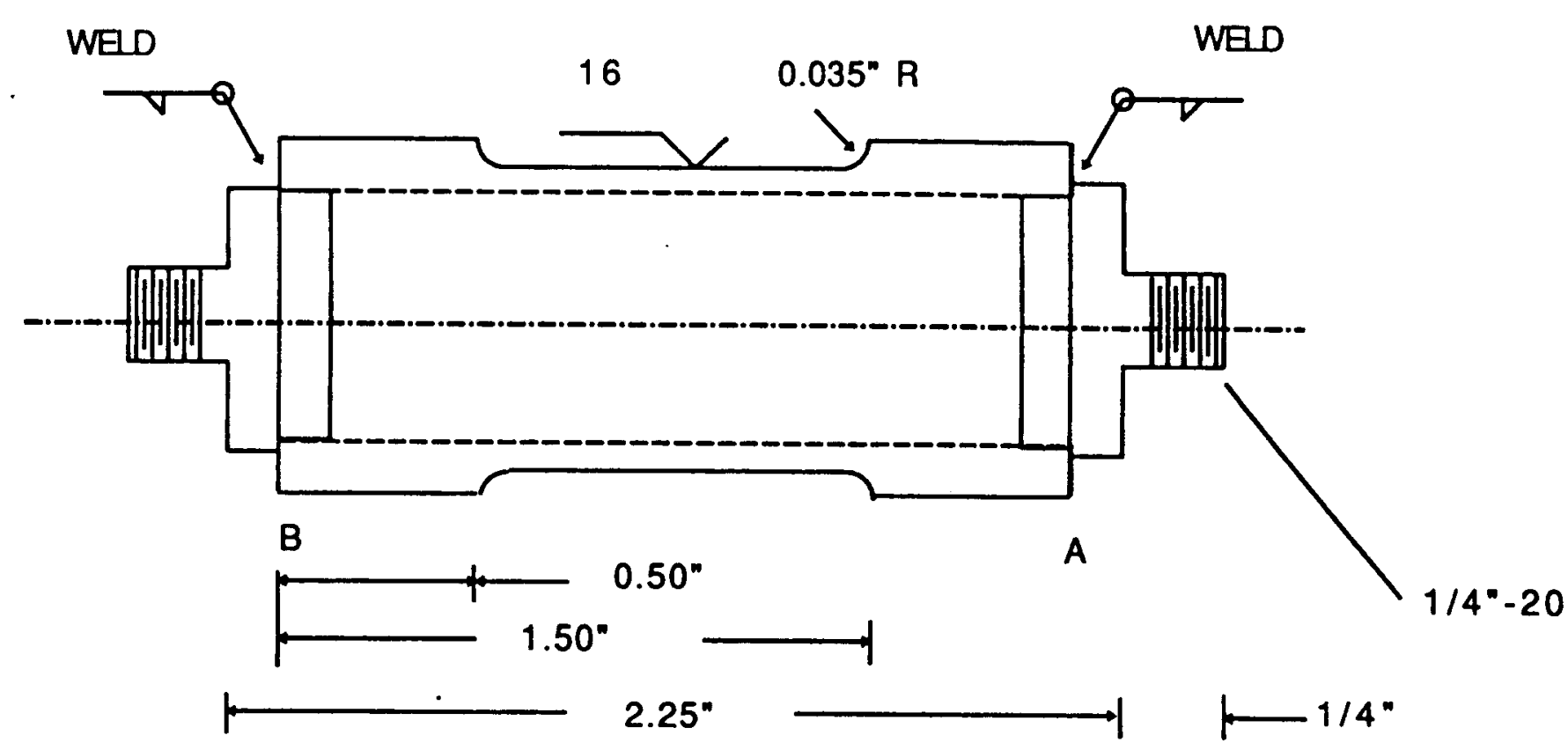

Figure 4-30.

GEOMETRY OF TEST SPECIMENS. 
used to measure the effects of a range of environmental facors. For the purposes of the test matrix, the following are designated:

1. The three materials/configurations for the metal tubes are:

tube 1: $800 \mathrm{H}$

tube 2: $800 \mathrm{H} /$ weld (tungsten $\operatorname{arc}$ ) $/ 800 \mathrm{H}$

tube 3: $800 \mathrm{H} /$ weld/T22

2. The six environmental factors are:
Environmental factors
Low level
High level
$\mathrm{T}: \quad$ temperature $\left({ }^{\circ} \mathrm{F}\right)$
180
400
A: aging $\left(400^{\circ} \mathrm{C} / 6 \mathrm{~h} / \mathrm{H}_{2} \mathrm{O}\right.$ quenched)
aged
as received
C: total conductivity ( $\mu \mathrm{mhos} / \mathrm{cm}$ )
0.1
0.5
$\mathrm{O}^{a}:$ dissolved oxygen (ppb)
3
200
$\mathrm{pH}: \mathrm{pH}\left(\right.$ at $\left.25^{\circ} \mathrm{C}\right)$
9.0
9.6
$\mathrm{S}_{0}^{-1}: \quad$ initial strain rate $\left(\mathrm{S}^{-1}\right)$
$10^{-8}$
$10^{-6}$

${ }^{a}$ Hydrazine (10 to $600 \mathrm{ppb}$ ) will be used to control dissolved oxygen. Increasing the hydrazine concentration decreases the dissolved oxygen concentration.

A $2^{6-3}$ fractional factorial design was constructed for each type of metal/configuration tube. The fractional factorials will allow the main effect of each environmental factor to be estimated:

$\begin{array}{rrrrrrrr}\text { No. } & \text { Metal tube } & \underline{\mathrm{T}} & \underline{\mathrm{A}} & \underline{\mathrm{C}} & \underline{\mathrm{O}} & \underline{\mathrm{pH}} & \underline{\mathrm{S}}_{0}^{-1} \\ 1 & \text { Tube } 1 & 180 & \text { Aged } & 0.1 & 200 & 9.0 & 10^{-8} \\ 2 & \text { Tube } 1 & 180 & \text { Received } & 0.5 & 3 & 9.0 & 10^{-8} \\ 3 & \text { Tube } 1 & 400 & \text { Aged } & 0.5 & 3 & 9.0 & 10^{-6} \\ 4 & \text { Tube 1 } & 400 & \text { Received } & 0.1 & 200 & 9.0 & 10^{-6} \\ 5 & \text { Tube 1 } & 400 & \text { Received } & 0.1 & 3 & 9.6 & 10^{-8} \\ 6 & \text { Tube 1 } & 400 & \text { Aged } & 0.5 & 200 & 9.6 & 10^{-8} \\ 7 & \text { Tube 1 } & 180 & \text { Received } & 0.5 & 200 & 9.6 & 10^{-6} \\ 8 & \text { Tube 1 } & 180 & \text { Aged } & 0.1 & 3 & 9.6 & 10^{-6} \\ 9 & \text { Tube 2 } & 400 & \text { Received } & 0.5 & 200 & 9.0 & 10^{-6}\end{array}$




$\begin{array}{lrrrrrrr}\text { No. } & \text { Metal tube } & \underline{\mathrm{T}} & \underline{\mathrm{A}} & \underline{\mathrm{C}} & \underline{\mathrm{O}} & \underline{\mathrm{HH}} & \underline{\mathrm{S}_{0}^{-1}} \\ 10 & \text { Tube } 2 & 400 & \text { Aged } & 0.1 & 3 & 9.0 & 10^{-6} \\ 11 & \text { Tube } 2 & 180 & \text { Received } & 0.1 & 3 & 9.0 & 10^{-8} \\ 12 & \text { Tube } 2 & 180 & \text { Aged } & 0.5 & 200 & 9.0 & 10^{-8} \\ 13 & \text { Tube 2 } & 180 & \text { Aged } & 0.5 & 3 & 9.6 & 10^{-6} \\ 14 & \text { Tube 2 } & 180 & \text { Received } & 0.1 & 200 & 9.6 & 10^{-6} \\ 15 & \text { Tube 2 } & 400 & \text { Aged } & 0.1 & 200 & 9.6 & 10^{-8} \\ 16 & \text { Tube 2 } & 400 & \text { Received } & 0.5 & 3 & 9.6 & 10^{-8} \\ 17 & \text { Tube 3 } & 400 & \text { Received } & 0.5 & 200 & 9.6 & 10^{-8} \\ 18 & \text { Tube 3 } & 400 & \text { Aged } & 0.1 & 3 & 9.6 & 10^{-8} \\ 19 & \text { Tube 3 } & 180 & \text { Received } & 0.1 & 3 & 9.6 & 10^{-6} \\ 20 & \text { Tube 3 } & 180 & \text { Aged } & 0.5 & 200 & 9.6 & 10^{-6} \\ 21 & \text { Tube 3 } & 180 & \text { Aged } & 0.5 & 3 & 9.0 & 10^{-8} \\ 22 & \text { Tube 3 } & 180 & \text { Received } & 0.1 & 200 & 9.0 & 10^{-8} \\ 23 & \text { Tube 3 } & 400 & \text { Aged } & 0.1 & 200 & 9.0 & 10^{-6} \\ 24 & \text { Tube 3 } & 400 & \text { Received } & 0.5 & 3 & 9.0 & 10^{-6}\end{array}$

For each metal tube, a first-order prediction model can be estimated by the method of least squares. This approximating model is:

$$
\text { Strain }=B_{0}+B_{1} T+B_{2} A+B_{3} C+B_{4} O+B_{5} p H+B_{6} S_{0}^{-1},
$$

where the unknown coefficients "B" are indexed 1 through 6 for the six environmental factors. The coefficients for two-factor interactions would be indexed by two numbers corresponding to the two factors. For example, the coefficient for the two-factor interaction between temperature (T) and aging (A) would be indexed by $12\left(\mathrm{~B}_{12}\right)$. Coefficients for two-factor and higher order interactions can not be estimated from the $2^{6-3}$ fractional factorial designs. The two-factor and higher order interactions are aliased or confounded with the main effect coefficients:

1. Fifteen degrees of freedom for estimating the experimental error variance are available from the complete experiment. This analysis assumes that the experimental error is constant for each type of metal tubing. The analysis of the individual fractional factorials should indicate if this assumption is correct. 
2. All main-effect coefficients in the individual fractional factorial designs are confounded with 2 two-factor interactions and higher order interactions. If lower case "bs" are estimates of the coefficients, the expected values of the estimated coefficients are as follows, assuming three-factor and higher order interactions are negligible:

Tube 1:

$$
\begin{array}{ll}
\mathrm{E}\left(\mathrm{b}_{1}\right)=\mathrm{B}_{1}-\mathrm{B}_{23}-\mathrm{B}_{56} & \mathrm{E}\left(\mathrm{b}_{4}\right)=\mathrm{B}_{4}+\mathrm{B}_{35}+\mathrm{B}_{26} \\
\mathrm{E}\left(\mathrm{b}_{2}\right)=\mathrm{B}_{2}-\mathrm{B}_{13}+\mathrm{B}_{46} & \mathrm{E}\left(\mathrm{b}_{5}\right)=\mathrm{B}_{5}+\mathrm{B}_{34}-\mathrm{B}_{16} \\
\mathrm{E}\left(\mathrm{b}_{3}\right)=\mathrm{B}_{3}-\mathrm{B}_{12}+\mathrm{B}_{45} & \mathrm{E}\left(\mathrm{b}_{6}\right)=\mathrm{B}_{6}+\mathrm{B}_{24}-\mathrm{B}_{15}
\end{array}
$$

Tube 2:

$$
\begin{array}{ll}
\mathrm{E}\left(\mathrm{b}_{1}\right)=\mathrm{B}_{1}+\mathrm{B}_{23}-\mathrm{B}_{56} & \mathrm{E}\left(\mathrm{b}_{4}\right)=\mathrm{B}_{4}-\mathrm{B}_{35}+\mathrm{B}_{26} \\
\mathrm{E}\left(\mathrm{b}_{2}\right)=\mathrm{B}_{2}+\mathrm{B}_{13}+\mathrm{B}_{46} & \mathrm{E}\left(\mathrm{b}_{5}\right)=\mathrm{B}_{5}-\mathrm{B}_{34}-\mathrm{B}_{16} \\
\mathrm{E}\left(\mathrm{b}_{3}\right)=\mathrm{B}_{3}+\mathrm{B}_{12}-\mathrm{B}_{45} & \mathrm{E}\left(\mathrm{b}_{6}\right)=\mathrm{B}_{6}+\mathrm{B}_{24}-\mathrm{B}_{15}
\end{array}
$$

Table 3:

$$
\begin{array}{ll}
E\left(b_{1}\right)=B_{1}+B_{23}-B_{56} & E\left(b_{4}\right)=B_{4}+B_{35}-B_{26} \\
E\left(b_{2}\right)=B_{2}+B_{13}+B_{46} & E\left(b_{5}\right)=B_{5}+B_{34}-B_{16} \\
E\left(b_{3}\right)=B_{3}+B_{12}+B_{45} & E\left(b_{6}\right)=B_{6}-B_{24}-B_{15}
\end{array}
$$

Combining estimates from the different fractional factorial designs can give estimates for some of the coefficients for two-factor interactions.

Example: Subtract the estimate for $B_{1}$ for Tube 1 from the estimate of $B_{1}$ for Tube 2:

$$
\begin{gathered}
{\left[E\left(b_{1}\right)\right]_{\text {Tube 2 }}\left[E\left(b_{1}\right)\right]_{\text {Tube 1 }}=\left(B_{1}+B_{23}-B_{56}\right)-\left(B_{1}-B_{23}-B_{56}\right)} \\
{\left[E\left(b_{1}\right)\right]_{\text {Tube 2 }}-\left[E\left(b_{1}\right)\right]_{\text {Tube 1 }}=2 B_{23} .}
\end{gathered}
$$

Factional factorial designs provide a great deal of information for a minimum number of test runs. It is important that each experimental run be completed to ensure that all estimates of the main effect coefficients can be calculated: There is little information from the experiment to calculate experimental error. To evenly spread the experimental error over all experimental runs, the test runs should be made in random order. Table 4-12 gives a random ordering of the test runs. 
Table 4-12

RANDOMIZED RUN ORDER FOR THE THREE-FRACTIONAL FACTORIAL DESIGN

\begin{tabular}{|c|c|c|c|c|c|c|c|}
\hline $\begin{array}{l}\text { Run } \\
\text { order }\end{array}$ & $\begin{array}{l}\text { Metal } \\
\text { tube }\end{array}$ & $\begin{array}{l}\text { Temp } \\
\left({ }^{\circ} \mathrm{F}\right)\end{array}$ & Aging & $\begin{array}{l}\text { Conductivity } \\
(\mu \mathrm{mhos} / \mathrm{cm})\end{array}$ & $\begin{array}{c}\text { Oxygen } \\
\text { (ppb) }\end{array}$ & $\mathrm{pH}$ & $\mathrm{S}_{2}^{-1}$ \\
\hline 1 & Tube 3 & 180 & Aged & 0.5 & 3 & 9.0 & 10.8 \\
\hline 2 & Tube 1 & 400 & Aged & 0.5 & 3 & 9.0 & $10-6$ \\
\hline 3 & Tube 2 & 400 & Received & 0.5 & 3 & 9.6 & $10-8$ \\
\hline 4 & Tube 2 & 400 & Aged & 0.1 & 3 & 9.0 & $10-6$ \\
\hline 5 & Tube 1 & 400 & Received & 0.1 & 200 & 9.0 & $10-6$ \\
\hline 6 & Tube 1 & 180 & Received & 0.5 & 200 & 9.6 & $10-6$ \\
\hline 7 & Tube 2 & 180 & Received & 0.1 & 200 & 9.6 & $10-6$ \\
\hline 8 & Tube 1 & 180 & Aged & 0.1 & 200 & 9.0 & $10-8$ \\
\hline 9 & Tube 2 & 180 & Aged & 0.5 & 3 & 9.6 & $10-6$ \\
\hline 10 & Tube 3 & 180 & Received & 0.1 & 3 & 9.6 & $10-6$ \\
\hline 11 & Tube 3 & 400 & Aged & 0.1 & 200 & 9.0 & $10-6$ \\
\hline 12 & Tube 2 & 400 & Aged & 0.1 & 200 & 9.6 & $10-8$ \\
\hline 13 & Tube 1 & 180 & Received & 0.5 & 3 & 9.0 & $10-8$ \\
\hline 14 & Tube 2 & 400 & Received & 0.5 & 200 & 9.0 & $10-6$ \\
\hline 15 & Tube 2 & 180 & Received & 0.1 & 3 & 9.0 & $10-8$ \\
\hline 16 & Tube 3 & 400 & Received & 0.5 & 200 & 9.6 & $10-8$ \\
\hline 17 & Tube 1 & 400 & Aged & 0.5 & 200 & 9.6 & $10-8$ \\
\hline 18 & Tube 3 & 400 & Aged & 0.1 & 3 & 9.6 & $10-$ \\
\hline 19 & Tube 3 & 180 & Received & 0.1 & 200 & 9.0 & 10.8 \\
\hline 20 & Tube 2 & 180 & Aged & 0.5 & 200 & 9.0 & $10-8$ \\
\hline 21 & Tube 3 & 180 & Aged & 0.5 & 200 & 9.6 & $10-6$ \\
\hline 22 & Tube 1 & 180 & Aged & 0.1 & 3 & 9.6 & $10-6$ \\
\hline 23 & Tube 1 & 400 & Received & 0.1 & 3 & 9.6 & $10-8$ \\
\hline 24 & Tube 3 & 400 & Received & 0.5 & 3 & 9.0 & $10-6$ \\
\hline
\end{tabular}




\subsubsection{Fort St. Vrain Ringheader Evaluation - G.E.C. Bell' and F. Wilson}

\subsubsection{Introduction}

The SGs of the Fort St. Vrain plant represent the most relevant and available source of design, fabrication, and operating experience data for application to the NP-MHTGR SG design process. The decommissioning process for the reactor presents an opportunity to assess the design, through testing and document review, and to integrate this information into the NP-MHTGR design. The information gathered will be used to ensure that the NP-MHTGR design and material specifications contain adequate information and sufficient margin to ensure mission integrity and design life such that problems experienced at Fort St. Vrain do not occur in the NP-MHTGR.

\subsubsection{Purpose}

The purposes of this testing were (1) to make an assessment of corrosion damage to the main steam ringheaders, (2) to evaluate the cause(s) of the cracking observed adjacent to the nozzles in the main steam ring, (3) to characterize the metallurgical condition of the bimetallic weld in the outlet header collector, and (4) to perform tensile and creep testing of the damaged and undamaged portions of the ringheaders.

\subsubsection{Status}

The following examinations and analyses have been completed:

- Metallurgical and microstructural

- Visual and fluorescent dye penetrant inspection of the main steam rings

- Optical microscopy and TEM

- Metallography of the BMW in the outlet header collector

- Chemical analyses of both ringheaders and the BMW

Tensile and creep tests were initiated on June 1, 1993, and are expected to be completed and data available by August 1, 1993.

\footnotetext{
*M. J. Schiff \& Associates, 1291 N. Indian Hill Blvd., Claremont, CA 91711-3897.
} 


\subsubsection{Results}

Extensive photographic documentation of the results of the various examination procedures has been compiled and will be reported in a final report of this effort. The most important observations are as follows. The OD-to-ID cracking found in the ringheader was caused by the exhaustion of creep ductility in the ringheader material. The cracking was found to be intergranular, with evidence of secondary cracks forming below the mouth of the crack. The profiles of the separating grain boundaries exhibit circular voids indicative of creep failure. The mechanism of the failure was creep.

A second observation was that there exists a difference in grain sizes within the same header body. It had been observed that cracking was confined to specific sections of the ringheader material; for instance, in half of ringheader B1-1. To determine the reason for this behavior, metallographic samples were prepared and examined from both "halves" of both B1-1 and B1-2. Optical microscopic examination of specimens from the two halves of B1-1 showed an obvious difference in grain size between the cracked and the uncracked portions of the header. The cracked material had a grain size of about ASTM 0 to 1, while the uncracked material was found to be between ASTM 4 and 5. The same analysis of specimens from the uncracked ringheader B1-2 showed both to have about the same grain size as the uncracked portion of B1-1. The source of the larger grains is not clear at this time. The difference in composition between the two halves of B1-1 which failed and did not fail suggests that there are two different heats involved. A limited search, however, of the QA records showed no evidence of multiple heats, and the material specifications and the manufacturer's certification also specify that only one heat of material was used to fabricate the ringheaders.

In summary, the tendency for cracking in a ringheader appears to be related to a large grain size in the material and that, together with the observation of creep voids in the grain boundary surfaces and in the crack tips, indicates the cause of the OD-to-ID cracking to be exhaustion of creep ductility in the ringheader material. 


\title{
SECTION 5
}

\section{SAFETY TECHNOLOGY}

\author{
J. C. Cleveland
}

\subsection{INTRODUCTION}

The AVR and safety research subprograms were conducted under the U.S. - German Umbrella Agreement for GCR Development. The programs involved cooperative work in the fields of reactor physics, fuel and fission product behavior, and thermofluid dynamics. Exchanges of computer codes and validation of codes by comparison with experimental results were key accomplishments of these cooperative efforts. Participating institutions included ORNL and GA from the United States and the KFA Nuclear Research Center, Jülich, Germany.

\subsection{AVR TEST PROGRAM}

The purpose of the AVR cooperation was to obtain experimental information from the AVR relevant to the performance and safety of the MHTGR and to compare measured results with analytical predictions. Five PWSs were established with the following titles:

- Measurement and Computation of Reactor Physics Parameters for the AVR

- Measurement and Computation of Plutonium Buildup in Selected LEU Fuel Elements

- Reactor Dynamics Testing and Analysis

- Loss-of-Coolant Accident (LOCA) Simulation Testing and Analysis

- Fission Product Release with Depressurization

A key activity in the AVR subprogram involved cooperative activities in planning, conducting, and analyzing the LOCA test at the AVR GCR ${ }^{191}$ Both pretest predictions and post-test analyses were conducted. The test was planned to create conditions which would exist if a rapid LOCA occurred at the AVR with the reactor operating at full power. The main LOCA test lasted $5 \mathrm{~d}$. The test demonstrated the safe response of this reactor to an accident in which the coolant escapes from the reactor core, and, furthermore, no emergency system operates to provide coolant flow to the core. After the test started, core temperatures increased for approximately $13 \mathrm{~h}$ and then began a gradual and continual decrease as the rate of heat dissipation from the core 
exceeded the simulated decay power. Throughout the test, temperatures remained below limiting values for the core and other reactor components.

The detailed results of the pretest predictions are reported in ref. 192, while the planning, experimental method, and post-test evaluation are presented in ref. 191. Other key experimental results from the AVR included data on the temperature coefficient of reactivity at normal operating temperatures and during the LOCA test, measurements of the buildup of plutonium isotopes in LEU fuel as a function of burnup, and the reactivity worth of control rods. Many detailed reports were received containing these data. Some of the physics data were used by GA for code validation activities. A test designed to measure the release of fission products from the primary circuit of the AVR during a rapid depressurization was also planned during this subprogram. However, the license for the test was not obtained by the AVR.

\subsection{SAFETY RESEARCH PROGRAM}

The safety research subprogram involved the KFA Research Center, Jülich, from the German side and ORNL and GA from the U.S. side. The objectives of the subprogram were:

- To provide a clear understanding of the top-level safety requirements and approach of the individual national programs

- To advance the understanding of HTGR safety through benchmarking and cross comparison and the extension of experimental data and analytical methods and models

- To improve the confidence level of the individual national safety programs through code validation and peer review

- To reduce the cost of the individual national safety programs through mutual cooperation on generic tasks by minimizing duplication of effort

Nine PWSs were established in this subprogram, and ORNL was involved in six. (PWSs are listed in detail in the 1988 HTGR annual report.) The task specifications were defined in a more general way than were the tasks of the AVR subprogram. Several KFA reports, particularly in the area of thermofluid dynamic experimentation and analysis, were received through this subprogram. Unfortunately, funding for the safety research subprogram was terminated in 1989 , and few of the tasks defined in the PWS were completed.

Prior to the licensing and commercial deployment of advanced GCRs, both the safe neutronic and thermal behavior of the reactor design and the safe behavior of the fuel and fission products must be proven under experimental conditions representing realistic reactor conditions. 
The methods used to predict the performance of the fuel and reactor must be validated against these experimental data. Through the AVR subprogram, and to a lesser extent the safety research subprogram, it became clear that international cooperation could play a role in achieving this goal. Many of the needs that were identified in these subprograms are now being pursued through IAEA CRPs in the areas of reactor physics, fuel and fission product behavior, and heat transport. Countries involved in these cooperative activities include China, Japan, Germany, France, Russia, Switzerland, and the United States. 


\title{
SECTION 6
}

\section{SHIELIDING ANALYSIS}

\author{
J. A. Bucholz
}

\subsection{INTRODUCTION}

This chapter summarizes the reactor shielding work performed for the commercial and NPR versions of the MHTGR from 1989 to 1993 . From November 1985 to May 1990, ORNL was an active member of the commercial MHTGR design team and worked very closely with GA in support of their design effort. With the inception of the NPR Program in 1990, the ORNL Shielding Task was asked to play a very different role-i.e., to cease any direct involvement with the actual design effort and to begin making preparations to assume a completely independent "confirmatory" role wherein ORNL would only review elements of the design as requested by HQ (DOE/NP-61) and/or the Idaho National Engineering Laboratory (INEL), to whom much of the oversight authority was later delegated. In January 1992, the NPR Program terminated all but 9 of 27 ongoing programs, including the ORNL Shielding Task. In February 1992, a "closeout status report" for the MHTGR Shielding Task was presented at a meeting in Germantown, Maryland, which was held at the request of the commercial MHTGR Program Director, P. M. Williams.

References 193 through 211 summarize ORNL's involvement from 1985 to the present, while refs. 200 to 211 summarize work completed or reported since January 1989. In particular, refs. 205 to 211 reflect the changed nature of the ORNL Shielding Task since the inception of the NPR Program in 1990. Several of these planning or verification documents ${ }^{205,209,211}$ will be mentioned only briefly below, since the bulk of their content is hopefully obvious from the respective titles. Others, such as refs. 202, 204, 207, 208, and 210, will be discussed in more depth since the technical results contained therein have direct bearing on design decisions common to both the commercial and NPR versions of the MHTGR. Of necessity, the summary information presented below will be very brief and is intended only to point the reader to the most appropriate reference. 


\subsection{ANALYSIS OF THE BOTTOM REFLECTOR AND NEUTRON STREAMING INTO THE HOT-GAS PLENUM ${ }^{200,202,203}$}

A report describing the initial streaming analysis of the large-diameter coolant holes in the lower reflector of the MHTGR ${ }^{200}$ was published in January 1989. Because the reference design at that time did not include any borated graphite pins in that portion of the bottom reflector block, below the bottom of the active core and above the top of the large-diameter coolant holes, the thermal and total fluence levels in the hot-gas plenum were found to be excessively high $\left(4.12 \mathrm{E}+20\right.$ and $4.13 \mathrm{E}+20 \mathrm{n} / \mathrm{cm}^{2}$, respectively), with a corresponding effective fast fluence (EFF) of $2.89 \mathrm{E}+19 \mathrm{n} / \mathrm{cm}^{2}$. The bulk of the work in CY 1989, therefore, focused on the analysis of 15 different design options aimed at lowering these fluences to an acceptable level while minimizing the impact on the total length of the bottom reflector block, the flow distribution block, and the post-block assemblies. These studies, described at length in ref. 202, are summarized below. Considerable effort was also expended in trying to quantify the uncertainties associated with these analyses. This included a review of all previous calculations and experimental measurements for the mockup of the lower reflector of the larger 2240-MW(th) HTGR at the Tower Shielding Reactor (TSR) experimental facility, and a detailed statistical estimate of the uncertainties in the present MHTGR shielding analyses based on a host of factors (see Sect. 6 and Appendix $\mathrm{G}$ of ref. 202, respectively). This effort also included a cross validation of the MHTGR shielding methods and data for the lower axial reflector against earlier experiments at the TSR, as described in ref. 203. In this study, one of the early but more applicable experiments at the TSR was reanalyzed using the same cross-section data and the same calculational sequence used for the lower axial reflector of the MHTGR. This included a onedimensional (1-D) XSDRNPM analysis, the results of which were then used as input to a 3-D MORSE Monte Carlo analysis, the results of which were then used as input to a two-dimensional (2-D) Department of Transportation (DOT) discrete ordinates analysis.

\subsubsection{The Analysis and the Results}

Reference 202 provides a detailed description of the "Two- and Three-Dimensional Analyses of Shielding Design Options for the Lower Axial Reflector of the MHTGR." Figure 6-1 shows an idealized sketch of the lower axial reflector of the MHTGR. Directly below the active core of the MHTGR, one has a bottom reflector block, a flow distribution block, and a post-block assembly, through which the large-diameter coolant holes pass en route to the hot-gas plenum. The post-block assemblies are supported by graphite posts resting on the solid graphite floor of 


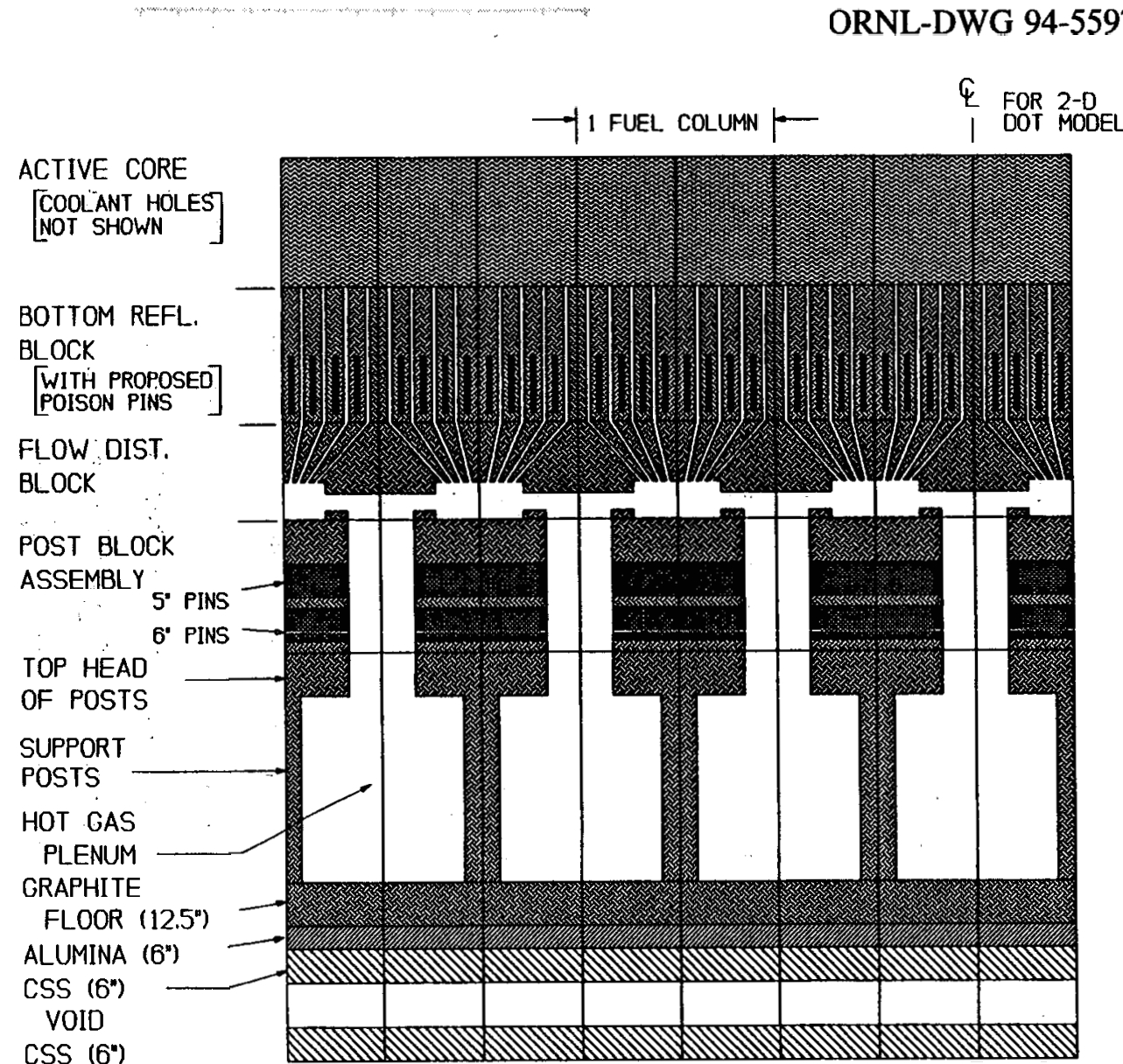

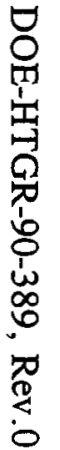

Figure 6-1.

SIDE VIEW OF THE LOWER AXIAL REFLECTOR, THE SUPPORT POSTS, THE HOT GAS PLENUM, AND THE CORE SUPPORT STRUCTURE. NOT DRAWN TO SCALE. 
the hot-gas plenum. The 12.5-in.-thick graphite floor is thermally insulated from the top 6-in.-thick section of the metallic core support structure (CSS) by a 6-in. pad of alumina ceramic. Of particular importance is the fact that the large, rounded-triangular coolant holes in the postblock assemblies have an equivalent diameter of 5.58 in. and represent $28.5 \%$ of the projected area directly below the 66 fuel columns comprising the annular core. Unlike the November 1988 reference design, it was assumed here that 8- or 16-in.-long borated graphite pins would now be located in the lower portion of the bottom reflector block, as shown in Figures 6-1 and 6-2.

To analyze the lower axial reflector and determine the fluence levels in the hot-gas plenum, a three-part "bootstrapped" analytic procedure was developed in which:

1. A 1-D, 27-group XSDRNPM axial analysis was performed for the lower portion of the core and all regions below the core. The resulting multigroup angular flux 6 in. above the top of the borated graphite pins in the bottom reflector block was then stripped off and used as the boundary flux for a subsequent 3-D MORSE analysis.

2. A 3-D, 27-group MORSE Monte Carlo analysis was then performed for a region starting 6 in. above the top of the borated graphite pins in the bottom reflector block and extending 7 in. below the bottom of these borated graphite pins. [Moreover, to improve the statistics associated with these Monte Carlo analyses, they were actually performed in four separate steps so as to more accurately calculate the emerging flux due to (a) uncollided neutrons from the fast-neutron source $(\mathrm{E}>3.05 \mathrm{eV}$ ), (b) the collided neutrons from the fast-neutron source, (c) uncollided neutrons from the thermal neutron source $(E<3.05 \mathrm{eV})$, and (d) the collided neutrons from the thermal neutron source.] This analytic model included an explicit 3-D representation of the 216 (0.5-in.-diam) borated graphite pins and the 108 (0.625-in.-diam) coolant holes found in each of the bottom reflector blocks illustrated in Figures 4-31 and 4-32. The multigroup annular flux 1 in. below the bottom of the borated graphite pins (i.e., at the top of the flow distribution block) was then stripped off and used as the boundary flux for a subsequent 2-D DOT analysis of the large-diameter coolant holes through the post-block assembly. Prior to the DOT analysis, fluxes in groups 15 to 27 were collapsed to a single thermal sink group.

3. A 15-group DOT analysis was then performed for the large-diameter coolant holes through the post-block assembly using a 2-D RZ model of the flow distribution block, 
ORNL-DWG 94-5598

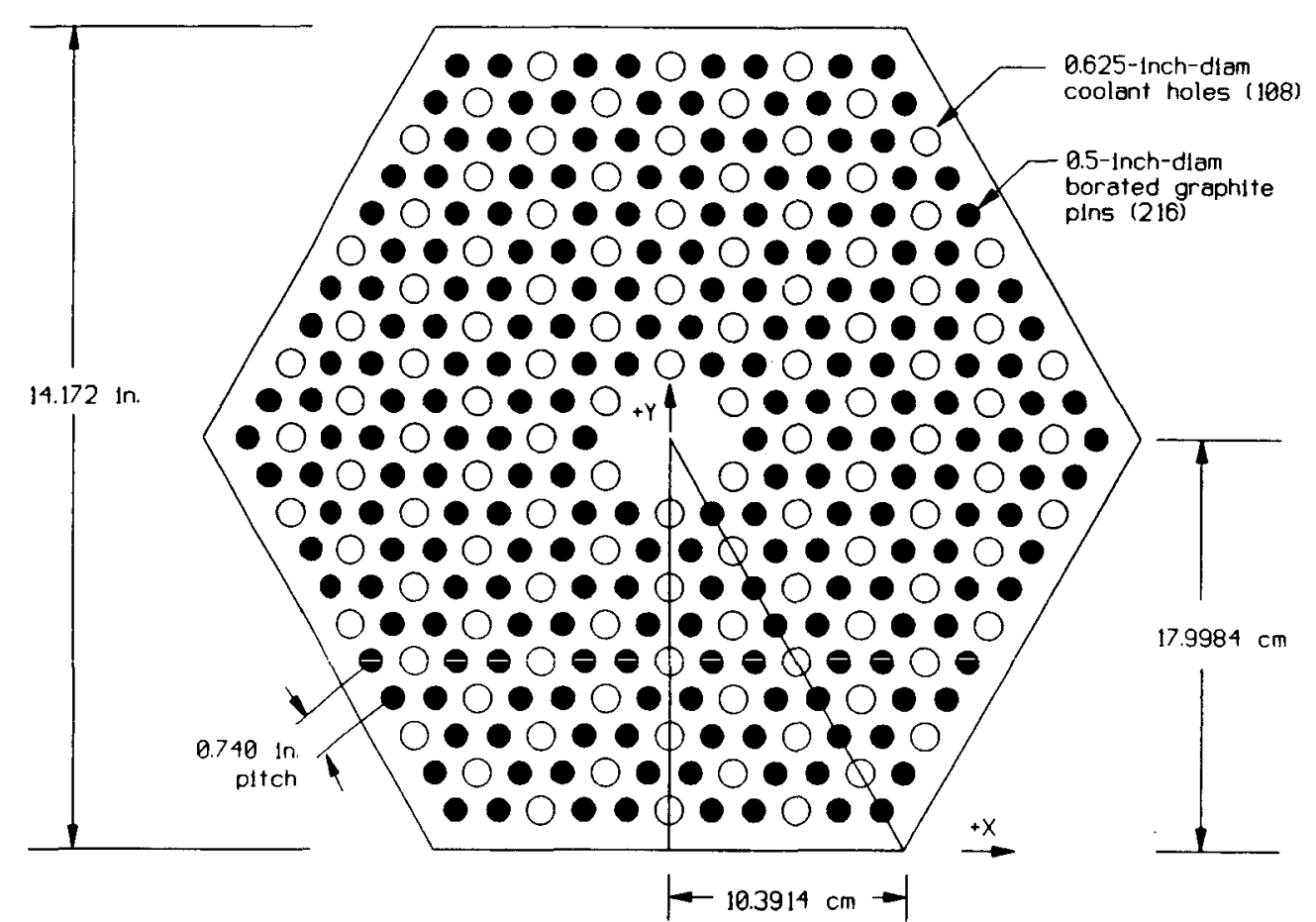

Figure 6-2.

PROPOSED DISTRIBUTION OF THE 216 0.5-INCH-DIAM BORATED GRAPHITE PINS AMONG THE 108 0.625--INCH-DIAM COOLANT HOLES IN THE BOTTOM REFLECTOR BLOCK, AND THE RIGHT TRIANGULAR WEDGE USED TO MODEL THIS CONFIGURATION IN THE 3-D MORSE SHIELDING ANALYSES. 
the post-block assemblies, the posts in the hot-gas plenum, the floor of the plenum, and the CSS.

Taken together, these codes and models represent a unique calculational sequence for the determination of the fluence in the hot-gas plenum.

The various design options described below were not postulated a priori but evolved during the course of the study as part of a continuing effort to reduce the total fluence in the hot-gas plenum to $1.0 \mathrm{E}+18$ or $1.0 \mathrm{E}+17 \mathrm{n} / \mathrm{cm}^{2}$. To accomplish this, it became apparent that somewhat thicker bottom reflector blocks would be required with more graphite between the bottom of the active core and the top of the borated graphite pins. A series of 3-D Monte Carlo analyses were performed for five different types of bottom reflector blocks:

1. Case E: having a 23.415 -in. block with 8 -in. borated graphite pins

2. Case $C$ : having a 31.220 -in. block with 8 -in. borated graphite pins

3. Case B: having a 39.025-in. block with 8-in. borated graphite pins

4. Case F: having a 39.025-in. block with 16-in. borated graphite pins

5. Case D: having a 46.830 -in. block with 16 -in. borated graphite pins

For each of the five bottom reflector blocks described above, high-order, 2-D neutron streaming calculations were performed for three different types of post-block assemblies:

1. Case 55: a 23.415-in. assembly with both 5- and 6-in.-long borated pins

2. Case 56: a 15.610-in. assembly with both 5- and 6-in.-long borated pins

3. Case 57: a 7.805-in. assembly with 6-in.-long borated graphite pins

Table 6-1 shows the broad-group, total, and effective fast-neutron fluence at the midplane of the hot-gas plenum for the various design options studied (Group A: E >0.9 MeV; Group B: $0.1 \mathrm{MeV}<\mathrm{E}<0.9 \mathrm{MeV}$; Group C: $3.05 \mathrm{eV}<\mathrm{E}<0.1 \mathrm{MeV}$; and Group D: E < $3.05 \mathrm{eV}$ ). The displacements per atom (dpa) that would result at these fluence levels are also given for each case, as well as the EFF, which has been defined by $\mathrm{CE}$ as:

$$
\mathrm{EFF}=t_{o}{ }^{*}[1.0 \phi(\mathrm{Grp} \mathrm{A})+0.5 \phi(\operatorname{Grp~B})+0.0025 \phi(\operatorname{Grp} C)+0.07 \phi(\operatorname{Grp} \mathrm{D})]
$$

Parenthetically, it should also be noted that the broad-group fluences and resulting dpa on that portion of the vessel adjacent to the cold duct would be approximately 3.5 times lower than the corresponding values at the midplane of the hot-gas plenum. Lastly, Table 6-1 also shows the distance (DZ) from the bottom of the active core to the top of the hot-gas plenum for each of the 
Table 6-1

\section{FLUENCES AT MIDPLANE OF HOT GAS PLENUM FOR VARIOUS CASES OF INTEREST}

\begin{tabular}{|c|c|c|c|c|c|c|}
\hline \multicolumn{7}{|c|}{$\begin{array}{l}\text { Description of the bottom reflector block, } \\
\text { with block height and pin length in inches }\end{array}$} \\
\hline $\begin{array}{l}\text { Descr. of } \\
\text { post block } \\
\text { assembly }\end{array}$ & $\begin{array}{l}\text { Descr. } \\
\text { of the } \\
\text { data }\end{array}$ & $\begin{array}{l}\text { Case E } \\
23.415^{\prime \prime} \\
8 " \text { pins }\end{array}$ & $\begin{array}{l}\text { Case C } \\
31.220^{\prime \prime} \\
8^{\prime \prime} \text { pins }\end{array}$ & $\begin{array}{l}\text { Case B } \\
39.025^{\prime \prime} \\
8^{\prime \prime} \text { pins }\end{array}$ & $\begin{array}{l}\text { Case F } \\
39.025^{\prime \prime} \\
16^{\prime \prime} \text { pins }\end{array}$ & $\begin{array}{l}\text { Case D } \\
46.830^{\prime \prime} \\
16^{\prime \prime} \text { pins }\end{array}$ \\
\hline $\begin{array}{l}\text { Case } 55 \\
23.415^{\prime \prime} \\
\text { block with } \\
5 " \text { and 6" } \\
\text { borated } \\
\text { pins }\end{array}$ & $\begin{array}{l}\text { DZ } \\
\text { Grp(A) } \\
\text { Grp(B) } \\
\text { Grp(C) } \\
\text { Grp(D) } \\
\text { Total } \\
\text { EFF } \\
\text { DPA }\end{array}$ & $\begin{array}{l}70.245 " \\
\\
2.911 \mathrm{E}+16 \\
6.024 \mathrm{E}+16 \\
8.802 \mathrm{E}+17 \\
7.193 \mathrm{E}+18 \\
8.163 \mathrm{E}+18 \\
\\
5.650 \mathrm{E}+17 \\
2.886 \mathrm{E}-04\end{array}$ & $\begin{array}{l}78.050 " \\
\\
9.022 \mathrm{E}+15 \\
1.402 \mathrm{E}+16 \\
1.688 \mathrm{E}+17 \\
1.889 \mathrm{E}+18 \\
2.081 \mathrm{E}+18 \\
\\
1.487 \mathrm{E}+17 \\
7.733 \mathrm{E}-05\end{array}$ & $\begin{array}{l}85.855 " \\
\\
1.543 E+15 \\
2.473 E+15 \\
3.130 E+16 \\
8.581 E+17 \\
8.935 E+17 \\
6.293 E+16 \\
3.090 E-05\end{array}$ & $\begin{array}{l}85.855 " \\
\\
1.836 \mathrm{E}+15 \\
3.112 \mathrm{E}+15 \\
4.219 \mathrm{E}+16 \\
4.396 \mathrm{E}+17 \\
4.868 \mathrm{E}+17 \\
\\
3.427 \mathrm{E}+16 \\
1.756 \mathrm{E}-05\end{array}$ & $\begin{array}{l}93.660 " \\
5.550 \mathrm{E}+14 \\
8.146 \mathrm{E}+14 \\
9.099 \mathrm{E}+15 \\
1.522 \mathrm{E}+17 \\
1.627 \mathrm{E}+17 \\
\\
1.164 \mathrm{E}+16 \\
5.939 \mathrm{E}-06\end{array}$ \\
\hline $\begin{array}{l}\text { Case } 56 \\
15.610 " \\
\text { block with } \\
5 " \text { and 6" } \\
\text { borated } \\
\text { pins }\end{array}$ & $\begin{array}{l}\text { DZ } \\
\text { Grp(A) } \\
\text { Grp(B) } \\
\text { Grp(C) } \\
\text { Grp(D) } \\
\text { Total } \\
\\
\text { EFF } \\
\text { DPA }\end{array}$ & $\begin{array}{l}62.440 " \\
\\
6.429 \mathrm{E}+16 \\
1.379 \mathrm{E}+17 \\
1.836 \mathrm{E}+18 \\
8.429 \mathrm{E}+18 \\
1.047 \mathrm{E}+19 \\
\\
7.279 \mathrm{E}+17 \\
3.927 \mathrm{E}-04\end{array}$ & $\begin{array}{l}70.245^{\prime \prime} \\
1.907 \mathrm{E}+16 \\
3.110 \mathrm{E}+16 \\
3.481 \mathrm{E}+17 \\
2.050 \mathrm{E}+18 \\
2.448 \mathrm{E}+18 \\
1.790 \mathrm{E}+17 \\
9.963 \mathrm{E}-05\end{array}$ & $\begin{array}{l}78.050 " \\
\\
3.356 \mathrm{E}+15 \\
5.515 \mathrm{E}+15 \\
6.445 \mathrm{E}+16 \\
7.964 \mathrm{E}+17 \\
8.697 \mathrm{E}+17 \\
\\
6.202 \mathrm{E}+16 \\
3.194 \mathrm{E}-05\end{array}$ & $\begin{array}{l}78.050 " \\
\\
3.728 E+15 \\
7.033 E+15 \\
8.787 E+16 \\
4.875 E+17 \\
5.861 E+17 \\
4.159 E+16 \\
2.251 E-15\end{array}$ & $\begin{array}{l}85.855 " \\
1.192 \mathrm{E}+15 \\
1.820 \mathrm{E}+15 \\
1.883 \mathrm{E}+16 \\
1.504 \mathrm{E}+17 \\
1.722 \mathrm{E}+17 \\
1.267 \mathrm{E}+16 \\
6.936 \mathrm{E}-06\end{array}$ \\
\hline $\begin{array}{l}\text { Case } 57 \\
7.805 " \\
\text { block } \\
\text { with 6" } \\
\text { borated } \\
\text { pins }\end{array}$ & $\begin{array}{l}\text { DZ } \\
\text { Grp(A) } \\
\text { Grp(B) } \\
\text { Grp(C) } \\
\text { Grp(D) } \\
\text { Total } \\
\\
\text { EFF } \\
\text { DPA }\end{array}$ & $\begin{array}{l}54.635 " \\
1.609 \mathrm{E}+17 \\
3.481 \mathrm{E}+17 \\
4.611 \mathrm{E}+18 \\
2.124 \mathrm{E}+19 \\
2.636 \mathrm{E}+19 \\
\\
1.833 \mathrm{E}+18 \\
9.867 \mathrm{E}-04\end{array}$ & $\begin{array}{l}62.440 " \\
4.514 \mathrm{E}+16 \\
7.487 \mathrm{E}+16 \\
8.475 \mathrm{E}+17 \\
5.104 \mathrm{E}+18 \\
6.071 \mathrm{E}+18 \\
4.420 \mathrm{E}+17 \\
2.444 \mathrm{E}-04\end{array}$ & $\begin{array}{l}70.245 " \\
8.070 \mathrm{E}+15 \\
1.329 \mathrm{E}+16 \\
1.578 \mathrm{E}+17 \\
1.870 \mathrm{E}+18 \\
2.049 \mathrm{E}+18 \\
1.460 \mathrm{E}+17 \\
7.533 \mathrm{E}-05\end{array}$ & $\begin{array}{l}70.245 " \\
8.941 E+15 \\
1.749 E+16 \\
2.186 E+17 \\
1.181 E+18 \\
1.426 E+18 \\
1.009 E+17 \\
5.453 E-05\end{array}$ & $\begin{array}{l}78.050 " \\
2.815 \mathrm{E}+15 \\
4.360 \mathrm{E}+15 \\
4.525 \mathrm{E}+16 \\
3.581 \mathrm{E}+17 \\
4.105 \mathrm{E}+17 \\
\\
3.018 \mathrm{E}+16 \\
1.647 \mathrm{E}-05\end{array}$ \\
\hline
\end{tabular}

Note: $\mathrm{DZ}=$ distance from bottom of active core to top of the hot gas plenum;

$=$ ht of bottom reflector block + ht of flow dist block $\left(15.16^{\prime \prime}\right)+$ ht of post block assembly + top of support posts (7.805")

$\mathrm{EFF}=$ effective fast fluence as defined by $\mathrm{CE}$

DPA $=$ displacements per atom in carbon steel 
15 design options studied. Anything in excess of 70.245 in. would require a reduction in the height of the hot-gas plenum or an increase in the overall length of the reactor vessel.

Selecting the final design options for use in the MHTGR will ultimately be GA's responsibility and will involve additional considerations such as the structural strength of the various blocks, reactor physics considerations, and thermal hydraulic considerations. With respect to the shielding results shown in Table 6-1, however, it would appear that total fluence levels below $1.0 \mathrm{E}+18 \mathrm{n} / \mathrm{cm}^{2}$ in the hot-gas plenum are achievable in a variety of ways but will require increasing the length of the bottom reflector block beyond the $23.415 \mathrm{in}$. shown in the reference design of November 1988. Furthermore, reducing the total fluence in the hot-gas plenum to $1.0 \mathrm{E}+17 \mathrm{n} / \mathrm{cm}^{2}$ is possible, but just barely. As shown in Sect. 3.3 of ref. 200 , this will require the addition of borated graphite pins in the floor of the hot-gas plenum. Their presence will reduce the total fluence in the hot-gas plenum by another factor of two. More detailed discussion of these results may be found in ref. 202.

\subsubsection{Initial Uncertainty Estimates}

Because the above calculations for the lower axial reflector were state of the art, there was no good way to "analytically" judge the absolute accuracy of the final results. This requires experimental validation using similar shield configurations exposed to similar spectra. At GA's request, a review of earlier experiments and analyses was conducted, as well as an independent statistical assessment of the uncertainties in the present calculations. These findings, summarized below, are discussed at length in Sect. 6 and Appendix G of ref. 202.

\subsubsection{Review of Earlier Experiments and Analyses}

The only remotely similar experiments performed in the past were for the lower axial reflector of the large 2240-MW(th) HTGR. These experiments, described in refs. 212 through 215, were performed at the ORNL TSR during the early 1980s. Moving away from the core, this experimental configuration consisted of:

- A composite (2-in. iron and 12-in. graphite) spectral modifier placed in front of the TSR-II reactor to obtain a spectrum more similar to that found 15.6 to 23.4 in. below the active core of the large 2240-MW(th) HTGR

- An upper layer of 110 or 216 borated graphite pins and 108 small-diameter coolant holes interspersed in each of seven 8-in.-thick hexagonal blocks

- An unpoisoned 9-in.-thick graphite layer containing 108 small-diameter coolant holes per hex 
- Two unpoisoned layers (16 and 14 in. thick, respectively) with a single 7.55-in.-diam coolant hole centered below each of the six outermost hexagonal regions containing the small-diameter coolant holes

- An 8-in.-thick layer of borated graphite with a total of 534 borated graphite pins distributed around the six 7.55-in.-diam coolant holes

- A 15.71-in.-thick flow distribution block in which the six 7.55-in.-diam coolant holes are merged into a single 19-in.-diam coolant hole located along the centerline of the system

- A 26-in. block of unpoisoned graphite containing a single 19-in.-diam coolant hole through the center

The modular construction of the experiment allowed for measurements behind each successive layer as the experiment progressed. While the final experimental configuration was intended as a means to validate the shielding analyses for the region below the super-large 19-in.-diam coolant hole servicing a typical 7-column region of the large 2240-MW(th) HTGR, some of the intermediate configurations were somewhat more typical of the lower axial reflector in the MHTGR. In one case of particular interest, the spectral modifier, the upper borated pin layer, and the 9-in. reflector were followed by a 16-in. graphite reflector, a second 8-in. borated pin layer, and a 14-in. graphite reflector, all three of which contained six 7.55-in.-diam holes for a total length of 38 in. In all, Sect. 6 of ref. 202 summarizes the comparisons of previous analytic results with previous experimental results for 17 different cases of potential interest. Based on these findings, it was concluded that:

When streaming paths through the coolant holes in the MHTGR can be and are adequately modeled with the 2-D DOT or 3-D MORSE codes, and high-order streaming analyses are performed with careful attention given to the DOT angular quadrature and the MORSE space/energy/angle biasing schemes so as to accurately model the transport of neutrons through such holes, then it would still appear (based on these earlier experiments and analyses) that the calculated fluxes in the region directly below such holes may frequently be on the order of 1.4 to 1.6 times too low, and occasionally (but seldom) more than a factor of 2.0 too low.

These observations are based primarily on the comparisons of calculated and measured values described in Sects. 6.1.5.1, 6.1.6, and 6.1.7 of ref. 202. Moreover, because these conclusions are based on the use of extremely sophisticated analyses for this particular experimental configuration, they should not be capriciously assumed to apply to less sophisticated analyses, or to configurations which differ significantly from the 2240 experimental mockup-either in terms of the overall geometry, the materials used, or the impingent flux spectrum. 


\subsubsection{Statistical Uncertainty Estimates for the Fluence in the Hot-Gas Plenum of the MHTGR}

Also at GA's request, a panel of Monte Carlo and discrete ordinates shielding experts reviewed an early draft of ref. 202 to identify and quantify the potential sources of uncertainty in the analysis of the lower axial reflector for the MHTGR. These included:

- Uncertainties in the source distribution

- The effect of cross-section uncertainties in deep penetration problems and in problems that are dominated by neutron streaming

- Uncertainties due to the angular quadrature used in the 1- and 2-D analyses

- The effect of geometric modeling approximations in the 1-, 2-, and 3-D analyses performed

- Uncertainties due to material compositions and densities

- Uncertainties due to numerical methods such as the finite difference algorithms in the 1-and 2-D analyses and/or the biasing schemes and sampling techniques in the 3-D Monte Carlo analyses

Probability-dependent multiplicative uncertainty factors were then postulated for each source of uncertainty, with different numerical values assigned as warranted for (1) the 1-D analysis in the graphite directly below the core, (2) the 3-D analysis through the upper borated pin layer, and (3) the 2-D analysis of the large-diameter coolant holes (cf. Appendix G of ref. 202). A systematic methodology for combining probability-dependent uncertainties was then used to obtain the overall multiplicative uncertainty factor for the fluence in the hot-gas plenum. Based on that statistical analysis, it was estimated that there was (1) a $90 \%$ probability that the actual fluence in the hot-gas plenum would be no more than 2.0 times the nominal fluence obtained from the highorder radiation shielding calculations, (2) a $95 \%$ probability that the actual fluence would he no more than 2.5 times the calculated fluence, (3) a $99.9 \%$ probability that the actual fluer: $v / 5$ uld be no more than 5.4 times the calculated fluence, and (4) a $99.99 \%$ probability that the actual fluence would be no more than 7.7 times the calculated fluence. It was noted, however, that the underlying uncertainties used in this statistical uncertainty analysis were merely "best guesses" and that a more credible basis for estimating or reducing these underlying uncertainties can only be obtained from shielding experiments that are specifically designed to model these particular features of the MHTGR. Lastly, it was noted that, in the absence of such experiments, "prudence would dictate that some additional margin should also be applied by the reactor designers." 


\subsubsection{Partial Validation of the Calculational Strategy and Cross-Section Data Using One of the Earlier TSR Experiments ${ }^{203}$}

Because the calculational strategy, geometric modeling, and nuclear cross-section data used in the recent analyses of the lower axial reflector of the MHTGR were different from those used in the previous analyses of the TSR experiments, and because of the many source code modifications that were necessary in these MHTGR analyses, GA and ORNL agreed that at least one of the earlier TSR experiments having some similarities with the MHTGR should be reanalyzed using current methods and data.

The series of experiments selected consisted of a spectral modifier ( 2 in. of carbon steel plus 12 in. of solid graphite); an 8-in. upper pin layer (Sect. A) having 2160.5 -in.-diam borated pins and 108 0.625-in.-diam holes distributed in each of seven hexagonal assemblies; and a 9-in. graphite reflector (Sect. B) with 108 0.625-in.-diam holes in each of seven hexagonal assemblies, followed by a 16-in. block of graphite (Sect. C), an 8-in. lower borated pin layer (Sect. E), and a final 14-in. block of graphite (Sect. D). Sections C, E, and D were penetrated by six large, 7.55-in.-diam coolant holes, with one located directly below each of the outermost hexagonal assemblies. Section E contained 72 borated graphite pins (per hexagonal assembly) in the graphite surrounding each of the large-diameter coolant holes. Experimental measurements of the flux were made with (1) a 10-in. Bonner ball that was most sensitive to fast neutrons above $0.1 \mathrm{MeV}$, (2) a 5-in. Bonner ball that was most sensitive to neutrons between $950 \mathrm{eV}$ and $0.1 \mathrm{MeV}$, (3) a cadmium-covered $\mathrm{BF}_{3}$ detector that was most sensitive to neutrons between 0.4 and $950 \mathrm{eV}$, and (4) a bare $\mathrm{BF}_{3}$ detector that was most sensitive to thermal neutrons below $0.4 \mathrm{eV}$. Measurements made at 4 and $30 \mathrm{~cm}$ behind the spectral modifier (without Sects. A, B, C, E, and D present) were used to validate the 1-D XSDRNPM analysis used for the spectral modifier; measurements made at 4 and $30 \mathrm{~cm}$ behind Sect. B (without Sects. C, E, and D present) were used to validate the 3-D MORSE analysis of the upper pin layer; and measurements at 4 and $30 \mathrm{~cm}$ behind Sect. D were used to validate the high-order DOT streaming analysis for the 7.55-in.-diam by 38 in.-long coolant holes.

Source terms for the TSR reactor were taken from Table 1 of ref. 216 and supplemented in the thermal energy range below $3.05 \mathrm{eV}$ with the results of a new 27-group $\mathrm{k}$-eff analysis using a 1-D spherical model of the TSR-II reactor. Detector response functions taken from Table B1 of ref. 214 were also supplemented in the thermal neutron energy range with ENDF-IV data for boron and pointwise cross-section data for both boron and cadmium taken from BNL-325. 
Because of the small size and spherical nature of the TSR reactor $(R<19.125$ in.), and the limited size of the experimental configuration with only seven hexagonal assemblies, an exact model of the system would have required significant alterations to the 3-D MORSE model described in Sect. 4 of ref. 202-i.e., 21 times more pins and holes, plus additional importance zones in the radial direction for the surrounding graphite. With such gross alterations, it is questionable if one could then claim to be validating the original, relatively simple, model used in the MHTGR analysis. Moreover, the offset nature of the six large coolant holes, with none along the centerline of the system, would have made an exact 2-D RZ DOT model of the entire system virtually impossible anyway. Given this paradox, and realizing that earlier benchmark-quality analyses of the experiment had previously been performed by Slater (see Sect. 6 of ref. 202), the approach taken here was to use the original MORSE model for a one-twelfth section of a typical hex and the original DOT model for a single large-diameter coolant hole in order to determine how accurately these simple models (which are more applicable to the actual MHTGR than to the TSR experiment) would actually compare to the experimental measurements. To account for the natural divergence of the neutrons radiating from the small spherical TSR reactor, a simple $1 / \mathbf{R}^{2}$ correction was therefore applied to the MORSE and DOT results thus calculated. A similar $1 / \mathrm{R}^{\mathrm{n}}$ correction was also applied to account for the geometric attenuation between the bottom of the experimental configuration and the effective center of detection for each detector. Details of these corrections are described in ref. 203.

Comparisons of the measured and calculated detector count rates at the locations described above are given in Table 6-2. Behind the spectral modifier, the measured results were never more than 1.0975 times higher or 1.0332 times lower than the calculated values; behind the upper pin layer and the follow-on 9-in. reflector, the measured results were never more than 1.681 times higher or 1.376 times lower than the calculated values; and at the bottom of the 7.55-in.-diam by 38-in.-long coolant holes, the measured results were never more than 2.604 times higher or 2.151 times lower than the calculated values. Based on a number of similarities with the lower axial reflector of the MHTGR, it would be reasonable to expect a similar margin of error for the analyses reported in ref. 202. Moreover, these deviations are entirely consistent with the uncertainties previously cited in Sect. 6 and Appendix G of that report. 


\section{COMPARISONS OF THE MEASURED AND CALCULATED DETECTOR COUNT RATES BEHIND THE SPECTRAL MODIFIER (BASED ON \\ A 1-D XSDRNPM ANALYSIS), BEHIND THE UPPER PIN \\ LAYER AND 9-INCH REFLECTOR (BASED ON A 3-D \\ MORSE ANALYSIS), AND AT THE BOTTOM OF A \\ 7.55-INCH-DIAM $\times$ 38-INCH HOLE THROUGH A \\ 16-INCH BLOCK OF GRAPHITE, A SECOND \\ BORATED PIN LAYER, AND A 14-INCH \\ BLOCK OF GRAPHITE (BASED ON A \\ 2-D DOT ANALYSIS).}

\begin{tabular}{|c|c|c|c|}
\hline \multirow[b]{2}{*}{$\begin{array}{l}\text { TYPE OF DETECTOR } \\
\text { \& IT'S LOCATION }\end{array}$} & \multicolumn{3}{|c|}{$\begin{array}{l}\mathrm{M} / \mathrm{C}=\text { Ratio of the measured count rate to the } \\
\text { calculated rate (after necessary corrections) }\end{array}$} \\
\hline & $\begin{array}{l}\text { BEHIND THE } \\
\text { SPECTRAL } \\
\text { MODIFIER }\end{array}$ & $\begin{array}{l}\text { BEHIND 1-ST } \\
\text { PIN LAYER } \\
\text { [SECT A \& B] }\end{array}$ & $\begin{array}{l}\text { AT BOTTOM OF } \\
7.55 " \text { DIAM } \times 38 " \\
\text { HOLES [SECT D] }\end{array}$ \\
\hline 10" Bonner ball, at $30 \mathrm{~cm}$ : & 0.9947 & 0.872 & 1.355 \\
\hline 5" Bonner ball, at $30 \mathrm{~cm}$ : & 0.9679 & 0.727 & 0.786 \\
\hline Cd-covered $\mathrm{BF} 3$, at $30 \mathrm{~cm}$ : & 1.0796 & 1.046 & 0.465 \\
\hline Bare $B F 3$ detec, at $30 \mathrm{~cm}$ : & 1.0562 & 1.681 & 1.544 \\
\hline 5" Bonner ball, at $7.5 \mathrm{~cm}$ : & 1.0031 & & \\
\hline Cd-covered BF3, at $4 \mathrm{~cm}$ : & 1.0975 & 1.080 & 0.712 \\
\hline Bare $\mathrm{BF} 3$ detec, at $4 \mathrm{~cm}$ : & 0.9831 & 1.499 & 2.604 \\
\hline
\end{tabular}

"Separate engineering corrections were applied to the MORSE and DOT results to account to the natural divergence of neutrons from the small spherical Tower Shielding Reactor, and to account for the geometric attenuation out to the "effective center of detection" for each detector. Neither of these features could be modeled in the MORSE and DOT analyses without a significantly altering the basic models described in DOE-HTGR-88303. 


\subsection{SHIELDING ANALYSIS OF THE HOLLOW CONTROL RODS AND OTHER DESIGN OPTIONS IN THE UPPER PLENUM OF THE COMMERCIAL MHTGR ${ }^{204}$}

Reference 196 previously described the shielding design analyses for the upper portion of the MHTGR system with the neutron shield bonnet located inside the reactor vessel. That comprehensive study focused on the effects of neutron streaming through the 12 empty reserve shutdown system (RSS) penetrations and identified streaming through the hollow control rods as an area requiring further study.

Reference 204 is a follow-up report that describes a series of high-order, 2-D shielding studies performed to determine both the amount and the effect of neutron streaming into the upper plenum through the hollow control rods, as well as through solid-tipped hollow control rods recently proposed by GA to reduce streaming. This report also describes a similar set of highorder shielding studies to assess the effectiveness of a newly proposed RSS hopper design in which the RSS hoppers (previously located inside the inner control assembly housings) would be relocated inside the upper plenum and sit directly atop the upper plenum shield cans, while the emergency release mechanism formerly used is replaced by a 3.4-in.-diam by 17.4-in.-long solid borated graphite plug, which would normally reside in that portion of the RSS penetration passing through the upper plenum shield cans.

These neutron shielding studies for the hollow control rods, the solid-tipped control rods, and the new RSS hopper/plug configuration were performed for (1) the 46.83-in. upper axial reflector currently in the reference design, (2) a modified vorsion of the 46.83 -in. reflector containing 8-in.-long borated graphite pins to protect the upper plenum shield cans, and (3) a somewhat thicker 62.44-in. upper axial reflector also containing 8 -in. borated graphite pins. The results of these detailed high-order streaming analyses for the $12 \mathrm{KSS}$ penetrations and the 30 control rod channels were then used in conjunction with previously published global 2-D results for the entire system to estimate the neutron fluence on the inner surface of the reactor vessel near the main flange, and along the inner surface of the upper plenum thermal shield, for eight different system configurations of potential interest (cf. Table 6-3). The objective of this study was to determine if some combination of shielding design options might make it possible to eliminate the 8-in.-thick shield ring in the upper plenum, described in ref. 198, and reduce or eliminate the neutron shield bonnet, described in ref. 196. 
Table 6-3

SUMMARY TABLE SHOWING THE MAXIMUM EFFECTIVE FAST FLUENCE

ON THE INNER SURFACE OF THE VESSEL NEAR THE FLANGE AND

THE MAXIMUM EFFECTIVE FAST FLUENCE ON THE INNER

SURFACE OF THE UPPER PLENUM THERMAL SHIELD FOR

THE EIGHT SYSTEM CONFIGURATIONS OF INEREST

\begin{tabular}{|c|c|c|c|c|c|c|c|c|}
\hline & \multicolumn{8}{|c|}{ CASE ID NUMBER } \\
\hline & 19.1 & 19.2 & 19.3 & 19.4 & 19.5 & 19.6 & 19.7 & 19.8 \\
\hline \multicolumn{9}{|l|}{ SYSTEM DESCRIPTION: } \\
\hline Reference design & Yes & No & No & No & No & No & No & No \\
\hline New RSS design with plug & No & Yes & Yes & Yes & No & Yes & Yes & Yes \\
\hline \multirow{2}{*}{$\begin{array}{l}\text { Hollow Control rods } \\
\text { (with solid-tipped ends) }\end{array}$} & Yes & Yes & Yes & Yes & Yes & Yes & Yes & Yes \\
\hline & No & No & & No & Yes & Yes & Yes & Yes \\
\hline \multirow{3}{*}{$\begin{array}{l}\text { Axial reflector }=46.83 " \\
\text { Axial reflector }=62.44^{\prime \prime} \\
\text { (with 8" borated pin layer) }\end{array}$} & Yes & Yes & Yes & No & Yes & Yes & Yes & No \\
\hline & No & No & No & Yes & No & No & No & Yes \\
\hline & No & No & Yes & Yes & No & No & Yes & Yes \\
\hline \multicolumn{9}{|l|}{ RESULTS: } \\
\hline $\begin{array}{l}\text { Max effective fast fluence } \\
\text { on vessel near flange }\end{array}$ & $1.38+17$ & $1.01+17$ & $5.79+16$ & $2.50+16$ & $1.18+17$ & $8.04+16$ & $3.80+16$ & $1.38+16$ \\
\hline $\begin{array}{l}\text { Max effective fast fluence } \\
\text { on dome of thermal shield }\end{array}$ & $3.21+18$ & $1.72+18$ & $9.15+17$ & $4.72+17$ & $2.81+18$ & $1.32+18$ & $5.29+19$ & $2.49+17$ \\
\hline
\end{tabular}

Fluence of $1.38+17$ to be interpreted as $1.38 \mathrm{E}+17 \mathrm{n} / \mathrm{cm}^{2}$ after 32 equivalent full power years. 
Referring to the summary level results in Table 6-3, several conclusions may be drawn:

1. For the reference design (case 19.1), the maximum EFF on the vessel near the flange $\left(1.4 \mathrm{E}+17 \mathrm{n} / \mathrm{cm}^{2}\right)$ is more than twice that previously calculated if one were to ignore the hollow control rods (as in ref. 196), but just $27 \%$ higher than that predicted $\left(1.1 \mathrm{E}+17 \mathrm{n} / \mathrm{cm}^{2}\right)$ using the very elementary considerations outlined in Appendix B of that report.

2. Use of the newly proposed RSS hopper design, by itself, will not substantially reduce the overall fluence levels in the upper plenum because of the high neutron leakage through and around the hollow control rods. Case 19.2, for example, shows that the EFF on the vessel near the flange would still be $1.0 \mathrm{E}+17 \mathrm{n} / \mathrm{cm}^{2}$. Nevertheless, because of the ability of the new hopper design to reduce or eliminate the very highly localized hot spots previously noted on the thermal shield directly above the RSS penetrations, this must still be regarded as a very desirable design change.

3. While the 8-in. borated pin layer in the upper axial reflector may be necessary to protect the bottom of the upper plenum shield cans from excessively high thermal fluxes, it will reduce the EFF in the upper plenum by no more than a factor of two. Case 19.3, for example, shows that the EFF on the vessel near the flange would only be lowered to $5.8 \mathrm{E}+16 \mathrm{n} / \mathrm{cm}^{2}$. Moreover, much of this reduction in the EFF may actually be due to the correspondingly lower position of the control rods in the 4-in. channels.

4. Using solid-tipped control rods in conjunction with the newly proposed RSS hopper/plug design could lower the EFF on the vessel to $8.0 \mathrm{E}+16 \mathrm{n} / \mathrm{cm}^{2}$ (cf. case 19.6), while using both of these in conjunction with the proposed 8-in. borated pin layer in the top of the 46.83-in. upper axial reflector (cf. case 19.7) could lower the EFF at that point to $3.8 \mathrm{E}+16 \mathrm{n} / \mathrm{cm}^{2}$.

5. Using all the above improvements in conjunction with a thicker 62.44-in. upper axial reflector (cf. case 19.8) could further lower the EFF on the inner surface of the vessel by the main flange to $1.4 \mathrm{E}+16 \mathrm{n} / \mathrm{cm}^{2}$. While the additional $15.61 \mathrm{in}$. of graphite in the upper axial reflector could normally be expected to reduce the EFF by about an order of magnitude, that is not the case when the block has a 4-in.-diam penetration. Moreover, because of the RSS penetrations and the control rod channels, the overall reduction factor between cases 19.7 and 19.8 was more like a factor of 2.7. 
6. While several of the configurations described in Table 6-3 were able to reduce the EFF on the inner surface of the vessel near the flange to below the proposed limit of $5.0 \mathrm{E}+16 \mathrm{n} / \mathrm{cm}^{2}$, it must be realized that the values cited here are nominal best estimates. Moreover, at the $3 \sigma$ confidence level, the actual fluence levels could be as much as 5.4 times higher than these nominal values, and some additional design margin should be provided beyond that.

7. Based on the nominal fluences associated with several of the system configurations described in Table 6-3, it would appear that one could eliminate the upper plenum shield ring described in ref. 198. After one allows for the uncertainties noted in item (6) and some additional design margin, however, the elimination of the upper plenum shield ring would seem unadvisable given the current fluence limit of $5.0 \mathrm{E}+16 \mathrm{n} / \mathrm{cm}^{2}$.

8. More disturbing than the nominal fluences on the side of the vessel near the main flange are the nominal fluences on the inner surface of the upper plenum thermal shield. If the 15.61-in.-thick neutron shield bonnet between the thermal shield and the reactor vessel were eliminated, the inner dome of the reactor vessel would be exposed to these same high fluence levels. Based on these results, the elimination of the neutron shield bonnet shown in ref. 196 would be totally impractical, despite the numerous proposed design changes analyzed in the course of this study.

In summary, the elimination of a previously proposed shield ring in the upper plenum may or may not be possible, depending on the design margin required, while the elimination of the neutron shield bonnet between the upper plenum thermal shield and the inner dome of the reactor vessel would appear to be totally impractical given the present neutron fluence limits for the vessel.

\subsection{ANALYSIS OF THE BORATED PIN ARRAYS IN THE PERMANENT SIDE REFLECTOR AND A PLANNED EXPERIMENTAL MOCKUP ${ }^{197,199,210}$}

Because of the lack of any significant neutron absorption in the 4-ft-thick graphite side reflector, the thermal neutron flux in the graphite reflector remains relatively flat and extremely high ( $>1.0 \mathrm{E}+13 \mathrm{n} / \mathrm{s} / \mathrm{cm}^{2}$ ). To protect both the core barrel and the reactor vessel from the high thermal fluences in the reflector $\left(>-1.0 \mathrm{E}+22 \mathrm{n} / \mathrm{cm}^{2}\right)$ after 32 effective full-power years of operation, 8 staggered rows of borated stainless steel pins containing 2 wt \% natural boron would be placed in the outermost 10 -in. region of the permanent side reflector. Nominally, these pins 
would measure 0.75 -in. in diameter and would be placed in holes drilled in the permanent side reflector blocks on a 1.25-in. center-to-center triangular pitch. Earlier studies for the commercial MHTGR (cf. ref. 197) for 1, 2, 4, 6, and 8 rows of pins suggest that 4 to 6 rows of pins would "nominally" be able to reduce the thermal flux on the reactor vessel to acceptable levels if there were no depletion in the borated steel pins, while yet another study (cf. ref. 199) suggests that $85 \%$ of the B-10 in the first row of pins and $35 \%$ of the B-10 in the second row of pins may be destroyed after 32 effective full-power years. Hence, CEGA has tentatively decided to use 8 rows of borated steel pins, but only take credit for 6 undepleted rows of pins over the lifetime of the system. Accordingly, Table $5.2 \mathrm{~b}$ of ref. 197 shows that with 6 to 8 rows of 0.750 -in.-diam borated steel pins on a 1.25-in. pitch, the total neutron fluence would be between $2.10 \mathrm{E}+17$ and $2.00 \mathrm{E}+17 \mathrm{n} / \mathrm{cm}^{2}$ after 32 equivalent full-power years, while the EFF on the vessel at that time would be between $3.24 \mathrm{E}+16$ and $3.16 \mathrm{E}+16 \mathrm{n} / \mathrm{cm}^{2}$. By way of comparison, the proposed design limit for the EFF on the vessel is only $5.0 \mathrm{E}+16 \mathrm{n} / \mathrm{cm}^{2}$.

Note that the original 3-D Monte Carlo analyses (ref. 197) showed that the transmitted component of the thermal flux would be attenuated by 4 to 5 orders of magnitude across these few rows of borated steel pins in the permanent side reflector and that, were it not for this strong thermal neutron attenuation, the EFF (see the CE formula) would be significantly higher. Moreover, it should also be noted that the lifetime of the core barrel and the reactor vessel are both contingent on these 3-D analyses being correct. For that reason, it is absolutely imperative that such calculations be validated against actual shielding experiments in which the geometric configuration of the borated steel pins relative to the outward flow of neutrons is faithfully reproduced, along with the impingent neutron spectrum. The need for such an experiment is further emphasized when:

- One realizes that no similar experiments against which one could validate these analyses have ever been performed

- One realizes that most of the thermal neutrons reaching the core barrel stream uncollided between these staggered rows of borated steel pins, and that the amount of streaming is sensitive to the space between the pins

- One realizes that the earlier analyses of the commercial MHTGR (cf. ref. 197) only examined the "nominal" case (i.e., the most heavily attenuated case) where the borated pin array extended infinitely far in an uninterrupted fashion in two directions (axially circumferentially); no attempt was ever made in that earlier analysis to calculate the 
potentially high peak fluxes that would exist in the real design at the axial or circumferential interface(s) between adjacent permanent side reflector blocks where the spacing between borated pins in adjacent blocks would be necessarily greater than the nominal spacing

Reference 210 therefore describes a series of 17 proposed shielding experiments designed to investigate the effectiveness of the borated pin array as a thermal neutron shield. These proposed experiments are also designed to determine the effectiveness of several proposed design fixes for reducing the neutron streaming at the interfaces between the permanent side reflector blocks. All 17 proposed experiments would be constructed by arranging four borated pin array blocks in different configurations in front of a thick graphite spectral modifier placed in front of the largebeam collimator at ORNL's TSR. (The borated pin array blocks used to construct these configurations are illustrated in Figure 6-3, while the seven basic experimental shielding configurations underlying these 17 variations are illustrated in Figure 6-4.) A global, 2-D analysis of the entire TSR and the spectral modifier upstream of the proposed experimental configurations is described in ref. 210, as well as the 3-D Monte Carlo analysis of all 17 proposed experiments. These 3-D analyses of the borated pin arrays experiments were performed using a boundary source based on a 48 -in.-thick spectral modifier. The primary objectives were to verify that the proposed experiments would be subjected to conditions (i.e., neutron spectra) similar to those in the MHTGR, to verify that statistically meaningful measurements could be made behind these configurations with the TSR operating at or below its maximum power of $1 \mathrm{MW}$, and to determine what (if any) proposed measurements or experiments might be extraneous and could be eliminated. The results of these detailed 3-D pre-experimental shielding analyses are also important insofar as they offer new insights regarding local thermal flux peaking and the various design options or "fixes" that might still be exercised in the actual design of the permanent side reflector to minimize such peaking.

The last and most involved step in the pre-experimental analysis was the actual 3-D MORSE Monte Carlo analysis of the various proposed experimental configurations. A total of 17 different variations of seven basically different experimental configurations were studied. Referring to the configurations in Figure 6-4, these included the analysis (1) of the flux directly behind the center of a permanent side reflector block (configuration A); (2) at the interface between two axially adjacent permanent side reflector blocks (configurations B2 and C2), where thin graphite spacers were used to simulate the ends of the pins being inset different distances from the top and bottom 
ORNL-DWG 94-5599

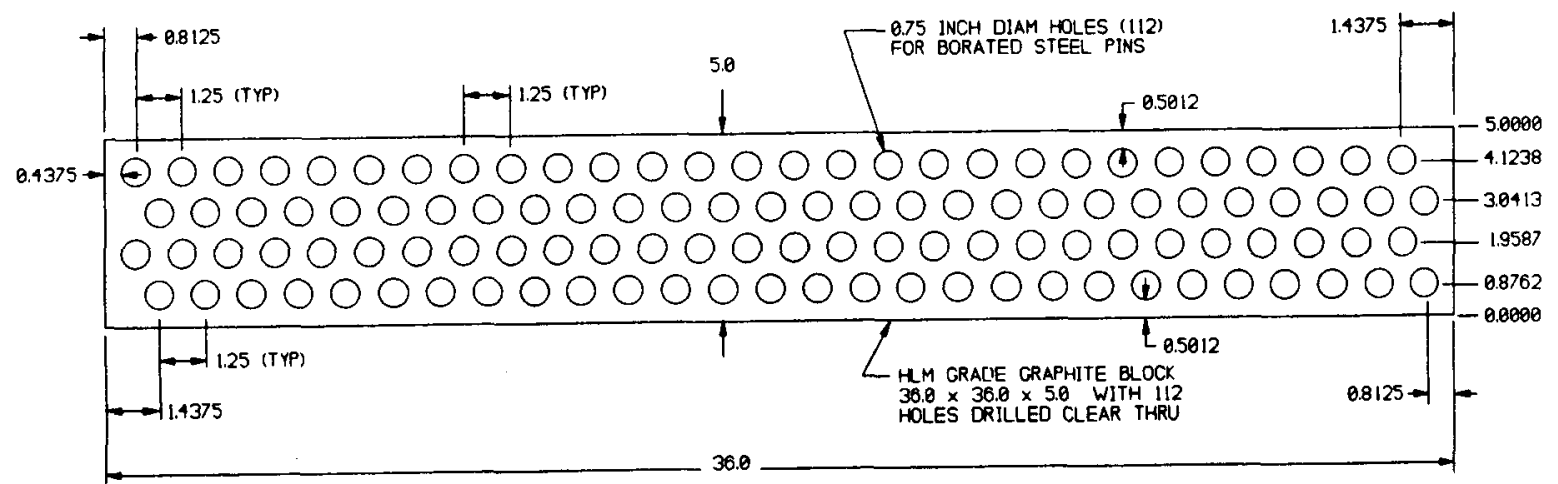

Figure 6-3(a).

DETAILED DRAWING OF A TYPICAL GRAPHITE BLOCK CONTAINING THE BORATED STEEL PINS TO BE USED IN THE EXPERIMENTS. FOUR SUCH BLOCKS WOULD BE REQUIRED FOR THE PLANNED SERIES OF EXPERIMENTS. ALL DIMENSIONS ARE SHOWN IN INCHES.

ORNL-DWG 94-5600

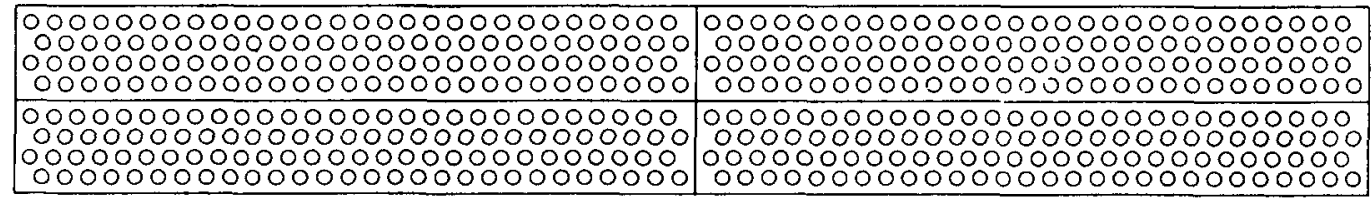

Figure 6-3(b).

TOP VIEW OF THE FOUR GRAPHITE PIN-ARRAY BLOCKS, ARRANGED AS SHOWN IN CONFIGURATION

BE OF FIG. 3-4. 
ORNL-DWG 94-5601

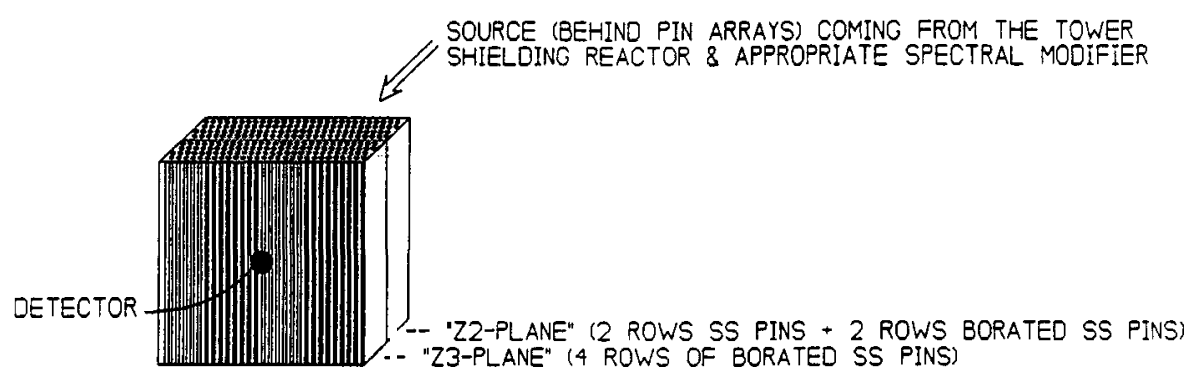

(A) NOMINAL CASE

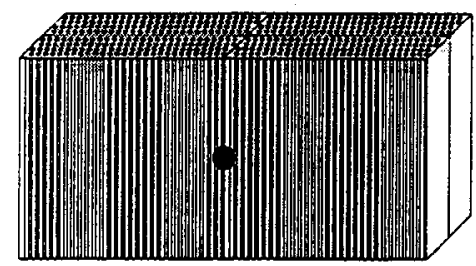

(B1) PINS ORIENTED VERTICALLY;
SEE DETAILED TOP VIEW

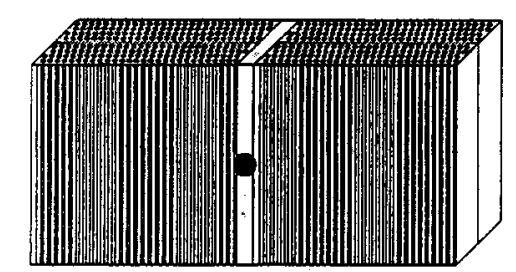

(C) GRAPHITE SPACER USED TO STUDY EFFECT OF PINS BEING INSET LAT RALLY
FROM THE SIDE(S) OF THE BLOCKS IN THE ACTUAL MHTGR

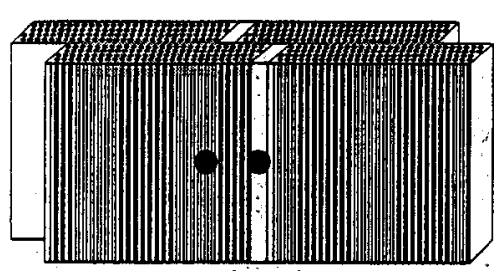

(D1) TO STUDY EFEECT OF OFFSETTING FIRST \& LAST 4 ROWS OF PINS LATERALLY IN THE ACTUAL' REACTOR

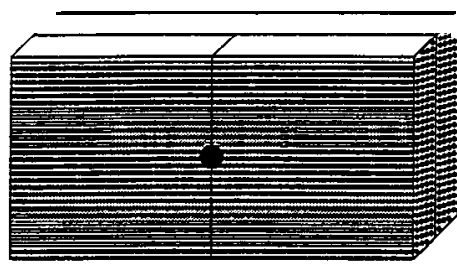

(B2) PINS ORIENTED HORIZONTALLY

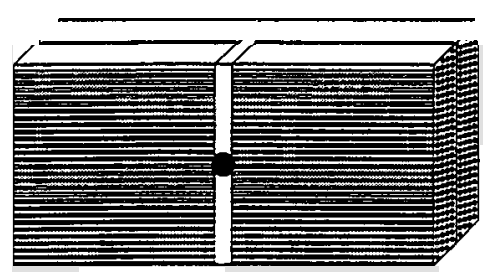

(C2) GRAPHITE SPACER USED TO STUDY EFFECT OF PINS BEING INSET AXIALLY FROM THE TOP \& BOTTOM OF THE BLOCKS IN THE ACTUAL MHTGR

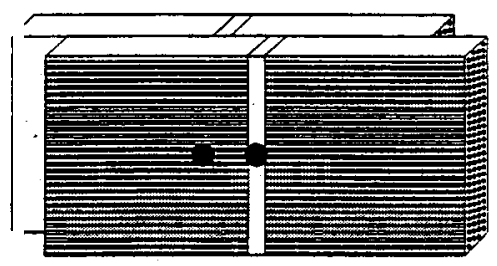

(D2) TO STUDY EFFECT OF OFFSETTINC FIRST \& LAST 4 ROWS OF PINS AXIALLY IN THE ACTUAL REACTOR

Figure 6-4.

ISOMETRIC VIEW OF THE PLANNED BORATED PIN ARRAY CONFIGURATIONS IF ONE WERE

ON THE OUTSIDE OF THE SYSTEM

LOOKING BACK TOWARD

THE REACTOR. 
of the blocks in the real design; and (3) for permanent side reflector blocks that did and did not have the first and last four rows of pins offset axially with respect to each other (configuration D2). These calculations also included the analysis of the flux at the interface between two circumferentially adjacent permanent side reflector blocks (configurations B1 and $\mathrm{C} 1$ ), where thin graphite spacers were used to simulate the pins being inset different distances from the sides of the blocks, and for permanent side reflector blocks that did and did not have the first and last four rows of pins offset laterally with respect to each other (configuration D1). Lastly, the effects of having or not having a 3-in. block of graphite downstream of configurations (A) and (C1) were also examined. In each case, the 3-D MORSE Monte Carlo code was used to calculate the 27-group scalar flux at a point (or points) directly behind the experimental configuration, as well as the overall response of the 10- and 5-in. Bonner ball detectors that would be used in the actual experiment, as well as the overall response of $\mathrm{Cd}$-covered and bare $\mathrm{BF}_{3}$ detectors that would be used in the actual experiment. The primary purpose of these 3-D Monte Carlo analyses was to ensure that statistically meaningful counting rates could be obtained for each type of detector with the TSR operating at or below its maximum power of $1 \mathrm{MW}$.

Sketches A, B1,.., D2 in Figure 6-4 show how the four borated pin array blocks might be arranged in front of the (48-in.) spectral modifier for study of the lateral and axial peaking effects between adjacent blocks in the permanent side reflector of the MHTGR, while Figure 6-5 shows the calculated bare $\mathrm{BF}_{3}$ detector response for the 15 original variations of these same configurations. Table 6-4 shows the calculated detector responses for the 10 - and 5 -in. Bonner ball detectors measuring the fast and intermediate energy neutrons, as well as for the Cd-covered and bare $\mathrm{BF}_{3}$ detectors measuring epithermal and thermal neutron fluxes at the point(s) of interest. These results clearly indicate that statistically meaningful measurements can be made for all of the configurations of interest, over the entire energy range of interest using these various detectors.

The results of these detailed 3-D pre-experimental shielding analyses also provide a number of insights that will be helpful in the actual design of the permanent side reflector. Relative to the nominal case directly behind the center of a permanent side reflector block (which is similar to assuming that one has an infinite and uninterrupted array of borated steel pins as in ref. 197), the localized peaking factors for the thermal flux incident on the inner surface of the core barrel at the interface between circumferentially adjacent reflector blocks may range from 54 to 188 . These peaking factors may be reduced by about an order of magnitude by having the borated pins distributed in two rows of permanent side reflector blocks which are offset 4 in. laterally with 
ORNL-DWG 94-5602

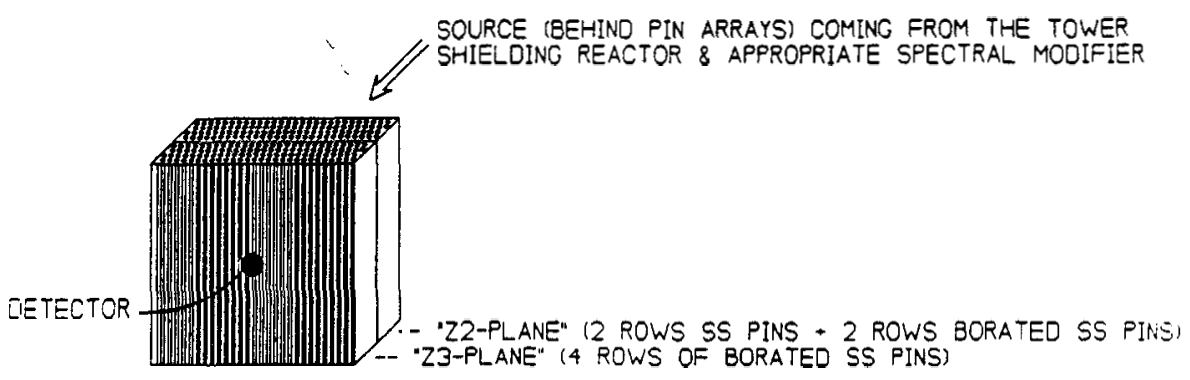

(A) Case P01, CP1F 281

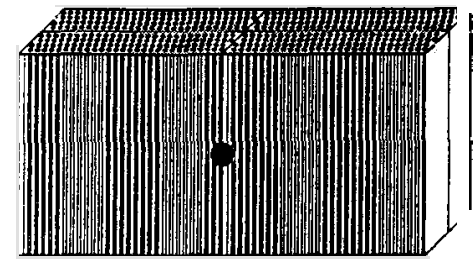

(81) Case P07. CPM $=4242$

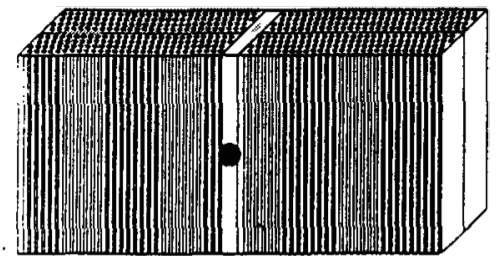

(C1) Cose PO6, Specer $=0.500^{n}, \mathrm{CPM}=15145$ Case P02, Spacer=1.125N, CPM= 52862

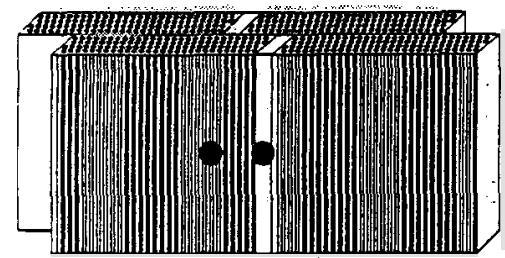

(O1) Case P19, Specer $=0.500 \mathrm{w}$ offset=2.0\%, CPW= 7301 Case P10, Specer $=0.500^{\circ}$ offset=4.0 case POO, spacer=1.125n offect=2. On' CPN=29645 Case P08, Spacer=1.125" offset $=4.0 \mathrm{n}$, CPW= 6700

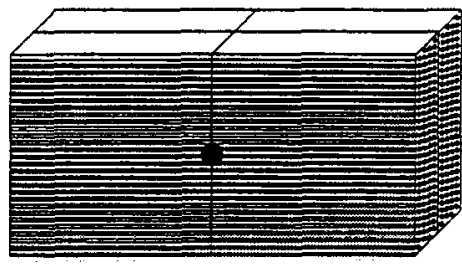

(B2) Case POS, CPM=2S4

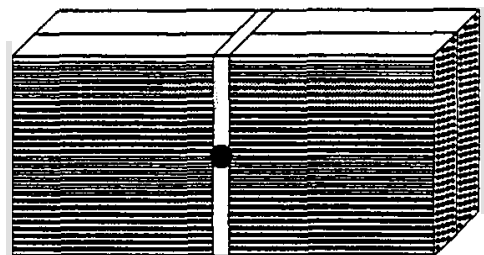

(C2) Case $P 04$, Spacer $=0.5^{\mathrm{N}}, \mathrm{CPM}=885$ Case P03, Specer=1.0m, CPM 3783

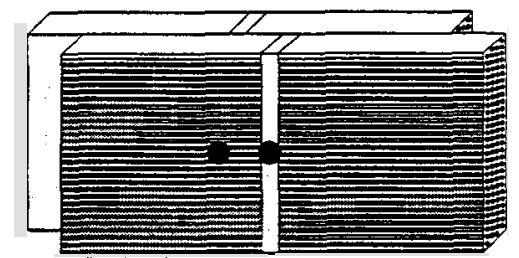

(02) Case P15, Spocer $=0.5 n$ Offset=2.0n, CPNa 451 Case P1L. Spacer $=0.5 \mathrm{n}$ of 1 set $=2.0 \mathrm{~m}, \mathrm{CPM}=435$ Case P13, spacer=1. On offset $=2$. On " CPN=133\%

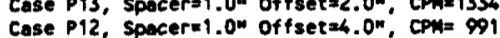

Figure 6-5.

\section{CALCULATED VALUES OF THE BARE BF3 DETECTOR COUNTING RATES FOR EACH OF THE 15 ORIGINALLY PLANNED CONFIGURATIONS IF THE TOWER SHIELDING REACTOR WERE OPERATING AT 1 KILOWATT. SEE DETAILED DATA IN TABLE 6-4.}


Table 6-4

CALCULATED COUNTS PER MINUTE FOR VARIOUS DETECTORS (WITH ESTIMATED FRACTIONAL STANDARD DEVIATIONS) BEHIND EXPERIMENTAL CONFIGURATIONS P01 THROUGH P15 WITH THE TOWER SHIELDING REACTOR OPERATING AT 1.0 KILOWATTS AND A 48-INCH SPECTRAL MODIFIER BETWEEN THE TSR COLLIMATOR AND THE EXPERIMENTAL SPECIMENS. THE RESULTS HERE ARE BASED ON THE COMBINED RESULTS OBTAINED FOR THE FAST NEUTRON SOURCE PROBLEM AND THE THERMAL NEUTRON SOURCE PROBLEM. THESE RESULTS ARE THEREFORE THE BEST ESTIMATE OF WHAT ONE WOULD ACTUALLY MEASURE IN THE EXPERIMENT.

\begin{tabular}{|c|c|c|c|c|c|c|c|c|c|c|c|c|c|}
\hline \multirow{2}{*}{$\begin{array}{c}\text { CONFIG } \\
\text { SKETCH } \\
\text { I.D. }\end{array}$} & \multirow{2}{*}{$\begin{array}{c}\text { SPACER } \\
\text { THICK } \\
\text { (in) }\end{array}$} & \multirow{2}{*}{$\begin{array}{c}\text { OFFSET } \\
\text { MODEL } \\
\text { I.D. }\end{array}$} & \multirow{2}{*}{$\begin{array}{c}\text { ANALY. } \\
\text { MODEL } \\
\text { I.D. }\end{array}$} & \multirow{2}{*}{$\begin{array}{l}\text { CRAY } \\
\text { TIME } \\
\text { (hrs) }\end{array}$} & \multirow{2}{*}{$\begin{array}{c}\text { DET. } \\
\text { LOC. } \\
\left({ }^{*}\right)\end{array}$} & \multicolumn{2}{|c|}{$10 "$ Bunner } & \multicolumn{2}{|c|}{$5^{*}$ Banner } & \multicolumn{2}{|c|}{ Cd-covered } & \multicolumn{2}{|c|}{ Bare BF3 } \\
\hline & & & & & & CPM & $\overline{F S D}$ & CPM & $\overline{\text { FSD }}$ & $\overrightarrow{\mathrm{CPM}}$ & $\overline{F S D}$ & $\overline{C P M}$ & FSD \\
\hline A & & & $P 01-48$ & 6.60 & 0 & 5093.3 & .030 & 11535.4 & .027 & 84.2 & .031 & 281.1 & .037 \\
\hline BI & & & $P 07-48$ & 23.4 & 0 & 5081.8 & .029 & 12105.5 & .027 & 112.2 & .031 & 4242.0 & .038 \\
\hline $\mathrm{Cla}$ & 0.500 & & P06-48 & 4.28 & 0 & 5489.0 & .031 & 13085.5 & .025 & 137.7 & .028 & 15144.8 & .017 \\
\hline $\mathrm{Clb}$ & 1.125 & & $P 02-48$ & 3.96 & 0 & 5612.9 & .031 & 13510.2 & .027 & 179.7 & .033 & $\$ 2862.2$ & .016 \\
\hline Dla & 0.500 & 2.00 & P11-48 & 5.26 & 1 & 5457.2 & .038 & 12494.5 & .030 & 123.5 & .033 & 5486.8 & .021 \\
\hline & & & & & 2 & 5433.1 & .035 & 12585.5 & .029 & 130.1 & .033 & 7300.7 & .021 \\
\hline DIb & 0.500 & 4.00 & $P 10-48$ & 6.75 & 1 & 5362.2 & .033 & 12573.7 & .029 & 111.4 & .031 & 1293.3 & .031 \\
\hline & & & & & 2 & 5496.2 & .035 & 13080.8 & .032 & 126.9 & .034 & 2340.0 & .026 \\
\hline Dic & 1.125 & 2.00 & P09-48 & 8.68 & 1 & 5389.1 & .034 & 13277.3 & .029 & 162.3 & .034 & 23452.4 & .013 \\
\hline & & & & & 2 & 5414.2 & .034 & 13550.9 & .030 & 174.4 & .035 & 29645.2 & .013 \\
\hline DId & 1.125 & 4.00 & P08-48 & 6.09 & 1 & 5371.5 & .028 & 12955.6 & .024 & 130.8 & .025 & 3685.0 & .025 \\
\hline & & & & & 2 & 5482.2 & .028 & 13396.9 & .025 & 151.4 & .027 & 6700.2 & .025 \\
\hline B2 & & & P05-48 & 3.97 & 0 & 5378.4 & .039 & 12138.2 & .033 & 83.0 & .033 & 253.7 & .038 \\
\hline $\mathrm{C} 2 \mathrm{a}$ & 0.500 & & P04-48 & 3.56 & 0 & 5617.1 & .038 & 12430.7 & .030 & 93.3 & .032 & 884.7 & .031 \\
\hline $\mathrm{c} 2 \mathrm{~b}$ & 1.000 & & $P 03-48$ & 3.06 & 0 & 5471.5 & .033 & 12632.1 & .030 & 113.1 & .036 & 3782.6 & .025 \\
\hline D2a & 0.500 & 2.00 & P15-48 & 6.02 & 1 & 5356.5 & .034 & 12333.5 & .026 & 89.0 & .031 & 353.5 & .034 \\
\hline & & & & & 2 & 5339.9 & .035 & 12332.3 & .026 & 89.2 & .029 & 451.4 & .032 \\
\hline D2b & 0.500 & 4.00 & $P 14-48$ & $\cdot 7.96$ & 1 & 5034.2 & .027 & 11893.6 & .023 & 92.5 & .030 & 337.1 & .041 \\
\hline & & & & & 2 & 5220.4 & .031 & 12170.4 & .025 & 97.1 & .028 & 435.1 & .037 \\
\hline D $2 c$ & $1.0 \times 0$ & 2.00 & P13-48 & 6.41 & 1 & 5315.8 & .035 & 12231.6 & .028 & 103.7 & .036 & 1012.8 & .026 \\
\hline & & & & & 2 & 5437.2 & .035 & 12542.1 & .027 & 108.1 & .036 & 1334.1 & .025 \\
\hline D2d & 1.000 & 4.00 & P12-48 & 5.44 & 1 & 5389.3 & .037 & 12531.4 & .032 & 99.2 & .033 & 641.3 & .044 \\
\hline & & & & & 2 & 5273.4 & .034 & 12501.9 & .030 & 103.8 & .032 & 991.3 & .035 \\
\hline
\end{tabular}

Detector 0 is at $y=0.0, x=0.0$; (ie. along system centerline); used for configurations with no offset Detector 1 is at $y=00, x=-(T / 2)$, where $T$ is the offset distance; (ie, in front of spacer in the 22 -plane) Detector 2 is at $y=0.0, x=+(T / 2)$, where $T$ is the offset distance; (ie, in front of spacer in the $z 3$-plane) 
respect to each other. Thermal flux peaking factors at the axial interface between axially adjacent blocks are not as large (typically 3.5 to 14.9 , depending on the design) and may be reduced by about a factor of 2 or 3 by offsetting the blocks in adjacent radial rings by 2 to 4 in. axially with respect to each other. While the primary purpose of this study was to assist in the planning and design of the pin-array shielding experiments, fine- and broad-group data reported in Appendix $E$ of ref. 210 may also be used in conjunction with earlier data in ref. 197 to provide some initial rough estimates of the thermal neutron flux incident on different localized regions of the inner surface of the core barrel in the actual MHTGR design.

\subsection{SCOPING STUDIES FOR THE NPR-MHTGR ${ }^{207}$}

This preliminary scoping assessment of the neutron shielding for the conceptual NPR design (and several variations of it) relies on new 1-D analyses of the NPR as well as extensive scaling of previous 2- and 3-D shielding results for the commercial MHTGR in order to arrive at rough estimates of the neutron fluences along the beltline of the NPR vessel, in the upper head of the reactor vessel, and the regions in and below the hot-gas plenum, including that portion of the reactor vessel near the cross duct. Besides the use of HEU, the absence of any thorium, and a somewhat flatter axial power distribution, the most obvious difference between the NPR and the commercial MHTGR is the use of lithium target elements distributed throughout the core (and perhaps in the outer reflector) of the NPR. In this report, ${ }^{207}$ differences between the commercial MHTGR and the NPR-MHTGR have been noted and evaluated; several methods of modeling the lithium targets in the core have been investigated; and lastly, differences between the 66,72 , and 84 fuel column designs have been investigated, including some sensitivity studies. Much more rigorous 2- and 3-D studies will be required over a period of several years to supplement the very preliminary scoping studies described in ref. 207.

One important lesson common to both the NPR and commercial MHTGR core designs relates to the placement of fuel assemblies in the outer row of the core and the attendant effect on the vessel fluence. While the 84 -column core has 30 assemblies in each of the outer two rows (with 1 assembly missing in each of the 6 corners of the outermost row) and only 24 assemblies in the innermost row, this design had a larger core barrel, and the EFF on the beltline of the vessel was comparable (to within a factor of two) to that for the smaller 66-column core, which had 24 assemblies in each of the outer 2 rows (with 1 assembly missing in each of the 6 corners of the outermost row) and only 18 assemblies in the innermost row. The once-proposed 
72-column core, however, had the same core barrel diameter as the original 66-column core, while the additional 6 assemblies were obtained by replacing the reflector blocks in the 6 corners of the outermost row with fuel assemblies. This places the corners of these assemblies about 7.1 in. closer to the core barrel than the next two closest assemblies. Moreover, the thickness of the graphite reflector between these assemblies and the core barrel would now be 9.7 in. less than the "average" amount of graphite seen by the rest of the core. Based on this, it is expected that the EFF on the inner surface of the reactor vessel (near these 6 locations) would be $1.55 \mathrm{E}+17 \mathrm{n} / \mathrm{cm}^{2}$ after 32 equivalent full power years of operation-i.e., 4.36 times higher than that for the original 66-column commercial MHTGR and 5.88 times higher than that for the 66-column NPR-

MHTGR. Moreover, this nominal estimate (which does not include the effect of uncertainties) is about three times higher than CEGA's design limit of $5.0 \mathrm{E}+16 \mathrm{n} / \mathrm{cm}^{2}$. Certainly, anyone wishing to optimize the performance of the commercial MHTGR by completing the last ring of fuel assemblies in the core should be very cautious of this effect.

\subsection{INVESTIGATION OF NEWLY PROPOSED RADIATION DAMAGE FUNCTIONS ${ }^{208}$}

One of the primary objectives of the shielding task is to determine the fast and thermal neutron fluence on the reactor vessel so that some estimate of radiation damage can be made over the lifetime of the system. In particular, one is interested in the fluence in the upper head, at the beltline of the vessel, and in that portion of the lower vessel adjacent to the cross duct. While shielding calculations for these regions are typically performed using 14 fast-neutron groups and 1 thermal group, the results are typically reported in terms of 4 broad energy groups:

1. $\mathrm{E}>0.9 \mathrm{MeV}$

2. $0.1 \mathrm{MeV}<\mathrm{E}<0.9 \mathrm{MeV}$

3. $3.05 \mathrm{eV}<\mathrm{E}<0.1 \mathrm{MeV}$

4. $\mathrm{E}<3.05 \mathrm{eV}$

Operational limits on the useful lifetime of a ferritic-based pressure vessel must be based on the expected embrittlement of the material due to radiation damage, which depends not only on the intensity of the incident radiation, but also on the spectrum of the incident neutrons. Due to the greatly reduced absorption of intermediate, epithermal, and thermal neutrons, the neutrons emerging from an MHTGR will have a much softer spectrum than an LWe-i.e., the MHTGR will have more intermediate and epithermal neutrons and relatively fewer fast neutrons than an LWR. Rather than ignore the radiation damage caused by these intermediate and epithermal 
neutrons, CE proposed in September 1986 that the radiation damage for the MHTGR vessel be gauged in terms of the EFF which they defined as:

$$
\begin{gathered}
\text { Fluence }(\text { EFF })=1.0 \times \text { Fluence }(\text { Grp A) }+0.5 \times \text { Fluence }(\text { Grp B) } \\
+0.0025 \times \text { Fluence }(\text { Grp C) }+0.07 \times \text { Fluence }(D)
\end{gathered}
$$

The hope and expectation was that operational limits for the MHTGR could then be based on the EFF in much the same way that NRC Regulatory Guide 1.99, Rev. 2, is used to determine operational limits for current generation LWRs based on the actual fast fluence above $1 \mathrm{MeV}$. Mansur and Farrell ${ }^{217}$ have since noted that while the degree of embrittlement is conventionally correlated with the fast-neutron fluence or with the total number of dpa (see ASTM Standard E693-79), both of which are measures of the production rate of point defects, radiation effects such as embrittlement are not driven by the total number of atoms displaced but by the small fraction of point defects that avoid annihilation by mutual recombination and are available to form clusters or to be absorbed at sinks. In short, radiation effects such as embrittlement are determined by the survival rate of point defects, not their production rate.

As a starting point for future work, ref. 208 formally defines and documents the concept of an EFF as a comparative measure of radiation damage for the ferritic materials in the MHTGR and develops several alternate sets of spectral weighting factors that might be used to estimate the EFF based on (1) the standard ASTM dpa damage function or the more recently proposed (2) Doran and (3) Wiedersich damage functions, which account for some (energy-dependent) incascade recombination effects and are therefore more representative of the number of surviving point defects in the metallic lattice that are actually available to cause property changes such as embrittlement. Differences in the calculated magnitude of the EFF due to the use of these three different damage functions versus the original $\mathrm{CE}$ formulation are significant (i.e., up to a factor of two or three in some instances, and more than a factor of ten in other instances) and are discussed separately for the upper portion of the reactor vessel near the main flange, at the beltline of the reactor vessel, in the hot-gas plenum, and on the top surface of the CSS. Moreover, it has yet to be determined if (1) the EFF or some other figure of merit should be used to gauge radiation damage, (2) whether or not the NRC will accept the EFF as a facilitating parameter for interpreting its current regulatory guides, and (3) which of the three or four methods of calculating the EFF would best correlate with radiation damage. Recommendations as 
to which damage function is the most realistic and which set of assumptions should be used for estimating the EFF during the licensing process are beyond the scope of this study and will have to be made later by researchers in the basic material sciences, the vendor, the DOE, or other regulatory agencies.

\subsection{MISCELLANEOUS ACTIVITIES ${ }^{205,209,211}$}

The purpose of the process described in the Verification and Validation Plan ${ }^{205}$ is to provide verified computer codes and validated shielding analysis methods for the confirmatory analysis of the shielding aspects of the MHTGR. In addition to reviewing industry and regulatory standards for verification and validation, this document lists all of the 1-, 2-, and 3-D shielding codes (such as ANISN, XSDRNPM, DOT, DORT, TORT, and MORSE) that would be used in the shielding analyses, as well as the SCALE and AMPX cross-section processing codes (such as BONAMI, NITAWL, XSDRNPM, ICE, and GIP) that would be needed, as well as the SAS2 and ORIGEN-S programs that would be needed to obtain the gamma sources in the fuel and other components at and after shutdown. It also describes a detailed verification plan for the major shielding codes (DOT and MORSE). More importantly, it describes a well-conceived experimental validation plan for complex shielding methods involving these codes. More specifically, it notes that a "shielding method" generally involves a complex analytic sequence requiring the use of one or more codes in such a way as to adequately estimate or approximate the flux in or downstream of a real shielding configuration, which often cannot be adequately represented by any single geometric model in any single code. Figure 6-6, for example, shows the analytic sequence for calculating the fluences on the upper internals and on the upper head of the reactor vessel, while Figure 6-7 shows the analytic sequence for calculating the fluences for the lower internals and the lower head of the reactor vessel, including those in the hot-gas plenum and those incident on the open end of the cross duct. While "verifying" that individual codes function as intended is generally fairly trivial, calculational methods involving specific complex analytic sequences tailored for individual problems or classes of problems must ultimately be "validated" against prototypic experimental configurations when the calculated results are critical to the design. Appendix A of ref. 205 lays out the experimental plan necessary to validate the methods used to calculate neutron streaming through various open channels into the upper and lower plenums and to calculate the thermal neutron attenuation through the staggered array of borated steel pins in the permanent side reflector of the MHTGR. 
ORNL-DWG 94-5603

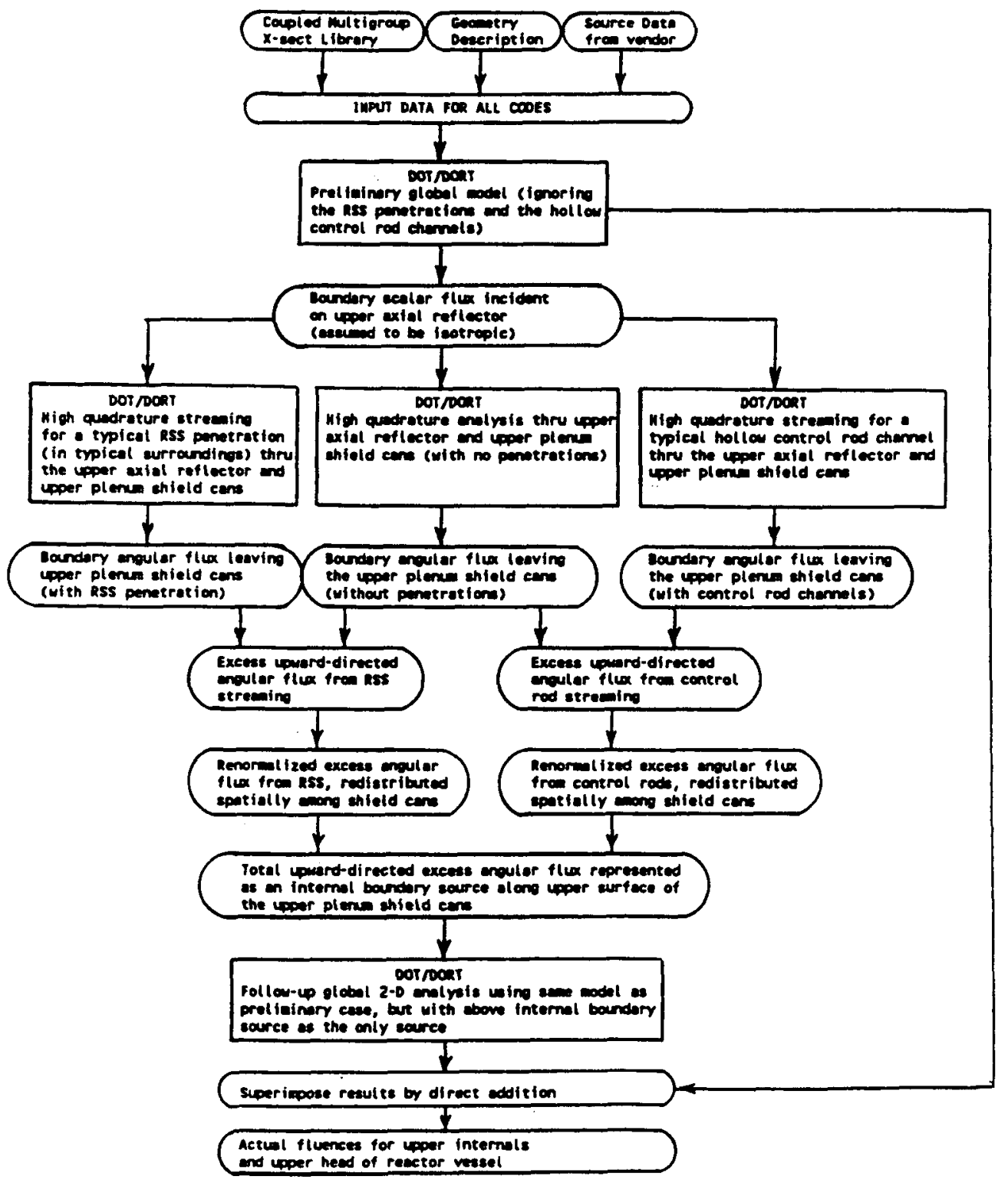

Figure 6-6.

\section{ANALYTIC SEQUENCE FOR CALCULATING FLUENCES ON THE UPPER INTERNALS AND THE UPPER HEAD OF THE REACTOR VESSEL.}




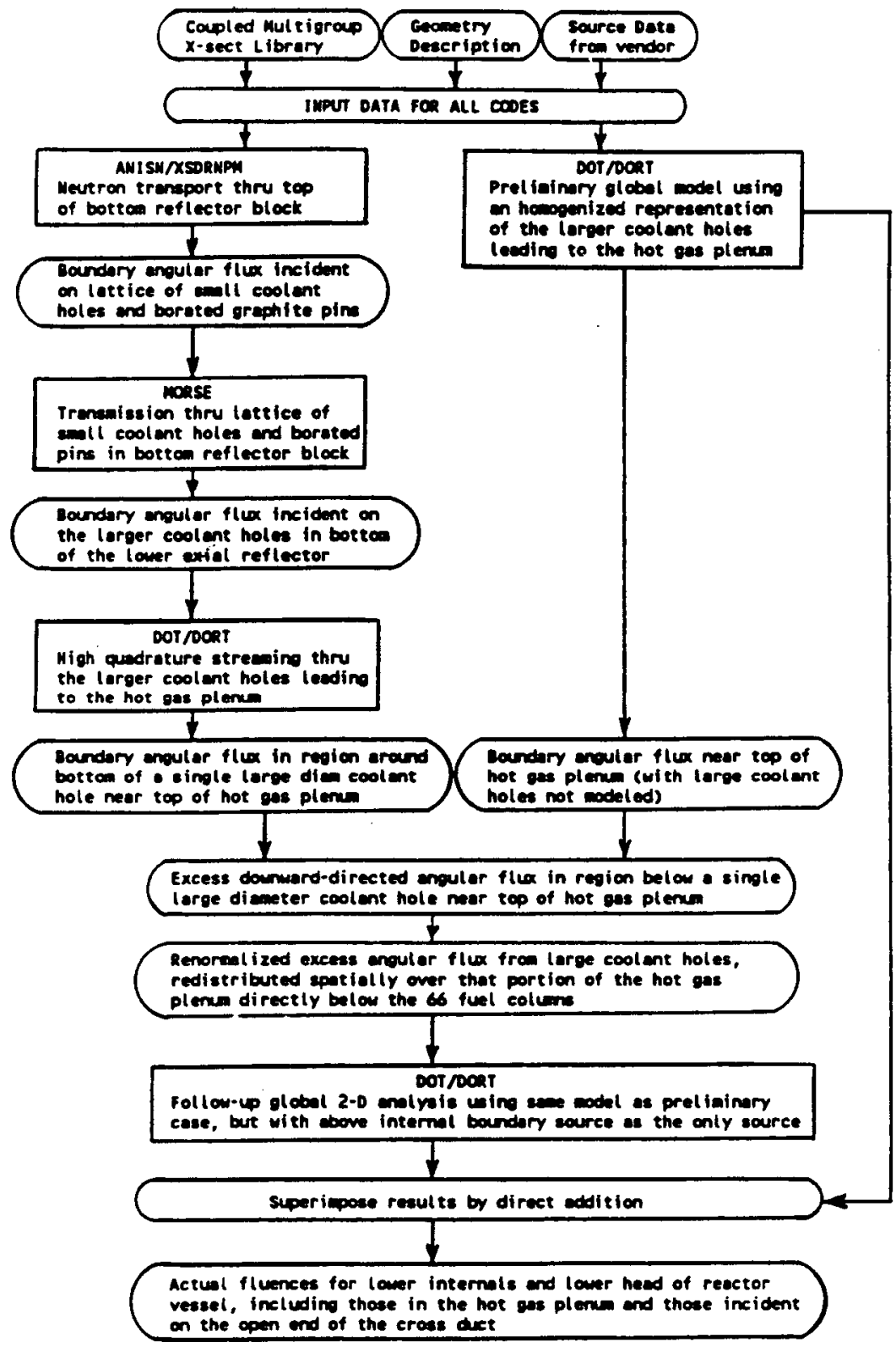

Figure 6-7.

\section{ANALYTIC SEQUENCE FOR CALCULATING FLUENCES FOR THE LOWER INTERNALS AND THE LOWER HEAD OF THE REACTOR VESSEL, INCLUDING THOSE \\ IN THE HOT GAS PLENUM AND THOSE
INCIDENT ON THE OPEN END OF THE CROSS DUCT.


Verification of the 3-D MORSE/SGC Monte Carlo shielding code on the Cray UNICOS system $^{211}$ was under way but only partially complete in January 1992 , at which time funds for a large number of NPR-related activities were abruptly terminated. The document, as issued, includes a detailed flow chart of the entire program and a description of each subroutine, as well as a more complete listing of the results for the eight standard MORSE sample problems. Considerable effort was also spent eliminating all known geometric tracking errors caused by machine roundoff on the Cray. Had this verification task been allowed to continue to its natural completion, however, additional new elements deemed necessary by the then current QA guidelines would have been included in this verification package. In particular, the eight original sample problems described in this document and elsewhere in the literature deal primarily with infinite air and air-over-ground calculations involving only concentric spheres representing the various geometric zones. While such benchmarks do test many of the fundamental aspects of the code, they accomplish very little in terms of testing the powerful 3-D COMJOM geometry options in the code. More importantly, they do not test or even demonstrate the far more powerful Multiple Array-of-Arrays (MARS) geometry package that must frequently be used in conjunction with COMJOM geometry options to solve the complex geometric modeling problems required for realistic MHTGR shielding analyses. The use of borated steel pins in the permanent side reflector of the MHTGR, for example, requires extensive use of both of these options together.

Calculational models for the borated pins in the permanent side reflector are illustrated in refs. 197 and 210, while 3-D calculational models for neutron streaming through the many holes in the lower axial reflector blocks are described in ref. 202. Had the initial "verification" of the MORSE-SGC code been funded to its completion, the results of one or more realistic problems involving these or similar complex geometries would have been compared with calculational results obtained by other independent calculational methods. Ultimately, the final "validation" of these models would have been accomplished by comparison against experimentally measured values obtained from a planned series of prototypical shielding experiments. Unfortunately, until funds for the commercial or NPR-MHTGR shielding task are restored, and results for realistic shielding problems requiring the simultaneous use of both the COMJOM and MARS geometry options compared against results obtained by other calculational methods or experiments, this report on the initial verification of the MORSE-SGC code for MHTGR shielding analyses must be regarded as a partially incomplete interim report. Moreover, completion of this work should be one of the first objectives if and when this shielding program is ever resumed. 
Lastly, a new, fine-group, fully coupled, neutron-gamma cross-section library based on the most recent ENDF/B-VI data was developed by the Radiation Shielding Information Center at ORNL for eventual use in the confirmatory MHTGR shielding analyses (cf. ref. 209). This library, known as NPRXS, has 197 neutron groups and 42 gamma groups. The desire to have a library based on newer ENDF/B-VI data was based on the fact that these data are known to contain significant improvements for a number of structural materials (notably, $\mathrm{Cr}, \mathrm{Fe}, \mathrm{Mn}$, and $\mathrm{Ni}$ ) and better representations of collision processes for all materials, as well as other refinements for both carbon and B-11. [Moreover, during the course of developing this library, the S(alpha,beta) thermal scattering data in the ENDF files for graphite were also corrected in July 1990 so as to more nearly resemble the original GASKET data reported by GA.] The neutron group structure, with 165 fast groups above $3.059 \mathrm{eV}$ and 32 thermal groups below $3.059 \mathrm{eV}$, was based on the 175 groups in the VITAMIN-J library (a European library based on ORNL's VITAMIN-C and VITAMIN-E libraries) and the 27 groups used in the SCALE shielding library, with deference to the VITAMIN-J boundaries at higher energies when the energy boundaries were essentially the same. The gamma group boundaries (which go up to $30 \mathrm{MeV}$ to accommodate some known $\mathrm{n} / \mathrm{g}$ reactions) were based on a combination of 41 of the 42 groups in the VITAMIN$\mathrm{J}$ library and the boundaries for the 18 gamma groups in the SCALE $27 \mathrm{n} / 18 \mathrm{~g}$ library. While this library does include U-235, U-238, and Th-232, it was always intended primarily as a shielding library-i.e., not a general-purpose library. Thus, it only has 38 nuclides commonly found in the structural and shielding materials in the MHTGR. At the request of the sponsor (DOE/NP-61), this cross-section library is not publicly available, although program participants may obtain it at no charge through the Radiation Shielding Information Center at ORNL. While the library is complete and has received a limited amount of in-house testing, the NPR Program was terminated before this library could undergo large-scale testing or be implemented in any day-to-day confirmatory analyses. 


\title{
SCETION 7
}

\section{HIGH-TEMPERATURE DESIGN CRITERIA}

\author{
Joseph J. Blass
}

In the United States, components of nuclear reactor systems are designed in accordance with applicable provisions of Sect. III of the ASME Boiler and Pressure Vessel Code. Section III provides for several classes of components. Included in class 1 are components that form part of the primary reactor coolant pressure boundary. For class 1 components at relatively low service temperatures $\left[371^{\circ} \mathrm{C}\left(700^{\circ} \mathrm{F}\right)\right.$ or less for ferritic steels and $427^{\circ} \mathrm{C}\left(800^{\circ} \mathrm{F}\right)$ or less for austenitic steels and high-nickel alloys], the applicable provisions are in Subsection NB of Sect. III. For class 1 components at higher temperatures, Code Case N-47 (ref. 183) is applicable. Four structural materials are permitted by the current edition of this case, and another material $(9 \mathrm{Cr}-1$ Mo-V) is expected to be added in the future. These materials and the corresponding temperature case limits for a service life of $300,000 \mathrm{~h}$ or less are listed below:

\begin{tabular}{|c|c|}
\hline \multicolumn{2}{|c|}{ ASME B\&PV Code Case $\mathbf{N}-47$} \\
\hline Structural material & Temperature limit ${ }^{\circ} \mathrm{C}\left({ }^{\circ} \mathrm{F}\right)$ \\
\hline $2.25 \mathrm{Cr}-1 \mathrm{Mo}$ steel & $593(1100)$ \\
\hline $9 \mathrm{Cr}-1 \mathrm{Mo}-\mathrm{V}$ steel & $649(1200)$ \\
\hline $\mathrm{Ni}-\mathrm{Fe}-\mathrm{Cr}$ Alloy $800 \mathrm{H}$ & $760(1400)$ \\
\hline 304 or 316 stainless steel & $816(1500)$ \\
\hline
\end{tabular}

In an MHTGR power plant based on the Rankine steam-turbine cycle, the heat-transfer tubes in the SG are considered class 1 components. In the NP-MHTGR SG, the helium inlet temperature of $686^{\circ} \mathrm{C}\left(1267^{\circ} \mathrm{F}\right)$ and the temperature limits in Code Case $\mathrm{N}-47$ led to the selection of Ni-Fe-Cr Alloy $800 \mathrm{H}$ for the FSH.

In an MHTGR power plant based on the indirect Brayton gas-turbine cycle, the heat-transfer tubes in the intermediate heat exchanger are also considered class 1 components. 
For this application, a helium inlet temperature of at least $850^{\circ} \mathrm{C}\left(1562^{\circ} \mathrm{F}\right)$, above the limits of Code Case N-47, is needed.

Potential process-heat applications for an MHTGR include production of alumina from bauxite and production of synthesis-gas or hydrogen by steam reforming of methane or steam gasification of coal. For these applications, helium inlet temperatures of about $950^{\circ} \mathrm{C}\left(1742^{\circ} \mathrm{F}\right)$ are needed. ${ }^{218}$

At the request of the DOE and one of its contractors, structural design criteria for these higher-temperature applications were formulated as a proposed ASME Code Case by an ad-hoc group called the Task Force on Very High-Temperature Design. A draft of the proposed case $e^{219}$ was completed in 1989 for consideration by relevant code committees. The proposed case has passed the Subgroup on Elevated-Temperature Design, and the Subcommittee on Design, and is awaiting transmittal to the subcommittee on Sect. III.

The draft case is patterned after relevant portions of Code Case $\mathrm{N}-47$ and is limited to $\mathrm{Ni}-\mathrm{Cr}$-Co-Mo Alloy 617 , temperatures of $982^{\circ} \mathrm{C}\left(1800^{\circ} \mathrm{F}\right)$ or less, and service lives of $100,000 \mathrm{~h}$ or less. A synopsis of the draft case and the significant differences between it and Code Case $\mathrm{N}-47$ are provided in ref. 220. Particular emphasis is placed on material behavior and allowable stresses. Recommendations are also provided on materials and structures development activities needed to place the design methodology on a sound and defensible footing. 


\title{
SECTION 8
}

\section{PHYSICS AND SHIELDING}

\author{
B. A. Worley
}

\subsection{PHYSICS}

\subsubsection{Introduction}

The NE-MHTGR physics work performed at ORNL from October 1989 through June 1993 has been carried out primarily under the international cooperative task discussed in Sect. 8.3. However, ORNL staff members also performed reactor physics analysis tasks for the NP-MHTGR program. Although the work performed at ORNL did not incorporate NE-MHTGR work that might be considered generic, several findings from the ORNL NP-MHTGR work that might impact future NE-MHTGR physics analysis are summarized herein.

\subsubsection{Errors in ENDF/B-V Graphite Data}

In the course of comparing temperature coefficient numerical benchmark results between ANL, INEL, and ORNL, a plot of temperature coefficient versus temperature revealed an inconsistency observed by all three organizations. Namely, the temperature coefficient curve, shown in Figure 8-1, portrayed an apparent unphysical trend. ORNL was assigned the task to uncover the source, if any, of the discrepancy.

The one common element of each organization's analysis was the ENDF/B-V cross-section data. After evaluating the sensitivity of the temperature coefficient to the data, the graphite $S(\alpha, \beta)$ on the ENDF/B-V was suspected of being incorrect. ORNL inspected over 800 plots of the ENDF/B-V $S(\alpha, \beta)$ data and visually determined that the incoherent scattering kernels were most likely incorrect, not only between 500 and $800 \mathrm{~K}$, but to some extent at all ten temperatures on the ENDF/B-V file. An example of the plots of the ENDF/B-V $S(\alpha, \beta)$ data is shown in Figure 8-2. Clearly, the data are suspect. Figure 8-2 is fairly typical of the extent of the apparent incongruous behavior of the data exhibited over the entire temperature range.

The source of the error was determined by ORNL to be a result of errors in the version of GASKET used to produce the ENDF/B-V incoherent graphite $S(\alpha, \beta)$ scattering kernels. The errors in GASKET (poor convergence as a result of insufficient precision from single precision 


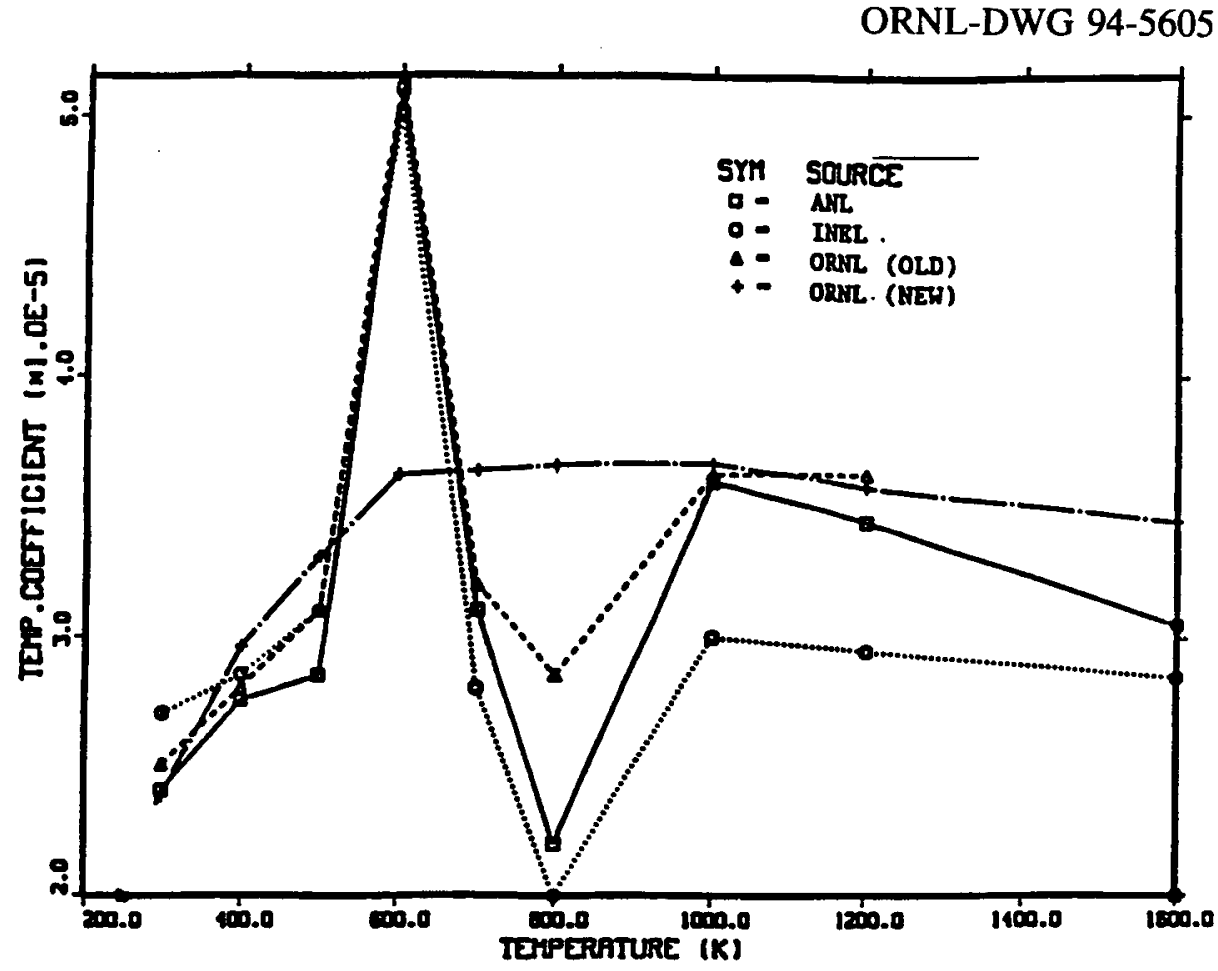

Figure 8-1.

TEMPERATURE COEFFICIENT OF REACTIVITY CALCULATED WITH NEW AND OLD SCATTERING MATRICES FOR GRAPHITE. 

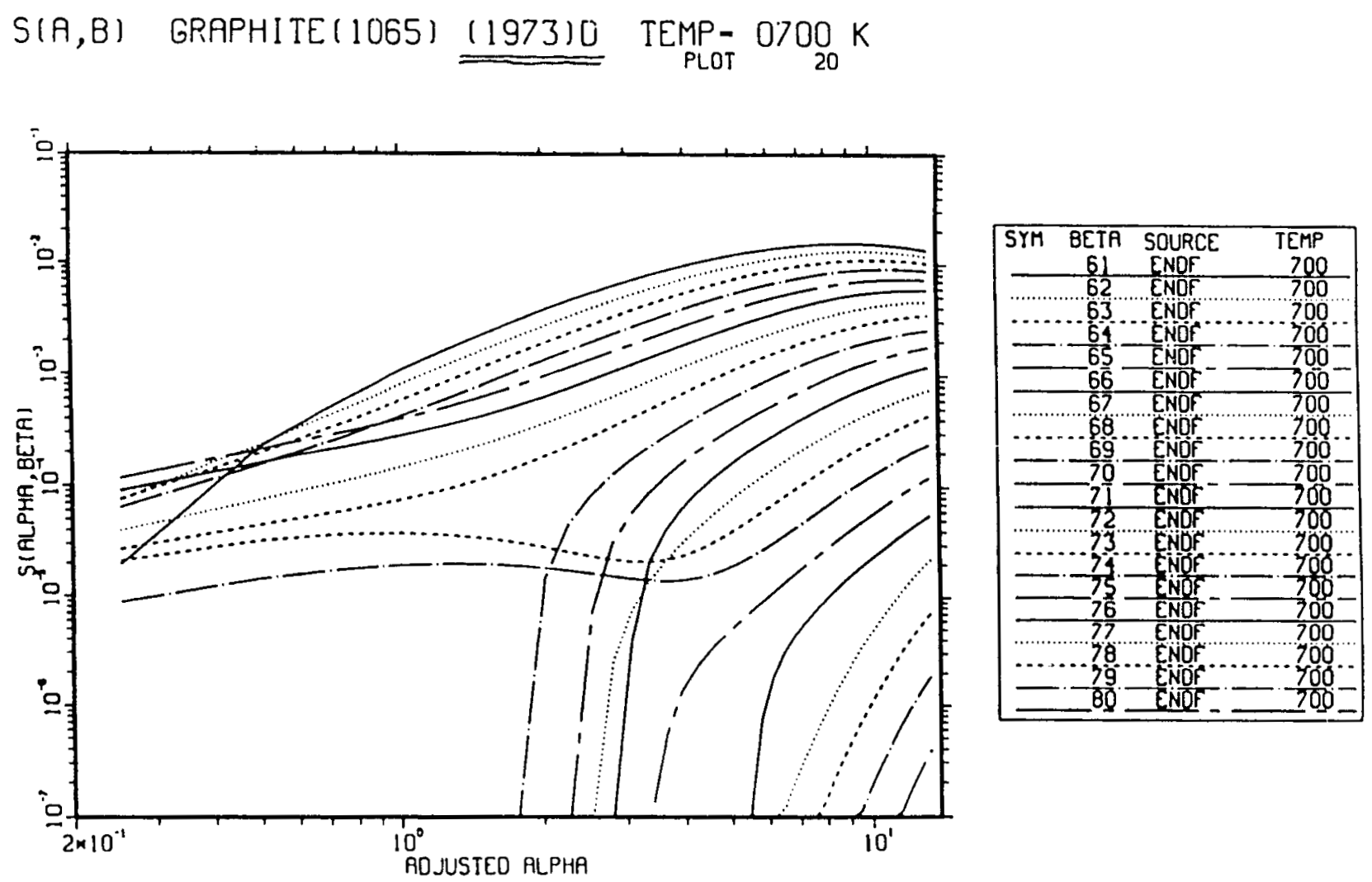

Figure 8-2.

$S(\alpha, \beta)$ VS ALPHA FOR VARIOUS VALUES OF BETA-DATA FROM ENDF/B-V DATA FILE. 
calculations) were corrected by ORNL and new, corrected $S(\alpha, \beta)$ data were generated for the ten temperatures specified on the ENDF/B-V file. Recalculation of the temperature coefficients was performed by ORNL using the new graphite scattering data [referred to as "ORNL (NEW)"], and a comparison of the original results to the revised results is shown in Figure 8-1. The use of the new graphite data results in a temperature coefficient dependence on temperature that appears to be more intuitively correct. In addition, plots of the $S(\alpha, \beta)$ data were regenerated and appear to be more natural in form than those curves plotted from the ENDF/B-V data files. A typical example of the plots of the new graphite data is shown in Figure 8-3, which is the revised plot of the data shown in Figure 8-2. Hundreds of plots of the new $S(\alpha, \beta)$ data were analyzed and show an "improvement" typified by the differences found in comparing Figure 8-2 to 8-3.

Subsequent comparisons of the new and old $S(\alpha, \beta)$ data to published experimental data ${ }^{221-223}$ confirm that the new 1991 graphite scattering data are correct, and the data values on the ENDF/B-V file are incorrect.

\subsubsection{Development of Graphite Cross-Section Scattering Covariances}

The existence of systems, with performance particularly sensitive to thermalization effects and with the need to compute the error in the calculations of the temperature coefficient of reactivity (which properly accounts for the correlation in temperature), drove our efforts to characterize the present status of the inelastic cross section of graphite and to calculate its covariance file.

Present ENDF/B evaluations of the scattering matrices of graphite are based on the incoherent approximation implemented in the GASKET code. ${ }^{224}$ For the particular case of a monatomic polycrystal, the scattering matrix in the incoherent approximation depends entirely on the frequency distribution of the phonon spectra, $\rho(\omega)$.

Three phonon spectra for graphite are available in the literature. The simplest and oldest one is the spectrum proposed by Egelstaff, ${ }^{225}$ which is quadratic up to a frequency $w_{1}$, linear up to $w_{2}$, flat up to $w_{3}$, and zero beyond $w_{3}$; this spectrum was found to be consistent with early measurements of $S(\alpha, \beta, T)$. A more basic approach corresponds to the spectrum calculated by Young and Koppel, ${ }^{226}$ who found $\rho(w)$ by solving the dynamic of the lattice; four elastic constants describe the four forces considered: two for first-neighbor interactions (at the same plane and adjacent plane) and two for bending angles (at the same plane) and bending adjacent 
$S(A, B)$ GRAPHITE(1065)

ORNL-DWG 94-5607

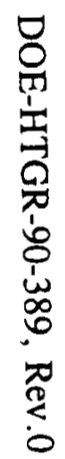

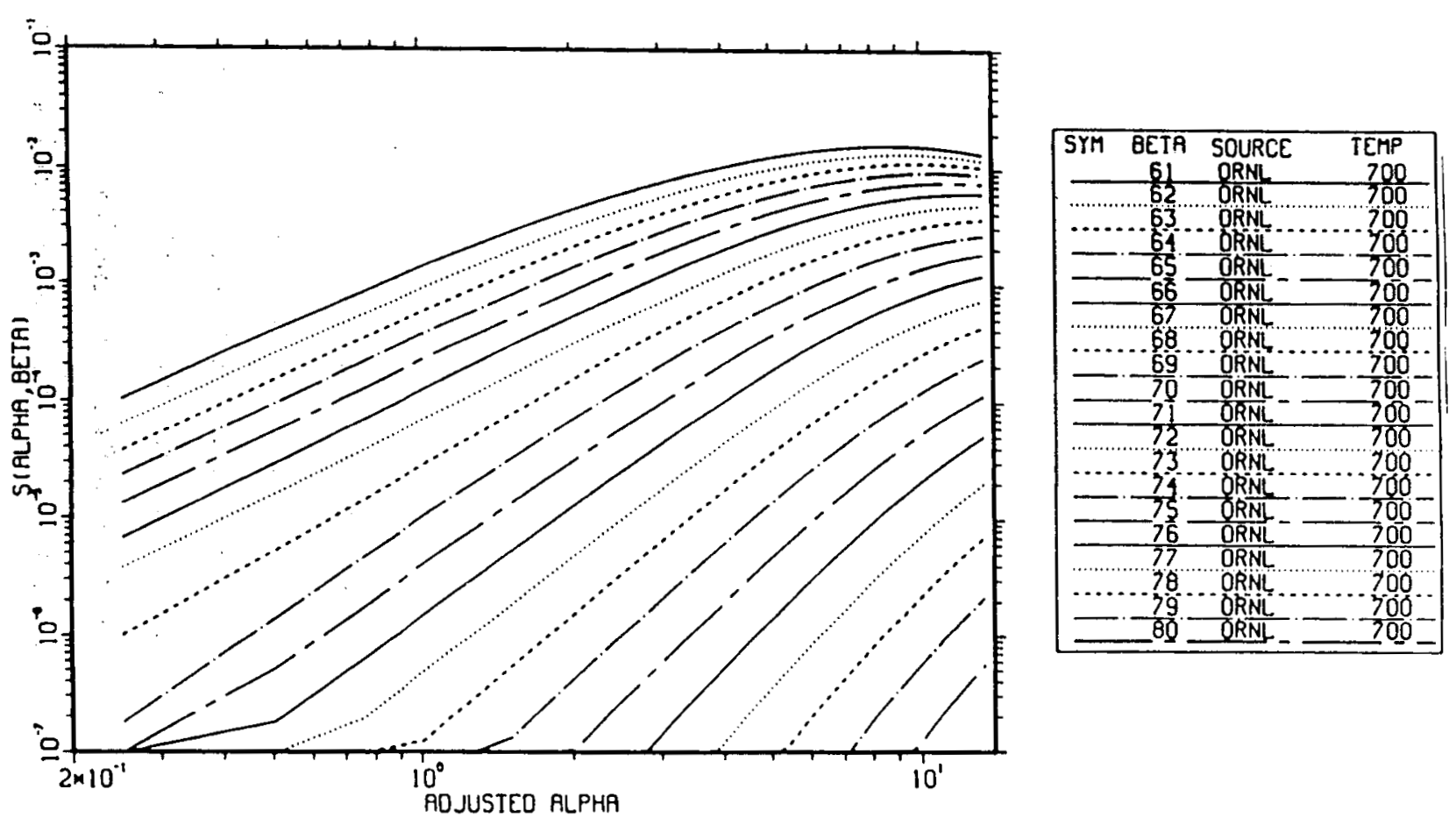

Figure 8-3.

$S(\alpha, \beta)$ VS ALPHA FOR VARIOUS VALUES OF BETA-DATA IS ORNL-GENERATED "1991 GRAPHITE SCATTERING DATA." 
planes. Two of the force constants were fitted to measured specific heat, the third was taken from the dispersion law measured in pyrolytic graphite, and the fourth corresponds to the benzene molecule. Note that this is the spectrum used for the ENDF/B evaluations.

The availability of highly intense neutron beams and large specimens of pyrolytic graphite allowed the direct measurement of the elastic forces of relevance for a better calculation of $\rho(w)$. Thus, the ORNL phonon spectrum ${ }^{227}$ was calculated by solving the dynamic of the lattice by including tensor forces up to the fourth neighbor with a total of eight elastic constants. The three spectra are shown in Figure 8-4.

Direct measurements of $S(\alpha, \beta, \mathrm{T})$ are scarce. Some of the documents are difficult to obtain or do not contain details to evaluate the experiments. Of four known authors $223,225,228,229$ only one had published in the open literature with enough information to be considered.

The experimental data of Carvalho ${ }^{224}$ are compared in Figures 8-5 and 8-6 with GASKET calculations corresponding to the three different phonon spectra. None of the spectra reproduce the considerable structure of the experimental data, which seem to be related, as Carvalho showed, to coherent effects not included in the GASKET calculations. Despite the large differences between the phonon spectra, neither of them seems to produce better results than the other; for example, as Figure 8-5 shows, at $\beta=0.15$, the ORNL spectrum produces results that agree quite well with the average of the experimental data, while for $\beta=0.60$, this is the case for the Egelstaff spectrum.

Our analysis of the data indicates that the incoherent approximation used in the evaluation of $S(\alpha, \beta, T)$ has a bias and that there are not enough experimental data to evaluate the covariance file "externally" (that is, by comparing the whole experimental data with the evaluation).

The evaluated scattering matrix is anyway a component of the real one; if its covariance matrix is found, an amplification factor has to be applied to include the effects of the biases. The covariance of the real scattering matrix can then be approximated by choosing an amplification factor compatible with the fluctuations shown in Figures 8-5 and 8-6.

The evaluation of the scattering matrix of the graphite is still based on approximations (incoherent approximation and phonon spectras) of the late 1960s. In the meantime, new highresolution measurements and analyses show that the observed structure of $S$ is due to the coherent part ignored by the evaluation. More detailed calculations of the phonon spectra are available and should be considered in future evaluations although they would not remove the lack of structure. 


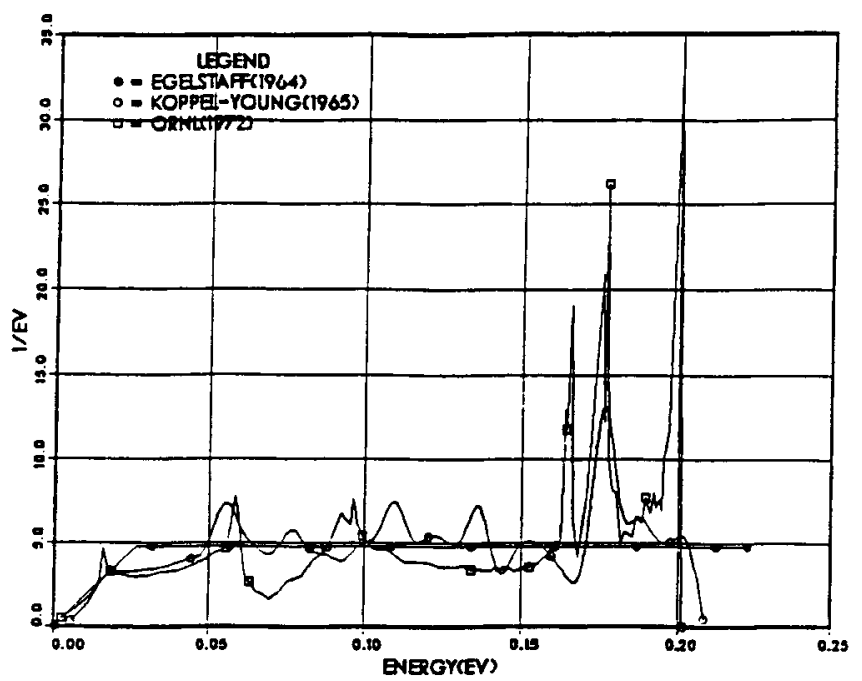

Figure 8-4.

PHONON DISTRIBUTIONS IN GRAPHITE FROM DIFFERENT AUTHORS.

ORNL-DWG 94-5609

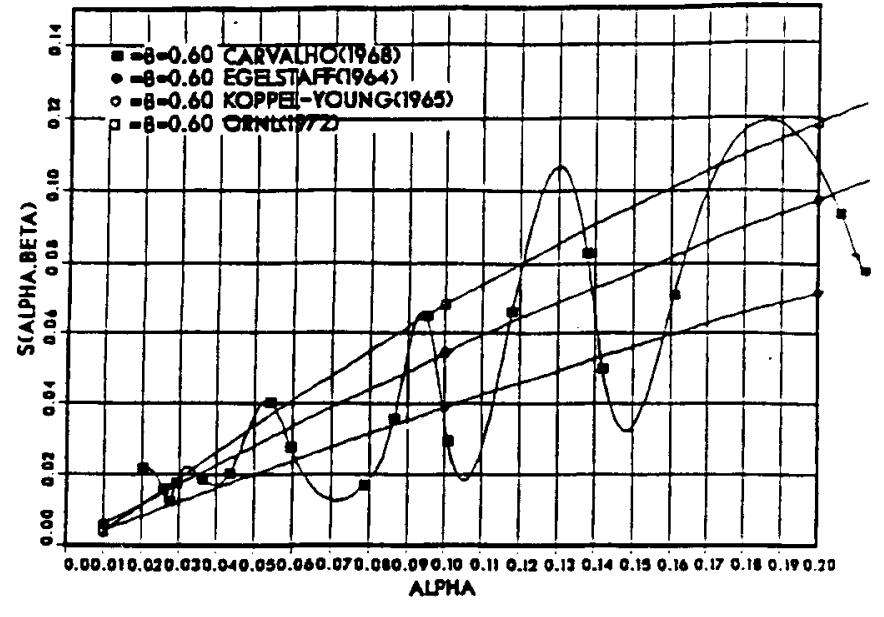

Figure 8-5.

THE EXPERIMENTAL RESULTS OF CARVALHO, GRAPHITE AT $533^{\circ} \mathrm{K}, \beta=0.15$, ARE COMPARED WITH GASKET CALCULATIONS USING THREE DIFFERENT SPECTRAS. 


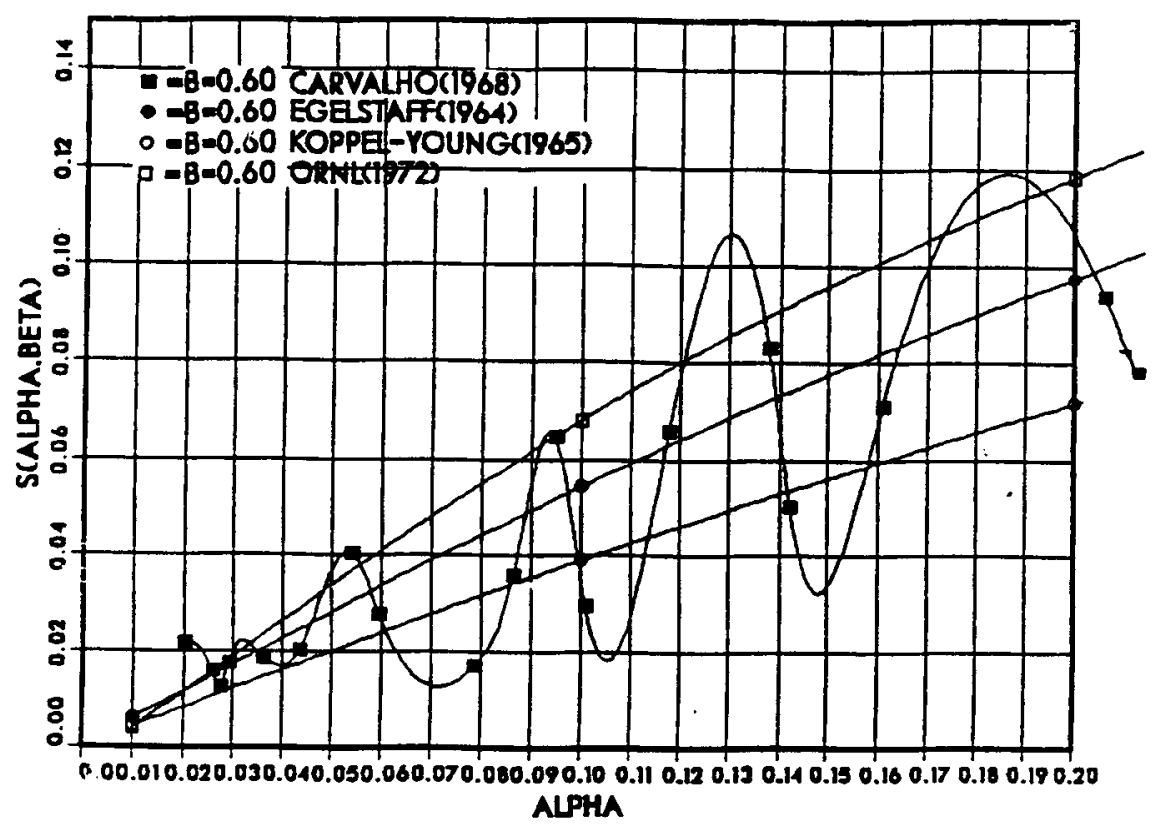

Figure 8-6.

THE EXPERIMENTAL RESULTS OF CARVALHO,

GRAPHITE AT $533^{\circ} \mathrm{K}, \beta=0.6$, ARE

COMPARED WITH GASKET

CALCULATIONS USING

THREE DIFFERENT SPECTRAS. 
Formulas for the covariance of the scattering matrix have been derived based on the incoherent approximation and a simplified phonon spectra. They look quite similar to the ones that give the scattering matrix itself, so no particular problem can be envisioned in computing them. The amplitude of the covariance depends on two parameters, the error in the frequencies $w_{2}$ and $w_{3}$, that could be adjusted to account for the differences between the structure (measured) and the continuous (evaluated). In this way, the covariance would be representative also of the biases introduced by the evaluation.

\subsection{INTERNATIONAL COOPERATION}

\subsubsection{Introduction}

ORNL has been participating in two international cooperative agreements from 1991 to 1993 directly supporting validation of models, codes, and data for analysis of LEU graphite systems. The purpose of the international agreements has been to provide continued exchange of technical information in the area of reactor physics and to carry out experiments under a collaborative arrangement to reduce the cost of research and development for the participating countries.

\subsubsection{CRP on the Validation of Safety-Related Physics Calculations for LEU Fueled HTGRs}

On the recommendation of the IAEA's Working Group on GCRs, the IAEA has established a CRP on the Validation of Safety-Related Physics Calculations for LEU Fueled HTGRs. This CRP was initiated in January 1990 and involves participation of countries with interests in gascooled graphite reactor technology: China, France, Germany, Japan, Russia, Switzerland, and the United States.

The objective of the CRP is to provide safety-related physics data for LEU fueled HTGRs for use in validating reactor physics codes and methods used by participating countries for analysis. At present, the main activities within the CRP are being carried out by the international project now under way at the PROTEUS critical facility at the Paul Scherrer Institute (PSI) in Villigen, Switzerland. Within this project, criticals will be conducted for LEU graphite systems to determine core reactivity; flux and power profiles; reaction rate ratios; worth of control rods, including reflector control rods; worth of burnable poisons; and the effects of water ingress on these parameters. These experiments will be conducted over a range of experimental parameters such as carbon-to-uranium ratio, core height-to-diameter ratio, and simulated water concentrations. To ensure that the experiments being conducted appropriately address the 
interests of each of the participating countries, specialists from each of the countries are taking part in planning and conducting the experiments.

From the U.S. standpoint, this CRP is an important activity because it will fill certain gaps in experimental data needed for validation of computer codes and methods which will be used to predict safety-related physics parameters for gas-cooled graphite reactors. Relative to the PROTEUS experiments, the specific interests of the United States are to obtain quality experimental data for core reactivity, neutron flux and power distributions, in-core and reflector control rod worth, burnable poison worth, and the effects of moisture ingress on these parameters.

ORNL has participated in each of the four RCMs of the CRP. The first meeting was held at PSI in May of 1990; the second meeting in May of 1991 at the JAERI laboratory in Tokai, Japan; and the third and fourth meetings at PSI in June 1992 and April 1993. The purpose of these meetings is to ensure that all the measurements of interest to the participants are incorporated into the PROTEUS experimental plans. During the meetings, the status of the PROTEUS experiments are reviewed as well as the assignments at PSI of technical personnel from each of the participating countries. A series of benchmark problems representative of the PROTEUS experiments and the very-high-temperature gas-cooled reactor (VHTGR) critical experiments at JAERI in Tokai are also being calculated by participants, and the results are submitted and compared during each meeting. During each meeting, possible follow-on experiments to those planned at PROTEUS are also discussed because of the long lead time necessary to initiate new experimental programs.

In addition to holding membership in the CRP and helping guide the direction of the overall experimental program, ORNL is carrying out three separate roles in support of the CRP:

(1) ensuring that the PROTEUS experimental data can qualify for validation of methods and models in accordance with U.S. QA standards, (2) assigning ORNL researchers to PSI in support of the PROTEUS experiments, and (3) participation in the CRP numerical benchmark program.

\subsubsection{PROTEUS QA Program}

ORNL has been actively involved in ensuring that the PROTEUS experiments will be carryed out and documented in sufficient detail such that the data provided by the experimental program can be used to validate codes and models in accordance with U.S. QA standards. Since the experiments are being conducted as part of an international agreement, ORNL does not have direct control over the activities which include QA. ORNL agreed to develop a QA program and provide the necessary manpower to perform periodic audits. Mr. Larry Jordan, ORNL Quality 
Department, spent two months at PSI in May and June of 1991 to develop a QA program in cooperation with PSI staff that would meet the MHTGR QA program requirements. The QA program included the development of a QA plan and procedures for the PROTEUS experiments. The scope of the QA program is focused on conducting the experiments and the gathering, recording, and analysis of the measured data.

Revision 0 of the QA plan was signed and implemented by PSI in June 1992, prior to initial criticality in July 1992. Revision 1 will be signed and implemented in September 1993. A QA audit was performed in July 1993 by Mr. Jordan and by Dr. Felix Difilippo of ORNL, who is directly involved in both the measurements and analysis of the PROTEUS experiments.

\subsubsection{Assignments of ORNL Researchers to PSI}

Dr. Felix Difilippo of ORNL was assigned to PSI from May 1991 through November 1991.

During his assignment, Dr. Difilippo participated in the modeling and analysis of different PROTEUS configurations to arrive at preferred methods for measuring criticality and subcriticality, including the measurement of the reactivity worth of control rods using the inverse kinetics method and the pulsed neutron source technique. The definition and measurement of kinetics parameters in systems heavily reflected with very low absorbing materials exhibit additional complications because of the different distributions of prompt and delayed neutrons. Upon defining consistent defintions of these parameters, the pulsed neutron techniques to measure reactivities were evaluated to find correction factors for spatial effects and to locate the detectors to minimize them. The theoretical foundation of the inverse kinetics method was also revisited to show how spatial effects can be calculated to design the experiments and to interpret the measurements. The results, for both techniques, were illustrated with examples of PROTEUS configurations calculated with computer codes in use at PSI and with the analysis of computergenerated "experimental" data. In the preliminary experiments, the pulsed neutron source was used to assess the amount of equivalent boron-10 impurities in the graphite of the PROTEUS facility. A crucial step in the analysis of the experiment was the comparison of measured and calculated values of the decay constant in order to determine the amount of Boron-10 contamination. Calculations were performed to evaluate the decay constant for complicated graphite configurations as well as to determine their sensitivities to the amount of Boron-10, structural materials, and the presence of the source. Details of Dr. Difilippo's work are documented in refs. 230 through 232. 
Mr. Gary Smolen of ORNL was assigned to PSI from June 1992 through July 1993 to work with other members of the international team at PROTEUS to document experimental plans, measurement procedures, and measured data according to requirements as defined in the PROTEUS QA plan. Mr. Smolen also collaborated with PSI staff in the planning and analysis of measurements made during the configuration I phase of the PROTEUS experiments.

\subsubsection{CRP Numerical Benchmark Program}

One of the main activities of the CRP is to develop a set of numerical benchmarks and collect participant calculational results as a means for comparing methods and data being used throughout the world in the analyses of LEU graphite reactor systems. Such comparisons are particularly important in the calculation of paramaters that cannot be experimentally confirmed.

Two series of benchmarks have been established to date. One set is representative of the PROTEUS pebble-bed configurations, and one set is representative of the VHTGR prismatic configurations. Partial sets of results from China, Russia, Japan, Germany, and Switzerland have been collected and documented by PSI. ORNL began participation in the benchmark program in March 1993. Results of calculations performed by ORNL will be documented and sent to PSI in October 1993.

\subsubsection{Cooperative Agreement with JAERI to Exchange Neutronics Information Under ANNEX-5}

The agreement under ANNEX-5 for direct exchange of neutronics information is documented in a letter from A. Millunzi dated February 23, 1990. This letter summarizes a meeting held at ORNL on February 21, 1990, during which JAERI delivered to ORNL three documents describing in detail the VHTGR-1 measurements of core criticality (CRP B6), burnable poison worth (CRP B9), and reflector control rod worths (CRP B11). The quality of documentation is extremely high.

A report on temperature coefficient measurements was also given to ORNL. The report contains valuable information typical of a laboratory report but does not contain the same level of detail of the CRP documents. Nonetheless, with just a small amount of additional information, perhaps already available in the other CRP documents, a well-documented validation effort could be carried out.

A summary of the VHTGR experimental plan was also given to ORNL. This plan was an earlier version of the plan shown in Table 8-1 of this report. 


\section{Table 8-1}

VHTRC CORE CONFIGURATIONS AND EXPERIMENTAL ITEMS IN THE PAST AND FUTURE

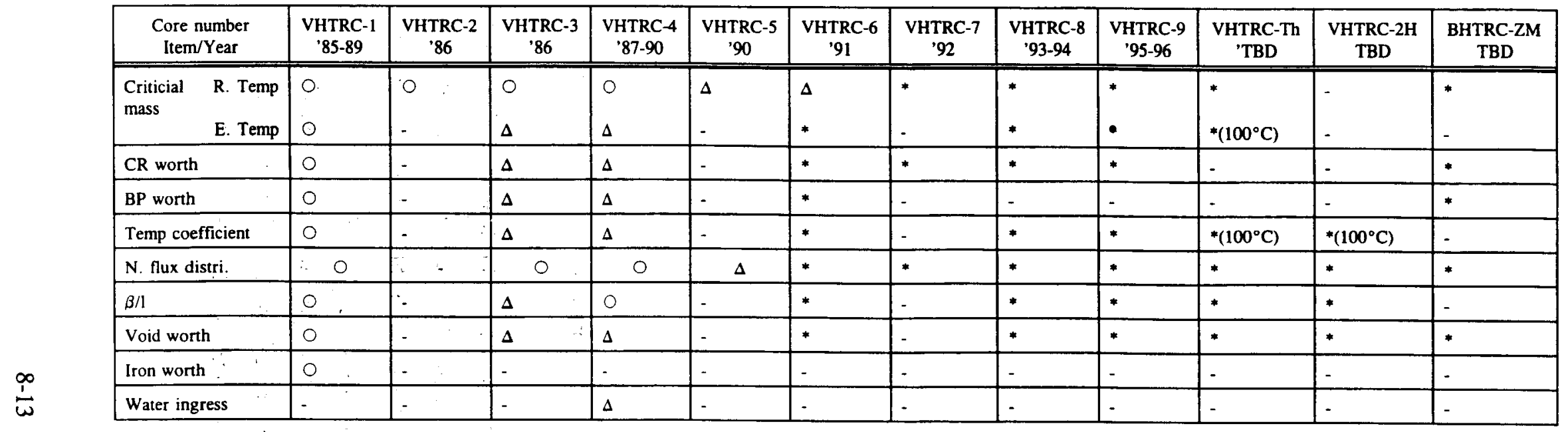

$O$ : Measurement, Data processing, SFAC evaluation finished

$\Delta:$ Meausrement finished

To be measured

Not planned

VHTRC-1 : $4 \% \mathrm{EU}$ (12pins/column) fuel Main data for HTTR safery review

VHTRC-2 : $4 \% \mathrm{EU}$ (15pins/column) fuel $\mathrm{C}^{233} \mathrm{U}$ is varied

VHTRC-3 : 6\%EU (12pins/column) fuel Enrichment is varied

VHTRC-4 : 2,4,6\% EU (12pins/column) fuel Axially zoned enrichment

VHTRC-5 : 2,4,6\% EU (12pins/column) fuel Axially zoned enrichment. Graphite spike pellets inserted.

VHTRC-6 : 2,4,6\% EU (12pins/column) fuel Axially zoned enrichment. Many BP rods inserted.

VHTRC-7 : 2,4,6\% EU (12pins/column) fuel Axially zoned enrichment. CR partially inserted.

VHTRC-8 : Large flat core, Interference between core and reflector.

VHTRC-9 : Annular core, Interference between core and reflector.

VHTRC-TB : Thorium rods loaded.

VHTRC-ZH : Zone heating device $\left(\sim 1200^{\circ} \mathrm{C}\right)$ equipped, One column is heated.

VHTRC-ZM : Accurate zone mockup (HTTR initial core and improved cores) 
The agreements reached during the February 21, 1990, meeting at ORNL was that ORNL perform an independent post-prediction of criticality, burnable poison worths, and control rod worths using state-of-the-art codes with the intent of comparing calculated results against those from JAERI. Funding for this activity became available in March 1993, and ORNL analysis of CRP B6 is scheduled to be completed in the fall of 1993.

\subsubsection{A Comparison of the VHTGR to the U.S. MHTGR Design}

The VHTGR is the most relevant, best documented, and most recent source of data that currently exists to meet the validation needs of the vendor. The most salient features of the VHTGR are the use of LEU fuel in prismatic fuel elements and the use of reflector control rods. In addition, some measurements of temperature coefficients at low temperatures (at and below $200^{\circ} \mathrm{C}$ ) have been completed. Table 8-2 compares the VHTGR design data to that of the MHTGR 450 MW(th) design.

\subsubsection{Existing VHTGR Data of Relevance to the MHTGR Program Needs}

A summary of the VHTGR Experimental Program Plan is shown in Table 8-1. A summary of the measurements of interest to the MHTGR follows:

\section{Core Criticality}

Validation of codes for predicting core criticality is an important first step in assessing the vendor's suite of codes and cross sections. Although numerous other measurements of criticality of HTGR systems have been made using the vendor codes, these VHTGR critical measurements are extremely well documented and are for an LEU-fueled core. The VHTGR criticality data are an excellent source of information for the vendor's validation of the new ENDF/B-VI cross-section library.

The VHTGR core criticality was obtained by loading the fuel rods step by step, keeping hexagonal symmetry within each fuel element. The neutron multiplication was observed at each loading step by the source multiplication technique using six neutron detectors. The number of fuel rods required to reach criticality was recorded, along with the positions of the VHTGR control rods (not to be confused with the mockup HTTR rods for which worths were measured in other VHTGR configurations). The worths of the VHTGR control rods and other reactivity adjustments were made, and the number of fuel rods required to reach a critical mass was determined, along with the critical mass of U-235. In addition, in the 
Table 8-2

COMPARISON OF VHTRC AND MHTGR

\begin{tabular}{|c|c|c|}
\hline Fuel & VHTRC & MHTGR \\
\hline $\begin{array}{l}\text { Fissile Fuel } \\
\text { Fertile Fuel } \\
\text { Fissile Fuel Enrichment, \% } \\
\text { Fertile Fuel Enrichment, \% } \\
\text { Particle Type } \\
\text { Fuel Compact ID, mm } \\
\text { Fuel Compact OD, mm } \\
\text { Fuel Compact Height,.mm } \\
\text { Fuel Compacts per Fuel Hole }\end{array}$ & $\begin{array}{c}\mathrm{UO}_{2} \\
\mathrm{~N} / \mathrm{A} \\
2,4,6 \\
\mathrm{~N} / \mathrm{A} \\
\mathrm{B} / \mathrm{SO}(2 \%, 4 \%) \\
\mathrm{TRISO}(6 \%) \\
18.00 \\
36.00 \\
36.00 \\
20\end{array}$ & $\begin{array}{c}\mathrm{UC}_{0.28} \mathrm{O}_{1.63} \\
\mathrm{UC}_{0.29} \mathrm{O}_{1.63} \\
19.8 \\
0.71 \text { (Nat. U) } \\
\text { TRISO } \\
0.0 \\
12.45 \\
49.30 \\
5 \text { (14 under dowel) }\end{array}$ \\
\hline Fuel Elements & VHTRC & MHTGR \\
\hline $\begin{array}{l}\text { Distance Across Flats, mm } \\
\text { Height, mm } \\
\text { Number of Fuel Holes } \\
\text { Fuel Hole OD, mm } \\
\text { Number of Coolant Holes } \\
\text { Coolant Hole OD, mm } \\
\text { Number of LBP Holes } \\
\text { LBP Hole OD, mm } \\
\text { LBP Hole Length, mm }\end{array}$ & $\begin{array}{c}300.0 \\
1200.0 \\
18(\max ) \\
36.0 \\
0 \\
\text { N/A } \\
0 \\
\text { N/A } \\
\text { N/A }\end{array}$ & $\begin{array}{l}360.0 \\
793.0 \\
210 \\
12.7 \\
120 / 6 \\
15.9 / 12.7 \\
6 \\
12.7 \\
781.5\end{array}$ \\
\hline Core & VHTRC & MHTGR \\
\hline $\begin{array}{l}\text { Inner Core Diameter, } m \\
\text { Outer Core Diameter, } m \\
\text { Active Core Height, } m \\
\text { H/OD } \\
\text { C/U (Initial Core) } \\
\text { C/U } \mathrm{U}^{235} \text { (Initial Core) }\end{array}$ & $\begin{array}{r}0.32 \\
1.14 \\
2.40 \\
2.11 \\
257-344 \\
6432-8600\end{array}$ & $\begin{array}{r}1.65 \\
3.50 \\
7.90 \\
2.26 \\
433 \\
4831\end{array}$ \\
\hline Control Rods & VHTRC & MHTGR \\
\hline $\begin{array}{l}\text { Number in Inner Reflector } \\
\text { Number in Outer Reflector } \\
\text { Number in Core } \\
\text { Control Rod Inner Radius, mm } \\
\text { Conrtol Rod Outer Radius, mm } \\
\text { Control Material }\end{array}$ & $\begin{array}{c}3 \\
12 \\
0 \\
60.0 \\
89.6 \\
\mathrm{~B}_{4} \mathrm{C}\end{array}$ & $\begin{array}{c}6 \\
24 \\
0 \\
52.8 \\
82.6 \\
\mathrm{~B}_{4} \mathrm{C}\end{array}$ \\
\hline
\end{tabular}


approach to criticality, the multiplication factor was measured at four subcritical configurations by the pulse source method using four in-core $\mathrm{BF}_{3}$ detectors.

Core criticality was also obtained at an elevated core and reflector temperature of $200^{\circ} \mathrm{C}$ using the same step-by-step loading approach described previously. These measurements provide another temperature for which use of the ENDF/B-V data can be validated. The measurements of temperature coefficient were obtained in a separate experiment that will be described in a following section.

\section{Reactivity Worth of HTTR Mockup Control Rods}

Reactivity worths of the HTTR mockup control rods were measured in the VHTRC-1 core using the pulsed neutron source method. Worths for five control rod configurations were measured:

- One control rod in center island

- Two control rods in center island

- Two control rods in the reflector

- Twelve control rods in the reflector

The control rod worth data are very relevant to the MHTGR design in that the worths of central reflector and outer radial reflector rods are measured. The experimental uncertainties in the measured values of rod worth are well documented.

\section{Neutron flux distributions}

Distributions of the ${ }^{63} \mathrm{Cu}(\mathrm{n}, \gamma){ }^{64} \mathrm{Cu}$ reaction rate in the radial and axial directions were measured in the VHTGR-1 core at room temperature and at $200^{\circ} \mathrm{C}$ by the activation technique. Natural $\mathrm{Cu}$ foils were used to measure the "radial" reaction rates from one fuel pin to the next. The axial reaction rate distribution was measured using a $\mathrm{Cu}$ wire at one location within the core for the room-temperature experiment and at two locations (core and reflector) for the $200^{\circ} \mathrm{C}$ experiment. At room temperature, the induced activities were measured with a Ge detector for the foils and with a Geiger-Müller counter for the wire. For the $200^{\circ} \mathrm{C}$ experiment, an $\mathrm{NaI}(\mathrm{TI})$ detector was used for the foils and wires. The axial $\mathrm{Cu}$ reaction rate distribution includes measurements made within the axial reflector and thus provides a good test for prediction capability at core/reflector interfaces. 


\section{Temperature Coefficient of Reactivity}

After room-temperature criticality measurements, four subcriticality measurements were made at $70,100,150$, and $200^{\circ} \mathrm{C}$ for a fixed configuration of fuel rods. The core and reflector were heated uniformly using 40 electric heaters, and the pulse neutron source was used to measure the multiplication factor. The temperature coefficient was then calculated for the three changes in temperature. Over this range of temperatures, the temperature coefficient was determined to range from about $-1.5 \mathrm{E}-4$ to $-1.7 \mathrm{E}-4$. Interpolation of curves for the MHTGR in this temperature range predict a value of about $-1.5 \mathrm{E}-4$ at beginning of cycle. These relatively comparable values are expected because of the dominating effect of the Doppler contribution for LEU fuel, thus making the VHTGR experiments a good source of validation data for the ability to predict temperature coefficients up to $200^{\circ} \mathrm{C}$.

Unfortunately, a good validation of the ability to predict the MHTGR temperature coefficient between 700 and $1000^{\circ} \mathrm{C}$ would best fulfill the needs of the MHTGR Program at this time.

\section{Additional Data for VHTGR-2 through VHTGR-6}

Criticality measurements have been made for various C/U-235 ratios at room temperature in the VHTGR-2 set of experiments. The entire set of measurements described above were also performed for various locations of the 2,4 , and $6 \%$ fuel pin enrichments in the VHTGR-3 and -4 sets of experiments. The VHTGR-5 experiment measures core criticality after insertion of graphite spike pellets, and the VHTGR-6 set of experiments provides the above range of measurements with various configurations of burnable poison rods inserted.

\section{Water Ingress}

One unique set of data of interest to the MHTGR Program is the water ingress experiments carried out in the VHTGR-4 set of experiments. The description and results of these measurements have not been published at this time. 


\section{SECTION 9}

\section{MHTGR-GT}

Howard T. Kerr

\subsection{PREFACE}

This report summarizes ORNL efforts on the MHTGR-GT Project during the reporting period and includes efforts funded by direct DOE funds (i.e., commercial MHTGR Program) and by ORNL internal discretionary funds [Laboratory Directors' Research and Development (LDRD) Program].

\subsection{BACKGROUND}

A brief description of the evolution of the MHTGR-GT Project will help explain the nature of technical inputs from various participants. In the summer of 1990, Professor Larry Lidsky of MIT presented a seminar at ORNL extolling the merits and performance potential of an MHTGR operating with a GT in a direct Brayton cycle. ORNL staff were impressed by Dr. Lidsky's assertions. A proposal was prepared and funds were obtained from ORNL's LDRD Program to conduct a feasibility assessment of the technology required to build and operate a direct-cycle (DC) MHTGR. This ORNL project began in January 1991 and extended through FY 1993 with total funding of $\$ 600,000$.

In April 1991, the Gas-Cooled Reactor Associates (GCRA), a utility industry-supported organization, submitted a proposal to the Empire States Electric Energy Research Company (ESEERCO) to perform a similar feasibility assessment of the DC MHTGR concept. ESEERCO persuaded DOE to jointly fund the project by redirecting existing program funds; the combined ESEERCO and DOE funding from June 1991 through September 1992 was about $\$ 328,000$. Additionally, about $\$ 200,000$ of MHTGR contractors private funds were used to support their respective participation.

Due to the similarity of efforts, ORNL and GCRA agreed to work in a collaborative effort beginning in June 1991, and GA, Bechtel, Stone and Webster, CE, and MIT agreed to join the "MHTGR-GT Evaluation Team." Preconceptual designs were developed, relevant technology assessments were performed, and key issues were identified. Preliminary results were reported in 
April 1992 in ESEERCO Research Report EP 91-19. Those results were so favorable that DOE agreed to provide an additional \$1.4 million support in FY 1993 for continued evaluations.

The original evaluation effort was focused on the DC concept, and some important design issues were identified. The amount of fission product contamination in the power conversion equipment would strongly impact the approach to maintenance, especially of the turbo-machinery. The orientation of the turbo-machine would be largely determined by the feasibility of magnetic bearings. These and other key issues are detailed in the ESEERCO report.

An indirect-cycle (IDC) concept was introduced into the evaluation as a means to avoid many of the issues associated with the DC design. Again, a preconceptual design was developed and extensive evaluations performed. The key issues for the IDC design have been identified.

Considerable efforts have been given to obtaining comparable cost estimates for both the direct and the indirect designs. A project report will be drafted in June 1993 summarizing the design features, performance capabilities, and outstanding issues to be resolved for both design approaches.

\subsection{ORNL TECHNICAL CONTRIBUTIONS}

ORNL has provided considerable technical input to the collaborative effort on the MHTGR-GT concepts and has had a major role in some key design areas. Brief descriptions of ORNL efforts follow:

1. Fission Product Contamination in the Primary Loop: Estimates were made of the release rates of selected fission products and of their distribution in the primary coolant loop. The release rate of silver and cesium from intact fuel particles was determined to be significantly greater for the GT cores (relative to the steam cycle core) because of the higher average fuel temperatures in the GT fuel. These fission products were presumed to be deposited preferentially in the helium power turbine of the DC design and in the intermediate heat exchanger of the IDC design. The presence of this fission product contamination will require that the DC plant be designed for remote maintenance of the turbo-machine.

2. Turbo-machine Design: ORNL did initial designs for the turbo-machines to be used in both the DC and IDC designs. A twin-shaft unit was developed for the IDC design to allow use of a synchronous generator. A single-shaft unit was developed for the DC design due to the strong need for a simpler mechanical 
configuration. However, the single-shaft turbo-machine must operate at higher rotational speeds (about $5000 \mathrm{rpm}$ ) and therefore requires a high-speed generator and a frequency converter.

3. Heat Exchanger Designs: ORNL staff has had a lead role in the design of the recuperators, the precoolers, the intercoolers for both the DC and IDC designs, and the intermediate heat exchanger for the IDC design. Analyses showed that the recuperator volumes could be substantially reduced while maintaining very high thermal effectiveness. This result enabled packaging of the power conversion hardware into a single vessel; this design approach has been accepted for the DC system.

4. Reactor Vessel Material: ORNL staff evaluated the requirements for the reactor vessel and selected $9 \mathrm{Cr}-1 \mathrm{Mo}-\mathrm{V}$ as the alloy best suited for this application. The vessel metal thickness required to satisfy the stress allowables for various operating modes was determined, and the vessel weight was calculated. ORNL also has determined the additional effort required to obtain the needed ASME Code qualification for this material in this application.

5. Fuel and Vessel Temperatures During Normal and Accident Conditions: ORNL staff developed models and calculated the spatial and time-dependent temperatures for normal operations and for loss of forced circulation (LOFC) accident conditions. These analyses showed that the peak fuel temperatures do not exceed $1600^{\circ} \mathrm{C}$. The peak vessel temperatures are also well within acceptable limits.

6. Selection of GT Cycle Design Parameters: ORNL, working closely with associates at MIT, performed detailed parametric analyses for the DC and the IDC designs, and specific design parameters were selected as the reference basis on which detailed component designs could be pursued.

7. Economic Analyses: ORNL has provided significant information on the costs of components, relative operating and maintenance costs, technology development costs, and other parameters that influence power costs. 


\section{SECTION 10}

\section{LIST OF REFERENCES}

1. Modular HTGR Plant Fuel/Fission Product Technology Development Plan, DOE-HTGR-86027, Rev. 1, April 1987.

2. Childs, K. W., HEATING 7.0 User's Manual, K/CSD/INF/90-32, Martin Marietta Energy Systems, Inc., Oak Ridge Gaseous Diffusion Plant, July 1990.

3. Copeland, G. L., Operating Guideline for In-Reactor Operation of HTGR Capsule HRB-21, M\&C Quality Assurance Document MET-FMT-OG-001, Martin Marietta Energy Systems, Inc., Oak Ridge Natl. Lab., June 1991.

4. Tang, I. M., HRB-21 Test Specification, DOE-HTGR-88331, Rev. D, December 1991.

5. Gas-Cooled Reactor Programs: High-Temperature Gas-Cooled Reactor Technology Development Program. Annual Progress Report for Period Ending December 31, 1981, ORNL-5871, Union Carbide Corp. Nuclear Div., Oak Ridge Natl. Lab., December 1981.

6. Allen, E. J., CACA-2: Revised Version of CACA-A Heavy Isotope and Fission Product Concentration Calculational Code for Experimental Irradiation Capsules, ORNL/TM-5266, Union Carbide Corp. Nuclear Div., Oak Ridge Natl. Lab., February 1976.

7. Ketterer, J. W., and Myers, B. F., Capsules HRB 17/18 Final PIE Report, DOE-HTGR-86083, Rev. 1, May 1987.

8. Packan, N. H., et al., Operating Plan for Capsule HRB-21 Irradiation, DOE-HTGR-88370, (ORNL/TM-11403), Martin Marietta Energy Systems, Inc., Oak Ridge Natl. Lab., December 1989.

9. Clemmer, E. D., Sweep Gas Sampling, ORNL Engineering Technology Division Procedure ETD-IE-SOP-005, Martin Marietta Energy Systems, Inc., Oak Ridge Natl. Lab., December 1988.

10. Emerson, L. C., HFIR Sweep Gas Counting and Analysis, M\&C Quality Assurance Document MET-FMT-OG-002; Martin Marietta Energy Systems, Inc., Oak Ridge Natl. Lab., June 1991.

11. Capsule HRB-21 Pre-Irradiation Report, DOE-HTGR-88357, Rev. C, General Atomics, San Diego, Calif., April 1991.

12. Bramblett, G. C., General Atomics, San Diego, Calif., to M. J. Kania, Oak Ridge Natl. Lab., "Prediction for HRB-21 Capsule," unpublished data of F. E. Hooks and M. B. Richards, General Atomics, in letter GA/ORNL-014-91, July 10, 1991. 
13. Martin, R. C., Status Report on Reference Fuel Accident Condition Database and Modeling, ORNL/NPR-90/13, Martin Marietta Energy Systems, Inc., Oak Ridge Natl. Lab., May 1990.

14. Martin, R. C., Status Report on Accident Condition Fuel Performance Models, ORNL/NPR90/30, Martin Marietta Energy Systems, Inc., Oak Ridge Natl. Lab., September 1990.

15. Martin, R. C., "Diffusion Modeling of Fission Product Release During Depressurized Core Conduction Cooldown Conditions," in Behavior of Gas Cooled Reactor Fuel Under Accident Conditions, proceedings of the IAEA Specialists Meeting (IWGGCR/25), Oak Ridge, Tennessee, November 5-8, 1990, International Atomic Energy Agency, Vienna, 1991.

16. Martin, R. C., Revised MHTGR High-Temperature Fuel Performance Models, ORNL/NPR92/16, Martin Marietta Energy Systems, Inc., Oak Ridge Natl. Lab., March 1992 (draft).

17. Myers, B. F., Cesium Diffusion in Silicon Carbide During Post Irradiation Anneals, Report HBK-TN-01/84, Kernforschungsanlage Jülich GmbH, Jülich, Germany, January 1984.

18. Röllig, K., "Capabilities of the Diffusion Model for Metallic Fission Products at Temperature Transients up to $1600^{\circ} \mathrm{C}$ - Case: Cs-137 Release from Spherical Fuel Element R2-K13/1," presented at the Technical Workshop on Fuel Performance Models and Fission Product Transport, Forschungszentrum Jülich, Germany, December 2-4, 1991.

19. Martin, R. C., Compilation of Interim Fuel Performance and Fission Product Transport Models and Database for Initial NP-MHTGR Design, ORNL/NPR-91/6, Martin Marietta Energy Systems, Inc., Oak Ridge Natl. Lab., July 1991 (draft).

20. Verfondern, K., Comparison Between JAERI and KFA Coated-Particle Failure Models Under Core Heatup Accident Conditions, ORNL/M-2209, Martin Marietta Energy Systems, Inc., Oak Ridge Natl. Lab., September 1992.

21. Verfondern, K., Possible Explanation for HFR-K3/3 IMGA Results, ORNL/M-2248, Martin Marietta Energy Systems, Inc., Oak Ridge Natl. Lab., September 1992.

22. Martin, R. C., Analysis of Fission Product Release Data for German Fuel Sphere HFR-K3/3, May 1993 (draft report).

23. Verfondern, K., Martin, R. C., and Moormann, R., Methods and Data for HTGR Fuel Performance and Radionuclide Release Modeling During Normal Operation and Accidents for Safety Analyses, Jül-2721, Kernforschungsanlage Jülich GmbH, Jülich, Germany, January 1993.

24. Baldwin, C. A., Martin, R. C., and Myers, B. F., User's Manual for Computerized MHTGR Bibliography System, ORNL/NPR-91/24, Martin Marietta Energy Systems, Inc., Oak Ridge Natl. Lab., May 1993 (draft).

25. Myers, B. F., Montgomery, F. C., and Morris, R. N., "Normal and Transient Fission Gas Release," presented at the Fuel Review Meeting, General Atomics, San Diego, Calif., May 12, 1993. 
26. Norris, R. N., MHTGR Fissile and Fertile Particle Burnup Determination by Gamma Spectroscopy, ORNL-TM-12310, Martin Marietta Energy Systems, Inc., Oak Ridge Natl. Lab., in press.

27. Schenk, W., Pitzer, D., and Nabielek, H., Fission Product Release Profiles from Spherical HTG Fuel Elements at Accident Temperatures, Jül-2234, Kernforschungsanlage Jülich GmbH, Jülich, Germany, September 1988.

28. The FIX - The Fully Integrated Control System, Intellution Incorporated, Norwood, Maine, 1988.

29. Morris, R. N., et al., Core Conduction Cooldown Test Facility Shakedown Tests, ORNL/NPR-91/25, Martin Marietta Energy Systems, Inc., Oak Ridge Natl. Lab., May 1992.

30. Morris, R. N., Current Status of the CCCTF - Summer 1992, ORNL/NPR-92/33, Martin Marietta Energy Systems, Inc., Oak Ridge Natl. Lab., October 1992.

31. Kania, M. J., and Valentine, K. H., The Irradiated-Microsphere Gamma Analyzer (IMGA) An Integrated System for HTGR Coated Particle Fuel Performance Assessment, ORNL5606, Union Carbide Corp. Nuclear Div., Oak Ridge Natl. Lab., 1980.

32. Gontard, R., Hürttlen, B., and Mehner, A. W., HBK-Projekt Hochtemperatur-Reaktor Brennstoff-Kreislauf Vorbestrahlungsbericht für die Experimente HFR-K3(D138.03) und FRJ2-K13(JK13), HBK-IB-4/82, Kernforschungsanlage Jülich GmbH, Jülich, Germany, June 1982.

33. Nabielek, H., Schenk, W., Heit, W., Mehner, A. W., and Goodin, D. T., "The Performance of High-Temperature Reactor Fuel Particles at Extreme Temperatures," Nucl. Technol. 84, 62-81 (January 1989).

34. Valentine, K. H., and Kania, M. J., IMGA Operating Manual, ORNL/TM-6576, Union Carbide Corp. Nuclear Div., Oak Ridge Natl. Lab., August 1979.

35. Gontard, R., and Nabielek, H., Performance Evaluation of Modern HTR TRISO Fuels, HTA-IB-05/90, Kernforschungsanlage Jülich GmbH, Jülich, Germany, July 1991; Table 2.2.3.2.

36. Schenk, W., and Nabielek, H., Kugelbrennelemente mit TRISO-Partikeln bei Störfalltemperaturen, Jül-Spez-487, Kernforschungsanlage Jülich GmbH, Jülich, Germany, January 1989; Tables 61, 97, and 139.

37. Brown, P. E., Inns, A. J., Pateman, R. J., Phillips, B. A., and Sharpe, B. M., PostIrradiation Examination of HTR Fuel Elements, AERE-G4740, Harwell Laboratory, Didcot, Oxon, England, May 1988; Tables 25 and 26.

38. Ketterer, J. W., Capsule HFR-B1 Postirradiation Report, HTGR-85-055, Rev. 1, GA Technologies, Inc., San Diego, Calif., August 1985. 
39. Conrad, R., Irradiation of GA Fuel Rods HTGR Real Time Simulating Operating Conditions in the HFR Petten Project D214.01, Design and Safety Report, Technical Note P/F1/87/5, Joint Research Centre, Petten, The Netherlands, 1987.

40. Myers, B. F., Plan for the Postirradiation Examination of Capsule 1 of the HFR-B1 Experiment, ORNL/TM-12348, Martin Marietta Energy Systems, Inc., Oak Ridge Natl. Lab., 1993.

41. Myers, B. F., Plan for the Postirradiation Examination of the HFR-B1 Experiment, ORNL/TM-11498, Martin Marietta Energy Systems, Inc., Oak Ridge Natl. Lab., November 1991.

42. Conrad, R., Burnette, R. D., and Myers, B. F., Irradiation of GA-HTGR Fuel Elements under Operating Conditions Simulating Real Time in the HFR Petten, RC/aj/93, Joint Research Centre, Petten, The Netherlands, 1993.

43. Kasten, P. R., et al., Gas-Cooled Reactor Programs High-Temperature Gas-Cooled Reactor Technology Development Program; Annual Progress Report for Period Ending December 31. 1987, DOE-HTGR-88272 (ORNL-6502), Martin Marietta Energy Systems, Inc., Oak Ridge Natl. Lab., March 1989.

44. Verfondern, K., et al., Rechenmethoden und Daten Zum HTR-Brennstoffverhalten und Zur Spaltproduktfreisetzung im Normalbetrieb und Storfall im Rahmen von Sicherheitsanalysen, Isr Forschungszentrum Jülich GmbH, Jülich, Germany, January 1992.

45. Myers, B. F., An Assessment of the Methods for Determining Defect of Failed Fractions in HTGR Coated Particle Fuels and Their Relationship to Particle Microstructure, ORNLHTGR-88260, Martin Marietta Energy Systems, Inc., Oak Ridge Natl. Lab., April 1989.

46. Myers, B. F., "The Effect of Water Vapor on the Release of Fission Gases from Uranium Oxycarbide in High-Temperature, Gas-Cooled Reactor Coated Fuel Particles," J. Am. Ceram. Soc. 75, 686-93 (1992).

47. Myers, B. F., "Effect of Water Vapor on the Release of Fission Gases from UCO in HTGR Coated Fuel Particles," in Behavior of Gas Cooled Reactor Fuel Under Accident Conditions, proceedings of the IAEA Specialists Meeting (IWGGCR/25), Oak Ridge, Tennessee, November 5-8, 1990, International Atomic Energy Agency, Vienna, 1991.

48. Myers, B. F., The Effect of Water Vapor on Release of Gaseous Fission Products from High-Temperature Gas-Cooled Reactor Fuel Compacts Containing Exposed Oxycarbide Fuel, DOE-HTGR-88486 (ORNL-6610), Martin Marietta Energy Systems, Inc., Oak Ridge Natl. Lab., August 1991.

49. Myers, B. F., Experiment HFR-B1: A Preliminary Analysis of the Water-Vapor Injection Experiments in Capsule 3, ORNL/TM-11846, Martin Marietta Energy Systems, Inc., Oak Ridge Natl. Lab., October 1992. 
50. Myers, B. F., Plan for the Postirradiation Examination of Capsule 1 of the HFR-B1 Experiment, ORNL/TM-12348, Martin Marietta Energy Systems, Inc., Oak Ridge Natl. Lab., 1991.

51. Homan, F. J., et al., Gas-Cooled Reactor Programs High-Temperature Gas-Cooled Reactor Technology Development Program: Annual Progress Report for Period Ending December 31, 1988, DOE-HTGR-88-369 (ORNL-12453), Martin Marietta Energy Systems, Inc., Oak Ridge Natl. Lab., September 1993.

52. Myers, B. F., "The Transport of Fission Products in SiC," in US/FRG Meeting on Fuel Performance under Accident Conditions, ed. H. Nabielek, HTA-IB-2/90, Forschungszentrum Jülich GmbH, Jülich, Germany, June 1990.

53. Hanson, et al., Specification for COMEDIE Test BD-1, DOE-HTGR-87095, Martin Marietta Energy Systems, Inc., Oak Ridge Natl. Lab.

54. Kelly, B. T., Final Report of the NPR Graphite Peer Review, ORNL/NPR-93/4, Martin Marietta Energy Systems, Inc., Oak Ridge Natl. Lab., June 1993.

55. Kennedy, C. R., Preirradiation Evaluation of Graphites for HTK-7, DOE-HTGR-88511 (ORNL/TM-11666), Martin Marietta Energy Systems, Inc., Oak Ridge Natl. Lab., September 1990.

56. Burchell, T. D., "Preliminary Assessment of the Irradiation Induced Dimensional Changes of Graphite from Capsule HTK-7," letter report, September 1992 (attachment to letter ORNL/PDCO/92-017, dated Oct. 14, 1992).

57. Burchell, T. D., Strizak, J. P., Nelson, G. E., Barker, D. L., and Bailey, J. L., Preirradiation Data Report for NP-MHTGR Graphite Irradiation Capsules HTN-1 and -2, ORNL/NPR-91/19, Martin Marietta Energy Systems, Inc., Oak Ridge Natl. Lab., December 1991.

58. Burchell, T. D., Robbins, J M, and Strizak, J. P., Assessment of Post-Irradiation Examination Data for HFIR Capsule HTN-1, ORNL/TM-11988, Martin Marietta Energy Systems, Inc., Oak Ridge Natl. Lab., December 1991.

59. Burchell, T. D., Robbins, J M, and Strizak, J. P., Assessment of Post Irradiation Examination Data for HFIR Capsules HTN-2 and -3, September 1993, to be published.

60. Robbins, J M, Burchell, T. D., Bailey, J. L., and Nelson, G. E., Pre-irradiation Data Report for NP-MHTGR Graphite Irradiation Capsules HTN-4 and HTN-5, September 1993, to be published.

61. Pedraza, D. F., "The behavior of interstitials in irradiated graphite," p. 437 in Phase Formation and Modification by Beam-Solid Interactions, ed. G. Was, D. Feollstaedt, and L. Rehn, Materials Research Society, Pittsburgh, 1992. 
62. Koike, J., and Pedraza, D. F., "Structural changes induced by electron irradiation in graphite," in Prodeedings of the International Conference on Beam Processing of Advanced Materials, 1993, in press.

63. Hembree, D. M., Jr., Pedraza, D. F., Romanoski, G. R., Withrow, S. P., and Annis, B. K., "Raman spectroscopy of C-irradiated graphite," in Beam-Solid Interactions, ed. M. A. Nastasi, L. R. Harriot, N. Herbots, and R. S. Averback, Materials Research Society, Pittsburgh, 1993, in press.

64. Koike, J., and Pedraza, D. F., "Structural change in graphite during electron irradiation," in Beam-Solid Interactions, ed. M. A. Nastasi, L. R. Harriot, N. Herbots, and R. S. Averback, Materials Research Society, Pittsburgh, 1993, in press.

65. Annia, B. K., Pedraza, D. F., and Withrow, S. P., "Topographical changes induced by high dose carbon-bombardment of graphite," J. Mater. Res. (October 1993), in press.

66. Xu, C. H., Fu, C. L., and Pedraza, D. F., "Simulations of point defect properties in graphite by a tight-binding force model," Phys. Rev. B (1993), in press.

67. Annis, B. K., and Pedraza, D. F., "Effect of friction on atomic force microscopy of ion implanted high oriented pyrolytic graphite," J. Vac. Sci. Technol. (1993), in press.

68. Pedraza, D. F., Annis, B. K., and Withrow, S. P., "Topography of ion-irradiated graphite," in Extended Abstracts. Proceedings of the 21st Biennial Conference on Carbon, State University of New York at Buffalo, June 13-18, 1993, American Carbon Society, 1993.

69. Niwase, K., Nakamura, K., Shikama, T., and Tanabe, T., "On the Amorphization of Neutron-Irradiated Graphite," J. Nucl. Mater. 170, 106 (1990).

70. Kelley, B. T., "On the Amorphisation of Graphite Under Neutron Irradiation," J. Nucl. Mater. 172, 237 (1990).

71. Mobasheran, A. S., "Examination of Experimental Data for Irradiation-Induced Creep in Nuclear Graphite," Ph.D. Thesis, University of Tennessee, Knoxville, Tenn., December 1990.

72. Kelley, B. T., The Analysis of Irradiation Creep in Reactor Graphites, ORNL/NPR-92/58, Martin Marietta Energy Systems, Inc., Oak Ridge Natl. Lab., June 1993.

73. Kelley, B. T., The Interaction of Dimensional Changes and Irradiation Creep in Reactrr Graphite, ORNL/NPR-92/60, Martin Marietta Energy Systems, Inc., Oak Ridge Natl. Lab., May 1993.

74. Kelley, B. T., and Burchell, T. D., "The Analysis of Irradiation Creep Experiments on Nuclear Reactor Graphite," CARBON, to be published.

75. Kelley, B. T., Analysis of the Changes in Graphite Properties Under Neutron Irradiation Due to Structural Changes, ORNL/NPR-92/61, Martin Marietta Energy Systems, Inc., Oak Ridge Natl. Lab., May 1993. 
76. Burchell, T. D., "Studies of Fracture in Nuclear Graphite," Ph.D. Thesis, University of Bath, United Kingdom, 1986.

77. Burchell, T. D., "A Microstructurally Based Fracture Model for Nuclear Graphites," in Status of Graphite Development for Gas-Cooled Reactors, proceedings of the IAEA Specialists Meeting held at Japan Atomic Energy Research Institute, Tokai-Mura, Japan, September 9-12, 1991, IAEA-TECDOC-690, International Atomic Energy Agency, Vienna, February 1993.

78. Burchell, T. D., and Strizak, J. P., "Modelling the Tensile Strength of H-451 Nuclear Graphite," in Proceedings of the 21st Biennial Conference on Carbon, State University of New York at Buffalo, June 13-18, 1993, American Carbon Society, New York, 1993.

79. Strizak, J. P., Interim Report on the Effects of Position and Specimen Size on the Tensile Strength of Grade H-451 Graphite: Billet 58-293, ORNL/NPR-92/52, Martin Marietta Energy Systems, Inc., Oak Ridge Natl. Lab., in publication.

80. Strizak, J. P., "The Effect of Volume on the Tensile Strength of Several Nuclear-Grade Graphites," in Status of Graphite Development for Gas-Cooled Reactors, proceedings of the IAEA Specialists Meeting held at Japan Atomic Energy Research Institute, Tokai-Mura, Japan, September 9-12, 1991, IAEA-TECDOC-690, International Atomic Energy Agency, Vienna, February 1993.

81. Strizak, J. P., "Spatial Variability in the Tensile Strength of an Extruded Nuclear-Grade Graphite," in Status of Graphite Development for Gas-Cooled Reactors, proceedings of the IAEA Specialists Meeting held at Japan Atomic Energy Research Institute, Tokai-Mura, Japan, September 9-12, 1991, IAEA-TECDOC-690, International Atomic Energy Agency, Vienna, February 1993.

82. Strizak, J. P., and Burchell, T. D., "The Effect of Stress Volume on the Tensile Properties of Graphite," in Proceedings of the 20th Biennial Conference on Carbon, University of California, Santa Barbara, June 23-28, 1991, American Carbon Society, 1991.

83. Strizak, J. P., "Tensile Strength Variability in H-451 Nuclear Grade Graphite," in Proceedings of the 21st Biennial Conference on Carbon, State University of New York at Buffalo, June 13-18, 1993, American Carbon Society, 1993.

84. "Division Requirements for Graphite Core Supports," ASME Boiler and Pressure Vessel Code, Subsection CE (draft) to Section III, Division 2/ACI 359, American Society of Mechanical Engineers, New York, 1990.

85. NP-MHTGR Engineering Development Plan, NP-60, Office of New Production Reactors MHTGR Division, October 1991.

86. Fatigue Data for the Graphite Core Components of the NP-MHTGR, ORNL Test Plan NP-GR-TP3, Rev. 3, Martin Marietta Energy Systems, Inc., Oak Ridge Natl. Lab., June 1992. 
87. Merkle, J. G., Smith, J. E., and Witt, F. J., "Failure Characteristics of EGCR-Type AGOT Graphite at Room Temperature," Abstract No. 137 of Papers Presented at the Seventh Conference on Carbon, Carbon, 3, 365, 1965; also see GCR Semiannual Progress Report for Period Ending September 30, 1965, ORNL-3885, Union Carbide Corp. Nuclear Div., Oak Ridge Natl. Lab., 1965, pp. 231-35.

88. Greenstreet, W. L., Yahr, G. T., and Valachovic, R. S., Fracture of Graphite, Quarterly Progress Report No. 9, for Period Ending January 1, 1972, ORNL-TM-3874, Union Carbide Corp. Nuclear Div., Oak Ridge Natl. Lab., August 1972.

89. Ely, R. E., "Strength of Magnesium Silicate and Graphite Under Biaxial Stresses," Ceram. Bull. 47(5), 489-92 (1968).

90. Ely, R. C., Biaxial Fracture Stresses for Graphite, Ceramic and Filled and Reinforced Epoxy Tube Specimens, RR-TR-65-10, U.S. Army Missiles Command, Redstone Arsenal, Ala., June 1965.

91. Ely, R. E., "Strength of Graphite Tube Specimens Under Combined Stresses," J. Am. Ceram. Soc. 48(10), 505-8 (1965).

92. Ely, R. D., Strength for Graphite and Two Types of Plastic Tubing Under Biaxial Stresses, RR-TR-63-18, U.S. Army Missiles Command, Redstone Arsenal, Ala., 1963.

93. Jortner, J., "Biaxial Mechanical Properties of AXF-5Q Graphite to $4000^{\circ} \mathrm{F}$," in Proceedings of the Conference on Continuum Aspects of Graphite Design. Gatlinburg. Tennessee, November 9-12, 1970, CONF-701105, U.S. Department of Commerce, National Technical Information Service, Springfield, Va., 1971.

94. Broutman, L. J., Krishnakumar, S. M., and Mallick, P. K., "Effects of Combined Stresses on Fracture of Alumina and Graphite," J. Am. Ceram. Soc. 53, 649 (1970).

95. Jortner, J., Multiaxial Behavior of ATJ-S Graphite, Technical Report AFML-TR-71-160, Air Force Materials Laboratory, Wright-Patterson Air Force Base, Dayton, Ohio, July 1971.

96. Yahr, G. T., Valachovic, R. S., and Greenstreet, W. L., "Deformation and Fracture of Thin-Walled Graphite Tubes Under Biaxial States of Stress," in Eleventh Biennial Conference on Carbon, Extended Abstracts and Program, Gatlinburg. Tenn., June 4-8, 1973, USAEC Report CONF-730601, Union Carbide Corp. Nuclear Div., Oak Ridge Natl. Lab., 1973.

97. Greenstreet, W. L., Yahr, G. T., and Valachovic, R. S., Fracture of Graphite, Quarterly Progress Report No. 10 for Period Ending April 1, 1972, ORNL-TM-3936, Union Carbide Corp. Nuclear Div., Oak Ridge Natl. Lab., October 1972.

98. Ely, R. E., Strength Results for Ceramic Materials Under Multiaxial Stresses, RR-TR-68-1, U.S. Army Missiles Command, Redstone Arsenal, Ala., April 1968.

99. Ely, R. E., Strength Results for Two Brittle Materials Under Biaxial Stresses, RR-TR-72-11, U.S. Army Missiles Command, Redstone Arsenal, Ala., 1972. 
100. Weng, T., "Biaxial Fracture Strength and Mechanical Properties of Graphite-Base Refractory Composites," AlAA J. 7(5), 851-58 (May 1969).

101. Weng, T., "Room Temperature Fracture Behavior of Polycrystalline Graphites Under Torsional and Biaxial Stresses," Paper No. MI 60, Presented at the Eighth Biennial Conference on Carbon, Buffalo, New York, June 19-23, 1967.

102. Weng, T., "Stress-Strain Properties of Grade ATJ Graphite Under Combined Stresses," pp. 222-35 in Proceedings of the Conference on Continuum Aspects of Graphite Design, Gatlinburg, Tenn., November 9-12, 1970, CONF-701105, U.S. Department of Commerce, National Technical Information Service, Springfield, Va., 1971.

103. Babcock, S. G., Green, S. J., Hochstein, P. A., and Gum, J. A., "Dynamic Biaxial and Elevated-Temperature Properties of ATJ-Graphite," p. 59 in Proceedings of the Conference on Continuum Aspects of Graphite Design, Gatlinburg. Tenn., November 9-12, 1970, CONF-701105, U.S. Department of Commerce, National Technical Information Service, Springfield, Va., 1971.

104. Jortner, J., Multiaxial Response of ATJ-Graphite, Technical Report AFML-TR-71253, Air Force Materials Laboratory, Wright-Patterson Air Force Base, Dayton, Ohio, December 1971.

105. Jortner, J., Multiaxial Response of ATJ-Graphite, Technical Report AFML-TR-73-170, Air Force Materials Laboratory, Wright-Patterson Air Force Base, Dayton, Ohio, October 1973.

106. Perkins, R. D., et al., Multiaxial Loading Behavior of Four Materials Including ATJ-S Graphite and RAD-6300 Carbon Phenolic, SAMSO-TR-69-393, Vol. 1, Material Response Studies (MARS II), Space and Missile Systems Organization, Los Angeles AFS, Los Angeles, Calif., August 1970.

107. Ho, F. H., et al., "Biaxial Failure Surfaces of 2020 and PGX Graphites," p. 127 in Transactions of the 7 th International Conference on Structural Mechanics in Reactor Technology, Vol. L, August 1983.

108. Hackerott, H. A., "Characterization of Multiaxial Fracture Strength of Transversely Isotropic AGOT Graphite," M.S. thesis, Kansas State University, 1982.

109. Yahr, G. T., Valachovic, R. S., and Greenstreet, W. L., "An Examination of Fracture Behavior of Graphite Through the Use of Splitting Tensile Tests," pp. 29-46 in Graphite Structures for Nuclear Reactors; Proc. Int. Conf. London, England, March 1972, Institute of Mechanical Engineering, :London; 1972.

110. Yahr, G. T., and Valachovic, R. S., "Application of Fracture Mechanics to Graphite Under Complex Stress Conditions," in Fracture Mechanics of Ceramics, Vol. 2, ed. R. C. Bradt, D. P. H. Hasselman, and F. F. Lange, Plenum Publishing Corporation, New York, 1973. 
111. King, K. R., Bird, J. O., and Bohn, J. R., Thermal Stress Behavior of Polycrastalline Graphite, Part I, AFML-TR-71-152, Air Force Materials Laboratory, Wright-Patterson Air Force Base, Dayton, Ohio, July 1971.

112. King, K. R., Bird, J. O., and Bohn, J. R., Thermal Stress Behavior of Polycrastalline Graphite, Part II. Biaxial Fracture of ATJ-S, AFML-TR-71-152, Pt. 2, Air Force Materials Laboratory, Wright-Patterson Air Force Base, Dayton, Ohio, December 1971.

113. King, K. R., Bird, J. O., and Bohn, J. R., Thermal Stress Behavior of Polycrastalline Graphite, Part III. Special Purpose Tests, AFML-TR-71-152, Pt. 3, Air Force Materials Laboratory, Wright-Patterson Air Force Base, Dayton, Ohio, December 1972.

114. Pears, C. D., and Starrett, H. S., Polygraphites Subjected to Temperature Stress Loadings, AFML-TR-73-59, Air Force Materials Laboratory, Wright-Patterson Air Force Base, Dayton, Ohio, March 1973.

115. Baker, D. L., Starrett, H. S., and Budde, C. L., Thermostructural Testing of Instrumented ATJ-S Graphite Shell Nosetips in the AFFDL 50 MW Facility, AFML-TR-76-26, Air Force Materials Laboratory, Wright-Patterson Air Force Base, Dayton, Ohio, April 1976.

116. Yahr, G. T., Determination of the Relative Thermal Rupture Resistance of Graphites, ORNL4467, Union Carbide Corp. Nuclear Div., Oak Ridge Natl. Lab., January 1970.

117. Derby, R. W., "Thermal Shock of Graphite Disks," Ph.D. thesis, Colorado School of Mines, 1968.

118. "Design Requirements for Graphite Core Supports," proposed Section III, Division 2, Subsection CE, ASME Boiler and Pressure Vessel Code, American Society of Mechanical Engineers, New York, 1990.

119. Gross, B., Srawley, J. E., and Brown, W. F., Jr., Stress-Intensity Factors for a Single-EdgeNotch Tension Specimen by Boundary Collocation of a Stress Function, Technical Note D-2395, National Aeronautics and Space Administration, Washington, D.C., August 19 rs

120. Rooke, D. P., and Cartwright, D. J., Compendium of Stress Intensity Factors, Her Ma Stationery Office, London, 1976.

121. Timoshenko, S. P., and Gere, J. M., Theory of Elastic Stability, 2d eü., McGraw-Hil. $\ldots$ Co., Inc., New York, 1961.

122. Romanoski, G. R., and Burchell, T. D., "Specimen Size Effect on Fracture Toughness of Nuclear Graphites," pp. 584-85 in Proceedings of the 20th Biennial Conference on Ca: 'hn, University of California, Santa Barbara, June 23-28, 1991, American Carbon Society

123. Romanoski, G. R., and Barker, D. L., Fracture Mechanics of H-451 and Stackpole 2020 Graphites, ORNL/NPR-92/12, Martin Marietta Energy Systems, Inc., Oak Ridge Natl. Lab., 1992. 
124. Romanoski, G. R., and Burchell, T. D., "The Effects of Specimen Geometry and Size on the Fracture Toughness of Nuclear Graphites, " in Status of Graphite Development for GasCooled Reactors, proceedings of the IAEA Specialists Meeting held at Japan Atomic Energy Research Institute, Tokai-Mura, Japan, September 9-12, 1991, International Atomic Energy Agency, Vienna, February 1993.

125. Test Specification - Fracture Mechanics Data for NP-MHTGR Graphite Reactor Internal Components, CEGA-001915, Rev. N/C, CEGA Corporation, San Diego, Calif., April 1992.

126. Oak Ridge National Laboratory New Production Reactors Project, Fracture Mechanics Data for the Graphite Core Components of the NP-MHTGR, ORNL/NPR-92/40, Martin Marietta Energy Systems, Inc., Oak Ridge Natl. Lab., 1992.

127. NP-MHTGR Test Procedure for Fracture Mechanics Data for the Graphite Components of the NP-MHTGR, Test Procedure No. NP-GR-PR2, Rev. 0, Martin Marietta Energy Systems, Inc., Oak Ridge Natl. Lab., 1992.

128. NPR Close-out Report on Fracture Mechanics, to be published.

129. (a) Fuller, E. L., Jr., Kopp, O. C., Burchell, T. D., and Underwood, A. D., Corrosion of Nuclear-Grade Graphites: Air Oxidation of H-451, ORNL/NPR/27, Martin Marietta Energy Systems, Inc., Oak Ridge Natl. Lab., October 1992; (b) Fuller, E. L., Jr., and Chilcoat, B. R., Graphite Corrosion Kinetics and Mechanisms: Rate Data, DOE-HTGR-88462, ORNL/GCR-90/2, Martin Marietta Energy Systems, Inc., Oak Ridge Natl. Lab.; and (c) Fuller, E. L., Jr., Kopp, O. C., and Underwood, A. D., "Kinetics and Mechanisms of Graphite Oxidation: A Microgravimetric System for Evaluation of Chemical and Structural Effects," p. 604 in Proceedings of the 20th Biennial Conference on Carbon, University of California, Santa Barbara, June 23-28, 1991, American Carbon Society, 1991.

130. Satterfield, C. N., Mass Transfer in Heterogeneous Catalysis, Massachusetts Institute of Technology Press, Cambridge, Mass., 1970; pp. 5 and 138-141 (also Fuller, E. L., Jr., and Chilcoat, B. R., Graphite Corrosion Kinetics and Mechanisms: Rate Data, DOE-HTGR88462, ORNL/GCR-90/2, Martin Marietta Energy Systems, Inc., Oak Ridge Natl. Lab.).

131. Marsh, H., Introduction to Carbon Science, Butterworths, London, 1989.

132. Richards, M. B., "Reaction of Nuclear-Grade Graphite with Low Concentrations of Steam in the Helium Coolant of an MHTGR," Energy 15 (1990).

133. Walker, P. L., Jr., Taylor, R. L., and Manish, J. M., "An Update on the Carbon-Oxygen Reaction," Carbon 29, 411 (1991).

134. Daccord, G., "Dissolutions, Evaporations, Etchings," p. 183 in The Fractal Approach to Heterogeneous Chemistry, ed. D. Avnir, John Wiley, New York, 1989.

135. Havlin, S., "Molecular Diffusion and Reactions," p. 251 in The Fractal Approach to Heterogeneous Chemistry, ed. D. Avnir, John Wiley, 1989. 
136. Kopelman, R., "Diffusion-Controlled Reaction Kinetics," p. 295 in The Fractal Approach to Heterogeneous Chemistry, ed. D. Avnir, John Wiley, 1989.

137. Bhatia, S. K., and Perlmutter, D. D., "Random Pore Model for Fluid-Solid Reactions: I. Isothermal, Kinetic Control," AIChE J. 26, 379 (1980).

138. Burnell, L. R., Campbell, T. K., and Tingey, G. L., Oxidation of TSX Graphite over the Temperature Range $450^{\circ} \mathrm{C}$ to $1200^{\circ} \mathrm{C}$, UNC Nuclear Industries Report No. HW-67792, 1961.

139. NP-MHTGR Specification for Air-Graphite Oxidation.

140. Fuller, E. L., Jr., Kopp, O. C., and Underwood, A. D., in press: (a) Proceedings of the 21st Biennial Carbon Conference, State University of New York at Buffalo, June 13-18, 1993, American Carbon Society, 1993, and (b) "Measurements of Air Oxidation of Commercial Graphites," in Proceedings of the 5th International Carbon Conference, Essen, Germany, 1992.

141. Fuller, E. L., Kopp, O. C., and Underwood, A. D., "Corrosion Kinetics and Mechanisms for Nuclear-Grade Graphites," in Proceedings of the National Academy of Corrosion Engineers Conference, New Orleans, 1993.

142. Fuller, E. L., Kopp, O. C., Burchell, T. D., and Underwood, A. D., Microgravimetric Ansysis of Corrosion of $\mathrm{H}-451$ Graphite by Coolant Impurities: Preliminary Report of Kinetics and Mechanisms, DOE-HTGR-88526, ORNL/GCR-90-3, Martin Marietta Energy Systems, Inc., Oak Ridge Natl. Lab., November 1992.

143. Kopp, O. C., Fuller, E. L., Jr., and Underwood, A. D., The Effect of Trace Elements on the Surface Oxidation of H-451 Graphite, ORNL/NPR-92/56, Martin Marietta Energy Systems, Inc., Oak Ridge Natl. Lab., December 1992.

144. Kopp, O. C., Fuller, E. L., Jr., and Cavin, O. B., Oxidized Residues from 2020 Graphite, ORNL/NPR-93/2, Martin Marietta Energy Systems, Inc., Oak Ridge Natl. Lab., May 1993.

145. Fuller, E. L., Jr., Status Report on High-Pressure Test Loop for Graphite Oxidation Studies, ORNL/NPR-90/33, Martin Marietta Energy Systems, Inc., Oak Ridge Natl. Lab., 1990.

146. Vollman, R. E., Ho, F-H., Anderson, J. K., Kapernick, R. J., and Haviland, V., Applications of High Strength Control Rod Materials, GA Letter Report, GA/ORNL-053-89, General Atomics, San Diego, January 1989.

147. Burchell, T. D., A Review of the Properties of Carbon Materials Suitable for MHTGR High-Temperature Control Rods, ORNL/NPR-90/1, Union Carbide Corp. Nuclear Div., Oak Ridge Natl. Lab., June 1981.

148. Carbon-Carbon Composite Control Rod Materials Design Data, NPR-CDN OR 007, Martin Marietta Energy Systems, Inc., Oak Ridge Natl. Lab., January 1992. 
149. $450 \mathrm{MW}(\mathrm{t})$ Control Rod Materials Selection, DOE-HTGR-90010, General Atomics, San Diego, September 1991.

150. Burchell, T. D., and Strizak, J. P., Technical Plan: Development of Carbon-Carbon Composite Materials for High-Temperature NP-MHTGR Control Rods, ORNL/NPR-92/6, Martin Marietta Energy Systems, Inc., Oak Ridge Natl. Lab., January 1992.

151. Burchell, T. D., Interim Report on the Thermal Physical Properties of H-451 Graphite, ORNL/NPR-92/54, April 1993.

152. Burchell, T. D., The Thermal Physical Properties of H-451 Graphite, NPR-MHTGR Letter Report, to be published.

153. Kennedy, C. R., Pre-irradiation Evaluation of Graphites for HTK-7, DOE-HTGR-88511, ORNL/TM-11666, Martin Marietta Energy Systems, Inc., Oak Ridge Natl. Lab., September 1990.

154. Burchell, T. D., Preliminary Assessment of the Irradiation Induced Dimensional Changes of Graphite from Capsule HTK-7, Letter report attachment to ORNL/PDCD/92-017, October 1992.

155. Haag, G., pp. 244-45 in Proceedings of the International Carbon Conference, Paris, France, July 16-20, 1990.

156. Haag, G., Delle, W., Nickel, H., Theymann, W., and Wilhelmi, G., "Development and Testing of Nuclear Graphites for the German Pebble-Bed High Temperature Reactor," pp. 128-32 in Proceedings of the IAEA Specialists Meeting (IWGGCR/11) on Graphite Component Structural Design, held at Japan Atomic Energy Research Institute, Tokai-Mura, Japan, September 8-11, 1986, JAERI-M-86-192, Japan, 1987.

157. Burchell, T. D., Oku, T., and Eto, M., pp. 278-79 in Proceedings of the International Carbon Conference, Paris, France, July 16-20, 1990.

158. Sata, S., Kawamata, K., Kuramada, A., Ugachi, H., and Awali, H., pp. 144-57 in Proceedings of the IAEA Specialists Meeting (IWGGCR/11) on Graphite Component Structural Design, held at Japan Atomic Energy Research Institute, Tokai-Mura, Japan, September 8-11, 1986, JAERI-M-86-192; Japan, 1987.

159. Oku, T., Ishiyama, S., Eto, M., Goto, Y., Urashima, K., and Inagaki, M., J. Jpn. Ceram. Soc. 96, 773-77 (1988):

160. Romanoski, G. R., and Burchell, T. D., pp. 241-47 in Status of Graphite Development for Gas-Cooled Reactors, proceedings of the IAEA Specialists Meeting held at Japan Atomic Energy Research Instituite, Tokai-Mura, Japan, September 9-12, 1991, IAEA-TECDOC-690, International Atomic Energy Agency, Vienna, February 1993.

161. Burchell, T. D., "Studies of Fracture in Nuclear Graphite," Ph.D. Thesis, University of Bath, United Kingdom, 1986. 
162. Burchell, T. D., pp. 49-58 in Status of Graphite Development for Gas-Cooled Reactors, proceedings of the IAEA Specialists Meeting held at Japan Atomic Energy Research Instituite, Tokai-Mura, Japan, September 9-12, 1991, IAEA-TECDOC-690, International Atomic Energy Agency, Vienna, February 1993.

163. Burchell, T. D., Tucker, M. O., and McEnaney, B., "Qualitative and Quantitative Studies of Fracture in Nuclear Graphites," in Proceedings of Materials for Nuclear Reactor Core Applications, British Nuclear Energy Society, London, 1987.

164. Burchell, T. D., "Modelling and Tensile Strength of H-451 Nuclear Graphite," p. 687 in Extended Abstracts and Proceedings of the 21st Biennial Conference on Carbon, State University of Buffalo at New York, June 13-18, 1993, American Carbon Society, 1993.

165. "Radiation Embrittlement of Reactor Vessel Materials," Regulatory Guide 1.99 (Rev. 2), U.S. Nuclear Regulatory Commission, Washington, D.C., May 1988.

166. Odette, G. R., Lomborozo, P. M., and Wullaert, R. A., "Relationship Between Irradiation Hardening and Embrittlement of Pressure Vessel Steels," pp. 840-60 in Effects of Radiation on Materials: Twelfth International Symposium, ASTM STP 870, ed. F. A. Garner and J. S. Perrin, American Society for Testing and Materials, Philadelphia, 1985.

167. Haggag, F. M., Nanstad, R. K., and Braski, D. N., "Structural Integrity Evaluation Based on an Innovative Field Indentation Microprobe," pp. 101-7 in Innovative Approaches to Irradiation Damage, and Fracture Analysis, PVP-Vol. 170, ed. D. L. Mariott, T. R. Mager, and W. H. Bamford, American Society of Mechanical Engineers, New York, 1989.

168. Haggag, F. M., "Field Indentation Microprobe for Structural Integrity Evaluation," U.S. Patent 4,852,397, August 1989.

169. Haggag, F. M., et al., "Use of Automated Ball Indentation Testing to Measure Flow Properties and Estimate Fracture Toughness in Metallic Materials," pp. 188-208 in Applications of Automation Technology to Fatigue and Fracture Testing, ASTM STP 1092, ed. A. A. Braun, Ashbaugh, and F. M. Smith, American Society for Testing and Materials, Philadelphia, 1990.

170. Haggag, F. M., "Application of Flow Properties in Microprobe to Evaluate Gradients in Weldment Properties," to be published in Proceedings of the ASM 3rd International Conference on Trends in Welding Research, Gatlinburg, Tennessee, June 1-5, 1992.

171. Haggag, F. M., "In-Situ Measurements of Yield Strength and Flow Properties Using a Novel ABI System," presented at the ASTM Symposium on Small Specimen Test Techiques and Their Applications to Nuclear Reactor Vessel Thermal Annealing and Plant Life Extension, New Orleans, Louisiana, January 29-31, 1992.

172. McCoy, H. E., Tensile and Creep Tests on a Single Heat of Alloy 800H, ORNL/TM-12436, in preparation. 
173. Grossbeck, M. L., Ehrlich, K., and Wassilew, C., "An Assessment of Tensile, Irradiation Creep, Creep Rupture, and Fatigue Behavior in Austenitic Stainless Steels with Emphasis on Spectral Effects," J. Nucl. Mater. 174, 264 (1990).

174. Barnes, S., "Embrittlement of Stainless Steels and Nickel-Based Alloys at High Temperature Induced by Neutron Irradiation," Nature 206, 1307 (1965).

175. Manson, S. S., and Muralidharan, U., "Analysis of Creep Rupture Data for Five Multi-heat Alloys by the Minimum Commitment Method Using Double Heat Term Centering," pp. 1-46 in Progress in Analysis of Fatigue and Stress Rupture, Vol. MPC-23, American Society of Mechanical Engineers, New York, 1984.

176. McCoy, H. E., Use of the MCM for Analysis of Alloy 800H Rupture Data, ORNL-TM (in progress).

177. Pepe, J. J., pp. 43-60 in Materials Property Data: Applications and Access, ed. J. G. Kaufman, MPC-Vol. 1, PVP-Vol. 111, The American Society of Mechanical Engineers, 1986.

178. McCoy, H. E., Final Analysis of ORNL Creep Data on $2.25 \mathrm{Cr}-1$ Mo Steel, ORNL-TM (in preparation).

179. Houstrup, J. P., Webster, K. E., and Zumbrun, H. R., MHTGR-NPR Steam Generator Bimetallic Weld Configuration Study, DPS-91-221, ABB Combustion Engineering Nuclear Power Systems, May 1991.

180. Materials Properties Council, Dissimilar Metal Weld Failure Analysis and Development Program, CS-4252, Vols. 1-8, Electric Power Research Institute, Palo Alto, Calif., 1987.

181. "Structural Integrity of Bimetallic Welds," NPR-DDN-13.22, in NP-MHTGR Engineering Development Plan, CEGA-91-0845, CEGA Corporation, San Diego, Calif., October 1991.

182. Test Specification for Structural Integrity Testing of Bimetallic Welds for NP-MHTGR Steam Generator, CEGA-002009, Rev. N/C (Draft), CEGA Corporation, San Diego, Calif., July 1992.

183. "Class 1 Components in Elevated Temperature Service, Section III, Division 1," Case N-4729, ASME Boiler and Pressure Vessel Code, American Society of Mechanical Engineers, New York, 1992.

184. Ryder, R. H., and Dahms, C. F., Design Criteria for Dissimilar Metal Welds, GA-C18697, General Atomics, San Diego, April 1988, and Bulletin 350, Welding Research Council, New York, January 1990.

185. Material Specification for SB-163 Mill-Annealed UNS-N08810 (Alloy 800H) Tubing for NPMHTGR Steam-Generator, 93789-CE-MS-004, Rev. 00, ABB Combustion Engineering Nuclear Power, December 1991. 
186. Material Specification for SA-213 Grade T-22 Seamless Tubing for NP-MHTGR SteamGenerator, 93789-CE-MS-005, Rev. 00, ABB Combustion Engineering Nuclear Power, December 1991.

187. "Welding of Alloy $800 / 800 \mathrm{H}$ Tubes to $21 / 4 \mathrm{Cr}$-1Mo Tubes," Welding Technique 93789-CEWT-001, Rev. 00, July 1992, Appendix A to Welding of Alloy 800/800H to Low Alloy Steels, General Requirement Welding Specification 93789-E-GR-004, Rev. 00, ABB Combustion Engineering Nuclear Power, August 1992.

188. "Standard Recommended Practice for Constant-Amplitude Low-Cycle Fatigue Testing," Standard E 606-80, in 1992 Annual Book of ASTM Standards, Vol. 03.01, American Society for Testing and Materials, Philadelphia, 1992.

189. Corum, J. M., "Evaluation of Weldment Creep and Fatigue Strength-Reduction Factors for Elevated-Temperature Design," J. Pressure Vessel Technol. 112, 333-39 (November 1990).

190. Blass, J. J., Battiste, R. L., and O'Connor, D. G., "Reduction Factors for Creep Strength and Fatigue Life of Modified 9Cr-1Mo Steel Weldments, Confirmation by Axial or Torsional Tests of Tubular Specimens with Longitudinal or Circumferential Welds," pp. 253-59 in Pressure Vessel Integrity 1991, ed. S. Bhandari et al., PVP-Vol. 213/MPC-Vol. 32, American Society of Mechanical Engineers, New York, June 1991.

191. Krueger, K., Cleveland, J., et al., "Preparation, Conduct, and Experimental Results of the AVR Loss-of-Coolant Accident Test," Nucl. Sci. Eng. 107, 99-113 (1991).

192. Cleveland, J. C., Pretest Predictions and Test Results for the AVR Loss-of-Coolant Accident Simulation, ORNL/GCR-89/2 (DOE-HTGR-88280), Martin Marietta Energy Systems, Inc., Oak Ridge Natl. Lab., February 1989.

193. Bucholz, J. A., and Childs, R. L., Preconceptual Shielding Design Analyses for the Lower Portion of the MHTGR Reactor System Incorporating a 350-MWth Annular Prismatic Core, ORNL/GCR-86/1 (HTGR-86-060), Martin Marietta Energy Systems, Inc., Oak Ridge Natl. Lab., June 1986; 380 pp (Applied Technology).

194. Bucholz, J. A., and Childs, R. L., Preconceptual Shielding Design Analyses for the Upper Portion of the MHTGR Reactor System Incorporating a 350-MWth Annular Prismatic Core, ORNL/GCR-86/4 (HTGR-86-112), Martin Marietta Energy Systems, Inc., Oak Ridge Natl. Lab., October 1986; 238 pp. (Applied Technology).

195. Bucholz, J. A., Revised Shielding Design Analyses for the Upper Portion of the MHTGR Reactor System Without the RSS Tube Shield Jacket Assemblies, ORNL/CGR-87/1 (DOEHTGR-87-006), Martin Marietta Energy Systems, Inc., Oak Ridge Natl. Lab., February 1987; 156 pp. (Applied Technology).

196. Bucholz, J. A., Shielding Design Analyses for the Upper Portion of the MHTGR Reactor System With the Neutron Shield Bonnet Located Inside the Reactor Vessel, ORNL/GCR-87/3 (DOE-HTGR-87-084), Martin Marietta Energy Systems, Inc., Oak Ridge Natl. Lab., August 1987; 242 pp. (Applied Technology). 
197. Bucholz, J. A., A 3-D Shielding Study of the Borated Steel Pins in the Permanent Side Reflector of the MHTGR and Their Effect on the Beltline Vessel Fluence, ORNL/GCR-88/2 (DOE-HTGR-88-109), Martin Marietta Energy Systems, Inc., Oak Ridge Natl. Lab., June 1988, 105 pp. (Applied Technology).

198. Bucholz, J. A., 2-D Analysis of the Upper Plenum Shielding Configuration for the MHTGR Inlet Coolant Ducts, ORNL/GCR-88/5 (DOE-HTGR-88-181), Martin Marietta Energy Systems, Inc., Oak Ridge Natl. Lab., September 1988, 35 pp. (Applied Technology).

199. Bucholz, J. A., and Childs, R. L., B-10 Depletion in the Borated Steel Pins Located in the Permanent Side Reflector of the MHTGR, ORNL/GCR-88/6 (DOE-HTGR-88-246), Martin Marietta Energy Systems, Inc., Oak Ridge Natl. Lab., November 1988; 35 pp. (Applied Technology).

200. Bucholz, J. A., Initial Streaming Analysis of the Large Diameter Coolant Holes in the Lower Reflector of the MHTGR, ORNL/GCR-89/1 (DOE-HTGR-88268), Martin Marietta Energy Systems, Inc., Oak Ridge Natl. Lab., January 1989; 63 pp. (Applied Technology).

201. Bucholz, J. A., ORNL Contribution to GA's MHTGR Radiation Dose Data Base, ORNL/JAB-89/2.28, Martin Marietta Energy Systems, Inc., Oak Ridge Natl. Lab., February 1989; 45 pp. (Applied Technology).

202. Bucholz, J. A., Two- and Three-Dimensional Analyses of Shielding Design Options for the Lower Axial Reflector of the MHTGR, ORNL/GCR-89/3 (DOE-HTGR-88303), Martin Marietta Energy Systems, Inc., Oak Ridge Natl. Lab., June 1989; 199 pp. (Applied Technology).

203. Bucholz, J. A., Cross Validation of MHTGR Shielding Methods and Data for the Lower Axial Reflector Against Earlier Experiments at the Tower Shielding Reactor, ORNL/JAB89/10.27, Martin Marietta Energy Systems, Inc., Oak Ridge Natl. Lab., October 1989; 84 pp. (Applied Technology).

204. Bucholz, J. A., Shielding Analysis of the Hollow Control Rods and Other Design Options in the Upper Plenum of the Commercial MHTGR, ORNL/GCR-90/1 (DOE-HTGR-88407), Martin Marietta Energy Systems, Inc., Oak Ridge Natl. Lab., February 1990; 65 pp. (Applied Technology).

205. Maerker, R. E., Barthold, W. P., and Bucholz, J. A., Verification and Validation Program Plan for the NPR-MHTGR Shielding Task, ORNL/NPR-90/11, Martin Marietta Energy Systems, Inc., Oak Ridge Natl: Lab., October 1990; 81 pp. (Applied Technology).

206. Slabaugh, H., and Maerker, R. E., Quality Assurance Plan for the NPR-MHTGR Shielding Task, ORNL/NPR-90/19, Martin Marietta Energy Systems, Inc., Oak Ridge Natl. Lab., November 1990. 
207. Bucholz, J. A., Initial Scoping Assessment of the Neutron Shielding for the Conceptual Design of the NPR-MHTGR and Several Proposed Variations, ORNL/NPR-90/41, Martin Marietta Energy Systems, Inc., Oak Ridge Natl. Lab., December 1990; 108 pp. (Applied Technology).

208. Bucholz, J. A., Impact of Using Newly Proposed Damage Functions to Assess the Effective Fast Fluence in the MHTGR, ORNL/NPR-90/58, Martin Marietta Energy Systems, Inc., Oak Ridge Natl. Lab., January 1991; 163 pp. (Applied Technology).

209. White, J. E., Roussin, R. W., and Bucholz, J. A., Specificauys for the NPR-MHTGR Shielding Cross-Section Library, ORNL/NPR-90/62, Martin Marietta Energy Systems, Inc., Oak Ridge Natl. Lab., February 1991; 13 pp. (Applied Technology). (See also Rev. 1, February 1992.)

210. Bucholz, J. A., Design and Pre-Experimental Analysis of the Proposed Borated Pin-Array Experiments for the MHTGR, ORNL/NPR-92/1, Martin Marietta Energy Systems, Inc., Oak Ridge Natl. Lab., January 1992; 280 pp. (Applied Technology).

211. Emmett, M. B., Verification of MORSE-SGC on the Cray UNICOS System, ORNL/NPR92/5, Martin Marietta Energy Systems, Inc., Oak Ridge Natl. Lab., May 1992; 66 pp. (Applied Technology).

212. Slater, C. O., and Cramer, S. N., Survey Analysis of Radiation Levels in the HTGR Lower Regions, ORNL/TM-8141, Union Carbide Corp. Nuclear Div., Oak Ridge Natl. Lab., 1982.

213. Muckenthaler, F. J., et al., Phase I Measurements for the HTGR Bottom Reflector and Core Support Block Neutron-Streaming Experiment, ORNL/TM-8977, Martin Marietta Energy Systems, Inc., Oak Ridge Natl. Lab., 1984.

214. Slater, C. O., Analysis of Phase I of the HTGR Bottom Reflector and Core Support Block Neutron-Streaming Experiment, ORNL/TM-9252, Martin Marietta Energy Systems, Inc., Oak Ridge Natl. Lab., 1984.

215. Slater, C. O., Analysis of Phase II of the HTGR Bottom Reflector and Core Support Block Neutron-Streaming Experiment, ORNL/TM-9485, Martin Marietta Energy Systems, Inc., Oak Ridge Natl. Lab., June 1985.

216. Maerker, R. E., and Muckenthaler, F. J., The Absolute Neutron Spectrum Emerging Through the Large Beam Collimator from the TSR-II Reactor at the Tower Shielding Facility, ORNL/TM-5183, Union Carbide Corp. Nuclear Div., Oak Ridge Natl. Lab., 1976.

217. Mansur, L. K., and Farrell, K., "On Mechanisms by Which a Soft Neutron Spectrum May Induce Accelerated Embrittlement," J. Nucl. Mater. 170, 236-45 (March 1990).

218. Kasten, P. R., Corum, M. R., and Rittenhouse, P. L., Research on Very High Temperature Gas Reactors, EPRI ER/NP-7372, Electric Power Research Institute, Palo Alto, Calif., July 1991 . 
219. "Draft Alloy 617 Code Case," Task Force on Very High Temperature Design, Subgroup on Elevated Temperature Design, ASME Boiler and Pressure Vessel Code, American Society of Mechanical Engineers, New York.

220. Corum, J. M., and Blass, J. J., "Rules for Design of Alloy 617 Nuclear Components to Very High Temperatures," pp. 147-53 in Fatigue, Fracture, and Risk 1991, ed. W. H. Bamford et al., PVP-Vol. 215, American Society of Mechanical Engineers, New York, June 1991.

221. Parks, D. E., Beyster, J. R., and Wikner, N. F., "Thermal Neutron Spectra in Graphite," Nucl. Sci. Eng. 13, 306-24 (1962).

222. Wikner, N. F., Joanou, G. D., and Parks, D. E., "Neutron Thermalization in Graphite," Nucl. Sci. Eng. 19, 108-29 (1964).

223. Carvalho, F., "Inelastic Scattering of Thermal Neutrons in Graphite," Nucl. Sci. Eng. 34, 224-36 (1968).

224. Koppel, J. V., Triplett, J. R., and Naliboff, Y. D., GASKET: A Unified Code for Thermal Neutron Scattering, GA-7417, General Atomics, San Diego, September 1966.

225. Egelstaff, P. A., Compilation of Early Scattering Data, AERE-R3931, Harwell Laboratory, Didcot, Oxon, England, 1962.

226. Young, J. A., and Koppel, J. V., "Phonon Spectra of Graphite," J. Chem. Phys. 42, 357 (1965).

227. Nicklow, R., Wakabayashi, N., and Smith, H. G., "Lattice Dynamics of Pyrolytic Graphite," Phys. Rev. B 5, 49-51 (1972).

228. Haywood, B. C., "A Compilation of Scattering Law for Graphite, Be and BeO at $22^{\circ} \mathrm{C}$," AERE-R4732, Harwell Laboratory, Didcot, Oxon, England, 1964.

229. Wittemore, W., "Neutron Scattering by Reactor Grade Graphite," GA-8284, General Atomics, San Diego, 1967. 
INTERNAL DISTRIBUTION

1-2. Central Research Library

3. Document Reference Section

4-5. Laboratory Records Department

6. Laboratory Records, ORNL RC

7. ORNL Patent Section

8-10. M\&C Records Office

11. C. A. Baldwin

12. S. J. Ball

13. R. L. Beatty

14. J. J. Blass

15. C. R. Brinkman

16. J. A. Bucholz

17. T. D. Burchell

18. J. M. Corum

19. D. F. Craig

20. R. L. Fellows

21. E. C. Fox

22. W. Fulkerson

23. E. L. Fuller

24. W. A. Gabbard

25. R. K. Genung

26. F. M. Haggag

27. H. W. Hayden

28. J. R. Hightower

29. D. O. Hobson
30. F. J. Homan

31. C. R. Hudson

32. D. T. Ingersoll

33. H. Jones

34. J. E. Jones, Jr.

35. H. T. Kerr

36. O. F. Kimball

37. J. F. King

38. D. A. Lee

39. H. E. McCoy

40. G. E. Michaels

41. R. N. Morris

42. B. F. Myers

43. R. K. Nanstad

44. N. H. Packan

45-46. P. L. Rittenhouse

47. O. M. Stansfield

48. J. P. Strizak

49. R. D. Taylor

50. K. R. Thoms

51. D. B. Trauger

52. D. F. Wilson

53. B. A. Worley

54. G. T. Yahr

\section{EXTERNAL DISTRIBUTION}

55. ABB/CENP, M/S 9354-0422, 1000 Prospect Hill Road, Windsor, CT 06095-0500
S. A. Caspersson

56. ABB COMBUSTION ENGINEERING NUCLEAR POWER, 1201 Riverfront Parkway, Bldg. 3, Chattanooga, TN 37402

Mit Basol

57. BECHTEL NATIONAL (BNI), P.O. Box 193965, 15D7, San Francisco, CA 94119

S. K. Ghose 
58-59. GAS-COOLED REACTOR ASSOCIATES, 10240 Sorrento Valley Road, Suite 300, San Diego CA 92121-1605

L. D. Mears

60-61. GENERAL ATOMICS, P.O. Box 85608, San Diego, CA 92186-9784

G. C. Bramblett

A. J. Neylan

62. GT-MHR PLANT DESIGN CONTROL OFFICE-EAST, 3206 Tower Oaks Blvd., Suite 300, Rockville, MD 20852-4220

R. R. Mills

63-64. GT-MHR PDCO-WEST, P.O. Box 85608, San Diego, CA 92186-9784

J. Kendall

D. Pettycord

65-66. KNOLLS ATOMIC POWER LABORATORY, P.O. Box 1072, Schenectady, NY 12301-1072

M. J. Kania

D. J. Krommenhoek

67. M. J. SCHIFF \& ASSOCIATES, 1291 N. Indian Hill Blvd., Claremont, CA 91711-3897 G. E. C. Bell, P. E.

68-69. NUCLEAR REGULATORY COMMISSION, NL/S-169, Washington, DC 20555

T. L. King

J. N. Wilson

70. STONE \& WEBSTER ENGINEERING, 245 Summer Street, P.O. Box 2325, Boston, MA 02107

W. J. Parker

71-72. DOE, NE-42, Washington, DC 20585

P. J. Karcz

73. DOE, OAKLAND OPERATIONS OFFICE, 1301 Clay Street, Oakland, CA 94612-5208

S. El-Safwany

DOE-HTGR-90-389, Rev.0 
74-75. DOE, OAK RIDGE OPERATIONS OFFICE, Office of Energy Research and Development, P.O. Box 2008, Oak Ridge, TN 37831-6269

H. E. Clarke

S. Martin

76. U.S. DEPARTMENT OF ENERGY, Actinide Recycle Division, Office of Nuclear Energy (NE-42), Washington, DC 20585

W. P. Chernock

77. U.S. DEPARTMENT OF ENERGY, Naval Reactors Office (NE-60), 3N06/NR Crystal City, Arlington, VA 22202

B. Demars

78-87. DOE, OFFICE OF SCIENTIFIC \& TECHNICAL INFORMATION, Office of Information Services, P.O. Box 62, Oak Ridge, TN 37831

For distribution as shown in TIC-4500, Distribution Category UC-522T (Gas-Cooled Reactor Technology) 